Inf

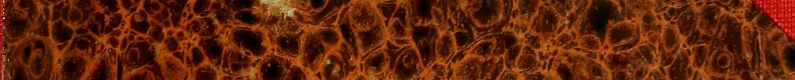

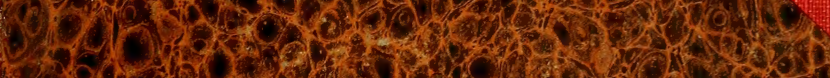

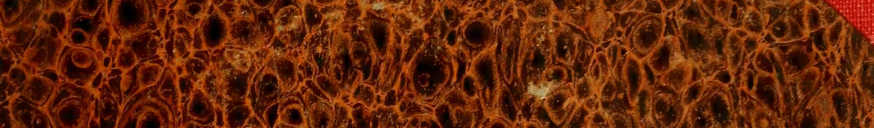

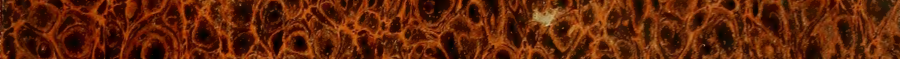

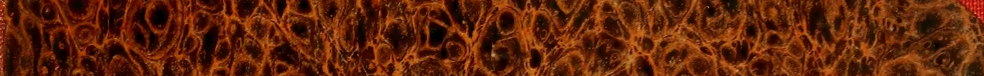

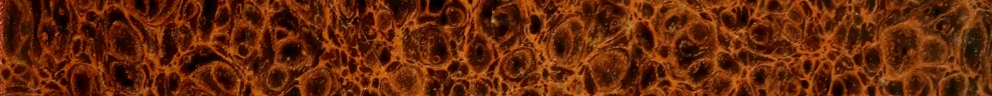

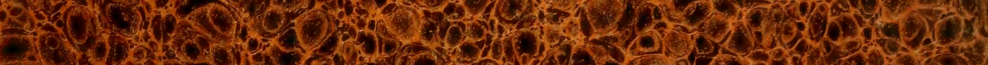
Co.5 (

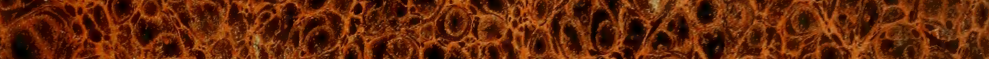
W.

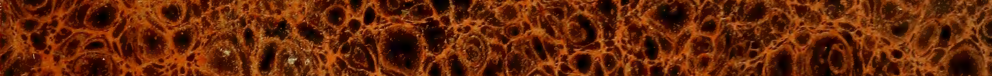
1.

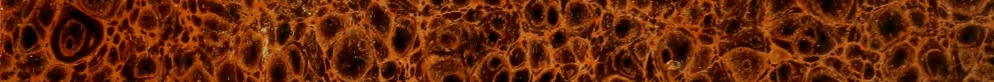
2.

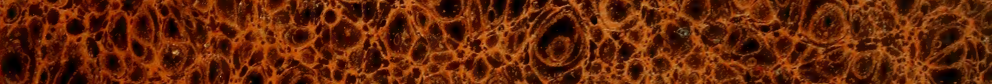

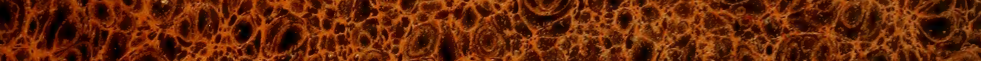

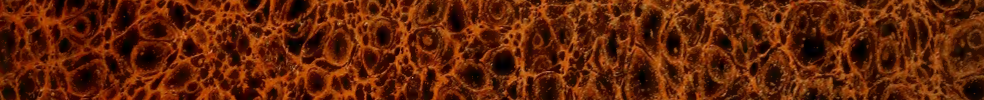

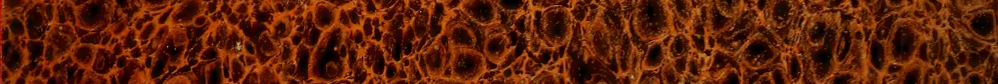

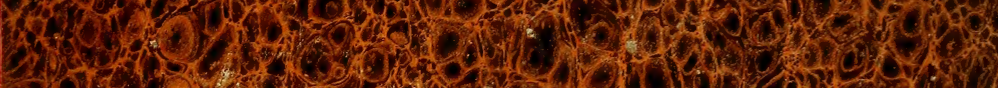

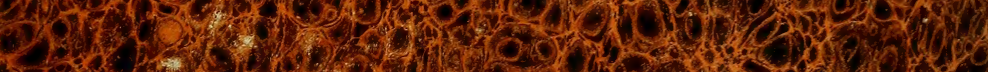

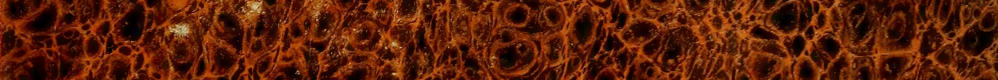

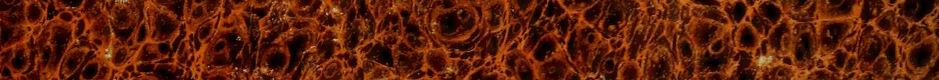

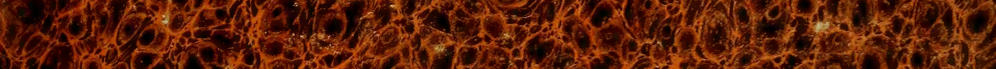

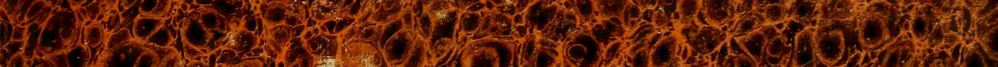

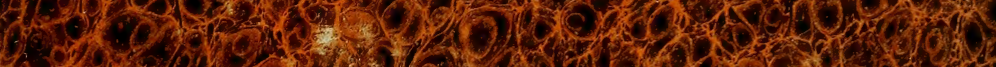

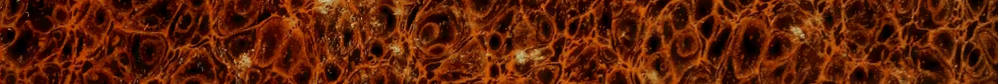

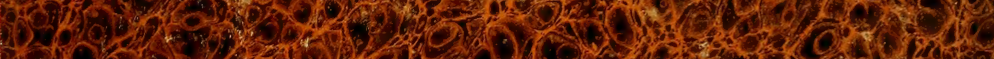

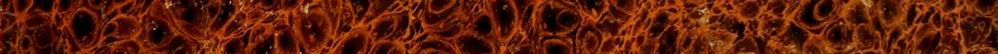

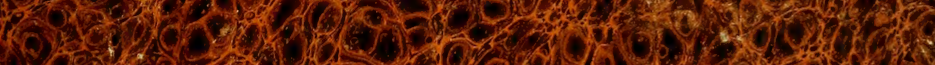

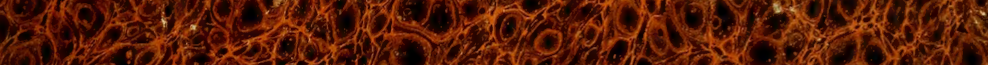

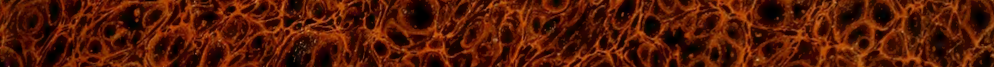

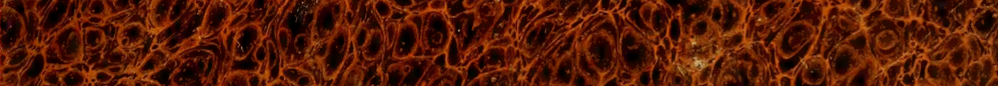

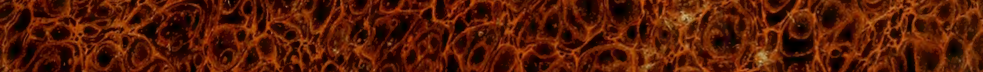

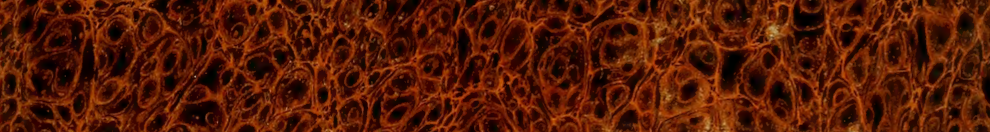
60.

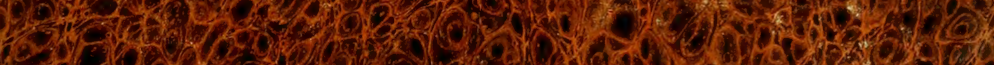

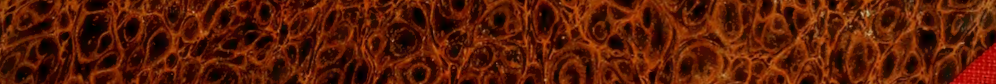

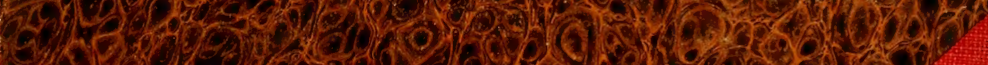

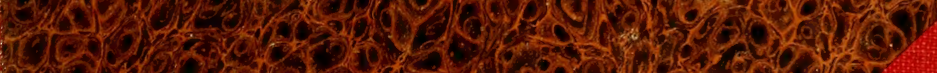

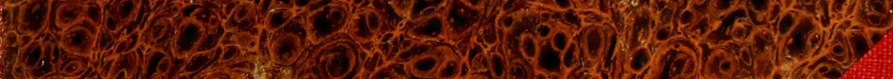

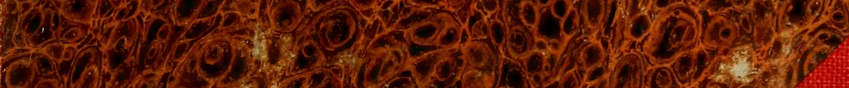

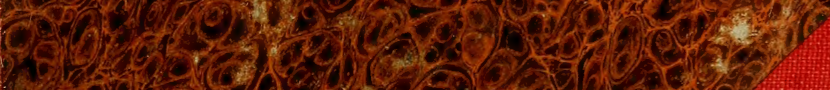




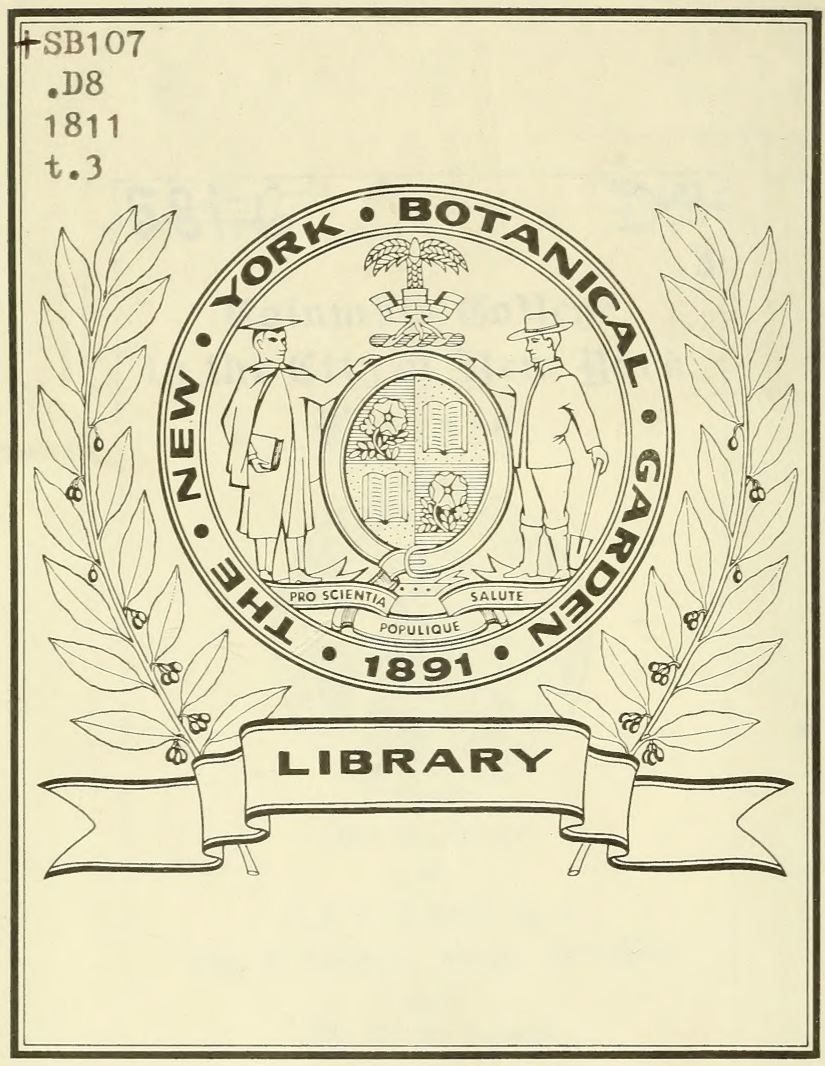


เ

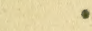





\section{LE BOTANISTE}

\section{CULTIVATEUR,}

\section{$\mathrm{OU}$}

Description, Culture et Usages de la plus grande partie des Plantes étrangères, naturalisées et indigènes, cultivées en France, en Autriche, en Italie et en Angleterre, rangées suivant la méthode de Jussieu ;

\section{PAR G. L. M. Du MONT de COURSET,}

Ancien Capitaine de Cavalerie, Membre correspondant de l'Institut de France, des Académies des Sciences de Rouen et d'Amiens, des Sociétés d'Agriculture de Pariset d'Evreux, des Sociétés des Sciences et Arts de Lille et d'Abbeville.

'Tant les ans et les soins et l'adroite culture Subjuguent l'habitude et domptent la nature ? Imitez ce grand art, et des plants délicats Nuancez le passage à de nouveaux climats.

Delille, l'Homme des Champs. SECONDE ÉDITION,

ENTIEREMENT REFONDUE ET CONSIDÉRABLEMENT AUGMENTÉ.

$$
\text { TOME TROISIÈ ME. }
$$

\section{A PARIS,}

Che $\{$ Deter ville, Libraire, rue Hautefeuille, no 8 ; l gOU J ON, Libraire, rue du Bac, No 33. 



\section{LE BOTANISTE \\ CULTIVATEUR.}

Suite de la CLASSE VIII,

O R D R E V I.

Les LABIÉES ( LABIAT AE)。

Calice tubulé, divisé en 5 , ou à 2 lèvres. Corolle tubulée, irrégulière, presque toujours à deux lèvres. Quatre étamines didynamiques insérées sous la lèvre supérieure de la corolle, quelquefois deux seulement; les deux autres avortees. Ovaire quadrilobe, style simplesortant du réceptacle entre les lobes de l'ovaire. Stigmate bifide. Quatre semences nues altachées par leur base au réceptacle dans le calice persistant. Embryon sans périsperme. Tiges le plus souvent herbacées, rarement frutescentes; rameaux quadrangulaires. Feuilles et fleurs opposées : les fleurs souvent accompagnées de bractées ou de poils, soli. taires ou verticillées; disposées en corymbe ou en épi, terminales ou axillaires.

Obs. La famille des labiées est naturelle; presque toutes les plantes se ressemblent en leur port; elles ont généralement la propriété de fournir de l'huile essentielle qui réside priacipalenent dans lè calice des fleurs.

III.

\section{0}




\section{2 étamines fertiles, 2 autres avortées.}

\section{Licope, Lycopus.}

Cal. tubuleux, 5-fide. Cor. tubulée, à 4 lobes presqu'égaux; le lobe sup. plus large et échancré. Etam. distantes.

1. Licope des marais, L. europceus.

Tige d'un à deux pieds, droite, carrée, un peu velue. Feuilles opp., oval. - obl., sinuées, dentées, d'un vert obscur. Fleurs blanches, avec quelques points rougeâtres, pétites, ax., verticillées.

Lieu. Les lieux aquatiques. Ind. $\%$. Fl. en juillet-sept.

2. L. de Virginie, L. virginicus.

Feuilles également dentées.

Lieu. La Virginie. . Fl. en août et septembre.

* L élevé, L. exaltatus, Lrv.

Tige de la hauteur de l'homme, ce en quoi cette espéce differe principalement de celle d'Europe. Feuilles profondément dentẻes en scie, presque pinnatifides. Corolles quadrifides, blanches; ses divisions ponctuées de rouge. Anthères didymes et rougeâtres. Les feuilles sup. sont pinnatifides. Toutes sont molles et velues. Les fleurs sont peiites, nombreuses, en verticilles très-serrés ; les div. cal. acuminées.

Lieu. L'Italie \%.

Cult. Pleine terre. Ces plantes ne sont guère cultivées que dans les jardins de botanique. Elles sont rustiques et viennent dans tous les terrains. On les multiplie par la séparation de leurs pieds.

\section{Améthysie, Amethystea.}

Cal. camp. 5-fide. Cor tubulée, presqu'à deux lères, à 5 lobes; l'inf. plus long et concave. Améthyste de Sibérie, A. ccerulea.

Tige d'un pied, draite carrée, à rameaux opp. Feuilles 
opp. pét., dentées, glabres; les inf. simples; les sup. à 3 lobes. Fleurs petites, d'un beau bleu, 3 ensemble, péd., ax. Les sommets de cette plante deviennent bleus.

Lieu. La Sibérie. Fl. en juin et juillet.

Cult. Pleine terre. Cette plante, assez jolie, se sème tous les ans dans la place ou elle doit rester. Son odeur est agréable.

\section{Cunile, Cunila.}

Cal. cylind., à ro stries et 5 dents. Cor. à 2 lèvres; la sup. droite, plane, échancrée; l'inf́. à 3 lobes. Semences dans le calice fermé par des poils.

1. Cunile thymière, C. thymoïdes, Hedeoma, Pers... Tige de 4 à 5 pouces, droite, carrée. Feuilles opp., ovales, obtuses, glabres. Fleurs petites, rougeâtres, péd., en verticilles axillaires.

Lieu. La France méridion. Fl. en juillet.

2. C. à feuilles de pouliot, C. pulegioides. Hedeoma, Pers.

Tiges droites, rameuses, pubescentes, de 7 à 8 pouces. F. opp., pét., ovales-lancéolées, garnies de 2 à 3 dents. Fleurs verticillées, ax.

Lieu. L'Amérique septentrionale. Fl. en août.

3. C. du Maryland, C. Mariana.

Tiges d'un pied, rameuses, grêles, droites. Feuilles opp., sessiles, ovales, pointues, dentées. Fleurs petites, en corymbes dichotomes, term. et ax.

Lieu. Id. $\nsucc$. Fl. en juillet - sept.

Cult. Les deux dernières sont cultivées dans les jardins de botanique. Leur cult. n'a rien de particulier; celles des sauges leur convient.

4. C. frutescente, C. fruticosa. Voyez Whesteringia. 


\section{Ziziphore, Ziziphora.}

Cal. cylind., long, strié, hispide, à 5 dentš, barbu à son entrée. Cor. tubulée, longue, à limbe court, à 2 levres; la sup. réfléchie, entière; l'inf. à 3 lobes.

I. Ziziphore à feuilles ovales, $Z$. capitata.

Tige carrée, de 2 pouces, à rameaux opp. Feuill. ovales, pointues. Fleurs purpurines, en petites têtes term.

Lieu. La Virginie. Fl. en juin et juillet.

2. Z. menu, Z . tenuior.

Tiges grêles, d'un pied. Feuilles lancéolées. Fleurs id., latérales, verticillées.

Lieu. Le Levant. Fl. id.

3. Z. à feuilles de thym, Z. acinoides.

Feuilles ovales. Fleurs latérales.

Lieu. La Sibérie. $\longleftarrow$. Fl. en juillet et août.

Cult. Pleine terre. Ces plantes se sèment en automne ou au printemps, dans la place où elles doivent rester. Elles fructifient dans nos climats.

\section{Monarde, Monarda.}

Cal. cylind., strié, à 5 dents. Cor. cylind., plus longue, à 2 lères; la sup. droite, étroite et entière, renfermant les étam.; l'inf. réfléchie, plus large, à 3 lobes, dont le moyen est plus long.

* I. Monarde fistuleuse ou velue, M. fistulosa. M. purpurascens, $\mathbb{N}$.

Tiges de 4 à 5 pieds dans les bons terrains, droites, tétragones, moelleuses, velues, rougeâtres. Feuilles opp., pét. , obl.-lanc., cordiformes à leur base, pointues, dentées, velues. Fl. d'un pourpre pâle, en assez grosses têtes term.

Lieu. Le Canada. $₹$. Fl. en juillet-août.

L'épithète fistulosa ne convient pas plus à cette espèce qu'à Ia lq $^{\mathrm{e}}$, qui est encore plus fistuleuse.

* 2. M. à longues feuilles, M. oblongata, H. K. M. longifolia, Lam.

J'ai cultivé cette espèce, et je n'ai trouvé d'autre différencé 
avec la précédente, qu'en ce que ses feuilles sont oblongtues, pointues et arrondies à leur base, au lieu d'être en cœur. La couleur de ses fleurs est un peu plus pâle.

Lieu. L'Amérique sept. $\longleftarrow$. Fl. en juillet-sept.

3. M. blanche, M. rugosa, H. K. An glabra? LAM.

Feuilles ovales - lanc., cordiformes, glabres, ridées.

Lieu. Id. ₹. Fl. id.

L'espèce décrite sous le nom de $\boldsymbol{M}$. glabra; LAM., a des liges droites, carrées, fistuleuses, de 2 pieds. Ses feuilles grandes, pét., cordif., pointues, dent.; ses fleurs en têtes term. * 4. M. écarlate, thé d'Oswego, M. coccinea, Mrch. M. didyma, Lin. M. purpurea, LAM.

Tiges droites, tétragones, fistuleuse, d'un pied et demi et plus. Feuilles opp., pét. , pointues, dentées, d'un beau vert. Fleurs assez longues, d'un écarlate foncé et vif, en têtes assez grosses, term. et verticillées. Les bractées colorées.

Lieu. Id. ₹. Fl. en juin-août.

* 5. M. ponctuée, M. punctata. M. lutea, Мгсн.

Tige droite, tétragone, de 2 pieds, rameuse, blanchâtre. Feuilles opp., pét., linéaires - lanc., pointues, légèrement dentées. Fleurs jaunes, ponctuées de pourpre, en verticilles au sommet des tiges. Les bractées colorées.

I,ieu. Le Maryland, la Virginie. $\sigma^{7}$. Fl. en juin-oct.

* 6. M. ciliée, M. ciliata.

Tiges à moitié couchées, redressées, tétragones, velues ; d'un pied. Feuilles opp., pét., distantes , crénelées. Fleurs blanches, petites, un peu ponctuées, en verticilles ax. au sommet des tiges. Les bractées colorées, luisantes, ciliées, ainsi que les calices.

Lieu. La Virginie.

Cult. Pleine terre. Les monardes aiment les terres légères, chaudes, substantielles. Elles languissent et périssent dans les sols argileux et froids, mêrme dans les bons fonds où d'autres plantes poussent avec vigueur. Il est essentiel de les replanter tous les deux ou trois ans. La partie de laquelle se sont élevées les tiges meurt ord.; c'est des rejets enracinés, abonsans sur-tout dans la première espèce et dans la quatrieme, 
zutour des pieds, qu'il en pousse de nouvelles. En enlevant la plante entiere, on plante ces nouveaux rejetons ou drageons; et si la terre n'est pas favorable à ces plantes, il faut y ajouter du sable et du terreau consommé. La quatrième se plaît dans le terreau de bruyère, et s'y multiplie à foisor. On vient de voir le moyen de leur multiplication; mais pour les obtenir, on en sème la graine sur vieille couche, au printemps; et quand les jeunes plantes ont environ un demi-pied de haut, on les place à demeure. L'exp. la meilłeure pour les monardes est la méridienne; la chaleur ne leur nuit pas. La quatrième, quoiquelle se propage en s'étendant, finit par périr, lorsqu'on n'a pas le soin de replanter ses rejets tous les ans ou tous les deux ans; la partie du pied qui a fourni les tiges fleuries n'en porte plus, et si les rejetons qui doivent fleurir l'année suivante ne sont pas bien enracinés, ils meurent en hiver, et la plante entière n'existe plus.

Us. Ces plantes sont agréables à voir dans le temps de leurs fleurs. Elles peuvent contribuer à l'ornement des parterres; $e t$ Lorsqu'elles sont dans un bon terrain et chaud, elles prennent an beau port et se chargent de tiges fleuries. La quatrieme est *." celle qui a les fleurs les plus grandes et les plus éclatantes; elle est d'usage en Amérique, et en infusion théforme.

7. Monaroe clinopade, $M$. clinopodia.

Tige carrée. Feuilles ov. - obl., acuminées, profondément dentées en scie, pết., lisses sur les deux surfaces. Fleurs pâles, disposées en tête, environnées de bractées.

Lіеи. La Virginie. $\Psi$.

Cult. Pleine terre.

\section{Westeringia.}

Cal. à 5 div. égales. Corolle à 2 lèvres; la supérieure bifide; l'inférieure à 5 parties égales, linéaires. Etamines didynamiques. Les 2 inférieures penchées sur la lèvre inférieure, lorsqu'elles sont défleuries.

* Westeringla rosmarinacea, Andr. Cunila fruticosa, VVILLD. 
Tige droite, tétragone dans sa jeunesse, garnie de plusieurs rameaux aussi tétragones, ouverts, disposés 3 par 3 par étage, couverts de poils blancs, courts et couchés. Feuilles verticillées, quaternées, ouvertes, sessiles, Iancéolées-linéaires, pointues, très-entières, d'un vert foncé en-dessus, blanches en-dessous, à bords un feu roulés comme celles du romarin, auxquelles elles ressemblent. Fleurs blanches, presque sessiles, au nombre de 4 ensemble, axillaires, situées au-dessous du sommet des rameaux; l'entrée du tabe garnie de poils blancs; Ies trois divisions inférieures marquées à leur base de points rougeâtres. Antlières jaunâtres, une fois plus grosses sur les deux filamens supérieurs que sur les deux autres. Style velu. Stigmate bifide, en crosse. Calice velu. Ovaire tétragone, la corolle a environ 7 à 8 lignes de diamètre.

Lieu.La Nouvelle-Hollande. Toujours vert. Fleuriten été.

Cult. Orangerie. Cet arbrisseau n'est pas du tout délicat. La terre de bruyère lui est favorable, et il vient bien aussi dans d'autres. O'n le multiplie aisément par ses graines qui mûrissent dans nos jardins et que l'on sème au printemps selon la manière indiquée pour les plantes de cette serre par les boutures faites dans la couche destinée à cette sorte de multiplication, et quĩ s'enracinent facilement; et par les marcottes.

Je pense qu'on pourroit essayer d'acclimater cet arbuste dans le midi et le milieu de la France en le plantant dans une terre légère et à l'exposition méridienne. Il ressemble beaucoup au romarin; mais son port est plus droit et plus régulier, et ses fleurs sont plus grandes; il lui manque l'odeur, qualité qui. donne tout l'avantage au romarin.

\section{Romarin, Rosmarinus.}

Cal. comprimé à son sommet et.à 2 levres; la sup. entière; l'info. 2-fide. Cor. plus longue, à 2 lèvres; la sup. à 2 part.; l'inf. à 3 div., dont la moyenne est plus grande. Filamens des étam. plus longs que la corolle.

* Romarin officinal, $R$. officinalis. Arbrisseau de 3 à 5 pieds, en buisson bien garni de rameaux- 
droits et très-feuillés. Feuilles opp., linéaires, étroites, blanchâtres en-dessous, roulées en leurs bords. Fleurs d'un bleu pâle, plusieurs ensemble, péd., ax.

Lieu. La France mérid. b. Fl. en janvier-mai. Toujours vert.

* Variétés à feuilles panachées, accidentelles.

Cult. Pleine terre. Cet arbrisseau est sensible aux froids du nord de la France. Les hivers rigoureux le font périr ; quoiqu'il soit très-répandu dans les jardins des campagnes, il arrive qu'après des gelées fortes et longues on en trouve rarement en vie au printemps. On ne peut, par cette raison, le planter dans des situations ouvertes; il faut le placer contre des murs ou à l'abri des haies exp. au midi. Les terres légères et chaudes sont celles qui lui conviennent le mieux. On le multiplie fort aisément de boutures, faites au printemps dans les terres ci-dessus et ’̀ l'oinbre, ou bien dans la place où l'arbuste doit rester, en les ombrageant lorsqu'elles sont au soleil. Elles s'enracinent en peu de temps.

Les variétés panachées sont délicates et ne peuvent se conserver qu'en orangerie et dans des terres légères et sèches. Si on leur en donne de plus substantielles, elles perdent peu à pet leurs panaches, et redeviennent entièrement vertes.

Us. Cet arbrisseau, toujours vert, peut être placé avantageusement sur les devants du bosquet d'hiver, dans le milieu de la France. Ses branches feuillées sont la base principale des bouquets de campagnes; c'est, pour la jeunesse des chaumières, le myrthe de la virginité.

Toutes ses parties ont une odeur aromatique agréable; elles sont toniques, cordiales, très-céphialiques et très-résolutives. C'est avec ses tiges flẹuries qu'on fait cette eau appelée eau de la reine de Hongrie. L'haile essentielle distillée de sa fleur est employée en pharmacie et en parfumerie. 


\section{Sauge, Salvia.}

Cal. presque camp., strié, à 2 lèvres; la sup à 3 dents; l'inf. bifide. Cor. dont le tube est large à son entrée, dont le limbe est à 2 lèvres; la sip. voûtée et échancrée; l'inf à 3 lobes dont le moyen est grand et obrond. 2 flamens d'étamines pédiculés, transversalement articulés et versatiles (le pérlicule propre inséré sur la corolle), connés par un bout avec une anthère stérile, distincts par l'autre avec une anthère fertile. 2 rudimens d'étam. stériles, petits et glanduliformes, interposés entre les filamens.

\section{P R E M I E R E S E C T I O}

* I. Sauge de Crète, $S$. Creticia.

Feuilles lanc. Calices à 2 folioles. Style double. Lieu. L'île de Candie. Ђ. Fl. en juin - août.

* 2. S. lyrée, S. lyrata.

Feuilles radicales, lyrées et dentées. Tige simple, d'un pied. Fleurs bleues, petites, verticillées. La levre sup. très-courte. Les divisions du calice épineuses.

Lieu. La Virginie. $\Psi$. Fl. en juin-août.

*3. S. officinale, S. officinalis.

Arbuste d'un pied, formant un large buisson, étendu et étalé sur la terre. Feuilles lanc.- ovales, entières, légèrement crénelées. Fleurs bleues, assez grandes, en épis term.

* Variétés. I. Sauge tricolore, S. tricolor.

* 2. S. panachée, $S$. variegata.

* 5. S. à feuilles étroites, $S$. angustifolia, minor.

* 4. S. à pecites feuilles, $S$. tenuior.

5. S. frisée, S. tomentosa, LIN., WILLDENow, Miller.

Lieu. La France mérid. Ђ. Fl. en juin et juillet. Toujours vert.

4. S. ̀̀ 3 lobes, S. triloba, S. bacciferà. 
Feuilles pét., très-ridées, à 3 lobes; celui du milieu alongé les latéraux ovales et obtus. Toute la plante cotonneuse.

Lieu. L'Europe mérid. Ђ. Fl. id.

* 5. SAUGE pormifere, $S$. pomifera.

Tige de 4 à 5 pieds. Feuilles lanc.-ovales, crénelées, ridées, cotonneuses. Flears bleues, en épis au sommet des tiges. Les calices obtus. La piqûre d'insectes produit sur les feuilles une protubérance semblable à celle des chênes qu'on nomme galle. C'est ce qui a fait donner à cette espèce l'épithète pomifère.

$A d d$. Les fleurs sont courtes et grosses; la levre inférieure est marquée à sa base d'une tache jaunâtre, entourée de lignes d'un bleu foncé. Anthères jaunes.

Lieu. L'île de Candie. $\Psi$. Fl. id.

6. S. effilée, S. virgata. Ortega, H. К.

Tige d'un à 2 pieds. Feuilles oblongues, cordiformes, ridées, crénelées. Les poils de la tige'et du calice glanduleux à leur sommet.

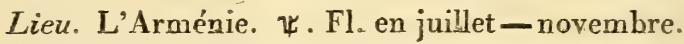

7. S. sauvage, S. sylvestris.

Tige carrée, pubescente. Feuilles grandes, pét., cordiformes, ridées, crénelées, tachées de blanc en-dessus. Fleurs en épis verticillés; les péd. blancs et cotonneux. Les bractées colorées acuminées, plus courtes que la fleur.

Lieu. La France mérid. ¥. Fl. id.

* 8. S. des bois, $S$. nemorosa.

Tige d'un pied. Feuilles lanc., un pen en cœur à leur base, dentées, planes. Fleurs bleues, en épis verticillés. Les bractées colorées, la lèvre inférieure réfléchie. Les épis tétragones avant la floraison.

Lieu. L'Autriche. $\%$. Fr. id.

9. S. visqueuse, $S$. viscosa, $\mathrm{J}_{\mathrm{ACQ}}$.

Feuilles oblongues, obtuses, crénelées, visqueuses. Fleurs: verticillées. Les bractées pointues et en cœur.

Lieu. L'Italie. $\psi$. Fl. en mai et juin.

* ro. S. des prés, $S$. pratensis.

Tige d'un pied et demi, carrée, velue. Feuillespét., ovalescbl., cordjormes, ridées et crénelées; les caulinaires amplexi- 
caules. Fleurs grandes, bleues, en épi verticillé et terminal. La levre sup. est très-voûtée et glutineuse.

Variété à feuilles profondément incisées.

Lieu. Les prés. Ind. $\nsucc$. Fl. id.

* I I. S. de l'Inde, $S$. indica.

Feuilles cordiformes, presque lobées; les sup. sessiles; toutes assez grandes, ridées, d'un vert foncé. Fleurs en verticilles presque nus et très-distans. Tige de 3 pieds. Cor. grandes et bleues. La levre inf., maculée en son bord, imite en quelque sorte le corps d'une abeille.

Lieu. L'Inde. $\Psi$. Fl en mai-juillet.

* I2. S. verbenacée, $S$. verbenaca.

Tige d'un pied, presque simple. Feuilles pét. , obl., obtuses, ridées, presque glabres, profondément crénelées, et même sinuées à leur base, d'un vert glauque. Fleurs bleues, petites, en épi grêle. La corolle plus petite que le calice.

Lieu. La France, l’Angleterre. $\sigma^{\top}$ ou $\Psi$. Fl. en juin-oct. 13. S. d'Autriche, S. austriaca.

Feuilles ovales, cordiformes, sinuées. Les radicales pét. Tige presque sans feuilles. Les étamines une fois plus longues que la corolle.

Lieu. L'Autriche. $\%$. Fl. en juin et juillet. * 14 . S. à longs épis, S. disermas.

Tiges d'un pied. Feuilles cordiformes, oblongues, ridées, cotonneuses. Fleurs blanches. Les étam. aussi longues que la corolle. Les anthères jaunes. Les bractées velues, cordiformes.

Lieu. La Syrie. $\Psi$. Fl. en juillet.

* 15. S. verticillée, $S$. verticillata.

Tiges d'un pied et demi, carrées et velues. Feuilles pétiolées, cordiformes, pointues, velues, dentées. Fleurs petites, bleues, nombreuses, verticillées. Le style tombant sur la levre inf.

Lieu. L'Allemagne. $\%$. Fl. en juin-novembre.

I6. S. à feuilles de rave, S. napifolia, H. K.

Feuilles cordiformes, crénelées, dentées; les inf. hastẻes et lyrées. Les verticilles presque nus. La levre sup. courte.

Lieu. L'Italie. $\%$. Fl. en juillet. Rapport à la précédente * I7. S glutineuse, S. glutinosa. 
Tiges de 2 pieds et demi, droites, carrées, velues. Feuilles pét., cordiformes, sagitiées, dentées, glutineuses, un peu ridées, d'un vert jaune. Fleurs jaunes, grandes, verticillées, en épi terminal, glutineuses. Les étamines très-saillantes. Cal. à 3 lobes.

Lieu. La Fr. mérid. ₹. Fl. id.

* i8. SAUGE à épis pendans, S. pendula, H.P.S. nutans, LAMARCK, illustr. 338.

Tige de 3 à 4 pieds, glabre, tétragone, verte, tachetée de points bruns. Feuilles ov.-obl., un peu ridées, pointues, crénelées. Fleurs petites, bleues, formant au sommet des tiges un trèslong épi composé de beaucoup de verticilles, et pendant à son extrémité. L'épi acquiert de la roideur et devient droit à mesure quela fructification se développe. Calices bruns. Bractées violettes.

Lieu. La Russie. ₹. Fl. en juin - septembre.

L'espèce $S$. Forskalia a des rapports avec celle-ci. Mais sa tige est presque nue. Ses feuilles sont lyrées et auriculées. La lèvre supérieure de la corolle eșt fendue jusqu'à moitié.

Lieu. Le Levant. $\Psi$.

SECONDE SECTION.

r9. S. dentée, $S$. dentata.

Feuilles linéaires, obl., dentées, pinnatifides. Verticilles de 2 fleurs. Div. du calice obtuses.

Lieu. Le Cap. Ђ. Fl. en décembre et janvier.

* 20. S. de Syrie, S. syriaca.

Tige grêle, d'un pied. Feuilles en cœur, dentées, ridées; les inf. très-ouvertes. Fleurs blanches ou bleues, en long épi term. Les bractées cordiformes, courtes et aiguës. Les calices cctonneux.

Licu. Le Levant. Ђ. Fl. en juillet.

2I. S. à feuilles rudes, S. scabra.

Toute la plante rude au toucher. Feuilles lyrées, dentées, ridées. Tige rameuse, paniculée.

Licu. Le Cap. Ђ. Fl. tout l'été.

22. S. ridée, $S$. rugosa, H. K. 
Feuilles cordiformes, obl. - lanc., crénelées, ridées, un peu velues. Les étam. plus courtes que la corolle. Fleurs blanches.

Cette espèce a les plus grands rapports avec la $14^{\mathrm{e}}$.

* 23 . S. de Nubie, S. nubia, H. K.

Tige d'un pied, simple, carrée. Feuilles obl., presqu'en cœur, à côtés inégaux, ridées, crénelées, un peu oreillées àleur base. Fleurs bleues, verticillées.

Lieu. L'Afrique. $\tau$. Fl. en juillet. 24. S. du Mexique, S. mexicana, Cav.

Tiges carrées, de 8 à 10 pieds. Feuilles ovales, pointues par les deux bouts, dentées en scie. Fleurs d'un beau bleu, en longs épis serrés et term.

Lieu. Le Mexique. Ђ. Fl. en mai - juillet, et en hiver.

* 25. S. élégante, $S$. formosa, L'Hérit.

Arbuste de 2 pieds, branchu. Feuilles cordiformes, assez larges, pointues, dentées, un peu velues, fermes, d'un beau vert. Fleurs axillaires, naissant dans les feuilles, grandes, d'un beau rouge écarlate, velues, beaucoup plus longues que le calice, qui est cependant fort grand, campanulé et à 3 lobes.

Lieu. Le Pérou. \$. Fl. presque toute l'année. Toujours vert.

* 26 . S. écarlate, $S$. coccinea.

Tiges de 3 à 4 pieds, carrées et velues, très-droites. Feuilles cordiformes, pointues, dentées, velues, douces au toucher. Fleurs écarlates, étroites, en épis veriicillés et term. La cor. deux fois plus løngue que le calice.

Lieu. La Floride orientale. Ђ. Fl. presque toute l'année. Toujours verte.

* 26 bis, S. fausse écarlate, S. pseudococcinea, Wilum.

Tige velue. Feuilles ovales, pointues, inégales à leur base. Fleurs écarlates, longues, dont la gorge est entr'ouverte et dilatée.

Cette espèce ne différe de la précédente que par la dilatation de l'entrée de la corolle, et par l'inégalité de la base de ses feuilles. Ces deux espèces ont une odeur forte et désagréable.

Lieu. L'Amérique mérid. b.

27. S. d'Abyssinie, S. Abyssinica.

Tige simple, carrée, d'un pied. Feuilles inf. 1 yrées; les sup. 
cordiformes. Fleurs bleues, verticillées, au nombre de six. Les calices mucronés et ciliés.

Lieu. L'Afrique. $\psi$. Fl. en juillet.

* 28. SAUGE des Canaries, S. canariensis.

Feuilles hastées, triangulaires, oblongues, obtuses, finement crénelées. Tige d'un mètre environ ( 5 pieds), branchue; les rameaux courts et opposés. Les jeunes pousses ainsi que les pétioles et le dessous des jeunes feuilles, couverts d'un tissu épais, très-blanc, lanugineux et transparent. Fleurs d'un pourpre pâle, en épis au sommet de la tige. Bractées et calices colorés.

Lieu. Les Canaries. Ђ. Fl. en juin - septembre.

* 29. S. d'Afrique, S. africana.

Tiges de 5 à 6 pieds, carrées. Feuilles un peu tronquées à leur base, oblongues, ridées, pointues, dentées. Fleurs d'un beau bleu, grandes, en épis term.

Licu. Le Cap. Ђ. Fl. une partie de l'été. Toujours verte.

* 3o. S. dorée, S. aurea.

Tiges fortes, très-rameuses, diffuses; Ies rameaux divergens, tortueux. Feuilles obrondes, très-entières, blanchâtres, tronquées à leur base. Fleurs d'un jaune foncé, ax., grandes. Cal. à 3 lobes, velu à sa base.

Lieu. Le Cap. Fl. en mai-novembre: rarement. Toujours verte.

5r. S. paniculée, S. paniculata.

Arbuste. Feuilles ovales, cunéiformes, denticulées, nues. Tige frutescente, droite, cylindrique, pourprée, rude au toucher. Feuilles petites, lisses, presque sessiles. Fleurs en panicule décomposé; la levre supérieure à peine plus longue que l'inférieure. Cal. à 3 div. dont les deux inf. sont pointues.

Lieu. Le Cap. Ђ. Fl. en juin - septembre. Toujours verte.

TROISIEME SECTION.

32. S. d'Egypte, S. agyptiaca.

Feuilles lanc., denticulées. Fleurs pédonculées. Fleurs petites, blanches.

Lieu. L'Egypte et les Canaries. O. Fl. en juin et juillet. 
33. S. verte, S. viridis, JAcQ., Desfont. , Flor. atlant.

Feuilles oblongues, crénelées. La lèvre sup. presque orbiculaire. Les calices fructifians, réfléchis. Rapports à la suivante.

Lieu. L'Italie. Fl. en juillet et août.

*34. S. ormin, S. horminum.

Tige de 2 pieds. Feuilles obtuses, crénelées. Les bractées des fleurs sup. stériles, grandes et colorées. Elles terminent agréablement l'épi. Variété à bractées rouges, et une autre à bractées violettes. L'épi s'amincit graduellement vers son sommet.

Lieu. L'Europe mérid. O. Fl. en juillet.

35. S. clandestine, S. clandestina.

Tiges carrées, velues, droites. Feuilles dentées, pinnatifides, très-ridées, crénelées. Fleurs en épi obtus, tronqué. Les corolles violettes, plus étroites que le calice chargé de poils glutineux.

Lieu. L'Italie. $\sigma^{\top}$. Fl. en mai - juillet.

S. clandestinoides, Hort. angl. Feuilles rouges.

Lieu. L'Amériq. sept. $\sigma^{7}$.

* 35 bis. S. d'Espagne, S. hispanica.

Tiges de 4 à 5 pieds, fortes, droites, carrées, rameuses, casm santes. Feuilles grandes, ovales, dentées, pointues, rudes au toucher, d'un beau vert; leur pétiole mucroné à sa base. Flenrs petites, bleues ou blanches, en épis carrés et imbricés. Cal. trifides; bractées ciliées:

Lieu. L'Espagne. Fl. Fl. en juillet et août.

* 36. S. sclarée, S. sclarea.

Tige de 2 à 3 pieds, droite, carrée, rameuse et velue. Feuilles grandes, pét. , crénelées, cordiformes, très-ridées. Fleurs bleuktres, en épi garni de bractées colorées, concaves, acuminées, plus longues que les calices.

Lieu. La France mérid. $\sigma^{\star}$. Fl. en août.

37. S. de Perse, S. ceratophylla.

Feuilles ridées, pinnatifides, laineuses. Les verticilles sup. stériles.

Lieu. La Perse. $\sigma^{7}$. Fl. en août.

* 38. S. éthiopienne, S. axthiopis.

Tige d'un pied et demi, cotonneuse, rameuse. Feuilles grandes, pét, ov.-oblongues, sinuées, dentées, blanchi- 
tres et laineuses. Fleurs blanches, verticillées. Les calices blanøs et laineux. Les bractées recourbées et presqu'épineuses.

Lieu. La Fr. mérid. $\sigma^{\pi}$. Fl. en juin. 39. SAUGE pinnée, $S$. pinnala.

Feuilles lyrées, pinnées, velues. La dernière ovale, plus grande. Calice enflé. Corolle droite

Lieu. Le Levant. $\sigma^{7}$. Fl. en juillet.

* 40. S. argentée, S. argentea.

Feuilles grandes, oblongues, dentées, anguleuses, laineuses, blanches, argentées. Les verticilles supérieurs stériles. Les bractées concaves. Fleurs blanches. Rapports aux espèces 36 et 38

Lieu. L'île de Candie. ơ . Fl. en mai-août.

41. S. rameuse, S. ceratophylloides. S. exasperata, $\mathrm{CAv}_{\mathrm{Av}}$

Tige paniculée, très-rameuse. Feuilles pinnatifides, ridées et velues.

Lieu. L'Egypte. ơ. Fl. en juin-août.

Cult. Les sauges de la premiere section sont toutes de pleine terre et viennent assez bien dans tous les terrains; mais les terres légères et chaudes sont celles qui leur conviennent toujours le mieux. La $3^{\mathrm{e}}$ espèce et ses variétés, qui sont les plus répandues dans les jardins, à cause de leur utilité, et quelques-unes pour l'aspect, sont sensibles aux grandis froids, sur-tout la variété à très-petites feuilles; mais elles le sont beaucoup moins dans les sols que je viens d'indiquer, sur-tout s'ils sont médiocres et pierreux. Toutes ces espèces se multiplient aisément, quand on les a une fois obtenues, en séparant leurs pieds, ou de rameaux enracinés, ou en se semant elles-mêmes. Il est nécessaire de replanter la $3^{\mathrm{e}}$ et ses variétés tous les deux ou trois ans. Elles sont sujettes à s'élargir considérablement et l'ancien pied périt souvent, lorsque leurs tiges latérales, couchées et enracinées, forment de nouveaux pieds. La plantation dè ces sauges se fait mieux en mars qu'en automne. On les obtient toutes par leurs graines semées en plate-bande ou dans des planches préparées pour recevoir les semis de plantes de pleine terre.

Les especes de la seconde section sont toutes de serre, exçepté la $25^{\mathrm{e}}$ et la $26^{\mathrm{e}}$, qui sont mieux en serre tempérée; les autres 
sont simplement d'orangerie. Leur terre doit être substantielle, consistante, mais pas trop forte. Beaucoup d'arrosemens en été, très-modérés en hiver, et placées près des jours dans cette saison. Quand elles sont dehors, une exp. chaude leur est favorable. On les obtient, comme celles de pleine terre, de leurs graines semées sur couche et en pot et conduites à la manière indiquée. On les multiplie par rejetons, et par boutures faites en pot sur couche ombragée. Plusieurs espèces ne manquent guère de s'enraciner par ce moyen. Elles n'ont besoin que des soins ord. de l'orangerie; mais la $25^{\mathrm{e}}$, la $26^{\mathrm{e}}$ et bis, un peu plus délicates, sont beaucoup mieux en serre tempérée, à cause de leur végétation et de leur floraison presque continuelle. La 26 e se sème souvent elle-même.

Les sauges de la $5^{\circ}$ section se sèment tous les ans sur vieille couche, et quand les jeunes plantes ont acquis de la force, on les plante, vers le mois de juillet, dans la place où elles doivent rester, en les abritant et arrosant jusqu'à leur parfaite reprise.

Us. Dans les sauges de la première section on a toujours dist tingué la $3^{\mathrm{e}}$ et ses variétés, dont les plus agréables sont la $\mathrm{I}^{\mathrm{r}} \mathrm{B}$ et la $2^{\text {e }}$. Si la $\mathrm{r}^{\text {te }}$ variété vouloit se varier davantage, elle seroit très-agréable à voir ; peut-être y réussiroit-on dans les terrains très-médiocres et pierreux. Les 9 , זo, II et i I sont assez belles. La $3^{\text {e }}$ sur les coteaux secs fera un bon effet.

La sauge officinale est tonique, cordiale, stomachique; elle est en usage non-seulement en méd., mais dans d'autres préparations. On la prend ordinairement en infusion théiforme. Les calices des fleurs fournissent de l'huile essentielle.

Dans celles de la seconde section, on doit considérer les 25,26 et $29^{\text {e }}$. La $25^{\mathrm{e}}$ a un beau feuillage toujours vert et des fleurs écla. tantes. $\mathrm{La}_{2} 6^{\mathrm{e}}$ a de jolis épis, mais son odeur est désagréable. $\mathrm{La}_{2} \mathrm{~g}^{\circ}$ orne, pendant l'été, les endroits où elle est, par ses fleurs d'un beau bleu. La $28^{\mathrm{e}}$ se distingue aussi par son coton abondant.

Parmi celles de la $3^{e}$ section, la $34^{e}$ est assez singulière par ses bractées colorées et d'un beau rouge; la $36^{\mathbf{e}}$ par ses propriétés stomachiques, errhines et anti-ulcéreuses; les 38 et $40^{\circ}$ par leurs grandes feuilles très-blanches, laineuses et argentées. 


\section{Autres espèces cultivées.} * 42. Sauge bicolore, $S$. bicolor, Desfontaives, Wilzde-
now.

Tiges de 2 à 3 pieds, tétragones. Feuilles épaisses, ovales, dentées. Fleurs penchées, au nombre de 6 par verticilles, disposées tout le long de la partie supérieure des tiges. Corolle d'un beau bleu, du double plus grande que celle de la sauge des prés. La levvre sup. comprimée, échancrée; l'inf. à 3 div., dont Ia moyenne est d'un beau blanc, concave et bilobée. Style trèssaillant. Rapports à la $\mathrm{I}_{\mathrm{i}}^{\mathrm{e}}$.

Cette espèce êst une des plus belles de ce genre.

Lieu. La Barbarie. $\%$.

* 43. S. tingitane, S. tingitana, Willde now.

Feuilles en cœur, dentées, assez grandes, ridées, d'un vert pâle. Calices épineux. Bractées très-entières, cordiformes, mucronées, concaves, ciliées. Fleurs blanches.

Toutes les parties de cette sauge ont une odeur forte et trèsdésagréable.

Lieu. L'Afrique sept. En serre. Toujours verte.

44. S. à feuilles de tilleul, S. tilicefolia, Willd. S. polystachia, CAv. S. lamifolia, J $\mathrm{ACQ}$.

Tige tétragone, ’̀ angles saillans, rameuse; les jeunes rameaux velus. Feuilles opp., pét. ovales, pointues, dentées en scie, molles, glauques en-dessous. Fleurs petites, bleues, disposées en plusieurs épis multiflores, en verticilles serrés ế terminaux. La lèvre sup. courte, l'inf. trifide, la div. moyenne échancrée.

Lieu. Le Mexique. $¥$. Fleurit à la fin de l'automne. * 45. S. phlomoïde, S. phlomoides, VaHL.

Tige droite, obtusément tétragone, silonnée, rameuse; les rameaux opp. et montans. Feuilles opp., pét. , ovales-oblongues, bordées de dents peu profondes et écartées, vertes en-dessus, pâles en-dessous. Fleurs d'un bleu léger, axillaires, assez distantes, verticillées, au nombre de $\mathbf{2}$ à 4 , et formant une sorte 
d'épi terminal garni de bractées. Toute la plante blanche et velue.

Lieu. L'Espagne. Ђ. Fl. une partie de l'année. Toujours verte. J'ai cultivé cette espèce, et je l'ai perdue.

* 46. S. à feuilles de germandrée, S. chamadrifolia, Gav.

Cette espèce a quelques rapports avec la sauge officinale par son odeur et ses feuilles ridées. Tiges nombreuses, rameuses, les unes droites, les autres couchées et redressées, presque cylindriques, légèrement velues. Feuilles pét., opp., ovales-elliptiques, crénelées, ridées, vertes en - dessus, blanchâtres et cotonneuses en-dessous, d'un pouce au plus de longueur. Fleurs d'un beau bleu, de grandeur moyenne, en épi terminal composé de verticilles de 4 à 6 fleurs pédicellées. La lère sup. velue est fermée par ses deux côtés qui se joignent; anthères brunes; style saillant. La corolle est blanche à son entrée, ainsi que les côtés de la levre supérieure, l'inférieure est beaucoup plus grande, arrondie, large, concave, échancrée au milieu.

Lieu. La Nouvelle-Espagne. Ђ. Fleurit en automne et à la fin de l'été.

* 47. S. acuminée, S. acuminata, VENT., Jard. Cels. S. angustifolia.

Tiges assez nombreuses, de $\overline{3}$ à 4 pieds de hauteur, droites, simples, tétragones, garnies de quelques poils blancs, d'un vert pourpre noirâtre. Feuilles opp., presque sessiles, lancéolées, étroites, pointues, très-entières, d'un vert brun. Fleurs d'un beau bleu, pédonculées, formant sur chaque tige un épi terminal, composé de 6 à 7 verticilles de 4 à 6 fleurs. La levre sup. velue; l'inf. beaucoup plus grande, arrondie, un peu ondulée en ses bords et échancrée à son sommet; son entrée est marquée de lignes blanches. Calice velu, noirâtre et strié.

Lieu. Le Mexique. $₹$. Fleurit en octobre et novembre.

Cult. Orangerie, excepté la $42^{\mathrm{e}}$, qui est de pleine terre, mais qui ne dure pas très-long-temps. Il est prudent de la multiplier le plus tôt possible si l'on veut la conserver, et elle mérite ces soins par l'agrément de ses fleurs. Les autres ne sont pas délicates; laplus simple orangerie leur suffit. On les propage par la séparation de leurs pieds au printemps. On fera bien, àla 
suite de cette opération, de faire reprendre la $47^{\mathrm{e}}$ dans une couche de chaleur modérée, elle en fleurira mieux en automne.

On cultive encore au Muséum les espèces suivantes. 48. SALVIA sypilea. Ђ. or. Du mont Sypile.

49. $S$. acetabulosa. b. Du Levant. Or.

5o. S. scabioscefolia. $\Psi$. La Tauride. S. habliciana, WILld.

Pleine terre.

51. S. patula. . . Desfont. ₹. La Barbarie. Or.

52. S. lanigera. $\sigma^{7}$. La Perse. Or.

55. S. runcinata, Liv. fils. $\sigma^{7}$. Le Cap. Or.

54. S. micrantha. ơ ou Ђ. Hort. lond. Le Pérou. Or.

55. S. serotina, JAcQ... o $\sigma^{\top}$. Le Levant. Pl. terre.

56. S. dominica, Liv. .... \%. Les Antilles. S. chaude.

57. S. à fleurs blanches, S. leucantha, Cav., Willd., Per-

soon.

M. Armano, de Milan, qui cultive cette espèce que je ne sam vois pas être introduite dans les jardins, m'a mandé qu'elle avoit l'aspect du buleja globuleux. Ses feuilles sont lancéoléeslinéaires, crénelées, ridées. Ses fleurs sont blanches et les calices très-velus et d'un violet rougeâtre. Elle est orig. du Mexique, $\Psi$, d'orąngerie, et se multiplie par la séparation de son pied et par les boutures.

* 58. S. circinata, Pers., CAv., Icon. Amara, JAcQ.

Tige droite, tétragone, brune, couverte de poils blancs glanduleux. Feuilles à longs pétioles, en cœur, pointues, crénø* lées, un peu ridées, et légèrement velues, pâles en - dessous. Fleurs bleues, en verticilles de 4 à 6 fleurs. Les bractées pointue. et ciliées; la lèvre supérieure échancrée.

Lieu. Le Mexique. ₹. Orangerie. Fleurit en août. 5g. S. arborescente, $S$. arborea, Hort. angl.

Lieu. La Grèce. Ђ. Orangerie.

6o. S. bullata, Hort. angl.

Lieu. L'Espagne. . Pleine terrs. 


\section{Collinsone, Collinsonia.}

Cal. à deux levres; la sup. à 3 dents; l'inf. 2-fide. Cor. beaucoup plus longue, infund., à limbe à 5 lobes inégaux; l'inf. plus long et frangé. 5 semences avortées, une seule reste et est globuleuse.

* I. Collinsone du Canada, C. canadensis.

Tiges droites, tétragones, de 2 à 3 pieds, presque simples. Feuilles pét., opposées, ovales, pointues, dentées, glabres et ridées. Fleurs jaunâtres, nombreuses, en panicule pyramidal et. terminal.

Lieu. L'Amérique sept. $\Psi$. Fl. en août-octobre.

2. C. à tige rude, C. scabriuscula, H. K., C. pracox, WALT.

Tige un peu velue et un peu rude au toucher. Feuilles ov., presqu'en cœur, légèrement velues; les inférieures pétiolées. Fleurs latérales et terminales.

Lieu. La Floride or. $\Psi$. Fl.

3. C. anisée, C. anisata, Hort. angl. An C. serotina, WALT. Caroline.

Cult. La $1^{\text {re }}$ est de pleine terre, et sa culture doit être la mềme que celle des sauges. Cependant cette plante est plus délicate sur le terrain et la température. Elle aime les terres. franches, un peu fraîches, d'un bon fond. Elle demande dans. le nord de la France une situation abritée. On l'obtient par ses semences semées sur couche tiede au printemps, et on la multiplie aisément en séparant son pied en février ou en mars. Quoiqu'elle résiste aux hivers ordinaires, il est toujours plus prudent d'en avoir un ou deux individus en pot, qu'on mettra en hiver sous un grand châssis, ou contre les jours de la serre; ou bien de couvrir son pied en hiver; ce qui est suffisant.

La $2^{\mathrm{e}}$ est d'orangerie.

Us. La première peut servir à la variété des parterres, êt même à leur agrément quand elle fleurit, ce qu'elle fait rarement lorsqu'elle ne se trouve pas dans le terrain qui lui convient, et tous les ans quand ce dernier lui est favorable, 
II. 4 étamines fertiles. Cor. ì une seule lèvre, la supérieure étant presque nulle.

\section{Bugle, Bugula, Ajuga, LiN., H. K.}

Cal. 5.fide, presqu'égal. Cor. tubulée, labiée; la lèvre supér. remplacée par 2 dents; l'inf. à 3 lobes, le moyen grand et presqu'en cœur.

1. Bugle du Levant, $B$. orientalis.

Tiges velues, laineuses, droites, simples, d'un pied environ. Feuilles opp., dentées, ovales, chargées de poils blancs; les inf. sess.; les sup. rétrécies en pétiole. Fleurs panachées de bleu et de blanc, verticillées, axillaires. La lèvre inf. tournée vers le ciel.

Lieu. Le Levant. $\%$. Fl. en mai et juin.

* 2. B. pyramidale, B.pyramidalis.

Tige de 4 à 6 pouces, droite, simple, couverte de poils blancs. Feuilles inf., grandes, crénelées; les sup. obl., obtuses, anguleuses et dentées. Celles du sommet courtes, sess. Fleurs bleues, en épi pyramidal, feuillé et term.

Lieu. Les champs. Ind. $\%$. Fl. en juin.

3. B. des Alpes, B. alpina.

Tige simple, feuillée, de 6 pouces. Feuilles ovales, obtuses, sess.; les inf. pas plus grandes que celles de la tige. Fleurs petites, bleues, verticillées, ax.

Lieu. Les hautes montagnes. $₹$. Fl. en mai et juin.

4. B. de Genève, B. genevensis.

Cette espèce a les plus grands rapports avec la seconde, dont Lamarck n'a fait que sa variété. Elle n'en differe que par ses feuilles plus cotonneuses, dont les supérieures sont un peu trilobées.

Lieu. Les champs. Ind. $\psi$. Fl. id.

与. B. rampante, B. reptans.

Ce tte espèce pousse des rejets traçans. Tige de 4 à 8 pouces, selon les terrains, droite, simple, carrée. Feuilles opp., ơ., 
bordées de dents anguleuses. Fleurs ord. bleues, en verticilles, garnies de bractées, dont les sup. sont colorées.

Lieu. Les endroits herbeux. Ind. Très-commune. $\%$. Fl.id.

Variété à fleurs blanches.

Cult. Pleine terre. Ces plantes ne sont guère cultivées que dans les écoles de botanique. Elles viennent dans presque tous les terrains.

La $5^{\mathrm{e}}$ est d'usage en méd.; c'est un bon vulnéraire astringent. Elle est employée dans les crachemens de sang et les fleurs blanches.

\section{Germandrée, Teucrium.}

Cal. 5-fide, camp. ou tubulé. Cor. à tube court, labié. Deus petites dents réfléchies sur le côté tiennent la place de la levre supérieure; l'inférieure à 3 lobes, celui du milieu plus grand. Les étamines saillantes au milieu des dents qui forment la levre supérieure.

P R E M I E R E S E C T T O N.

InGERMandréE multiflore, $\boldsymbol{T}$. multiflorum.

Tiges droites, rameuses, grêles, d'un pied. Feuilles petites , pétiolées, ovales, dentées. Fleurs purpurines, pédicellées, 2 or 3 ensemble, vertic. , et formant des grappes alongées et term.

Lieu. L'Espagne. $\%$. Fl. en juillet-septembre.

* 2. G. du Canada, T. canadense.

Tiges droites, simples, ciliées, d'un pied et demi. Feuilles. pét. , ov.-lanc., dentées, blanchâtres en-dessous. Fleurs blanchâtres, en épi term.

Lieu. L'Amérique sept. $₹$. Fl. en août et septembre.

*3. G. d'Hircanie, T. hircanicum.

Tiges de 2 à 3 pieds, droites, rameuses, velues, presque tétragones. Feuilles pét., cordiformes, oblongues, obtuses, crénelées, ridées. Fleurs d'un pourpre foncé, en épis serrés. longs, cylind., term.

Lieu. La Perse. そ. Fl, en août et octobre. 
* 4. Germandrée aquatique, $T$. scordium.

Tiges rameuses, en partie étalées sur ‘a terre. Feuilles sess.; ovales-oblongues, dentées, pubescentes, blanchâtres. Fleurs d'un pourpre pâle, 2 ensemble, ax. , péd.

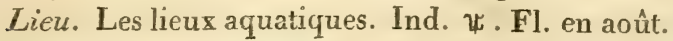

* 5. G.sauvage, $T$. scorodonia. Sauge sauvage.

Tiges d'un à 2 pieds, droites, fermes, velues, tétragones. Feuilles, pét., cordiformes, dentées, ridées, crénelées. Fleurs jaunâtres, en grappes unilatérales et term.

Lieu. Les bois. Ind. $\Psi$. Fl.en juillet.

* 6. G. officinale, $T$. chamcedris. Petit chêne.

Tiges nombreuses, rameuses, en partie couchées, velues, de 4 à 5 pouces. Feuilles ov., pét., profondément crénelées, d'un vert lisse en-dessus. Fleurs purpurines, 2 ou 3 ensemble dans. Ies aisselles sup.

Lieu. Les bois. Ind. $\%$. Fl. en juin. Toujours verte.

* Variétés à tiges plus ou moins velues, plus ou moins couchées, à feuilles oblongues, à épis plus droits et plus garnis de fleurs.

* 7. G. luisante, $\boldsymbol{T}$. lucidum.

Cette espèce est bien distinguée de la précédente. Ses tiges s'élèvent jusqu'à un pied et demi à 2 pieds; elles sont quăa drangulaires, d'un rouge brun, droites et glabres. Feuilles inf. et caulinaires, ovales, cunéiformes, pét. ou rétrécies en pétiole, opp., profondément dentées, lisses, glabres, d'un beau vert en-dessus, pâles et un peu velues en-dessous. Celles du sommet des tiges ovales, très-entières. Fleurs purpurines, péd. , 3 ou 5 ensemble, verticillées, axillaires, un peu unilatérales.

Lieu. Les Alpes. $\%$. Fl. id. Toujours verte.

* 8. G. des Pyrénées, T.pyrenaicum.

Tiges étalées sur la terre, longues de 3 à 4 pouces. Feuilles opp., arrondies, crẻnelées, cunéiformes à leur base, velues. Fleurs blanches, en têtes arrondies, assez larges et term.

Licu. Les Pyrénées. . Fl. en juin et juillet.

* g. G. de montagne, T. monianum.

Tiges nombreuses, de 5 à 6 pouces, disposées en touffe, en 
partie couchées. Feuilles opp., lin.-larc., très-entières, glabres et vertes en-dessus, blanchâtres et cotonneuses en-dessous, à bords roulés. Fleurs blanches, en têtes aplaties, sess. et term.

Lieu. La Fr. $\longleftarrow$. Fl. en juillet-octobre. Toujours verte. L'espèce que je cultive a les fleurs jaunes.

10. G. couchée, T. supinum.

Cette espèce differe peu de la précédente. Ses feuilles son Iin., aussi à bords roulés. Fleurs disp. id.

Lieu. Id. $\psi$. ou $\sigma^{x}$. Fl. id.

* II. G. cotonneuse, T. polium.

Tiges nombreuses, en touffe, couchées et redressées, rameuses, cylind., blanches, cotonneuses. Feuilles opp., sess., oblongues, obtuses, crénelées, à bords roulés, blanches et cotonneuses. Fleurs blanches, jaunâtres ou purpurines, selon les variétés , ramassées en têtes arrondies, compactes et term.

Lieu. La France mérid. Ђ.Fl. en juillet-septembre. Toujours verte.

Variétés assez nombreuses.

* 12. G. jaunâtre, $T$ ' flavicans, Laмarck. T. aureum,

Cav.

Tiges id., cotonneuses, en touffe. Feuilles opp. , sessiles, -vales-obl., obtuses, crénelées, plus larges que celles de la précédente. Fleurs jaunes, en têtes sess. et term. Leur couleur est souvent verdâtre.

Lieu. La Fr. mérid. Ђ. Fl. id. Toujours verte. * 13. G. à fleurs en tête, T. capitatum. Cylindricum, LAm.

Tiges d'un pied, droites, cylind., blanchâtres , presque simples. Feuilles lanc., un peu pointues, q. f. obtuses, crénelées, à bords roulés, blanchâtres. Fleurs d'un blanc un peu jaunâtre ou rougeâtre, en têtes pédonculées, ovales, arrondies et term.

Lieu. Id. b. Fl. en juillet et août Toujours verte. 
SECONDE SECTION.

* I4. Germandrée campanulée, $T$. campanulatum, Lamarer et $\mathrm{H}$. K.

Tiges assez nombreuses, herbacées, la plupart étalées sur la terre, où elles s'enracinent; quelques-unes redressées, tétragones. Feuilles opp., multifides, d'un vert glauque. Fleurs blanches, un peu ponctuées de violet, ax., sol., latérales; q. f. il se trouve une fleur terminale plus grande, campanulée, à 6 div., 6 étam. et un style bifide.

Lieu. Le Levant. $\Psi$ ou $\sigma^{7}$. Fl. en août.

* 15 . G. de nissole, $T$. nissolianum.

Tiges plus ou moins couchées, glabres, rameuses, diffuses, de 4 à 6 pouces. Feuilles trifides et quinquéfides, à découpures menues. Fl. ax., sol., péd. Les calices à 5 dents égales et spinulifor es.

Obs. J'indique ici cette espèce d'après les autorités de Lamarck et d'Aiton; mais j'observe en même temps qu'une espèce que je cultive est absolument conforme à la description de la $14^{\circ}$, et qu'elle a les calices de la 15 e.

* 16. G. d'Espagne, T. fruticans.

Arbuste de 4 à 5 pieds. Tiges et rameaux nombreux, un peu grêles et blanchâtres. Feuilles opp., pét., ovales, très-entières, luisantes et vertes en-dessus, blanches en-dessous. Fleurs grandes, d'un bleu violet, pâle, latérales, sol., péd.

Lieu. L'Espagne. Ђ. FI. en juin $\rightarrow$ septembre. Toujours vert. I7. G. à larges feuilles, $\boldsymbol{T}$. latifolium.

Feuilles très-entières, rhomboïdales, pointues, velues, cotonneuses en-dessous.

Lieu. L'Espagne. Ђ. Fl. en juin-septembre. 18. G. à grandes feuilles, $T$. macrophyllum, LamarcK- $T$ : abutiloides, L'HÉritier.

Arbuste de 4 pieds, à rameaux lâches, velus et tétragones. Feuilles opp. , pét. , cordiformes, molles, crénelées, aussi larges que la main. Fleurs petites, en épis péd., ax., plus courts. que les feuilles.

Lieu. Madere. 
* ig. G. maritime, $T$. marum.

Petit arbuste dont les tiges sont très-nombreuses, en buisson arrondi, très-rameuses, droites et blanches. Feuilles petites, ov., pointues, entières, blanches, sur-tout en-dessous. Fleurs purpurines, ax., unilatérales, en épis alongés et term.

Lieu. L'Espagne. ๖. Fl. en juillet-septembre.

* 20 . G. de Portugal, T. lusitanicum, Lamarck. T. asiaticum, Liv. , H. K.

Cette plante me paroît bien distinguée du teucrium massiZiense. Tiges ligneuses inf., droites, grêles, d'un pied. Feuilles pét. , opp., lanc., oblongues, presque lin. légèrement crénelées, étroites, ridées, d'un vert sombre en-dessus, pâle en-dessous. Fleurs rougeâtres, purpurines, une ou 2 à chaque aisselle, un peu distantes, en épis longs et term.

Lieu. Le Portugal. b. Fl. en juin-octobre. Toujours verte. * 21. G. à odeur de pomme, T. massiliense.

Tiges un peu plus ligneuses que celles de la précédente, rameuses, droites, foibles, grisâtres, d'un pied et demi. Feuilles ovales, en cœur, crénelées, ridées, blanchâtres en-dessous, vertes en-dessus. Fleurs d'un pourpre rose, en grappes droites, ax. et term.

Lieu. La Fr. mérid. Ђ.Fl. en juillet-septembre. Toujours verte.

22. G. royale, T. regium, Schreb.

Tige rameuse. Feuilles ovales, dentées. Fleurs en verticilles rameux, pourpres. Les feuilles florales très - entières et sessiles.

\section{Lieu. L'Espagne.}

* 23. G. de Madere, T. maderense, Lamarck. T. betonicum, L'Héritier, H. K.

Arbrisseau de 2 à 3 pieds, rameux. Tiges droites, velues dans leur jeunesse. F. opp., pét. , ov.-obl., obtuses, arrondies à leur sommet, crénelées régulièrement, entière à leur base, molles, tomenteuses, douces au toucher, d'un vert grisâtre. Fleurs d'un pourpre foncé, ax., formant au sommet des tiges plusieurs épis assez longs.

Lieu. Madère. Ђ. Fl. en août. Toujours vert. 
* 24. Germandrée hétérophylle, T. heterophyllum. T. canariense, LAMARCK.

Arbrisseau de 4 à 5 pieds. Tige ferme, droite, rameuse, cylind. Feuilles pét., opp., elliptiques, arrondies à leur sommet, crénelées régulièrement dans presque tout leur contour, velues, très-douces au toucher. Fleurs latérales, solitaires, laineuses à l'extérieur.

Lieu. Madère Fl. en juin; rarement dans mon jardin. Toujours verte.

25. G. à calice enflé, $T$. inflatum, H. K.

Feuilles oblongues, acuminées, inégalement dentées, pubescentes. Fleurs en épis sessiles et term. Les calices enflós et velus.

Lieu. La Jamaïque. $\Psi$. Fl, en août - octobre. * 26. G. jaune, $T$. flavum.

Tiges de 2 pieds, rameuses, pubescentes. F. opposées, pét, ovales, obtuses, crénelées, un peu épaisses, vertes et luisantes en-dessus, disposées ordinairement en croix sur 4 rangs. opposés. Fleurs d'un jaune pâle, péd., 2 à 3 ensemble, ax., formant des épis terminaux.

Lieu. La France mérid. 5. Fl. en juillet - septembre. Toujours verte.

* Variété plus basse, à feuilles plus petites, blanchâtres endessous. L'épi de fleur aussi long et aussi garni. Indigène en Corse, rustique.

TROISIE ME SECTION.

* 27: G. botride, $T$. botrys.

Tiges droites, tétragones, velues, de 5 à 6 pouces. Feuilles opp., pét., multifides. Fleurs purpurines, ax., latérales, péd. , 4 on 3 ensemble.

Lieu. La France. Fl. en juillet - sept.

* 28. G. ivette, T.chamapitis. Ajuga chamapitis, Willd.

Tiges droites ou couchées, de 4 à 6 pouces, velues, rougeâtres, abondarnment garnies de feuilles, dont les inférieures sont longues et spatulées, et les supérieures divisées en trois lanières, très-étroites. Fleurs jaunes, ponctuées de pourpre ? sess., latérales, sol.

Lieu..... Ind. F. Fl, en juillet. 
29. G. fausse ivette, $\boldsymbol{T}$. pseudo-chamcepitis.

Tige de 5 à 6 pouces, velue et rameuse. Feuilles opp., péd. , blanches, avec des lignes rouges, assez grandes, en grappe terminale.

Lieu. La France méridionale. panulato?

* 3o. G. musquée, T. iva.

Tiges de 3 à 4 pouces, rameuses, diffuses, couchées, trèsvelues. Feuilles opp., nombreuses, rapprochées, obl., ligulaires, velues, légèrement dentées. Fleurs rougeâtres, sess, , ax., sol.

Lieu. Id.

3r. G. épineuse, $\boldsymbol{T}$. spinosum.

Tige droite, tétragone, rameuse, paniculée, d'un pied. Les rameaux aigus et un peu épineux à leur sommet. F. opp., ov. - obl., en coin à leur base; les inf. pinnatifides; les sup. petites et dentées. Fl. blanches, petites, ax., péd. Les corolles retournées. Epines droites, aiguës, ax.

Lieu. L'Espagne. Fl. en août et sept.

Cult.Les germandrées de la premiere section sont de pleine terre. Cependant les cinq dernières de cette section sont sensibles au froid du nord de la France. Pour les y conserver, il faut les planter sur des coteaux ou talus de terre médiocre, pierreuse et sablonneuse, abritées de l'est et du nord, exp. au, midi. Il est prudent d'avoir de ces espèces aussi en orangerie. Quant aux autres elles sont assez rustiques, et viennent dans la plupart des terrains. On les multiplie de graines semées sur vieille couche ou lit préparé à cet effet, et par la séparation de leurs pieds en autome ou en mars.

Les espèces de la seconde section sont d'orangerie, excepté la $25^{e}$, qui est de serre chaude. Ces plantes demandent une bonne terre, une exp. chaude en été, avec des arrosemens proportionnés à la température, et à être placées près des jours dans la serre en hiver. La $26^{\mathrm{e}}$ résiste quelquefois à nos hivers en pleine terre; mais le plus souvent elle est mutilée par la gelée ou périt entierement, sur-łout si elle est dans un bon terrain, et ș̣̂ 
sa végétation a été considérable. On les multiplie par leurs graines semées en pot sur couche, et conduites à la manière indiquée; par les marcottes; par leurs rejetons; par la sépa. ration de leurs pieds et par les boutures. Ces dernieres réussissent dans la plupart des espèces ; les cinq dernières de la première section peuvent se multiplier par ce moyen; elles s'enracinent aisément.

Les espèces de la dernière section étant la place où elles doivent rester, mais dans des terres légères, sablonneuses, chaudes et bien exposées, ou sur de vieilles couches. Quand on prend cette dernière manière, il faut enlever alors les jeunes plantes en motte, pour les placer à leur destination, et les arroser et les abriter jusqu'à leur reprise.

Us. Toutes ces germandrées sont cultivées dans les collections de plantes étrangères ; plusieurs contribuent à l'ornement des jardins.

эrmi celles de la premiere section, on distingue les 3,7 et $8 \mathrm{e}^{\mathrm{e}}$, et les 5 dernières. La $3^{\mathrm{e}}$ est celle dont les épis sont du plus bel aspect. Les cinq dernieres forment de petites touffes assez jolies.

Dans la seconde section on remarque les $16,18,19,21$, 23 et 26 e.

La i $^{\mathrm{e}}$ est des plus agréables par ses grandes fleurs et son feuillage.

La $19^{e}$ est un petit arbuste fort joli par son feuillage, son odeur et ses fleurs.

La $2 \mathrm{I}^{\mathrm{e}}$, par son odeur assez forte, imitant celle de la pomme, et aussi par ses fleurs.

Le marum, ou $19^{e}$ espèce, attire si singulièrement les chats, que ceux-cif finiroient, en se roulant dessus, par le détruire, si on ne les en éloignoit pas.

En médecine on fait usage de la $4^{\mathrm{e}}$, qui a une odeur d'ail, et qui est anti-septique, sudorifique, emménagogue; de la $6^{\mathrm{e}}$, comme tonique, incisive, fébrifuge; de la $19^{\mathrm{e}}$, comme céphalique, pénétrante, tonique, anti-hystérique. On employoit autrefois la $28^{\mathrm{e}}$, dont l'odeur est résineuse, et qui passoit pour très-emménagogue, nervinę et tonique. 
Obs. Pour la facilité et la clarté des indications de culture, j'ai été obligé d'intervertir l'ordre que les botanistes ont suivi dans la nomenclature des germandrées et des sauges. Il en sera de même dans les autres grands genres.

\section{Autres espèces cultivées.}

* 32. G. à feuilles de romarin, T. rosmarinifolium, Hort. Cels.

Cette espèce ressemble au romarin par son port, ses tiges, ses feuilles et leur disposition.

Tige tétragone, droite, rameuse, blanche sur les jeunes pousses . Feuilles opp., sessiles, linéaires, étroites, en pointe obtuse, vertes en-dessus, avec la nervure blanche, blanches en-dessous: à bords roulés, et accompagnées, dans leurs aisselles, de 2 à 4 petites feuilles. Fleurs pourpres, marquées de 3 lignes, plu foncées à la base de la lèvre inférieure, disposées en épis termi. naux.

Lieu..... . Fl. en été. 33. G. de Virginie, T. virginicum, WILLD.

Tige rouge, pubescente, de 3 décim. ( un pied) de hau Feuilles ovales, cordiformes, inégalement et profondément de tées, imitant celles de l'ortie, blanchâtres en-dessous, porté sur de longs pétioles. Fleurs bleues ou rougeâtres, en grapp . courtes et term.

Lieu. La Virginie. $₹$. Fl. en juillet et août. 34. G. d'Orient, G. orientale, Liv.

Feuilles multifides ou pinnatifides, à pinnules linéaires. Fleurs grandes, d'un bleu rougeâtre, en grappes composées.

Lieu. Le Levant, l'Arménie. $\Psi$. Fl. en juillet et août. 56. G. à feuilles de myrthe, T.myrtifolium, Desfont., Cat。

Lieu. Le Levant. . Cultivée au Muséum.

Cult.Les espèces 32 et 35 sont d'orangerie; les deux autres de pleine terre. La $32^{\mathrm{e}}$ n'est pas facile à conserver en hiver. Il lui faut beaucoup de lumiere et une serre sèche. Elle ne doit être arrosée que très-rarement dans cette saison. On la multiplie par ses graines semées selon la manière indiquée pour les plantes de cette serre. Pendant l'été on la mettra en plein soleil. 
La $35^{\mathrm{e}} \mathrm{m}$ 'est inconnue. Les 33 et $34^{\mathrm{e}}$ doivent recevoir la culture des espèces de la première section.

Je fais observer quela première espèce de ce genre est délicate, et ne peut passer en pleine terre que dans le milieu et le midi de la France. Dans lenord, on fera bien de la cultiver en orangerie.

\section{4 étamines fertiles. Corolle à 2 lèvres. Calice quinquéfide.}

\section{Sariette, Satureia.}

Cal. strié. Cor. à limbe à 5 lobes presqu'égaux. Etam. distantes. I. SARIETte à feuilles linéaires, S. juliana.

Tiges droites, ligneuses, de 8 à 10 pouces, un peu rameuses à leur base. F. lin.-lanc., étroites, dures, opp. Fleurs petites, blanches, verticillées sur la moitié des tiges. Les verticilles trèsrapprochés en faisceaux.

Lieu. L'Italie. ₹ ou Ђ. Fl. en mai-septembre.

* 2. S. verticillée, $S$. thymbra.

Tiges grêles, de 2 pieds. F. opp., petites, ovales-obl., pointues. Fleurs un peu plus grandes, d'un rouge vif, en verticilles serrés et velus au sommet des tiges.

Lieu. L'île de Candie. Ђ. Fl. en mai - juillet. Toujours verte.

*3. S. de montagne, S. montana. Thymus montanus., N.

Tiges dures, ligneuses, rameuses, d'un pied. F. opp., lin.lanc., étroites, sessiles, ponctuées, mucronées. Fl. blanches, 2 ou 3 ensemble sur le même péd., ax.

Lieu. La France mérid. ๖.Fl. en juillet.

Ses fleurs sont teintes d'un pourpre léger, plus grandes et plus labiées que celles des autres espèces de ce genre, et garnissent une grande partie de la longueur des tiges. Souvent leur pédoncule commun se biffurque; chaque pédicule porte 3 ou 4 fleurs; une seule reste dans la dichotomie.

Obs. Le calice peu labié, et la forme des feuilles, me paroissent être les seuls motifs qui aient déterminé à mettre cette espèce 
dans ce genre. Les autres parties de la fleur ont beaucoup plus d'analogie aux thyms et aux mélisses.

L'espèce Satureia graca ne diffère de la précédente que par ses feuilles moins mucronées, par ses corymbes de fleurs qui sont solitaires et géminés et par ses collerettes plus courtes que les corymbes. Ses feuilles sont pourpres en-dessous, et parsemées en-dessus d'atômes luisans. Les corolles sont d'un blanc pourpré, avec trois taches presque à leur base.

* 4. S. capitée, S. capitata. Thymus capitatus., BARR., N.

Tige d'un pied. Rameaux grêles et blanchâtres. F. petites, étroites, pointues, dures, blanchâtres, ciliées, ponctuées, carénées, opp. Fleurs purpurines, en têtes term.

Lieu. Le Levant, la France méridionale. octobre.

* 5. S. des jardins, S. hortensis.

. Tige rougeâtre, raméuse, de 7 à ro pouces. F. lanc.-lin: Fleurs petites, rougeâtres, 2 ensemble, péd., ax.

Lieu. La France méridionale. Fl. en juin - août. 6. S. branchue, $S$.viminea.

Feuilles lanc.-ovales, très-entières. Glabres en-dessus, velues et'rudes en-dessous. Pédoncules ax., triflores. Les collerettes linéaires. Rapports aux cuniles.

Lieu. La Jamaïque. Ђ. Fl.

Cult. Les deux premières espèces sont d'orangerie; les deux suivantes passent en pleine terre dans le milieu de la France, mais sont assez sensibles au froid dans le nord. Cependant dans des situations abritées et des terres légères el sablonneuses, elles peuvent résister à nos hivers ordinaires. La cinquième est cultivée dans les potagers, où elle se resème tous les ans elle-même et en abondance. La sixieme est de serre chaude. On multiplie et on obtient les quatre premières par leurs grainessemées en pot sur couche, à la manière indiquée. On peut aussi les propager par leurs rejetons, près de leur pied, ou en séparant avec atten. tion ce dernier. Ces plantes aiment une terre substantielle, mais pas trop compacte, et de la chaleur. En hiver elles doivent être placées près des jours de la serre.

Us. Les sariettes sont de petites plantes assez jolies dans Io III. 
temps de leurs fleurs. Elles ont toutes une odeur aromatique perm nétrante. La cinquième est d'un usage assez fréquent en cuisine, sur-tout pour l'assaisonnement des fèves de marais. Elle est stomachique, diurétique, atténuante.

On cultive au Muséum une autre espèce de sáriette nommée S. globulifera, Desfont., Cat. : elle est de l'Amérique sept. $\tau$, et de pleine terre. Sa culture doit être la même que celle de la $5^{\mathrm{e}}$ espèce.

8. SARIETTE des rochers, S. rupestris, Willd., JAcQ. S. thymifolia, Scop.

Cette espèce est presque frutescente. Ses feuilles sont ovales, dentées, un peu pointues, ponctuées en-dessous. Fleurs en cimes unilatérales, pédonculées, axillaires. Les divisions du calice obtuses.

Lieu. La Carniole. $\%$, Fleurit en juin et juillet.

Cult. Plein air.

\section{Hysope, Hyssopus.}

Cal. presque strié. Le tube de la corolle égal au calice; le limbe à 2 lèvres ; la sup. courte et échancrée ; l'inf. à 3 lobes, dont celui du milieu est plus grand, un peu en cœur et crénelé. Etam. distantes.

* I. Hysope officinale, $\boldsymbol{H}$. officinalis.

Tiges droites, nombreuses, frutescentes, d'un pied et demi. Feuilles opp., linéaires-lanc., étroites, pointues, très-entières. Fleurs bleues, plısieurs ensemble, ax., unilatérales, formănt des épis fevillés et term.

Lieu. La France méridionale. ๖. Fl. en juin-septembre. Toujours verte.

Variétés. I. à fleurs rouges.

2. à fleurs blanches.

3. à feuilles velues.

4. à feuilles de myrte, $\boldsymbol{H}$. mrrtifolius, DrsFont. $\boldsymbol{H}$. decussatus, Persoon. H. officinalis, Y. LAM. 
Celte variété ou espèce a ses feuilles d'un vert pâle et plus étroites. Ses fleurs sont d'un violet foncé. Son pays originaire est inconna.

5. à feuilles panachées. Accidentelle.

* 2. H. à feuilles de moldavique, $\boldsymbol{H}$. lophantus.

Tiges d'un pied et demi , tétr., ram. F. opp., ov.-obl., un peu en cœur à leur base, obtuses, crénelées. Fl. bleuâtres, assez grandes, 3 à 5 ensemble, péd., ax. La corolle renversée.

Lieu. La Sibérie. $\longleftarrow$. Fl. en août et septembre.

* 3. H. à feuilles de scrophulaire, $\boldsymbol{H}$. nepetoides.

Tiges droites, à 4 angles tranchans, glabres, branchues, de 5 pieds. F. op., pét. , cordiformes, pointues, dentées en scie, grandes et d'un vert jaune. Fleurs blanches, très-petites, nonbreuses, en épi serré, cylind. term.

Lieu. La Virginie, le Canada. $\%$. Fl. en août-octobre. * 4. H. à feuilles de basilic, $H$. ocymifolius, Lamarck. Elsholtia cristata, Persoon. Menta ovata, $\mathrm{C}_{\mathrm{Av}} \ldots$

Tige très-rameuse, formant un petit buisson arrondi, d'un pied environ. F. opp., ovales, pointues, dentées, pét. Fleurs petites, d'un pourpre pâle, nombreuses, unilatérales, en épis très-serrés et term. L'autre côté de l'épi , qui n'a point de fleurs, est garni sur les côtés de deux rangs de bractées.

Lieu... . Fl. en juillet et août.

Cult. Pleine terre. La première, depuis long-temps cultivée, se plaît dans les terres légères et exposées au soleil; elle ne dure pas long - temps à l'ombre et dans les terres fortes et fraîches. Les fortes gelées lui font perdre une partie de ses tiges, et abrègent aussi sa durée. Il faut la renouveler tous les 3 ans, en la multipliant à cet effet par les marcottes ou les boutures. Sa plan. tation se fait avec plus desuccès en mars. Les boutures se font au printemps. La $4^{\mathrm{e}}$ variété me paroît plus délicate.

Les $2^{\mathrm{e}}$ et $3^{\mathrm{e}}$ espèces s'obtiennent par le semis fait sur vieilles couches ou planches de terre légère, préparées. Lorsque ces plantes ontacquis de la force, ce qui arrive vers le mois de juillet, on les enlève, s'il est possible, en motte, et on les plante à demeare. Ces especes viennent assez bien dans tous les terrains. La $3^{e}$ se sème ordinairement elle-même. 
$\mathrm{La} 4^{\mathrm{e}}$ se sème au printemps en place, dans une bonne terre un peu légère et bien exposée; ou sur vieille couche, pour être repiquée en motte : ces soins sont ensuite inutiles. Quandune fois cette plante s'est semée elle-même sur couche ou en pleineterre, il en lève chaque année en abondance.

Us. L'hysope officinale forme un buisson assez agréable dans le temps de ses fleurs. Ses propriétés aromatiques ne laissent aucun doute sur ses effets, qui sont communs à presque toutes les plantes de cette classe. On la prescrit dans l'asthme, dans les embarras du poumon, et pour inciser les matières glaireuses.

Les 2 autres font peu d'effet par leurs fleurs. La $3^{\mathrm{e}}$ a un beau port, et son aspect est si différent des hysopes, qu'on a de la peine à se figurer qu'elle en est une espèce; aussi Jussieu doutet-il si elle est véritablement congénère.

La $4^{\mathrm{e}}$ est cultivée pour son odeur. En effet, elle en a une trèsaromatique, forte et pénétrante, mais agréable et approchant de celle de la rose.

\section{Chataire, Nepeta.}

Tube de la corolle long et courbé, ouvert à son entrée, à limbe à 2 lèvres; la sup. échancrée, l'inf. à 3 lobes; les 2 latéraux très-courts et réfléchis; celui du milieu plus grand, crénelé et concave. Etam. rapprocbées.

* i. Chataire commune, $N$. cataria.

Tige carrée, branchue, de 2 à 3 pieds, blanchâtre. Feuilles opp., pét. , cordiformes, denté es en scie, blanchâtres en-dessous, un peu ridées. Fleurs d'un pourpre pâle ou blanches, verticillées en épis term., accompagnées de bractées sétacées.

Lieu. Ind. $\%$. Fl. en juillet - sept.

2. C. de Hongrie, N. pannonica, H. K., JAcQ.

Tige carrée, très-rameuse, d'un pied et demi. Feuilles opp.; pét. , cordiformes, obl., dentées et nues. Fleurs d'un bleu trèspâle, en grappes term.

Lieu. La Hongrie, l'Autriche. $\Psi$. Fl. en août - octobre. * 3. C. bleue, N. carrulea, H. K.

Feuilles oblongues, en cœur, velues, presque sessiles. Fleurs en grappes pédonculées, velues ot multiflores. 


\section{E L A B I É T S.}

Lieu.... $\%$. FI, en mai et juin.

* 4. C. violette, $N$. violacea, H. K.

Tige carrée, rameuse, blanchâtre, de 3 à 4 pieds. Feuilles ovales - obl., cordiformes à leur base, légèrement crénelées, peu pétiolées, d'une couleur cendrée. Fleurs violettes, petites, en paquets opposés, formant des épis interrompus et velus.

Lieu. L'Espagne. ₹. Fl. en juillet-sept.

* 5. C. à đleurs lâehes, $N$. nepetella, H. K.

Tige d'un pied, très-rameuse. Feuilles pét. , obl.-lanc. , cordiformes, profondément dentées en scie, cotonneuses. Fleurs rougeâtres; en bouquets, formant des grappes lâches et term. ; toute la plante blanchâtre.

Lieu. L'Europe mérid. $₹$. Fl. en juillet - septembre.

*6. C. nue, C. nuda.

Tiges carrées, simples, de 4 pieđs. Feuilles oblongues, dentées, sessiles. Fleurs blanchâtres, en verticilles nus, formant des grappes paniculées", term. Bractées un peu épineuses.

Lieu. Id. ₹. Fl. en juin - août.

* 7 . C. d'Italie, $N$. italica.

Tige simple, d'un pied et demi. Feuilles pét., cordiformes, crénelées. Fleurs blanches, en verticilles garnis de beaucoup de bractées, et disposés en épi term.

Lieu. L'Italie. $\%$. Fl. id.

8. C. à longs épis, $N$. hirsuta.

Tige rameuse, d'un pied et demi. Feuilles ovales-oblongues, crénelées. Fleurs petites, purpurines, en verticilles serrés, garnis de bractées subulées et formant des grappes term. Les verticilles inf. pédiculés.

Lieu. La Sicile. $\%$.

9. C. à feuilles de germandrée, $N$. teucrioides. $N$. incana, H. K.;

Willd., Bot. cult., éd. I. N. orientalis, Miller.

Ces différentes dénominations sont synonymes à cette espèce. Elles se rapportent aussi à la chataire de Tournefort. Cataria orientatis teucriifolia, lavandula odore, verticillis flortmo crassissimis.

Plante blanchâtre dans toutes ses parties. Tige carrée, de zpiedșa 
Feuilles petites, pét., cordiformes, crénelées. Fleurs en verticilles séparés, garnis de beaucoup de bractées, velues, à bords blancs. Lieu. Le Levant. $\nsucc$.

10. Chat taire tubéreuse, $N$. tuberosa, H. K.

Tige de 3 à 4 pieds, laineuse, blanchâtre, rameuse. Feuilles cordiformes, oblongues, crénelées, pubescentes. Fleurs d'un pourpre violet, verticillées, garnies de beaucoup de bractées, oblongues, acuminées, formant des épis term.

Lieu. L'Espagne. భ. Fl. en juin - ạoût.

1. C. laineuse, $N$. lanata, H. K., JAcQ.

Feuilles oblongues, cordiformes, velues. Les verticilles des fleurs garnis de bractées ovales, nerveuses, ridées, un peu scarieuses, formant des épis term. Les lobes latéraux de la lev. inf. simplement ouverts.

Lieu..... . Fl. en mai et juin.

12. C. de Virginie, N. virginica. Pycnanthemum aristatum. Mrchaux.

Tiges droites, fermes, carrées, rameuses, d'un pied et demi. Feuilles sessiles, lanc., glabres, entieres. Fleurs petites, blanches, en verticilles ax. et en têtes term. La lève infér. n'est point concave; les bractées sont terminées par une barbe.

Lieu. L'Amérique sept. $\longleftarrow$. Fl. en août.

13. C. multifide, N. multifida, Lrs. fils, Botryoides, H. K. N. bipinnata, $\mathrm{CAv}$.

Tige de 6 pouces, carrée, rougeâtre, rameuse. Feuilles pét., multifides, à découpures linéaires, presqu'égales, d'un vert cendré. Fleurs petites, blanches, en épi nu, term.

Lieu. La Sibérie. Fl. en juin et juillet.

I4. C. pectinée, N. pectinata. Bystropogon pectinatum, L'Héritier, H. K.

Tige tétragone, branchue et rameuse. Feuilles pétiolées, cordiformes, veineuses, dentées en scie. Fleurs petites, jaunes, disposées en épis verticillés et terminaux.

Lieu. La Jamaique. ๖. FI. en déc. et janvier.

Cult. Pleine terre, excepté la $14^{\mathrm{e}}$, qui est de serre chaude. Toutes les autres chataires sont rustiques, et croissent dans presque tous les terrains, pourvu qu'ils ne soient ni trop ombragés 
ni trop humides. On les multiplie par leurs graines semées dans des planches destinées à ces sortes de semis. On peut enlever les jeunes plants au mois de juillet, et les placer à demeure. Quand on les possède, on les propage par la sẻparation de leurs pieds, cn automne ou en mars. Plusieurs se sèment elles-mêmes.

Us. La plupart de ces plantes ne font pas un grand effet; cependant quelques-unes se font remarquer, et ne laissent pas que de varier les parterres de plantes étrangères. La $10^{\circ}$ se distingue avantageusement par ses beaux épis nombreux et bien colorés.

La premiere est carminative, incisive. On appelle particulièrement cette espece chataire, ou herbe aux chats, parce que ces animaux se roulent souvent sur cette plante; mais ils préferent cependant la germandrée maritime, teucrium marum.

\section{Autres espèces cultivées.}

\section{* I5. C. réticulée, Nepeta reticulaia, Willd.}

Cette espèce forme un buisson d'un mètre et plus de hau= teur. Tiges droites, rameuses, tétragones, à angles arrondis, canaliculées sur les faces, rougeâtres sur les angles, fermes, parsemées de poils blancs, longs et rares. Feuilles opposées en croix, sessiles, presque amplexicaules, oblongues, pointues, crénelées, très-ridées, légèrement velues, d'un vert foncé et souvent tachetées d'un jaune verdâtre. Fleurs verticillées, en épis terminaux, très-longs ; les verticilles au nombre de vingt environ; les fleurs nombreuses, pressées dans leurs verticilles, accompagnées de bractées, ovales, pointues, dentées, colorées, d'un violet pâle, veinées et paroissant réticulées. Corolle d'un violet pâle ou d'un bleu purpurin foncé; la levre supérieure droite et échancrée en cœur; l'inférieure à 3 divisions, dont la moyenne, plus grande, est creusée en cuiller, dentée et ondulée en ses bords. Calice velu, cylindrique, à 5 divisions pointues.

Lieu. La Barbarie. $\%$. Fleurit en été.

Cult. Pleine terre. On la multiplie par les graines et par Ia séparation de son pied au printemps. Elle se plaît dans 
les terrains secs et chauds, où elle se multiplie souvent d'elle-même.

Us. Cette chataire, par son port et ses longs épis bien colorés, est une des plus intéressantes.

16. Chataireà longues fleurs, Nepetalongiflora, Vent., Jard.

Cels.

Tiges droites, tétragones, nombreuses, striées, légèrement duvetés, rameuses, de 5 décim. , d'un vert cendré. Rameaux courts. Feuilles pétiolées, opposées, ovales-cordiformes, obtuses, crénelées, ridées, légèrement velues. Fleurs d'un bleu foncé, un peu velues, pédonculées, disposées en grappes terminales droites, composées de plusieurs verticilles presque unilatéraux. Le tube deux fois plus long que le calice. Souvent la grappe est terminée par des bractées bleues, à la manière de la sauge ormin.

Lieu. La Perse. $\nsucc$. Fleurit pendant une partie de l'année.

Cult. Pleine terre; la même que celle des autres chataires. 17. C. crispée, Nepeta crispa, Willd.

Tige rameuse, droite, haute de 3 à 5 décimètres. Feuilles opposées, en cœur, obtuses, inégalement dentées, ridées, ondulées, frisées, tomenteuses, blanchâtres sur les deux surfaces, de 2 à 3 cent. Fleurs bleues, pédonculées, en grappes terminales, interrompues, composées de plusieurs verticilles pauciflores. Bractées velues et sétacées, très-petites.

Lieu. . . . * . Fleurit en juillet et août.

Cult. Pleine terre. Cette espece mérite d'être cultivée pour I'ornement des parterres.

18. C. de l'Uckraine, $N$. ucranica, Lin.

Feuilles lancéolées, dentées en scie, nues, sessiles. Fleurs bleuâtres, en panicules.

Lieu. L'Ukraine. $\longleftarrow$. Fleurit en juin et juillet.

39. C. multifide, N. multifida, LIN. N. Lavandulacea, LIN., Suppl.

Tige droite, presque simple. Feuilles inférieures pétiolées; les supérieures sessiles, oblongues, à 3,4 et 6 lobes oblongs et alternes. Fleurs très-petites.

Lien. La Sibérie. $\tau$. Fleurit en juillet et août. 
zo. C. odorante, $N$. suaveolens, Hort. angl. $\Psi$.

Cult. Les trois dernières espèces sont de plein air.

2r. C. à feuille de marum, N. marifolia, $C_{A v}$., Icon. Vojez Melissa cretica.

En général les chataires ne sont pas toutes très-vivaces et d'une conservation certaine. Quand leurs graines ne mûrissent pas, et qu'on n'a pas eu l'attention de les propager par une autre voie, il faut s'attendre à perdre plusieurs espèces. Ce sont des plantes, à l'exception de la première, des pays méridionaux, qui demandent de la chaleur, et une terre plus légère que forte, dans le nord́ de la France,pour qu'elles puissent s'y maintenir quelques années.

\section{Pérille, Perilla.}

La div. sup. du cal. très-courte. Cor. de la chataire. Le lobe moyen non crénelé. Etam. distantes. Style à 2 parties.

PérIlle à feuilles de basilic, $\boldsymbol{P}$. ocymoides. Melissa perilloides, Lam.

Feuilles ovales, dentées en scie. Fleurs blanches, petites. Bractées longues, foliacées.

Lieu. L'Inde. . Fl. en juillet et août.

Cult. Serre chaude.

\section{Lavande, Lavandula.}

Cal. ovale, denté, soutenu par une bractée. Cor. renversée, plus longue, à limbe à 5 lobes presqu'égaux. Etam. non saillantes.

* I. Lavande commune, L. spica. Aspic.

Tige courte, divisée en rameaux nombreux, droits, simples, carrés, qui s'élèvent à a à 3 pieds. Feuilles opp., sess., lanc.lin., roulées en leurs bords, d'un vert grisâtre. Fleurs bleues, en épi simple, interrompu à sa base et term.

Lieu. La Fr. mérid. Ђ. Fl. en juillet-sept. Toujours verte.

Variété à fleurs blanches.

Id. à larges feuilles, L. latifolia.

¥2. L. stoechade, L. stoechas. 
Tige assez droite, trèsfferme, rameuse; les rameaux tétragones, très-fenillés. Feuilles opp., sess., linéaires, étroites, blanchâtres, à bords roulés. Fleurs d'un violet foncé, en épi dense, court, carré, terminé par un paquet de feuilles florales, d'un pourpre bleuâtre. Ces épis sont tous terminaux et imbricés de bractées.

Lieu. Id. Ђ. Fl. en mai-juillet. Toujours verte.

Variété à rameaux nus à leur sommet. Stoechas pedunculata, Miller.

5. LaVANde verte, $L$. viridis, H. K., L'Héritier.

Feuilles sess., linéaires, ridées, velues, roulées en leurs bords. Fleurs en épi, terminées par un toupet ou un paquet de feuilles florales. Les bractées entières.

Lieu. Madère. Ђ. Fl.id.

* 4. L. dentée, L. dentata.

Tige rameuse, d'un pied et demi. Les rameaux carrés et grêles. Feuilles opp., sess., lin., étroites, profondément crénelées, même pectinées, un peu velues en-dessous. Fleurs d'un bleu rougeâtre pâle, en épi terminal, peu serré, quelquefois couronné par quelques feuilles florales.

Lieu. L'Espagne, le Levant. ๖. Fl. en juin-septembre. Toujours verte.

* 5. L. pinnée, L. pinnata, JAcQ.

Tige d'un pied, branchue, nue à sa base. Feuilles opp. , irès-rapprochées, pét. , pinnées; les pinn. lin., cunéiformes, obtuses, simples, ou bi ou trifides à leur sommet, d'une couleur grisâtre. Fleurs violettes, en épis terminaux, imbricés de bractées ou d'écailles uniflores.

Lieu. Madère. $\sigma^{T}$ ou 3-annuelle. Fl. en avril. - octobre.

*6. L. multifide, L. multifida, Wilud.

Tiges droites, carrées, blanchâtres, d'un pied environ, velues. Feuilles opp., pét, , bipinnées, d'une couleur cendrée. Fleurs bleuâtres, en épi tétragone et spiraliforme.

Lieu. L'Espagne, les Canaries. or. Fl, id.

${ }^{*}$ j. L. à feuilles d'aurone, L. abrotanoides, LaMAR cK. L.canariensis, Miller. L. elegans, Desfont.

Tiges de 2 pieds, carrées et velues. Feuilles opp., bipinnées, 
vertes, presque glabres, à folioles menues, décurrentes, garnissant la partie inf. de la tige. La feuille entière plus grande que celle de la précédente. Fleurs d'un bleu foncé, en plusieurs épis grêles, opp., rapprochés de l'épi terminal, plus long que les autres, et souvent tourné en spirale.

Lieu. Les Canaries. $\sigma^{\nearrow}$ ou $\tau$.

Obs. Il paroît par la synonymie de Pluk. Alm., que cite Aiton dans son espèce pinnata, et que cite de même Lamarck dans celle-cı, que cette espèce, selon Aiton, n'est pas même une variété de la $L$. pinnata. Elle diffère cependant par ses feuilles très-vertes et plus grandes.

8. L.à feuilles épaisses, L. carnosa, Liv.

Feuilles pét. , ovales, cordiformes, dentées en scie, charnues. Fleurs en épi tétragone; les calices recourbés. Floraison sans feuilles.

Lieu. Les Indes or. $\sigma^{7}$ FI. en juin.

9. L. hétérophylle, L. heterophylla, Viviani, Elench., Pers., Desfont, Cat.

Feuilles elliptiques, sessiles, dentées incisées etlinéaires، Fleurs en épis cylindriques.

Lieu. L'Espagne, la Barbarie, le Levant. Ђ. Cultivée au Muséum.

Cult. On cultive depuis long-temps la première espèce dans les jardins pour son odeur, ses propriétés etl'agrément. Elle croît assez bien dans tous les terrains. Cependant ceux qui lui conviennent le mieux sont les légers, chauds et bien exposés. Les fleurs auront d'autant plus d'odeur que leurs pieds seront dans une terre médiocre, légère comme les coteaux exposés au midi. On la plante ordinairement en bordure ou en petites palissades. Elle ne dure pas bien long-temps dans les bons terrains, mais elle y est plus belle. On doit la renouveler tous les 3 ans, et la tondre à 5 ou 6 pouces de terre après la floraison. Il faut faire en sorte que ses rameaux partent de la surface de la terre, et qu'elle ne forme pas de souche au-dessus. A cet effet on la plantera de manière que la partie inférieure de ses rameaux soit dans la terre. Par ce moyen ses jeunes rameaux 
s'enracineront; la plante deviendra mieux fournie; et quand on la déplantera, on trouvera de jeunes plants bien enracinés.

Les autres espèces sont d'orangerie, excepté l'avant-dernière, qui est de serre chaude. Elles demandent une bonne terre, et une exposition méridienne en été, près des jours, pendant l'hiver, dans la serre, et peu d'arrosemens dans cette saison. Pour le reste, les soins ordinaires. On les multiplie par leurs graines semées sur couche et en pot à la manière indiquée. Lorsque les jeunes plantes ont été bien conduites, elles fleurissent dans le même été. La cinquième est, de toutes celles d'orangerie, la plus sensible au froid et à l'humidité. Elle périt quelquefois la première année.

Us. La lavande commune peut trouver place dans les jardins d'agrément. On la rencontre avec plaisir, à cause de son odeur et de ses buissons fleuris. Elle est cordiale, céphalique et wulnéraire. On en fait une eau qui est d'un fréquent usage. On en tire aussi de l'huile essentielle.

Les espèces 5,6 et 7 ont un joli feuillage.

La $2^{\mathrm{e}}$ et la $3^{\mathrm{e}}$ contribuent à la variété parmi les plantes de de serre. La $2^{\mathrm{e}}$ se remarque par ses toupets colorés.

\section{Crapaudine, Sideritis.}

Cor. égal au calice ou plus longue, à limbe presqu'égal, a 2 lobes sup. et 3 inf., dont le moyen est plus large et crénelé. Etam. non saillantes. 2 stigm. inégaux, dont l'un embrasse l'autre à sa base.

* I. Crapaudine des Canaries, S. canariensis.

Tige de 2 à 3 pieds, assez droite; les rameaux très-ouverts et très-cotonneux. Feuilles pét., assez grandes, cordiformes, crénelées, épaisses, veloutées, vertes en-dessus, blanchâtres et cotonneuses en-dessous. Fleurs petites, blanches, verticillées, en épi terminal souvent penché; les verticilles sont laineux, et la couleur générale de la plante, excepté le dessus des feuilles, est d'un blanc jaunâtre.

Lieu. Les Canaries. Fl. en mai-août. Toujours verte. 
* 2. C. blanche ou de Crète, S. cretica, LamareK. S. candicans, H. K.

Cette espèce differe de la première assez sensiblement. Sa tige est moins haute; ses rameaux föibles, très-cassans. Ses feuilles plus petites, un peu verdâtres en-dessus. Les fleurs sont au nombre de 8 , verticillées. Toute la plante est couverte d'un coton très-blanc et doux au toucher.

Lieu. Madère, l'île de Candie. Đ. Fl. id. Toujours verte.

3. C. de Syrie, S. syriaca.

Tige ligneuse inf., poussant des jets foibles, de 2 pieds et demi, couverts d'un duvet laineux. Feuilles inf. pét., ov.oblongues, obtuses ; les sup. sess., très-entières, toutes cotonneuses comme les tiges. Fleurs jaunâtres, verticillées, au nombre de 6 , en épis interrompus et term.

Lieu. Le Levant. Ђ. Fl. en juin-sept. Toujours verte.

* 4. C. perfoliée, S. perfoliata.

Tige rameuse, velue, tétragone, de 2 pieds. Feuilles inf. pét., ov.-obl., molles, crénelées, velues; les sup. entières, ridées, opp., amplexicaules.'Fleurs blanches, avec des lignes pourpres, 6 par verticilles, en épis term.

Lieu. Le Levant. $\longleftarrow$. Fl. en août-novembre.

*5. C. de montagne, S. montana.

Tiges presque couchées, velues, d'un pied, garnies dans toute leur longueur de feuilles petites, ovales, velues, terminées par une pointe. Fleurs jaunes, tachées de pourpre en leurs bords, au nombre de 6 par verticilles lâches. Les calices roides et épineux.

Lieu. L'Italie. Fl. en juillet et août.

6. C. noirâtre, S. elegans, MUrRAYE, H. K. S. nigricans, H. P:

Tige diffuse, velue. Les div. cal. presqu'égales et épineuses. La corolle blanche et son limbe noir.

Lieu... Fl. en juillet.

* ๆ. C. spatulée, S. romana.

Tiges simples, carrées, velues, couchées et redressées à la floraison, garnies dans toute leur longueur de feuilles alongées, spatulées, obtuses, dentées; les sup. très-rapprochées. Fleurs 
blanches, au nombre de 6 par verticille, garnissant presque toute la tige. Les calices roides et piquans.

Lieu. L'Italie. ơ. Fl. en juin-août.

*8. Crapaudine blanchâtre, S. incana, Cav.

Souche ligneuse, de laquelle s'élèvent plusieurs tiges droites, cotonneuses, de 8 à io pouces. Feuilles lanc. -lin., trè-droites, cotonneuses, blanchâtres. Fleurs jaunes, en verticilles séparés, avec des bractées dentées. Les calices épineux.

Lieu. L'Espagne. Ђ. Fl. en juillet et août.

* 9. C. à feuilles d'hysope, S. hyssopifolia.

Tiges simples, dures, de 7 à I o pouces. Feuilles oblongues, spatulées, très-entières. Fleurs en verticilles serrés, formant un épi court, compacte et term.

Variété à feuilles plus étroites, pointues, vertes, et dont l'épi est composé de verticilles séparés.

Toutes deux ont des bractées dentées et épineuses.

Licu. L'Italie, la Fr. mérid. ¥. Fl. en juin-novembre.

10. C. scordioïde, S. scordioides, CAv.

Tiges de 7 à 8 pouces, redressées, laineuses. Feuilles obl., velues, dentées. Fleurs jaunâtres, en verticilles distincts et épineux, disposés en épi terminal. Les bractées ovales, dentées, épineuses.

Lieu. La France mérid. $\Psi$. Fl. en août-nov.

* I I. C. velue, S. hirsuta.

Souche de laquelle s'élèvent des tiges redressées, velues, de 4 à 7 pouces. Feuilles petites, obl., obtuses, dentées, velues. Fleurs en verticilles écartés; la lèv. sup. blanche, l'inf. jaune. Bractées dentées, cordiformes.

Lieu. Id. ₹. Fl. en juin et juillet.

* 12. C. glauque, S. glauca, H. P., CAv., Wilud.

Tiges nombreuses, rameuses, grêles, presque nues ou peu feuillées, carrées, glauques. Feuilles très-distantes, opposées, sessiles, petites, spatulées, très-entières et glauques. Fleurs petites, blanches, disposées en verticilles de 6 fleurs, qui terminent les tiges et les rameaux : non odorantes.

Lieu... ঋ. Fl. en août et sept.

Cult. Les espèces I , 2, 5, Z et $12^{\circ}$ sont absolument 
à'orangerie: Aiton indique toutes les autres de pleine terre. Il est vrai que dans les hivers doux, et dans les situations abritées et chaudes, ces plantes pourroient résister dans le nord de la France; mais je puis assurer que les gelées les endommageront considérablement, et les feront périr en peu de temps. Il est certain qu'elles se conserveront mieux dans les terres légères et aux situations ci-dessus ; cependant je les ai essayées différentes fois, et dans plusieurs endroits, sans succès. Ces plantes ont, il est vrai, peu d'agrément, et ne méritent pas de grands soins; mais les cultivateurs des pays septentrionaux qui voudront les cultiver en pleine terre, doivent du moins en avoir quelques individus en pot, pour pouvoir les mettre à l'abri pendant l'hiver. On voit que je ne parle ici que de laculture septentrionale ; ces plantes passeront très-bien en plein air dans le milieu de la France, et même à Paris, dans les froids ordinaires.

Celles d'orangerie aiment une terre substantielle, un peu consistante. Il leur faut très-peu d'arrosemens en hiver, et sur-tout l'air renouvelé. On les multiplie toutes par leurs graines, qui mûrissent dans nos climats lorsque les étés sont chauds. On les sème en terrine sur couche à la manière indiquée.

Us. Parmi toutes ces crapaudines, la $1^{\text {re }}$ et la $2^{\mathrm{e}}$ sont sans contredit les plus belles et les plus dignes des soins du cultivateur. Leur blancheur est tout-à-fait remarquable, et varie agréablement la verdure des autres feuillages.

13. C. pullulante, Sideritis pullulans, Vent., Jard. Cels.

Tige droite, cylindrique, rameuse, velue, rude au toucher, garnie de rejets à sa base, de 6 décim. de hauteur. Rameaux opposés, montans. Feuilles opposées en croix, ovales-lancéolées, ridées, presque drapées, d'un vert cendré; les inférieures pétiolées; les supérieures sessiles. Fleurs sessiles, droites, presque couvertes par les bractées, disposées en épis solitaires, courbés, verticillés, terminaux ; la levre supérieure blanchâtre ; l'inférieure d'un jaune soufre. Anthères de la même couleur.

Lieu. Le Levant. Ђ. Fleurit en août et septembre.

Culi. Orangerie. 
Cette espèce a, selon Ventenat, beaucoup de rapport avec les espèces, $S$. distans et $S$. laurica.

\section{Menthe, Mentha.}

Cor. un peu plus longue que le calice, à 4 lobes presqu'égaux; le sup. un peu plus large et échancré. Etam. distantes.

\section{Verticilles en épis terminaux.}

* I. Menthe sauvage, M. sylvestris. Baume sauvage.

Tige de 2 pieds, droite, cảrrée, blanchâtre. Feuilles opp. , sess., ov.-obl., pointues, dentées, blanches et cotonneuses endessous. Fleurs rougeâtres, en épis alongés. Les étam. beaucoup plus longues que la corolle.

Lieu. . . Ind. $\%$. Fl. en juillet-sept.

* 2. $M$. verte, $M$. viridis, Menthe romaine.

Tige d'un pied et demi, droite, carrée, rameuse, glabre. Feuilles lanc., sess., pointues, dentées en scie, les dents un peu distantes. Fleurs rougeâtres, en épis grêles, alongés et rétrécis en pointe. Les étamines plus longues que la corolle.

Lieu. La France, l'Angleterre. $\%$. Fl. en août.

* 3. M. poivrée, $M$. piperita.

Tiges carrées, droites, légèrem ent velues, d'un pied et demi, glabres à leur base. Feuilles pét. , ovales - obl. , pointues, dentées en scie. Fleurs rougeâtres, en épis un peu courts, cylindriques, obtus à leur sommet. Interrompus à leur base.

Variété à épis alongés et presque en tête.

Lieu. L'Angleterre. $\longleftarrow$. Fl. en août. * 4. M. ridée, Menthastre, $M$ rotundifolia.

Tige de 2 pieds, droite, rameuse, cotonneuse. Feuillessess., ovales - arrondies, épaisses, ridées, légèrement dentées, douces au toucher, blanches et cotonneuses en-dessous. Fleurs carnées, en épis grêles, longs et pointus.

Lieu. Ind. $\%$. Fl. id.

* 5. M. frisée, M. crispa.

Tiges carrées, velues, rameuses, d'un pied et demi. Feuilles 
sess., assez grandes, cordiformes, pointues, dentées, ridées, ondulées et crispées en leurs bords. Fleurs rougeâtres, en épis alongés, cylindriques, un peu pointus. Souvent en tête. Etamines égales à la corolle.

Lieu. La Sibérie. . Fl. id. Rapports avec la précédente. 5 bis. M. à feuilles de lavande, M. lavandulafolia, DEsfont.

H. P. , PERSoun.

Feuilles linéaires-lancéolées, presque entières. Fleurs en épi grêle, les hractées sétacées, plus longues que le calice. Toute la plante blanchâtre; odeur de la sauge.

Lieu. L'Amérique. $\psi$.

\section{Verticilles en têtes terminales.}

*6. M. aquatique, $M$. aquatica.

Tiges d'un pied et demi, droites, carrées, velues. Feuilles pét., ovales, dentées, velues, d'un vert pâle ou grisâtre. Fleurs violettes, en un verticille terminal, en forme de tête arrondie; assez souvent il y a un second verticille au-dessous.

Lieu. Ind., très-commune. $\longleftarrow$. Fl. en juillet.

La menthe velue, $M$. hirsuta, ne paroît être, ainsi qu'Hudson la observé, qu'une variété de la précédente, dont elle ne diffère que par ses feuilles, qui sont presque sessiles et pubescentes: 7. M. citrounée, $M$. citrata, Wilid. $M$. odorata, Sмiтн.

Tiges très-glabres. Feuilles elliptiques, obtuses, dentées en scie, glabres, pétiolées. Etamines plus courtes que la corolle. Calices parsemés de points résineux. Cette espèce a encore beaucoup de rapports avec la M. aquatique. Elle a une odeur de citron très-agréable.

Eieu. L'Europe. $\%$.

Verticilles axillaires.

* 8. M. cultivée, $M$. sativa. Baume des jardins.

Tiges carrées, droites, rameuses, rougeâtres, un peu velues, d'un à 2 pieds. Feuilles un peu pétiolées, assez grandes, ovales 2

II. 
wn peu pointues, dentées en scie, d'un vert obscur. Fleurs d' in bleu pâle. Les étam. plus longues que la corolle.

Lieu. L'Angleterre. $\%$. Fl. id.

La menthe rouge, $M$. rubra, Smith, a beaucoup de rapport à l'espèce précédente; sa tige est flexueuse quoique droite, ct rouge. Les dents des feuilles sont velues; ses corolles sont ponctuées. On la trouve dans les lieux humides, sur les bords des ruisseaux.

* 9. Menthe des jardins, $M$ : gentilis, $\boldsymbol{M}$. pratensis.

L'espèce précédente a beaucoup de rapports à celle-ci. Tiges droites, carrées, très-rameuses, brunes. Feuilles pét., ovales, pointues, dentées en scie, vertes des deux côtés, très-peu velues. Fleurs purpurines, en verticilles, garnissant la moitié de la longueur des tiges. Etam. plus courtes que la corolle, qui est velue à son sommet.

Lièu. Près d'Abbeville. Ind. $\%$. Fl. en juillet.

* Iо. M. des champs, $\boldsymbol{M}$. arvensis, $\boldsymbol{M}$. procumbens, Flore paris.

Tiges en grande partie couchées, velues, rameuses. Feuilles ovales, dentées, velues, d'un vert grisâtre. Fleurs violettes. Les calices très-velus.

Lieu. Dans les champs et les potagers. Très-commune. Ind. $\%$. Fl. en novembre.

* I I. M. pouliot, $M$. pule gium.

Tiges nombireuses, grêles, étalées sur la terre. Feuilles petites, ovales, arrondies, légèrement dentées. Fleurs roses, en verticilles sur presque toute la tige; point de bractées.

Lieu. Près Abbeville, selon Belleval. Ind. $\%$. Fl. en août.

* I2. M. cervine, M. cervina. Pulegium cervinum, Millier.

Tiges de 8 à io pouces, grêles, lisses, rameuses. Feuilies glabres, très-étroites., lin., pointues, ponctuées. Fleurs carnécs, en verticilles très-garnis, écartés et arrondis, avec des bractées palmées.

Lieu. La France mérid. $\tau$. Fl. en juin - août.

Fleurs non verticillées. Bystropogon, L'Héritier, H. K.

* 15. M. des Canaries, M. canariensis.

Tige de 5 is 4 pieds, droite, branchue, roide, brune, me 
peu velue dans sa jeunesse. Feuilles opp., ovales, arrondies, crénelées, molles, vertes, cotonneuses et pâles en -dessous. Fleur blanches, très-petites, nombreuses, ramassées en petites têtes cotonneuses et sphériques, péd., ax.

Li ieu. Les Canaries. Ђ. Fl. en juillet et août. Toujours verte. x . M. M. plumeuse, M. plumosa.

Cette espèce différe de la précédente par la disposition de ses fleurs, qui forment des panicules axillaires et term., dichotomes. Les calices sont plumeux.

Lieu. Ind. Ђ. Fl. id. Toujours verte.

15. M. à corymbes, M. corymbosa. Encycl. An bystropogon punctatum, H. K. ?

Tige droite, rameuse, paniculée, d'un à 2 pieds. Feuilles opp., pét., ovales, glabres, d'un beau vert, crénelées et ponctuées. Fleurs purpurines, en corymbes convexes, péd., ax.

Lieu. Id. 万. Fl. id. Toujours verte.

Obs. Toutes les menthes ont leurs feuilles opposées.

Cult. Les 12 premières espèces, excepté la $5^{\mathrm{e}}$ bis, sont rustiques et viennent dans tous les terrains. $\mathrm{La} 12^{\mathrm{e}}$ est mieux dans les terres légères; elle languit dans les terres fortes et trop fraiches. Elles se multiplient toutes par leurs drageons, souvent très-incommodes. Leur plantation se fait en automne, mais mieux en mars, avec les rejets ou drageons nouveaux. Cette opération par laquelle on se procure de nouveaux pieds est nécessaire si l'on veut conserver les espèces de ce genre. L'expérience m'a prouvé qu'en les laissant aller à leur nature traçante, non-seulement les vieux pieds meurent, mais aussi par la suite les nouveaux quand on ne les a pas sevrés. Cela arrive principalement dans les terres fortes qui conviennent moins aux menthes que les anciens sols terreautés des jardins potagers, et les terres noires, sablonneuses, amendées. Les 3 dernières sont d'orangerie ainsi que la $5^{\circ}$ bis. Leur terre doit être substantielle, un peu consistante. On les multiplie par leurs graines, qui souvent mûrissent dans nos climats, et que l'on sème à la manière indiquée pour les semis de plantes d'orangerie. On peut aussi les propager avec succès de boutures faites en pot 
sur couche. Ces espèces demandent un peu de chaleur en été. Elles ne sont pas délicates en hiver.

Us. Les 12 premieres ont toutes à-peu-près les mêmes vertus. Elles sont toniques, stomachiques, anti-émétiques, vulnéraires, astringentes. On fait principalement usage des espèces 3, 8 et 9. La troisième a une odeur plus forte et un go ût âcre , assez semblable à celui du poivre. On fait avec son essence des pastilles qui donnent au palais une fraîcheur imitant celle que produit l'éther. La onzième est employée avec succès en infusion théiforme, dans l'asthme humide, les toux opiniâtres, pour faciliter l'expectoration.

Les trois espèces d'orangerie ne font pas un effet remarquable. Elles ne peuvent qu'ajouter à la variété.

\section{Terrète, Glecoma.}

Cor. du double plus longue que le calice, qui est strié , à 2 lèvres; la sup. bifide; l'inf. à 3 div., dont la moyenne est plus grande et échancrée. Les anthères rapprochées par paires', en croix double.

Téríte lierre terrestre, G. hederacea.

Tiges longues, velues, étalées sur la terre. Feuilles opp., pét., en cœur, réniformes, crénelées et velues. Fleurs bleues ou violettes, péd., ax.

Lieu. . . . Ind. Très-commune. ₹. Fl. en mars - mai.

Us. Cette plante est très - aromatique, chaude, astringente, expectorante.

\section{Lamier, Lamium.}

Cal. à 5 dents, barbu, ouvert à son sommet. Cor. plus longue, dont l'entrée renflée' est garnie des deux côtés de dents réfléchies. Le limbe à 2 lévres; la sup. voûtée et souvent entière; l'inf. plus courte, à 2 lobes.

* i. Limier à grandes feuilles, $L$. orvala.

Tige d'un picd et demi, rameuse, carrée, rougeâtre. Feuilles opp., pét., grandes, cordiformes, acuminées, inégalement dentées en scie, ridées, yertes en-dessus, rougeâtres en-dessons. 
Fleurs grandes, rouges, panachées, sess., en verticilles ax. Lieu. L'Italie. ₹. Fl. en mai - juillet.

2. L. lisse, Li. lavigatum.

Tiges d'un pied, carrées, rougeâtres, rameuses, lisses. Feuilles pét., cordiformes, ridées, dentées, presque glabres. Fleurs purpurines, assez grandes, en verticilles ax.

Lieu. La France. $\Psi$. Fl. en mars - oct.

3. L. ridé, L. rugosum, H. K.

Feuilles cordiformes, aiguës, ridées, velues, ainsi que les tiges. Fleurs en verticilles multiflores. Une seule dent sétacée à l'entrée de la corolle.

Lieu. L'Italie. $\leftarrow$. Fl. en juillet.

* 4. L. d'Italie, L. garganicum.

Tiges carrées, branchues, velues, d'un pied et demi. Feuilles cordiformes, dentées, assez petites, velues, portées sur de longs pétioles. Fl. d'un pourpre rose, grandes, en verticilles ax.

Lieu. L'Italie. $\nsucc$. Fl. en avril - juin.

5. L. blanc, L. album. Ortie blanche.

Tiges d'un pied, droites, carrées, velues, simples. Feuilles opp., pét. , cordiformes, acuminées, dentées en scie. Fleurs blanches, grandes, sess., en verticilles ax.

Lieu..... Ind. Très-commune. $\psi$. Fl. en avril - sept.

Variété à fleurs carnées.

6. L. taché , L. maculatum.

Tiges foibles, d'un pied. Feuilles opp., pét. , cordiformes, pointues, légèrement dentées, et marquées d'une tacbe blanchâtre qui disparoît ensuite. Fleurs blanches, sess., verticillées, ax., assez grandes.

Lieu. La France mérid. $\%$.

э. L. pourpre , L. purpureum.

Tiges en grande partie couchées, carrées, rameuses. Feuilles pét.; les inf. petites, obtuses, crénelées; les sup. plus grandes, cordiformes, rapprochées. Fleurs purpurines, assez petites, en verticilles ax.

Variété à feuilles entières.

Lieu. . ... Ind. F. Fl. en mai. 
8. L. embrassant, $L$. amplexicaule.

Tiges gi êles, simples, en partie couchées. Feuilles rad., pét., petites, arrondies, crénelées; les sup. sess., arrondies , presqu'incisées, rapprochées par paire, avec celles qui leur sont opposées. Fleurs d'un rouge vif, sess., en verticilles ax.

Lieu. . . . Ind. I. Fl. en mars - juillet.

9. Lamier à feuilles de pariétaire, $L$. molle, H. K.

Feuilles pét., presque dentées; les inf. cordiformes; les sup. ovales. Fleurs blanches. Cette espèce ne paroît être qu'une variété de la cinquième.

Lieu. . . . . . Fl. en avril et mai.

Cult. Pleine terre. La première et la quatrième sont cultivées pour l'agrément des jardins; les autres, étrangères, ne le sont guère que dans ceux de botanique. Elles viennent dans tous les terrains; la première en demande un meilleur que les autres, et doit être changée de temps en temps de place, ou relevée, en lui donnant de nouvelle terre. On les obtient de graines semées dans une planche préparée à cet effet. Vers le mois de juillet on peut enlever les jeunes plantes pour les placer à demeure. On les multiplie ensuite en séparant leurs pieds en automne ou en mars.

Us. La première est une fort belle plante qui ajoute à l'ornement des jardins, et mérite les soins des cultivateurs. La quatrième a aussi un joli aspect.

La cinquïme, très-commune, est d'usage en méd., comme vulnéraire, astringente. Elle est recommandée, peut-être sans beaucoup de raisons, dans les maladies de la matrice et les fleurs blanches. J'ai vu cette plante, qui, dans le pays que j'habite, est une mauvaise herbe difficile à détruire, cultivée dans le jardin de l'hôpital d'Auch avec beaucoup de soin pour pouvoir la conserver.

On cultive aussi au Muséum l'espèce $L$. hirsutum, LAm., indigène au Mont d'Or en Auvergne. Elle est $\psi$ et de plein air. Elle a des rapports avec la deuxième espèce. Ses feuilles sont en cœur, pubescentes. Ses fleurs, d'un pourpre léger, forment des verticilles de 4 à 8 fleurs. Leur tube est courbé. 


\section{Galéope, Galeopsis.}

Cal. à 5 dents épineuses. Cor. à tube court, dont l'entrée est ure peu dilatée et garnie de 2 dents. Le limbe à 2 levres; la sup. voûtée, presque crénelée; l'inf. à 3 lobes, dont les deux latéraux sont petits, et le moyen plus grand est échancré et. crénelé.

I. GALÉope des champs, G. ladanum.

Tige carrée, droite, rameuse, un per velue, d'un pied. Feuilles opp., lanc., pointues aux deux bouts, dentées, blan. châtres en-dessous. Fleurs purpurines, avec une tache jaune sur la lèvre inf., sess., verticillées. Calices presque épineux.

Lieu. Les champs. Ind. Fl. en juillet et août.

Variété à fleurs jaunes et plus grandes, G. grandiflora, Willd. G. ochroleuca, Pers., Lam. G. villosa, Smith. 2. G. piquant, G. tetrahit. Ortie morte.

Tige de 2 à 3 pieds, droite, branchue, carrée, renflée aux articulations, hérissée de poils rudes et piquans. Feuilles pét. , ovales-lanc. , pointues, dentées en scie, velues et rudes. Fleurs panachées de pourpre et de jaune, verticillées au sommet des tiges. Calices très-épineux.

Lieu. .... Ind. Fl. Fl. en août.

Variété à fleurs blanches, et une autre à grandes fleurs jaunes et pourpres, G. cannabina, WiLld. G. versicolor, Pers., Curtis.

3. G.jaune, G. galeopdolon. Cardiaca sylvatica, Fl. fr. Ortie morte. Leonurus galeopdolon, WiLld. Galeopdolon vulgare, Persoon.

Tiges d'un pied, simples, foibles, velues. Feuilles pét., ovales, en cœur, pointues, dentées, d'un vert obscur. Fleurs entièrement jaunes, sess., verticillées.

Lieu. Les haies. Ind. $\%$. Fl. en mai et juin.

Cette espèce n'a point de dents à ses calices.

Ces plantes ne sont point cultivées et n'ont aucune propriété reconnue. 
Si la variété de la seconde n'étoit pas , elle mériteroit d'être placée dans les jardins. Je l'ai vue à la hauteur de 3 à 4 pieds, faisant beaucoup d'effet.

\section{Bétoine, Betonica.}

Cal. à 5 dents très-aiguës. Cor. plus longue, à tube courbé, à limbe à 2 levres; la sup. droite, obronde, entière ou bifide; l'inf. à 3 div., dont la moyenne est plus large et échancrée.

*. I. BÉtorve officinale, $B$. officinalis.

Plante en touffe arrondie. Tiges simples, droites, carrées, d'un pied. Feuilles opp., pét. , en cœur, oblongues, obluses, ridées, velues, un peu rudes, à crénelures arrondies, d'un gros vert. Fleurs rouges, verticillées en épi interrompu. Calices et bractées glabres.

Lieu. Les bois près Boulogne. Ind. $\Psi$. Fl. en juillet et août. Variété à fleurs blanches.

2. B. danoise, B. stricta. B. officinalis, Pallas.

Fevilles inf.cordiformes, plus larges que celles de la première; celles de la tige lanc., arrondies à leur sommet. Tiges droites, terminées par des fleurs verticillées, en épis denses; la lève sup. entière; les calices velus.

Lieu... . ₹. Fl. en juin et juillet.

3. B. blanchâtre, B. incana, H. K.

Les feuilles de cette espèce sont plus larges et pas si longues que celles de la $\mathrm{r}^{\mathrm{re}}$; elles sont velues. La tige est plus basse et ses épis plus denses; les fleurs plus grandes et de couleur de chair. La levre sup. bifide; le lobe moyen de la levre inf. crénelé. Le tube cotonneux.

Lieu..... . F1. id.

* 4. B. du Levant, B. orientalis. B. grandiflora, Thumlief, Flor, paris.

Tiges stériles couchées, étalées sur la terre. Tiges fructiferes d'un pied, simples, tétragones. Feuilles opp. , pét. , oblongues, en cœur à leur base, crénelées, d'un vert pâle. Fleurs d'un pourpre pâle, en épi non interrompu et term. Cette plante forme 
des touffes fort étendues. Ses feuilles sont fort longues, et à bords presque paralleles.

Lieu. Le Levant. $\%$. Fl. en juin et juillet.

* 5. B. alopécuroïde, B. alopecuros.

Tige simple, très-velue, épaisse, de 8 à ro pouces. Feuilles larges, en cœur arrondi, à grandes crénelures, épaisses, velues, d'un vert pâle; les inf. ont de longs pét.; les sup. sont presque sess. Fleurs d'un jaune pâle, en épi term. , feuillé à sa base. La levre sup. bifide:

Lieu. L'Europe mérid. $\%$. Fl. en juillet.

* 6. B. velue, B. hirsuta.

Lamark dit que cette espèce est moins élevée que la $I^{\text {re. Elie }}$ l'est au contraire davantage dans mon jardin. Tige d'un pied et demi, droite, carrée, velue. Feuilles opp., pét., oblongues, en cœur, obtuses, ridées, velues, une fois au moins plus grandes que celles de la $I^{\text {re }}$. Fleurs d'un rouge vif et foncé, plus grandes, en épi serré et feuillé à sa base.

Lieu. Les Alpes. $\%$. Fl. id.

j. B. à grandes fleurs, B. grandiflora, Curtis, Mag., Wrlud.

Feuilles radicales grandes, en cœur, pétiolées, pubescentes, obtuses, largement dentées. Tiges d'un pied, pubescentes, tétragones. Fleurs rassemblées au nombre de 8 à 10 par verticilles distans; les supérieurs rapprochés; tous accompagnés de feuilles. Corolle rouge, quatre fois plus grande que le calice, dont les bords sont velus et les dents très-pointues.

Lieu. La Sibérie. $\%$.

Cult. Pleine terre. Ces plantes sont rustiques et croissent dan s tous les terrains. La plupart aiment les lieux un peu ombragés, et les sols frais et d'un bon fond. On les obtient par leurs graines semées en planches destinées pour ces sortes de semis de pleine terre, et on les multiplie en séparant leurs touffes en automne ou en mars.

Us. Les bétoines sont cultivées dans toutes les collections de plantes et dans les jardins de botanique. Plusieurs, et particuiièrement la $4^{\mathrm{e}}$, ne déparent pas les parterres. La première est depuis long-temps en usage comme sternutateire, céphalique, 
apéritive. Elle a une odeur assez particulière, qui est subtile et pénétrante.

\section{Stachide, Stachys.}

Cal. anguleux, à 5 dents acuminées. Cor. à tube court, labiée.

La levre sup. voûtée, échancrée; l'inf. réfléchie sur les côtés, 3-fide; la div. moyenne plus grande et échancrée. Étam. défleuries, rejetées sur le côté.

I. Stachide des bois, S. syluatica.

Tige de 2 à 3 pieds, carrée, rameuse, velue, brune. Feuilles opp., pét. , cordiformes, pointues, velues, dentées. Fleurs d'un rouge très-foncé; la lèv. inf. tachée de blanc; verticillées, en épi lâche et term. Plante très-fétide.

Lieu. Les haies, les bois. Ind. Fl. en juillet.

* 2. S. à feuilles arrondies, S. circinnata, L'Hérit. S. canariensis, $\mathrm{J}_{\mathrm{ACQ}}$.

Tige d'un pied et demi, carrée, velue, rameuse. Feuilles opp. , pét. , cordiformes, arrondies, régulièrement crénelées, velues, douces au toucher, un peu blanchâtres. Fleurs d'un pourpre pâle, au nombre de 6 par verticilles, en épi term.

Lieu. La Barbarie. ₹. Fl. en mai-juillet.

3. S. des marais, S. palustris.

Tige simple, rougeâtre, de 2 pieds. Feuilles lin.-lanc., longues, étroites, sess., pointues, deniées en scie, d'un vert noir. Fleurs purpurines, maculées de jaune, au nombre de 6 , verticillées, en épi term.

Lieu. Ind. $\Psi$. Fl. en août.

* 4. S. des Alpes, S. alpina.

Tige simple, carrée, relue, rougeâtre, d'un pied et demi. Feuilles pét., opp., obl., pointues, dentées, molles et velues. Fleurs d'un rouge obscur, en verticilles multiflores, qui ne forment pas d'épi. Les feuilles inférieures sont assez grandes, un peu en cœur à leur base. Les calices sont évasés. Toute la plante a une odeur forte.

Lieu. La France. $\%$. Fl. id.

*5. S. germanique, S. germanica. Épi fleuri. 
Tige droite, carrée, cotonneuse, blanchâtre, de 2 pieds. Feuilles ovales, pointues, dentées, épaisses, cotonneuses, blanchâtres. Fleurs purpurines, en verticilles multiflores, aussi cotonneuses, formant un épi term.

Lieu... Ind. $\%$. Fl. en juillet.

* 6. S. laineuse, S. lanata, S. sibirica, H. P.

Cette espèce est bien distinguée de la précédente, avec laquelle cependant elle a des rapports. Tiges en grande partie couchées, radicantes, redressées à moitié pour la floraison, carrées, d'un pied et demi , couvertes, ainsi que toutes les autres parties de la plante, d'un coton fort épais et très-blanc. Feuilles pét., opp., ov. - oblongues, obtuses, entières, épaisses, dont le vert qui est sous le coton est peu sensible. Fleurs de même que la précédente.

Lieu. La Sibérie. $\mathcal{H}$. Fl. tout l'été.

* 7. S. à feuilles oblongues, S. intermedia, H. K.

Cette espèce a aussi des rapports avec les 2 précédentes. Ses feuilles sont oblongues, presqu'en cœur à leur base, crénelées; sa tige un peu laineuse; verticilles multiflores. Calices à div. un peu piquantes.

Lieu. La Caroline. $\Psi$. Fl. en juin et juillet.

M. Boucher, correspondant de l'Institut, m'a communiqué un échantillon d'une espèce de ce genre, qui a beaucoup de rapport à celle-ci d'Aiton, et qui peut-être est la même. Elle se rapproche de la $5^{\mathrm{e}}$, mais elle est moins blanche et moins laineuse sur toutes ses parties. Ses feuilles ne sont pas cordiformes à leur base ; elles sont ov.-lanc., moins épaisses et plus fortement dentées que celles du germanique. Les dents calicinales sont terminées par une épine courte, jaunâtre et piquante. Ses verticilles distans avoisinent aussi cette espèce de celle des Alpes. Elle est indigèneà Abbeville.

* 8. S. de Crète, S. cretica.

Cette plante forme un buisson arrondi, fort large et très-garni de tiges de 2 pieds, carrées, cotonneuses, blanchâtres. Feuilles pét., cordiformes, arrondies, crénelées, cotonneuses, blanchâtres. Fleurs nombreuses à chaque verticille, purpurines.

Lieu. L'île de Candie. $\%$. Fl, id. 
9. STACHIDE maritime, S. maritima, JACQ.

Tiges de 8 à ro pouces, dures, pubescentes. Feuilles rad., en cœur ou elliptique, oblongues, obtuses, crénelées, cotonneuses. Fleurs en verticilles, jaunâtres, formant un épi dont les bractées sont aussi longues que les fleurs et très-entières.

Lieu. La Fr. mérid. $\%$. Fl. en juillet. 10. S. d'Éthiopie, S. athiopica, JAcQ.

Verticilles de 2 fleurs. Feuilles en cœur, ridées, profondément dentées, velues.

Lieu. Le Cap. . FI. en avril-juillet.

* II. S. hérissée, S. hirta.

Tiges couchées à leur base, redressées ensuite, carrées, velies, d'un pied dans la partie élevée. Feuilles opp., pét., obl., en cœur, obtuses, ridées, velues, crénelées, d'un vert sombre. Fleurs purpurines, au nombre de 6 , verticillées; les dents cal. piquantes. Cette espèce est très-traçante.

Lieu. L'Itahie, la Fr. mérid. ₹ . Fl. en juillet.

* 12. S. droite, S. recta, JAcQ. S. bufonia, Flor. paris.

Feuilles cordiformes, elliptiques, crénelées, rudes au toucher. Tiges montantes. Verticilles presqu'en épis. Feurs jaunes. La levre droite.

Lieu. L'Europe mérid. Fl, id. $\Psi$ ou

* 13. S. annuelle, $S$. annua.

Tige droite, carrée, branchue, glabre, d'un pied. Feuilles pét., ridées, ovales, oblongues, obtuses, crénelées, glabres. Fleurs assez grandes, blanches, avec quelques points rouges, en verticilles de 6 fleurs. La lèvre inférieure, jaune : ponctuée.

Lieu. La Fr., près Abbeville. Ind. Fl. en juillet et août.

Obs. Je crois que ces deux espèces se ressemblent beaucoup, et qu'elles nesont, comme le dit Lamarck, qu'une variété l'une de l'autre. La $12^{\mathrm{e}}$, qui est indiquée $\psi$ dans Aiton, a été plusieurs fois dans mon jardin.

4. S. ridée, S. rugosa, H. K.

Feuilles lanc., rétrécies à leur base, cotonneuses, ridées, dentées en scie. Verticilles de 6 fleurs. Dents cal. obtuses. Flenrọ̧ jaunes.

Lieu. Le Cap. Ђ. Fl. en juillet. 
15. S. des champs, S. arvensis.

Tiges foibles, rameuses, velues, d'un pied. Feuilles opp., pét., cordiformes, obtuses, crénelées, presque glabres. Fleurs blanches ou carnées, avec quelques taches pourpres, en verticilles de 6 fleurs. Les corolles de la longueur des calices.

Lieu. Les champs. Ind. Fl. en août. 16. S. à larges feuilles, S. latifolia, H. K.

Feuilles larges, cordiformes, ridées, velues. Verticilles multiflores, presqu'en épis. La lève sup. bifide; les div. aiguës.

Lieu... ๖. Fl. en juin et juillet.

* I7. S. épineuse, S. spinosa.

Tiges grises, garnies de beaucoup de rameaux verts, cylindriques. Feuilles opp., sess., étroites, presque linéaires, acuminées, glabres; leurs bords légèrement ciliés. Fleurs blanches, assez petites, axillaires, pédonculées. Les rameaux se terminent, lorsqu'ils sèchent, par une pointe.

Lieu. La Crète. G. Toujours verte. Fleurit une partie de l'année.

* 18. S. de Palestine, S. palestina.

Tige droite, d'un pied environ, rameuse, blanche, tomenteuse. Feuilles opp., sess., ovales - oblongues, rictées, légèrement tomenteuses. Fleurs d'un purpurin pâle, assez petites, verticillées, au nombre de 5 à 6 , axillaires, au sommet de la tige et des rameaux. Calices striés.

Lieu. L'Arabie. Đ. Fleurit en août.

Cult. Les espèces 10,14 , I7 et 18 sont d'orangerie. On pourroit y ajouter la $2^{\mathrm{e}}$, quoiqu'Aiton la meite en pleine terre; je l'y ai plantée deux fois, et elle y a péri. Cependant elle n'est pas délicate; et comme il lui faut beaucoup d'air en hiver, parce qu'elle pousse et s'affoiblit dans la serre, il seroit à desirer qu'elle pût se conserver en pleine terre. On y réussira dans des positions moins froides que celle que $j$ 'habite. Toutes les autres stachides sont rustiques, et croissent dans presque tous les terrains. On les multiplie toutes par leurs graines; celles d'orangerie semées en pots sur couche; celles de pleine terre en planches destinées à les recevoir. Quand on les a une fois obtenues, on les propage facilement par la séparation de leurs pieds, en 
fevrier ou en mars. Il y en a beaucoup qui se sèment elles mêmes, comme les $4,5,6,8$ et I I $^{\mathrm{e}}$, et qui ne s'étendent que trop. Les espèces d'orangerie mûrissent leurs graines dans nos climats septentrionaux.

- Us. Ces plantes ajouteht peu à l'agrément des jardins. Celles qui se font le plus remarquer sont la $6^{\mathrm{e}}$, par sa grande blancheur, et la 8 e, par ses larges buissons arrondis. Elles n'ont aucune utilité reconnue.

La $17^{\mathrm{e}}$ forme un petitarbuste très-touffu, qui a une odeur forte et peu agréable. On le multiplie de boutures et de narcottes.

* ig. Stachide écarlate, Stachys coccinea, Willd.

Tiges droites, tétragones, pubescentes, rameuses, de près d'un mètre. Feuilles opposées, pétiolées, ovales-cordiformes, oblongues, obtuses, crénelées, un peu ridées, glabres en dessus, peu velues en-dessous, d'un vert frais; les pétioles canaliculés. Fleurs disposées au nombre de 6 par veriicilles distans et terminaux, accompagnés de 2 bractées ou feuilles de la même forme que les autres. Corolle écarlate, de 3 centim. de Iongueur, couverte en dehors de poils courts et glanduleux, a tube un peu courbé; la lèvre supérieure droite, concave, trèsentière, arrondie; la levre inférieure grande, à 3 lobes, dont le moyen est large, un peu échancré à son sommet, et les latéraux réfléchis en dehors. Filamens rouges. Anthères blanchâtres avec un peu deviolet, à 2 lobes globuleux. Style blanc. Stigmate bifide. Calice pentagone, à divisions égales, pointues, brunes et chargées des mêmes poils que ceux de la corolle.

Lieu. ..... Ђ. Fleurit presque toute l'année.

Cult. Orangerie. Cette plante étant en végétation pendant l'hiver comme pendant l'été, exige dans la serre une place oiz elle puisse recevoir le plus d'air et de lumière possible, pour qu'elle ne s'étiole pas. Il lui faut peu d'arrosemens dans cette saison, et maintenir sa terre modérément sèche. On la multiplie très-facilement de boutures faites dans la couche propre à cette voie de propagation; et par ses graines qui mûrissent dans nos jardins, et que l'on sème au printemps, sur couche et sous châssis. Elle périt par l'humidité.

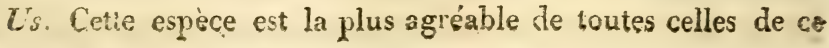


genre par la couleur de ses fleurs et leur succession; elle or neroit les parterres si l'on pouvoit l'acclimater; ce qui, peutêtre, ne seroit pas difficile, car elle n'est pas délicate. Il est bon de la renouveler de temps en temps, les jeunes pieds étant plus beaux que les vieux, et ces derniers ne subsistant pas longtemps.

20. S. à feuilles de scordium, $S$. scordioides, Desfont., Cat.

Persoon.

Tige laineuse, montante, rameuse. Feuilles linéaires-lancéolées, dentées en scie. Verticilles de 4 à 6 fleurs. Toute la plante blanchâtre.

Lieu. Maroc. 万.

Cult. Orangerie. Cultivée au Muséum.

\section{Ballote, Ballota.}

Cal. pentagone, à 10 stries et 5 dents, ouvert à son sommet. Cor. plus longue, souvent velue, à 2 lèvres; la sup. concave, crénelée ; l'inf. à 3 lobes, dont le moyen est plus grand et échancré.

ฯ. Ballote fétide, $B$. nigra, Marrube noir.

Tiges d'un pied et demi, carrées, velues, rameuses, brunâtres. Feuilles op., pét., ovales, crénelées, d'un vert noirâtre. Fleurs d'un rouge foncé, ax., péd., en verticilles imparfaits, unilatéraux. Plante très-puante.

Variété à fleurs blanches, B. alba, H. K., Liv.

Lieu... Ind. $\%$. Très-commune le long des murs. Fl. en juillet-nov.

* 2. B. laineuse, B. lanata, Willd. Leonurus lanatus, Pers.

Panzeria.

Tiges en partie couchées, épaisses, carrées, blanches, laineuses, d'un pied. Feuilles opp., pét., palmées, à 5 à 5 div., incisées, vertes en - dessus, blanches et laineuses en - dessous. Fleurs assez grandes, jaunâtres, en verticilles serrés, dans les aisselles des feuilles sup.

Lieu. La Sibérie. $\Psi$. Fl. en juillet et août.

5. B. de l'Inde, $B$. disticha. 
Tige carrée, de 2 pieds. Feuilles opp., pét. , un peu en cœur, à grandes dentelures, velues, vertes en-dessus, pâles en-dessous. Fleurs'rougeâtres, en verticilles ax., composés de 2 paquets de fleurs, plus ou moins unilatéraux.

Lieu. Les Indes or. Fl. Fl. en août.

Cult. La $2^{\mathrm{e}}$ est de pleine terre, et se cultive comme les stachides. La $3^{\mathrm{e}}$ est de serre chaude. On ${ }^{\circ}$ sème celle - ci tous les ans sur couche chaude.

Us. La $2^{\mathrm{e}}$ est agréable à voir par la blancheur de ses tiges, qui s'oppose avec le vert tendre de la surface supérieure des feuilles. Elle mérite d'être cultivée dans les parterres de plantes $\Psi$ étrangères.

\section{Marrube, Marrubium.}

Cal. à Io stries; dans quelques espèces à 5 dents; dans la plupart à ıo, alternativement plus peities. Cor. un peu plus longue, à 2 lèv.; la lèv. sup. étroite et souvent bifide; l'inf. à 3 div., dont la moyenne est plus large et échancrée.

\section{r. Calices à 5 dents.}

*. Marrube cunéiforme, $M$. alysson.

Tiges droites, carrées, d'un pied. Feuilles opp. , cunéiformes, inégalement crénelées ou incisées, ridées, plissées. Fleurs petites, purpurines, verticillées, sans bractées. Toute la plante Jlanchâtre.

Lieu. L'Espagne, l'Italie. $\Psi$. Fl. en juillet et août. * 2. M. très-blanc, M. candidissimum.

Feuilles presqu'ovales, laineuses, soyeuses, échancrées et crénelées à leur sommet. Les dents cal. subulées.

Lieu. Le Levant. $¥$. Fl. id.

3. M. à feuilles oblongues, $M$. peregrinum, Willd., MrLler.

Tige rameuse à sa base. Feuilles oblongues, ridées, veineuses, dentées, blanchâtres, soyeuses; les dents plus grandes au sommet des feuilles; celles des calices pointues, en alêne.

Lieu. L'Autriche, la Sicile, la Crète. $\psi$. 4. M. paniculé, M. paniculatum, Encycl. M. creticum, Wilud. 
'Tiges très-rameuses, diffuses, paniculées, d'un pied et demi. Feuilles ovales, dentées, ridées; les sup. sessiles. Fleurs blanches, petites, sessilles, verticillées, ax.

Lieu. Le Levant. $\nsucc$.

5. $M$. couché, $M$. supinum.

Rameaux carrés, couchés, nombreux. Feuilles opp., pét., ov., très-petites, crénelées, ridées, vertes en-dessus, blanches endessous. Fleurs blanches, verticillées. Les dents du calice sétacées, droites et velues. Tiges couchées.

Lieu. L'Espagne. ₹. Fl. en août - oct.

\section{Calices à r 0 dents.}

* 6. M. commun, M. vulgare.

Tiges carrées, dures, droites, cotonneuses, blanchâtres, de 2 à 3 pieds. Feuilles pét., ovales, inégalement crénelées, ridées, cotonneuses, verdâtres. Fleurs blanches, petites, sess., nombreuses, verticillées. Les dents cal. sétacées et crochues.

Lieu. Ind. ₹. Fl. en juin-sept.

* ๆ. M. d'Espagne, M. hispanicum.

Tiges carrées, branchues, droites, velues. Feuilles cordiformes, crénelées, ridées, velues, pét $t_{\text {, }}$ un peu ridées, d'un vert blanchâtre. Fleurs blanches, tachetées de rouge, verticillées. Les dents cal. aiguës. Le calice ouvert et évasé.

Lіеи. L'Espagne. $\leftarrow$. Fl. en juillet et août.

8. M. d'Afrique, M. africanum.

Feuilles cordiformes, arrondies, crénelées et échancrées. Cow rolles velues. Calices épineux.

Lieu. Le Cap. ఒ. Fl. en juillet-sept. * 9. M. faux dictamne, M. pseudodictamnus.

Tiges de 2 pieds, rameuses, presque cylindriques. Feuilles pét., en cœur, arrondies, crénelées, épaisses. Fleurs purpurines, nombreuses, verticillées. Les calices très-évasés, presque planes. Toute la plante cotonneuse et blanche.

Lieu. L'ile de Candie. Ђ. Toujours vert. FI. en juin-août. ro. $M$. acétabule, $M$. acetabulosum.

Tiges carrées, branchues, de 2 pieds. Feuilles pét., en cœur, arrondies, crénelées. Fleurs d'un blanc purpurin, nombreuses, III. 
verticillées. Les calices s'évasent encore plus que ceux de la précédente; après la chute des corolles ils deviennent plus longs que le tube, et leur limbe est symétriquement divisé en 20 dents mucronées. Toute la plante blanchâtre.

Lieu. Id. భ. Fl. id.

* ix. Marrube crépu, $M$. crispum. $M$. cinereum, LaM.

Tige droite, d'un pied et demi, tétragone, brune, chargée de poils blancs, dontles branches et les rameaux sont opposés. Feuilles opposées, pétiolées, cordiformes à leur base, presque vertes en-dessus, presque labiées, ridées, crispées et velues, rondes, crénelées , pâles en-dessous. Fleurs d'un pourpre pâle, verticillées, axillaires. Calices à ro stries et à I 2 à 15 dents.

Lieu. L'Italie, l'Espagne. Ђ. Fl. en été. Toujours vert.

Cult. Excepté les quatre dernières espèces qui sont d'orangerie, toutes les autres sont de pleine terre, et ne demandent pas plus de soin que les stachides, dont la culture leur convient parfaitement. Elles se plaisent dans les situations chaudes et les terres substantielles un peu légères. Leur multiplication est la mêtme que celle des stachides.

Les espèces d'orangerie ne sont pas délicates. Elles demandent pendant l'hiver la lumière et l'air renouvelé, pour qu'elles ne s'étiolent pas dans cette saison. On les propage par leurs semences et les boutures.

Us. La plupart des espèces de marrube étant remarquables par leur blancheur, ne laissent pas que de faire de l'effet dans les parterres, en les opposant aux plantes vertes.

La $9^{e}$ est d'usage en médecine comme incisive, stimulante et détersive. Son odeur est assez agréable. Elle est généralement cultivée dans les collections.

\section{Agripaume, Leonurus.}

Cal. pentagone, à 5 dents acuminées. Cor. souvent plus longue; labiée. La lèv. sup. velue, entière, concave; l'inf. réfléchie, à 3 div. presqu'égales. Anthères parsemées de points luisans.

* y. Agripaume vulgaire, L. cardiaca. Cardiaque. Tiges droites, de 4 à 5 pieds, dures, carrées, glabres, garnies . 
danstoute leur longueur, de feuilles opp., pét., d'un vert ๑bscur, un peu ridées et sillonnées; les inf. arrondies, découpées en 3 lobes incisés; les sup. étroites, à 3 lobes simples et pointus; celles du sommet presqu'entières, lancéolées, pointues. Fleurs purpurines, petites, en verticilles serrés, assez petits, nombreux, garnis de folioles sétacées.

Lieu..... Ind. ou naturalisé. $₹$ ou $\sigma^{\top}$. Fl. en juillet.

Variété a fleurs blanches.

Variété à feuilles un peu crispées, $L$. crispus, DEsfonis.

2. A. à feuilles simples, $L$. marrubiastrum.

Tige de 2 à 3 pieds, carrée, feuillée, glabre. Feuilles opp.; pét., simples; les unes ovales, les autres lanc., dentées. Fleurs petites, verticillées. Les dents cal. épineuses; la corolle très $\rightarrow$ courte.

Lieu. L'Autriche. Fl. en juin-août。

*3. A. de Tartarie, L. tartaricus.

Tiges carrées, feuillées, de 4 à 7 pieds. Feuilles pết., opp.; velues, divisées en 3 découpures laciniées. Fleurs rougeâtres, verticillées. Les feuilles inf. beaucoup plus larges que les sup.

Lieu. La Russie. ₹. Fl. id.

Cette espèce a beaucoup de ressemblance avec la $\mathbf{I}^{\mathrm{re}}$. 4. A. de Sibérie, L. sibiricus.

Tige de 2 pieds, garnie dans toute sa longueur, comme les précédentes, de feuilles assez grandes, divisées en découpures profondes et linéaires. Fleurs rouges, verticillées. Les corolles une fois plus longues que les calices.

Lieu. La Sibérie. ơ . Fl. id.

5. A. condensé, $L$. condensatus, Noв. Phlomis condensata, Hort. Zuric.

Tige droite, tétragone, presque glabre. Feuilles opposées; pinnatifides, à 3 pinnules principales. Chacune divisée en 3 à 5 segmens alternes, presque glabres et d'un vert sombre. Fleurs rougeâtres, disposées en verticilles serrés et peu distans, garnissant tout le sommet des tiges. Les divisions du calice à pointes épineuses.

Lieu..... Cultivé à Milan.

Cult. Pleine terre. Ces plantes ne sont guère cultivées que 
dans lesjardins de botanique. La $\mathrm{I}^{\mathrm{re}}$ et la $3^{\mathrm{e}}$ se sèment abondam= ment elles-mêmes. On sème les autres tous les ans en pleine terre, soit en place, soit dans des planches, pour les repiquer ensuite, vers le mois de juillet, à demeure. La $3^{e}$, qui est vivace, se multiplie aussi parla séparation deson pied. Elle a un beau port.

La I $^{\text {re }}$ a une odeur désagréable. On la recommandoit antrefois dans la cardialgie. Elle peut être anti-hystér ique à cause çe son odeur.

\section{Phlomide, Phlomis.}

Cal. anguleux, à 5 dents. Cor. oblongue, labiée. La lèv, sup. velue, voûtée, comprimée, recourbée, presque bifide; l'inf. à 5 div., dont la moyenne est plus grande et à 2 lobes.

* I. Phlomide frutescente, $P$. fruticosa.

Arbuste formant un buisson arrondi, assez touffu et étalé. Tiges de 2 à 5 pieds, couvertes d'un coton jaunâtre. Feuilles opp. , pét. , cordiformes, obtuses, entières ou très-légèrement dentées, verdâtres et douces au toucher en-dessus, blanchàtres et cotonneuses en-dessous. Fleurs jaunes, grandes, verticillées, et en têtes arrondies et term.

Lieu. L'Espagne, la Sicile. ๖.Toujours vert. Fl. en juillet septembre.

* Variété à larges feuilles.

* Id.... à feuilles oblongues et étroites.

* 2. P. à fleurs pourpres, $P$. purpurea.

Tiges de 2 à 5 pieds, moins ligneuses que celles de la précédente, branchues, couvertes d'un coton blanc. Feuilles opp. , pét., étroites, oblongues, obtuses, un peu en cœur à leur base, crénelées, blanches et très-cotonneuses sur les deux surfaces. Fleurs d'un pourpre lézer, verticillées. Les collerettes linéaires, obtuses, et plus courtes que le calice.

Lieu. Le Portugal. b. Toujours verte. Fl. id., mais moins long-temps.

3. P. lychnite, P. Irchnitis.

Tige d'un pied, velue, blanchâtre. Feuilles étroites, lancéolées, pointues, sess., blanches et cotonneuses. Fleurs jaunes, 
verticillées, garnies d'un coton d'un jaune pâle. Les collereties sétacées. Toute la plante très-laineuse.

Lieu. L'Europe mérid. b. Toujours verte. Fl. id.

* 4. P. laciniée, P. laciniata.

Tiges d'un pied et demi. Feuilles pinnées, les pinnules alt., laciniées et dentées. Les radicales grandes et persistantes; les caulinaires plus petites, toutes vertes. Fleurs pourpres, verticillées. Les calices laineux.

Lieu. Le Levant. $\%$. Fl...

* 5. P. herbe du vent, P. herba venti.

Tiges en partie couchées, redressées pour la floraison, d'un pied et demi, velues, cotonneuses. Feuilles oblongues, sessiles, dentées, vertes en-dessus, blanchâtres en-dessous. Fleurs d'un pourpre vif, verticillées et en tête terminale. Les collerettes hispides.

Lieu. La France mérid. $\%$. Fl. en juillet - sept.

* 6. P. tubéreuse, $P$. tuberosa.

Tiges simples, de 5 à 6 pieds, carrées, droites, rougeâtres. Feuilles opp. , pét., cordiformes, ridées, assez grandes, pointues, rudes au toucher, dentées, d'un vert foncé et lisse. Fleurs purpurines, verticillées, sur une grande partie de la longueur des tiges. Les collerettes hispides, subulées.

Lieu. La Sibérie. . Fl. en juin - sept.

7. P. blanche, $P$. zeilanica.

Feuilles lancéolées, un peu dentées. Fleurs blanches, en tête terminale. Les calices à 8 dents. La levre supérieure très-courte et fermée; l'inférieure grande et ouverte.

Lieu. Les Indes or. $\sigma^{7}$. FI. en juin - oct.

8. P. d'Amérique, $P$. caribcea.

Tige herbacée. Feuilles ovales-lanc., velues. Fleurs en verticilles obronds, très-serrées. Les collerettes sétacées et velues. Calices courbés, à 8 dents, dont une très-longue.

Lieu. Les Indes occid.

9. P. a feuilles de chataire, $P$. nepetifolia.

Tige id. Feuilles cordiformes, pointues, dentées, un per: cotonneuses. Les calices à 6 à 8 dents; la dent sup. el l'inf. plus 
grandes. Corolle de la couleur de celle de la suivante, mais trois. fois plus petite.

Lieu. Les Indes or. Fl. en sept. et oct.

* io. Phlomide queue de lion, $P$. leonurus.

Arbrisseaa de plus de 6 pieds, dont les tiges et les rameaux. sont droits, pubescens dans leur jeunesse, quadrangulaires, à angles arrondis. Feuilles opp., lanc.-pointues, dentées $\in \mathbf{n}$ scie, étroites, un peu velues, nerveuses. en - dessous, d'un vert foncé. Fleurs d'un bel écarlate, longues, étroites, velues, verticillées, le long des tiges et des rameaux. Les calices décagones, à ıo dents.

Lieu. Le Cap. Ђ. Toujours vert. Fl. en oct - déca 1. P. nain, $P$. leonitis.

Feuilles ovales, obtuses, petites, un peu cotonneuses, crénem lées. Les calices à 7 dents barbues. Corolle de la couleur de la. précédente,

Lieu. Le Cap. \$. Toujours verte. Fl: en juin et juillet.

Cult. Les espèces 2, 3 , xo et I I sont d'orangerie. La première passe fort bien en pleine terre dans les hivers ordinaires, sur-tout lorsqu'elle est dans un sol médiocre ; mais dans les fortes gelées, elle est fortement attaquée et quelquefois périt. On peut en mettre quelques pieds dans les terres légères, sablonneuses, pierreuses et exposées au midi; mais il est prudent d'en avoir aussi en pots pour rentrer en hiver. Il ne faut qu'une simple couverture pour la conserver. Les. autres sont absolument de serre. Leur terre doit être franche, consistante et substantielle. Elles seront exposées au soleil pendant l'été, et aussi près des jours qu'il est possible çans la serre. Les deux et troisième passent bien sous le châssis.La ảixième, poussant beaucoup en racines, doit être dépotée au printemps, et plantêe. dans un assez grand vase. Si on la mettoit dans un trop petit il faudroit la changer en été, et cela arrêteroit sa végétation, on celle-ci seroit languissante, et ses fleurs avorteroient en partie, ou ne s'épanouiroient pas avant l'hiver. Cette piante doit donc aroir loute la terre qu'iliui faut pour pousser et fleuriz; beaucoup d'arrocemens pendant le cours de l'été, et bien exposéę ₹n sutomne. Quand on la force par le moyen des couctues. 
ou des châssis, on avance un peu sa floraison, mais une partie de ses fleurs avorte : il faut la laisser en plein air; et en la conduisant comme je viens de l'indiquer, elle fleurira bien dans son temps. Cette espèce se multiplie fort aisément de boutures faites au printemps, en pot, sur eouche ombragée; elles s'enracinent en peu de temps. Les autres phlomides de serre peuvent aussi se propager par ce moyen; mais leurs graines mûrissant en France, on préfére cette voie, qui donne de plus belles plantes et en abondance. On les sème en pot, en terrine, sur couche, à la manière indiquée.

Les espèces 7, 8 et 9 sont de serre chaude. On les séme tous les ans sur couche et en pot, et on les repique sur une autre couche chaude ou on les laisse pour fructifier, ou bien en pot, qu'on rentre dans cette serre.

Les autres sont de pleine terre. Elles viennent assez bien dans tous les terrains. On les multiplie par la séparation de leurs pieds er mars, et on les obtient par leurs graines semées sur des planches ou lits préparés à cet effet. La quatrième n'est pas aussi indifférente sur le terrain. On pourroit essayer avec apparence de succès la troisième en pleine terre, en ayant des individus en pot pour réparer sa perte.

Us. Ces plantes $n^{\prime}$ ont aucune atilité reconnue; mais les deux premières forment des buissons assez agréables à la vue par leur blancheur et leurs fleurs. La dixième est la plus belle de toutes. Elle est dũ plus bel aspect lorsque toutes ses tiges et ses rameaux sont décorés de ses verticilles écarlates. La quatrième ne fleurit que très-rarement, du moins dans nos climats. J'en ai un pied qui, depuis 4 ans, n'a encore poussé que ses feuilles radicales. La sixïeme est remarquable par sa hauteur, et même: par ses fleurs:

* 12. P. des Indes, P. indica, Wilud.

Tige de 2 à 3 décim. tétragone, velue. Feuilles opposées; situées sous chaque rameau opposé en croix, pétiolées, ovales. lancéolées, obtuses, dentées, velues, d'un vert foncé. Fléurs au nombre de 5 à 7 , disposées en $\mathbf{l}$ ou 2 verticilles au-dessous du sommet des tiges et des rameaux, munis d'une cols lerette de plusieurs folioles linéaires, courbées et velaes. Co:- 
rolle blanche; la lèvre supérieure peu ouverte, courte et velue; l'inférieure deux fois plus longue, à 3 divisions, dont la moyenne, plus grande, est presque plane. Calice à $\eta$ à 8 dents.

Lieu. Les Indes. Fleurit en juillet.

Cult. Ses graines se sèment sur couche au printemps, et on en repique les plantes à la place où elles doivent rester, qui doit être dans un sol léger et chaud.

Cette plante n'a d'autre mérite que celui d'être étrangère, si c'en est un.

* 13. Phlomine du Levant, P. samia, Liv..., Willn...,

Milier.., Desfont. , FI. atlant. Vent., Choix de plantes.

Tiges simples, nombreuses, droites, tétragones, un peu rudes, d'un brun foncé, de 8 décim. Feuilles opposées, petites, crénelées, pointues, ridées, d'un vert foncé en-dessus, blanchâtres et drapées en-dessous ; les inférieures en cœur; les supérieures ovales. Fleurs au nombre de 10 à 12 , sessiles, formant chaque verticille axillaire. Corolle d'un violet cendré, aussi grande que celle de la phlomide frutescente, pubescente; la lèvre supérieure en casque; l'inférieure plus longue, à 5 lobes. Calice à ro stries et 5 divisions terminées par une pointe épineuse. Toutes ces parties sont couvertes de poils glanduleux.

Lieu. Le Levant. Ђ. Fleurit au commencement de l'été.

Cult. Orangerie, et pleine terre dans le midi de la France. Cette espèce, depuis long-temps connue, a été cultivée par Miller en pleine terre, où elle a résisté jusqu'à l'hiver de $\mathbf{7} 70$ qui l'a détruite. Il est donc très-possible qu'elle se soutienne, dans les pays méridionaux, en plein air, sans dommage; mais dans le nord, elle exige l'orangerie. Elle ne s'y multiplie pas aisément, parce que ses graines ne mûrissent pas, et que son pied ne s'élargit pas; mais on peut alors la pro-ager de boutures faites dans la conche qui leur est destinée.

I 4. On cultive encore au Muséum le phlomis d'Italie, $P$. italica, Simitr.

Lieu. Le Levant. Ђ. Sa culture doit être assimilée à celle des trois premières espèces auxquelles il a des rapports. \$5. Et à Paris, le phlomis de nissole, P. nissolii, dant les 
feuilles radicales sont presque sagitiées, abondamment cotonneuses; celles de la tige oblongues. Les fleurs sont jaunes, séparées les unes des autres, et les calices sont bordés de dents aiguës.

Lieu. Le Levant. Cette espèce a été aussi cultivée par Miller.

Cult. Pleine terre et orangerie, exposition chaude et terrain sec. 16. P. gigantesque, $P$. giganteo, Hort. angl.

Lieu. La Grèce. $\Psi$. Plein air.

\section{Molucelle, Molucella.}

Cal. très-grand, turbiné, à limbe campanulé et à dents épineuses; la dent sup. plus écartée. Cor. plus petite, labiée. La lèvre sup. entière, concave; l'inf. à 3 div.; dont la moyenne est alongée et échancrée.

* I. Molucelle lisse, M. lavis.

Tiges droites, fermes, épaisses, tétragones, de 2 pieđs. Feuilles opposées, pét., ovales, orbiculaires, entières dans leur partie inf., incisées et bordées de dents mucronées dars la sup., minces et molles. Corolles blanches, au centre d'un caJice fort ample, évasé en entonnoir et à 5 dents, vericillées au nombre de 5 à ro, et garniesinférieurement d'épines aiguës.

Lieu. La Syrie. F. Fl. en juillet et août.

* 2. M. épineuse, M. spinosa.

Tiges id., de 3 à 4 pieds. Feuilles opp., ovales, échancrées en cœur à leur base, irrégulièrement incisées, minces et assez glabres. Fleurs dont la lèv. sup. est d'un rose pâle, et l'inf. jaunâtre, en verticilles ax. disposés le long des tiges et garnies de bractées piquantes. Le calice forme deux levres, dont l'inf. est bordée de 7 dents, et la sup. se termine par une épine.

Lieu. Le Levant. F. Fl. id.

Cult. Ces plantes se sèment sur couche et y restent, si on peut les y laisser, ou se repiquent, quand les jeunes plantes sont assez fortes, dans une bonne terre légère et exposée au midi, ou elles fleurissent et fructifient quelquefois dans nos climats.

Ces plantes sont cultivées pour la singularité de leur port, et sur-tout de leurs fleurs. Elles ont une odeur assez forte, qui n'est point agréable à beaucoup de personnes. L'huile essentielle qu'on en extrait est employée en pharmacie. 


\section{4 étamines fertiles. Corolle à 2 lèvres. Calice à 2 lères.}

\section{Clinopode, Clinopodium.}

Limbe du calice à 3 div. sup., et à 2 parties inf. Cor. élargie à son entrée, labiée. La lèvre sup. droite, échancrée ; l'inf. 3-fide. La div. moyenne plus grande et échancrée.

I. Cuinopode commun, $C$. vulgare. Basilic sauvage.

Tiges droites, carrées, velues, de 2 à 4 pieds. Feuilles opp. , pét., ovales, légèrement dentées, velues. Fleurs purpurines, en verticilles serrés, et en tête arrondie, term.

Lieu.... Ind. ₹. Fl, en juillet.

2. C. d'Egypte, C. aggrptiacum.

Cette espèce a beaucoup de rapports avec la précédente, ei n'en differe que parce qu'elle est plus petite, moins velue, et que les verticilles sont plus petits. Elle est aussi plus rameuse.

Lieu. L'Egypte. $\%$.

* 5. C. blanchâtre, C. incanum, LiN. Pycnanthemum, Michaux.

Tige de 2 à 5 pieds, carrée, rameuse, blanchâtre. Feuilles opp., pét., ovales, pointues, dentées, vertes en-dessus, blanchâtres en-dessous. Fleurs petites, purpurines, en 2 ou 3 verticilles au sommet de la plante, garnis de folioles sétacées.

Lieu. L'Amériq. sept. $\Psi$. Fl. en juillet - oct.

๕. C. ridé, C. rugosum. Hyptis radiata, Willd.

Tiges carrées, droites, velues, rameuses, de 5 à 5 pieds. Feuiiles ovales-lanc., ridées, crénelées. Fleurs petites, blanchâires, en têtes péd., ax. et term. Les têtes sont aplaties, et leur sollerette, qui ressemble à un calice commun, donne à ces fleurs l'aspect des scabieuses.

Lieu. La Caroline mérid. \&. Fl. en juin et juillet.

Cult. $\mathrm{La}_{2}{ }^{\mathrm{e}}$ et la $\bar{j}^{\mathrm{e}}$ sont de pleine terre, et croissent daris presque tous les terrains. Elles se plaisent dans les terres un pea Segeres et chaudes. La $4^{e}$ est do sarre chaude. On obtient cos 
plantes par le semis. Les graines des espèces de pleine terre se sèment en planche ou plate-bande. Celles de la $4^{\mathrm{e}}$ en pot, sur couche et sous châssis. On les multiplie ensuite en séparant leurs pieds. La $\mathrm{I}^{\mathrm{re}}$ est très commune dans les haies.

$U s$. Ces plantes ont un assez beau port. La $3^{e}$ mérite d'être cultivée.

5. C. à fleurs en tête, C. capitatum, Swartz. Hyptis capitata, WILLD., JACQ.

Feuilles ovales, planes, glabres, un peu blanchâtres, dentées. Fleurs blanches, en têtes axillaires, pédonculées, garnies d'une collerette de la longueur des fleurs.

Lieu. La Jamaïque. Ђ.

Cult. Serre chaude.

\section{Origan, Origanum.}

Cal. inégal , tantôt à 2 lèvres. ou 2 part. ; tantôt presqu'à 5 dents. Cor. à tube comprimé, labiée ; la lèvre sup. droite, échancrée; l'inf. 3-fide, presqu'égale. Fleurs serrées, en épi imbricé de bractées ovales, uniflores, colorées.

* I. Origan d'Egypte, O. agyptiacum. Marjolaine à coquilles.

Tige d'un pied et demi, branchue. Feuilles arrondies, un peu épaisses, blanchâtres, cotonneuses, creusées en cuiller. Fleurs d'un rouge pâle ou. blanches, en épis arrondis, serrés, sans bractées.

Lieu. L'Egypte. Ђ. Toujours vert. Fl. en juin - août.

* 2. O. de Crète, dictamne, O. dictamnus.

Tige d'un pied et demi, rameuse, cotonneuse. Feuilles orbiculaires, très-entières, épaisses, charnues, très-cassantes et aisées à se détacher, ridées, très-cotonneuses, blanchâtres. Les feuilles supérieures des épis vertes et obrondes, beaucoup plus petites. Fleurs purpurines, en épis paniculés, feuillés et pen-n. dans : ces épis sont rougeâtres, verdâtres et glabres.

Lieu. L'île de Candie. ๖. Toujours vert. Fl, id.

3. O. du Levant, O. sipyleuma. 
Tiges grêles, rougeấtres, carrées, douces au toucher. Feuilles nvales, glabres, d'un gris cendré. Fleurs pourpres, en épis penchés.

Lieu. Le Levant. Ђ. Toujours vert. Fl. id. 4. Origan d'Amorgos, O. toumefortii, H. K.

Cette espèce a l'aspect de la $2^{\mathrm{e}}$. Ses feuilles sont épaisses, orbiculaires, tantôt glabres, tantot velues. Fleurs en épis tétragones, imbricés de grandes bractées obrondes.

Lieu. L'île d'Amorgos. Ђ. Fl. en antit. Toujours vert.

* 5. O. marjolaine, O. majoranoides, WiLLD.

Tiges nombreuses, de 8 à 10 pouces, droites et grêles. Feuilles petites, ovales, obtuses, très-entières et vertes. Fleurs blanches, en épis arrondis, compactes et pubescens.

Lieu. L'Orient. $\Psi$. Fl. en juin et juillet.

La marjolaine , O. majorana, croît en Portugal et dansla Palestine : elle est $\odot$.

6. O. de Grèce, O. heracleoticum.

Tiges carrées, d'un pied et demi, velues, rougeâtres. Feuilles ovales, obtuses, velues, presque sessiles, imitant celles de la marjolaine. Fleurs petites, blanches, en épis longs, péd., rassemblés.

Lieu. L'Europe mérid. $\nVdash$. Fl. en juin-nov.

7. O. de Syracuse, $O$. onites.

Tige d'un pied et demi, branchue. Feuilles petites, cordiformes, cotonneuses, un peu plus larges que celles de la 5 e. Fleurs petites, blanches, en épis alongés, rassemblés et veloutés.

Lieu. La Sicile. $\%$. Fl. id.

*8. O. commun, O. vulgare.

Tiges nombreuses, rougeâtres, carrées, de 2 à 3 pieds. Feuilles pét., ovales, légèrement dentées, velues en - dessous. Fleurs petites, rouges ou blanches, en épis arrondis, rassemblés, paniculés, term., dont les bractées sont colorées.

Variété plus petite, $O$. humile.

Lieu. ...Ind. ₹. Fl. id. Très-commune.

* 9. O. de Smyrne, O. smyrneum.

Tiges cylindriques, de 2 à 3 pieds, velues, droiles, un peu 
purpurines. Feuilles opp., pét., ovales, entières, velues, douces au toucher; quelques-unes légèrement dentées. Fleurs blanches, en épis rassemblés en faisceau ombelliforme.

Lieu. La Crète. ๖. Fl. en été. Toujours vert.

* ro. O. roide, O. maru.

Tiges droites, rameuses, roides, très - feuillées, d'un pied. Feuilles opp., sess., ovales, pointues, roides, nombreuses, rapprochées, couvrant les tiges. Fleurs blanchâtres, pourprées, en têtes denses, terminales, velues, trois fois ternées.

Lieu. La Crète. ๖. Fl. en été. Toujours vert.

I I. O. de Crète, O. creticum, Mrller.

Tiges tétragones, d'un pied et demi. Feuilles ovales, obtuses, trèsentières, velues, d'une odeur forte et aromatique. Fleurs petites, blanches, accompagnées de bractées membraneuses, du double plus longues que le calice, disposées en longs épis prismatiques, droits et serrés comme ceux de l'origan commun.

Lieu. L'Europe australe. $\Psi$. Fleurit en juillet.

On cultive au Muséum encore une autre espèce nommée O. pallidum. Elle est orig. du Levant, $₹$ et de pleine terre.

Cult. Les 5 premières espèces et les trois dernières sont d'orangerie. Elles aiment la chaleur, et redoutent l'humidité constante. Pendant l'hiver, il faut les mettre le plus près des jours possible, sans quoi elles s'étioleront et s'altéreront. La $2^{\mathrm{e}}$ surtout doit être bien placée dans cette saison, et arrosée très-modérément; elle n'est pas très-facile à conserver long-temps, et elle périt souvent sans qu'on s'y attende. On doit en avoir toujours de jeunes pieds pour remplacer les pertes. Ces plantes se multiplient par le semis, et aisément de boutures faites dans le courant de l'été, en pots remplis d'une bonne terre, légèrement sablonneuse, et conduites à la manière indiquée. La $2^{\mathrm{e}}$ doit avoir toujours un air libre, même ses boutures; il ne faut que garantir ces dernières du soleil. La $10^{\circ}$ ne vit pas long-temps. Les autres sont de pleine terre. Elles demandent, comme celles d'orangerie, une exposition méridienne et des terres légères. La commune vient par-tout. On les multiplie aisément en séparant leurs pieds en mars. 
Une partie des origans seroit beaucoup mieux en plein air que dans les serres, dans les pays où l'hiver n'est pas rigoureux, et placée sur des coteaux d'une terre légère, à une exposition absolument méridienne. Il en est de même de toutes les plantes labiées qui ne sont pas très - délicates, et sur-tont de celles qui ont une odeur très-aromatique.

Us. Ces plantes ne laissent pas que de contribuer à la variété, et elles méritent d'être cultivées à cause de leur odeur. La I ${ }^{\mathrm{re}}$ est assez jolie. La $2^{\mathrm{e}}$. est fort remarquable par sa blancheur et par son odeur forte. C'est vraisemblablement le vrai dictamne des anciens. Toutes ont une odeur aromatique assez pénétrante; elles sont toniques, cordiales, stomachiques, comme presque toutes les plantes labiées

\section{Thym, Thymus.}

L'entrée du calice fermée de poils. Sa lèv. sup. à 3 dents; l'inf. à 2 pointes sétacées ou bifide. Cor. courte, labiée. La lèv. sup. échancrée; l'inf. à 3 lobes, dont le moyen est plus large.

* г. Thy serpolet, $T$. serpyllum.

Très-petit arbuste de 4 à 6 pouces de haut. Tiges grêles, dures, nombreuses, diffuses, rougeâtres, presque toutes couchées sur la terre. Feuilles petites, opp., planes, ovales, un peu ciliées, vertes, et plus ou moins velues. Fleurs purpurines ou blanches, en épis courts ou en têtes terminales. Les calices sont colorés.

* Variétés. I. à odeur de citron. Celles-ci a les tiges plus grandes, grêles, velues. Ses feuilles inf. vertes; les sup. grisâtres, B. citratum.

2. Plus ve lue, et à fleurs d'un pourpre foncé. $T$. serpillum villosum.

5. Velue, à feuilles étroites.

4. Glabre, id.

5. Inodore, inodorum, Nов. J'ai trouvé cette variété dans les sables mariimes d'Ambleteuse, d'autant plus singulière que la sécheresse naturelle 
de cet endroit devroit au contraire rendre l'odeur des thyms plus pénétrante. Je l'ai plantée dans mon jardin, et depuis qu'elle y est, elle est toujours sans odeur.

Lieu. Ind. b. FI. en juin-août. Toujours vert.

2. T. filiforme, $\boldsymbol{T}$. filiformis, H. K.

Tiges filiformes, inclinées. Feuilles cordiformes, pointues, très-entières, pét. Fleurs ax., sol. , péd.

Lieu. Les îles Baléares. Ђ. F1. en juin et juillet.

*3. T. commun, T. vulgaris.

Petit arbuste en touffe arrondie, dont les tiges nombreuses, cylind., rameuses, un peu velues, s'élèvent de 6 à ro pouces. Feuilles petites, étroites, d'un vert cendré. Fleurs blanches, petites, verticillées, en épi term.

Lieu. La Fr. mérid. Ђ. Fl. en mai-aon̂t. Toujours vert.

$\not$ ariétés. I. à feuilles plus larges, latifolius.

2. blanchâtre.

* 3. à petites têtes.

* 4. à feuilles panachées.

* 4. T. cilié, $T$. zigis.

Tiges grêles, nombreuses, rameuses. Feuilles étroites, lin. , ciliées à leur base, rassemblées. Fleurs blanches, petites, verticillées. Cet arbuste forme une petite touffe très-serrée.

Lieu. Id. Ђ. Fl. en août.

* 5. T. des Alpes, T. alpinus. Calamintha alpina, Fl. fr. Acinos, Pers.

Feuilles obtuses, concaves, un peu dentées en scie. Verticilles de 6 fleurs.

Lieu. Les Alpes, la Suisse. $\%$. Fl. en juin-sept. * 6. T. mastic, $T$. mastichina.

Petit arbuste d'un pied et demi à 2 pieds, rameux; les rameaux droits, blanchâtres et durs. Feuilles très-petites, ovaleslanc. , un peu pointues, entières, blanchâtres. Fleurs blanches, verticillées, en épi et en têtes term. Les calices de cette espèce sont remarquables par leur blancheur et leurs dents sétacées, un peu piquantes et velues.

Lieu. L'Espagne. Ђ. Fl. en juillet-sept. Toujours vert. 
* 7. Tнум de Virginie, $T$. virginicus, Lis. Satureia vir giniana, Liv., Sp. , MrLu.

Cette plante a le port et les fleurs d'une sariette; mais les poils abondans qui ferment l'entrée dela corolle la rendent aux thyms.

Tige droite, tétragone, glabre. Branches opposées. Feuilles opposées, lancéolées, pointues, canaliculées, un peu ondulées en leurs bords, peu pétiolées, glabres et vertes. Fleurs d'un pourpre pâle, disposées en deux ou trois verticilles serrés au sommet des tiges et des branches, dont le dernier est terminal. La levre inférieure marquée de taches violeites.

Lieu. L’Amérique sept. . Fl. en juillet.

* 8. T. champêtre, $\boldsymbol{T}$. acinos. Calamintha arvensis, Fl. fr. Acinos vulgaris.

Tiges en partie couchées, grêles, rameuses, un peu velues. Feuilles opp., petites, ovales, pointues, dentées ou entières et velues. Fleurs purpurines, 5 ou 6 à chaque verticille, sol. sur les pédoncules.

Lieu. Les champs. Ind. Fl. en juin-août.

9. T. à grandes fleurs, T. patavinus, H. K. , J AcQ. Acinos patavinus, Pers.

Tiges presụue ligneuses. Feuilles ov., dentées. Fl. verticillées. La corolle renflée à son entrée, plus longue que le salice.

Lieu... o . Fl. id.

Iо. $\mathrm{T}$. piperelle, $T$. piperella.

Tiges couchées et tombantes. Feuilles très-petites, ovales; obtuses, nerveuses, très-entières et glabres. Fleurs axillaires, sess., solitaires. Les feuilles sont parsemées de points dorés.

Lieu. L'Espagne. Ђ.

Cult. Les espèces 2, 6 et I o sont d'orangerie, et doivent être cultivées et multipliées comme les origans de cette température. Les autres sont de pleine terre Ces thyms, et particulierement le commun et la variélé à odeur de citron du serpolet, ne se plaisent que dans les terres chaudes, légères, peu substantielles, et à une exposition méridienne. Elles viennent cependant dans les autros terrains, même dans les argileux; mais elles sont sujettes a y périr dans les froids un peu rigoureux. On les multiplie facilement en séparant leurs touffes en mars, et les arro- 
sant légèrement jusqu'à leur reprise; mais ces multiplications ne réussissent bien que dansles terres ci-dessus indiquées. On plante ordinairement le thym en bordure dans les potagers; on le trunsì plante tous les trois ou quatre ans, et on le tond tous les ans après la fleur. Cette espèce ne peut être garantie du froid que dans les terres médiocres et légères, ainsi que la variété du serpolet citronnée ; celle-ci se multiplie comme le thym ou en cou-

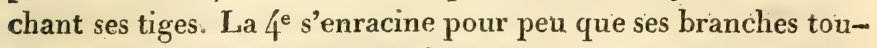
chent la terre. La variété à feuilles panachées du thym commun est très-susceptible de périr parle froid dans le nord de la France. Comme celle du serpolet à odeur de citron, on fera bien d'avoir des individus en pots de ces deux variétés.

Us. Le thym commun est', comme l'on sait, d'un ùsage fréquent en cuisine. Il est, ainsi que le serpolet, chaud et aromatique, et ils ont toutes les vertus des plantes labiées. La 6 e esa pèce forme un petit arbuste assez joli, et fort remarquable par ses calices. Elle a une odeur presqu'aussi pénétrante que celle du marum, mais plus agréable. Les autres se cultivent dans les jardins de botanique. Les espèces 8 et 9 se sèment tous les ans en place. La variété à feuilles panachées du thym commun est très-jolie.

\section{Thymbra。}

Cal. du thym, mais point velu en-dedaris, marqué seulement; à l'extérieur et des deux côtés, d'une ligne velue. Corolle labiée; la lèv. sup. bifide; l'inf. trifide, presqu'égale. Style moitié bifide.

* I. Thy mbra en épi, $T$. spicata.

Petit arbuste. Tige brune, de 5 à 6 pouces. Feuilles très-étroites, pointues, sessiles. Fleurs pourpres, en épi terminal.

Lieu.L'Espagne, le Levant. ๖. Fleurit en juin et juillet. Toujours vert.

2. T. verticillée. $T$. verticillata. An var. precedentis?

Tige d'un pied. Feuilles étroites, lanc. ponctuées. Fleurs pourpres, sessiles, en verticilles terminaux. Les bractées plus grandes que les feuilles.

Lieu. Id. . Fl. id. Toujours vert. 
Cult. Orangerie. La même que celle des origans de cette serre. On les obtient par leurs graines semées en pot sur couche à la manière indiquée.

\section{Mélisse, Melissa.}

Cal. aride; la partie sup. plane et à 3 dents; l'inf. 2-fide. Cor. labiée. La lèv. sup. un peu voûtée, bifide; l'inf. à 5 lobes, dont le moyen est un peu en cœur.

* I. MÉLisse des jardins, M. hortensis. M. officinalis. Citronnelle.

Cette plante forme un large buisson, garni de beaucoup de tiges carrées, rameuses, de 2 à 3 pieds. Feuilles opp., pét., ovales, dentées, un peu ridées et velues, d'un vert lisse. Fleurs petites, blanches, verticillées, ax., souvent unilatérales.

Lieu. La France mérid. $\%$. Fl. en juin-octobre.

Variété à feuilles plus velues. Mélisse romaine.

* 2. M. calament, M. calamintha. Calamintha, Fl. fr.

Tiges d'un à 2 pieds, droites, velues. Feuilles pét., ovales : dentées, obtuses, moins velues. Fleurs assez grandes, purpurines, portées sur des pédoncules rameux, et disposées en grappes alongées et ax.

* Variété à plus grandes fleurs pourpres et à feuilles oblongues. , M. grandiflora. Espèce suivant WiLld. et Desfont.

Lieu. La France. La variété, d'Italie, భ. Fl. en juin-sept. 3. M. parviflore, M. nepeta. Calamintha parviflora, Fl. fr.

Tiges foibles, grêles, rameuses, blanchâtres, d'un pied et demi. Feuilles très-petites, ovales, dentées, velues, blanchâtres. Fleurs blanches, mêlées de pourpre, portées sur des péd. rameux, axillaires, plus longs que les feuilles. Calice à 5 dents presque égales.

Lieu. La France, l'Angleterre. $\%$. FI. en juillet-octobre. 4. M. de Crête, $M$. cretica. Calamintha cretica, Fl. fr. Nepela marifolia, C.Av.

Tiges presque simples, droites, de 8 à ro pouces. Fe uilles petites, opp., pét., ovales, légèrement dentées. Fleurs très-petites, rougeâtres, en grappes terminales. Les péd. très-courts. 
Lieu. La Fr. mérid. 万 ou 3-annuelle. Fl. en juin et juillet.

5. M. frutescente, $M$. fruticosa.

Tiges et rameaux grêles, effilés. Feuilles ovales, pointues, cotonneuses en-dessous, petites, imitant celles du marum. Fleurs blanches.

Lieu. L'Espagne. Fl. en juillet-sept. * 6. M. globulaire, M. globularia, H. P.

Tiges cylindriques, striées, pubescentes, garnies de feuilles verticillées, quaternées ou quinées, ovales, pointues, dentées en scie, ridées. Fleurs.....

Lieu. L'Amérique mérid. \$. Toujours vert.

Cult. Les 3 premières sont de pleine terre. La première vient dans tous les terrains. Les 2 autres ne se conservent que dans les terres légères, médiocres et exposées au midi. O.. les multiplie par la séparation de leurs pieds en automne ou en mars, et par leurs graines semées dans des planches de terre prédparées pour ces semis. La première, très-répandue, se ème elle-même. Les 2 avant-dernières sont d'crangerie, et leur culture se rapporte à celle des origans de cette température. Elles demandent les mêmes terres et les mêrmes situations. La $6^{\text {e }}$ est de serre chaude. Je l'ai perdue sans avoir vu les fleurs. On me l'a envoyée sous ce nom. Ce n'est qu'à ce titre que je l'ai insérée dans cet ouvrage. Peut-être se rapporte-t-elle à une autre espèce, ou n'est-elle pas de ce genre.

Us. Ces plantes sont aromatiques, et ont les propriétés reconnues dans la plupart des plantes labiées. La i $^{\text {re }}$ est d'un usage beaucoup plus fréquent. Son odeur imite celle du citron et est fort agréable. Elle est cordiale, stomachi ${ }_{2}$ ue, anti-asthmatique. On s'en sert en infusion théiforme. On en fait aussi une eau fort estimée autrefois, et connue sous le nom d'eau des Carmes. On doit en cueillir les feuilles avant la floraison.

Les espèces 2, 3 et 4 seroient peut-être mieux placées dans le genre thym, à cause des poils qui ferment l'entrée des calices pendant la maturation des graines, et qui en revêtent aussi le, tube de la corolle. 


\section{Dracocéphale, Dracocephalum.}

Cal. 5-fide, presqu'égal. Corolle renflée à son entrée; la levv. sup. voûtée, échancrée dans quelques espèces; l'inf. à 3 lobes, dont les latéraux sont plus courts et droits, et le moyen plus grand, alongé, entier ou à 2 lobes.

* I. Dracocéphale de Virginie, $D$. virginianum.

Tiges simples, carrées, droites, glabres, de 2 à 3 pieds. Feuilles opp., lin.-Ianc., légèrement dentées et glabres. Fleurs roses ou carnées, en épi terminal, assez grandes, horizontales et nombreuses.

Lieu. le Canada, la Virginie. $¥$. Fl. en juillet-sept.

* 2. D.des Canaries, D. canariense.

Tige de 2 pieds environ, rameuse, carrée, rougeâtre. Feuilles opp., pét., à 3 à 5 fol., lanc., pointues, dentées en scie, ridées, d'un vert foncé. Fleurs rougeâtres, avec des lignes blanches, en épi serré et terminal. Odeur de térébenthine.

Lieu. Les Canaries. $\sigma^{\top}$ ou trisannuelle. Fl. en juillet - sept.

3. D. denticulé, D. denticulatum, H. K.

Feuilles ovales-lanc., sessiles, denticulées à leur sommet. Fleurs distantes, purpurines, assez grandes, en épis term.

Lieu. La Caroline. v. Fl. en août.

* 4. D. d'Autriche, D. austriacum.

Tiges rameuses, obtusément carrées, un peu velues, de 8 à ro pouces. Feuilles opp., sess., étroites, lanc.-lin., glabres, presque toutes dentées ou incisées; les découpures se terminent en pointe épineuse. Fleurs d'un bleu pourpré, opp., ax., presqu'en épi.

Lieu. La Sibérie, l'Autriche. $\%$. FI.....

L'espèce $D$. peregrinum, qui ne paroît être qu'une variété de celle-ci, s'en distingue cependant par ses feuilles moins incisées.

* 5. D. à feuilles d'hysope, D. ruyschiana.

Tiges d'un pied, glabres, carrées, rameuses; les rameaux opposés. Feuilles sess., opp., lanc. - lin., entières, glabres. Fleurs bleues, assez grandes, verticillées, en épi termainal. 
Lieu. La Suède, la Suisse, la Sibérie. $¥$. Fl. en juin et juillet.

* 6. D. de Sibérie, D. sibiricum.

Tiges rameuses, carrées, de 5 pieds. Feuilles pét., cordiformes, oblongues, pointues, dentées en scie. Fleurs purpurines, en verticilles ax. ou corymbes pédonculés, souvent latéraies.

Lieu. La Sibérie. $\%$. Fl. en juin-août.

* 7. D. à grandes fleurs, D. grandiflorum.

Tiges d'un pied, carrées, simples, pubescentes. Feuilles opp. , pét., crénelées; les rad. cordiformes; les caulinaires orbiculées, sess. Fleurs bleues, grandes, verticillées, ax.; la lèv. inf. tachetée de brun; un peu barbues.

Lieu. La Sibérie. $\%$. Fl. en juillet.

L'espèce altaiense, Willd. g. dont Linné n'a fait qu'une variété de la précédente, s'en distingue cependant assez pour en être séparée.

8. D. penché, D. nutans.

Tige d'un pied, rameuse, obtusément carrée. Feuilles opp. , pét., légèrement dentées; les inf. ovales, obtuses; les sup. oblongues, presqu'entières. Fleurs bleuâtres, verticillées, un peu pendantes.

Lieu. Id. «. Fl. id.

* 9. D. moldavique, D. moldavica.

Tiges de 2 pieds, carrées, rameuses, rougeâtres. Feuilles opp., pét., ovales-oblongues, dentées, obtuses; celles du sommet ont leurs dents terminées par un filet. Fleurs bleues, purpurines ou blanches, verticillées, ax., formant des épis feuillés et terminaux. Les dents des bractées sont aussi garnies d'un filet:

Lieu. La Moldavie. Fl. id. Io. D. blanchâtre, $D$. canescens, Mirter.

Toute la plante couverte d'un duvet blanchâtre. Tige carrée, d'un pied. Feuilles inf. pét; ovales-oblongues, émousées, dentées. Fleurs grandes, blanchâtres, avec un peu de viołet, $2 u$ : nombre de 5 ensemble, verticillées.

Lieu. Le Levant. F. Fl. id. 
II. Dracocéphale à bractées rondes, ou à feuilles de saule, D. pellaium.

Tige de ro pouces, carrée, garnie dans sa longueur de feuilles ; ét., dentées; les inf. ovales, obtuses; celles du sommet saliciformes. Fleurs petites, bleues, verticillées, ax.; les bractées arrondies, bordées de dents sétacées.

Lieu. Le Levant. Fl. id.

12. D. à fleurs de thym, D. thymiflorum.

Tiges d'un pied, tétragones, garnies, dans leur longueur, de feuilles petites, opp., pét., trinerves; les inf. ovales, dentées; les sup. obl., presqu'entières. Fleurs petites, bleuâtres, verticillées. Les cálices sillonnés.

Lieu. La Sibérie. Fl. en juin-sept.

I3. D. varié, D. variegatum, VEnt., Jard. Cels.

Tige droite, tétragone, sill onnée entre ses angles, noueuse, rameuse, glabre, purpurine, de 4 décimètres. Feuilles opposées; les inférieures pétiolées (les su érieures sessiles), ovales, oblongues, pointues, dentées à leur sommet, d'un vert foncé en-dessus, pâles en-dessous. Fleurs d'un rouge violet, rayées de blanc, droites, sessiles, au nombre de 4 rar verticille, disposées en épis droits, courts, tétragones et terminaux.

Lieu. La Caroline. ₹. Fl. en août.

Cult. Parmi ces expeces il n'y a que la seconde qui soit d'orangerie, encore dans les hivers doux, et même ordinaires, elle résiste en pleine terre. D'ailleurs, elle n'est que bisannuelle, el se sème souvent elle-même. Les autres espèces sont de pleine terre. Les $\pi$ sont rustiques, et viennent assez bien dans tous les terrains. On les obtient par leurs graines semées sur couche ou en planches de bonne terre, et conduites à la manière indiquée; et on les multiplie en séparant leurs pieds en automne ou en mars. Les es jèces se sè.nent en place ou sur couche. Elles doivent être placées dans une terre un peu légère et substantielle, et à une exposition chaude. Plusieurs sont traçantes, surtout la $4^{\mathrm{e}}$. Il est essentiel de relever tous les ans au printemps ces dernières, pour les replanter de suite et en faire des pieds séparés. Il en doit être de même, ainsi que je l'ai dit à l'article 
des menthes, de toutes les plantes traçantes qui finissent par périr quand on ne les cultive pas ainsi chaque fois qu'elles s'étendent. Quoique les dracocéphales viennent dans presque tous les terrains, néanmoins les terres légères, amendées anciennement, et l'exposition du midi leur conviennent davantage, et ils s'y maintiennent bien plus long-temps dans' une belle végétation. Faute des soins indiqués ci-dessus, on ne les conserve que peu d'années, à l'exception de la I ${ }^{\text {re }}$ espèce.

$U s$. Presque tous les dracocéphales vivaces sont d'assez belles plantes, dont les fleurs sont agréables à voir. On distingue cependant parmi elles les $\mathrm{I}^{\mathrm{re}}, 4^{\mathrm{e}}, 5^{\mathrm{e}}$ et $7^{\mathrm{e}}$. La $9^{\mathrm{e}}$ a une odeur forte, assez aromatique, qui imite un peu celle de la mélisse. Elle est cordiale. On en extrait de l'huile essentielle pour la pharmacie. On fait un ratafiat avec ses fleurs. Mais il ne m'a pas paru agréable.

Ventenat a observé que lorsqu'on touche les fleurs de la Ize espèce el de la ${ }^{\mathrm{re}}$, en leur faisant décrire un demi-cercle, elles restent immobile dans la position où on les met. Cette propriéié caialeptique, dit le même auteur, doit exister aussi sur d'autres plantes labiées. Il y a cependant apparence que cet effet est dûà d'autres circonstances, car j’aì essayé de le produire sans l'avoir aucunement remarqué.

\section{Mélissot, Melittis.}

Cal. grand, turbiné, 3-fide, inégalement bilabié, plus ample que le tube de la corolle. Cor. du double plus longue, à limbe dilaté, ouvert, labié; la lèv. sup. entière, plane; l'inf. à 3 grands lobes inégaux, entiers ou crénelées. * Mélissot, Mélisse sauvage, M. melissophyllum.

Tiges carrées, velues, d'un pied, garnies, dans toute leur longueur, de feuilles ovales, pét., velues, crénelées. Fleurs carnées ou blanches, avec une tache purpurine; grandes, ax. , péd.

Lieu. La France, l'Angleterre. $\varkappa$. Fl. en mai et juin.

Variété à feuilles ovales, un peu en cour. La Suisse. Cette variété est peut-être l'espèce $M$. grandiflora de Curtis.

Cult. Cette plante se cultive comme la mélisse des jardins. 


\section{Horminelle, Horminum.}

Eal. turbiné, strié, supérieurement à 3 dents, inf. bifide: Corolle du double plus longue, cylindrique, labiée, la levre sup. concave et bifide, l'inf. à 3 lobes.

I. Horminelue des Pyrénées, Horminum pyrenaicum, Lin. Melissa pyrenaica, WILLD.

Tige peu élevée, simple, droite, tétragone, légèrement velue, presque nue dans sa partie supérieure. Feuilles radicales, ovales-arrondies, ridées, crénelées, à petioles courts. Fleurs. bleuâtres, pédonculées, verticillées, en épi terminal.

Lieu. Les Pyrénées. ఛ .

Cult. Plein air. La même que celle des mélisses, auxquelles. cette plante à des rapports.

?. H. jaune, H. caulescens. Ortega, Persoon. Lepichinia spieata, WILld.

Tige feuillée. Feuilles ovales-oblongues, crénelées. Fleurs, pâles. Calices piquans. Bractées en cœur, acuminées.

Lieu. Le Mexique. $\psi$.

Cult. Orangerie. Cultivée au Muséum.

\section{Germaine, Germanea.}

Eal petit, 5-fide, à 2 levres; la div. sup. plus grande. Cor. la-. biée, renversée. La lèv. sup. un peu éperonnée à sa base, à 3 lobes, dont le moyen est plus long et en cœur; l'inf. plus petite, concave; entière ou ondulée.

* I. Germaine à feuilles d'ortie, G. urticaefolia, Lam. Plectranthus fruticosus, L'HéRItier, H. K.

Tige de 2 pieds environ, droite, très-branchue, cylindrique, glabre, d'un gris cendré ; les rameaux tétragones, rougeâtres et. pubescens. Feuilles opp., pét., assez grandes, cordiformes, dentées en scie, ridées, pointues, d'un vert foncé. Fleurs d'un bleu pâle, tachées de points bruns, en grappes nues et term.

Lieu. Le Cap. b. Fl. en automne. Toujours verte.

Cult Orangerie. Cette plante demande une terre consistante 
et substantielle, peu d'arrosemens et de la chaleur. Elle est sensible à l'humidité des serres ordinaires, et elle y perd souvent. une partie de ses jeunes pousses; une serre plus sèche lui convient beaucoupmieux; et comme elle fleurittard, s'il venoit des pluies dans cette saison, on feroit bien de la rentrer alors pour jouir mieux de ses fleurs. On la multiplie aisément de boutures faites en pot sur couche dans le cours de l'été. Elles s'enracinent en peu de temps, et fleurissent en automne comme les vieux pieds.

Us. Cette plante a un beau feuillage et des fleurs assez agréables à la vue. Elle mérite une place dans les serres et parmi les arbustes de cette température. On lui a donné le nom de germanie en l'honneur de M. Saint-Germain, cultivateur et amateur de plantes étrangères à Paris.

2. G. nudiflore, G. nudiflora. Plectranthus nudiflorus, WILLD.

An ocymis species, Juss.

Tige tétragone, droite, pubescente, de 8 à 9 pouces; feuilles inférieures pétiolées, pointues, cordiformes, dentées, ridées, glabres en-dessus, pubescentes en-dessous et sur leurs nervures; les supérieures petites, amplexicaules. Pétioles ailés. Fleurs petites, à tube courbé, fermé à son entrée, disposées en grappes unilatérales, composées de verticilles rassemblés et formant un panicule terminal.

Lieu. La Chine. $\psi$.

Cult. Serre tempérée. Des jardiniers la nomment basilic de la Chine, Plectranthus punctatus. $\boldsymbol{V}$. basilic 8 .

3. P LECTRANTHUS strobiliferus, Hort. angl.

Lieu. Les Indes or. Cultivé en Angleterre.

\section{Basilic, Ocymum.}

Cal. labié; la lèvre sup. large et orbiculée; l'inf 4-fide. Cor. z tube court, renversée; la levre sup. à \& lobes égaux; l'inf. plus longue, entière, crénelée. Les filamens des étamines in. clinés, dont 2 plus courts; à leur base une éminence.

* 1. Basilic commun, O. basilicum.

Tige d'un pied, droite, dont les rameaux sont tetragone. epposés en croix et redressés. Feuilles opp., pét., ovales-laus. . 
planes, lisses, d'un vert foncé. Fleurs blanches ou purpurines, péd. , verticillées, formant des grappes droites, simples et terminales.

Lieu, Les Indes or. Fl. en juillet.

Variétés. I. A grappes vertes.

2. A grappes violettes.

3. Basilic commun, moyen.

4. A grappes vertes ou violettes.

5. Basilic commun, à feuilles larges.

6. Basilic d'Amérique.

2. Basilic à feuilles bullées, O. bullalum. Cette espèce est plutôt une variété de la I $^{\mathrm{re}}$.

Tige droite, d'un pied, rameuse. Feuilles ovales, longues de 4 à 6 pouces, épaisses, concaves en-dessous, ridées, plissées ou crispées en-dessus. Fleurs blanches, verticillées, en épis serrés. Les corolles frangées.

Lieu. L'Inde. Fl id.

5. B. velu, O. hispidum, Var. O. sanctum.

Tige d'un pied et demi, paniculée, à rameaux longs et tétragones. Feuilles d'un vert grisâtre, un peu velues. Fleurs blanches, petites, en longues grappes term. Espèce inodore.

Lieu. Les Indes or. Fl, en septembre.

* 4. B. à petites feuilles, O. minimum

Tige de 5 à 6 pouces, garnie de rameaux très-nombreux, qui forment un petit buisson arrondi. Feuilles petites, opp., ovales, pointues. Fleurs blanches, petites, verticillées, ax.

Variété à feuilles violettes et obtuses.

Lieu. L'Inde.

5. B. à épis nombreux, O. polystachion.

Tige droite, rameuse, tétragone, à angles tranchans, de 2 pieds. Feuilles opp., pét., ovales, obtuses avec une pointe, dentées. Fleurs blanchâtres, en grappes longues, unilatérales, ax.

Lieu. Id. Fl. id.

6. B. de Ceylan, O. gratissimum. O. zeilanicum, Burn. Arbuste de 2 \̀ 5 pieds, à rameaux droits, velus, tétragones. 
Feuilleś opp., pét, ovales, pointues, crénelées, vertes endessus, blanchâtres el ponctuées en-đessous. Les pétioles velus. Fleurs petites, blanchâlres, penchées, au nombre de 6 par verticilles, disposées en grappes term.

Lieu. Les Indes or. Ђ. Fl. en juillet.

Selon Desfontaines, le basilic de Ceylan, $\boldsymbol{O}$ zeilanicum, se distingue de l'O. gratissimum. Il en fait une espèce particulière. 7. B. à petites fleurs, $O$ tenuiflorum.

Tige d'un à deux pieds, rameuse, rougeâtre, velue. Feuilles ovales-obl., obtusément dentées, molles, portées sur de longs pétioles. Fleurs petites, purpurines, en épis longs et terminaux. 3 fleurs de chaque bractée.

Lieu. Id. or. Fl. id.

8. B. ponctué, O. punctatum. Plectranthus punctatus, L'HÉritier, H. K.

Tige d'un pied, cylind., garnie à sa base de rameaux velus, marqués de points roussâtres. Fleurs bleuâtres, penchées, en épis péd. et term. Feuilles opposées, pétiolées, ovales, dentées, ridées et velues.

Lieu. L'Afrique. $0^{7}$. Fl. en janvier-mai. 9. B. à feuilles étroites, O. menthoides.

Tige rameuse, de 7 pouces. Feuilles petites, opp., quelquefois ternées ou quaternées, pét., linéaires-lanc., deniiculées. Fleurs rougeâtres, petites, verticillées, en épis term.

Lieu. Les Indes or. Fl. en juillet. 10. B. à grandes fleurs, O. grandiflorum; L'HÉRIT.

Arbuste de 2 à 5 pieds, rameux. Feuilles opp. , pét., ovales, dentées, glabres et vertes. Fleurs blanches, grandes, en grappe courte et term.

Lіеu. L'Afrique. Ђ.

Ix. B. à feuilles en cœur, O. molle, H. K.

Toute la plante pubescente. Tige obtusément carrée. Feuilles ovales, pointues, inégalement dentées en scie, ridées, molles, cordiformes. Fleurs d'un violet blanchâtre. Les bractées arrondies, cunéiformes; odeur agréable.

Lieu. Les Indes or. Fl. en sept. et octobre.

12. B. des moines, Ocymum monachorum. 
Tige droite, presque cylindrique, légèrement velue, de 5 décimètres. Feuilles opposées, pétiolées, ovales, obtuses, dentées en scie, légèrement ciliées. Fleurs petites, blanches; la lève inférieure purpurine ; disposées en grappes composées de verticilles de 6 fieurs. Bractées en cœur. Filamens pourpres, de la longueur de la corolle, sans éminence à leur base, mais remplacée par des poils.

Lieu. Les Indes.

Cult. Toutes ces espèces sont de serre chaude. Mais Ies fon ont pas besoin. On les sème sur couche en avril, lorsque les gelées ne sont plus à craindre, ou sous châssis. Lorsque les jeunes plantes ont acquis assez de force pour être transplantées, on les enleve avec leur motte pour les mettre dans des pots moyens, remplis de bonne terre, un peu légère et très-substantielle. On place ces pots sur les fenêtres des serres. On peut aussi laisser une partie de ces plantes sur couche pour l'utilité; mais dans nos climats, il est rare qu'elles fructifient en plein air. Les espèces b se cultivent de même, excepté qu'on les rentre en serre chaude, où elles passent, sur les tablettes de cette serre, Ie temps de leur durée, qui n'est pas bien longue. Avant de placer les pots de basilic où ils doivent rester, il faut, lorsqu'ils sont empotés, les plonger dans une couche tempérée, et les arroser de temps en temps jusqu'à leur parfaite reprise, et qu'ils aient pris de la force.

Us. Ces plantes sont cultivées, sur-tout les espèces. $\mathrm{T}, 2$ et 4 , pour leur odeur agréable. On sait l'usage qu'on fait de la première daas.les cuisines. La quatrième est plus jolie. Elles sont cordiales, céphaliques, détersives, fortifiantes, résolutives. Leux huile essentielle est employée en pharmacie et en parfumerie.

\section{Trichostema.}

Cal. labié, supérieurement 3-fide, inférieurement plus court et bifide. Cor. à tube court. La levre sup. comprimée, en fausille; l'inf. à 3 lobes, dont le moyen est plus petit et oblong. Filamens des étam. très-longs et courbés.

Irichostema dichotome, $T$. dichotoma. 
Tige de 7 à 8 pouces, rameuse. Feuilles opp., petites, arrondies, imitant celles de la marjolaine. Fleurs petites, purpurines, ax.

Lieu. La Virginie, la Pensylvanie. Fl. en juin et juillet.

Cult. Cette plante se sème sur couche au printemps, et peat y rester pour fleurir et fructifier.

\section{Brunelle, Brunella.}

Cal. supérieurement plane, trorqué, à 3 dents, inf. trifide, plus étroit. La levre sup. de la corolle concave, entière ou it 2 lobes; l'inf. à 3 lobes, dont le moyen est plus grand of. échancré. Filamens des étam. fourchus ou à 2 dents à leur sommet; une dent anthérifere, l'autre nue. Stigmate bifide, rarement 4-fide.

I. BRUNelle commune, B. vulgaris.

Tige carrée, velue, à moitié couchée, de 6 à io pouces, selon les situations. Feuilles opp., ovales-obl., un peu velues, legèrement dentées. Fleurs bleuâtres, en épi serré et terminal, imbricé de bractées ciliées.

* Variété à plus grandes fleurs, rouges ou blanches.

Les feuilles supérieures, dans cette variété, sont distantes de l'épi. P. grandiflora, Willd., Desfont. Ces auteurs en font une espèce distincte.

Autre variété à longues feuilles, $\boldsymbol{B}$. longifolia, Pers. $\boldsymbol{B}$. hyssopifolia, H, P., et Flor. paris.

Lieu. Ind. $\%$. Fl. en juillet et août.

* 2. B. à feuilles d'hysope, B. hyssopifolia.

Tige d'un pied, carrée, un peu velue. Feuilles opp., sess., lanc., un peu étroites, très-entières. Fleurs assez grandes, d'un pourpre bleuâtre, en épi moins serré. Les feuilles sup. presque contiguës à l'épi.

Lieu. La Fr. mér. ₹. Fl. id.

3. B. découpée, B. laciniata.

Tiges couchées, rameuses, rougeâtres, velues. Feuilles rad. pét., ovales-obl., entières; les sup. découpées. Fleurs 
d'un blanc jaunâtre ou rougeâtre, en épi term. Les pétioles velus.

Lieu. La France. près Abbeville. Ind. ₹ . F1 id. Cette espèce, selon Willd, n'est qu'une variété de la brunelle grandiflore, variété de la première dans cet ouvrage.

Variété à fleurs bleues

4. Brunelle odorante, B. odorata. Cleonia lusitanica, LINNÉ, H. K.

Tiges de 6 pouces, très-velues. Feuilles alongées, rétrécies en pétiole, obtuses, très-dentées; celles du sommet pinnatifides. Fleurs grandes, violettes, tachetées de blanc, en épi term., imbricé de bractées laciniées. Stigm. 4-fide. Celte espèce a été distraite de ce genre, et l'on en a, pour elle seule, constitué un sous le nom de Cleonia, Willd. , Desfont.

Lieu. La Fr. mér. Fl. en juin et juillet. * 5. B. à feuilles ovales, $B$. ovala, Desfont.

Tiges assez grosses, longues d'un pied et demi, un peu courbées, d'un brun violet, tétragones, canaliculées sur deur faces, glabres. Feuilles pétiolées, opposées, ovales-lancéolées, obtuses, entières ou légèrement dentées, ridées, avec des nervures brunes et saillantes en-dessous, vertes en-dessus, glabres. Fleurs bleues, en épi verticillé, sessile, long de 5 à 6 centimètres, assez gros et brun. Etamines bleues. Bractées larges, concaves, pointues, plus longues que le calice et moins que la corolle.

Lieu. L'Amérique septentrionale. $\Psi$. Fleurit en juillet.

Cult. Pleine terre. La première, ind., ne se cultive pas; elle est trop commune. Les 2 autres viennent dans tous les terrains, et se multiplient aisément par la sépa ation de leurs touffes quí s'élargissent. La quatrième se sème en planches au printemps, et se plante ensuite à demeure, à une bonne exposition. La cinquième se propage d'elle-même par ses semences.

$U s$. Ces cinq espèces sont assez agréables à voir en fleur, surtout la première variété de la prenière espèce.

L'espèce $B$. pensilvanica ne paroît être qu'une variété de 12 précédente, $B$. ovata; et $B$. intermedia, une variété assez dis- 


\section{LES LA BIE ES}

tincte de la première espèce. Celle-ci a ses fleurs bleues plus grandes que les espèces vulgairos, et ses feuilles inférieures sinuées et dentées.

\section{Toque, Scutellaria.}

Cal. très-court, à limbe entier, avec une écaille concave à la lèvre sup. Cor. beaucoup pluslongue, fléchie à sa base; la lèv. sup. voûtée, comprimée et garnie de 2 dents à sa naissance; l'inf. plus large, échancrée. Stigm. à peine bifide. Calice fermé après la floraison, couvrant les semences.

Cette écaille à la partie supérieure du calice forme une bosse lenticulaire.

1. Toque du Levant, $S$. orientalis.

Tige carrée, couchée. Feuilles opp., incisées, presque triangulaires, vertes en-dessus, blanchâtres et cotonneuses en-dessous. Fleurs d'un beau jaune, en épis term., obtusément tétragones.

Lieu. Le Levant. $₹$. Fl. en juillet et août.

2. T. blanche, $S$. albida.

Feuilles presque cordiformes, dentées en scie, ridées, opaques. Fleurs blanches ou violettes, en épi unilatéraux. Les bractées ovales.

Lieu. Id. $\%$. Fl. en juin et juillet.

3. T. des Alpes, $S$. alpina.

Tiges de 6 à 8 pouces, rameuses, un peu couchées. Feuilles opp., pét., ovales, crénelées, en pointe obtuse, un peu velues. Fleurs assez grandes, en épi term. La "lèvre sup. velue et bleue, l'inf. blanchâtre.

Lieu. Les Alpes, la Suisse. $\%$. Fl. en juin-octobre. 4. T. à grandes fleurs, $S$. lupulina.

Tiges couchées. Feuilles cordiformes, incisées, dentées, pointues, glabres. Fleurs jaunes ou blanches, grandes, en épis imbricés, arrondis, tétragones.

Lieu. La Sibérie. $\Psi$. Fl. id.

5. T. de Virginie, S. lateriflora. 
Feuilles lisses, rudes sur leur nervure principale, en cocur et lancéolées. Fleurs en grappes latérales et feuillées. Corolles bleues, très-petites.

Lieu. Le Canada, la Virginie. $\%$. Fl. id.

6. Toque commune, $S$.galericulata.

Plante très-traçante. Tiges droites, carrées, rameuses, d'un pied et demi. Feuilles opp., cordiformes, lanc., dentées, glabres. Fleurs bleues, au nombre de 2 à chaque aisselle, et tournées d'un même côté.

Lieu. Les bois. Ind. $\Psi$. Fl. id.

7. T. mineure, S. minor.

Tige de 4 à 5 pouces, grêle, rameuse. Feuilles inf. ovales, cordiformes, obtuses. Fleurs rougeâtres, disposées comme celles de la précédente.

Lieu. La France. $\%$. Fl. en juillet et août.

* 8. T. d'Italie, S. peregrina.

Tige carrée, de 2 pieds. Feuilles cordiformes, dentées. Fleurs en épis alongés et unilatéraux. Corolles violettes.

Lieu. L'Italie. $\Psi$. Fl. en juin-octobre.

9. T. élevée, $S$. altissima.

Tige de 3 à 4 pieds; les rameaux grêles. Feuilles alongées, cordiformes, acuminées, dentées en scie. Fleurs pourpres, à long tube, en épis presque nus etterm.

Lieu. Le Levant. $\psi$. Fl. en juillet et août.

* I o. T. de Crète, $S$. cretica.

Tige ligneuse, de 2 pieds, rameuse. Feuilles obtuses, cordiformes, dentées ; les dents arrondies; velues en-dessous, vertes en-dessus. Fleurs blanches, petites, imbricées de bractées sétacées, en épis term.

Lieu. La Crète. $\%$. Fl. en juillet.

Cult. Pleine terre. Ces plantes croissent dans presque tous les terrains. La première est plus délicate, et demande à être mieux exposée. On les obtient par leurs graines semées sur vieilles couches en terre légère, ou mieux encore dans la place où elles doivent rester, si la terre est bonne et favorable à la germination. Il vaut mieux les semer en automme qu'au printemps. La transplantation des espèces étrangères ne réussit pas toujours, lors- 
qu'on les plante à racines nues. Quelques-unes ne sont pas de longue durée. Elles subsistent un peu plus long-temps quand elles sont dans un sol de médiocre qualité.

$U$ s. Les espèces $\mathbf{I}, 4$ et $\mathbf{9}$ sont les plus agréables, et peuvent contribuer à la décoration des parterres. On les cultive toutes dans les jardins de botanique. On a bien de la peine à détruire la commune lorsqu'on l'a une fois mise dans les plate-bandes, ainsi que la 8 e. Elles tracent toutes deux considérablement.

On cultive encore au Muséum les espèces suivantes:

II. T. en arbrisseau, $S$. fruticosa.

Lieu. La Perse. b. Corolle jaune, à long tube.

12. T. à feuilles entières, $S$. integrifolia.

Lieu. La Sibérie. $\psi$ 。

Et en Angleterre :

13. T. à feuilles d'hysope, S. hyssopifolia.

Lieu. L'Amérique sept. $\%$.

ז4. T. pubescente, S. pubescens, Hort. angl.

Lieu. Id. ₹.

Cult. Pleine terre.

\section{Prasi, Prasium.}

Cal. turbiné ; la lèv. sup. large, 3-fide; l'inf. bifi de. Cor. plus longue; la lèv. sup. concave, échancrée; l'inf. plus large, à 3 div., dont la moyenne est plus grande. 4 semences en baie. * Prasi majeur, $P$. majus.

Tige de deux pieds, garnie de beaucoup de rameaux grêles. Feuilles ovales-obl., dentées en scie, pointues, molles. Fleurs blanches, assez grandes, verticillées, ax., peu nombreuses. Baies noires dans leur maturité.

Lieu. L'Espagne, l'Italie. ๖. Fl. en juillet.

Le prasi mineur a aussi des fleurs blanches marquées de quelques points pourpres; il est d'Italie et $\Psi$. Il se distingue du premier par les crénelures ou dents de ses feuilles qui sont cloubles.

Cull. Orangerie. Cet arbuste $n^{\text {'est }}$ point délicat. Il ne de : mande qu'à être garanti de la gelée. Terre ordinaice. Mult. par iII. 
ses rejetons, qu'il pousse assez abondamment, mais qui ne sont pas toujours enracinés, ou par boutures en été, en pot sur couche ombragée.

Us. Ce petit arbuste fait peu d'effet. Il n'est guère cultivé que dans les collections de plantes étrangères. Ses semences en baie sont une circonstance peu commune parmi les labiées.

\section{O R D R E V I I.}

\section{Les Scrophulaires (SCROPHULARI Ae).}

Calice divisé, souvent persistant. Corolle ordinairemènt irrégulière, à limbe divisé. Quatre étamines didynamiques, quelquefois deux. Un ovaire et un style, le stigmate simple ou bifide. Fruit capsulaire, biloculaire, bivalve à son sommet, quelquefois plus profondément. Réceptacle central, faisant l'office de cloison séminifère des deux côtés.

Herbes, quelquefois arbustes. Fleurs accompagnées de bractées. Feuilles opposées ou alternes.

Obs. Le muflier, la digitale et les autres personnées à feuilles alternes se rapprochent des molênes et des autres solanées capsulaires, ce qui établit le passage des tétrandriques aux pentandriques.

I. 4 étamines didynamiques.

\section{Budlèje , Budleja.}

Cal. 4-fide, petit. Cor. tubulée, 4-fide. Étam. courtes, non saillantes. I stigm. Caps. oblongues, à valves à 2 parties ou 4 valves.

* I. Budù̇Je globuleuse, B.globosa.

Tige de 6 à 7 pieds, droite, à rameaux opp., tétragones es 
blancs dans leur jeunesse, comme sur les jeunes pousses des tiges. Feuilles opp., ovales, très-alongées, pointues, dentées, ridées, d'un vert très-foncé en-dessus, très-blanches en-dessous. Fleurs petites, d'un jaune doré, odorantes, réunies en boule sur un réceptacle cómmun; péd. term.

Lieu. Le Chili. ๖. Fl. en juin. Toujours verte.

* 2. B. à feuilles de sauge, B. salvifolia, H. K., LaMarcK.

Lantana salvifolia, Lin.

Tige de 6 à 7 pieds, droite, peu rameuse, carrée, blanche et cotonneuse, sur-tout dans sa jeunesse. Feuilles opp., lanc., pointues, crénelées, ridées, d'un vert foncé en-dessus, blanches en-dessous. Fleurs blanches, ramassées en petits corymbes cotonneux, formant des grappes term.

Lieu. Le Cap. ๖. Fl. en septembre. Toujours verte.

* 3. B. à feuilles de saule, B. salicifolia, VA HL. Willd.

Tige droite, tétragone, rameuse; les rameaux opp., blanchâtres et cotonneux. Feuilles opposées, pétiolées, lancéoléesoblongues, pointues, ondées en leurs bords, glabres et d'un beau vert en-dessus; blanches, cotonneuses en-dessous et relevées par une principale nervure, et plusieurs la'érales qui aboutissent à une autre ondulée qui parcourt la circonscription de la feuille près de ses bords. Fleurs très-petites, blanchâtres, rassemblées en forme d'épis pédonculés qui forment des panicules terminaux.

Lieu. L'Amérique. Ђ. Toujours verte.

Cult. La première est ordinairement cultivée en pleine terre. Elle y réiste fort lien dans les hivers ordinaires; mais quand le froid passe le $6^{\mathrm{e}}$ degré, elle est alors a taquée, et si la gelée devient plus forte, elle perd toutes ses tiges, et souvent son pied; cepenciant elle n'est pas aussi sensible dans les terres médiocres. La perte qu'elle fait par le froid est en proporion de sa végétation précédente. Cet arbrisseau vient dans tous les terrains, et fait de grands progrès dans les terres fortes et franches; mais, comme je viens de le dire, cette belle végétation causese souvent sa perte. Sa situation doit être abritée. On le multiplie aiséizent de marcottes et de boutures. Celles-ci se font, lorsqu'il commence à pousser, avec le bois de l'année précédente, les nouveaux 
étant trop tendres. On les met dans un pot rempli de bonne terre d'oranger, que l'on plonge dans une couche ombragée. Elles s'enracinent au bout de deux mois. On les rentre l'hiver sous un châssis, et au bout de deux ans, on peut les planter à la place où elles doivent rester. Dans le nord de la France, il est nécessaire d'avoir des pieds de cet arbrisseau en pot. II demande alors de grands vases, et à être souvent changé.

La seconde et la troisieme sont d'orangerie. Elles ne sont pas du tout délicates, et ne demandent que les soins ordinaires des plantes de cette serre. On les multiplie toutes deux par boutures faites en été dans la couche destinéeà cettevoie de multiplication ; elles s'enracinent au bout d'un mois, et forment de bons pieds l'année suivante.

Us. La première est un bel arbrisseau fait pour la décoration des jardins. Son feuillage d'un vert sombre, et qui, au moindre vent, montre en même temps sa blancheur; ses fleurs en gros boutons d'or, qui se peignent sur sa couleur foncée, rendent cette espèce fort agréable à la vue. La seconde et la troisième n'ont pas à beaucoup près les inêmes avantages. On les cultive cependant dans les collections de plantes étrangères; mais elles ne peuvent qu'ajouter à la variété.

\section{Scopaire, Scoparia.}

Cal. 4-fide. Cor.à tụ̂be court, dont l'entrée est velue, et le limbe à 4 lobes. 4 étam. non saillantes. I stigm. Caps. sphérique.

* Scopaire doux, S. dulcis.

Tige sexangulaire, rameuse, de 2 pieds. Feuilles ternées, verticillées, ovales, dentées, d'un vert foncé. Fleurs petites, blanches, barbues en leurs bords, péd., ax.

Lieu. La Jamaïque. F. FI. en juin-sept.

Cult. Cette plante se sème sur couche chaude, en terrine. Lorsque les jeunes semis ont assez de force, on les enleve en motte, et on les met ou sur une autre couche pour y rester, ou en pot qu'on .uet sur les fenêtres de la serre chaude, ou même en pleine terre, à une exposition chaude.

Elle n'est guère cultivée que dans les jardins de botanique. 


\section{Capraire, Capraria.}

Cal. à 5 part. Cor. camp., à tube court, à limbe 5-fide, presqu'égal. 4 étam. pas tout-à-fait didynamiques. Stigm. à 2 lobes. Caps. acuminée, à valves, dont les bords sont fléchis en-dedans, quelquefois à 2 parties.

* I. Capraire biffore, C. biflora, Thé d'Amérique vulg.

Plante sous-ligneuse, rameuse et droite, de 3 à 4 pieds. Feuilles alt. ovales, élargies et dentées vers leur sommet, glabres, un peu épaisses. Fleurs blanches, petites, 2 ou 3 ensemble, péd., ax.

Lieu. Les Antilles. . Fl. en juillet et août.

2. C. lancéolée, C. lanceolata, H. K.

Feuilles opp., linéaires - lancéolées, très-entières. Fleurs en grappes, composées, terminales.

Lieu. Le Cap. Ђ. Fl...

* 3. C. ondulée, C. undulata, H. K., LAM.

Tiges cylindriques, de 4 à 6 pieds, d'un brun rougeâtre sur les jeunes pousses, droites et roides. Feuilles opp. et quaternées, ovales, sessiles, pointues, très-entières, petites, ondulées; les sup. presqu'en cœur. Fleurs en grappes spiciformes. Les feuilles sont très-rapprochées et garnissent toute la longueur des jeunes tiges.

Lieu. Id. Fl. en mars-juillet. 4. C. naine, C. humilis, H. K.

Plante pubescente. Feuilles opp., ou ternées, ovales, dentées en scie, pét. Fleurs ax., dont les pédoncules sont plus courts que les pétioles.

Lieu. Les Indes or. Fr̃. en juillet et août. $\odot$.

5. C. luisante, C. lucida, H. K. Tredia lucida, Pers.

Plante glabre. Tiges tétragones. Feuilles opp., obl., pointues, fortement denticulées en scie, lisses ; leurs pétioles ailés. Fleurs purpurines, marquées d'une tache d'un pourpre noirâtre près de l'entrée du tube, qui est velue, disposées ord. 3 ensemble sur le même pédoncule axillaire.

Lieu. Le Cap. o . Fl, en avril et mai. 
Cult. La $\mathrm{I}^{\text {re }}$ est de serre tempérée ou de serre chaude. Sa culture n'a rien de particulier. On l'obtient par ses graines semée au printemps sur couche ou sous châssis, et conduites à la manière ir diquée pour les plantes de cetie température, et on la propage par les boutures qui s'enracinent facilement en pots sous châssis. Les $2^{\mathrm{e}}$ et $3^{\mathrm{e}}$ sont d'orangerie. Les $4^{\mathrm{e}}$ et $5^{\mathrm{e}}$ sont délicates; mais comme elles ne durent pas, on les sème sur couche chaude. Lorsque les jeunes plantes peuvent être transplantées, on les plante sur une autre couche pour y fructifier, ou dans des pots qu'on place à une bonne exposition, lorsque les plantes qu'ils conlievnent sont bien reprises. On multiplie la $3^{\text {e }}$ par les boutures et lesmarcottes. Les dernieres sont plus sûres, parce que les premières ne m'ont pas encore donné le succès que j'avois lieu. d'en attendre, quoique les feuilles nombreuses doivent contribuerà un prompt enracinement. Les marcottes sont difficiles à faire par la grande roideur des branches et des rameaux.

Cs. La I $^{\text {re }}$ n'a aucune autre qualité que celle d'avoir des feuilles odorante;, dont les Américains se servent en guise de thé; elle n'est pas de longue durée. La $\mathrm{Z}^{\mathrm{e}}$ a un feuillage assez remarquable, et qui a du rapport à celui du galé à feuilles en cœur.

Elle se trouve dans la plupart des collections de plantes étrangeres, mais elle n'y est pas nombreuse en individus.

\section{Haller, Halleria.}

Cal. petit, à 5 lobes inégaux, persistant. Corolle grande, ventrue à son entrée, à limbe droit, oblique, à 4 div. inégales, dont la sup. est plus grande et échancrée. I stigm. Baie obronde, acuminée par le style, à 2 loges polyspermes.

* Haller luisant, H. lucida.

Arbuste de 4 pieds, glabrè à rameaux opposés, nombi eux et grêles. Feuilles opp., ovales, pointues, dentées, luisantes. Fleurs d'un rouge brun, sol. ou 2 ensemble, ax., latérales et penchées.

Lieu. L'Afrique. Fl. en juillet. Tonjours vert.

Cult. Orangerie. Cet arbusle n'est point délicat ; telle place 
dans la serre lui est assez indifférente. Il demande une terre coasistante et bonne, et à être dépoté tous les ans au printemps, Mult. par les marcottes et par boutures faites en été en pot sur couche ombragée. Elles ne s'enracinent pas toujours aisément. Leur succes dépend beaucoup, ainsi que pour la plupart, du moment où on les fait. Cet arbuste a besoin d'arrosemens assez fréquens en été ; il est mieux un peu àl'ombre que trop exposé au soleil.

Us. Il fleurit assez souvent. Comme il est toujours vert, il varie les autres feuillages.

\section{Scrophulaire, Scrophularia.}

Cal. à 5 lobes. Cor. globuleuse, à limbe rétréci, à 2 lèv. La sup. à 2 lobes, avec un appendice; l'inf. plus courte, à 3 lobes. I stigm. Caps. acuminée, obronde; les bords des valves fléchis en-dedans.

1. Scrophulaire du Maryland, S. marylandica.

Tige à 4 angles obtus. Feuilles cordiformes, dentées en scie, pointues, arrondies à leur base. Fleurs herbacées, en grappes term. Cette espèce ne differe de la suivante que par sa plus grande élévation et par ses feuilles, qui n'ont pas 3 principales nervures.

Lieu. L'Amérique sept. . Fl. en mai-juillet.

* 2. S. noueuse, $S$. nodosa. Herbes aux écrouelles.

Tige carrée, noirâtre, de 2 à 3 pieds. Feuilles pét., opp. , quelquefois ternées, cordiformes, pointues, dentées, à 3 nervures, d'un vertobscur. Fleurs d'un pourpre noirâtre, en grappes rameuses et term.

Lieu. Ind. $\longleftarrow$. Fl. id.

* 3. S. aquatique, S. aquatica. Herbe du siége.

Tige droite, à 4 angles ailés, rameuse, de 3 à 4 pieds. Feuilles assez grandes, opp., pét., cordiformes, un peu obtuses, crénelées. Fleurs de couleur ferrugineuse, en grappe interrompue et term.

Lieu. Ind. $\%$ ou $\sigma^{7}$. Fl. id. 


\section{CIASSE VIII, ORDREVIIa}

4. Scrophulatre auriculée, $S$. auriculata.

Feuilles en cœur, cotonneuses en-dessous, doublement dentées en scie, appendiculées à leur base. Fleurs en grappes tern., d'un pourpre terne.

Lieu. L'Espagne. $\%$. F1. en juillet.

5. S. à feuilles de scordiun, S. scorodonia, H. K.

Tige de 4 pieds, rameuse. Feuilles cordiformes, doublement dentées en scie; les sup. alternes. Fleurs petites, brunes, en panicules terminaux, trichotomes, divisés par des feuilles.

Lieu. L'Angleterre. $\%$. Fl. en mai-juillet.

6. S. à feuilles de bétoine, $S$. betonicifolia.

Tige tétragone, de deux pied̉s environ de hauteur. Feuilles opposées, pétiolées, cordiformes, oblongues, ridées, dentées; les dents très-entières, profondes à la base des feuilles. Flcurs d'un pourpre verdâtre, en panicule terminal. Anthères jaunes.

Lieu. L'Espagne. . Fl. id.

7. S. du Levant, S. orientalis.

Tige de 2 pieds et demi, très-garnie dans sa partie inf. de feuilles lanc., dentées en scie, pét.; les caulinaires ternées. Les rameaux opp. Fleurs petites, brunes, en grappes composées au sommet des tiges.

Lieu. Le Levant. $\longleftarrow$. Fl. en juillet et août.

8. S. à feuilles de sureau, $S$. sambucifolia.

Tige grosse, de 4 à 5 pieds, carrée et velue. Feuilles ailées; les pinnules interrompues, cordiformes, inégales, pointues. Fleurs rougeâtres, mêlées de vert, en grappes term.; les pédonc. ax. géminés, dichotomes.

Lieu. L'Espagne. ₹. Fl. id.

* 9. S. à feuilles luisantes, $\mathcal{S}$. lucida.

Tige d'un pied et demi, épaisse, glabre, presque cylindrique. Feuilles inf. bipinnées, un peu charnues, trés-glabres et luisantes. Fleurs d'un brun obscur, mêlé de vert, en grappes làches, géminées, ax. et term.

Lieut. Le Levant. $¥$ ou $\sigma^{7}$. Fr. en juin-aoutt.

* ro. S. à fleurs blanches, S. altaica, H. K., Suppl. Murraye. Feuilles en cceur, orales, doublement dentées en scie, les 
dents dirigées vers la base. Fleurs blanches, en grappes composées, non-feuillées.

Lieu. La Sibérie. $\%$. Fl. en mai.

II. S. précoce, $S$.vernalis.

Tige de 2 pieds, carrée, velue. Feuilles cordiformes, doublement dentées, pubescentes, marquées de veines noires; leurs pétioles très-velus. Fleurs jaunes, en bouquets portés sur des péd. ax. et rameux.

Lieu. La France, l'Angleterre. $\sigma^{7}$. F1. en mars-mai. x2. S. canine, $S$ canina.

Tige d'un pied et demi. Feuilles inf. alongées, incisées, presque pinnatifides; les pinnules très-découpées. Fleurs d'un pourpre noirâtre, petites, en grappe terminale, nue; les péd. bifides ou 3-fides.

Liеu. La France mérid. ou $\sigma^{\top}$. Fl. en juin - août. * i3. S. géminiftore, $S$. peregrina.

Tiges d'un pied et demi, droites, lisses, simples. Feuilles pét., en cœur, pointues, dentées, luisantes; les sup. alternes. Fleurs d'un pourpre obscur, au nombre de deux sur chaque péd., ax.

Lieu. La Fr. mérid. Fl. en juin et juillet. 14. S. à feuilles lancéolées, $S$. glabrata, H. K.

Tige sous-ligneuse. Feuilles obl., lanc. , cordiformes, glabres, doublement dentées en scie. Fleurs en grappes paniculées, tricholomes et term.

Lieu. Les Canaries. ơ. Fl. en avril et mai.

15. S. à tige grêle, $S$. arģuta, H. K.

Feuilles en cœur, glabres, doublement dentées. Fleurs rouges, en panicules axillaires, dichotomes; les capsules. acuminées.

Cette espèce diffère de la $\mathrm{I}^{8}$ par ses tiges et ses feuilles glabres, et par ses fleurs plus petites et rouges.

Lieu. Madère. Fl. en mai et juin.

r6. S. de Barbarie, S. mellifera, L'Hérit., H. K.

Tige droite, glabre, ferme, quadrangulaire. Feuilles ailées ; les fol, un peu interrompues, ox-obl., inégalement dentées; 
les sup. ternées. Fleurs grandes et verdâtres; le fond de la corolle rempli d'un suc mielleux.

Lietı. La Barbarie. . Fl. en juillet et août.

I7. Scrophulaire frutescente, $S$. frutescens.

Feuilles un péu charnues, sessiles, glabres, recourbées à leur sommet. Fleurs d'un vert noirâtre, ax., petites, d'un pourpre noir, blanches sur les côtés.

Lieu. Tunis. Ђ. Fl. en juin - août.

18. S. trifoliée, S. trifoliata, Fl. atlant. S. appendiculata, JAcQ., Wruld. S. lavigata, VAHL.

Tige simple ou peu rameuse, droite, glabre, tétragone, striée, d'un à 2 pieds. Feuilles en cœur, glabres, lisses, luisantes, veineuses, pét., inégalement dentées. Fleurs pédicellées, en petites grappes, de couleur pourpre, assez semblables á celles de la scrophulaire aquatique. Capsule lisse, mucronée.

Lieu. Près de la mer, en Barbarie. $\%$.

Cult. Excepté les cinq dernières espèces, qui sont d'orangerie, toutes les autres sont de pleine terre, et croissent dans presque tous les sols et les situations, à moins qu'ils ne soiert trop secs et trop chauds, car ces plantes aiment assez les endroits ombragés et frais. Cependant dans le nord de la France, les espèces originaires du Levant et de l'Espagne exigent une situation plus exposée au soleil, et une terre plus légère et point fraîche. Elles viennent, il est vrai, très-bien dans les bons fonds; mais comme elles y poussent trop vigoureusement, elles sont alors sujettes à périr en hiver. On les obtient toutes par leurs graines semées sur couche pour celles d'orangerie, du Levant et de l'Espagne, et en planches préparées pour les autres. Quand les jeunes plantes ont environ 6 à 8 pouces de haut, on les plante à deneure, en les abritant jusqu'à leur reprise. Celles d'orangerie se plantent en pots, et ne demandent que les soins ordinaires. Quelques espèces se sèment elles-mêmes.

$\boldsymbol{U}_{s}$. Les scrophulaires n'ont aucun effet agréable. Elles ne sont cultivées que dans les jardins de botanique. La 8 e a un assez beau port.

La seconde est employée en médecine comme résolutive, 
émolliente. On la dit bonne dans les humeurs scrophuleuses et hémorroïdales. Elle a une odeur désagréable.

rg. S. écarlate, S. coccinea, Willd., Mrller.

Feuille ovales, quaternées, amplexicaules, imitant celles de lortie. Fleurs écarlates, en épis verticillés.

Lieu. La Vera-Crux.

Cult. Serre chaude. Miller a cultivé celte espèce, et sans doute peu de temps, car il n'en parle que légèrement. Elle paroit n'être que bisannuelle. On conduira donc son semis comme celui de toutes les plantes qui exigent cette température: elle fleurit la seconde année.

\section{Dodart, Dodartia.}

Cal. camp., court, anguleux, à 5 dents. Cor. tubulée, à limbe à 2 levres ; la sup. échancrée; l'inf. plus large, plus longue et trifide. Stigm. bifide. Caps. globuleuse, couverte par le calice.

* Dodart du Levant, $D$. orientalis.

Tiges droites, d'un pied, rameuses, en faisceau paniculé; les rameaux efflés. Feuilles peu nombreuses; les inf. opp.; les sup. alt. , peiites, distantes, sessiles, linéaires, pointues, trèsentières et glabres. Fleurs d'un pourpre foncé, alternativement axillaires, en petites grappes lâches et term.

Lieu. Le Levant. $₹$. Fl. en juillet.

Cu't. Pleine terre. Tout terrain. Cette plante trace beaucoup, et souvent à plus de 12 pieds d'elle. On la multiplie par conséquent aisément par ses drageons en automne. Il est à croire qu'elle n'est vivace que par ses drageons, car je ne l'ai guere vu pousser dans l'endroit où elle a fleuri l'année précédenie.

Us. Si cette plante avoit des fleurs d'une conleur un peu plus claire, elle seroit assez jolie, car elles sont nombreuses. 


\section{Gérarde, Gerardia.}

Cal. 5-fide. Cor. tubulée, à limbe inégal, presqu'à 2 lères ề à 5 lobes; les div. arrondies on un peu en cceur. 4 étam. courtes. I stigm. Capsule à 2 valves.

GÉRARDE pourprée, $G$. purpurea.

Tiges d'un pied, filiformes, lisses. Feuilles linéaires, trésentieres, opp. ou alternes. Fleurs d'un pourpre foncé, opp., presque sessiles,' sol., ax.

Lieu. L'Amériq. sept. Iut. Fl. en juillet et août.

Cult. Pleine terre. Cette plante se sème au printemps, et se plante ensuite à demeure.

On connoît I f espèces de ce genre, dont très-peu sont eultivécs.

\section{Linaire, Linaria, Antirrhinum, Lis.}

Cal. à 5 parties. Cor. terminée à sa base par un éperon, à tube renflé, à limbe à a lèvres; la sup. bifide et réfléchie; l'inf. 3-fide, ayant un palais élevé à son entrée. Un rudiment d'une 5e étam. à peine visible. I stigm. Caps. ovale, percée de trous à son sommet.

* 1. Livaire cymbalaire ou lierrée, L. cymbalaria.

Tiges nombreuses, rampantes, glabres, couvrant la terre ou les.murs. Feuilles alt., pét., arrondies, en cœur, à 5 lobes, pelites et très-lisses. Fleurs bleues, avec un palais jaune, ax., sol., péd.

Lieu. Indes. $\longleftarrow$. Fl. tout l'été.

2. L. auriculée, L. elatine. Velvotte.

Tiges foibles, couchées, velues, rameuses. Feuilles opp., hastées, velues, très-entières; les sup. auriculées et alt. Fleurs jaunes, avec la levre d'un violet noirâtre, péd., ax., sol.

Lieu. Ind. Fl. en août.

2 bis. L. bâtarde, L. sputria.

Ceite espece ne differe guere de la précédente. Toutes sæs. 
feuilles sont ovales, obrondes, molles et velues; les inf. opp., les sup. alternes.

\section{Lieu. Id. F. Fl. id.}

3. L. à vrilles, $L$. cirrhosa.

Tiges longues, couchées, rameuses. Feuilles alt., sagittées. Fl. petites, d'un bleu pâle et le palais blanchâtre, ax., sol., péd. Lieu. L'Egypte. Fl. en juillet.

4. L. d'Egypte, L. agyptiaca.

Tiges droites, effilées, très-rameuses. Feuilles alt., hastées ou ovales, presque sessiles. Fleurs jaunes, ax., sol., péd. Le palais ponctué de pourpre; l'éperon bleuâtre.

Lieu. L'Egypte. Fl. id.

* 5. L. trifoliée, L. triphylla.

Tiges droites, simples, glabres, de 8 à 10 pouces. Feuilles ovales, lisses, un peu charnues, 3 ensemble à chaque noud. Fleurs blanchâtres, avec un palais d'un jaune safran, grancies, en épi terminal.

Cette espèce est sujette à varier dans la forme de ses feuilles et dans la couleur de ses fleurs. Ses tiges sont souvent couchées par le poids des feuilles. Lorsque la plante a beaucoup de végétation, les feuilles sont alors plus grandes, ternées seulement à la base des tiges, opposées dans leur partie moyenne, alternes, petites, et pointues à leur sommet, toutes très-glauques. Fleurs blanches; l'éperon ainsi que la levre supérieure d'un beau violet, et le palais d'un jaune plus ou moins safrané.

Lieu. La France. Fl. en juin-sept.

*6. L. pourprée, L. purpurea.

Tiges droites, lisses, rameuses, de 2 à 4 pieds. Feuilles linéaires, sess., glabres, quaternées dans la partie infér. des tiges, alternes dans le haut. Fleurs violettes, assez petites, en épis term. Toute la fleur est unicolore.

Lieu. L'Europe mérid. ₹. Fl. en juillet-sept.

7. L. à couleurs variées, $L$. versicolor.

Feuilles linéaires - lancéolées; les inf. ternées. Tige droite. Fleurs en épi term., grandes, très - nombreuses, d'un jaune pâle, avec un palais safrané. L'éperon droit et violet.

Lieu.... F. Fl. en juillet-sept. 
* 8. Linaire striée, L. striata, Fl. fr. L. tepens, Lin.

Tiges en partie couchées, ensuite redressées, d'un à 2 pieds, très-rameuses et glauques. Feuilles étroites, lin., glauques. Fleurs d'un blanc gricâtre, veinées de bleu, avec un palais jaunâtre, petites, en épi lâche et term.

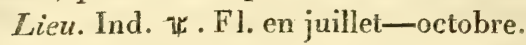

9. L. sparte, L. spartea, CAv. L. juncea, LAM.

Tige d'un pied, paniculée, droite et glabre. Feuilles infér. ternées; les sup. subulées, çanaliculées, charnues. Fleurs jaunes; le palais d'un rouge vif ou jaune ; très-glabres, en grappes.

Lieu. L'Espagne. oт. Fl. en juin-octobre.

10. L. biponctuée, L. bipunctata.

Tiges d'un demi-pied, velues, rameuses, droites, paniculées. Feuilles sessiles, lin., glabres ; les inf. quaternées. Fleurs pelites, jaunes, en épis fort courts, presqu'en têtc et term. On remarque 2 points sur leur palais.

Lieu. L'Espagne, la Fr. mérid. F. Fl. en juin - août. II. L. triste, L. tristis.

Tiges rameuses, foibles, d'un pied. Feuilles lin.; les infér. ternées ou opp.; les sup. éparses.Fleurs grandes, presque sess., jaunâtres ou roussâtres, en épis terminaux; le palais d'un noir brun.

Lieu. L'Espagne. $\%$. Fl.id.

La linaire des Pyrénées a beaucoup de rapports à la précédente. Ses fleurs sont entierement jaunes.

12. L. couchée, L. supina.

Tiges foibles, tombantes, glabres, de 8 à ro pouces. Feuilles sess., lin. - lanc., glauques; les inf. verticillées; les sup. éparses. Fleurs jaunes, avec deux taches violettes sur leur palais. grandes, en épi court et serré; l'éperon droit.

Licu. L'Espagne, la Fr. Fl. en juillet. 13. L. champêtre, L. arvensis.

Tiges droites, d'un pied, peu rameuses. Feuilles étroites, lin.; les inf. quaternées. Fleurs jaunâtres, avec un éperon blanc, en épi court et term.

Variété à fleurs bleues.

Lieu. La France, l'Angleterre. Pl. id. 
¿4. L. pelissérienne, $L$ pelisseriana.

Tige de 5 à 6 pouces, droite, très-glabre. Feuilles étroites, lin., alt. ; les inf. lanc., ternées. Fleurs petites, violettes, avec un palais blanc, rayé , en épis lầches.

Lieu. La France. F. Fl. id.

15. L. visqueuse, L. viscosa.

Tiges de 3 à 4 pouces, droites, presque simples. Feuilles alt., lin.; les inf. quaternées. Fleurs d'un jaune doré, en grappes.

Lieu. L'Espagne. Fl. id. 16. L. multicaule, L. multicaulis.

Tiges nombreuses, filiformes, foibles, rameuses. Feuilles lin., étroites, charnues, quinées inf., alt. au sommet. Fle urs jaunes, peu nombreuses, en têtes.

Lieu. Le Levant. F. Fl. en mai - juillet. 17. L. des Alpes, L. alpina.

Tiges de 4 à 8 pouces, presque couchées, menues, rameuses, diffuses. Feuilles lin.-lanc., glauques, quaternées. Fleurs d'un bleu pourpre, avec le palais orangé, striées, en grappes term.

Lieu. La Suisse, les hautes montagnes. ơ. Fl. en juilletnov.

18. L. cornue, L. bicornis.

Tiges de 2 pieds, droites, tétragones, rameuses. Feuilles sess., dentées, ovales, opp. Fleurs jaunâtres, en grappes. Capsules bicornes.

Lieu. Le Cap. Fl. en juillet et août.

19. L. à larges capsules, L. macrocarpa, H. K. Nemesire chamadrifolia, VENT.

Feuilles opp., ovales, dentées, pét. Pédoncules ax., uniflores.

Capsules comprimées, carénées, tronquées.

Lieu. Le Cap. $\%$. Fl. en mars.

20. L. velue, $\boldsymbol{L}$. villosa.

Espèce très-velue. Tiges simples, d'un pied, foibles. Fenilles opp. ovales, sess., velues. Fleurs blanches, opposées, latérales.

Lieu. L'Espagne. $₹$ ou 
2i, Linaire à feuilles d'origan, $L$. origanifolia.

Tiges de 4 à 5 pouces, dures, grêles, rameuses, velues. Feuilles la plupart opp., ovales-oblongues. Fleurs d'un violet pâle, alternes. Le palais droit.

Lieu. La Fr. mérid. ₹. Fl. tout l'été. 22. L. mineure, L.minor.

Toute la plante velue. Tige de 4 à 6 pouces, droite, trèsrameuse. Feuilles petites, lanc., obtuses, étroites, velues, alt. Fleurs petites, violettes, sol., péd., ax.

Lieu. Les lieux secs. Ind. Fl. en juin-nov. 23. L. hérissée, L. hirta.

Tiges droites, simples, d'un pied. Feuilles lanc., obtuses, hérissées de poils en leurs bords. Fleurs jaunes, en épis term.; une division calicinale très-grande.

Lieu. L'Espagne. Fl. id.

* 24 . L. à feuilles de genet, L. genistifolia.

Tiges droites, glabres, de 2 pieds; les rameaux effilés et paniculés. Feuilles sess. , alt. , lanc., acuminées. Fleurs d'un jaune pâle, très-vif sur le palais, en grappes paniculées et effilées.

Lieu.L'Autriche, les Alpes, la Sibérie. $飞$.Fl. en juillet et août. 25. L. de Montpellier, monspessulana: galioides, Encycl.

Tiges droites. Feuilles linéaires-filiformes, succulentes, éparses et rassemblées ; les éperons plus courts que le calice. Fleurs d'un blanc teint de violet, avec un palais jaune.

Cette espèce ressemble beaucoup à la $8 \mathrm{e}$.

Lieu. La France mér. ₹. Fl. en juin - août.

* 26 . L. commune, L. vulgaris.

Tiges droites, simples, d'un pied et demi, garnies, dans toute leur longueur, de feuilles nombreuses, éparses, linéaires, étroites, rapprochées. Fleurs grandes, d'un jaune pâle, avec le palais safrané, en longs épis term.

Lieu. Ind. $\sigma^{\top}$ ou $\Psi$. Fl. en juillet - sept. 27. L. à fleurs blanches, $L$. chalepensis.

Tige d'un pied, droite, rameuse. Feuilles lin.-lanc., alt. , verticillees inférieurement. Fleurs blanches, petites, en longues grappes term. Le calice plus long que la corolle.

Lieu. Le Levant. Fl. en juin et juillet 
28. L. bordée, L. marginata, Fl. atlant.

Tiges couchées, glabres, cylind., rameuses. Feuilles lanc.lin., glauques, glabres, un peu épaisses ; les inf. verticillées, au nombre de 3 à 6 ; les sự. alt., éparses. Fleurs d'un jaune pâle ou d'unjaune ferrugineux, avec deux taches d'un pourpre foncé à leur palais, renflées, de la grandeur de celles de la linaire commune, en têtes ou en grappes courtes et term.

Lieu. Le mont Atlas. $\Psi$.....

* 29. L. à feuilles de paquerette, L. bellidifolia. Anarrhinum bellidifolium, Desfont.

Obs. On a distrait cette espèce de ce genre, à cause de l'absence du palais et de sa lèvre inférieure plane.

Tige droite, cylind., rameuse, d'un à 2 pieds. Feuilles rad. ligulées, dentées, glabres. Celles de la tige ont 3 ou 4 découpures pointues. Fleurs petites, très-nombreuses, d'un bleu violet pâle, en épis term. Corolle sans palais.

Lieu. La France mérid. $\sigma^{7}$. Fl. en juin-sept.

* 5o. L. du Canada, L. canadensis.

Tiges foibles, filiformes. Feuilles att., distantes, lin., poinzunes. Fleurs petites, violettes, alt. ; l'éperon mince et pointu, en épis lâches, courts et term.

Lieu. Le Canada, la Virginie. Fl. en juillet et août.

Cult. Les especes $\leftarrow$ II $, 19,20,28$ sont d'orangerie, et n'en demandent que les soins ordinaires. Leur multiplication est la même que celle des autres espèces, à l'exception qu'on les met dans des pots lorsque les jeunes plantes ont assez de force pour être enlevées. Toutes les autres espèces sont de pleine terre. Voyez la culture du genre suivant.

Us. Une partie assez nombreuse des linaires est cultivée pour l'agrément des jardins. Quelques-unes ont de jolies fleurs et qui durent long-temps. Parmi ces espèces nombreuses, on doit distinguer les linaires 5, 6, 7 , 8, 9, I I , I 7, 24, 25, 26, 29 . La commune est une des plus belles. Elles n'ont aucun autre. usage. 


\section{Autres espèces cultivées.}

3r. Linatre divisée, Linaria bipartita. Antirrhinum bipartitum, Vent., Jard. Cels. Antirrhinum orchideflorum, H.P.

Tiges cylindriques, glabres, peu nombreuses, d'un vert glauque; les fertiles droites, rameuses; les stériles couchées et simples. Rameaux axillaires. Feuilles sessiles, linéaires-lancéolées, pointues; les unes alternes, les autres opposées, mê.ne verticillées, toutes glabres et glanques. Fleurs d'un violet bleuâtre, pédiculées, alternes, écartées, formant au sommet des tiges et des rameanx des grappes simples et droites. L'éperon en forme d'alêne ; le palais blanchâtre, légèrement velu, d'un jaune orange à sa base; la levre supérieure droite à deux divisions.

Lieu. La Barbarie. Fleurit en été.

*32. L. élégante, Linaria elegans, H. P. L. parviflora, H.

Tiges d'un pied ( 3 décim.), cylindriques, droites, glabres et couvertes, ainsi que les feuilles, d'une efflorescence glauque. Feuilles alternes, d'autres opposées, sessiles, linéaires, pointues, un peu charnues, très-entières. Fleurs disposées en épi court au sommet des tiges. Corolle très-petite, de 4 à 5 mill. ; l'éperon d'un blanc herbacé, pIus long qu'elle; le palais garni de petits poils; la lère supérieure d'un jaune verdâtre, pointue, et rayée de lignes violettes; l'inférieure jaune, divisée en 3 dents obtuses. Calice à 5 divisions bordées, ainsi que les feuilles supérieures, de cils glanduleux.

Lieu. L'Espagne. Fleurit en juillet.

Cult. Ces deux espèces se sèment au printemps, sur couche ou dans la place ou elles doivent rester. Dès qu'on a eu une fois la seconde, on n'a pas besoin de recueillir ses graines; elle se sème elle-même en si grande abondance, qu'au printemps on en voit des pieds par-tout. Rien d'ailleurs d'élégant dans cette linaire à laquelle on a donné si gratuitement ce nom.

53. L. à grandes fleurs, Linaria triornithophora. Antirrhinum triomilhophorum, Vent., Jard. Malm. Lin., Curt., Mag, 
Tiges droites, sous-ligneuses à leur base, penchées et herbacées à leur sommet, cylindriques, rameuses, glauques, de I 2 décim. de hauteur. Feuilles verticillées, ordinairement au nombre de 4, sessiles, lancéolées-pointues, très-entières, d'un violet terne, munies d'autant de bractées, et formant sur les tiges et les rameaux des grappes courtes et terminales. Le tube rayé; l'éperon droit, en forme de poinçon, d'un violet pâle ; le palais saillant et jauuâtre.

Lieu. L’Amérique. ₹. Fleurit en automne.

Cult. Orangerie. Cette plante, comme toutes les herbacées vivaces de celte serre, doit être placée près des jours, afin d'être préservée de l'humidité qui lui est funeste. On la multiplie, ainsi que les autres linaires, par ses graines semées au printemps sur couche, et les jeunes plants sont repiqués ensuite en pots, et conduits à la manière ordinaire.

$\boldsymbol{U}$. Celte espèce se distinguant de ses sœurs par la grandeur de ses corolles, mérite les soins des cultivateurs, et enrichira, pendant l'automne, les lieux où sont placés les végétaux de cette température.

Obs. On a donné à cette linaire le nom de triornithophore, qui signifie trois oiseaux, parce qu'on a trouvé à ses fleurs une ressemblance avec trois oiseaux.

34. L. réticulée, L. reiiculata, Desfont. L. pinifolia, PoIRET.

Tiges droites, cylindriques, un peu velues vers leur sommet. Feuilles sess., éparses, presque filiformes. Fleurs d'un jaune pâle, disposées en épis serrés, dont le nombre forme un beau. panicule terminal.

Lieu. La Barbarie. $\Psi$.

Cult. Pleine terre. La mêne que celle des autres linaires. Foy. Mufier. Cult. 


\section{Muflier, Antirrhinum.}

Le caractère de ce genre ne differe de celui de la linaire qu'en ce que la corollen'a point d'éperon, et qu'elle est seulement bossue à sa base. La capsule est inégale à sa base, oblongue ou obronde.

* i. Muflier majeur, A. majus. Orontium, Persoox. Mufle de veau, gueule de lion.

Tige de 2 à 3 pieds, rameuse, glabre. Feuilles opp. et alt., lancéolées, lisses, entières, d'un vert foncé. Fleurs grandes, ordinairement purpurines, avec un palais jaune, en épi term. Lieu. Ind. đo. Fl. en juin-août. Commune sur les murs. Variétés. I. à feuilles rondes.

2. à fleurs doubles.

5. d'autres couleurs.

* 2. M. rubicond, A. orontium. Orontium arvense, Persoor. Tige d'un pied, peu rameuse. Feuilles oblongues, étroites, glabres, opp. Fleurs d'un rougevif, sess., sol., ax.

Lieu. La France. Fl. en juillet-sept.

* 5. M. asarin, A. asarina. Orontium, Persoor.

Tiges velues, foibles, en partie couchées, rameuses, diffuses. Feuilles opp., cordiformes, arrondies, lobées. Fleurs blanches, arec une teinte rouge, grandes, ax. , péd., sol.

Lieu. La France mérid. $\longleftarrow$. Fl, en juillet.

* 4. M. velouté, A. molle. Oronitum, Persoon.

Tiges couchées, très-cassantes, veloutées dans leur jeunesse, rameuses. Feuilles opposées, ovales, très-entières, cotonneuses et très-molles. Fleurs grandes, blanches, avec le palais jaune et la levre supérieure striée de rouge, disposées en épi terminal.

Lieu. L'Espagne. Ђ. Fl. en juillet-nov. Toujours vert.

Cult, Les deux premières espèces sont de pleine terre. La troisie : e y passe aussi dans les hivers ordinaires des pays septentrionaux ; mais il est prudent, pour ne pas la perdre, d'en avoir un pot ou deux en serre. La quatrième est d'orangerie, 
ou de pleine terreen en faisant une plante annuelle. Les linaires et les mufliers $\%$ de pleine terre sont rustiques, et viennent dans tous les terrains; cependant si l'on considere les lieux ou l'on trouve les indigènes, ils se plaisent dans les endroits chauds, exposés au midi, et dans les terres légères. On n’en trouve guère à l'ombre et dans les sols humides et forts. On les multiplie tous par leurs graines semées en terre douce, et en planches ou lits préparés your ces sortes de semis. Los $\psi$ et de pleine terre se plantent ensuite à la place ou ils doivent rester, et ceux d'orangeric en pots. Les réussiront beaucoup mieux si on les sème en place. Au reste, la plupart des mufliers et des linaires se resement eux - mêmes quand ils fructifient. Il y en a même qui en deviennent incommodes, par le nombre de pieds que leurs semences fournissent. Cependant, à l'égard des espèces des pays méridionaux, il vaut mieux s'assurer de les conserver, en recueillant du moins une petite partie de leurs graines.

Us. Les mufliers ont tous de grandes et d'assez belles fleurs. La première est depuis long-temps cultivée pour l'agrément des jardins; elle varie assez dans sa couleur. La plus belle variété est celle dont les fleurs sont d'un rouge vif avec un palais jaune La quatrième est aussi agréable à voir ; ses fleurs sont encore plus grosses et durent plus long-temps. La troisième a d'assez grandes fleurs, mais sa tige foible et basse en diminue l'effet. 5. M. toujours vert, A. sempervirens, LAPEYr., Willd.

Cette espèce a beaucoup de rapports avcc le mufier velouté. Elle en differe par ses feuilles, qui ne sont que pubescentes, et qui sont persistantes; par sa tige sous-ligneuse el frar ses fleurs: teintes de rouge.

Lieu. La France mérid... b.

Cult. Orangerie.

\section{Némésis, Nemesia, VENT.}

Cal. à 5 parties persistantes. Corolle garnie à sa base d'un éperon, à tube court, à limbe à 2 lèvres; la supérieure droite e $e_{t}^{\frac{t}{t}}$ bifide; l'inférieure horizontale, échancrée. Le palais saillart. 
4 étamines didynamiques. Ovaire libre. I style. I stigmate simple. Capsule comprimée, oblongue, tronquée à son sommet, à 2 loges et 2 valves carénées.

I. NÉmésis fétide, Nemesia fœetens, Vent., Jard. Malm.

Tige droite, cylindrique, grisâtre, très-rameuse, de 2 décim. Branches opposées, rapprochées, tétragones, brunes et glabres. Feuilles pétiolées, opposées en croix, linéaires-lancéolées, pointues, trinerves, glabres, légèrement dentées, d'un vert foncé en - dessus; les supérieures très - entières et sessiles. Fleurs grisâtres, veinées de pourpre; le palais d'un rouge orangé ; pédiculées, disposées en grappes droites, simples, courtes, et munies de bractées dans les aisselles desquelles naissent les fleurs.

Lieu. Le Cap. Ђ. Fleurit en été.

Cult, Orangerie.

Cette plante a une odeur forte et désagréable.

Dans ce genre devroit être placée la linaire nº 19 .

\section{Ustérie, Usieria.}

Cal. à 5 parties persistantes. Corolle campanulée, à tube ventru, à limbeà 5 div. échancrées, les deux supérieures droites; les inférieures ouvertes. 4 étamines. Style en alêne. Stigmate simple ; 2 ovaires réunis en un corps ovale ; 2 capsules réunies, s'ouvrant par le sommet, à 5 valves. Semences ovales.

* Ustérie grimpante, Usteria scandens, Cav., Icon. Maurandia semperflorens, Curt., Mag., Willd.

Plante couchée, ou grimpante quand on lui donne un support, garnie de beaucoup de branches et de rameaux grêles, volu-s biles, cylindriques, glabres, d'unvert brun, qui s'entrelacent les uns dans les autres, et forment ainsi, à l'aide d'un tuteur, un buisson épais, cylindrique, d'environ I mètre et demi. Feuilles alternes, quelques-unes opposées, pétiolées, triangulaires; le lobe inoyen beancoup plus alongé que les autres, ainsi presque sagittées, entières, à 3 nervures, glabres, vertes 
en-dessus, glauques en-dessous. Fleurs axillaires portées sur des pédoncules guère plus longs que la corolle, solitaires, unilatérales. Corolle pourpre, de 4 cent. de longueur, de la forme de celle des digitales et des galanes, plissée longitudinalement endessus, renflée dans son milieu, un peu velue, ouverte à moitié en son limbe divisé en 5 parties arrondies, presqu'égales, 2 supérieures et 3 inférieures, toutes légèrement échancrées à leur sommet; les 2 étamines plus courtes, courbées. Anthères blanches. Filamens blancs et velus à leur base. Style et stigmate simples. Calice à 5 divisions ovales, pointues, 3 supérieures et 2 inférieures; les 3 premières d'un vert brun.

Lieu. Le Mexique. $\longleftarrow$. Fleurit une partie de l'année.

Cu?t. Orangerie. Semée sur couche au printemps, et repiquée ensuite en pots, ou en pleine terre, à une bonne exposition, quand on a assez d'individus.

Cette plante a des fleurs assez intéressantes pour qu'on lui donne les soins de la culture. Elles sont nombreuses, et se suc cèdent depuis le commencement de l'été jusqu'au milieu de l'hiver. Comme ses tiges sont très-foibles, et extrêmement ra-. meuses et que ses rameaux pendent de tous còtés, il lui faut un tuteur; ou bien on la palissera contre un mur jusqu'à l'arrivée des premiers froids, qu'on la rentrera dans une serre ou elle continuera de fleurir.

\section{Digitale, Digitalis.}

Cal. à 5 parties inégales. Cor. tubulée à sa base, supérieurement dilatée et ouverte, à limbe oblique, à 4 lobes inégaux. Un rudiment d'une 5e étam. Stigm. simple ou à 2 lames. Caps. ovale, acuminée.

* I. Digitale pourprée, D. purpurea. Gants de Notre-Danie: Gantelée.

Tige de 2 à 4 pieds, droite, simple, velue, cylind. Feuilles ait., ovales-lanc., pointues, ridées, blanchâtres et cotonneuses. Fleurs grandes, purpurines, tigrées intérieurement, perdantes, en épi unilatéral, long et term. 
Lieu. Ind. $\sigma^{7}$. FI. en juillet-sept.

Variété à grandes fleurs blanches.

2. Digmale à fleurs roses, D. minor.

Tige d'un pied environ, pubescente. Feuilles obl., sess., vertes des deux côtés, velues. Fleurs roses, en grappe peu garnie et term. Corolle ventrue, ponctuée de pourpre endedans.

Lieu. L'Espagne. $\%$. Fl. id.

\section{D. décurrente, D. thapsi.}

Tige d'un à 2 pieds. Feuilles ovales-lanc., dentées à leur sommet, blanchâtres, sur-tout en - dessous, semi-décurrentes. Fleurs purpurines, avec des taches sanguines, pendantes, unilatérales, en grappe term. Rapport à la $\mathbf{I}^{\mathrm{re}}$.

Lieu. Id. $₹$. Fl. en juin et juillet.

* 4. D. à grandes fleurs, D. ambigua. D. grandiflora, Fl. fr.

D. intermedia, Rath.

Tige d'un à deux pieds, droite, simple, un peu velue. Feuilles lanc., pointues, amplexicaules, glabres et velues en leurs bords. Fleurs jaunâtres, tâchées de pourpre int., grandes, en épi term. La lèvre échancrée.

Lieu. La Suisse, les Alpes. ¥. Fl. id.

L'espèce $D$. ocroleuca, PErs., ambigua, JAcQ. , a beaucoup de rapport à celle-ci. Sa lèvre n'est point échancrée, mais pointue.

* 5. D. jaune, D. lutea.

Tige de 2 à 3 pieds, simple, glabre. Feuilles lanc., étroites, dentelées, glabres, vertes. Fleurs d'un jaune pâle, en épi long.g, unilatéral et term.

Lieu. La France. $\%$. Fl. id.

* 6. D. ferrugineuse, D. feriuginea, WiLtD.

Tige de 5 à 6 pieds, droite, simple ou peu rameuse. Feuilles radicales nombreuses, longues d'un pied, rayées longitudinalement, disposées en grande rosette; les caulinaires éparses, sess, , un peu velues, diminuant de longueur à mesure qu'elles. 
approchent du sommet. Fleurs de couleur ferrugineuse, nom breuses, en très-long épi droit et terminal.

Lieu. L'Italie. $\psi$. Fl. id. * . D. à fleurs rousses, $D$. obscura.

Tige d'un pied et demi, peu rameuse. Feuilles éparses, se-a. mi-amplexicaules, lin.-lanc., pointues, étroites, glabres, très-entières. Fleurs roussâtres, en grappes term. Corolle courbée, ventrue, barbue sur son bord; la levre sup. courte, relevée, à deux lobes; l'inf. à 3 lobes.

Lieu. L'Espagne. $\%$. Fl. id.

Variété. D. lavigata, Persoon. Cette digitale tient le milieu entre la précédente et la $\mathbf{I}^{\mathrm{e}}$ ou sa variété. Corolle ferrugineuse; la lèvre inférieure jaunâtre, veinée et striée de pourpre.

* 8. D. des Canaries, D. canariensis.

Tige droite, peu rameuse, les rameaux droits, de 2 à 5 pieds, cylind., velue. Feuilles alt., sess., lanc., acuminées, dentées en scie, velues. Fleurs d'un jaune rougeâtre, en épi term.; la levre sup. plus longue que l'inf.

Lieu. Les Canaries. Ђ. Fl. en juin et juillet. Toujours vertea * 9. D. de Madère, D. sceptrum.

Tige droite, ligneuse, rameuse, très-velue dans sa jeunesse. Feuilles longues, rapprochées, sess., spatulées, dentées dars Jeur milieu, acuminées, blanchâtres et velues en-dessous, formant une large rosette au sommet des branches. Fleurs perim dantes, jaunâtres et rougeâtres, en épi term., dont les bractées linéaires sont plus longues que les fleurs.

Lieu. Madère. Ђ. Fl. id.

Cult. Les 7 premières espèces sont de pleine terre et rustiques; cependant la $2^{\mathrm{e}}$ est un peu plus délicate. Elles aiment les lieux exposés au soleil, et pour les voir dans leur beauté, il faut que la terre soit douce et d'un bon fond. Ordinairement ces plantes se sèment elles-mêmes, sur-tout la $x^{\text {re }}$, la $5^{\mathrm{e}}$ et la $6^{\mathrm{e}}$. Quand on a recueilli leurs graines, il vaut mieux les semer aussitôt que d'attendre au printemps. Le semis se fera avec succès dans des terres un peu légères; elles lèveront de bonne heure, et pourront être placées à demeure dans le courant de juin. Elles ne fleurissent pas la première année, et quelquefois même la seconde. 
On peut aussi multiplier les $\longleftarrow$ par la séparation de leurs pieds en mars. Les espèces I , 5, 6 se sèment elles-mêmes et ne demandent aucun soin.

Les 2 dernières sont d'orangerie. Leur terre ảoit être douce; consistante et substantielle. On doit les mettre pendant l'hiver anssi près des jours qu'il est possible, étant très-sujettes à s'étioler et à chancir lorsque l'humidité est trop grande. On les multiplie par leurs graines semées en pot sur couche, et conduites à la manière indiquée. En général, les semis des digitales réussissent beaucoup mieux en les faisant aussitòt après la maturité des graines qu'au printemps. Les espèces d'orangerie doivent être très-modérément arrosées en hiver et bien exposées en été. La $8^{\mathrm{e}}$ et la $9^{\mathrm{e}}$ mûrissent très-bien leurs graines dans le nord de la France.

Us. Plusieurs espèces de digitale sont agréables à voir dans le temps de leurs fleurs. La $\mathrm{I}^{\mathrm{re}}$, qui est la plus commune, est aussi la plus belle. La $6^{\mathrm{e}}$ a un port superbe, qui fait beaucoup d'effet dans les grands parterres. La $\delta^{e}$ a des épis de fleurs d'une couleur remarquable. La $9^{\mathrm{e}}$ est une belle espèce, qui mérite d'être cultivée pour son port et ses grandes feuilles.

10. Digrtals. à petites fleurs, $D$. parviflora, $\mathrm{J}_{\mathrm{AcQ}}$. D. ferruginea, LAM.

Tige simple. Feuilles linéaires, très-entières, obtuses, bordées de coton blanc. Fleurs peiites, par rapport à celles des autres espèces, jaunâtres, ferrugineuses, plus eourtes que les bractées, disposées en épi terminal.

Lieu. . . $\sigma^{x}$.

* ir. D. orientale, D. orientalis, Lamarck.

Tige d'un mètre environ, simple, glabre, légèrement anguleuse. Feuilles alternes, sessiles, linéaires-lancéolées, très-entières, glabres. Fleurs blanchâtres, assez grandes, disposées en épi lâche et terminal. La lèvre supérieure presque nulle; l'inférieure grande, plane, en spatule, pubescente sans être b arbue.

Lieu. Le Levant. $\%$.

Variété. D. lanata, Willd. Corolle brune. La lèvre infévieure très-longue, veinée et ponctuée de pourpre. 
Cult. Pleine terre. La même que celle des autres espèces rustiques.

J'ajoute à la multiplication des digitales, que non-seulement il - st nécessaire de semer leurs graines aussitôt après leur maturité, mais que celles des espèces 4,7 et Ir sur-tout seront mieux semées dans des terrines, parce qu'elles ne lèvent pas toujours la première année, et qu'en général la germination des digitales n'a guère d'époque déterminée. La $9^{\mathrm{e}}$ ne leve ordinairement que la seconde année. Celle-ci, ainsi que la 8 e, peuvent se multiplier de boutures.

\section{Deux étamines.}

\section{Calcéolaire, Calceolaria.}

Cal. à 4 lobes. Cor. à tube très-court, à limbe à 2 levres; la sup. très-petite; l'inf. grande, enflée, concave, en forme de sabot, et élevée dans l'entrée du tube. Étam. courtes, à anthères recourbées. I stigm. Caps. conique, à 4 valves à son. sommet.

\section{x. Calcéolatre pinnée, C. pinnata.}

Tige de 2 pieds, droite, cylind., pubescente, enflée à ses nœuds, rameuse. Feuilles opp., ailées avec impaire, à 9 à $x 3$ folioles obl., dentées, obtuses, molles, pubescentes. Fleurs jaunes, péd. au sommet de la tige et des rameaux.

Lieu. Le Pérou. F. Fl. en juillet-octobre.

2. C. à feuilles spatulées, C. fothergilii, H.K. An C. uniflora?

LAMARCK.

Tiges à peine d'un pouce, divisées à leur base. Feuilles opposées, pét., obtuses, spatulées, très-entières, velues. Les pédoncules solitaires ou géminés, en forme de hampes, soutiennent chacun une fleur jaune, dont Ya lèvre inférieure plus longue est rouge sur ses côtés, et antérieurement marquée de taches jaunes.

Licu. Les îles Falkland. જ̛ ou $\Psi$. Fl. en mai-août.

Cult. La première est de serre chaude ou serre tempérée; la. seconde d'orangerie. Ces plantes se sèment au printemps sur 
couche ou sous châssis, en pots, et se conduisent à la manière ord. de celles de ces températures. En mettant la première dans la tannée de la serre chaude, on peut l'y multiplier de boutures, et avoir ainsi une plus longue succession de fleurs.

On connoît environ 46 espèces de ce genre, et il y en à̀ peine trois cultivées en Europe.

\section{Genres qui ont des rapports avec les scrophu. laires. Feuilles opposées.}

\section{Colomnée, Columnea.}

Cal. velu, à 5 parties. Cor. beaucoup plus longue, tubulée, courbée, velue en-dehors, bossue à sa base, à limbe à 2 lèvres; la sup. voûtée, entière et plus longue ; l'inf. plus courte, à 5 lobes. 4 étam. didynamiques, à anthères réunies. I style. Stigmate bifide. Caps. globuleuse, molle, à 2 loges polyspermes; la cloison charnue, séminifere.

* i. Colomnée droite, C.erecta, Lamarck. Cyrilla pulchella, u'Héritier, Willd. Achimenes coccinea, Brown., Pers. Les racines de cette plante sont fibreuses; mais elles ont en outre beaucoup de petits cylinảres formés d'écailles imbricées, blancs dans la terre, et verts pour peu qu'ils soient près de sa surface. Tiges très-nombreuses, rougeâtres, grêles, feuillées dans toute leur longueur, d'un pied et demi. Feuilles opp., pét. , ovales, crénelées, velues, douces au toucher. Fleurs ax., péd., souvent sol., d'un rouge écarlate très-vif.

Lieu. La Jamaique. $¥$. Fl. en juillet-nov.

2. C. velue, C. hirsuta, Swartz, H. K.

Tiges grêles, longues, velues, grimpantes. Feuilles opp., pét., ovales, crénelées, pointues, couvertes de duvet. Fleurs d'un rouge écarlate, velues, péd. , ax. , sol. ou géminées.

Lieu. La Jạmaïque, la Martinique. ๖. Fl. en nov.

Cult. Serre chaude. La première fleurit très-bien sur les taBlettes de la serre, et elle n'est pas plus belle et plus vigoureuse dans une tannée. Sa terre doit être consistante et substantiella: 
Beaucoup d'arrosemens en été, très-peu en hiver. Elle se multiplie tant que l'on veut, en partageant ses racines. Quand quelques-uns de ces cylindres se répandent dans les pots voisins, ou dans tout autre endroit ou ils peuvent reprendre, ilss'enracinent de suite et forment de nouvelles plantes On la dépote tous les ans au printemps. Elle pousse un peutard. La seconde m'est inconnue. Elle est cultivée au Muséum.'

Us. Les fleurs de la première sont si éclatantes qu'on a de la peine à les fixer. Cette plante forme des touffes du plus joli aspect pendant la fin de l'été et tout l'automne, et décore agréablement la serre.

\section{Beslère, Besleria.}

Cal. à 5 parties. Cor. tubuleuse, renflée à sa base et à son sommet, à 5 lobes inégauz. 4 étamines didynamiques. Ovaire glanduleux à sa base. I style. Stigmate bifide. Fruit mou, presqu'en baie, à une loge polysperme.

Miller a cul ivé trois espèces de ce genre, qui sont :

x. Beslère à feuilles de mélissot, $\boldsymbol{B}$. melittifolia, WirLd。 Feuilles ovales.

Lieu. La Martinique.

2. B. jaune, B. lutea, J JCQ. Feuilles ovales-lancéolées, dentées en scie.

Lieu. La Jamaïque.

3. B. à crêtes, B. cristata, WıLtid.

Feuilles ov. Calices colorćs, dent. Limbe de la corolle entier. Lieu. Id.

4. B. dentée en scie, B. serrulata, $\mathrm{J}_{\mathrm{A} \text { CQ. }}$.

Feuilles oblongues, pointues aux deux bouts. Calices dentés en scie. Cor. glabre dont le limbe est denté. Arbusțe grimpant.

Lieu. L'Amérique mérid.

Ces plantes sont de serre chaude et $\varsubsetneqq$. On les obtient et on les multiplie par leurs graines semées selon la manière indiquée pour les arbustes de celte serre. Il est apparent que ces plantes, difficiles à élever et à conserver, ne se trouvent guère à présent dans les collections. 
Ce genre ne paroît différer du précédent que par un ovaire glanduleux à sa base, et par son fruit à une seule loge polysperme.

\section{Gratiole, Gratiola.}

Cal. à 5 part., avec deux bractées à sa base. Cor. tubulée, striée, presqu'à 2 lèv.; la sup. à 2 lobes ou échancrée; l'inf. 3-fide et égale. 4 éíarn., dont 2 fertiles et 2 stériles. Rudinant d'une 5 e. I style. I stigm. à 2 lobès. Caps. ovale, à 2 loges polyspermes, et à 2 valves dont les cloisons leur sont parallèles. Le réceptacle séminifere, plane et central.

* I. Gratiole officinale, G. officinalis. Herbe à pauvre homme.

Tiges droites, d'un pied, simples et glabres. Feuilles opp., sess., ovales, dentées, lissej, à 3 nervures. Fleurs jaunâtres, avec un peu de rouge, ax., sol., péd.; la levre sup. relevée; l'inf. un peu barbue

Lieu. La France. $\Psi$. Fl. en juin et juillet.

2. G. à feuilles de thym, G. monnieria.

Tiges rampantes, nombreuses, très-rameuses, de 5 à 7 pouces. Feuilles opp., petites, ov.-obl., entieres, lisses, succulentes. Fleurs blanches, péd., ax., sol.

Lieu. Les deux Indes et les îles de la mer du Sud. $\longleftarrow$. Fl. id. 3. G. inégale, G. incequalis.

Feuilles oblongues, obtuses, un peu dentées. Fleurs pédicellées; la l'evre sup. droite.

Lieu. La Caroline

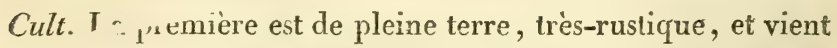
dans tous les terrains, pourvu qu'ils soient un peu frais. On Ia multiplie assément en coupant des morceaux de sa touffe, qui s'élargit en traçant. Cette opération peut se faire en automne comme en mars.

La deuxième est de serre chaude. Cette plante aime l'humidité. La troisième m'est peu connue.

Us. La première a peu d'effet. Elle est cultivée dans leş jardins de botanique à cause de ses propriétés. Elle est fort amere 
et violomment purgative, émétique et hydragogue. Elle est recommandée dans l'hydropisie. On s'en sert cependant assez rarement en méd.

\section{Mimule, Mimulus.}

Cal. prismatique, å 5 dents. Cor. tubulée, à 2 levvres; la sup. bifide et réfléchie; l'inf. 3-fide, avec un palais élevé. 4 étam. didynamiques, à anthères réniformes. I style. Stigm. bifide. Caps. ov., à 2 loges, polysperme, à 2 valves réunies par une nervure.

* I. Minule de Virginie, $M$. ringens. Fleur de moine. Tiges droites, peu rameuses, carrées, lisses, d'un à 2 pieds. Feuilles opp., semi-amplexicaules, obl., émoussées, linéaires, dentées. Fleurs d'un bleu pâle, assez grandes, ax. , péd., opp. , sol.

Lieu. La Virginie, le Canada. . Fl. en juillet et août.

2. M. ailé, M. alatus, H. K.

Tige droite, ailée, tétragone. Feuilles ovales, pét.

Lieu. L'Amériq. sept. ₹. Fl. en juillet et août.

Cult. Pleine terre. Ces plantes se plaisent dans les lieux humides et un peu ombragés, dans les terres douces. Elles sont rustiques, et se multiplient par la séparation de leurs pieds en automne et en mars, et par leurs graines semées, aussitôt après leur maturité, en planche ou plate-bande exp. à l'est. On les cultive dans les jardins de botanique et dans les collections de plantes étrangères, oì la première fait un bon effet.

* 3. M. glulineux, M. glutinosus, WiLLD. M. aurantiacus,

Curt., Mag.

Tige ligneuse ou sous-ligneuse, cylindrique, de 3 pieds environ de hauteur, rameuse; les rameaux opposés, visqueux et bruns. Feuilles opposées, sessiles, presque connées et engầnantes, ovales-lancéolées, légèrement dentées, très-visqueuses, glabres et d'un vert sombre. Fleurs d'un jaune orangé, longues de 4 centimètres (un pouce et demi), pédonculées, opposées, axillaires, solitaires. Le tube est enfermé jusqu'aux deux tiers dans le calice, qui a 4 angles saillans et qui est aussi visqueux. 
Lieu.... ๖. Toujours vert. Fleurit tout l'été et une partie dè l'automne.

Cult. Orangerie. Cette espèce craint l'humidité en hiver et la stagnation de l'air; elle ne dure pas très-longotemps. Au bout de 3 à 4 ans elle périt ou devient languissante. Il faut donc Ia renouveler tous les ans pour avoir de jeunes pieds qui fleurissent beaucoup mieux que les vieux. On y parviendra aisément par ses graines dont une partie mûrit dans nos jardins, et que l'on sème comme toutes celles des plantes de cette serre; et par les boutures que l'on fait au prinitemps dans la couche destinée à ce moyen de propagation, ou dans des pots ombragés et plongés dans une couche tempérée. Sa terre doit êtresubstantielle : meilleure elle sera, plus l'arbuste fleurira; et comme il ne vit pas long-temps et que l'on peut lui donner aisément beaucoup de doubles, on ne risque rien de lui fournir une végétation luxuriante.

$\boldsymbol{U}$ s. Cette plante ajoute beaucoup à l'agrément et à la variété par son port d̊roit et la couleur de ses fleurs, qui est encore relevée par la teinte foncée de son feuillage.

IV. Genre qui a du rapport avec les scrophulaires. Feuilles alternes.

\section{Broualle, Browalia.}

Cal. tubulé, 5-fide. Cor. tubulée, à limbe plane, à 5 lobes pres. qu'égaux ; le sup. plus grand. 4 étam., dont deux plus longues, à anthères assez grandes, fermant l'entrée de la cor. I style. Stigm. à 4 lobes. Caps. à deux loges, polysperme, à 2 valves bifides à leur sommet, qui se détachent facilement et n'en forment alors qu'une, avec une cloison séminifere, plane, parallèle aux valves.

z. Brovalle à tige basse, $\boldsymbol{B}$. demissa.

Tige rameuse, pubescente, d'un pied. Feuilles alt., pét., ov.-pointues et velues. Fleurs d'un violet bleuâtre, sol., axilJaire. 
Lieu. L'Amérique mérid. Fl. en juillet-sept. * 2. B. élevée, B. elata. Vulg. violette bleue:

Tige de deux pieds, glabre, très-rameuse. Feuilles plus pointues et plus glabres. Fleurs d'un beau bleu, à bong tube, ax., sol., péd. au sommet des rameaux. Les lobes de la corolle sont échancrés en cœur à leur sommet, et le supérieur est marqué à sa base d'une tache d'un blanc jaunâtre, qui se perd dans la couleur du fond.

Lieu. Le Pérou. Fl. id.

Cult. Serre chaude. Ces plantes étant annuelles $n^{\prime}$ ont pas besoin d'y entrer, même pour fructifier. On les sème au printemps sur couche et sous châssis, dans des vases ou en pleine terre. Quand elles sont assez fortes pour être cultivées, on les ôte en motte ou avec le déplantoir, et on les plante à une exposition méridienne, dans la place où elles doivent rester. Cependant, comme elles ne fructifient qu'en automne, et qu'il arrive assez souvent, sur-tout dans le nord de la France, que cette saison est humide et pas assez chaude pour mûrir leurs graines, il est prudent, pour ne pas perdre l'espèce, d'en mettre un ou deux individus en pots assez grands pour qu'on ne soit pas obligé d'en changer. Ces pots seront mis sous un châssis ouvert pendant toute la journée, et les broualles y perfectionneront leurs semences. On pourroit aussi les placer dans la serre chaude; mais elles sont sujettes à s'étioler.

Cult. La seconde est actuellement, et avec raison, cultivée dans plusieurs jardins, qu'elle orne par ses buissons dont les fleurs nombreuses se succèdent pendant un très-long temps. Les deux anthères qui se trouvent juste à l'entrée de la corolle, et qui forment deux points noirs luisans, ressemblent assez a deux yeux d'araignée. 


\section{O R D R E V I I I.}

\section{Les Solanées (Solan te.}

Calice ordinairement à cinq divisions, presquie toujours persistant. Corolle souvent régulière et di. visée en cinq. Presque toujours cinq étamines atlachées au bas de la corolle. Un ovaire et un style; le stigmate simple, quelquefois sillonné. Fruit le plus souvent biloculaire, polysperme, ordinairement en baie; les réceptacles séminifères au centre, opposés à la cloison, quelquefois capsulaire, à deux valves, la cloison parallèle aux valves. Embryon autour d'un type farineux.

Herbes ou arbrisseaux. Feuilles alternes; dans que ques genres deux feuilles florales partant du même point. La disposition des fleurs varie.

$O b s$. La série naturelle dessolanées renferme plusieurs genres, les uns à capsule, les autres à baie, qu'on ne peut séparer, aydnt une corolle régulière, cinq étamines, un fruit biloculaire, un embryon à périsperme et les feuilles alternes. Les capsulaires se rapprochent des scrophulaires par la cloison parallèle aux valves : les solanées à baie s'unissent aux borraginées.

\section{Fruil capsulaire.}

\section{Celsie, Celsia.}

Cal. à 5 part. Cor. en roue, ouverte, à 5 lobes inégaux. 4 élan. didynamiques, à filamens velus. I stigm. Caps. à 2 valves.

1. Celsis du Levant, $\boldsymbol{C}$. orientalis.

Tige droite, cylind., simple, d'un pied et demi, garnie, dans 
toute sa longueur, de feuilles alt., éparses, 2 fois ailées, à fol. dentées et glabres. Fleurs petites, sess., d'un jaune pâle, sol., ax.

Lieu. Le Levant. Fl. en juillet et août.

2. C. à longs pédoncules, $C$. arcturus.

Tiges foibles, velues, d'un pied. Feuilles rad. ailées avec une impaire large, arrondie, crénelée; celles de la tige alt. ou opp., simples, pét., ov.-arrondies, dentées. Fleurs jaunâtres, en épi lâche au sommet de la tige.

Lieu. L'île de Candie. ơ. Fl. id.

* 3. C. de Crète, C. cretica.

Tige droite, simple, pubescente, de 2 pieds. Feuilles radicales, lyrées; celles de la tige alt., sess., amplexicaules, en cœur, ridées, dentées. Fleurs grandes, jaunes, marquées de deux taches ferrugineuses, en longue grappe term. Les bractées aussi longues que les fleurs.

Lieu.Id. et les Indes or. $\sigma^{7}$. Fl. en juillet.

Cult. La $\mathrm{I}^{\mathrm{re}}$ est de pleine terre, mais délicate. A moins qu'elle ne soit dans un sol léger, médiocre et bien exposé, elle a de la peine à résister à l'hiver, et souvent elle y périt lorsqu'on la sème en automne, qui est cependant le temps le plus favorable. Dans nos climats, il vaut mieux la sener en pot aussitôt après la maturité des graines, et la planter ensuite en pleine terre avec les autres plantes de cette durée, dans l'année suivante. Les autres sont d'orangerie. On les sème de même en pots; toute la différence qu'il y a, c'est qu'elles y restent. Au reste, ces plantes, qui ont beaucoup de rapports aux molènes, leur sont inférieures en aspect.

4. C. lancéolée, C. lanceolata, Vent., Jard. Cels.

Tiges foibles, cylindriques, striées, blanchâtres, de 5 décimètres ( un pied et demi) environ de hauteur; rameaux alternes, ouverts. Feuilles alternes, pétiolées, lancéolées; les supérieures sessiles, inégalement dentées, de deux pouces et demi de longueur. Fleurs d'vn jaune jonquille, tachetées de pourpre à leur base, couvertes de poils de la même couleur, de 14 à 15 lignes de diamètre, solitaires, pédonculaires, axillaires.

Lieu. L'Egypte. ' 4 . Fleurit au printemps.

Cult. Orangerie. 
On cultive encore au Muséum une autre espece nommée par Desfont. Celsia heterophylla. Elle est $\sigma^{\top}$ et d'orangerie.

\section{Hémithome, Hemithomus.}

Cal. à 5 parties. Cor. en roue, irrégulière, très - ouverte, à 5 lobes inégaux. 4 étam. égales, inclinées. Anthères sagittées. Stigmate simple, recourbé. N.

* Hémithome écarlate, $H$. coccineus. $H$. fruticosus, L'Hér. Hemimeris coccinea, WILld. Celsia linearis, JAcQ.

Tiges rameuses, de 2 pieds. Les rameaux bruns, un peu grêles et roides. Feuilles verticillées : à 3 feuilles principales, longues, linéaires-lanc, pointues, molles, accompagnées de plusieurs autres dans le même verticille, mais plus petites et plus étroites. Fleurs d'un bel écarlate, pédonculées, solitaires, disposées en longs épis làches et terminaux La corolle est ringente, brune dans son centre, et marquée sur cette couleur de 5 raies vertes.

Lieu.Le Pérou. Ђ.Fl. en juillet-octobre. Toujours vert.

Cet arbrisseau a les plus grands rapports au genre précédent et au suivant, et je ne vois pas de raison assez déterminante qui ait pu séparer ce genre du genre celsie.

Cult. Serre tempérée, terre consistante. arrosemens trèsmodérés en hiver. Cette plante est très-susceptible de la moindre humidité dans cette saison et de l'effet de l'air peu renouvelé. Ces circonstancesla font périr ou la mutilent considérablement. Il lui faut absolument une serre sèche et une place contre les croisées pour qu'elle puisse avoir toute la lumière possible. Sans ces attentions, on risque de perdre tous les individus qu'on peut avoir. On la multiplie aisément de boutures faites pendant le courart de l'été, soit en pots sous châssis, soit dans la couche. Quand elles auront été repiquées en pot et reprises, on doit les placer à une exposition chaude et très - aérée, pour qu'elles puissent se fortifier et ne pas trop pousser avant leur entrée en serre. Plus on aura contribué à les empêcher de prendre une trop grande végétation, mieux elles se conserveront en hiver, qui est la saison critique pour les jeunes plantes. 
* Hémiméride à feuilles d'ortie, hemimeris urticifolia, Willd. Celsia urticifolia, Cur't., Mag.

Caractère de l'hémithome.

Tige garnie de beaucouid de branches et de rameanx tétragones, d'un brun léger. Feuilles opp., ovales, pointues, fortement dentées en scie, d'un beau vert, glabres et luisantes. Fleurs écarlates, pédonculées, axillaires, disposées en grappes terminales qui s'alongent beaucoup à mesure que la fructification se fait. Le bouton de la fleur, avant de s'ouvrir, a la même forme que ceux des molênes et de l'hémitome. La corolle ressemble aussi à celle de ce dernier : les étamines, presqu'égales, n'ont pas leurs filamens velus. Anthères jaunes. Les divisions du calice réfléchies en dehors.

Lieu. L'Amérique australe. Ђ. Toujours verte. Fleurit une grande partie de l'année.

Cult. Orangerie. Cette plante n'est pas délicate et passe beaucoup mieux l'hiver que l'hémithome. Comme elle est continuellement en végétation, elle demande, dans sa résidence hivernale, le plus de lumière possible. La serre tempérée ne lui convient pas, parce qu'elle s'y étiole en poussant à contre-temps: les tablettes des croisées d'une serre froide, pourvu qu'il n'y gêle pas, lui sont favorables. Peu d'arrosemens en hiver, fréquens en été, et l'exposition du midi. Multiplication par ses graines, qui mûrissent dans nos jardins, que l'on sème et conduit comme celles de toutes tes plantes d'orangerie; et par les boutares faites en été dans la couche indiquée, qui s'enracinent en peu de temps. Terre douce et consistante.

Us. L'hémiméride et l'hémithome qui, par les fleurs, ont tant de rapports ensemble, méritent d'être cultivées pour l'ornement des jardins, et principalement l'hémiméride, dont la floraison se succede pendant long - temps, et qui se maintient beaucoup mieux. Peut-être pourroit - on acclimater cette dernière au poin d'en faire un arbuste de plein air. Elle rivaliseroit alors avec la fuscie pourl'agrément, ettoutes deux nous prouveroient que Ies plantes des terres australes sont les plus susceptibles d'enrichir nos jardins et de s'habituer à nos climats. 


\section{Molêne, Verbascum.}

Cal. à 5 part. Cor. en roue, ouverie, à 5 lobes inégaux. 5 étamines inégales, à filamens inclinés et velus à leur base. r stigm. Caps. à 2 valves, ovale ou globuleuse.

* I. Molêne officinale, Bouillon blanc, $V$. thapsus.

Tige ord. simple, épaisse, lanugineuse, blanchâtre, de 4 à 6 pieds. Feuilles grandes, alt. , ov.-obl., pointues; les radicales en rosettes; les caulinaires décurrentes, épaisses, blanchâtres, lanugineuses, douces au toucher. Fleurs jaunes, en paquets, sess., disposées en un très-long épi term.

Lieu.... Ind. ণ̋. Fl. en juillet et août.

* 2. M. thapsoïde, $\boldsymbol{V}$. thapsoides.

Tige id., mais rameuse et moins haute. Feuilles grandes, alt. , sess., très-décurrentes, oblongues, un peu étroites , pointues, cotonneuses. Fleurs jaunes, moins grandes que celles de la $\mathrm{I}^{\mathrm{re}}$, en épis term. plus lâches.

Lieu. La France. $\sigma^{7}$. Fl. id.

* 3. M. de Boerhaave, $V$. Boerhaavii.

Feuilles sess., non décurrentes, presque lyrées, assez glabres. Fleurs jaunes; les anthères purpurines, en épi term.

Lieu. L'Europe mérid. Fl. id.

4. M. hémorrhoïdale, $\boldsymbol{V}$. hemorrhoidale, H. K.

Feuilles ov.-obl., rétrécies à leur base, cotonneuses, obtusément crénelées. Fleurs en grappes spiciformes, alongées; les paquets de fleurs sans bractées.

Lieu. Madère. $\sigma^{x}$. Fl. en juin-août.

* 5. M. lychnite, $V$. lychnitis.

Tige de 3 à 4 pieds, droite, cylindrique, un peu cotonneuse. Feuilles alt., cunéiformes, obl., molles, douces au toucher; les caulinaires sess., blanchâtres en-dessous. Fleurs d'un jaune pâle, petites, péd., en longs épis droits et racémiformes.

Variété à fleurs blanches.

Lieu. Près Abbeville. Ind. o7. Fl. id.

L'espèce $V$. floccosum a beaucoup de rapports à celle-ci. 
Sa lige est cotonneuse et d'un beau pourpre. Ses feuilles sont ovales, presqu'entières. Les poils des filamens des étamines sont blancs.

Orig. de la Hongrie. Cultivée en Angleterre. $\sigma^{7}$.

* 6. M. phlomoïde, $V$. phlomoides.

Tige droite, épaisse, lanugineuse, paniculée ord. à son som. mè, de 5 à 6 pieds. Feuilles rad. en rosette, ov.-obl., pét. , colonneuses, drapées, très-douces au toucher; les caulinaires alt., sess., crénelées. Fleurs grandes, jaunes ou blanches, odorantes, en plusieurs épis formant le panicule.

¿ieu. La France, l'Italie, les Sables des Dunes. Ind. $\sigma^{7}$ Fl. id.

7. M. ferrugineuse, $V$. ferrugineum.

Tige droite, rameuse, de 3 à 4 pieds. Feuilles rad. obl., en cœur, doublement crénelées ; les caulinaires presque sess. , également crénelées; toutes ridées et velues. Fleurs grandes, ferrugineuses, en longs épis.

Lieu. L'Europe inérid. ₹. Fl. en mai-août.

8. M. mucronée, $\mathscr{V}$. mucronatum, Encycl

Tige épaisse, ferme, blanchâtre, cotonneuse, ramifiée à son sommet, de 6 à 8 pieds; les rameaux nombreux. Feuilles rad. en rosette, ov.-obl., très-cotonneuses, longues de 2 pieds; les caulinaires éparses, amplexicaules, blanchâtres; celles du som. met courtes, mucronées. Fleurs jaunes, grandes, sess., formant, par les rameaux qu'elles couvrent, un beau panicule term.

Lieu. L'île de Candie. ơ .

* 9. M. noire, $V$. nigrum.

Tige droite, rameuse, rougeâtre, de 2 pieds. Feuilles alt., pét., ov.-obl., en cœur, crénelées, d'un vert obscur. Fleurs jaunes; les filamens rouges, en épis term.

Lieu. . . Ind. $\%$. Fl. id.

* 10. M. sinuée, $V$. sinuatum, LAM.

Tige droite, foible, rameuse, cotonneuse, de 3 pieds. Feuilles rad. pét., obl., profondément sinuées ou pinnatifides, très cotonneuses; les caulinaires amplexicaules, alt., sess., molles, 
peu cotonneuses. Fleurs jaunes, en épis racémiformes, Iàches et grêles.

On cultive une variété de cette espèce, qui est la molêne ondulée de Lamarck, $V$. undulatum. EHe diffère de la sinuée par un duvet plus abondant, par ses rameaux foibles, par ses feuilles radicales très-sinuéesłet ondulées, et par ses fleurs sessiles.

Lieu. La France mérid. o7. Fl. id.

I1. MoLẾNe en lyre, $\mathcal{V}$. lyratum, EncycI.

Tige foible, courbée, de 2 pieds. Feuilles rad. ov.-obl., un peu anguleuses, crénelées, presque glabres, pét.; les canIinaires cordiformes, pointues, sess., dentées. Fleurs d'un beau jaune, grandes, en longs épis term.

Lieu. L'Espagne.

* 12. M. purpurine, $V$. pheniceum.

Tige d'un pied et demi, droite, menue. Feuilles ovales, crénelées, ridées, vertes, presque glabres. Fleurs pourpres, distantes, en grappes lâches et term.

Variétés. * r. A fleurs d'un rouge rose.

* 2. A fleurs pâles.

Lieu. L'Europe mérid. $\nsucc$. FI. en mai-juillet.

* I3. M. blattaire, V. blattaria. Herbe aux mites.

Tige droite, glabre, de 2 à 3 pieơs. Feuilles obl., glabres; les inf. ondées, crénelées ou incisées; les sup. amplexicaules, crénelées. Fleurs jaunes, planes; les filamens violets, en épis. lâches et term.; solitaires sur chaque pédoncule simple.

Lieu... Ind. Fl. en juillet et août.

Variétés. I. A feuilles longues et laciniées.

2. A fleurs blanches.

* I4. M. blattariforme, $V$. blattarioides, H.P. V. viscidulum,

PERs.

Tige droite, rameuse, de 3 pieds. Feuilles sess., obl., pointues; les inf. sinuées; les sup. alt., amplexicaules, pointues; toutes molles, épaisses, presque glabres. Fleurs d'un beau jaune, grandes; les filamens purpurins, en longs épis term.; ordinairement au nombre de deux, portées sur des pédoncules. très-courts.

Lieu. La France. $\odot$. 
* I5. M. à lige nue, $V$. myyconi. Ramonda pyrenaica, Pers.

leuilles rad. en rosette, nombreuses, ovales, obtuses, cré-nclées, ridées, extrêmement laineuses, épaisses, d'un vert obscur. Hampes de 4 à 6 pouces, rougeâtres, nues, portant chacune un bouquet de fleurs d'un bleu purpurin, un peu penchées.

Lieu. Les Pyrénées. $\%$. Fl. en mai. 16. M. à grandes fleurs, $V$.osbeckii. $V$. bugulcefolium, Encycl.

Tige feuillée. Feuilles incisées, nues. Fleurs très-grandes, au nombre de 2 sur le même péd. Les calices laineux.

Lieu. L'Espagne. $\sigma^{7}$. Fl. en juillet et août.

Obs. Le bouton des fleurs des molênes est toujours à 5 angles.

Cult. Excepté la $4^{\mathrm{e}}$, qui est d'orangerie, mais qui se multiplie comme les autres, toutes les molênes sont de pleine terre. La $15^{\mathrm{e}}$ cependant est un peu délicate, et si l'on en mei des individus en pleine terre dans le nord de la France, il est bon d'en avoir aussi en pot pour placer à l'abri des grands froids. Cette espèce d'ailleurs mérite ces soins. Les molênes viennent dans presque tous les terrains, pourvu qu'ils ne soient pas frais et ombrazés; elles se plaisent toutes dans les lieux secs et exposés au soleil : les terres chaudes, un peu légères et substantielles sont celles ou elles élèvent le mieux leurs hautes tiges, et ou elles fleurissent et fructifient davantage. Il leur faut à presque toutes les situations les plus ouvertes. On les trouve ordinairement dans les lieux pierreux, les cours, etc. J'ai rencontré la $6^{\mathrm{e}}$ espèce, dans sa plus belle végétation, sur les dunes de sable pur. Ces plantes se multiplient souvent elles-mêmes par leurs graines; mais de crainte qu'elles ne manquent de se semer, il faut les cueillir dans leur matarité, sur-tout les espèces érrangères, et les semer peu de temps après, ou de suite, dans des terres douces, légères et sablonneuses. Comme elles ne fleurissent pas ordinairement la première année, on les plantera i demeure lorsqu'elles auront 4 à 5 feuilles : si l'on attendoit plus tard, la reprise ne seroit pas certaine et ces plantes souffrent toujours à la transplantation. Les espèces $\longleftarrow$ peuvent se multiplier par leurs rejetons. La douzième se multiplie ainsi: on sépare son pied au commencement du printemps, et les parties sépa- 
rées se plantent de suite avec un peu de terreau mêlé avec de la terre. La quinzième demande un peu d'ombre; le grand soleil lui fait tort : la terre de bruyère lui convient. On la propage par seś rejetons enlevés au printemps.

Us. La plupart des molênes sont de belles plantes dont le port est droit et l'aspect de leurs fleurs agréable à la vue. Parmi elles on distingue les especes $1,6,7,8,1$ 1 , 12, 14, 15 .

La première est d'un usage fréquent en médecine. On emploie ses fleurs en irfusion; elles sont émollientes et béchiques: mais il faut les mettre infuser dans un nouet, pour empêcher les poils des étamines de se mêler avec l'eau, et de produire la loux en s'attachant au pharynx. Cet inconvénient fail qu'on préfère les fleurs de guimauve ou de pas-d'àne, qui ont les mêmes propriétés.

17. Molt̂́ne épineuse, $\boldsymbol{V}$. spinosum, Liv.

Arbuste épineux, très-rameux, paniculé, dont la tige tortueuse a environ I pied et demi (un demi-mètre) de hauteur, et les rameaux terminés par un épine. Feuilles alternes, ov.-obl., dentelées ou incisées, molles, cotonneuses, finissant en pétiole à leur base. Fleurs petites, d'un jaune citron, disposées en panicules roides et terminaux.

Lieu. L'île de Candie. Ђ.

Cult. Orangerie.

18. M. pulvérulente, $V$. pulverulentum, Sмгтн.

Tige rameuse. Feuilles ov.-obl., presque dentées, pulvérulentes sur les deux surfaces. Fleurs grandes, d'un beau jaune. Les poils des filamens blancs; les anthères d'un rouge de vermillon.

\section{Lieu. L'Angleterre. $\sigma^{\top}$.}

I9. M. pinnatifide, $V$. pinnatifidum, VAHL.

Feuilles linéaires-lancéolées, pinnatifides; les pinnules obtuses, dentées. Fleurs sessiles, glomérulées.

Lieu. La Grèce. $\tau$. 20. M. glabre, $V$. glabrum, Hort. angl. $\sigma^{7}$.

2r. M. du Caucase, $V$. caucasicum, Hort. angl.

Lieu. Le Caucase. $\psi$. 
Cult. de ces 4 espèces. Pleine terre; la même que celle des espèces précéḋentes.

\section{Jusquiame, Hyoscyamus.}

Cal. tubulé, 5-fide. Cor. infund., à linbe ouvert obliquement, à 5 lobes inégaux. Stigm. capité. Caps. ovale, comprimée des deux côtés, sillonnée, s'ouvrant en travers.

I. Jusquiame noire, $\boldsymbol{H}$. niger. Potelée.

Tige d'un à deux pieds, rameuse, épaisse, cotonneuse, douce au toucher, visqueuse. Feuilles alt., grandes, cotonneuses, molles, profondément découpées et sinuées, amplexicaules. Fleurs d'un jaune pâle, veiuées de pourpre noirâtre, sess., en longs épis.

Lieu. Les cours, les lieux incultes. Ind. or. Fl. en juin.

2. J. blanche, $H$. albus.

Tige moins haute et moins rameuse. Feuilles ov.-obl., molles, un peu anguleuses, sinuées, obtuses, pétiolées. Fleurs d'un blanc sale, presque sess., ax., sol.

Lieu. La France mérid. F. Fl. en août.

* 3. J. fluette, $H$. pusillus.

Tige grêle, de 5 à 6 pouces. Feuilles alt., lin-lanc., dentées; les dents alongées, presque glabres, pét. Fleurs d'un jaune pâle, noirâtres en-dedans, ax. , presque sess. Les calices épineux.

Lieu. La Perse. (1. Fl. en juillet.

* 4. J. de Sibérie, $\boldsymbol{H}$. physalodes.

Tige d'un pied et plus, velue. Feuilles alt., pét., ov., en cœur, très-entières, vertes. Fleurs blanchâtres, violettes endedans, 2 à 5 ensemble, péd., en bouquet term.

Lieu. La Sibérie. ₹. Fl. en mars et avril.

* 5. J. dorée, H. aureus.

Tige d'un pied environ, foible, grêle, velue. Feuilles pét., éparses, un peu en cœur, arrondies, anguleuses, dentées, molles, d'un vert grisâtre; les pétioles très-velus. Fleurs d'un beau jaune, et d'un pourpre noir en-dedans, péd. , ax. et term., pendantes.

- Lieu. La France mérid. ₹ ou 3 - annuelle. Fl, en marsoctobre. 
6. Jusquiame à fleurs pendantes, $H$. scopolia.

Tige d'un à trois pieds, droite, cylind., glabre. Feuilles alt., géminées, ovales, enilieres, pointues, glabres, décurrentes sur les pétioles. Fieurs d'un pourpre jaunâtre, ax., sol., péd., pen. dantes.

Lieu. La Carniole. $\psi$. Fl. en mai.

Cult. Excepté la cinquième, qui cependant, avec quelcries abris et une terre légère et médiocre, peut être cultivée en plein air, les autres especes sont de pleine terre. La premiere est très-commune, et ne se culive pas. Les autres espèces se sèment en terres légères et se culivent dans les jardins de botanique. La quatrième a un assez beau feuillage, et mérite quelques soins. Elle languit à l'ombre, et ne se plaît, comme toutes les jusquiames, que dans les sols un peu secs, mais bons. On l'obtient par ses graines, qu'on seme comme les autres annuelles, et l'on plante les jeunes individus à demeure aussitôt qu'ils ont quelques feuilles. On la muliplie ensuite en séparant son pied. La cinquiome se propage par ses semences, en pot, sur couche. Lorsqu'elle a quatre à cinq feuilles, on la met dans de petits pots. Celte espece n'aime pas plus l'humidité que les autres; il lui faut une terre un peu légère, et, pendant l'hiver, le plus d'air et de jour possible. Il est prudent d'en avoir des - individus en orangerie dans le nord de la France, lorsqu'on en met en plein air.

$\boldsymbol{U}_{s}$. La cinquième est la plus remarquable de toutes par la couleur variée de ses fleurs. La première est vénéneuse, assoupissante, dangereuse à l'intérieur; extérieurement anodine et résolutive, cependant encore à craindre. Son contre-poison est l'émétique et le vinaigre. On sait l'usage pernicieux qu'ont fait il y a quelques années, de la poudre de jusquiame mêlée arx tabac, des filous connus sous le nom d'endormeurs.

7.J. réticulée, $\boldsymbol{H}$. reticulatus, Lin., Miller.

Cette espèce a beaucoup de rapport avec la première. Les feuilles de sa tige sont ovales, tr̀es-glabres en-dessus. Ses bractées sont sessiles, ovales, entières. Ses fleurs rouges, réticujées deveines obscures, sont portées sur des pédoncuies très-courts.

Lieu. L'Orient, o7. 
8. S. à feuilles de bette, H. betajolius, Lamarck. H. datora, Forsck.

Cette espèce se distingue des autres par ses fenilles, qui imitent celles de la bette par leurs dents anguleuses et leurs longs pétioles. Sa tige s'élève a la hauteur d'un demi-mètre. Elle est droite et garnie de feuilles alternes, ovales, pointues, avec deux ou trois dents, un peu épaisses. Ses fleurs sont d'un jaune verdâtre à l'extérieur, d'un noir pourpre avec deux taches blanches en-dedans, disposées en grappes feuillées, unilatérales et terminales.

Lieu. L'Egypte, l'Arabie. $\sigma^{7}$.

Cult. La septième de pleine terre; la huiteme d'orangerie. Ces plantes s'obtiennent et se propagent par leurs graines. Elles ne sont guère cultivées que dans les jardins de botanique, a cause de leur courte existence, et des soins qu'il faut prendre pour les réobtenir.

\section{Tabac, Nicoliana.}

Cal. en godet, 5-fide. Cor. beaucoup plus longue, infund., 5-fide, régulière. Stigm. échancré. Caps. à 2 valves.

* r. TAbac frutescent, $N$. fruticosa.

Cette espèce a beaucoup de rapport avec la suivante. Tige de 3 à 5 pieds, droite, simple ou peu rameuse, cylind., pubescente, jaunâtre. Feuilles lanc., amplexicaules, presque pétiolées, pointues, molles, entières, d'un vert jaune. Fleurs purpurines, assez grandes; le limbe plane, en bouquets lâches et term.

Lieu. La Chine, 5ou 3-annuel. Fl. en juillet-nov. Toujours vert.

* 2. T. de Virginie, N. tabacum.

Tige de 4 à 5 pieds, droite, cylind. Feuilles ov.-lanc.; pointues, sess., décurrentes. Fleurs purpurines, en bouquets lâches et term.

Lieu. La Virginie. ○. Fl. id. 
*Variétés. I. A feuilles étroites, lanc., pointues, sess.; calices pointus, et dont le tube des fleurs est très-long. Tabac pointu vulg.

*2. A feuilles très-larges, grandes, vertes, décurrentes; dont les fleurs sont grosses, le tube beaucoup plus court. Tabac camus vulg.

* 5. Tabac rustique, V. rúsica.

Tige id., de 2 pieds. Feuilles pét., ovales, obtuses, trèsentières, velues. Fleurs d'un jaune pâle; les divisions obtuses, en bouquets term.

Lieu. L'Amérique. Fl. id.

* 4. T. paniculé, $N$. paniculata.

Tige de 2 à 3 pieds, paniculée, rameuse, verte. Feuilles pét. , en cœur, très-entières, velues, et d'un vert assez sornbre. Fleurs petites, d'un vert jaune; le limbe plus jaune; le tube long et étroit ; les divisions très-courtes, disposées en panicules fort lâches et fort étendus.

Lieu. Le Pérou. Fl. id.

*5. T. glutineux, N. glutinosa.

Tige de 3 pieds, rameuse, velue. Feuilles pét. , cord. , trèsentières et très-visqueuses. Fleurs assez petites, d'un pourpre verdâtre obscur, en grappes unilatérales et term. Les div. de la corolle inégales, une sur-tout plus longue que les autres, donnent au limbe un aspect labié.

lieu. Le Pérou. F. Fl. id.

Cult. Pleine terre, excepté la première. Aiton a indiqué les deux dernières de serre chaude. C'est sans doute parce qu'elles ne se sèment pas elles-mêmes, ou que la graine n'a pas, en pleine terre, la chaleur nécessaire pour germer; mais dès que ces semences sont levées sur couche, ces deux. plantes croissent fort bien en pleine terre, et $\mathbf{y}$ fructifient comme les cultivées.

Tous ces tabacs se sèment ord. sur couche en avril ; et quand ils ont environ 7 à 8 feuilles, on les enlève pour les planter, à 2 pieds environ de distance l'un de l'autre et par rangs, dans le terrain qui leur est destiné. Leur terre doit être substantielle, anciennement amendée, consistante, mais point du 
tout compacte; leur situation doit être ouverte et exposée au soleil. Lorsque les tabacs sont plantés, il est bon de les arroser un peu, si le temps est à la sécheresse. Quand ils ont environ deux pieds de haut, on les arrête en coupant leur sommet. Les feuilles deviennent alors plus nombreuses et plus larges. On laisse quelques pieds croître en tige pour avorr les semences; mais ces derrières sont si fines et si productives, qu'il en faut bien peu pour couvrir de jeunes plants une grande surface de terrain. Ces feuilles se recueillent plusieurs fois en automne, et on les enfile pour les faire sécher à l'ombre.

L'espèce 2 et ses variétés sont les tabacs qu'on cultive le plus ord. La première variété est la meilleure. La deuxième produit davantage, parce que ses feuilles sont plus grandes; mais, de l'aveu des fumeurs et des preneurs de tabac, elle lui est inférieure. Les feuilles de la première sont aussi bonnes que celles de la première variété et de la deuxième. Celte espèce se cultive en pot, parce qu'elle dure 2 ou 3 ans, lorsqu'on la met en serre tempérée en hiver. Elle fleurit très-long-temps; elle devient alors une plante d'agrément. Les espèces 4 et 5 ne sont cultivées que par curiosité, et dans les jardins de bolanique; elles n'ont ni effet ni utilité. La troisième se sème souvent eile-même.

Us. On connoît les effets bons et mauvais du tabac; son fréquent usage est certainement plus pernicieux qu'utile; il l'est moins pris en fumée qu'en poudre. Lorsqu'on en prend trop de cette dernière manière, il étourdit, et cause quelquefois la perte de la mémoire. Il est assez singulier qu'on ait pu s'accoutumer et prendre plaisir à se servir decette poudre puante, avec laquelle on donne cent fois par jour une espèce de question à son nez. Le tabac est émétique et purgatif violent. $O_{\mathbf{n}}$ l'emploie avec succès dans l'apoplexie et sur les noyés, en injectant sa fumée en forme de lavement.

On l'appelle nicotiane, du nom de M. Nicot, ambassadeur de France en Portugal, dans l'année 1560 , époque où il l'a fait connoître en Europe. 


\section{Autres espèces cultivées.}

6. Tabac nain, N. pusilla, Willd. N. 7iumilis, Miller.

Feuilles radicales ovales - lancéolées, étalées sur la terre, obtuses, ridées. Tige d'un pied et demi, qui se divise en 3 ou 4 rameaux, jortant chacun une petite feuille, et terminés par un épi lâche de fleurs d'un vert jaunâtre, petites, tubulées, dont le calice est très-court ; les divisions du limbe pointues.

Lieu. L'Amérique méridionale.

${ }^{*}$ 7. T. ondulé, $N$. undulata, Vent., Jard. Malm. An N. odo rata, Hort. angl. ?

Tige simple, droite, cylindriq̣ue, velue inférieurement, de 2 à 3 pieds de haut. Fevilles pétiolées; les radicales couchées, spatulées, festonnées; celles de la tige alternes, ovales, pointues, ondées, d'un vert foncé en-dessus et de l'odeur des tabacs usuels. Fleurs d'un blanc de lait, assez grandes, d'une odeur de jasmin, pédiculées, peu nombreuses, portées, au nombre de trois, sur des pédoncules communs terminaux.

Lieu. La Nouvelle-Hollande. $\psi$ ou $\mathbf{5}$-ann. Fleurit à la fin de l'été et tout l'automne.

* 8. T. à feuilles de dentelaire, $N$. plumbaginifolia. Dinegro.

N. crispa, Pers.?

Cette espèce a beaucoup de rapports à la précédente. Elle en differe par une tige très-branchue, garnie de poils blancs ; par ses feuilles moins grandes, étroites, ondulées, assez fermes, sensiblement bordées de poils blancs, sessiles, amplexicaules; par ses fleurs beaucoup plus nombreuses, mais d'environ moitié plus petites, dont le tube est moins gros. Elles n'ont pas non plus son odeur agréable.

Lieu. ₹ ou 3-ann. Fleurit dans le même temps et aussi longtemps.

Cult. Serre tempérée. Ces deux dernières espèces mûrissent leurs graines dans nos jardins; on les sème au printemps dans des pots remplis de bonne terre substantielle, que l'on plonge dans une couche sous châssis. Quand les jeunes plants sont bons ̀̀ être enlevés, on les repique chacun dans un pot, et on les fait 
Teprendre sous un châssis ombragé. On les place ensuite à une bonne exposition méridienne où elles fleurissent et fructifient. On ne peut les conserver en hiver qu'en levr donnant une serre sèche et presque point d'arrosemens, étant fort susceptibles de se chancir par l'humidité. Ordinairement même une grande partie des tiges se pourrit; mais si le pied n'est pas at taqué, il repousse au printemps. On les fortifiera et on rendra les plantes plus vigoureuses si, dans cette så̉son, on les met sous un châssis dans une couche nouvelle.

La $7^{\mathbf{e}}$ a plus d'avantage; ses fleurs plus grandes et leur odeur lui donnent des droits à quelques soins.

\section{Stramoine, Pommette, Datura.}

Cal. grand, tubulé, ventru, à 5 angles et à 5 div. , caduc, excepté sa base qui est persistante. Cor. grande, infund., à long tube, à limbe à 5 angles, 5 plis et 5 pointes. Stigm. à 2 sillons. Caps. hérissée de pointes ou glabre, ovale, à 2 loges, dont la cloison est à 2 ou plusieurs parties. Semences réniformes.

* i. Strataline féroce, D. ferox.

Tige d'un pied et demi, branchue. Feuilles ailt. , pét. , ov-lanc., glabres, anguleuses en leurs bords. Fleurs blanches, moins grandes que celles de la suivante. Frutit armé de pointes épineuses très-fortes.

Lieu. La Chine. FI. en juillet - sept.

* 2. S. commune, D. stramonium. Pomme épineuse, endormie.

Tige de 3 à 4 pieds, creuse, très branchue. Feuilles pét., larges, anguleuses, pointues, glabres. Fleurs blanches, grandes, sol., ax., et dans les dichotomies des branches. Fruit épineux.

Lieu. L'Amérique sept. Fl. id. Naturalisée.

* 3. S. à fleurs violeties, $D$. tatula.

Tige de 4 à 5 pieds, branchue et pourprée. Feuilles larges très-anguleuses. Fleurs d'un pourpre violet, à tu've plus long III. 
et plus étroit. Fruit id., plus long. Même dispasition de fleurs que la précédente.

Lieu. . . Fl. id.

* 4. Stramoine velue, D. metel.

Tige de 5 pieds, branchue, cotonneuse. Feuilles presqu'en* tières, ayan seulement 2 ou 5 légères dentelures. Fleurs blancires; le tube un peu verdâtre et long; disposées comme les précédentes. Fruit épineux, penché.

Lieu. L'Asie, l'Afrique, les Canaries. Fl. en juin sept.

* 5. S. fastueuse, D. fastuosa. Trompette du jugement.

Tige de 4 pieds, d'un beau pourpre, branchue. Feuilles larges, glabres, sinuées, pétiolées. Fleurs d'un pourpre éclatant en-dehors, et d'un blanc satiné en-dedans; le limbe grand, à $\mathrm{I} 0$ angles; disposées comme les précédentes. Souvent cette fleur est garnie d'une ou de deux autres fleurs qui s'élevent de son centre l'une sur l'autre, de manière qu'on la prendroit pour une fleur pleine. Fruit tuberculé, globuleux, penché.

Lieu. L'Egypte. Fl. en jullet-nov.

6. S. lisse, D. levis, H. K. et Liv., Suppl.

Tigeherbacée, fistuleuse. Feuilles glabres. Fruits glabres, sans épines et droits.

Lieu. L'Afrique. Fl, id.

* 7. S. en arbre, D. arborea,Brugmansia candida, PERSoos. Tige cylindr., forte, épaisse, glabre, presque ligneuse, de I2 à I 4 pieds de haut, rameuse et droite. Feuilles ov.-lanc., pointues, très-entières, vertes, molles etlégèrement velues. Fleurs blanches, avec des raies longitudinales d'un jaune pâle, d'un piedenviron de longueur, pendantes; le limbe ouvert et plissé, à 5 angles. Capsule glabre, sans épines, à 2 loges.

Lieu. Le Pérou. Ђ. Fl. en août.

Cult. Les espèces 2 et 5 sont, pour ainsi dire, naturalisées. Elles se sèment ordinairement elles-mêmes, lor squ'il y en a eu une fois dans un jardin. Cependent dans les pays sept., comme elles levent un peu ard, la $5^{\mathrm{e}}$ sur-tout ne porte pas toujours ses graires à maturié. Los antros sont plus délicates, et doivent être semées sur couche, pt plantées ensuite dans la place qui leur 
est destinée. Ces plantes aiment les terres très-substantielles, lẻzères et chaudes. Les terrains forts, argileux, frais et ombragés ne leur sont pas favorables; rarement elles y fructifient et y preno nent leur force naturelle. Il leur faut une bonne exposition et toute la chaleur de l'éié. La $5^{\mathrm{e}}$ et la $7^{\mathrm{e}}$ méritent plus que toutes les autres les soins des cultivateurs. La $5 \mathrm{e}$, pour être dans sa beauté, exige absolument les meilleures terres et les plus chaudes. La $\eta^{\mathrm{e}}$ est un arbrisseau qu'on cultive dans des vases, pour pouvoir le rentrer en hiver en serre tempérée, ou il est beaucoup mieux qu'en serre ehaude. Dans cette dernière serre, il pousse à contre-temps, c'est-à-dire en hiver, et languit ensuite err été. Le principal objet de sa culture consiste à le conserver en entier pendant l'hiver; à faire en sorte qu'il n'entre point en sève pendant cette saison; à le mettre en plein air à une bonne exp. en été ; et vers le mois d'août, qui est le temps de sa floraison dans le pays que j'habite, à le placer à une exp. chaude. On le multiplie facilement de boutures faites au printemps en pot, sur couche ombragée. Ses arrosemens doivent être rares en hiver, étant sujet à chancir par l'humidité; mais en été il faut qu'ils soient fréquens. On le propage aussi par ses graines qui mûrissent dans nos jardins, et qu'on sème au printemps dans des pots sur couche, suivant la pratique indiquée pour les arbrisseaux de serre.

* 8. S. cornue, D. ceratocaula, Jace., Ortega.

Tige d'un pied et demi, cylindrique, couverte d'une efflorescence grise, se divisant en 2 ou 3 branches très-ouvertes et peu rameuses. Feuilles alternes, pétiolées; le pétiole canaliculé; oblongues, profondément sinuées, ondulèes, à angles arrondis, d'un vert grisâtre en-dessus, blanches et tomenteuses en-dessous. Fleurs pédonculées, axillaires, solitaires. Corolle blanche, formant un large entonnoir d'un décimètre et demi ( 6 pouces) de diamètre, à 10 angles, dont 8 plissés, violets en-dessous, marqués de trois lignes brunes, lisse et luisante sur les deux surfaces. Tube pentagone. Anthères grises et droites. Stigmate jaune, en forme de champignon. Calice semblable à ceux des autres espèces. Capsule ovale-arrondie, très-glabre, pendante. Semences noires, réniformes, avec la cicatrice (hy turns) blanche. 
Lieu. L'île de Cuba. $\odot$. Fleurit à la fin de l'été.

Cult. Les graines de cette plante, qui fructifie ordinairement, se sèment sur vieille couche ou sur couche chaude, et les jeunes individus se repiquent ensuite à la place où ils doivent rester. Elle aime les terres chaudes et substantielles. Quand une fois on l'a acquise, et qu'elle a été semée sur une couche de l'année précédente où elle a pu mûrir ses semences, nul soin à prendre ensuite. Il en lève tous les ans dans la terre de cette couche, et pour peu qu'on ait attention de sarcler les jeunes plantes, de leur donner des tuteurs et de les arroser dans les temps secs, elles fleuriront trè6-bien, et l'on jouira assez long-temps de leurs fleurs.

Us. Les stramoines sont toutés de belles plantes par leur port, la largeur de leurs feuilles, et la grandeur de leurs fleurs, dans plusieurs espèces, odorantes. C'est dommage qu'elles soient presque toutes annuelles; mais quand elles se trouvent dans un sol léger et substantiel et dans une situation chaude, elles se propagent elles-mêmes par leurs semences. La $5^{\text {e }}$ est la plus intéressante des annuelles par la monstruosité de ses fleurs; mais elles ne deviennent ainsi qu'avec beaucoup de soins et d'engrais. La $8^{\mathrm{e}}$ joint à de belles fleurs une odeur trèsagréable le soir et le matin, qui se répand à une assez grande distance; elles ne s'ouvrent jamais dans le milieu du jour. La $\eta^{\mathrm{e}}$ est très-remarquable par ses fleurs gigantesques. J'ai eu en l'année 1807 un pied assez élevé de cette plante qui portoit à son sommet 20 fleurs rangées en rond, horizontalement, régulièrement distantes l'une de l'autre, épanouies dans le même temps, qui présentoient la forme d'une batterie de canons $\mathrm{c}$ irculaire. Cet arrangement et ces circonstances m'ont paru fort singuliers.

Les stramoines sont narcotiques et dangereuses à l'intérieur; on ne peut respirer quelque temps l'odeur suave de leurs fleurs sans ressentir son effet sur le cerveau. Elles méritent d'être cultivées pour l'ornement des jardins; mais celles à fleurs olorantes en petit nombre. 


\section{Solandra.}

\section{Caractère des Stramoines, Datura.}

Quoique Desfontaines ait placé ce genre dans la section suivante, l'examen que j'ai fait du fruit de cet arbrisseau ne me permet pas de l'y admettre. Il n'est pas une baie; sa nature est la même que celle des fruits des stramoines non épineuses; il a les plus grands rapports à celui du datura arborea, la même consistance, à peu de chose près, la même forme et les mêmes semences. Malgré Swartz, qui en fait un genre distinct, je pense que cette plante ne devroit être qu'une espèce du genre précédent, et si je ne l'y ai pas insérée, c'est par considération pour les lumières de cet auteur et de Desfontaines, et par la conviction de la foiblesse des miennes. C'est cependant aussi l'opinion de Lamarck.

C'est aussi, je crois, à tort que des jardiniers anglais confondent cette espece avec le porllandia hexandra, qui, selon la place qu'a donnée Jussieu à ce dernier, ne sauroit avoir des rapports avec elle.

* Solandra à grandes fleurs, S. grandiflora, Swartz, Bot. cult. édit. $\mathrm{I}^{\mathrm{re}}$, tom. III. Datura sarmentosa, LAir.

Je culive cet arbrisseau depuis plusieurs années, et je n'âi pas encore remarqué qu'il pouvoit être grimpant ou sarmenteux. Peut-être l'estuil cependant dans son pays originaire. Tige forte, grise, de 5 à 4 mètres ( 5 à $x .8$ pieds) de hauteur, dont les branches et les rameaux sont roides, presque horizontauet dardant de tous côtés; ces derniers, pubescens et un peu anguleux dans leur jeunesse, sont terminés par ume touffe de feuilles alternes, rapprochées, pétiolées, ovales - lancéolées, pointues, très-entières, un peu épaisses, vertes en-dessus, pâles en-dessous, velues sar-tout sur la surface inférieure ei sui leurs bords; qui sont un peu roulés. Fleurs solitaires, grandes, terminales. Corolle en entonnoir, tubuiée; la base du zube couverte par le calice; à 6 côtes peu saillantes, et à 5 nervares Elevées; à 5 divisions larges, arrondies, frangées en leurs 
bords. Calice monophylle, à 5 côtes très-saillantes, divisé peu profondément en deux parties. 5 étamines à filamens un peu courbés. Anthères larges et grisâtres. Style saillant. Fruit capsulaire, sans aucune aspérité, de la même forme que celui de la stramoine en arbre, contenant beaucoup de semences comprirées, entourées d'une espèce de pulpe sèche.

* Variété à feuilles glabres. Portlandia hexandra, Hortul, Bot. cult. , éd. Ire, t. II. Erreur.

Cult. Serre chaude. Le solandra peut aussi passer en serre tempérée; mais il est quelquefois sujet à perdre l'extrémité de ses branches. Dans la serre chande, il faut le placer près des jours, et avoir attention de le nettoyer lorsqu'il commence à pousser des pucerons qui ne tardent pas à couvrir ses jeunes feuilles. Sa terre doit être plus consistante que légère. Il demande des arrosemens assez fréquens dans le temps de sa végétation, et l'on ne doit lui en donner que de très-modérés dans le temps de son repos. L'humidité le faisant chancir, on le multiplie par ses graines semées au printemps sur couche chaude et conduites comme tous les autres semis de cette serre; par boutures en pot dans une bonne couche ombragée. Elles s'enracinent au bout de six semaines. Il faut ne les faire qu'au moment où cet arbrisseau commence à enfler ses boutons; en feuilles elles ne réussissent pas aussi bien. Dans le temps de son repos elles sont susceptibles de pourrir avant le temps de la pousse. Pendant l'été cet arbrisseau doit sortir de la serre cliaude et jouir d'un air pur.

$\boldsymbol{C}^{\top} s$. Cet arbrisseau mérite d'être cultivé pour la beauté de son feuillage, et sir-tout pour ses grandes fleurs odorantes. Il est vrai qu'ainsi que celles des stramoines elles durent peu de temps, cependant plus long-temps qu'elles.

\section{Fruit is baie.}

\section{Mandragore, Mandragora.}

Cal. turbiné., 5- de. Cor du double plus longue, camp., 5-fide. Etam. insérćes su fond de la cor., à flamens dilatés à leur 
base et connivens, filiformes et divariqués à leur sommet.

Ovaire garni de 2 glandes à sa base. Stign. en tête et sillonné.

Baie globuleuse, entourée à sa base par le réceptacle.

* Mandragore sans tige, $M$. acaulis. Atropa maindragora;

LINNÉ.

Racine longue, grosse, fusiforme, fourchne. Feuilles rad. ov.-lanc., pointues, grandes, très-entières, un peu ondulées, glabres. Fleurs solitaires, droiles, d'un blanc pourpré, au sommet des péd. rad. Baie ronde, de la grosseur d'une pomme.

Lieu. Le Levant, l'Europe mérid. $\nVdash$. Fl. en mars et avril.

Cult. Cette plante demande une bonne terre franche et profonde : sa racine s'enfonçant beaucoup en terre, s'y conserve plusieurs années quand le froid ne l'attaque pas. Sa situation favorable est le pied d'un mur exposé an midi. Quand la gelée est un peu forte, il faut la couvrir de litière. Ses graines mûrissant dans nos climats, se sèment aussitôt après leur maturité, en pots qu'on rentre pendant l'hiver à l'abri du froid. Elles levent en février, et les jeunes plantes peuvent être plantées à demeure l'automne suivant. Elles ne fleurissent qu'au bout de 4 à 5 ans.

Us. La mandragore n'est cultivée que comme objet de curiosité. Elle n'a aucun agrément. Elle est narcotique, et l'écorce de sa racine est très-purgative : elle est peu employée à cause de son danger. Lorsqu'elle porte beaucoup de pommes, ces fruits étalés sur la terre produisent un effet remarquable. Les limaces en sont très-friandes.

Toutes les vertus attribuées autrefois aux racines de cette plante sont de pures fables.

\section{Belladone, Acropa.}

Cor. du double plus longueque le cal., camp. 5-fide. Filamens des étam. filiformes, à anthères courtes. Stigm. en tête, à 2 sillons. Baie obronde, attachée au calice.

* r. Belladone commune, A. belladona.

Cette plante, haute de 4 à 5 pieds, forme un buisson ouvert, large et étendu. Sa tige est très - branchue, grosse et épaisse. Feuilles ovales, pointues, grandes, entières, pét., molles, pu- 
bescentes, Fleurs brunes, péd., ax., sol. Baies noires, pleines. de jus.

Lieu. Forêt de Boulogne. Ind. ₹. Fl. en juin et juillet. Commune en France.

* 2. Belladone d'Espagne, $A$.frutescens.

Arbrisseau de 4 à 6 pieds. Tiges grisâtres, rameuses, tor tueuses, en buisson. Feuilles pét., alt., arrondies, en cœur, presque obtuses. Fleurs jaunâtres, sol. ou 2 ou 3 ensemble, ax.

Lieu. L'Espagne. Đ. Fl. en juillet et août, ou, selon Aiton, en janvier-mars.

Cette différence de temps de la floraison vient de la température qu'on lui donne.

* 3. B. à feuilles de nicotiane, $A$. arborescens. Cestrum cama. panulatum, LAM.

Arbrisseau rameux, dont l'écorce est grisâtre et le bois. moelleux. Feuilles alt., presque sess., ov.-lanc., molles, trèsen ieres et vertes. Fleurs blanchâtres, tubulées, pédonculées et axillaires.

\section{Lieu. L'Amérique mérid. Ђ.}

Cult. La belladone $x^{\text {re }}$ ne se culive que dans les jardins de. bolanique. Elle vient dans presque tous les terrains, et se multiplie elle-même par ses semences et ses longues racines. La $2^{e}$ est de serre tempérée. Elle n'est point délicate. Sa terre doit être consistante, et les arrosemens ne doivent pas lui manquer en été. On l'obtient de graines semées au printemps sur couche; les jeunes plants mis en pot et conduits à la manière indiquée. On peut la mettre en plein air en même temps queles autres plantes ả'orangerie, et l'y laisser pendant le même temps. La $3^{\mathrm{e}}$ est de serre chaude, mais elle peut passer en serre tempérée. On la. Ėime comme la $2^{\mathrm{e}}$, et on la conduit de même.

Us. Les fruits de la $\mathrm{I}^{\mathrm{re}}$ sont extrêmement dangereux. Ils ont donné la mort à plusieurs enfans qui en ont mangé. Cependant jeferai observer que cette plante étant assez commune, et les baies plènes d'un suc doux, invitant à les prendre et à les sucer, il est étonnant qu'il n'arrive pas plus d'accidens aux enfans, qui $\mathrm{m}^{2}$ en connoissent nullement le danger. Elle est narcotique ar. 
premier degré. Le remède est l'émétique et ensuite le vinaigre étendu d'eau. Les autres espèces sont cultivées moins pour l'agrément que pour la variété.

En Italie on fait avec le suc des fruits de la $1^{\text {re }}$ une espece de fard dont les femmes se servent comme cosmétique. C'est ce qui lui a fait donner le nom de belladona, ou belle-dame.

On cultive encore au Muséum la belladone couchée, $A$. pro. cumbens, C.av... Elle est du Mexique et $\odot$.

\section{Nicandra.}

Cal. à 5 angles et à 3 divisions. Corolle grande, canepanutée, presque à 5 lobes. Filamens des étamines filiformes, dilatés a leur base et rapprochés au-dessus de l'ovaire. Anthères ovales. Baie sphérique, d'une consistance presque sèche, entièrement couverte par le calice aggrandi, à 5 angles comprimés.

* NICANDRA phigsalodes. Atropa physalodes, Lin., Bot. cult., éd. I ${ }^{\text {re. }}$ Physalis, Mrller, Lamarck.

Tige anguleuse, forte, de 4 à 5 pieds, jaunâtre ou pourprée et rameuse, formant un large buisson. Feuilles oblongues, pointues, sinuées, anguleuses, d'un vert jaune. Fleurs grandes, d'un bleu léger, presque entières. Calices fermés et à angles aigus.

Lieu. Le Pérou. $\odot$. Fleurit en juillet-septembre.

Cult. La même que celle des stramoines an nuelles.

\section{Coqueret, Physalis.}

Cal. 5-fide. Cor. en roue, 5-fide. Anthères oblongues, conniventes. Stigm. obtus. Baie globuleuse, enfermée dans le caw lice agrandi en forme de vessie. Plusieurs sem. réniformes.

$$
\text { I. Espéces } 4 \text { ou b. }
$$

* 1. Copunret alkekenge, $\boldsymbol{P}$. alkekengi.

Plante très-traçante. Tiges d'un pied, rameuses. Feuilles pét. Qvales, pointues, enlières et géminées. Fleurs blanches, sol: 
ax. Baie rouge, ainsi que le calice vésiculeux qui la renferme, de la forme et de la grosseur d'une cerise.

Lieu. La France. $\Psi$. Fl. en juillet-septemb.

2. Coquerét de Pensylvanie, $\boldsymbol{P}$. pensyluanica.

Tiges d'un pied, droites, rameuses. Feuilles pét., alt., oval., obtusément anguleuses en leurs bords, vertes, un peu cotonneuses en-dessous. Fleurs jaunes, sol., péd., ax. Baies petites, rouges.

Lieu. L’Amérique sept. ₹ . Fl. id.

* 3. C. de Curaçao, P. curassavica.

Tige d'un pied. Feuilles ovales, pét., ondées, pubescentes, grisâtres. Fleurs jaunâtres, sol., ax., péd.

Lieu. L’Amérique mérid. ₹. Fl. id.

* 4. C. visqueux, $P$. viscosa.

Tige de 2 pieds, rameuse, paniculée. Feuilles pét., ovales, ondées, obtuses, un peu cotonneuses. Fleurs jaunâtres, avec des taches jaunes, ax., sol., péd. Baies ovales, orangées, visqueuses.

Lieu. L'Amérique, Buenos-Ayres. $\%$. Fl: en juillet.

5. C. du Pérou, P. peruviana.

Tiges élevées, à rameaux divergens, pubescentes ainsi que les feuilles, qui sont cordiformes, très-entières. Fleurs jaunes, avec 5 taches brunes, sol., pendantes, péd.

Lieu. L'Amérique mérid. Ђ. Fl. en avril-oct.

6. C. barbu, P. aristata, H. K.

Tige frutescente. Feuilles oblongues, entières, glabres; les rameaux, les pétioles et les pédoncules lanugineux. Les dents cal. barbues.

Lieu. Les îles Canaries. ๖. Fl. . .

7. C. somnifère, $P$. somnifera.

Tiges d'un à deux pieds, rameuses, cotonneuses, grisâtres. Feuilles pét., ovales, entières, molles, pubescentes. Fleurs d'un jaune pâle, petites, 3 à 5 ensemble, ax., péd.

Lieu. Le Levant, l'Espagne, le Mexique. ๖. Fl. en juillet et août. Toujours vert.

* 8. C. arborescent, $\boldsymbol{P}$. arborescens.

Tige de 4 à 5 pieds, rameuse; les rameaux tortueux. Feuilles 
ovales, presque obtuses, ondées, pét., d'un vert grisâtre. Fleurs jaunâtres avec des taches brunes, péd., rassemblées, ax., roulées.

Lieu. Les environs de Campèche. Fl. en juillet. Toujours vert.

\section{Espèces}

9. C. anguleux, $P$. angulata.

Tiges d'un à deux pieds, tendres, anguleuses, glabres et très-rameuses. Feuilles pét., ovales, pointues, anguleuses, glabres et point luisantes. Fleurs petites, d'un jaune pâle, avec des taches roussâtres, ax., sol., perdantes.

Lieu. Les deux Indes. Fl. en juin-septemb.

10. C. pubescent, $\boldsymbol{P}$. pubescens.

Tiges d'un pied et demi, succulentes, anguleuses, trèsrameuses, pubescentes. Feuilles ovales, pét., anguleuses, molles, velues, visqueuses, d'un vert sombre. Fleurs petites, jaunâtres, avec des taches d'un pourpre foncé, ax. , pendantes.

Lieu. Les deux Indes et la Virginie.

II. C. couché, $\boldsymbol{P}$. prostrata, JACQ. , L'HÉRIT'.

Tiges couchées, très-rameuses, cylind., hérissées de poils blancs, d'un pied. Feuilles alt., un peu ovales, molles, glabres, un peu charnues. Fleurs violettes, ax., péd., veinées de pourpre.

Lieu. Le Pérou. Fl. en août et septemb. 12. C. nain, $P$. minima.

Tiges d'un pied, très-rameuses. Feuilles presqu'en cœur, pointues, un peu anguleuses, péd., molles. Fleurs petites, jaunâtres, avec 5 taches brunes, ax.; les péd. plus longs que les feuilles.

Lieu. Les Indes orient. Fl. en juillet et août. 15. C. de Barbade, P. barbadensis.

Tiges de 2 à 3 pieds, velues, creuses, cylind. Feuilles pét., cordiformes, pointues, molles, velues. Fleurs jaunes, avec des taches brunes, ax., sol.; les pédoncules plus courts que les pétioles.

Lieu. Les Antilles. Fl... 
14. Coqueret velu, $P$. pruinosa.

Tiges très-rameuses. Feuilles velues. Les pédoncules droits. Anthères jaunes. Baies presque turbinées:

Lieu. L'Amérique. Fl. en juillet et août.

15. Coqueret à gros fruit, P. phyladelphica, Lam

Lieu. L'Amérique sept. $\odot$. Cultivé au Muséum.

Cult. Dans la première section, les espèces I et 2 sont de pleine terre; les $3,4,5$ et $8^{e}$, de serre chaude; les 6 et $7^{\mathrm{e}}$ d'orangerie, ou mieux de serre tempérée. Parmi les coquerels de la seconde section, excepté le $10^{\ominus}$ et le $15^{\mathrm{e}}$, les autres sont délicats. Ceux qui sont de serre demandent une bonne terre, très-peu d'arrosemes en hiver, et de la chaleur en été. Ils craignent l'humidité lorsqu'ils sont en serre. Tous s'obtiennent et se multiplient par leurs graines, qui mûrissent dans nos climats, et que l'on sème, en pot et sur coucbe, pour les espèces de serre et les nière ordinaire indiquée. Les espèces $\psi$ se plaatent en pots; les ou restent sur des couches, ou se plantent en terre légère et substantielle à une bonne exposition. La première ne se mulviplie que trop d'elle-mểme dès qu'une fois on an a un pied; il z'est pas facile ensuite de la détruire.

$U_{S}$. Les coquerets, excepté le premier, que l'on cultive pour son utilité dans un coin, ne se trouvent guère que dans les jardins de bolanique. Ils ne font aucun effet agréable. Les baies de la première et de la septième sont très-diurétiques, anodines et rafraîchissantes; cependant, comme elles sont d'une famille qui n'est pas des plus innocentes, on ne doit pas en faire un trop grand usage. On les emploie en infusion. Il est à. présumer que les fruits des autres especes ont a-peu-près les. mêmes propriétés.

\section{Witheringia, L'HśriT.}

Galice en godet et presqu'à 5 dents, persistant. Corolle à tube court avec / f fosseties melliferes en dedans; l'entrée du tùbe fermée de poils; le limbe divisé en 4 parties ouvertes; 4 étaaines alternes, avec les fossettes attachées au milieu du 
tube, à filamens courts, velus, et des deux côlés de leur base appendiculés. Anthères conniventes, oblongues. I style. x stigmate en crête. Baie à 2 loges et plusieurs semences.

IVITHERINGIA solanacea, L'HÉRIT., WILLD.

Tige herbacée, cylindrique, anguleuse, un peu velue, d'ur. rouge terne, de 2 à 3 décimètres. Feuilles alternes, un peu velues, pétiolées. Fleurs d'un jaune pâle, à divisions du limbe marquées de 3 lignes, disposées en ombelles multiflores, axilo laires et sessiles. Filamens blancs, velus en dedans, glabres a l'extérieur.

Lieu. L'Amérique mérid. \%.

Cult. Serre chaude.

\section{Morelle, Solanum.}

Cal. 5-fide. Cor. en roue, à tube court, à limbe plas grand, ouvert, 5-fide. Antlières oblongues, conniventes, s'ouvrant ark sommet par 2 trous. Sligm. obtus. Baie obronde ou oblongue, ponctuée à son sommet.

\section{Espèces sans piquans, 廿 ou}

* 1. Morelle à feuilles de molêne, S. verbascifolium.

Arbrisseau de 7 à 8 pieds. Tiges droites, rameuses. Feuilles ovales, pointues, épaisses, veloutées, cotonneuses, vertes endessus, blanches en-dessous. Fleurs nombreuses, blanches, en ombelle term.

Lieu. L'Amérique mérid. ๖. Fl. . Toujours vert.

*2. M. auriculée, S. auriculatum, H. K.

Cette espèce n'est qu'une variété de la précédente; elle n'en differe que par deux stipules en forme d'oreillettes axillaires, e par les fleurs en grappe. Les oreillettes tombent souvent, et toutes les feuilles n'en sont pas garnies.

Lieu. L'île de France. ๖. Fl... Toujours verte.

3. M. effilée, $S$. virgatum, LAM.

Tiges et rameaux effilés, dichotomes. Feuilles ovales, arron- 
dies à leur base, pointues, pét., entières, cotonneuses en-deso sous. Fleurs violettes.

Lieu. Les îles Canaries. 1 .

* 4. Morelue diphylle, S. diphyllum.

Arbuste de 5 pieds. Tige noirâtre, rameuse, à 2 nervures Iongitudinales. Feuilles géminées ou ternées, l'une plus petite que l'autre, opp., entières et glabres. Fleurs petites, blanchâtres, en cîmes opposées aux feuilles. Baies orangées.

Lieu. Les Indes occident. Ђ. Fl. en juin et juillet. Toujours vert.

* 5. M. lycioïde, S. lycioides, Encycl.

Tige et rameaux diffus, étalés; les anciens terminés par une pointe dure. Feuilles alt., lanc. - pointues, éparses, petites, entières, glabres. Fleurs à 5 pointes, jaunes, qui débordent le limbe qui est blanc; sol., péd., ax. Ces fleurs ne s'ouvrent qu'une fois. Baies petites, rouges.

Lieu. L’Amériq. mérid. \%.

Cet arbrisseau a l'aspect d'un liciet, et pourroit former un genre distinct.

*6. M. faux piment, S. pseudocapsicum. Amomum vulg.

Petit arbrisseau rameux, de 5 à 4 pieds. Fenilles lanc., entières, molles, un peu sinuées, pointues. Fleurs blanches, sol. ou en petites ombelles, portées sur de courts pédoncules. Baies rouges, de la grosseur d'une cerise.

Lieu. Madere. Ђ. Fl. en juin-sepiembre. Tonjours vert. 7. M. ramassée, S. aggregatum, LAMARcK. Atropa solanacea,

Lix. Mant, Willd.

Arbuste de 4 à 6 pieds, peu rameux. Feuilles disposées par paquets à l'enároit des nœud̉s, orales - obl., entières, lisses et coriaces. Fleurs d'un bleu p âle, sol. Raies jauncs.

Lieu. La Guinée. 5.

* 8. M. à gros fruit, S. macrocarpon.

Tige anguleuse, d'wn piod. Feuilles grandes ct sinuées. Fleurs grandes, bleues. Baies jaunes, de la grosenur d'une pomme.

Lieu. Le Pérou. 7 r ou Fl. en août.

* 9. M. à feuilles de chêne, S. quercijolium 
Tiges anguleuses, droites, rameuses, d'un pied et demi. Feuilles obl., décurrentes, pinnatifides, plus ou moins profondément. Fleurs violettes, en grappes terminales. Baie ovale.

Lieu. Le Pérou, $¥$ ou $\odot$. Fl. en juillet.

10. M. laciniée, S. laciniatum, H. K.

Tige sous-ligneuse, très-glabre. Feuilles pinnatifides; les fol. lanc., aiguës. Fleurs en panicule axillaire, au nombre de $x$ ou 3.

Lieu. La Nouvelle-Zélande. $₹$. Fl. en juillet et août.

* II. M. radicante, $S$. radicans.

Plante rampante, qui s'enracine à ses nœuds. Tiges foibles, couchées, lisses et rameuses. Feuilles pinnatifides, assez grandes et glabres. Fleurs petites, violettes, en grappes, à l'opposẻ des feuilles. Baies rouges.

Lieu. Le Pérou. $\nsucc$. Fl. id.

* 12. M. à corymbes, $S$. corymbosum.

Tige de 2 pieds, épaisse, anguleuse, rameuse. Feuilles éparses, entieres, décurrentes sur le pétiole, pointues, ovales, glabres. Fleurs petites, violettes, en panicule ax.

Lieu. Id. $\%$. Fl. id.

23. M. à feuilles lancéolées, $S$. subinerme, H. K.

Tige ligneuse. Feuilles lanc. - elliptiques, très-entières, glabres en-dessus, cotonneuses en-dessous. Fleurs en cîmes farineuses.

Lieu. Les Indes occid. F. Fl. id.

I4. M. à verrues, S. muricatum, L'HérITIER, H. K. S. scabrum, LAM.

Tige ligneuse, radicante; les jeunes pousses verruqueuses. Feuilles obl.-lanc., entières, pubescentes. Baies turbinées, panachées.

Lieu. Le Pérou. Ђ. Fl.

* I5. M. douce-amère, S. dulcamara. Vigne de Judée.

Tige de 7 à $S$ pieds, sarmenteuse, grimpante. Fenilles alk. pét., oblongues, cordiformes, entières ou divisées. Fleurs vislettes, en grappes. Baies rouges.

Lieu. Ind. 5. E1. en juin et juillet. 
Variété à feuilles épaisses et velues, de l'Afrique:

Variété de la première à feuilles panachées.

* I6. Morelite de Buenos-Ayres, $S$. Bonariense.

Tige presque sans piquans, point du tout sur les rameaux anciens, de 8 à ro pieds; les rameaux droits et d'un brun noir. Feuilles alt., pét., ovales - cbl. , pointues, ondées, sinuées, un peu échancrées à leur base. Fleurs blanches, grandes, en corymbe au sommet des rameaux. Baies orangées.

Lieu.Buenos-Ayres. ๖. Fl. en juin-sept. Toujours vert.

\section{Espèces armées de piquans, $¥$ oü 5 .}

* I7. M. sodomée, S. sodomaum.

Arbrisseau de 3 pieds. Tiges et rameaux roides; courts, armés de piquans jaunâtres; les rameaux noirátres. Feuilles presque ailées, profondément découpées en lobes obtus et réguliers, munies de piquans des deux côtés, d'un vert foncé. Fleurs violettes ou bleues, en panicules. Baies d'abord panachées de blanc et de vert, jaunes ensuite.

Lieu. Le Cap. ๖. Fl. en juin et juillet. Toujours vert.

* I8. M. de Caroline, S. caroliniense, Michaux.

Tige de 2 pieds, légèrement velue, armée de piquans jaunấtres. Feuilles grandes, ovales, aiguës, découpées en lobes pinnatifides, garnies de piquans. Fleurs assez grandes, bleues ou blanches.

Lieu. La Caroline. $\%$. Fi. en juillet-sept.

* I. M. hérissonne, S. aculeatissimum, Encycl., WiLld.

Tige de 3 à 4 pieds, rameuse, hérissée de piquans très-aigus, d'un brun violet, et si nombreux qu'ils la couvrent dans toute sa longueur. Feuilles cordiformes, anguleuses, molles, velues, hérissées des deux côtés des mêmes piquans. Fleurs blanches, en petites ombelles latérales. Baies d'abord variées de blanc et de jaune, noires ensuite.

Lieu. La zône torride. 5. Fl. en juillet. Toujours verte. * 20. M. pyracanthe, S. pyracantha, Encycl.

Tige ligneuse, blanchâtre, cotonneuse dans sa jeunesse, raa meuse, armée, ainsi que les branches, de piquans nombreux, 
longs et roides, d'une couleur de feu aurore. Feuilles longues, étroites, pointues, cotonneuses, sinuées, garnies des mêmes piquans, principalement sur leur nervure. Fleurs d'un bleu clair, en corymbes latéraux. Baie d'un rouge pâle.

Lieu. L'île de Madagascar. Ђ. Fl. en' août. Toujours verte. 21. M. à feuilles de stramoine, $S$. stramonifolium, H. K.

Tige ligneuse, de 6 pieds; rameaux couverts de duvet, garnis de piquans bruns et rares. Feuilles très-grandes, en cœur, anguleuses, lobées, presque nues, un peu cotonneuses en-dessous. Fleurs d'un bleu pâle.

Lieu. Les Indes occid. Ђ. Fl. en juin-sept. Toujours verte. * 22. M. des Indes, $S$. indicum.

Tige de 3 pieds, d'un brun pourpre, armée de piquans courts, jaunâtres, élargis à leur base. Feuilles ovales, un peu sinuées, anguleuses, cotonneuses en-dessous, quelques-unes entières, garnies de piquans droits sur la nervure. Fleurs bleuâtres, en grappes. Baies petites, écarlates.

Lieu. Les deux Indes. $\$$. Fl. en juillet. Toujours verte. 25. M. de Palestine, $S$. sanctum.

Tige de 3 pieds, cotonneuse, garnie de grosses épines courtes et jaunâtres; rameaux diffus. Feuilles cotonneuses, blanchâtres, sinuées et lobées, bordées de poils, presque sans piquans. Fleurs grandes, violettes. Baies rouges, petites.

Lieu. L'Egypte. Ђ. Fl. en juillet. Toujours verte. * 24 . M. bordée, S. marginatum.

Tige de 6 à 8 pieds, forte, droite, couverte dans sa jeunesse, ainsi que les rameaux, d'un duvet blanc, garnie de piquans fermes et épars. Feailles grandes, munies de piquans, cordiformes, un peu épaisses, blanches et cotonneuses en-dessous, d'un beau vert en-dessus, avec une bordure blanche, légèrement sinuées et ondées. Fleurs grandes, blanches, en grappes un peu pendantes; la plupart stériles; une ou deux sur chaque grappe, fertiles ; on les connoît aisément à leur calice plus grand et hérissé. Baies d'abord marbrées de blanc et de vert, jaunes ensuite, de la grosseur d'une pomme.

Lieu. L'Afrique. . Fl. tout l'été. Toujour verte. * 24 bis. M. à épines blanches, S. argyracantha. III. 
Cette espèce a des rapports avec la morelle bordée par la forme de ses fleurs, leur disposition, et par la situation de ses épines. Tige droite, grosse, ferme, rameuse, couverte, ainsi que les rameaux, les pédoncules et les pétioles, de petits paquets de duvet cotonneux, et tous armés, ainsi que les principales nervures des feuilles, d'aiguillons blancs et crochus. Feuilles pétiolées, alternes, ovales, presqu'en cœur à leur base, obtusément pointues, sinuées en leurs bords, cotonneuses sur les deux surfaces. Fleurs violettes, de la grandeur de celles de la morelle bordée, pédonculées, axillaires, solitaires ou géminées. Le limbe divisé en six parties et plissé. Le plus souvent 6 étam. courtes qui ne se réunissent pas en pointe à leur sommet. Calice à 6 ou 7 divisions, cotonneux, couvert de petits aiguillons, plus gros dans les fleurs fructifères que dans celles où le fruib avorte, comme il arrive dans l'espece précédente.

Lieu.... ๖. Fl. en été, la tige n'ayant encore que quatre pouces de hauteur.

* 25. Morelle cotonneuse, S. tomentosum.

Tige de 2 pieds, un peu fléchie, garnie ainsi que ses rameaux, de piquans courts et fins. Feuilles cordiformes, ondées, entières, arrondies, cotonneuses, grisâtres, sans piquans. Fleurs bleues, en grappes latérales au sonmet des rameaux. Baie jaunes.

Lieu. Id. Ђ. Fl. en juillet et août. Toujours verte. 26. M. roide, $S$. rigidum, LAM.

Tige roide, droite, d'un pied, armée de piquans droits et courts. Feuilles ovales, aiguës, ondées, sinuées, garnies sur leurs côtẹ́s, de piquans nombreux, droits, roides, blanchâtres. Fleurs blanches, en grappes.

\section{Lieu..... b.}

* 27 . M. à piquans rouges, $S$. igneum.

Tige de 3 pieds, rameuse, armée d'épines rouges qui se perdent, ainsi que celles des feuilles, par la culture. Feuilles lanc., pointues aux deux bouts, très-entières, un peu ciliées. Fleurs blanches, en grappe. Baies rouges.

Lieu. L'Amérique mérid. Ђ. Fl. tout l'été. Toujours verte.

* 28. M. gigantesque, S. giganteum, Encycl., JAce. 


\section{ES SOE A I E ES.}

Tige droite, de 4 à 5 pieds, hérissée de piquans courts', ‘̂gus, élargis à leur base. Feuilles grandes, lanc., pointues, trèsentières, sans piquans, vertes en-dessus, blanches et cotonneuses en-dessous. Fleurs d'un violet pâle, en corymbe terminal et droit. Baies rouges, petites.

Les feuilles de cette espece deviennent glabres en serre chaude.

Lieu. Le Cap. Ђ.Fl. en août et sept. Toujours verte. 29. M. naine, $S$. humile, Encycl.

Tige droite, très-rameuse, d'un pied et demi ; les rameaux armés de piquans blanchâtres, droits, roides et nombreux. Feuilles presqu'ovales, sinuées, à lobes obius, irréguliers; chargées de piquans de chaque côté. Fleurs violettes, en grappes latérales.

\section{Lіеи... Б.}

3o. M. sarmenteuse, S. sarmentosum, Encycl. S. lancecefolium, $\mathbf{J}_{\mathrm{ACQ}}$.

Tige sarmenteuse, droite, cylind., armée de piquans courts, de ro pieds. Feuilles ovales-lanc., entières, aiguës, glabres, sans piquans, géminées, une plus petite que l'autre. Fleurs blanches, en grappes latérales. Baies rouges.

Lieu. L'Amérique mérid. ' 5 .

3r. M. de Campèche, S. campechiense.

Tige de 2 pieds, rameuse, pourprée, garnie de piquans nombreux. Feuilles grandes, oblongues, en cour, à 5 lobes obtus, blanchâtres en-dessous. Fleurs blanches, un peu violettes, stériles et fertiles. Fruits blancs.

Lieu. L'Amérique. ๖. Fl。 en juillet.

\section{Espèces sans piquans, 害。}

3. M. tubéreuse. Pomme-de-terre. S. tuberosum.

Racine tubéreuse; tige tendre, très-rameuse, en buisson. Feuilles ailées avec impaire; les fol. ovales, très-entières, pointues, glabres. Fleurs blanches ou violettes.

Lieu. Le Pérou. FI. en juillet-sept.

Plusieurs variétés dans la couleur des tubercules. 
33. Hortule pomme-d'amour, S. Iycopersicum. Tomate.

Tige de 2 ou trois pieds, trè-rameuse, tendre, cassante Feuilles ailées avec impaire; les fol. incisées, glabres. Fleurs en grappes simples. Le limbe de la corolle à 7 divisions. Fruit rouge, très-gros, comprimé au sommet et à sa base, profondément sillonné sur les côtés, rempli d'un jus acide.

Lieu. L'Amérique mérid. Fl. en juillet-sept. 34. M. noire, S. nigrum.

Tige d'un à 2 pieds, anguleuse, très-rameuse. Feuilles ovales, pointues, dentées, anguleuses, molles, sol. ou géminées. Fleurs petites, blanches, en petites grappes latérales et penchées. Baies moires.

Lieu. Ind. Commune. Fl. en juillet.

Tariétés. * I. M. à baies jaunes, $S$. villosum.

Lieu. Les Barbades.

Rameaux cylind., velus. Feuilles anguleuses un peu velues.

* 2. M. à grosses baies noires, $S$. guineense.

Lieu. La Guinée.

Rameaux anguleux, dentés. Feuilles trés entières, glabres.

3. M. à petites baies noires, $S$. virginicum.

Lieu. La Virginie.

Rameaux anguleux, dentés. Feuilles ondées, glabres.

* 4. M. à baies rouges, $S$. rubrum.

Lieu. Les Indes occid.

Tige glabre. Feuilles obl., ovales, acuminées, dentées, glabres. Fleurs en ombelles penchées.

* 35. II. d'Ethiopie, S. athiopicum.

Tige dure, rameuse. Feuilles ovales, anguleuses, ondulées. Fleurs blanches, en corymbes latéraux; les péd. uniflores̀ et penchés. Baies rouges, à côtes arrondies.

Lieu. L'Ethiopie, la Chine. Fl. en juillet. * 36. M. aubergine, Melongène, $S$. melongena.

Tige d'un pied environ, rameuse, cotonneuse, rougeâtre ou 
verte, selon la couleur du fruit qu'elle porte. Feuilles ovales, pointues ou obtuses, sinuées, pét., un peu cotonneuses. Fleurs solitaires, ou 2 ou 3 ensemble sur les péd. divisés, pendans, épais et blanchâtres; blanches ou bleues. Fruit alongé, cylindrique, long de 5 à 7 pouces, ferme, violet ou jaune, et pendant.

Variété à fruit blanc, de la forme exactement d'un œuf de poule. Plante à œuf, $S$. melongena ovifera.

Lieu. L’Asie, l’Afrique, l’Amérique. Fl. en juillet.

\section{Espèces munies de piquans,}

37. M. mammiforme, S. mammosum.

Tige de 3 à 4 pieds, garnie d'aiguillons et de poils. Feuilles grandes, inégalement lobées, anguleuses, velues, armées de quelques piquans. Fleurs blanches, éparses sur la tige, d'un bleu pâle. Fruit jaune, pendant, de la grosseur d'une prune.

Lieu. L'Amiérique nérid. 58. M. ciliée, S. ciliatum, H. P., LAM.

Tige droite, un peu ciliée, garnie de piquans droits, trèsaigus. Feuilles larges, en cœur, sinuées, anguleuses; les lobes pointus, glabres; ciliées en leurs bords, armées de piquans. Fleurs petites, bleuâtres, en petites grappes.

Lіеи....

Cult. Dans la $\mathrm{r}^{\mathrm{re}}$ section des morelles vivaces, les espèces $\mathrm{r}$, $2,4,5,7,8,10,12,13$, I 4, sont de serre tempérée ; et, excepté la $5^{\mathrm{e}}$, à la réserve de sa variété d'Afrique, toutes les autres sont d'orangerie. Dans la seconde section, les espèces 20 , $2 \mathrm{I}, 22,23,27,30$, sont de serre tempérée. Les autres de cette section sont d'orangerie. L'espèce r 9 est un peu délicate, et dans les hivers froids et humides elle seroit mieux en serre tempérée. Cependant toutes ces morelles ne demandent pas une température égale à celle qu'on donne ord. aux serres tempérées. Elles se conservent généralement beaucoup mieux, s'étiolent moins, et deviennent plus robustes dans un degré de température plus bas. Leur terre doit être consistante et substantielle. Lcurs arrosemens fréquens en été, rares en hiver ; et, pendant 
cette saison, elles doivent jouir de tout le jour qu'il est possible deleur donner. On les sort en été avec les plantes délicates d'orangerie, et elles restent en plein air à une exposition chaude depuis le mois de juin jusqứa la fin de septembre. On les multiplie toutes parleurs graines, qui mûrissent ordinairement dans nos climats. On les sème en terrine sur couche en mars ou avril, et quand les jeunes morelles sont assez fortes, on les plante chacune dans un pot, qu'on plonge dans une couche ombragée pour accélérer Ieur reprise. Au bouŕ d'un mois elles peuvent être traitées comme les vieux pieds. Les espèces annuelles de la 马e et fe $^{\mathrm{e}}$ section se sement sur couche en avril, et leurs jeuncs. plantes ou restent sur la mểme couche, ou se repiquent dans des planches de bonne terre légere, à l'exposition du midi, pour y fleurir et fructifier. Les espèces 35,36 et 37 sont plus délicates, et exigent plus de chaleur pour qu'elles portent leurs fruits. à la maturité.

Toutes les morelles qu'on cultive en serre doivent être changées de vases tous les ans au moins; il en est même qu'il faut dépoter deux fois par an. Elles font toutes beancoup de racines.

La pomme-de-terre, qui est de toutes les morelles la plus utile, a plusieurs variétés, qui consistent dans leurs tubercules; les. principales sont :

1. La rouge; très-gros tubercule.

2. Lagrosseblanche.

3. La marbrée de ces deux couleurs.

4. La noire, ou plutôt violette, c'est-à-ảire, la peau.

5. La petite ronde et blanche.

La $i^{\text {re }}$ et la $3^{\text {e }}$ sontcelies qu'on cultive le plus ordinairement pour les bestiaux. Parmi les autres, la noire est préférable, parce qu'elle est grosse, point dure, et n'a point un goût fort. La petite ronde est pour le moins aussi bonne, et elle a l'avantage d'être précoce, et de pouvoir être employée en juin; mais elle est petite, et par conséquent pas aussi profitable.

On cultive la pomme-de-terre en plein champ et cans les potagers La meilleure manżere de la cultiver en plein champ me. paroît ềtre celle-cì.

Après avoir donné à la terre qui doit la reevoir tous les. 
labours d'hiver nécessaires pour aneublir la terre, et la nettoyer de toutes les herbes et racines vivaces; après l'avoir hersée, on forme avec le binot des sillons profonds, droits, à 2 pieds environ de distance les uns. des autres. Cette opération, qui se fait à la fin de mars ou au commencement d'avril dans le nord de la. France, étant achevée, on charrie des engrais bien consommés ou de vieux fumiers dans les sillons qu'on arrange avec la fourche dans leur fond. L.orsque les sillons sont tous amendés, on plante les pommes-de-terre sur ces engrais à 2: pieds de dis. tance, et la plantation faite, on les recouvre en tracant des sillons, avec la même charrue, dans les intervalles. Ce labour fait, les sillons qui contiennent les pommes-de-terre sont presqu'entièrement remplis; mais on a soin d'unir la terre, en faisant passer la herse plusieurs fois dans le champ.

A mesure que les pommes-de-terre élèzent leurs tiges, on trace de nouveaux sillons dans leur intervalles pour les butter Car plus on renouvelle cette opération, plus les pommes-deterre produisent de tubercules; leur quantité et leur grosseur sont toujours en raison des engrais, et sur-tout des facons qu'on leur donne, en leur fournissant de temps en temps de nouvelle terre.

Dans les potagers, on fume simplement le terrain avant de les planter, et l'on fait des trous à un pied et demi de distance les uns des.autres en quiconce, dans lesquels on plante la pomme, que l'on recouvre ensuite au rateau. Ceite manière est aussi très-bonne; mais quelle que soit celle qu'on empioie, I'essentiel est de butter les plantes, de les travailler et de les nettoyer.

La pomme-de-terre se plante dans son entier, ou coupée par morceaux, de maniere que chaque morєeau contienne au moins un nœud ou œillet.

Us. La plupart des morelles de serre sont assez agréables pan leur feuillage et leurs fruits. Parmi elles on distingue les espèces $\mathrm{x}, 5,6,36, \mathrm{x} 7,19,20,2 \mathrm{x}, 22,24,25,27$ et 28 ; -

Latrente-troisième est cultivée, dans la France méridicnale, pour l'usage de ses fruits. On en fait des potages qui ontlan couleur d'un jus d'écrevisses. 
La trente-sixième l'est par curiosité, sur-tout sa variété, dont le fruit est fort remarquable, et si semblable à un œuf, qu'on s'y tromperoit facilement. C'est un aliment rafraîchissant employé dans le midi.

Tout le monde connoît l'usage de la pomme-de-terre. Ce tubercule farineux et nourrissant peut suppléer au pain. On en fait beaucoup de préparations très-agréables, légères el saines. Sa fécule s'obtient en râpant les tubercules frais dans l'eau. Elle tombe au fond du vase; et après l'avoir entièrement dépouillée de toutes autres matières, en la lavant plusieurs fois, et ôtant l'eau par inclinaison, elle devient d'un blanc pur. Elle est alors très-nourrissante. On en fait des gelées douces et légères, qui conviennent aux convalescens. C'est un amidon de la plus grande blancheur, et meilleur que celur des autres farines.

La plupart des fruits des morelles sont narcotiques et dangereux à l'intérieur.

\section{Autres espèces cultivées.}

3. Morelle à feuiles de sauge, S. salvifolium, Encycl, sect. I. Arbrisseau. Feuilles sesșiles, ovales-oblongues, pointues, d'un vert foncé, un peu blanchâtres en-dessous. Fleurs blanches, velues, pédonculées, en grappe. Toutes les parties de la plante sont couvertes d'un duvet formé par de petits poils waissans, au nombre de 7 à 8 , de chaque glande.

Lieu. La Guyane fançaise. ๖.

Cult. Serre chaude.

* 40. M. inclinée, S. reclinatum, H. P., sect. I.

Tige grosse, d'un vert noir, herbacée, d'un pied et plus, cannelée par la décurrence des pét. , et fourchue. Feuilles alt., grandes, pinnatifides ; les pinnules longues, étroites, presque linéaires, terminées en pointe obtuse, opposées; la terminale plus longue que les autres; décurrentes sur leur pétiole, qui court lui-même sur la tige, d'un vert noirâtre. Fleurs blenes, grandes, pédonculées, en grappes axillaires, vers le sommet de la tige, et quelques-unes sclitaires. Toute la plante est ir ès-glabre. 
Les fleurs sont légèrement inclinées.Le fruit assez gros et jaune. Lieu. . . . 低. Fl. en juillet.

* YI.M. à feuilles de bette, S. betaceum, C.Av., Icon, sect. I. Tige de 8 à I 0 centimètres, cylindrique, charnue, succulente, glabre, simple jusqu'au sommet, ou elle se divise en rameaux. Feuilles grandes, ovales, pointues; quelques-unes lobées à leur base, très-entières, d'un vert foncé, glabres et planes. Fleurs blanches, opposées aux feuilles, d'un rose pâle, en bouton, disposées en. grappes pendantes, un peu velues; les divisions du limbe roulées à leur sommet. Baies ovales, de la grosseur d'un œuf de pigeon; d'abord vertes, rayées de brun, ensuite rouges.

Lieu.... ๖. Fleurit en été.

* 42. M. de Bahama, S. bahamense, section 2.

Tige cylindrique, rameuse, armée de piquans. Feuilles pétiolées, lancéolées, sinuées, obtuses, d'un vert léger en-dessus, munies sur leurs nervures de longs piquans en alêne. Fleurs blanches ou violettes, en grappes droites à l'extrémité des rameaux. Fruit jaune, dans sa maturité de la grosseur d'un pois.

Lieu. Les îles de l'Amérique. Ђ.

* 43. M. à feuilles de chalef, $S$. eleagnifolium, CAv., Icon. WILld, section 2.

Tige ligneuse, cylindrique, tomenteuse, blanchâtre, sans aiguillons dans sa jeunesse, en acquérant ensuite. Feuilles alternes, ovales-oblongues; les supérieures très-entières, sans piquans; les inférieures sinuées, munies d'aiguillons sur leur nervure et sur leur pétiole; blanches en-dessous, vertes en-dessus. Fleurs bleues, disposées en grappes, à divisions roulées à leur sommet. Anthères non conniventes. Baies globuleuses, jaunes, glabres, marquées d'un point à leur sommet.

Lieu. L'Anaérique méridionale. b. Fleurit en été et en automne.

* 44. M. à feuilles lancéolées, S. lanceolatum, CAv., Icon., sect. 2 .

Tige d'un mètre environ, ligneuse, cylindrique, rameuse, cotonneuse, munie d'épines rares et courtes. Feuilles alternes, lancéolées, très-entières, cotonneuses en-dessous. Fleurs d'un 
bleu pâle, à divisions étroites et obtuses à leur sommet, disposées en panicule terminal; baies globuleuses, de la grosseur d'un pois.

Lieu.... Ђ. Fì. en été.

* 45. Morelle coagulante, S. coagulans, L. Willd, sect. 2 . Tige ligneuse, cotonneuse, armée d'épines longues, droites et jaunâtres. Feuilles éparses, oblongues, sinuées, ondulées, à lobes arrondis, entiers et cotonneux; armées de piquans vers leurs bords. Fleurs disposées en grappes situées le long des tiges. Calice très-velu et très-épineux. Baie de la grosseur d'une noix, globuleuse, jaune et glabre.

Lieu. L'Arabie. 5 .

Les Égyptiens emploient ses baies pour faire cailler promptement le lait.

* 46. M. violette, S. violaceum, Orteg A, sect. 2.

Tige droite, ligneuse, cylindrique, rayée de gris et de brun, verdâtre, cotonneuse dans sa jeunesse, armée, ainsi que ses. rameaux très-courts et d'un brun violet, d'aiguillons à crochets, forts, jaunâtres, recourbés. Feuilles alternes, pétiolées, échancrées en cœur à leur base, ovales, obtuses, largement sinuées, munies sur leurs nervures d'aiguillons droits, piquans, violets à : ur base, légèrement colonneuses. Fleurs violettes, au nombre de 6 à 7 grappes, opposées aux feuilles. Pédoncules épineux. Divisions du limbe ondulées en leurs bords. Antheres réunies. Calice court, épineux.

Lieu.... 万.

* 4. . I. aquatique, S. aquaticum, H. P., sect. 2.

Tige droite, grosse, ferme, simple ou rameuse, cylindrique, d'un violet noiratre, velue, parsemée d'aiguillons droits et un peu courbés, forts et piquans. Feuilles alternes, pétiolées, grandes, cordiformes, largement et profondément' sinuées ou lobées, garnies des mêmes aiguillons sur leurs nervures et sur. leur pétiole, longues et larges de 2 décimetres et demi, velues, un peu molles, d'un vert gai.

Lieu.... h. 
On cultive encore plusieurs autres espèces de morelle que je ne ferai qu'indiquer ici.

\section{PREMIERESECTION。}

48. M. du Pérou, S. peruvianum. - Le Pérou.

49. M. triangulaire, S. triquetrum. Ђ. La Nouvelle-Espagne,

$\mathrm{C}_{\text {AV. }}$. Cette espèce est grimpante et a des rapports avec la douce-amère.

5o. M. à feuilles épaisses, S. crassifolium, LAM. Ђ. Le Cap. 5 r. M. nodiflore, S. nodiflorum, JACQ. 马. L'ille de France. 52. M. à grandes fleurs, $S$. grandiflorum. b.

SECOIDE SECTION.

55. M. écarlate, S. coccineum, JAcQ. 万. L'Asie. 54. M. polygame, $S$. polygamum, VALH. Ђ. L'Amér. mérid. 55. M. lépreuse, $S$. leprosum, Ortega. Ђ. Le Chili. 56. M. de Miller, S. milleri, JAcQ. Ђ. Le Cap. 57 . M. cunéiforme, $S$. cuneifolium, JAcQ. 万. Le Pérou.

On connoît I 40 espèces de ce genre.

Cult. Serre chaude ou tempérée. La même que celle des autres morelles qui exigent cette température. Elles se multiplient de mêrne par leurs graines qui mûrissent ordinairement dans nos jardins.

En général, les morelles sont des plantes dont beaucoup d'amateurs et même de jardiniers abandonnent ou du moins négligent la culture, parce qu'elles offrent moins d'avantages qu'elles ne demandent de soin. On les cultive dans les écoles et les jardins ce botanique établis pour l'instruction; mais il est rare d'en trouver une grande collecion daas ceux des amateurs. Le degré de chaleur qu'elles exigent pour la plupart, le défaut qu'elles ont presque toutes de se chancir dans un air qui ne peut être, en hiver, assez renouvelé pour elles, de se charger de kermès, de cochenilles et de tous les insectes qui infestent les serres, éloignent nécessairement de leur culture. Cependant il en est dont le feuillage, les fleurs et les fruits font un effet assez remarquable pour inviter à leur donner le traitement qui leur convient. Quand on 
a de grandes serres, et plusieurs de différentes grandeurs et températures, on peut les cultiver avec succès en leur en destinant une où elles puissent avoir un air pur ou souvent renouvelé, et le degré de chaleur qui leur est favorable. Alors cette collection ne laissera pas que d'être intéressante par la réunion des différentes formes, des diverses couleurs de leurs fleurs et de celles deleurs fruits sur-tout, qui produiront une agréable variété. Mais il n'appartient qu'aux souverains et aux Plutus de ce siècle, qui cependant rarement destinent leurs richesses à la culture, à posséder ces différentes constructions. Les amateurs se contenteront des espèces les plus faciles, et de celles qui, par leurs qualités, peuvent le plus les dédommager de leurs soins, telles, par exemple celles que j'ai désignées à la fin de la culture de cet article.

\section{Nycterium, Vent.}

Cal. 4 à 5-fide. Corolle irrégulière, 4 à 5-fide. 4 à 5 étamines à filamens très-courts, à anthères inégales; l'inférieure plus. longue et penchée. Style penché. Baie obronde.

NYCTERI UM cordifolium, VENT. Solanum vespertilio, H. K.,

WILLD., Bot. cult., éd. 1., n $3_{\text {I }}$.

Tige droite, cylindrique, d'un gris cendré, hérissée d'aiguillons, d'un mètre environ de hauteur, rameuse; les rameaux alternes, axillaires, couverts aussi d'aiguillons rapprochés, bruns et courts. Feuilles alternes, pétiolées, en cœur, ovales, aiguës, ondées, chargées de quelques piquans, d'un vertfoncé etvelues en-dessus, drapées en-dessous. Fleurs peu nombreuses, de couleur lilas, imitant celles des papilionacées, disposées en corymbe lâche et ouvert. Baie de la forme d'une cerise.

Lieu. Les Canaries, où cet arbrisseau est connu sous le non de realgareta. Toujours vert. Fleurit en été.

Cult. Orangerie. La même que celle des morelles qui ne sont pas délicates, comme celle de Buenos-Ayres.

\section{Piment, Capsicum.}

Cal. , cor. , anthères et stigmate de la morelle. Baie presque sèche; de formes variées. Semences comprimées. 
* 1. Piment ánnuel. Piment des jardins. Corail des jardins. Poivre de Guinée, C. annuum.

Tige d'un pied environ, anguleuse, foible, rameuse. Feuilles lanc., obl., pointues, entières. Fleurs bianches. axill., péd. Fruit rouge.

Variétés. x. A fruit arrondi et glabre.

2. A fruit ovale.

5. A fruit alongé.

Il y a encore plusieurs autres variétés.

Lieu. Les Indes. Fl. en juillet et août.

2. P. à baies, C. baccatum.

Tige frutescente, lisse, rameuse. Pédoncules géminés. Petit fruit rouge.

Lieu. Id. Đ. Fl. en juin-sept.

3. P. à fruit en cœur, C. grossum.

Tige sous-ligneuse. Fruits charnus, en cœur et de forme variée.

Lieu. Id. ₹. F1. en juillet.

Variété. P. abaissé, C. deflexum.

* 4. P. en arbrisseau, C. frutescens.

Tige de 2 à 3 pieds, très-rameụse, glabre; les rameaux droits et verts. Feuilles petites, lanc.-pointues, molles, entières. Fleurs petites, blanches, sol., péd. Fruits rouges, ovales, droits.

Lieu. Id. Ђ. Fl. en juin-sept.

5. P. cerise, C. cerasiforme.

Cette espèce a de très-grands rapports avec la précédente, dont elle ne paroît différer que par ses fruits, qui sont globuleux, de la grosseur d'une cerise, rouges ou jaunâtres. C'est un arbrisseau sous - ligneux, rameux et glabre, dont les feuilles sont alternes, lancéolées, pointues, et les fleurs d'un blanc jaunâtre.

Lieu. Le Brésil. ๖. Fleurit id.

On cultive encore une autre espèce nommée piment violet, $C$. violaceum : elle est de la Chine et $\sigma^{\top}$. An capsicum sinense, Willd.?

Cult. La première se cultive souvent dans les jardins, $\mathrm{O}_{\mathbf{x}}$ la 
sème au printemps sur couche. Lorsqu'elle a 4 ou 5 feuilles, on la plante soit sur une couche, soit en bonne terre légère, et à une exposition très-chaude. Les fruits se forment en août et septembre. Cette plante exige beaucoup de chaleur, et l'on ne peut avoir de beaux fruits qu'en la lui donnant.

Les autres pimens sont de serre chaude. Ils demandent une bonne terre, des arrosemens fréquens en été, et peu en hiver. On les multiplie par leurs graines semées sur couche en pot ou terrine, sous châssis, et conduites à la manière des morelles. Ces plantes peuvent rester dehors pendant 3 ou 4 mois, à une bonne exposition. Leurs fruits sont mûrs en hiver.

Us. Les fruits des pimens sont âcres, brûlans, aromatiques , digestifs. On les confit dans le vinaigre. On en met souvent dans les cornichons, auxquels ils donnent un bon goût.

Les espèces b contribuent à la diversité des serres pendant l'hiver, par leurs fruits d'un beau rouge. Elles exigent beaucoup de lumiere dans cette saison.

\section{Liciet, Lycium.}

Cal. en godet, court, 5-fide ou à 5 dents. Cor. plus longue, tubulée, à limbe droit, à 5 lobes, ou plane à 5 part. Filamens des étam. enflés et velus à leur base, insérés au milieu de la cor. Anthères obrondes. Stigm. à 2 sillons. Baie obronde. Sem. réniformes.

* i. Liciet de Chine, L. chinense, Lamafok. L. barbarum, H. K. Var.

Tige de 8 à $\mathbf{2} 2$ pieds, dont les rameaux très-nombreux, longs et flexibles, sont anguleux, un peu épineux, violets dans leur jeunesse. Feuilles alt., petites, ovales, pointues, molles, entières. Fleurs d'un violet purpurin, ordinairement 2 au 3 ensemble et latérales. Cal. 5-fide. Etam. plus longues que le style.

Lieu. La Chine. §. Fl. tout l'été.

* 2. L. à feuilles étroites, L. barbarum. Jasminoïde.

Cette espèce ne differe de la précédente que par ses feuilles un 
peu plus larges; par ses fleurs d'un blanc pourpré, et principalement par ses calices, qui sont 3-fides. Etam de la longueur du style.

Lieu. Id. l'Afrique, l'Europe. Ђ. Fl. id.

3. L. d'Europe, L. europaum.

Tige de 6 à 8 pieds, formant un buisson irrégulier et diffus; les rameaux épineux, blanchâtres. Feuilles obl. -lanc., succulentes, glabres, obliques et d'un vert cendré. Fleurs petites, blanchâtres, latérales.

Lieu. La France mérid. Ђ. Fl....

* 4. L. d'Afrique, L. Afrum. Jasmin d'Afrique vulg.

Arbrisseau de 6 à 8 pieds, très-rameux, diffus, en buisson irrégulier; les rameaux roides et blanchâtres, garnis de forts piquans. Feuilles linéaires, très-étroites, d'un vert blanchâtre. Fleurs d'un violet foncé, à long tube et latérales.

Lieu. L'Espagne, le Cap. Ђ.Fl. une partie del'été. Toujours vert.

Variété. L. charnu, L. carnosum, Duhamez. L. ilalicum, Miller. L. rigidum, Thunb.

Cet arbrisseau, dont on fait une espèce, ne paroît différer du précédent que par sa moindre élévation. Ses tiges et ses rameaux sont droits. Ses feuilles, formées de même, sont charnues. Ses baies sont sphériques.

Lieu. Le Cap. Ђ.

* 5. L. glauque, L. boerhaaviafolium. Ehretia halimifolia, L'HéRIT.

Tige droite, de 5 à 6 pieds et plus, rameuse, glabre; les jeunes rameaux blanchâtres; les vieilles tiges d'un brun noirấtre. Feuilles alt., ovales, très-entières, pointues, d'un vert glauque, blanchâtres. Fleurs d'un violet clair, en panicules terminaux, odorantes.

Lieu. Le Pérou. Ђ. Fl. en avril. Toujours vert.

Cult. Les 3 premières espèces sont de pleine terre. Les 2 premières sont depuis long*temps cultivées dans les jardins. Elles viennent dans tous les terrains, et se multiplient très-facilement, et souvent trop abondamment, par leurs drageons, qui 


\section{CLASSEVIII. OR DRE VIII.}

poussent en grand nombre et très-loin de leurs pieds. On lẹs arrache en automne, pour les planter à l'endroit qu'on leur destine. Ce sont des arbrisseaux très-rustiques et très-vivaces. La $3^{\mathrm{e}}$ est moins répandue, mais sa culture est la même. La $4^{\mathrm{e}}$ est d'orangerie, et n'en demande que les soins ordinaires; elle n'est pas du tout délicate. On l'obtient et on la multiplie par ses semences mises sur couche, en pot, et conduites à la manière indiquée; par boutures et par marcoltes; mais ces deux moyens sont peu sûrs et ne valent pas l'autre. Sa variété se cultive et se propage de même. La $5^{\mathrm{e}}$ est de serre tempérée, où elle est mieux qu'en serre chaude, parce qu'elle y est sujette à s'étioler en hiver; elle passe d'ailleurs fort bien dans cette serre, et peut être dehors pendant tout l'été. Je l'ai multipliée avec succès par les boutures faites en pot sur couche ombragée ou en tannée, dans les mois de mai et de juin.

Us. Les 2 premiers liciets sont ordinairement employés dans les jardins à garnir des murs et des berceaux. En les taillant tous les ans, et les élevant à tige simple, qu'on laisse se couronner de ses rameaux nombreux, ils font un effet agréable par le nombre de leurs fleurs et leurs branches pendantes; mais en automne il faut raccourcir ces dernières. Quand la q est bien fleurie, son aspect ne laisse pas que de plaire; mais l'arbrisseau a toujours une forme irrégulière, sur-tout quand on l'abandonne à sa nature. La dernière se fait remarquer par la couleur de son feuillage, et par ses fleurs odorantes, dont elle est cependant avare.

LYCIUII japonicum. $V$. serissa.

\section{Cestreau, Cestrum.}

Cal. court, en godet, à 5 dents. Cor. plus longue, infund., à tube grêle, un peu dilaté; à limbe plissé et 5-fide. Filamens des étam. insérés au milieu de la cor., nus à leur base, souvent denticulés, non saillans. Anthères arrondies. Stigm. obtus. Baie ovale, à 2 loges. Semences obrondes.

* r. Cestreau de nuit, C. nocturnum. Galant de nuit. Tigedroite, cylind., de plus de 6 pieds, peu rameuse. Feuilles 
aì., pét. , ovales, pointues, entières, d'un vert forcé et molles. Fleurs verdâtres, en faisceaux, péd., ax.

Lieu. L'Amérique mérid. Ђ. Fl. en nov. Toujours vert. * 2. C. de jour, C. diurnum. Galant de jour.

Tige de 8 à ro pieds, rameuse, grisâtre; les rameaux droits; pubescens. Feuilles alternes, pét., ovales-obl., pointues, trèsentières, fermes, douces au toucher. Fleurs blanches, en faisceaux ombelliformes, péd., ax. et term., odorantes. Etamines nues.

Lieu. Id., la Havane. Ђ. Fl. id. Toujours vert.

* 3. C. du soir, C. vespertinum, L'Hérit , H. K. Galant du soir. C. confertum, Mrller.

Tige de 8 à ıo pieds, blanchâtre, rameuse. Feuilles obl., ovales, un peu obliques à leur base, éparses, d'un vert pấle; péd. très-courts. Fleurs d'un blanc violet, en faisceaux ombelliformes; le tube long, filiforme; les étamines nues, d'une odeur de vanille, sur-tout le soir.

Lieu. L'Amérique mérid. F. Fl. en mai-juillet. Toujours vert.

* 4. C. à feuilles de laurier, C. laurifolium, L'Hérit. C. venenatum, Lamarck. An sp. distincta?

Tige droite, rameuse, cylind., grisâtre. Feuilles larges, elliptiques, arrondies, irès-entières, fermes, coriaces, très-lisses et d'un beau vert. Les pétioles noirs; cette couleur, s'étendant sur la nervure des feuilles, forme une opposition remarquable. Fleurs d'un jaune pâle; les péd. plus courts que les pét. Etam. presque nues.

Lieu.Id. Ђ. Fl. en août. Toujours vert.

Le cestreau à larges feuilles, cestrum macrophyllum, VENT., que cet auteur a jugé assez différent de celui à feuilles de laurier pour en faire une espèce, a le même port. Ses feuilles sont un peu plus grandes, moins coriaces. Ses fleurs sont absolument sessiles et d'un blanc de lait lorsqu'elles viennent de s'ouvrir, et les filamens sont pourvus d'une petite dent. Du reste, cette espèce ressemble à la précédente, et le temps de sa floraison est le même.

Elle est originaire des Antilles, b et toujours verte. 
* 5. Cestreau à oreillettes, C. auriculatum, L'HÉrit., H. K.

C. hediunda, H. P., LArr. An sp. distincta?

Tiges de 4 à 5 pieds, grisâtres, glabres; les rameaux droits, garnis d'oreillettes stipulaires. Feuilles pét., obl.-lanc., pointues, très-entières, molles, d'un vert jaunâtre. Fleurs verdâtres, avec une teinte rougeâtre, en faisceaux term. et ax. Etamines nues.

Lieu. Le Pérou. Ђ. Fl. en juin. Toujours vert.

* 6. C. à baies noires, C. jamaicense, Lamarck. C. parqui, L'Hérițer.

Tiges droites, rameuses, grisâtres. Feuilles lanc., pointues, étroites, onciulées en leurs bords, alt., pét., vertes. Point de stipules. Fleurs jaunes, odorantes, bien ouvertes en étoile; leur limbe bordé de blınc, en faisceaux ombelliformes, ax. , odorantes.

Lieu. Les Antilles. Ђ. Fl. en mars. Toujours vert.

Ces deux espèces semblent dériver l'une de l'autre.

Cult. Serre chaude on tempérée. Ces plantes viennent très-bien

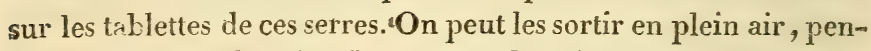
dant les 3 mois de l'été. Leur terre doit être bonne et consistante; les a rosemens fréquens. Dépotées au moins une fois par an, à cause de la quantité de racines qu'elles font. Multiplication par les boutures faites en pot sur couche ou dans une tannée; elles s'enracinent fort aisément : la $4^{\text {e }}$ seulement est plus Iong-tem 1 's à faire des racines, mais elle en a au bout de 3 mois. Les autres fleurissent la même année qu'on a pianté leurs boutures.

$L^{i} s$. Les cestreaux n'ont pas de fleurs bien saillantes; la $2^{\mathrm{e}}$ et 1a $6^{\mathrm{e}}$ en portent cependant d'assez agréables, et qui ont une odeur douce. Mais ils varient les serres par leur feuillage, et sur-tout la $4^{e}$ espèce, qui en a un remarquable par sa fraîcheur et sa netteté.

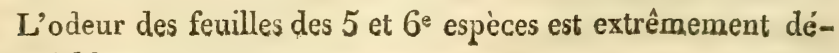
sagréable. 


\section{Autres espèces cultivées.}

* 7. C. ondulé, C. undulatum, Fl. péruv.

Tiges droites, grises, cylindriques, peu rameuses. Feuilles alternes, pétiolées, lancéolées, pointues, ondulées, fermes, très-glabres, d'un vert luisant en-dessus, pâle en-dessous; le pétiole brun. Fleurs d'un jaune pâle, odorantes, en grappes ou faisceaux o mbelliformes, axillaires, presque sessiles. Leur odeur approche de celle du muguet.

Lieu. L'Amérique mérid. . Toujours vert Fleurit en hiver.

Cult. La même que celle de la quatrième espèce, à laquelle elle a des rapports.

J'ajoute à la culture des cestreaux qu'une bonne serre tempérée leur suffit en hiver; encore les espèce 5 et $6^{\mathrm{e}}$ peuvent-elles passer non-seulement en orangerie, mais même en pleine terre, contre un mur, ou dans tout autre endroit exposé au midi. C'est ainsi qu'on les cultive en Bretagne et à Paris. On fera bien cependant de les couvrir de litière à l'approche de la gelée, et d'en conserver des individus en vase pour les suppléer en cas de perte.

Autres espèces décrites par J ACQUIN, Hort. Schoenb., mais qui ne se trouvent dans aucun de mes auteurs.

8. C. velu, C. hirsutum, $\mathrm{J}_{\mathrm{ACQ}}$.

Arbuste d'une odeur fétide. Tige cylindrique, droite, de 8 pieds. Feuilles lancéolées, pointues, très-entières, cotonneuses en-dessous, de 5 pouces de longueur. Fleurs vertes, inodores, sessiles, en faisceaux pédonculés, axillaires.

Lieu. . . Fl. en avril.

9. C. cauliflore, G. cauliflorum, J J

Tige rameuse, frutescente, glabre, cendrée, de 3 pieds. Feuilles elliptiques, pointues, très-entières, de 3 à 7 pouces de Iongueur. Fleurs odorantes, blanches, pédonculées, rassemblées sur les tiges, nues et axillaires.

Lieu. Fl, en avril-mai.

I0. C. à feuilles de saule, $C$. salicifolium, $\mathrm{J}_{\mathrm{ACQ}}$. 
Arbrisseau glabre', de 5 pieds. Rameaux nombreux. Feuilles alternes, linéaires-lanc., pointues, acuminées, de 5 pouces de longueur. Fleurs vertes, pédiculées, en panicules axillaires.

Lieu. Caraque. Fl. en nov.-déc.

j I. Cestreau pendant, C. pendulinum, JacQ.

Arbrisseau giabre. Plusieurs tiges rameuses, de 6 pieds, foibles ainsi que les rameaux, qui pendent naturellement. Feuilles elliptiques, très-entières, de 2 à 3 pouces. Fleurs vertes, sessiles, paniculées, terminales.

Lieu. Les Indes occidentales. Fl. deux fois l'année. Les fleurs ont, pendant la nuit, une odeur agréable.

12. C. très-fétide, C. foetidissimum, JAcQ.

Arbrisseau glabre. Plusieurs tiges droites, de Io pieds de haut. Feuilles alternes, ovales-lanc., très-entières, planes, mincès, très-fétides. Fleurs jaunâtres, pédonculées, solitaires ou réunies jusqu'au nombre de six, axillaires et terminales.

Lieu. Id. Fl. odorantes pendant la nuit. 13. C. non fétide, C. odontospermum, $\mathrm{J}_{\mathrm{ACQ}}$.

Arbrisseau glabre. Tige rameuse, droite, de 6 pieds. Feuilles alternes, lancéolées, pointues, très-entières, fermes, planes, de 3 à 4 pouces. Fleurs d'un blanc de neige, sessiles, pédonculées, terminales et axillaires.

Lieu... Fl. en septemb. 14. C. en faisceau, C. fastigiatum, JACQ.

Arbrisseau glabre. Tige droite, de 4 pieds. Feuilles oblongues, pointues, très-entières, luisantes, d'un beau vert, de 3 pouces de longueur. Fleurs blanches au sommet des tiges en faisceaux, pédonculées, axillaires. 5. C. teinturier, C. tinctorium, $\mathrm{J}_{\mathrm{ACQ}}$.

Arbrisseau glabre. Tige droite, de 4 pieds. Feuilles ov.-lanc., très-entières, pointues, planes, luisantes, de 3 pouces de longueur. Fleurs blanches, en grappes axillaires et termin.

Lieu. Caraque. Fl. deux fois l'année.

Cult. Ces 8 dernières espèces sont de serre chaude, et vraisemblablement elles doivent être cultivées comme les premières, 4 : depuis long-temps et mieux connures : elles sont cultivées Vienne. 


\section{Genres qui ont des rapports avec les solanées.}

\section{Daphnot, Bontia.}

Cal. petit, 5-fide, persistant. Cor. beaucoup plus longue, tubulée, à limbe à 2 lèvres ; la sup. droite, échancrée; l'inf. roulée, velue et à moitié trifide. 4 étam. didynamiques. I style. Stigm. à 2 lobes. Baie en forme d'olive, acuminée, spongieuse, à 2 loges à 2 parties, dont chacune contient I ou 2 sem.

* Daphnot des Antilles, B. daphnoides. Olivier bâtard. Arbrisseau dont le tronc, dans son pays naturel, devient trèsgros, et dont les rameaux sont nombreux et glabres. Feuilles alt., éparses, obl., étroites, lisses, vertes, un peu épaisses. Fleurs d'un jaune rougeâtre, ax., sol.

Lieu. Les Antilles. Ђ. Fl. en juin. Toujours vert.

Cult. Serre tempérée. Cet arbrisseau s'étiole et pousse : contre-temps dans la serre chaude maintenue à son degré ordinaire. Sa terre doit être bonne, et en même temps consistante; celle employée pour toutes les plantes d'orangerie lui convient. Les arrosemens doivent lui être épargnés lorsqu'il ne pousse pas, et, comme les daphnés, il denuande un air souvent renouvelé. On le multiplie par ses graines, que l'on tire de son pays originaire, ou d'autres où elles mûrissent, et que l'on sème seIon la manière indiquée pour les plantes de cette température; et par boutures que l'on fait au printemps dans des pots sous cloches ou sous châssis. Elles s'enracinent assez facilement.

Us. Cette plante, toujours verte et d'un assez beau port, est cultivée chez les amateurs de végétaux étrangers. Il est assez difficile de lui faire passer l'hiver sans qu'elle ne s'étiole, ou que ses rameaux ne s'altèrent, à moins de la mettre dans une serro maintenue au $8 \mathrm{e}$ degré, et oì l'air se renouvelle aisément.

\section{Brunsfel, Brunsfelsia.}

Cal: camp., court, à 5 dents. Cor grande, infund., ả trés long tube; à limbe plane, un peu ringente, et á 5 lobes inéro- 
gaux. 5 étam. inégales, dont une stérile. Anthères réniformes. I style. Stigm. en tête. Baie plus grosse qu'une cerise, à une loge polysperme. Le réceptacle séminifere, charnu.

\section{* Brunsfeld d'Amérique, $B$. americana.}

Arbre de la grandeur du pommier dans son pays originaire. Dans nos serres il ne forme qu'un arbrisseau de 6 à 8 pieds. Feuilles alt., ovales, obl., très-entières, épaisses, d'un vert terne. Fl. grandes, d'un blanc pur et mat, qui devient jaune en sefanant; 2 ou 3 ensemble au sommet des tiges et des rameaux.

Lieu. La Martinique. Đ. Fl. en été. Toujours vert.

Variété à feuilles étroìtes, cultivée à Londres.

Cult. Serre chaude; bonne terre plus forte que légère; peu d'arrosement en hiver. On ne doit le dépoter que lorsqu'il en a absolument besoin, parce qu'il souffre alors, et qu'il est aussitôt attaqué par les cochenilles. Il aime beaucoup la chaleur, et ne fleurit bien que lorsqu'on la lui donne. Mult. par les boutures faites au moment ou l'arbre entre en sève. Elles sont enracinées au bout de deux mois, si elles ont été coupées sur de jeunes rameaux en vigueur. On les fait en pot qu'on plonge dans une tannée et qu'on ombrage, ou sous des châssis de couche chaude.

* 2. B. ondulé, B. undulaia, Swartz, Willd. B. grandiflora, Hort. lond.

Tige droite, d'un gros brun et gercée. Rameaux cylindriques. Feuilles alternes, pétiolées, ovales-lancéolées, oblongues, reIevées aux deux bouts, fointues, longues d'un décimètre et demi, fermes, glabres, vertes des deux côtés. Fleurs au nombre de $3 \dot{a} 4$, terninales, presque sessiles. Tube long d'un décimètre, un peu courbé, d'un blanc verdâtre; limbe un peu irrégulier, d'un beau blanc, très-ouvert, de 8 centimètres de diamètre, partagé jusqu'aux deux tiers en 5 divisions, dont les bords sont crénelés, ondulés et même frisés; l'entrée du tube évasée. Etamines guère plus longues que le tube. Anthères réniformes, d'un gris blanchâtre. Ces fleurs ont une odeur infiniment agréable, qui a des rapports à celle des fleurs du jasmin du Cap et du volcameria fragraus. 
Lieu. L'Amérique méridionale. Toujours vert. Fleurit au printemps.

3. B. pourpre, B. purpurea.

4.B. maculé, B. maculata.

Hort. angl.

Lieu. La Jamaïque. $¥$. Cultivés en Angleterre.

Cult. La même que celle du brunsfel d'Amérique.

Les fleurs des brunsfels, sur-tout de la seconde espèce, sont belles et ont une odeur suave. Quand l'arbre est en pleine végétation, elles se succèdent pendant une partie de l'été, et parfument alors la serre; mais ces arbres sont sujets à languir lorsqu'on ne leur donne pas le traitement qui leur convient. Une terre très-substantielle, plus argileuse que noire, des arrosemens fréquens en été et sur leurs feuilles, et la chaleur, sont les bases principales de leur culture, c'est - à - dire les seuls moyens de leur donner de la vigueur et de la leur conserver.

\section{Calebassier, Crescentia}

Cal. à 2 parties égales et caduques. Cor. grande,presque camp., ả tube inégal, ventru et courbé; à limbe droit, 5-fide, inégal; les div. dentées, sin. 4 étam: didynamiques. Anthères penchées. I style. Stigm. en têtte. Baie très-grosse, cucurbitacée, à I loge, à écorce dure, int. pulpeuse. Sem. nombreuses, nichées dans la pulpe, presqu'en cœur, à 2 loges.

I. Calebassier à feuilles longues, $\boldsymbol{C}$. cujete.

Arbre de la hauteurd'un pommier, dont le tronc est tortueax; l'écorce ridée et le bois blanc. Les rameaux nombreux, longs et horizontaux, sont garnis, à chaque noud, de faisceanx de feuilles au nombre de 9 à ro, lancéolées, acuminées, entières. et glabres. Fleurs d'un blanc pâle, sol., pendantes, péd. Les fruits ont depuis 2 pouces jusqu'à I pied de diamètre.

Lieu. Les Antilles, l'Amérique mérid. Ђ. Fl....

Variétés. I. A feuilles étroites. Fruit moins gros, globuleux ou ovale.

2. A fruit dur, petit, de la grosseur d'un œuf. Feuilles ovales. 
2. Calebassier à feuilles larges, C. latifolia, Mrluxr. C. cucurbitana, Swartiz, Willd.

Arbre de 18 à 20 pieds, droit, branchu, à écorce blanchâtre et lisse. Feuilles alt., à pétioles courts, entières, et d'un vert foncé. Fleurs petites, d'un jaune foncé, naissant dans les aisselles des grosses branches. Fruit rond ou ovale, de la grosseur d'un citron.

Lieu. Campèche. G. Cultivé à Londres.

Cult. Serre chaude. Terre substantielle, un peu Iégère. Arrosemens fréquens dans la végétation, presque nuls dans l'état de repos. Cet arbre exige la plus grande chaleur de nos climats; elle ne sera jamais trop forte pour Iui. Pour peu qu'il languisse, il est bientôt attaqué par les insectes. Il demande un air souvent renouvelé. Mult. par ses graines tirées de son pays orig., semées au printemps en pot, sur couche et sous châssis, et conduites à la manière indiquée.

Us. Cet arbre n'est qu'un objet de curiosité en Europe. En Amérique il est très-utile. La pulpe de ses fruits est regardée dans ces pays comme un excellent vulnéraire consolidant. On en fait un sirop qui est spécialement employé dans les maladies de poitrine.

Lorsqu'on a retiré avec l'eau bouillante la pulpe des fruits, its servent alors comme ustensiles de ménage, en assiettes, cuillers, bouteilles, seaux, etc. On les nomme alors couis. C'est sans. doute ce nom qui a fait donner en France à des pots de terre celui de couets.

L'écorce du fruit de la seconde espèce est trop cassante poux être employée à ces usages. Son bois est blanc.

\section{O R D R E I X.}

\section{Les Borraginées ( BORRAGINR̈质)}

Calice à cinq divisions. Corolle ordinairement régulière. Presque toujours cinq étamines. Ovaire 
simple ou quadrilobe. Un style. Un stigmate bifide, ou sillonné, ou simple. Ordinairement quatre semences, tantôt dans un péricarpe capsulaire ou en baie ; tantôt nues, attachées au bas du style, et ordinairement environnées du calice persistant. Embryon sans périsperme.

Herbes, quelquefois arbrisseaux ou arbres. Feuilles alternes, souvent rudes.

\section{Fruit à baie. Tige frutescente ou arborée.}

\section{Patagonule.}

Cal. très-petit, à 5 dents. Cor. en roue, à tube très-court, à limbe plane, à 5 parlies. Anthères arrondies. Style deux fois bifide à son sommet. 4 stigm. Caps, ovale, acuminée, posée sur le calice agrandi, à 5 part.

* Patagonule d'Amérique, $P$. americana. Cordia patagonula, H. K.

Arbrisseau bien garni de branches et peu élevé. Feuilles obl.lanc., glabres des deux côtés, pét., alt., pointues, dentées en scie dans leur moitié supérieure. Les rameaux garnis de poils rares. Fleurs en bouquets terminaux.

Licu. L'Amériq. mérid. Ђ. Fl. en juin-août. Toujours vert.

Cult. Serre chaude. Cet arbrisseau n'est pas délicat, et se multiplie de marcottes et de boutures; il a un peu l'aspect d'un princs ou d'un alaterne. Quoiquej'aie un individut résélevé, je n'ai pas encore vu ses fleurs.

\section{Sebestier, Cordia.}

Cal. tubulé, denté à son sommet. Cor. à tube égal ou plus long, à limbe à 5 part. , rarement à 4 à 8.5 étam., rarement 4 à $\mathcal{E}_{\text {。 }}$ Anthères oblongues. Style deux fois bifide à son sommet. 4 stigm. Fruit accru par le calice, contenant un noyau a $\$ \log e s$ et $4 \mathrm{sem} .2$ ou 3 loges souvent avortées. 
1. Sebestier à feuilles glabres, $C$. mixa, Sebestier domestique: Arbre de la hauteur d'un prunier, dontles feuilles sont ovales, glabres en-dessus, et les fleurs en corymbes latéraux. Calices à Io stries.

Lieu. Les Indes or. , l'Egypte. Ђ. Fl ...

* 2. S. à feuilles rudes, C. sebestena.

Tige de ro à 14 pieds, droite, rameuse à son sommet; cylind., velue, rude dans sa jeunesse et sur ses jeunes rameaux. Feuilles alt., pét, grandes, ovales-oblongues, pointues, planes, rudes au toucher, d'un vert sombre et très - entières. Fleurs d'un rouge aurore, de la grandeur et presque de la forme de celles du laurose, en grappes droites et term.

Lieu. Les deux Indes. . Fl. en mai-juillet. Toujours vert. 5. S. à longues feuilles, C. collococca.

Feuilles ovales, oblongues, très-entières. Fleurs en corymbes. Les calices cotonneux intérieurement.

Lieu. La Jamaïque. Ђ. Fl ...

Cult. Serre chaude et tannée dans leur jeunesse, sur - tout pour les espèces I et 3. La seconde peut se passer de la couche lorsque sa tige est ligneuse. Leur terre doit être consistante, et les arrosemens très-fréquens en été. La seconde, poussant beaucoup en racines et en rameaux, demande à être changée de vase au moins une fois par an. Mult. par leurs graines tirées de leur pays orig., et semées à la manière indiquée pour les plantes de serre chaude, et par les boutures, moyen plus expéditif, faites en pot et en tannée ou dans une couche chaude en mars ou avril. Elles s'enracinent aisément, et prennent jusqu'à I à 2 pieds de hauteur dans la même année, particulièrement l'espèce 2. Celleci, lorsqu'elle a un peu d'âge, peut passer 2 mois de l'été dehors, à une bonne exp., selon Miller; mais si l'on veut avoir une succession de fleurs pendant une partie de l'été, on la tiendra en serre chaude. Cette espèce est une desplus belles plantes que l'on puisse cultiver.

Us. La seconde a beaucoup d'effet dans la serre lorsqu'elle est en fleur. Son feuillage est d'ailleurs large, et la couleur de ses corolles agréable. 
Les sebestes, fruits rafraîchissans, en usage en méd. , viennent de la première espèce.

Miller dit que le bois de la seconde parfume les lieux ou on le brûle. Je l'ai essayé plusieurs fois, et je n'ai jamais senti que l'odeur de bois vert. Peut-être a-t-elle cette qualité dans son pays naturel.

\section{Autres espèces cultivées.}

4. Sebestier à larges feuilles, C. macrophylla, Liv., Miller. Arbre de 40 à 60 pieds ( 15 à 20 mèires), mais dont le tronc n'a pas plus de 18 à 20 pouces de diamètre. Rameaux velus, se bifurquant plusieurs fois et s'inclinant vers la terre. Feuilles alternes, velues, rudes au toucher, longues de 2 à 4 décimètres, entières, pétiolées, bordées de petites dents. Fleurs blanches, tubulées, à 3 divisions arrondies, unilatérales, en grappes, naissant dans les bifurcations des rameaux. 3 étamines insérées au sommet du tube. Anthères vacillantes.

Lieu. Les Antilles, l'Amériq. mérid. ๖. Cultivé au Muséum. 5. S. à feuilles de verveine, $C$. gerascanthus. Vulg. Bois de Chypre.

Feuilles lancéolées, ovales-oblongues, rudes au toncher. Fl. blanches, en grappes terminales. Les calices à ro stries, 5 étam. Lieu. Id. ๖. Cultivé au Muséum.

Les tiges de cette espèce se divisent en rameaux cylindriques, et sont duvetées dans leur partie supérieure.

6. S. denté , C. dentata. An C. spinescens?

Rameaux cendrés, flexueux, couverts de poils roides. Feuilles pétiolées, alternes, assez grandes, légèrement dentées ou anguleuses en leurs bords, d'un vert foncé en-dessus, pâles en-dessous. Fleurs blanches, en grands panicules étalés et terminaux. Cette espèce est fort belle.

Lieu. L’Amériq. mérid. Ђ. Cultivé au Muséum.

On cultive encore les espìces suivantes.

7. S. à feuilles luisantes, C. nitida, VAHL.

8. S. à petites fleurs, C. parviflora, ORtega.

Cult. Serre chaude. Ne cultivant pas ces sebestiers, je ne peux rien dire de particulier sur chacun. Il est probable qu'ils doi- 
vent l'être comme la seconde espèce de ce genre, étant tous de la zône torride.

L'espèce C.scabra d'Andrieux me paroît être la seconde.

L'espèce $C$. obliqua, WiLld, est cultivée à Gênes, chez Madame Durazzo.

\section{Cabillet, Ehretia.}

Cal. 5-fide. Cor. tubulée, à limbe à 5 lobes. Anthères obrondes. I style. Stigm. à 2 lobes. Baie à 4 loges. 4 sem. divisées en deux hémisphères, à 2 loges.

* x. Cabrillet à feuilles de laurier tin, $E$. tinifolia.

Arbre de 20 à 50 pieds. Tronc droit. Cîme epaisse. Feuilies alt., ov. - obl., très-entières, glabres, un peu pointues, nerveuses en-dessous. Fleurs petites, blanches, nombreuses, en Erappes term.

Lieu. La Jamaïque. Ђ. Fl. en février.

* 2. C. bâtard, E. bourreria. Bourreria succulenta, JAcQ. Cordia bourreria, Amæn. Acad.

Arbrisseau de 7 à 8 pieds, irrégulier. Feuilles ovales, trèsentières, vertes, glabres, luisantes, pét. Fleurs blanches, nombreuses, en grappes term., odorantes.

Cette espèce a fleuri dans la serre chaude du Muséum au. commencement de l'automne. Elle avoit alors 2 mètres ( 6 pieds) d'élévation. Ses baies sont de la grosseur d'un pois, lisses et de couleur orangée.

Lieu. Les Antilles. 万. Fl... a

Cult. Serre chaude. Quand ces plantes ont acquis de la force, elles peuvent passer une partie de l'été en plein air. Elles se contentent en hiver de la serre sans tannée. On les multiplie par leurs graines tirées de leurs pays nat., et semées à la manière ordinaire. Elles se propagent aussi facilement de bouiure:

Us. Les cabrillets sont cultivés dans les serres pour y contribuer à la variété. La deuxième est plus agréable que la. première par ses fleurs odorantes; mais l'autre l'est dasantage. par son port.

On cultive actuellement ì Londres une autre espece sous le noun de Ehretia noves. 


\section{Varrone, Varronia.}

Cal. tubulé , à 5 dents. Cor. tubulée, à limbe à 5 part. ouverles. Anthères penchées. I style. 4 stigm. Fruit couvert par le calice, contenant un noyau à 4 loges et $4 \mathrm{sem}$.

1. Varrone à long épi , $\boldsymbol{V}$. curassavica.

Feuilles lancéolées, ridées, assez grandes, alt. Tige sarmenteuse. Fleurs blanches, en épis oblongs et serrés.

Cette espèce ne differe guère de la suivante. C'est un arbrisseau qui s'élève à $\mathbf{2} 2$ à 15 pieds de hauteur, dont les feuilles sont hérissées en-dessus de très-petits tubercules, cotonneuses et douces au toucher en-dessous.

Lieu. L’Amériq. mérid. Ђ. Fl.. .

2. V. de la Martinique, $\bar{V}$. martinicensis.

Cette espèce, qui a des rapports avec la première, a des feuilles plus étroites, pubescentes, ovales, acuminées. Ses épis sont oblongs.

Lieu. La Martinique. ๖.

3. V. à grandes fleurs, $V$. mirabilioides, JAcQ., Swartz,

Willd. $V$. geniculata, Pers.

Feuilles ovales, ridées, dentées en scie. Fleurs grandes, en épis arrondis et inégaux. Corolles en coupe.

Lieu. L'île de Cuba. 5 .

-* 4. V. corymbifere, $V$. corymbosa, Lin. $V$. lineata, Swartz, Willd. $V$. humilis, JAcQ.

Feuilles lancéolées, rétrécies aux deux bouts, velues endessous, rudes en-dessus. Fleurs ể corymbe, dont le pédoncule commun tient à la base du pétiole de la feuille.

Lieu. L'Amériq. mérid. \$.

5. V. velouté, $\boldsymbol{V}$. mollis, Desfont., Cat.

Lieu. L’Amériq. mérid. Ђ. Cultivée au Muséum.

Cult. Serre chaude. Les varrones doivent être cultivées comme les espèces des deux genres précédens : auxquels elles ont beaucoup de rapports. 


\section{Pittone, Tournefortia.}

Cal. petit, à 5 part. Cor. tubulée , à tube globuleux à sa base, à limbe ouvert, 5-fide. Etam. non-saillantes. I style. Stigm. entier. Petite baie ovale, q. f. à 4 côtés, à 2 parties hémisphériques, int. osseuses, à 2 loges. 2 sem.

x. Pittone grimpante, $T$. volubilis, Lam.

Tige sarmenteuse, grimpante, de ro à I 2 pieds. Feuilles ov., pointues, dont le pétiole est réfléchi. Fleurs petites, blanches, en épis rameux, ax. et term.

Lieu. Les Antilles. Ђ. Fl. en juillet.

2. P. naine, $T$ '. humilis, Mrluler.

Tige de 3 pieds. Rameaux grêles. Feuilles lanc., sessiles, rudes, d'un vert sombre en-dessus, pâles en-dessous. Fleurs blanches, en épis ax.

Lieu. L'Amériq. mérid. Ђ. Fl. en juin.

3. P. frutescente, $T$. suffruticosa. $T$. incana, LAM.

Tige de 5 à 6 pieds. Rameaux droits et grêles. Feuilles ov.lanc. , veries en-dessus, cotonneuses en-dessous, sessiles. Fleurs blanches, unilatérales, en épis term. et ax.

Lіеи. La Jamaique. Ђ. Fl.....

* 4. P. à larges feuilles, T. cymosa, Liv. T. macrophylla, Lam. $T$. foetidissima, Miller.

Feuilles assez grandes, ovales-lancéolées, nues. Pédoncules rameux. Fleurs en épis alongés et pendans.

Lieu. Id. Ђ. F1. en juillet.

Tige ligneuse, rude et cylind., de 9 pieds, dont les rameaux sont bruns, rudes et velus. Feuilles alt. , ovales, péc., veineuses et d'un vert foncé. Fl. en épis très-ram. et term. Baies rondes et blanches.

Lieu. L’Amériq. mérid, $\gg$.

5. P. très.velue, $T^{\prime}$. hirsutissima, Swartz.

6. P. arborescente, $T$. arborescens, LAM.

Tiges ligneuses, anguleuses, rudes au toucher. Feuilles pétiolées, alternes, ovales-lancéolées, entières, blanches et cotonneuses en-dessous. Fleurs en épis courts et rameux.

Lieu. L'Inde. Ђ. 
7. P. rude, T. scabra, LAM.

Rameaux grêles, souples. Feuilles petites, pétiolées, alternes, ovales-oblongues, obtuses, très-rudes au toucher, légèrement dentées, ridées et velues en-dessous. Fleurs en épis rameux et term.

Lieu. L'Amérique mérid.

8. P. à feuilles de laurier, Tournefortia laurifolia, Vrnt,; Choix de plantes.

Tiges volubiles, de 3 mètres, cylindriques, rameuses. Feuilles alternes, péliolées, ovales-oblongues, très-entières, pointues, d'un vert foncé en-dessus, longues de 12 cent. Fleurs jaunes, droites, sessiles, distantes, unilatérales, disposées en épis formant, par leur réunion, une cîme termin.

Lieu. Les Antilles. Ђ. Fleurit en été.

Cette espèce a beaucoup de rapport avec la pittone grimpante $\mathbf{n}^{\circ} \cdot \mathbf{x}$.

* 9. P. changeante, Toumefortia mutabilis, Vent., Choix de plantes.

Tige droite, cylindrique, rameuse, d'un gris cendré, blanchâtre et tomenteuse à son sommet, de 6 décim. Feuilles alternes, pétiolées, rapprochées, ovales-lancéolées, poiniues, très-entières, pubescentes, rudes au toucher, d'un vert foncé en-dessus, longues de 8 cent. Fleurs d'un blanc verdâtre, marquées d'une bande noire qui s'étend ensuite sur toute la corolle, droites, serrées, sessiles, unilatérales, pédonculées, formant une cîme droite et terminale.

Lieu. L'île de Java. ๖. Fleurit au printemps.

Cult. Serre chaude.

On cultive encore une autre espèce sousle nom de $T$. lucida.

Cult. Serre chaude. Ces plantes sont cultivées au Muséum et dans d'autres grandes collections de plantes étrangères. Elles ne le sont guère chez les amateurs, parce qu'elles n'ont pas un intérêt assez marqué pour se les procurer. On les obtient de leurs graines tirées de leur pays originaire, et seinées selon la manière indiquée dans les notions préliminaires de cet ouvrage. On peut ensuite les multiplier par les marcottes, t les boutures faites en pots sous châssis. 


\section{Fruit à une ou deux capsules.}

\section{Hydrophylle, Hydrophyllum.}

Cal. à 5 part. Cor. camp., 5-fide, int. sillonnée, à 5 stries, melliferes, bordées, et embrassant les filamens des étamines. Étam. non-saillantes. Anthères oblongues, penchées. Stigm. bifide. Caps. globuleuse, à I loge et I semence; 3 autres avortées.

* I. Hydrophylle pinnée, $\boldsymbol{H}$. virginianum.

Tiges basses, simples, nombreuses, formant de grosses touffes. Feuilles alt. , pinnées, à 5 fol. , dont 3 confluentes à leur base, et les 2 autres libres et lobées, toutes dentées. Fleurs blanches, en grappes courtes et term.

Lieu. La Virginie. ₹. Fl. en mai.

2. H. anguleuse, $\boldsymbol{H}$. canadense.

Cette espèce ne differe de la précédente que par ses feuilles, qui sont palmées, à 5 à $\rceil$ lobes anguleux, dentées et pointues, sess. , glabres et luisantes. Les pédoncules des fleurs sont un peu plus courts.

Lieu. Le Canada. $\%$. Fl. id.

Cult. Pleine terre. Plantes très-rustiques qui croissent dans tous les terrains, et particulierement dans les lieux frais et ombragés. Mult. par leurs graines semées en planches, et par la séparation de leurs pieds en automne ou en février. Elles se sèment souvent elles-mêmes.

Us. Ces plantes, lorsqu'elles sont en fleur, forment des touffes assez agréables; mais elles perdent leurs feuilles de bonne heure, et ne font plus aucun effet dans l'été.

\section{Ellise, Ellisia.}

Cal. profondément 5-fide. Cor. plus petite, infund., 5-fide. Étam. non-saillantes. Anthères obrondes. Stigm. bifide. Caps. coriace, à 2 loges, 2 valves, posée sur le calice étoilé; 2 sem. l'une sur l'autre. 
Ertise de Virginie, E. nyctelea.

Tiges très-rameuses, diffuses, de 5 à 7 pouces. Feuilles alt., pét., pinnatifides, à découpures pointues, avec une dent de chaque côté et velues; leur pétiole canaliculé, semi-amplexicaule. Fleurs blanches, penchées, sol., péd.

Lieu. La Virginie. Fl. Fl: en juillet et août.

Cult. Pleine terre.

\section{Arguze, Messerschmidia.}

Cal. à 5 part. Cor. infund. ou hypocr., à limbe 5-fide, plissé ou. plane. Etam. non saillantes. Anthères subulées, droites. Stigm. en tête. Caps. subéreuse, cylind., émoussée à son sommet, avec un ombilic à 4 dents; se partageant en deux parties hémisphériques, à 2 sern. osseuses.

1. Arguze de Tartarie, M. arguzia.

Petice plante de 5 à 6 pouces, velue, rude, rameuse. Feuilles sess., alt., ovales - oblongues, lanugineuses, blanchâires. Fleurs blanches, infund., en faisceaux corymliformes, term.

Lieu. La Tartarie or., près de la rivière d'Argun, la Sibérie. $\Psi$. Fl. en juin-oct.

* 2. A. frutescente, $M$. fruticosa.

Tiges très-droites, velues, cylindr., rudes an toucher, ainsi que les feuilles, qui sont alt., pét., lanc.-obl., pointues, saliciformes, très-entières et velues. Elles sont presque horizontales. Fleurs nombreuses, blanches, odorantes, en faisceaux ombelliformes au sommet des tiges.

Lieu. Les îles Canaries. Đ. Fl. en juin-oct.

Cult. La I $^{\text {re }}$ est de pleine terre, et se cultive comme toutes les plantes $\tau$ de la famille des borraginées. La $2^{\mathrm{e}}$ est d'orangerie. On l'obtient par ses graines semées sur couche à la mánière indiquée. Les soins ordinaires de l'orangerie lui suffisent. On la multiplie aussi facilement de boutures faites dans la couche destinée à cette voie de propagation. Ses fleurs ont une odeur qui approche de celle du muguet.

On cultive encore au Muséum l'espèce $M$. angustifolia, LAM. Elle est orig. des Canarics, 5 et d'orangerie.

III. 
Ohs. Ces deux derniers genres devroient être, ainsi que Desfontaines les a placés, dans la section précédente,à cause de leurs fruits en baie.

\section{Melinet, Cerinthe.}

Cal. à 5 part. Cor. tubulée, ventrue, 5-fide ; son entrée nue. Antheres droites. I stigm. 2 caps. osseuses, à 2 loges et 2 semences.

* I. Melinet à fleurs obtuses, C. major.

Tiges droites, succulentes, glabres, d'un pied et demi. Feuilles alt. , sess. , amplexicaules, ov.-obl., obtuses, entières, molles, un peu velues en leurs bords et glauques. Fleurs assez grandes, d'un pourpre mêlé de jaune, en épis courts et ax.

Lieu. La France mérid. Fl. en juillet et août.

Variété à fleurs tout-à-fait jaunes, C. aspera. Espèce selon Willn et Roth. Ses feuilles sont rudes au toucher et les étamines ne sont pas plus longues que la corolle.

* 2. M. à fleurs pointues, C. minor.

Tiges droites, rameuses, d'un à 2 pieds. Feuilles alt., amplexicaules, entières, d'un glauque bleuâtre, glabres. Les inf. obl., spatulées, obtuses. Fleurs assez pętites, jaunes, latérales, pointues, en grappes spiciformes et roulées. Les feuilles ont souvent des taches.

Lieu. L'Autriche, l'Europe mérid. $\sigma^{x}$. Fl. en juin-oct.

Cult. Pleine terre. Ces plantes, orig. des pays mérid. de la France, se plaisent dans les terres légères, chaudes et un peu sèches. Quand l'été a été chaud, elles fructifient aisément, et alors se sémerít elles-mêmes. Lorsqu'on en recueille la graine, il faut la semer aussitôt en plate-bande de terre légère; et si 'on craint le grand froid, co mme dans le nord de la France, il faut alors en répandre quelques semences dans des terrines que l'on mettra l'hiv er à l'abri. Au printemps, on pourra planter les mottes entières de ces terrines dans la place où les plantes doivent rester. On peut aussi les semer au printemps, sur couche, dans les pays septentrionaux. Les melinets sont assez johis et ne dépareront pas les parterres de fleurs. 


\section{Dichondra, Forst.}

Cal. à 5 parties oblongues. Cor. égale au calice, campanulée, à 5 parties ovales, ouvertes, plus longues que le tube. Étamines alternes avec la corolle, à filamens en alêne. Anthères ovales, en cœur. Ovaire arrondi, à 2 parties. Style divisé en deux. 2 stigmates en tête. Capsule entourée du calice agrandi, à deux parties et deux loges. Semences solitaires dans chaque loge, globuleuses, avec une enveloppe cornée.

DICHONDR A carolinensis, MrCh. Demidofia repens, Gmerin. Plante rampante, légèrement pubescente sur toutes ses parties. Feuilles alternes, réniformes, sans échancrures, vertes des deux côtés. Fleurs petites, penchées, solitaires sur chaque pédoncule. Calices velus, ciliés.

Lieu. La Caroline. $\Psi$.

Cult. Orangerie. Cultivée au. Muséum.

III. 4 semences nues. Entrée de la corolle libre. Plantes la plupart herbacées, rudes au toucher.

\section{Coldène, Coldenia.}

Cal. à 4 part. Cor. infund, à limbe ouvert. 4 étam. Ovaire à 4 lobes. 4 styles. 4 stigm. Fruit à 4 caps. rudes et 4 pointes. Les caps. rapprochées, monospermes。

Coldène couchée, $C$. procumbens.

Tiges d'un pied, rameuses, cylind, velues, étalées sur la. terre. Feuilles alt., ovales, arrondies et inclinées, plissées, inégales à leur base et velues. Fleurs petites, ax., Iatérales, sess.

Lieu. Les Indes or. Fl. en juillet et août.

Cult. Serre chaude. Cette plante se sème tous les ans sur couche, et se conduit à la maniëre de toutes les plantes de cette température. Peu cultivée. 


\section{Héliotrope, Heliotropium.}

Cal. tubulé, à 5 dents. Cor. hypocr., 5 -fide, et 5 dents entre ses divisions. Stigm. échancré.

* i. Héliotrope du Pérou, H. peruvianum.

Arbuste de 2 à 3 pieds, dont les rameaux nombreux sont velus. Feuilles alt., éparses, ovales, très-ridées, velues, pét., pâles en-dessous. Fleurs petites, sessiles, d'un blanc violet, ramassées d'abord en corymbe qui ensuite se développe en épiś roulés et unilatéraux.

Lieu. Le Pérou. Ђ. Fl. presque toute l'année. Toujours vert.

2. H. à feuilles d'ormin, $\boldsymbol{H}$. indicum.

Tige droite, d'un pied et demi, peu rameuse. Feuilles pét. . ovales, en cœur, pointues, ridées, rudes au toucher, d'un vert foncé. Fleurs sessiles, bleuâtres, en épis latéraux et roulés.

Lieu. Les Indes occid. Ђ. Fl. en juillet et août.

5. H. à petites fleurs, $H$. parviflorum.

Tiges droites, rameuses, pubescentes, d'un pied et demi Feuilles opp. et alt., ovales, pointues, ridées, rudes au toncher, pét. Fleurs très-petites, sess., unilatérales, en épis roulés, sol. ou géminés.

Lieu. Id. Fl. id.

* 4. H. d'Europe, H. europaum. Herbe aux verrues.

Tige 'rameuse, pubescente, d'un pied. Feuilles alt., pét. : ov., obtuses, très-entières, ridées, velues, rudes. Fleurs blanches, sess., unilatérales, en épis géminés et term.

Lieu. La France. Fl. en juin - octobre.

5. H. couché, H. supinum.

Tiges étalées sur la terre, nombreuses, velues, rameuses. Feuilles ovales, entières, pét. , cotonneuses, blanchâtres. Fleurs petites, blanches, disp. id.

Lieu. La Fr. mérid. Fl. en juin et juillet.

6. H. ̀̀ feuilles glauques, $H$. curassavicum.

Tiges droites ou couchées, ramenses, glabres, glauques. 
Feuilles sessiles, lanc. - lin., glabres, sans veines, d'un vert glauque, alt. et opp. Fleurs petites, blanches, disposées id.

Lieu. Les Indes occid. F. Fl. id.

Cult. Excepté les espèces 4 et 5 , les autres sont de serre chaude. Mais comme, à la réserve de la première, elles sont annuelles, leur culture est, à la chaleur près qu'il leur faut pour fleurir et fructifier, la même que celle des espèces 4 et 5 . Ces héliotropes sont peu cultivés dans d'autres jardins que ceux de botanique. Quand on veut les avoir, on sème sur couche en pots les espèces de serre chaude, et les deux autres simplement sur vieille couche ou dans des planches de terre légère. Les espèces délicates se replantent en pot ou restent sur une couche chaude. Celles d'Europe se plantent en pleine terre ou plutôt se sement en place. Ces plantes exigent toutes une terre chaude, sèche, légère et bien exposée au soleil.

La première demande une bonne terre terreautée, consistante, des arrosemens très-fréquens en été, et, pendant cette saison, une situation abritée et chaude. Elle doit être dépotée deux fois par an, au printemps et en août, et tenue propre, c'est-à-dire, débarrassée de ses feuilles fanées, et de quelques rameaux souvent trop nombreux. On peut l'élever à tige, et lui former une sorte de tête; mais j'ai éprouvé que c'étoit contrarier absolument sa nature; $j$ 'en ai perdu ainsi trois pieds pour lui donner cette forme. D'ailleurs elle n'est pas avantageuse, parce que la plante donne moins de fleurs, et c'est dans cette partie qu'est sa principale qualité. Le moyen d'en avoir de plus belles et davantage est de sacrifier tous les ans un ou deux pieds, qu'on met en pleine terre à une exposition méridienne; elle s'étend ålors beaucoup et se charge de fleurs jusqu'aux premières gelées. On la multiplie ordinairement de boutures ou de rejetons; ils reprennent tous deux également bien, et forment de bons pieds l'année suivante. Il est bon de renouveler cet arbuste de temps en temps, les jeunes pieds fleurissant mieux que les vieux. Cet héliotrope n'est pas absolument de serre chaude. Il s'y étiole en hiver, et se trouve heaucoup mieux en serre tempérée; mais i? ne faut pas que la gelée l'atteigne. Les arrosemens doivent lui être très-épargnés en hiver, et la lunière lui est trè-nécessairs. 
dans cette saison, qu'il ne passe pas souvent sans s'altérer. On le sème aussi sur couche dans un terreau léger, et l'on recouvre très-peu les graines.

Us. L'héliotrope du Pérou n'a d'agréable que l'odeur de ses fleurs; mais elle est si suave que l'on ne considere qu'elle. Elle imite beaucoup celle de la vanille. C'est à Joseph de Jussieu que nous sommes redevables de cet arbuste intéressant.

$\mathrm{La} 4^{\mathrm{e}}$ espèce, à laquelle on attribuoit des vertus, n'en a absolument aucune.

\section{Viperine, Echium.}

Cal. à 5 part. Cor. à tube court, à limbe ample, camp., oblique, et à 5 lobes inégaux. Stigm. bifide.

* 1.Viperine frutescente, E. fruticosum, E. africanum.

Tige de 2 à 3 pieds, rameuse à son sommet. Feuilles alt., lanc. , rétrécies à leur base, velues, rudes, poirt veinées. Fleurs purpurines, sol., ax.; les fol. cal. lancéolées et pointues. Les étamines ne sont pas plus longues que la corolle.

Lieu. Le Cap. ๖. Fl. en mai et juin.

* 2. V. gigantesque, E. giganteum.

Tige ligneuse, de 6 à 7 pieds. Feuilles lanc., nerveuses, étroites, velues, blanchẩtres, rudes au toucher, ainsi que les rameaux. Les folioles cal. obl.-lancéolées, aiguës. Styles hérissés. Fleurs en épi terminal, d'un bleu céleste.

Lieu. Madere. . Fl. en mai. Toujours vert.

* 3. V. blanchâtre, E. candicans.

Tige épaisse, ferme, très-roide, brune, nue, de 6 pieds environ, couverte de poils blancs dans sa jeunesse, terminée par plusieurs rameaux qui portent, ainsi que la tige, à leur sommet, une rosette de feuilles lancéolées, alongées, pointues, assez larges, rétrécies à leur base, revêtues de poils rudes, courts, d'un vert grisâtre et bleuâtre. Les bractées et les calices rudes. Les étam. plus longues que la corolle. Fleurs d'un beau bleu, en grappe terminale. Toute la plante blanchâtre, argentée dans son pays originaire.

Lieu. Les îles Canaries. \$. Fl. en juillet-septembre. Toujours verte. 
* 4. V. élevée, E. strictum, H. K.

Tige rameuse, droite. Feuilles pét., obl.-lanc., velues; rudes. Fleurs petites, bleues. Les corolles presque camp. Les étam. saillantes.

Lieu. Les îles Canaries. ๙ $^{\star}$ Fl. une partie de l'année. 5. V. lisse, $\boldsymbol{V}$. laevigatum.

Tige glabre. Feuilles lanc., nues, rudes au toucher en leurs bords, sur leur nervure et à leur sommet.

Lieu. Le Cap. Ђ. Fl. en juin et juillet.

6. V. à feuilles de plantain, E. plantagineum. E. creticum, LAMARCK.

Feuille rad. ovales, pét. Fleurs violettes. Tiges couvertes de poils non rudes.

Lieu. L'Italie. Fl. en juillet-oct.

э. V. d'Italie, E. italicum. E. pyrenaicum, Lin., Mant... . An. E. altissimum, J $\mathrm{ACQ}$.

Tige velue. Feuilles lin.-lanc. , rudes et velues; les inf. nerveuses. Cor. presqu'égale. Les étam. saillantes. Fleurs d'un pourpre pâle.

Lieu. La France, l'Angleterre. $\%$. Fl. en juillet et août.

8. V. commune, E. vulgare.

Tige de deux pieds, droite, velue, chargée de points bruns et rudes. Feuilles longues, étroites, velues, très-rudes au toucher. Fleurs bleues et rouges, en épis latéraux et écartés, qui, par leur réunion, forment un long épi term.

Eieu..... Ind. $\sigma^{7}$. Fl. en juillet-sept.

9. V. de Crète, E. creticum. E. prostratrum, Desfont.

Tiges relues, rameuses, couchées, rudes. Feuilles linéaires, verruqueuses. Fleurs d'un beau rouge, en épis axillaires. Etam. plus longues que la corolle.

Lieu. La France mérid. or. Fl. id. 10. V. à fleurs violettes, $E$. violaceum.

Les étam. de la même longueur que la corolle. Le tube plus. court que le calice. Fleurs pourpres. Cette espèce a beaucoup de rapports à la commune.

Lieu. L'Autriche. F. Fl. en juillet.

1. V. du Levant, E. orientale. 
Tige rameuse. Feuilles caulinaires ovales. Fleurs latérales sol., grandes, campanulées.

Lieu. Le Levant. Fl. id.

12. Viperine de Portugal, E. lusitanicum.

Curolle plus longue que les étamines. Tige de 2 pieds. Feuilles rad. longues d'un pied et velues. Fleurs en épis latéraux. Plante glabre.

Lieu. L'Europe mérid. Fl, id.

Cult. Les 5 premières especes sont d'orangerie, et n'en exigent que les soins ordinaires. Leur terre doit être plus forte quetrop légère, mais très-substantielle; les arrosemens fréquens en été. Muli. par leurs graines semées sur couche en pot, et conduites à la manjère ind quée. Les autres sont de pleine terre, et se sèment en terre légère au printemps, et pour les en place. Il vaut inieux semer ces dernières en automne qu'au printemps, et même celles d'orangerie; on est plus sûr de leur germination: cependant ces espèces lèvent aussi fort bien en mars ou avril. Ces plantes aiment les terres sèches. On propage aussi, par les boutures faites en mai, les espèces b. Quelques-unes s'enracinent aisément.

Us. De toutes ces viperines, la deuxiène est la plus belle par sa couleur argentée, sur-tout dans son pays originaire; la troisième par ses larges touffes de feuilles, et la commune par ses beaux épis. Cette dernière est d'usage en médecine comme vulnéraire, adoucissante, diurétique, et n'est point déplacée dans les parterres, quoiqu'elle soit indigène.

\section{Autres espèces cultivées.}

13. V. à grandes fleurs, E. grandiflorum, ANDR., VENT., Jard. Malm. E. formosum, PERS.

Arbrisseau dont la tige est droite, cylindrique, glabre, d'un gris brun, de 5 pieds environ de hauteur, rameuse; les rameaux alternes et droits. Feuilles alternes, rapprochées, sessiles, amplexicaules, lancéolées, pointues, très-entières, d'un vert foncé, hérissées en-dessus de poils roides à base tuberculeuse, glabres 
en-dessous. Fleurs d'un rose tendre, grandes, pédiculées, formant ensemble une cîme lâche, très-ouverte et axillaire.

Lieu. Le Cap. Ђ. Toujours vert. Fleurit au printemps.

Cult. Orangerie. Celle des autres viperines de cette serre convient à cette espèce, qui, par la couleur de ses fleurs, mérite d'être cultivée et muliipliée, soit par ses graines, soit par bouturt $S$.

On cultive encore à la Malmaison les espèces suivantes : 14. V. argentée, E. argenteum, Andr.

Tige rameuse. Feuilles éparses, linéaires, aiguës, velues et soyeuses. Fleurs en épi terminal feuillé.

Lieu. Le Cap.

15. V. à aiguillons, E. ferox., ANdr., Pers. E. ferocissimum, Hort. angl.

Tige frutescente, rude, presqu'épineuse. Rameaux et feuilles garnis d'aiguillons. Fleurs d'un beau violet, à limbe presqu'égal, ouvert, obtus, dont le tube est court; disposées en épis terminaux.

\section{Lieu. . b.}

16. V. à feuilles glauques, E. glaucophyllum, ANdr., J ACQ.,

PrRsoon.

Tige frutescente. Raneaux et calices glabres. Feuilles lancéolées, glauques, sans nervures, d'une consistance sèche en leurs bords. Fleurs bleues et rouges, presque régulières, en bouquets.

Lieu. Le Cap. Ђ.

17. V. à fleurs en têtes, $\boldsymbol{E}$. capitatum, Thunb., Persoon.

Tige velue. Feuilles rudes et garnies de poils. Fleurs peiites; à limbe égal, disposées en têtes corymbiformes; les étamines plus longues que la corolle.

Lieu. Le Cap. 万. Cultivée chez madame Durazzo, à Gênes.

Cult. Ces quatre dernières espèces sont aussi d'orangerie et doivent être cultivées comme les cinq premières. Bonne terre. Mult. par boutures : celles de la quinzième ne s'enracinent pas facilement. On cultive au Muséum une autre espèce qui m'a paru fort belle et très-distincte. Sa tige grosse est très-droite et nue, sans branches ni rameaux; elle porte à son sommet une touffe de grandes feuilles lancéolées, disposées en rosette. Ses fleurs sont bleues. Elle a des rapports à la viperine gigantesque. 
On la nomme echium fastuosum. Elle est d'orangerie, $b$, et originaire de Madere.

Je tiens de M. Cels une viperine qui, par ses feuilles lancéolées, sessiles, oblongues et glauques, pourroit se rapporter à la seizième, si elles n'avoient pas une principale nervure trèsdistincte. Orangerie. Ђ.

\section{Gremil, Lithospermum.}

Cal. à 5 part. Cor. infund., petite, à 5 lobes, Stigm. bifide. Sem * lisses, ou simplement glabres.

* r. Gremil officinal, L. officinale. Herbe aux perles.

Tiges de 2 à 3 pieds, rameuses et rudes. Feuilles alt., sess., nombreuses, lanc., entières, à 3 nervures et pointues. Fleurs blanches, ax., sol. Semences blanches, luisantes comme de petites perles.

Lieu. Dans les champs et les chemins. Ind. $₹$. Fl. en mai août.

2. G. des champs, $L$. arvense.

Tiges de 8 à ro pouces, rameuses, foibles. Feuilles ovales, pointues, molles et un peu étroites. Fleurs petites, blanches, term. Semences ridées.

Lieu. Dans les champs. Ind. Fl. en mai et juin.

3. G. violet, L. purpureo-coruleum.

Tiges d'un pied; les florif'eres droites, les stériles couchées: Feuilles lin.-lanc., pointues, sessiles, vertes, un peu rudez. Fleurs violettes, plus grandes que celles de la première, en petites grappes ax.

Lieu. La France. $\longleftarrow$, Fl. en juin.

4. G. frutescent, L. fruticosum, Miller.

Tige de 6 à ro pouces, rameuse, tortueuse, velue. Feuilles sessiles, lin., étroites, alt., rudes; leurs bords souvent roulés. Fleurs purpurines, ássez grandes, en épi court et termin.

Lieu. La France mérid. $₹$. Fl. en juin.

* 5. G. à fleurs jaunes, L. orientale. Anchusa orientalis, Lxx.

Tiges d'un pied et demi, velues, rameuses et presque toutes couchées. Feuilles alt., sess., lanc., pubescentes; les rad. assez 
grandes. Fleurs jaunes, sol. dans les bractées, disp. en épis fort longs et term.

Lieu. Le Levant. $\%$. Fl. id.

6. G. calleux, L. callosum, VALH. L. angustifolium, ForsK:

Tige frutescente, diffuse. Feuilles lancéolées-linéaires, chargées de verrues et rudes au toucher. Corolles trois fois plus longues que le calice.

Lieu. L'Égypte, près du Caire. Ђ.

7. G. distique, $L$. distichum, Ortega.

Feuilles roulées en leurs bords. Corolles blanches, jaunes a l'entrée du tube. Semences blanches, luisantes.

Lieu. L'île de Cuba. ๑, Cultivée à Gênes, chez madame Dưrazzo, à Milan, et à Londres, où l'on cultive aussi l'espèce $L$. tenuiflorum, d'Égypte, $\odot$ et de pleine lerre.

Obs. J'ai cru suivre les intentions de Jussieu en plaçant dans ce genre la cinquième espèce, comme l'ont fait Lamarck et Aiton. L'absence des écailles de la corolle ne permet guère de la placer parmi les bugloses.

Cult. Les quatre premières espèces sont de pleine terre. La quatrième est un peu délicate, et, dans le nord de la France, doit être plantée dans des terres légères et bien exposées, ou passer l'hiver en orangerie. Les trois premieres ne se cultivent pas. Les deux avant-dernières sont d'orangerie, et ne demandent que les soins ordinaires. On les obtient par leurs graines semées sur couche, ou dans des planches préparées pour ces semis. Quand les jeunes plantes ont quelques feuilles, on les met en pot, qu'on plonge dans une couche ombragée, ou qu'on place simplement à l'ombre pour les faire reprendre. La dernière est de serre.

$U s$. Ces plantes ont peu d'agrément, et ne sont guère cultivées que dans les jardins de botanique. Les semences de la première, lorsque cette plante est dans un lieu sec et chaud, font un effet remarquable par leur blancheur. Plusieurs personnes s'imaginent que cette plante est le vrai thé; cependant rien de si désagréable que l'infusion de ses feuilles : malgré cela on trouve des gens qui ne peuvent s'en désabuses. Les graines de catte es. pèce sont rép utées diurétiques et apéritives. 


\section{Pulmonaire, Pulmonaria.}

Cal. pentagone, 5-fide. Cor. infund., presqu'à 5 lobes, droite et ouverte. Stigm. échancré.

* I. Pulmonaire à feuilles étroites, $P$. angustifolia.

Plante basse, en grosse touffe. Feuilles rad. elliptiques; celles de la tige lanc.-obl., amplexicaules; toutes rudes au toucher, velues, entières, tachetées ou non tachetées. Tiges de ro à I2 pouces, feuillées, terminées par un bouquet de fleurs d'abord rouges, et ensuite bleues.

Lieu. La France, l'Allemagne, la Suisse. $\nsucc$. Fl. en avril et mai.

* Variété à feuilles tachetées de blanc. Les taches rudes semblent élevées. $P$. saccharata, Miller.

* 2. P. officinale, $P$. officinalis.

Cette espèce ne differe guère de la précédente ; ses feuilles rad. sont un peu en cœur; celles de la tige ovales-obl.; toutes rudes, velues et maculées. Fleurs id.

Variété à fleurs blanchìes.

Lieu. La France. Ind. $\tau$. Fl. id.

5. P. paniculée, $P$. paniculata, H. K. Mertensia, Pras.

Feuilles ov.-lanc., obl., acuminées, un peu velues. Lues calices courts, à 5 parties hispides. Fleurs bleues.

Variété à fleurs blanches.

Lieu. La baie d'Hudson. $₹$. Fl. en mai et juin. * 4. P. de Virginie, P. virginica. Mertensia, Pers.

Tiges de 2 pieds, foibles, presque nues. Feuilles rad. , longues, obtuses, lanc., entières, vertes, portées sur de longs pétioles. Fleurs bleues, quelquefois rouges ou blanches, grandes, ouvertes, en larges bouquets paniculés et pendans.

Lieu. La Virginie. $₹$. Fl. en mars-mai. 5. P. maritime, P. maritima. Mertensia, PERS.

Tige rameuse, couchée. Feuilles ovales. Calices courts. Fleurs d'un bleu pourpre. Semenceś glabres et lisses.

Lieu. L'Angleterre. Fl. en juillet. 6. de Sibérie, P. sibirica, Lrn. Meriensia, Pens. 
Feuilles radicales en cœur, glauques et glabres. Fleurs en corymbes rameux, pendantes.

Lieu. La Sibérie.

Cette plante a beaucoup de rapports avec lés deux espèces précédentes, dont elle semble tenir le milieu.

Persoon a divisé ce genre, et a p lacé les quatre dernières especes soús le nom Mertensia, Rотн.

Cult. Toutes les pulmonaires sont de pleine terre et très-rustiques; elles croissent dans tous les terrains, sur-tout dans les lieux légèrement ombragés. Elles se multiplient en séparant leurs touffes. Leur séparation se fait en automne. La quatrième ne s'élargit pas tout-ä-fait autant.

Us. Ces plantes ne laissent pas que de concourir à l'agrément des jardins par leurs fleurs, qui, dans les deux premieres, sont rouges et bleues sur la même touffe; cés couleurs dépendent du plus ou moins de temps qu'elles sont épanouies. La quatrième est la plus belle. Ses panicules et ses fleurs plus grandes lui donnent beaucoup de grâce; mais sa végétation dure peu : elle perd en deux mois et ses fleurs et sés feuilles, de manière que, pendant l'été, on n'en voit aúcun vestige.

La seconde espèce est usuelle : on la dit pectorale, astringente, mucilagineuse; cependant elle est peu employée.

\section{Onosme, Onosma.}

Cal. à 5 part. Cor. du genre suivant, mais son entrée nue.

1 stigmate.

Onosme viperine, $O$. echioides.

Tige droite, ord. simple, d'un pied, garnie de poils blancs. Feuilles longues, étroites et velues. Fleurs jaunâtres, en épis roulés et term.

Lieu. La France méridionale. $\nsucc$. Fl. en mai. Commune en Sibérie.

Cult. La même que celle des viperines de pleine terre. Elle aime les lieux secs.

On cultive au Muséum l'espèce onosma simplicissima, dont les corolles sont ventrues et les feuilles linéaires. Elle est $\sigma^{x}$, et vient de la Sibérie, Pleine terre. 
Et, il y a peu de temps, en Angleterre, une espèce nommée $O$. arenaria, originaire de la Hongrie, $₹$ et de plein air.

IV. 4 semences nues. Entrée de la corolle garnie de 5 écailles saillantes dans la corolle, entr'ouvertes extérieurement. Plantes la plupart à feuilles rudes.

\section{Consoude, Symphytum.}

Cal. à 5 part.Cor. camp., ventrue, à limbe droit, resserré, à 5 dents. Les écailles oblongues, subulées, conniventes. I stigmate. * I. Consoude officinale, $S$. officinale.

Racine noire en-dehors. Tige de 2 pieds, branchue, velue, ailée par la décurrence des feuilles. Feuilles lanc., assez grandes, velues, rudes au toucher, décurrentes. Fleurs rouges ou blanches, péd., en épi lâche, unilatéral et un peu courbé.

Lieu. Ind. $₹$. Fl, en mai-oct.

* 2. C. tubéreuse, S. tuberosum.

Racine blanche en-dehors. Tige de 2 à 3 pieds. Feuilles plus petites, semi-décurrentes; les sup. opp. Fleurs d'un jaunepâle, presque blanches.

Lieu. L'Allemagne, la France. $\%$. Fl. id.

Cult. Pleine terre. Ces plantes viennent par-tout. La seconde est plus cultivée que la premiere, parce qu'elle est moins commune, et qu'elle n'est pas traçante. La première est une plante fort incommode, qu'on a bien de la peine à détruire lorsqu'elle a été une fois dans un jardin, et qu'elle est restée long - temps dans sa place. Ses racines profondes la multiplient toujours.

Us. Sans la nature traçante de la première, elle ne seroit pas déplacée dans les jardins d'agrément, et vaudroit bien d'autres. qu'on y cultive. Elle est fréquemment employée en médec. comme incrassante, astringente et très-consolidante. Elle est excellente dans les pertes chez les femmes.

3. C. du Levant, S. orientale.

Feuilles ovales, presque pétiolées, rudes au toucher. Fleurs bleues. 
Lieu. Les environs de Consiantinople. $\%$. Fleurit en mai. 4. C. très-rude, $S$. asperrimum, Hort angl.

Lieu. La Sibérie. $\%$. Fleurit en juillet.

Cult. Plein air.

\section{Lycopside, Lycopsis.}

Cal. 5-fide. Cor. infund., à tube courbé, à limbe court, à 5 lobes. Ecailles convexes, conniventes. Stigm. bifide.

x. Lycopside vésiculaire, $L$. vesicaria. Echioides violacea, Desfont. , Fl. atl.

Tige d'un pied, anguleuse, rameuse. Feuilles alt., sess., très-entières, lin. - lanc., pointues, hispides. Fleurs bleues ou rougeâtres, unilatérales, en épis feuillés et term.

Lieu. L'Europe mérid. Fl. en juin et juillet.

2. L. noirâtre, L. nigricans, LAMARCK. Echioides nigricans,

Desf.

Cette espèce ne diffère de la précédente que par la couleur noirâtre de ses fleurs et ses calices enflés, pentagones, plus longs que la corolle.

Lieu. Le Levant. $\sigma^{7}$.

3. L. brune, L pulla.

Toute la planie couverte de poils blanchâtres et mous. Tiges d'un pied, droites. Feuilles alt., sess., lanc., très - entières , pointues, d'un vert pâle. Fleurs rougeâtres, péd., en épis feuillés et term.

Lieu. L'Allemagne. ơ . Fl. id.

4. L. des champs, L. arvensis.

Toute la plante hérissée de poils rudes. Tige d'un pied et demi, rameuse, anguleuse, droite. Feuilles alt., sess., semiamplexicaules, alongées, étroites, très-rudes. Fleurs d'un bleu rougeâtre, en épis feuillés, roulés et unilatéraux.

Lieu... Ind. Fl. id.

Variété à feuilles ondulées, L. undulata.

5. L. du Levant, L. orientalis, LamarcK.

Toute la plante hérissée de poils rudes. Tige de deux pieds; droite, anguleuse, rameuse. Feuilles alt. , sess., oy.-lanc., en- 
tières, pointues. Fleurs blanches et rougeâtres sur le tube, en épis feuillés, unilatéraux et terna.

Lieu. Le Levant.

6. Lycopside jaune, L. lutea, Lamarck.

Tiges nombreuses, cylind., d'un pied, rameuse à leur sommet. Feuilles alt. , sess., obl., pointues, entières. Fleurs jaunes, disposées id. Toute la plante velue.

\section{Lieu. L'Afrique?}

Cult. Pleine terre. Ces espèces ne sont cultivées que dans les écoles de botanique. Elles se sèment tous les ans, en planches, ou dans la place où elles doivent rester.

\section{Scorpionne, Myosotis.}

Cal. 5-fide. Cor. hypocr., à tube court, à limbe plane, à 5 lobes échancrés. Ecailles convexes, conniventes. I stigm. Semences lisses ou rudes.

I. Scorpionne des champs, $M$. anvensis.

Tiges d'un pied, rameuses. Feuilles oblongues, étroites, velues. Fleurs d'un bleu pâle, petites, en épis roulés, presque paniculés. Semences lisses.

Lieu... Ind. F. Fl. en avril-août.

2. S. des marais, $M$. palustris. Souvenez - vous de moi vulg.

Cette espèce differe assez de la précédente. Ses tiges sont plus droites. Ses feuilles un peu plus grandes et point velues. Ses fleurs une fois plus larges, bien ouvertes, d'un bleu céleste et fort agréable, avec des points jaunes, disp. id. Semences lisses,

Lieu. Les lieux aquatiques. Ind. $\%$. Fl. id.

*3. S. hérissée, M. Lappula.

Tige droite, d'un pied et deni, rameuse. Feuilles éparses, étroites, hérissées de poils. Fleurs bleues, petites, en épis lâches, roulés et term. Semences hérissées.

Cette espèce forne un large buisson. Ses feuilles sont lancéoléesoblongues, pointues, marquées de fortes nervures. Ses fleurs sont toujour's latérales; les écailles ou glandes de l'entrée du tube sont d'un bleu violet plus foncé.

Lieu. La Fr. nérid. Fl. id. 
4. S. jaunâtre, M. apula.

Tige plus basse. Feuilles étroites, lanc., velues. Fleurs jaunes, très-petites, en grappes feuillées. Semences nues.

Cult. Pleine terre. Ces plantes ne sont cultivées que dans les écoles. J'invite cependant à placer dans les lieux humides des jardins la seconde, qui est fort commune dans nos prés. La fleur est très-jolie.

\section{Buglose, Anchusa.}

Cor. infund. , à 5 lobes droits et ouverts. Ecailles ovales, saillantes, conniventes. Cal.5-fide. Stigm. échancré. Sem. gravées à leur base.

* 1. Buglose officinale. A. officinalis. Anchusa italica, Retz., Willd.

Racine noire en-dehors, blanche en-dedans. Tiges de 2 à 3 pieds, rameuses, cylind. Feuilles alt., lanc., pointues, d'un vert un peu grisâtre. Fleurs d'un bleu foncé ou blanches, en épis unilatéraux, roulés et term. Toute la plante couverte de poils, et rude au toucher.

Lieu. La France. ₹. Fl. en juin-octobre.

2. B. paniculée, A. paniculata, H. K. A. macrophylla, Lam.

Feuilles lancéolées, rudes, très-entières. Fleurs péd., en pac nicule dichotome et divariquée. Les calices à 5 divisions subu= lées.

Lieu. Les Canaries. $\sigma^{7}$. Fl. en mai et juin. * 3. B. à feuilles étroites, $A$. angustifolica.

Cette espèce est beaucoup plus petite que la première. Une partie de ses tiges est ì moitié couchée. Feuilles obl.-lanc., entières, très-rudes. Fleurs bleues, blanches ou purpurines, petites, disp. comme la première.

Lieu. L'Europe mérid. «. Fl. id.

* 4. B. ondulée, $A$. undulata.

Tige d'un pied, vslue, cannelée, peu rameuse. Feuilles lin.es lanc., dentées, rudes, ondulées. Fleurs bleues, disp. id.

Lieu. L'Espagne. ₹. Fl. en juillet et août. 


\section{*5. Buglose teignante, B. tinctoria.}

Tige de 8 à ro pouces, presque couchée. Feuilles lanc.-lin. , obtuses, d'un vert blanchâtre. Fleurs bleues, pourpres ou blanches, disp. id. Toute la plante est presque laineuse et rude. Les étamines sont plus courtes que la corolle.

Lieu. La Fr mérid. ఒ. Fl. en juin-octobre. *6. B. à larges feuilles, $A$. sempervirens, Alkanet.

Tiges d'un pied et demi, très-velues. 'Feuilles alt., ovales, pointues, velues, pét., d'un vert blanchâtre sur leurs nervures. Tleurs petites, bleues, en épis glomérulés.

Lieu. L'Espagne, l'Angl., près Abbeville. Ind. ₹. Fl. en mars-juillet,

g. B. yerruqueuse, A. vermucosa, H. P., LAm.ancK.

Espèce très rude au toucher. Tiges foibles, couchées, de 8 ì 10 pouces. Feuilles alt., ovales-lanc., parsemées de grosses verruesblanches. Fleurspetites, d'an jaune pâle, latérales, sol., péd.

Lieu. L'Egypte, $\odot$.

AnCHUSA orientalis. Voyez lithospermum 5.

Cult. Les bugloses I, 3 et 6 sont rustiques et ne redoutent que les froids extraordinaires. Les espèces 4 et 5 sont un peu sensibles aux gelées. La $2^{\mathrm{e}}$, quoique des Canaries, est indiquée en pleine terre par Aiton. Cornme je ne la connois pas, je ne peux décider si elle peut réellement y résister; mais il est à présumer qu'elle est délicate, et que si on ne la met pas en serre, il faut du moins la placer à l'abri du froid autant qu'il est possible. La $\eta^{\mathrm{e}}$ ne $\mathrm{m}^{\text {'est }}$ pas plus connue, et son lieu natal indiqueroit cu'elle n'est pas plus rustique que la seconde. Mais comme elle est annuelle, il est assez égal qu'elle soit de plein air ou d'orangerie. Dans ces doutes, le cultivateur doit faire des essais, en mettant ces espéces en pleine terre, à une bonne exp., et en garcant quelques individus en pots de la $2^{e}$ pour les rentrer pendant l'hiver en orangerie.

En général, les bugloses se plaisent dans les bonnes terres, douces et franches, et à une situation un peu chaude. La première, cepen iant, croìt fort bien à l'ombre, ainsi que la $5^{\mathrm{e}}$. Mult. par leurs graines semées en planche de terre préparée; et, quand on les a obtenues, par la séparation de leurs pieds, 
en février ou àu commencement de mars. La première trace beaucoup.

Us. La premiere se cultive dans les jardins pour son utilité。 Elle est employée en médecine avec la bourrache, comme béchique et diurétique; mais j'ose dire que ces plantes, dont on fait cependant un usage assez fréquent, sont fort aqueuses et par conséquent, assez indifférentes. On les recommandeen bouillons, parce qu'on les croit nitreuses; un peu de nitre dans ces sortes de remèdes rempliroit beaucoup mieux l'objet. Il y a dans toutes ces plantes, depuis long-temps usuelles, beaucoup de préjugés anciens, et beaucoup de réformes à faire.

Les racines de la $5^{\mathrm{e}}$ donnent une teinture rouge employée dans la pharmacie. Elle est astringente. On la nomme orca. netie.

\section{Bourrache, Borrago.}

CaI. à 5 part. Cor. en roue, 5 -fide et ouverte. Ecailles obtuses, échancrées. I siigm. Semences ridées, couvertes par le calice connivent.

Les anthères rassemblées forment une pyramide au centre de la fleur.

* I. Bourrache commune, $\boldsymbol{B}$. officinalis.

Tige d'un pied et demi, rameuse, fistuleuse, succulente, lendre, hérissée de poils piquans. Feuilles alt., lanc., larges, obtuses, ridées, hérissées des mêmes poils. Fleurs d'un beau bleu, q. f. carnées ou blanches, bien ouvertes, en étoile.

Lieu. Le Levant? Naturalisée. Fl. en juin-septembre. 2. B. des Indes, B. indica.

Tige de 10 pouces, grêle, velue. Feuilles obl., amplex., alt. ou opp., parsemées de verrues blanches. Fleurs d'un bleu pâle, ax., sol., péd., marquées int. de 5 taches aurores.

Lieu. Les Indes or. Fl. en juin-octobre.

3. B. d'Afrique, C. africana.

Tige rameuse, velue, de 6 à 8 poucés. Feuilles ovales, opp., pét., chargées de verrues blanches. Fleurs pelites, bleuâtres, 
jaunes en-dedans, avec 6 taches purpurines, en bouquets atr ssommet des rameaux.

Lieu. Le Cap. Fl. en juillet et août.

* 4. Bourrache du Levant, $B$. orientalis.

Feuilles rad. grandes, pét., cordiformes, pointues, rudes, d'un gros vert. Tiges d'un pied et un peu plus, velues. Fleurs petites, d'un pourpre bleuâtre, en bouquets terminaux.

Lieu. Les environs de Constantinople. $\Psi$. Fl. en mars-mai.

Cult. La première se sème tous les ans elle-même, et vient dans tous les terrains. Les 3 et $4^{\mathrm{e}}$ se sèment sur couche ou en plate-bande destinée à ces sortes de semis, au printemps. Lorsque les jeunes plantes sont assez fortes pour être transplantées, on les place, soit dans des pots, soit en bonne terre légère et exposée au midi, en plein air. La quatrième vient assez bien par-tout; elle s"étend beaucoup dans les sols profonds et doux, et on la multiplie facilement par la séparation de ses pieds, en automne ou en février ; mieux en automne, parce qu'elle pousse de bonne heure. Elle est assez rustique, et fait un grand étalage pour de petites fleurs.

Us. En médecine, la bourrache commune a les mêmes propriétés que la buglose. C'est uneassez jolie plante lorsqu'elle est couverte de fleurs; on se sert de ces dernières pour parer la salade, avec les capucines. La quatrième n'a pas des fleurs d'un effet agréable; mais c'est la seule vivace de ce genre; elle est ord. cultivée dans les jardins de plantes étrangères.

5. B. à feuilles épaisses, Borrago crassifolia, VENT., Jard. Cel.

Tiges peu nombreuses, courbées, redressées, cylindriques, rameuses, lisses, glauques, de 4 décim. Feuilles alternes, sessiles, lancéclées, pointues, garnies en-dessus et sur leurs bords de petits tubercules portant un aiguillon à crochet; charnues, glauques. Fleur's couleur cle chair, pédiculées, axillaires, solitaires. Limbe irrégulier, à division linéaire. Calice ventru. Etamines inégales.

Lieu. La Perse. ¥. Fleurit en été.

Cult. Pleine terre. 


\section{Rapette, Asperugo.}

Cal. 5-fide, inégal, garni de dents entre ses div. Cor. à tube court, à 5 lobes. Ecailles convexes, conniventes. I stigm. Semences couvertes par le calice agrandi et comprimé.

Rapette couchée, $A$. vulgaris.

Tiges foibles, anguleuses, rameuses, velues, alternes ou opposées. Fleurs violettes, ax.

Lieu. Lá France. Fl. en avril et mai.

Cetie plante n'est cultivée que dans les écoles de botanique.

\section{Cynoglosse, Cynoglossum.}

Cal. à 5 part. Cor. inf., courte, à 5 lobes. Ecailles convexes, conniventes. Stigin. échancré. Sem. comprimées, fixées au style par leur côté intérieur, planes, rudes ou lissés, ou dentées en leurs bords.

I. Cynoglosse officinale, $C$. officinale. Langue de chien.

Tige rameuse, garnie de duvet, de 2 pieds. Feuilles assez larges, lanc. , sess. , ondulées, molles, douces au toucher, d'un rert grisâtre. Fleurs petites, rougeâtres, péd., en épis nus, penchés et lâches.

Lieu.... Ind. $\sigma^{T}$ ou . Fl. en mai-septęmbre.

Variété plus petite, sans duvet, à feuilles vertes, C. semper. virens, H. K. Cynoglossum montanum, LAMARCK. C. syivaticum, Hoffmann.

Cette variété est une espèce, selon Lam. et Desfont.; ses feuilles sont oblongues, rudes au toucher.

2. C. de l'A pennin, C. apenninum.

Tige épaisse, de 2 pieds, couverte de feuilles éparses, longues, étroites, lanc. , sess. Les rad. grandes, pét., ovales. Fleurs d'un rouge pâle, ensuite bleuâtres, d'abord en gros bouquets denses, qui, en se ramifiant, forment un sommet paniculé. Toute la plante est couverte d'un duvet doux.

Lieu. Les Alpes, les Apennins. $\sigma^{7}$. Fl. en avril-juin. 
* 3. Cynoglosse argentée, C. cheirifolium.

Tige droite, striée, rameuse, blanchâtre, d'un pied ei demi. Feuilles rad. nombreuses, longues, étroites, molles, couvertes d'un duvet argenté. Les caulinaires oblongues, obtuses. Fleurs

- rouges, en grappes courtes et term.

Lieu. L'Espagne, le Levant. ơ. Fl, en juin et juillet.

4. C. peinte, C. pictum. C. creticum, Vilinars.

Feuilles lanc., cotonneuses. Les sup. en cœur à leur base. Fleurs d'un bleu pâle, agréablement veinées de rouge. Les co= rolles presqu'égales au calice; ses div. obrondes et dilatées.

Licu. Madère. $\Psi$ ou $\sigma^{7}$. Fl. en août.

\section{Semences à bord denté.}

\section{* 5. C. printanière, C. omphalotes.}

Feuilles pét., ovales, pointues, vertes, presque glabres. Tíges grêles, de 6 pouces, portant des fleurs d'un beau bleu, avec des raies blanches, péd., latérales et term.

Lieu. L'Europe mérid, $\nsucc$. Fl. en mars-mai.

* 6. C. à feuilles de lin, C. linifolium. Vulg. Nombril de Vénus.

Tiges d'un pied, glabres, ramenses. Feuilles alt., lin.-lanc., molles, glauques, gìabres en-dessns. Fleurs blanches, péd. , en panicules term., souvent unilatérales.

Lieu. Le Portugal. Fl. en juin-août.

Cult. Pleine terre, excepté la quatrième, qui est d'orangerie. Les cynoglosses sont assez agréables pour qu'on leur donne quelques soins. Elles se plaisent dans les terres légères, chaures et cependant substantielles; les étrangères sur-tout exigent nine bonne exp. Les espèces ou or doivent être semées en automne dans la place oì elles doivent rester. Ces plantes souf-a frent beaucoup à la transplantation. Les $¥$ se sèment en plarches aussi dans la même saison, et on les plante à demeure dans l'été ou l'automne suivant. La cinquième se mulíplie beaucoup en élargissant ses touffes; on en a autant qu'on le peut desirer. La quatrième ne demande que le traitement ordinaire aux plantes de serse. 
Us. Les cynoglosses peuvent contribuer à décorer les platebandes des parterres, les unes par leurs fleurs, comme les 5 et $6 \mathrm{e}$; les autres par leur feuillage, comme les 2 et 3 . On dit les feuilles de la première vulnéraires, détersives. Elles sont peu employées.

Les pilules qui portent le nom de cynoglosse doivent leur effet à l'opium qu'on y met.

7. C. à petites fleurs, C. micranthum, Desfont., Cat. Cultivée au Muséum.

On cultive aussi l'espèce $C$. virginicum, dont les feuilles sont amplexicaules. Elle est

\section{Genres qui ont des rapports avec les borraginées.}

\section{Nolane, Nolana.}

Cal turbiné à sa base, à limbe à 5 parties ouvertes. Cor. camp., presque à 5 lobes égaux. 5 étam. courtes. Antheres sagittées. Ovaire quintuple. I style. I stigm. en tête. 5 caps. à écorce succulente, presqu'en baies, chacune à 2 ou 4 loges. * Nolane couchée, $N$. prostrata.

Cette plante a entièrement l'aspect d'un liseron. Tiges grêles, feuillées, glabres, couchées, étalées sur la terre, d'un à 2 pieds. Feuilles ovales - lanc., glabres, géminées ou ternées. Fleurs grandes, d'un bleu un peu rougeâtre, péd., dans les dichotomies, et ax.

Lieu. Le Pérou. F. Fl. en juillet - septembre.

Cult. Cette plante peut se semer dans la place où elle doit rester lorsque la terre est bonne et légère, et qu'elle est à une exposition chaude. Mais comme dans le nord de la France elle ne mûrit pas toujours ses graines, même dans cette si= Luation, il est bon de la semer aussi sur des couches oì on la laisse: elle fleurit alors très-bien et fructifie.

Us. Les fleurs de cette plante sont assez belles. Lorsqu' ell e a fructifié sur couche, on en a ord. les années suivantes sanz avoir besoin de la semer. 


\section{Falkie, Falkia.}

Cal. à 5 part. Cor. camp., à limbe agrandi, à ro part. 6 étam. inégales. 4 ovaires. 2 styles et 2 stigm. 4 semences nues, couvertes par le calice.

FaLKie rampante, $F$. repens. Convolvulus falkia, ThUnb, $J_{A \in Q}$.

Cette plante a beaucoup de rapports aux liserons. Elle en differe par ses semences nues. Tiges sarmenteuses. Feuilles en cœur portées sur de longs pétioles.

Lieu. Le Cap. $\%$. Fl. en mai.

Cult. Orangerie,

\section{O R D R E X.}

\section{LES LISERONS (CONVOLVULI).}

Calice à cinq divisions, le plus souvent persistant. Corolle régulière, et ordinairement partagée en cinq. Presque toujours cing étamines insérées au bas de la corolle et alternes à ses divisions. Style et stigmate simples ou partagés. Fruit capsulaire, souvent triloculaire, quelquefois à deux ou quatre loges, à une ou plusieurs semences; les semences sont marquées d'une cicatrice; elles sont osseuses et attachées au bas d'une cloison cenl rale; les valves libres, appliquées au bord et vers les angles de la cloison. Embryon courbé.

Herbes, quelquefo's arbrisseaux. Les tiges souvent laiteuses, s'entortillent la plupart autour des supports qu'elles rencontrent. Feuilles ordinairement alternes.

Obs. Les liserons, les borraginées et les polémoines. se ressemblent par leurs corolles régulières à cinq divisions, par leurs 
étamines et leurs feuilles alternes. Les liserons different des po. lémoines par la cloison de leurs valves, et des borraginées par leurs semences, qui ne sont pas nues. Le principal caractère de l'ordre consiste dans l'arrangement respectif des valves et de la cloison.

\section{Un seul strle.}

\section{Liseron, Convolvulus.}

Cal. à 5 part. Cor. camp., rar. infund., à limbe à 5 plis, souvent entier, anguleux; les angles aigus ou dentés. Etam. inégales, dont les filamens sont rapprochés. Ovaire à moitié enfoncé dans les glandes hypogynes. $x$ style. Stigmate bifide. Caps. souvent à 3 loges, rar. à 2 à 4 ; à $\mathbf{I}$ ou 2 sem. I. Liseron des champs, C. arvensis.

Tiges grêles, grimpantes ou rampantes. Feuilles alt., lisses, sagittées, à lobes pointus, tournées d'un seul côté, mucronées. Fleurs blanches, roses, ou purpurines, ou panachées, péd., ax., sol.

Lieu. Les champs. Ind. ₹. Fl. en juin - septemb.

2. L. des haies, C. sepium.

Tiges plus hautes, grimpantes. Feuilles alt. , pét., sagittées, à lobe tronqué. Fl. blanches, grandes, ax., sol. , péd.

Lieu. Les haies. Ind. $\%$. Fl. id.

3. L. scammonée, C. scamonia, scammonée de Syrie.

Racines épaisses, charnues, laiteuses. Tiges grimpantes, peu velues, de 3 pieds. Feuilles alt., hastées, triangulaires. Fleurs grandes, d'un bleu purpurin, au nombre de deux sur chaque péd. ax.

Lieu. Le Levant. $¥$. Fl. en juillet et août. Pleine terre. 4. L. rayé, C. lineatus. C. spicafolius, Lam.

Tiges foibles, velues, de 3 à 4 pouces. Feuilles sess, obl. , soyeuses, blanchâtres, rayées par leurs nervures. Fleurs rougeâtres, velues en-dehors, au nombre de 2 sur les péd.

Lieu. La Fr. mérid. $\psi$. Fl. en juin. Orangerie. 5. L. de Sibérie, C. sibiricus. 
Feuilles en cocur, acuminées, lisses. Pédoncules uniflores. Lieu. La Sibérie. Fl. en juillet et août.

5. Liseron à feuilles d'hermanne, l'Hérxt. Willd. C. cre natus, $\mathrm{J}_{\mathrm{ACQ}}$.

Tiges grimpantes, cotoneuses, argentées. F. presque hastées, en cœur, oblongues, obtuses, crénelées. Fl. géminées, pédon c.

Lieu. Le Pérou. $¥$. Pleine terre ou orangerie.

7. L. à feuilles de piloselle, C. pilosellafolius, LAM.

Tiges légèrement velues, couchées. Feuilles alternes, lancéolées, sessiles, vertes, velues. Fleurs petites, au nombre de 4 à 6 sur des pédoncules axillaires, beancoup plus long que les feuilles. Folioles calicinales velues, ovales, pointues.

Lieu. Le Levant. $\longleftarrow$. Orangerie.

8. L. de Sicile, C. siculus.

Tiges rampantes, d'un pied. Feuilles entieres, en cœur, ov. pointues, pét. Fleurs bleues, sol., ax., sess.

Lieu. L'Europe mérid. Fl. id.

* 9. L. tricolor, C. tricolor. Belle-de-jour.

Tiges couchées, velues, d'un à 2 pieds. Feuilles alt., sess., lanc-ovales, glabres. Fleurs grandes, d'un beau bleu sur leurs bords, blanches au milieu, jaunes dans le centre, péd., ax., sol.

Lieu. L'Espagne, la Sicile. Fl. id.

* ro. L. soldanelle, C. soldaneilla.

Tiges d'un pied, rameuses, rampantes. Feuilles alt., réniformes, glabres, un peu épaisses, pét. Fleurs pourpres, grandes, ax., sol., péd.

L:eu. Dansles sables près de la mer. Ind. Fl. en juin et juī. II. L. de la Caroline, C. carolinus.

Tiges menues, grimpantes. Feuilles cordiformes, entières ou à 5 lobes velus. Fleurs purpurines, y ou 2 sur les péd. ax.

Lieu. La Caroline. $\Psi$. FI. en juillet. Pleine terre. 22. L. farineux, C. farinosus.

Tiges grimpantes, couvertes d'un duvet blanc. Feuilles cordiformes, acuminées; les unes entières, les autres a 3 lobes, ondulées. Fleurs purpurines, 2 ou 5 sur les péd. ax.

Lieu. Matère. $\%$. Fl. en mai el juin. Orangerie.

35. L. panduriforme, C. pariduratus. 
Tiges longues, grêles, grimpantes. Feuilles pét.; les inf. entières, cordiformes; les sup. sinuées, panduriformes, à 3 lobes. Fleurs grandes, à fond pourpre et limbe blanc, péd., ax., sol.

Lieu. La Caroline, la Virginie. $₹$. Fl. en juin - sept. Pleine terre.

If. L. des Canaries, C. canariensis.

Tiges grimpantes. Feuilles cordiformes, pubescentes, poinfues, molles, cotonneuses. Flcurs d'un bleu pâle, un peu veIues, sur des pédoncules ax., multiflores.

Lieu. Les Canaries. ๖. Fl. en mai - sept. Orangerie. I5. L. althæiforme, C. althreaides.

Tiges grêles, volubiles. Feuilles; les inf. cordiformes, sinuées et dentées; les sup. presque palmées. Fleurs grandes, rougeâtres, au nombre de 2 sur les pédoncules. Toute la plante couverte d'un duvet soyeux.

Variété plus longue et argentée, à feuilles incisées.

Lieu. Le Levant. La variété, la Sicile. . Fl. en juin - sept. Orangerie.

16. L. du Caire, C. cairicus.

Feuilles palmées, presque pinnées, dentées. Pédoncules filiformes, paniculés. Calices lisses.

Lieu. L'Egypte. Fl. en juin et juillet.

* I7. L. argenté, C. cneorum.

Arbuste de 2 pieds, très-ramelix, formant un buisson lien garni. Feuilles nombreuses, sur-tout au sommet des tiges et des rameaux, éparses, obl., étroiles, douces au toucher, couvertes d'un duvet soyeux et argenté. Fleurs blanches, ramassées e!r espèce d'ombelle term.

Lieu. L'Espagne, le Levant. Ђ. F1. en mai-juillet. Toujours vert. Orangerie.

L'espèce à feuilles d'olivier, C. olecefolius, LAm., ne differe de la précédente que par ses folioles calicinales qui sont courtes et obtuses, et par ses feuilles plu; étroites. Même lieu, mêtue. température, même durée.

* I8. L. linéaire, C. cantabrica.

Tiges Jrnites ou perrchées selon les variétés, velues, d"ur pied et demi. Feuilles sessiles, lin,-lanc., aiguës, velues. Flon 
moyennes, roses ou blanches, term., au nombre de 2 ou 3 sur les péd.

Lieu. L'Europe mérid. Ђ. Fl. une partie de l'été. Orangerie. Variété à tige droite et rameuse.

I9. Liseron effilé, C. scoparius.

Tiges glabres, rameaux effilés, droits et simples. Feuilles alt., distantes, courles, lin., un peu velues. Fleurs blanches, velues en-dehors, péd., sol., term. Les calices ovales, aigus, soyeux.

Lieu. Les Canaries. Ђ. Fl. en août et sept. Orangerie. 20. L. thyrsoide, C. floridus.

Tige de 4 pieds. Rameaux grêles. Les floriferes paniculés. Feuilles éparses, obl.-lanc., rétrécies à leur base, un peu velues. Fleurs nombreuses, petites, blanches, disposées en panicule term.

Lieu. Les Canaries. Ђ. Fleurit en août. Orangerie.

2т. L. fruticuleux, C. fruticulosus, Lamarck.

Tiges sous-ligneuses, volubiles, de 3 à 4 pieds. Feuilles lin.lanc., échancrées à leur base. Fl. petites, rayées de pourpre, péd.

Lieu. Les Canaries. Ђ. Fl. en avril et mai. Orangerie. 22. L. stipulé, C. stipulatus, Lamarск.

Tiges herbacées, volubiles. Feuilles pét., div. en 5 parties, ovales-lanc., dentées, mucronées. Fleurs petites, blanches, péd., ax., sol. Toute la plante glabre.

Lieu. Le Levant.....

25. L. sans. bractées, C. ebracteatus.

Tiges volubiles, d'un pied et demi. Feuilles alt. , cordiformes, sa-jittées, pointues, à lobes alongés, pét. Fleurs petices , blanches, sol.

Lieu.....

24́. L. sagitté, $C$. medium.

Tiges menues, glabres et grimpantes. Feuilles lin., hastées, acuminées; les lobes ou oreillettes dentés. Fleurs ped., ax., sol. 5 fol. cal. sagittées.

Lieu. Les Indes. or. Fl. en juillet et août. 25. L. à 3 dents, C. tridentatus.

Tiges volubiles. Feuilles alt, cunéiformes, à 5 pointes, glam 
bres. Fleurs à fond purpurin et à limbe d'un blanc jaunâtre, péd., ax., sol.

Lieu. Ind. Fl. id. 26. L. velu, C. obscurus. L. de Java.

Tiges volubiles, velues, de 3 à 4 pieds. Feuilles alt. , cordiformes, pointues, pét., un peu velues eir-dessous. Fleurs blanches, péd., ax., sol. Calices glabres.

Lieu. Les Indes or. Fl. id.

27. L. muriqué, C. muricatus.

Tige lisse, hérissée de pointes molles. Feuilles entières, cordiformes. Fleurs purpurines, portées sur des pédoncules épais et multiflores. Calices lisses.

Lieu. Id. Fl. id.

28. L. à gros fruit, C. macrocarpus.

Tiges grêles, volubiles. Feuilles palmées, presque digitées, à 5 lobes pointus, glabres, pét., d'un vert léger. Fleurs grandes, purpurines, péd., ax., sol. Fruit gros coname une noix.

Lieu. Les Indes occid. Fl.id.

29. L. pentaphylle, C. pentaphyllus.

Tiges pét. Péd. et calices hérissés de poils roussâtres. Tige assez grosse, volubile, rameuse. Feuilles alt., digitées, à 5 fol. ov. , acuminées, entières, sess. Fleurs d'un blanc jaunâtre, péd., ax., sol.

Lieu. Id. Fl. en août et sept.

3o. L. à feuilles épaisses, C. pes capree.

Feuilles bilobées, péd. uniflores.

Lieu. Les Indes or. Fl. en juin et juillet. 3r. L. patate, C. batatas.

Tiges foibles, volubiles, traînantes, s'enracinant à chaque nœud, où elles forment des tubercules. Feuilles cordiformes, hastées, à 5 nervures.

Lieu. Les deux Indes. $\nsucc$. Fl. . . . Serre chaude.

* 32. L. en ombelle, C. umbellatus.

Tiges volubiles. Feuilles alt., cordiformes, pointues. Fleurs d'un beau jaune, formant une ombelle. 
Lieu. Les Indes occid., Saint-Domingue. $\psi$. Fl. en juin et juillet.

\section{Liserow turbith, C. turpethum.}

Racines laiteuses, qui s'enfoncent très-profondément en terre. Tiges à 4 ailes, volubiles, rameuses. Feuilles alt., cordiformes, anguleuses, crénelées, pointues; les pét. ailés. Fleurs grandes, 5 ou 4 sur les péd., ax.

Lieu. L'île de Ceylan. ㄲ. Fl. . . . Serre chaude.

* 34. L. nerveux, C. speciosus, H. K. C. nervosus, Burm.

Tiges fortes, épaisses, dont l'écorce est blanchâtre, couvertes d'un duvet blanc et soyeux dans leur jeunesse, grimpantes, longues et s'élevant à une grande hauteur. Feuilles alt., grandes, cordiformes, pointues, entières, d'un beau vert en-dessus, très-blanches et cotonneuses en-dessous. Fleurs assez grandes, d'un blanc pourpré, péd., axillaires, souvent solitaires.

Lieu. Les Indes or. Ђ. Fl. . . S Serre chaude.

55. L. jalap, C. jalapa. Vrai jalap.

Racine noirâtre en-dehors, blanche et laiteuse en-dedans, 'Tiges volubiles, de 8 à ro pieds. Feuilles ovales, presqu'en cœur, obtuses, ondulées, velues en-dessous. Fleurs d'un jaune pâle, péd., ax., sol.

Lieu. Le Mexique. Ђ. Fl. en août et sept. Serre chaude ou orangerie.

36. L. à feuilles larges, C. brasiliensis.

Feuilles larges, échancrées et garnies de deux glandes à le ur base. Péd. triflores.

Lieu. L'Amérique mérid. ₹. FI. . . Serre chaude.

Cult. Toutes les espèces vivaces de pleine terre ou de serre, excepté les indigènes, se sèment au printemps sur couche; celles de serre en pot, et seront conduites à la manière ordinaire indiquée pour les plantes de ces températures. Plusieurs espèces annuelles de pleine terre peuvent l'être aussi sur couche où elles peuvent rester, et où elles fleuriront mieux qu'en pleine terre. Les autres se sèment ou en place, ce qui est préférable, pcurvu que la terre soit légère; ou en planches préparées. Les భ de pleine terre peuvent aussi se semer en place. Quelques-unes, sur-tout celles qui ne sont pas volubiles, se multiplient par les 
boutures faites en été en pot, sur couche abritée. Elles s'enraci-m nent assez facilement. Les deux dernières espèces peuvent se propager par leurs tubercules et leurs racines. La plupart des liserons se plaisent dans les terres un peu légères et chaudes. Ceux de serre exigent une terre meilleure et plus consistante; peu d'arrosemens en hiver, fréquens en été, et une bonne exposition dans cette saison. Les 5 dernières espèces de serre chaude sont délicates et exigent de la chaleur. Cependant la $34^{\epsilon}$, quand elle est un peu âgée, et que sa tige est faite, peut être mise dans un coin de la serre pour en palisser les tiges sur les murs. Elle ne pourroit d'ailleurs subsister long-temps isolée par l'embarras qu'elle causeroit. Elle pousse dans un seul été plus de ro pieds de tige.

Us. Parmi le peu de liserons que je cultive, les espèces tes plus agréables sont la $9^{\mathrm{e}}$, par la grandeur et la couleur variée de ses fleurs; la $17^{\circ}$, par son feuillage presqu'aussi argenté que le protée de cette nuance; la $34^{\mathrm{e}}$, par ses superbes feuilles et las $3_{2}{ }^{\mathrm{e}}$ par ses ombelles. On trouve peu de liserons culivés, exeepté dans les jardins de botanique.

Le suc épaissi des racines de la $5^{\mathrm{e}}$ est la scammonée, en usage en médecine; c'est un purgatif assez violent, dont l'cffet est sûr, mars qu'on n'administre que lorsqu'il est nécessaire de donner de fortes secousses à la machine humaine.

Les racines de la $5 \mathrm{I}^{\mathrm{e}}$ sont les patates, aliment fort commun dans les deux Indes, dont on fait usage comme nous faisons de la pomme-de-terre.

Le turbith, ou celles de la $33^{\mathrm{e}}$, donnent un suc laiteux et gluant, en usage en médecine, comme cathartique et vomitif.

Les racines de la $35^{\mathrm{e}}$ donnent le vrai jalap. Ce purgatif, qui. est fréquemment employé, est un des meilleurs que l'on connoisse, quand on le donne avec circonspection. Il agit à de trèspetites doses, et comme il n'a pas d'odeur, il n'est pas désagréable à prendre.

On regarde la soldanelle ind., I $o^{\mathrm{e}}$ espèce, comme un bon purgatif.

On cultive encore plusieurs autres especes dont la culture. 
répond à celle des espèces indiquées ici. Leur lieu originaire et leur durée détermineront celle qui leur convient. Les plus récemment cultivées sont :

37. Convozruzus paniculatus, Lin., JACQ. Feuilles palmées à 7 lobes. Fleurs paniculées.

Lieu. Le Nalabar. $\Psi$.

38. C. pentapetaloïdes. C. humilis, JAcQ. Fleurs solitaires, à 5 divisions.

Lieu. Majorque. $\odot$.

5g. C. glaber, Hort. angl.

Lieu. La Guyane. $v$.

40. C. flagelliformis, Hort. ang\$.

Lieu. Les Indes or. 5 .

Excepté la 38, qui est de pleine terre, les autres sont de serre chaude.

On connoît I 40 à I 50 espèces de ce genre.

\section{Quamoclit, Ipomoea.}

Cal. 5-fide. Cor. infund., longue, à limbe plissé, 5-fide ou à 5 dents. Stigm. en tête. Caps. à 3 loges polyspermes.

* I. Quamoclit écarlate, $I$. coccinea. Jasmin d'Amérique vulg.

Tiges grêles, volubiles, de 6 à 7 pieds. Feuilles en cœur, acuminces, anguleuses à leur base. Fleurs d'un bel écarlate, plusieurs sur le même péd., ax.

Lieu. Les Indes occid. Fl. en juillet-sept.

2. Q. étoilé, I. Lacunosa.

Feuilles cordiformes, acuminées, marquées de trous, anguleusas à leur base. Péd. presqu'uniflores, plus courts que les fleurs.

Lieu. La Virginie, la Caroline. Fl. en juillet.

3. Q. à trois lobes, I. triloba.

Feuilles en cœur, à 5 lobes. Péd. triflores. Tige de 10 à 12 pieds. Fleurs pourpres.

Lieu. Les Indes occid. Fl. en juin et juillet. 4. Q. lierré, I. hedercefolia. 
Feuilles à 3 lobes et en cœur. Péd. multiflores et racémiformes.

Lieu. L'Amérique mérid. Fl. en juillet.

5. Q. à feuilles de tame, I. tamifolia.

Feuilles en cœur, acuminées, velues. Fleurs rassemblées.

Lieu. La Caroline. Fl. en juillet.

6. Q. épineux, I. bona nox.

Tige garnie d'aiguillons. Feuilles cordiformes, aiguës, trèsentières. Fleurs ternées. Corolles entières.

Lieu. Les Indes occid. Fl. id.

7. Q. palmé, I. pes tigridis.

Feuilles palmées. Fleurs rassemblées. Toute la plante velue.

Lieu. Les Indes or. Fl. en août.

* 8. Q. à feuilles ailées, I. quamoclit.

Tige de 7 à 8 pieds, volubile, rameuse. Feuilles pinnatifides, à découpures linéaires, étroites. Fleurs écarlates, presque solitaires.

Lieu. Les Indes or. Fl. en juillet - sept.

9. Q. tubéreux, I. tuberosa.

Feuilles palmées, à 7 lobes lancéolés, aigus, très-entiers. Péd. triflores.

Lieu. Les Indes occid. $\%$. FI....

Cult. Les 5 premières espèces sont de pleine terre; les autres de serre chaude. Ces plantes se cultivent comme les liserons, auxquels elles ont beaucoup de rapports. Leur terre doit être légère, substantielle, et leur exposition méridienne, même pour celles de pleine terre. On les sème toutes sur couche, et on les plante ensuite, savoir celles de serre chaude en pot, et cellec. de pleine terre à la place où elles doivent rester.

La premiere n'est point du tout délicate; elle ne demande qu'une situation chaude pour fleurir. Elle fructifie aisément dans nos climats, et se sème souvent elle-même; mais ces jeunes plantes lèvent ordinairement trop tard pour porter leurs fleurs. Il vaut mieux l'élever comme les autres sur couche.

Us. Ces plantes ont la plupart des fleurs d'une couleur éclatante. Elles ne laissent pas que de concourir à l'ornement des lieux oil on les plante. Elles doivent être, ainsi que les liserons 
volubiles, placées de manière que leurs tiges puissent se soutenir. Le bas des murs est une place qui leur est à tous égards favorable, pourvu qu'ils soient exposés au midi. On fait des berceaux annuels avec la première espèce.

* Io. Quamoclit hédéracé, I. hederacea. Convolvulus, Lin., Wrlld., Bot. cult., édit. r ${ }^{\mathrm{re}}$.

Tiges grimpantes, rougeâtres, de 2 à 3 pieds. Feuilles alternes, cordiformes, entières et à 5 lobes, un peu velues. Fleurs purpurines, au nornbre de 3 sur des pédoncules axillaires.

Lieu. L'Asie, l'Afrique, l'Amérique. ๑. Fleurit en juillet et août.

* I1. Q. pourpre, I. purpurea. Convolvulus, Lix., Willd., Bot. cult. , édit. $I^{\text {re }}$.

Tiges volubiles, de 2 à 3 mètres, brunes. Fenilles en cœur, entieres. Fleurs grandes, pourpres dans le tulie de la corolle, à l'extérieur et sur les 3 plis; d'un blanc tirant sur le violet sur le limbe. La corolle très-entière. Fruit pendans.

Variétés souvent sur la même plante. 1. A fleurs entierement pourpres,

2. A fleurs blanches.

3. A fleurs panachées.

Lieu. L'Amérique. $\odot$. Fleurit en août et septembre.

* I2. Q. nil, I. nil. Convolvulus, Lin., Willd., Bot. cult., édition $\mathrm{I}^{\mathrm{re}}$.

Tiges volubiles. Feuilles cordiformes, trilobées. Fleurs bleues. Corolle presque à 5 divisions. Les pédoncules plus courts que les pétioles. Fruits droits.

Lieu. L'Amérique mérid. $\odot$. Fl. id.

Ces trois espèces n'ayant qu'un stigmate en tête et non bifide, doivent faire partie de ce genre, et être par conséquent distraites de celui des liserons, dont le stigmate est bifide.

Cult. Pleine terre. La même que celle des liserons annuels et $\mathrm{du}$ liseron tricolor, etc. Cependant comme ces trois dernières sont originaires des pays chauds, on fera bien de les semer sur couche chaude pour les repiquer ensuite dans une bonne terre en plein air et à une exposition méridienne, où elles mûriront leurs graines. Il est essentiel de leur donner de bons supports : 
ả cause de la hauteur de leurs tiges et du nombre de leurs rameaux.

Ces trois espèces sont belles et peuvent être employées à la décoration des jardins. Elles sont susceptibles de former des berceaux et des palissades agréables, avec la capucine et les pois de senteur.

II y a environ 60 espèces connues de ce genre.

\section{Plusieurs styles.}

\section{Liserolle, Evolvulus.}

Cal. à 5 part. Cor. en roue, 5-fide. 4 styles. 4 stigm. Caps. 4 loges et à 4 valves.

x. Liserolue à feuilles de lin, $E$. linifolius.

Tiges droites, menues, velues, de 6 à 9 pouces. Feuilles alt., lanc., sess., velues. Fleurs petites, bleuâtres, une à cinq sur chaque péd. long et ax.

Lieu. La Jamaique. r. Fl. en août et sept.

2. L. alsinoïde, E. alsinoides.

Tiges grêles, étalées, velues, diffuses, de 9 pouces. Feuilles alt., pét., presqu'en cœur, obtuses et velues. Péd. ax. bi ou triflores.

Lieu. Les Indes or. Fl. en juin et juillet.

Cult. Serre chaude. Ces plantes ne sont cultivées que dans les jardins de botanique. On les sème en pot, sur cuuche et sous châssis,

\section{Cresse, Cressa.}

Cal. à 5 parties penchées, et 2 bractées très - petites. Corolle á peine plus longue que le calice, tubuleuse, à 5 divisions. Anthères obrondes. Capsule à une loge, 2 valves, s'ouvrant par sa base. Une seule semence.

Cresse de Crète, C. cretica, Lam., Wilid., Desfont.

Cet arbuste sous-ligneux forme un petit buisson très-rameux, dont les rameaux sont velus, diffus, et qui ne s'élève guère qu'à I2 à 15 centínètres (un demi-pied). Feuilles alternes, sessiles, 
ovales, pointues, entières, velues, très - petites et très-nombreuses. Fleurs petites, disposées en têtes terminales.

Lieu. La Crète, l'Italie, etc. $๘$, Ђ.

Cull. Orangerie. Cette plante se rencontre rarement dans les collections. Elle est cultivée au Muséum.

\section{Genres qui ont des rapports aux liserons.}

Cette section n'offre aucune plante actuellement cultivée. La cuscute, qui en fait partie, est une parasite que, loin de chercher à posséder, on tâche de détruire. Elle pousse de petits filamens rouges qui s'entortillent autour de certaines plantes, et dont il est assez difficile de les débarrasser. Ses fleurs sont blanches, petites, ramassées par paquets. Elle est ind. $¥ . \mathrm{La}$ cascute épithyme est de la même nature.

\section{O R D R E X I.}

\section{Les Polémoines (Polemonta).}

Calice divisé. Corolle régulière, à cinq lobes. Cinq étamines insérées au milieu du tube de la corolle. Un ovaire et un style, le stigmate triple. Capsule environnée du calice persistant, triloculaire, trivalve, polysperme; chaque valve pourvue, dans son milieu, d'une cloison intérieure ou d'une côte saillante; le réceptacle ou la cloison centrale, trigone, appliqué angulairement anx parois des valves.

Herbes ou arbrisseaux. Feuilles alternes ou opposées. Fleurs terminales ou axillaires. 


\section{Phlox, Phlox.}

Cal. 5-fide ou à 5 part. conniventes. Cor. tubulée, infund., à tube long et limbe plane, à 5 div. Etam. inégales, non saillantes, dont les filamens sont insérés au fond du tube, et qui lui sont adnés. Anthères sagittées.

* x. Phlox paniculé, $P$. paniculata.

Tiges de 3 à 4 pieds, nombreuses, droites et glabres. Feuilles opp., lanc., planes, pointues, sess., rudes en leurs bords. Fleurs d'un pourpre pâle ou lilas, nombreuses, en corymbes paniculés et term. Les div. de la corolle arrondies.

Lieu. L'Amérique septentr. $\%$. Fl, en août et septemb.

Variété à feuilles panachées. Accidentelle. Les panaches ne tiennent pas.

* Variété à fleurs blanches.

2. P. ondulé, $P$. undulata, H. K.

Cette espèce differe peu de la précédente; ses feuilles sont obl. - lanc. , ondulées et rudes en leurs bords. Fleurs bleuâtres , disposées id. Les divisions de la corolle presqu'émoussées.

Lieu. Id. $₹$. Fl. en juillet et août.

* 3. P. blanc, P. suaveolens, P. candida.

Tiges d'un pied et demi, très-glabres. Feuilles ovales-lanc.; très-glabres, acuminées, entières, d'un vert jaunâtre, ainsi que les tiges. Fleurs d'un blanc pur, plus grandes que les précédentes, en grappe paniculée, term., odorantes.

Lieu. Id. Fl, en juin et juillet.

* Variété à feuilles panachées de blanc. Constante.

J'ignore ce qui a pu déterminer Michaux à faire du phlox suaveolens une variété du $P$. maculata, puisqu'ils n'ont aucun rapport entre eux par leurs tiges, leurs feuilles, leurs fleurs et leur port.

* 4. P. maculé, P. maculata.

Tiges très-droites, de 3 à 5 pieds, un peu rudes, tachetées, dans toute leur longueur, d'un grand nombre de points bruns, alongés, très-proches les uns des auires. Feuilles lanc. - obl., 
pointues, glabres. Fleurs d'un pourpre blenàtre, en grappes alongées, garnies, bien régulières et tern.

Lieu. Id. $\Psi$. Fl. en août et sept.

* 5. Phlox de la Caroline, $P$. caroliniana.

Tiges de 2 pieds, rudes au toucher. Feuilles sess., lanc., entières, à bords réfléchis, glabres et lisses. Fleurs d'un beau pourpre, en especces de vericilles rapprochés, formant ensemble un corymbe fasciculé et term. Cette espèce différe peu de la suivante.

Lieu. La Caroline. $\psi$. Fl. en juillet et sept.

Variété. Latifolia, Mrснаux.

*6. P. glabre, $P$. glaberrima.

Tige d'un pied et demi, un peu grêle. Feuilles linéaireslanc., étroites, pointues, entières, glabres. Fleurs d'un pourpre clair, en corymbe lâche et term.

Lieu. L'Amérique seplentr. $\%$. Fl. en juin-aô̂t,

* 7 . P. divariqué, $P$. divaricala.

Tiges d'un pied, foibles, ordinairement inclinées, rameuses, dichotomes. Feuilles ali., sess., ovales-lanc., courtes, pointues. Fleurs plus grandes que celles des espèces précédentes, d'un bleu léger, en grappes lâches et terminales. Les péd. géminés.

Lieu. Id. $\psi$. Fl. en avril-juin.

* 8. P. rampant, P. replans, Mrсh., Vent. P. stolonifera, Hort. angl.

Tiges nombreuses, cylindriques, pubescentes, d'un brun rougeâtre: les unes couchées, rampantes, poussant des rejets et ne portant pas de fleurs; les autres droites, simples et fertiles. Feuilles opposées, pétiolées, très-entières, glabres, concaves et d'un beau vert en-dessus, pâles en-dessous : celles des Liges stériles nonabreuses; celles des fertiles ovales-lancéolées, plus courtes et plus étroites que les autres, qui sont ovales. Fleurs d'un lilas violet ou bleu pâle, odorantes, de la grandeurde celles de la petite pervenche, pédonculées et disposées en corymbes terminaux; quelques-unes axillaires, composées de 5 à 10 fleurs.

Lieu. La Caroline. $*$. Fleurit au printemps. 
* 9. P. velu, P. pilosa.

Tiges peu nombreuses, d'environ un pied. Feuilles lanc.pointues, sessiles et un peu velues Fleurs d'un beau pourpre rose, avec un tube grêle et violet, divisé en 5 parties ovales, disposées en corymbe au sommet des tiges. Calice à divisions brunes, membrancuses en leurs bords. Pédoncules pubescens, accompagnés d'une bractée lancéolée, ovale, pointue et brune.

Lieu. La Virginie. $\tau$. Fl. en juin.

* Io. P. subulé, P. subulata.

Tiges couchées, rampantes, étalées sur la terre, où elles forment de larges tapis, radicantes, velues et grises. Feuilles rassemblées en faisceaux opposés, tiès-nombreux, linéaires-lanc.; très-étroites, un peu épaisses, sessiles, ouvertes, très-glabres, quelquefois légerement velues en leurs bords, terminées par une pointe particulière, blanche, un peu concaves en-dessus et veries. Fleurs d'un joli lilas pourpre, opposées, dont les divisins sont échancrées, et le limbe très-plane, marqué dans son centre d'une étoile, d'un pourpre violet à sa base. Calice velu, d'un violet noirâtre ou d'un vert foncé.

Lieu. La Virginie. $₹$. Fleurit dans les premiers jours $d u$ printemps. Toujours vert.

* I r. P. setacé, P. setacea.

Cette espece a des rapports à la précédente; cependant elle en est bien distincte. Ses tiges et ses branches sont aussi rampantes, mais moins étalées; ses liges florifères se redressent. Elle est garnie de poils sur toutes ses parties, excepté les fleurs. Les feuilles inférieures et celles des tiges stériles sont très-étroites, sétacées; celles des tiges fleuries opposées, élargies à leur base, lancéolées, pointues, longues de 8 à ı lo lignes. Fleurs d'un joli rose, tronquées, et un peu échancrées au sommet de leurs di-. visions, marquées dans le centre d'une étoile rouge à sa base, pédonculées, solitaires dans les aisselles inférieures, géminées dans les supérieures, et au nombre de trois terminales. Calice très-velu.

Lieu. Id. Fleurit id. $\psi$. Toujours vert.

* i2. P. à feuilles ovales, P. ovata, Mrleer-

I'euilles radicales et inférieures, ovales-elliptiques, finissan: 
en pétiole à leur base, un peu épaisses, très-entières et presque glabres, d'un vert foncé; les supérieures ovales, presque sessiles, velues, moins grandes. Tiges grêles, d'un pied environ de hauteur, portant à leur sommet des fleurs solitaires sur leur pédoncule, grandes, d'un pourpre léger, et leurs divisions arrondies à leur sommet.

Lieu. L'Amérique sept. $\nsucc$. Fleurit en juillet.

* I5. Phlox frutescent, $P$. fruticosa, Hort. angl.

Tiges frutescentes, dures, droites, roides, cylindriques, rameuses et glabres. Feuilles, les unes lancéolées, oblongues, les autres ovales, toutes presque sessiles ou entièrement, trèsglabres et d'un beau vert. Celles qui sont oblongues ont environ deux pouces et demi de longueur, les autres un pouce et demi à deux pouces; leurs fleurs bleues, en corymbes terminaux.

\section{Lieu..... . Fleurit en été.}

4. P. pyramidal, P. pyramidalis, Hort. angl.

Cult. Presque tous les phlox sont rustiques et supportent les gelées sæn en être affectés. Ils viennent très-bien'dans les terres fortes et argileuses, ou la plupart se multiplient, même plus qu'on ne veut. La septième seulement aime les sols plus légers et plus chauds. Mult. par la séparation de leurs pieds en automne ou en février. Leur culture est extrêmement facile. La onzième ainsi que la treizième craignent les fortes gelées qui les mutilent : il est prudent d'en avoir des pieds en orangerie.

Us. Il est pen de plantes dont l'effet soit plus agréable que celles-ci, et qui contribuent davantage à la décoration des jardins. Leurs gerbes fleuries embellissent tous les lieux qu'elles habitent; les unes sourient à la nature dans son retour à la vie; les autres parent les premiers jours de la scène automnale. Une suite do ylox, soit aux bords d'une prairie, soit près des rives d'un cours d'eau limpide, est d'un aspect charmant dans le temps de leurs fleurs. Les espèces ro et I I forment des tapis fleuris dans les premiers jours du printemps. 


\section{Polémoine, Polemonium.}

Cal. en godet, 5-fide. Cor. en roue, à tube court, à limbe à 5 lobes. Filamens des étamines plus larges à leur base. Anthères penchées.

* I. Polémorne bleue, Valériane grecque, P. cœeruleum.

Tiges de 2 pieds et plus, droites, nombreuses. Feuilles ailées, sess., alt., à folioles nombreuses, obl., entières, d'un vert foncé. Fleurs bleues, droites, en bouquets term. Cette plante forme des touffes serrées et arrondies.

Variété à fleurs blanches.

Lieu. L'Angleterre. $\%$. Fl. en mai-juillet.

* 2. P. rampante, $P$. reptans.

Tiges nombreuses, un peu couchées et redressées. Feuilles ailées, à 7 fol. distantes, alt. , étroites, pointues, d'un vert sombre. Fleurs d'un bleu pâle, plus petites, disposées en bouquets term. et un peu penchés.

Lieu. L'Amériq. sept. $\%$. Fl. en avril et mai.

3. P. sibiricum, Hort. angl.

Lieu. La Sibérie. $\psi$. Fleurit en juin.

Cult. Pleine terre. Ces plantes sont aussi rustiques et aussi faciles à cultiver que les phlox. Elles croissent dans tous les terrains, mais elles sont plus belles dans les lieux ouverts que dans les ombragés. Elles se sèment elles-mêmes, et il est facile de les multiplier en séparant leurs touffes.

Us. Les polémoines sont cultivées pour l'agrément des jardins. En effet elles y contribuent par leurs fleurs qui couronnent leurs tiges. La première est plus belle et forme une gerbe droite.

\section{Bonplande, Bonplandia.}

Cal. tubuié, persistant, à 5 dents. Cor. monopétale, un peu irrégulière; le tube plus long que le calice, rétréci inférieurement; le limbe à 5 divisions échancrées, dont les deux supérieures sont droites et la $5^{\mathrm{e}}$ pendante. Etamines courbées, insérées un peu au-dessous de l'entrée du tube. Anthères arrondies, comprimées. Ovaire presque trigone; stigmate trifide. 
Capsule trigone, a 5 loges, 3 valves et trois semences elliptiques. Souvent une ou deux avortent.

* Bonpla nde à fleurs geminées, B. geminiflora.

Tige droite, d'un pied et plus, cylindrique, rameuse et velue. Feuilles alternes, lancéolées, pointues aux deux bouts, dentées en scie, marquées de nervures latérales qui forment des plis et rendent les feuilles presque gaufrées. Fleurs d'un bleu violet, d’une consistance légère, plus petites que celle du phlox, géminées, axillaires et terminales. Filamens rougeâtres. Anthères jaunâtres.

Lieu. La Nouvelle-Espagne. or ou $\nsucc$. Fleurit vers la fin de l'automne.

Cult. Comme cette plante fleurit tard, et qu'elle pourroit par conséquent être atteinte de la gelée, il faut la mettre en vase; alors elle fleurit dans la serre. On l'obtient par ses graines semées au printemps sur couche, et les jeunes plantes repiquées en pots.

Elle a peu d'agrément, et n'est cultivée, dans les collections, qu'à cause de sa qualité d'étrangère. Sa courte durée n'invite pas d'ailleurs à lui donner beaucoup de soins. Elle a une odeur désagréable.

J'ai cru devoir insérer ce genre dans cet ordre, auque? il a bien des rapports. Il tient davantage à celui des phlox. qu'à tout autre de cet ordre. Cependant la forme de la corolle, qui imite un peu celle des violettes, lui donne aussi quelqu'analogie avec ces dernières.

\section{Cantu, Cantua.}

Cal. en godet, 5 à 5-fide. Cor. infund., à tube cylind., à limbe dilaté et ouvert, à 5 lobes. Filamens des étam. égaux, non dilatés, q. f. saillans. Semences ailées à leur sommet.

Cantu rouge, C. rubra. Ipomoea rubra, Lin., H. K. C. coronopifolia, WILLD.

Feuilles pinnatifides, à fol. linéaires. Tige aroite, élevée. FL. rouges, en épis paniculés et pendans.

Lieu. La Caroline mérid. ๖. Fl. en septembre.

Cult. Serre chaude. La même que celle des quanoclî́s. 


\section{Lightfoolia, L'HÉRITIER。}

Cor. à 5 pét., dont le fond est fermé de valves staminifères. Cal. à 5 fol. Stigm. 3 à 5 -fide. Caps. à 3 à 5 loges, à 3 à 5 valves Obs. Ce genre n'est pas dans Jussieu ; mais j'ai cru, d'après son observation dans l'appendice, devoir le placer ici.

I. LightFоотіA à feuilles en lance, $L$. oxycoccoides, L'HériTIER, H. K. Lobelia tenella, Lin.

Feuilles lancéolées. Rameaux filiformes, couchés.

Lieu. Le Cap. \$. Fl. en juillet.

2. L. à feuilles subulées, L. subulata. Id.

Feuilles subulées. Pétales linéaires.

Lieu. Id. ₹.Fl, en août.

Cult. Orangerie. Ces plantes sont assez nouvellement connues. On ne les a possédées, dans le jardin de Kew, qu'en 1787 .

\section{Cobée, Cobcea, CAv.}

Cal. monophylle, à 5 divisions et à 5 angles comprimés et ailés à leur base. Corolle monopétale, plus longue que le calice, campanulée, striée, à limbe à 5 parties crénelées. 5 étamines attachées au fond du tube, saillantes, courbées. Anthères oblongues, dont une échancrée. Ovaire ovale, à 3 à 5 sillons, entouré d'un corps glanduleux, pentagone. Style plus long que les étamines. 3 à 5 stigmates subulés. Capsule ovale, acuminée, à 3 à 5 loges. Semences imbricées. Cav., Icon.

* r. Сове́E grimpante, C. scandens, C.Av.

Tiges ligneuses, sarmenteuses, foibles, grêles, glabres, de 6 à 8 mètres de longueur. Feuilles alternes, portées sur de courts pétioles, ailées avec impaire, à 3 paires de folioles opposées, ovales-oblongues, glabres, très-entières, vertes ou pourprées. Les pétioles terminées par une vrille plusieurs fois divisée. Fleurs d'abord d'un jaune pâle, ensuite violettes, en cloche, pubescentes, de 5 à 6 cent. de diamètre ( 2 pouces 
environ ). Le tube large, avec des bandes violettes. Filets des étamines blancs et velus. Anthères jaunes.

Lieu. Le Mexique. Ђ. Fleurit en été.

Cult. Serre tempérée ou orangerie. Bonne terre substantielle. Arrosemens fréquens dans le temps de sa plus grande végétation, car elle est presque toujours en sève. Un vase trop grand l'affoiblit et souvent la fait périr. Quand on est obligé de la changer, il faut que son vase ne soit guère plus grand que celui qu'elle avoit. Lorsque cette plante a tapissé son pot de racines, elle pousse alors si prodigieusement, qu'en un an elle peut couvrir tout le mur ou les vitraux d'une serre; mais elle languit jusqu'à ce qu'elle ait fait plusieurs racines. On la perd assez fréquemment lorsqu'elle est jeune par cette raison, et lorsqu'on lui coupe ses principales tiges. Cependant quand elle est forte, elle souffre ces mutilations, souvent nécessaires pour la restreindre. On la multiplie par les marcottes, qui s'enracinent assez aisément, et par les boutures. Ces dernières se font avec succès dans tous les temps. Les jeunes cobées doivent être mises dans de très-petits pots, que l'on plongera dans une bonne couche pour assurer leur reprise, ei qu'on ne changera que lorsque les racines les auront entièrement garnis.

Us. La cobée est une des plus belles plantes que l'on puisse cultiver pour l'ornement des jardins. Elle l'est actuellement dans plusieurs. C'est à M. Cavanille qu'on en doit la connoissance, ainsi que de plusieurs autres plantes intéressantes. Cependant, elle a le défaut assez gênant de s'emparer de trop d'espace. On peut la palisser en plein air pendant l'été. Elle supporte sans dommage 5 degrés de congélation. Ce genre appartient à la famille de polémoines. La ressemblance de sa fleur avec celle de la bignone de Virginie, prouve les rapports qui se trouvent entre ces deux ordres, et établit le passage de l'ún à l'autre.

2. C. en arbre, C. arborescens, Hort. angl.

Lieu. Les Indes or. Ђ.

Cult. Serre chaude. Cultivée en Angleterre. 


\section{O R D R E I I.}

\section{Les Bignones (BIGNoni AE).}

Calice divisé. Corolle ordinairement irrégulière, à quatre ou cinq lobes. Presque toujours cinq étamines, une souvent stérile. Un ovaire, un style et un stigmate simple ou bilobé. Fruit biloculaire, tantôt capsulaire, polysperme; la clcison séminifère opposée ou parallèle aux valves; tantôt coriace, li. gneux, s'ouvrant seulement par le sommet, renfermant peu de semences; la cloison séminifère s'avan. cant le plus souvent des deux côtés en aile qui partage les loges. L'embryon sans périsperme.

Herbes, arbrisseaux ou arbres. Feuilles opposées, rarement alternes.

\section{Fruit capsulaire, bivalve. Tige herbacée.}

\section{Galane, Chelone.}

Cal. à 5 part. et 3 bractées. Cor. tubulée à sa base, enflée à son entrée, à limbe à 2 lèvres; la sup. échancrée; l'inf. 3-fide. 4 étam. didynaniques. La $5^{\mathrm{e}}$ stérile. I stigm. Caps. ovale, à 2 loges, 2 valves, à cloison et polysperme. Semences nombreuses, membraneuses en leurs bords.

* I. Galane blanche, C. alba, Noв. C. glabra, Lin.

Tiges de 3 à 4 pieds, obtusément tétragones, sillonnées dans les intervalles, glabres, presque simples. Feuilles opposées, lancéolées-oblongues ; leurs côtés réfléchis en-dedans et formant la gouttière ; simplement dentées en leurs bords, pointues, à nervures saillantes et parallèles, d'un vert foncé en-dessus. Fleurs blanches, plus grosses qque celles des autreళ 
espèces, disposées en épis serrés et terminaux. Le cinquième flament vert et glabre soulement à son extrémité.

Lieu. La Virginie, le Canada. $₹$. Fleurit en septembre et octobre.

*2. Galane pourpre, C. purpurea, Nов., Miller. C. obliqua, Liv.

Tiges un peu moins hautes que celles de la précédente, cylindriques, moins fortes et moins simples. Feuilles opposées, pétiolées, ovales-lancéolées, pointues, presque planes, fortement et doublement dentées, nerveuses, presque ridées, d'un vert léger. Fleurs d'un beau pourpre rosé, moins grandes, disposées en épis serrés, terminaux et axillaires. Le cinquième filament blanc et glabre sur toute sa longueur.

Lieu. Id. ซ. Fleurit id.

Obs. Ces deux espèces sont si différentes entr'elles, qu'on ne peut les réunir ou en faire une variété l'une de l'autre. Les adjectifs spécifiques glabra et obliqua ne sauroient les distinguer ; la première n'étant pas plus glabre que la seconde, et celle-ci n'ayant rien d'oblique.

* 3. G. à panicule, C. penstemon. Penstemon pubescens, H. K. C. penstemon, Liv. Mant.

Tige d'un pied et demi, cylindrique, pubescente. Feuilles opposées, lancéolées, sessiles, amplexicaules. Fleurs purpurines, blanchâtres, pédonculées, en panicule terminal. Le 5e filament élargi à son sommet, et barbu dans sa partie supérieure.

Lieu. L'Amérique sept. $\%$. Fl. id.

Variété à larges feuilles.

4. G: lisse, C. lcevigata. Penstemon levigata, H.K., Wrlud

Penstemon, Mirler.

Tige glabre. Feuilles inférieures ovales, acuminées, pétiolées, très-entières ; les sup. amplexicaules, lancéolées, dentées. Corolles ouvertes, à deux lèvres. Fleurs violettes.

Lieu. Id. $\Psi$. Fleuritid.

* 5. G. campanulée, C. campanulata, Cav. Penstemon, Wirld. C. foliosa, Bot. cult. éd. I.

Tiges nombreuses, droites, cylindriques, feuillées sur 
toute leur longueur, d'un à 2 pieds, formant de larges touffes. Feuilles opposées en croix, peu distantes, ovales - lancéolées, étroites, sessiles, finement dentées en scie, acuminées, trèsglabres. Fleurs d'un rouge foncé en-dehors, blanchâtres endedans, disposées en épi terminal, et souvent unilatérales. Les bractées plus éloignées du calice que dans les autres espèces. * 6. G. barbue, C. barbata, CAv. C. ruellioides, Andr.

Tiges de 4 a 5 pieds, droites, rameuses, peu feuillées, glabres, cylindriques. Feuilles radicales longues, étroites, 'lancéolées, presque spatulées, très-entières, glabres, un peu épaisses, d'un vert grisâtre ; celles des tiges opposées, sessiles, beaucoup plus courtes et lancéolées. Fleurs d'un écarlate rose, horizontales, solitaires ou géminées, pédonculées, disposées en grappes terminales, qui s'alongent beaucoup à mesure que la fructification s'opère. Corolle tubulée, à deux levres; la supérieure échancrée ; l'inférieure à 3 divisions arrondies, garnie, à l'entrée du tube, de poils jạnes et marqués de lignes plus rouges. 5 étamines blanches, dont deux attachées sur la partie inférieure du tube; 2 libres des deux còtés de l'ovaire, et la cinquième stérile, et insérée sur la partie supérieure du tube. Anthères géminées et courbées.

Lieu. Le Mexique. $\longleftarrow$. Fleurit tout l'été et une partie de l'automne.

Obs. Aiton et Willdenow nous ont fait deux genres séparés de celle-ci; l'un sous le nom de chelone, l'autre sous celui de penstemon. Cette distinction n'étant fondée que sur le cinquième filament stérile, qui est glabre dans chelone et barbu dans penstemon, me paroît bien légère.

Cult. Pleine terre. Les 4 premières espèces sont très-rustiques. Elles aiment les terres franches et un peu fraîches. Les 2 dernières; originaires du Mexique, sont un peu délicates. Dans les premiers temps de leur introduction en France on les cultivoit en orangerie; mais on a reconnu, et je l'כ́prouve moimême tous les ans, qu'elles passent fort bien en plein air. II faut seulement, dans les froids rigoureux, mettre un peu de litière sur leurs pieds, dans les climats septentrionaux. On les multiplie toutes par la séparation de leurs touffes au com- 
mencement du printemps. Les deux dernieres demandent une terre plus substantielle pour fleurir en abondance. On peut aussi les propager par leurs graines qui mûrissent assez sourent, surtout celles de la cinquième qui se resème elle-même.

$\boldsymbol{Z}$ 's. Les galanes sont toutes de belles plantes qui contribuent beaucoup à l'ornement des jardins. Les deux premières épanouissent leurs fleurs dans un temps ou elles sont rares, et durent un mois ou deux dans cet état. Les deux dernières décorent les lieux où elles sont placées pendant toute la belle saison, et ne finissent de fleurir que lorsque le froid met un terme à ces agréables jouissances. La sixième se multiplie aussi très-facilement de boutures faites au printemps.

\section{Sesame, Sesamum.}

Cal. à 5 part.; la div. sup. plus petite. Cor. à tube court, dont l'entrée est camp., grande et oblique, á limbe 5-fide. La div. inf. plus longue. 4 étam. didynamiques. Le rudiment d'une 5e. Stigm. à 2 lames. Caps. oblongue, presque à 4 angles, a 4 sillons, et 2 loges. Semences nombreuses fixées sur un rétacle central et grêle.

I. Sesame du Levant, $S$. orientale.

Tige carrée, de 2 pieds, peu rameuse. Feuilles obl. - ov. ? opp., un peu velues. Fleurs d'un blanc sale, en épi lâche et terminal.

Lieu. Les Indes or. If. Fl. en juillet.

2. S. de l'Inde, $S$. indicum.

Tige plus haute. Feuilles inf. trifides. Fleurs id.

Lieu.L'Inde. Fl. en juillet.

Cult. Serre chaude. Ces ulantes se sement en terrine, sur couche et sous chàssis; quand elles sont levées et assez fortez pour être séparées, on les met chacune dans des pots qu'on plonge dans une autre couclie chaude. Lorsqu'elles sont bien reprises on les place co serre cinande ou sous des cinassic pour y fleurir et fructifier. Elles re peuvent porter leurs graines à la maturité dans nos climats qu'au moyen d'me chaleur constante. 
Au reste elles ne sont cultivées que dans les jardins des curieux et de botanique. En Amérique et dans le Levant, on fait une bonne huile avec leurs graines.

\section{Josephinia, VENT.}

Calice à 5 lanières droites et égales. Corolle à tube court et gorge enflée, à 2 lèvres; la supérieure droite, l'inférieure horizontale, 3-fide. 4 étamines didynamiques, plus courtes que la corolle. Rudiment d'une cinquième. Ovaire verruqueux, entouré par le disque. Style de la longueur des étamines. Stigmate 4-fide. Noix hérissée de pointes, à 5 à 5 trous à son sommet, et à autant de loges, contenant 4 à 3 semences cylindriques fixées au bas des loges.

Ce genre a été dédié à S. M. l'Impératrice Joséphine par Ventenat.

Joséphine Impératrice, J. Imperatricis, Vent, Jard. Malm.

Tige droite, cylindrique, rougeâtre et tétragone vers son som met, rameuse, noueuse, de 7 décimètres de hauteur. Rameaux opposés et ouverts. Feuilles opposées, pétiolées, en cœur, ovales, pointues, un peu velues, d'un beau vert; les inférieures sinuées et dentées, longues de $\mathrm{x} 3$ centimètres et larges de 8 , les supérieures crénelées, presque entières. Fleurs d'un blanc jaunâtre, nuancées à l'extérieur de pourpre, tachetées de points rouges en dedans, de la grandeur de celles du sésame. Corolle monopétale, irrégulière. La levre supérieure à 2 lobes.

Lieu. La Nouvelle-Hollande. $\sigma^{7}$. F1. en été.

Cult. Orangerie. Cette plante doit avoir la même culture que la calomeria. On la sème en automne ou au printemps dans des pots remplis de terre de bruyère ou de bonne terre substantielle. On pique les jeunes plantes d'abord dans de petits pots, et on les garantit du froid pendant l'hiver. Comme elles auront tapissé leurs vases au printemps, on leur en donnera de plus grands lorsqu'elles seront sorties de la serre, sans retrancher aucuné räcine,pour ne pas retarder la floraison qui doit avoir lieu en été. Si on sème cette plante en automne, elle pourra, à l'aide de la chaleur, fleurir dans l'été suivant. La Joséphine est une assez belle III. 
plante, sur-tout par son port. Il est probable que ses graines mûriront dans nos jardins, ou du moins dans ceux du milieu de Ia France.

\section{Millingtonia.}

Calice campanulé, court, à 5 dents. Corolle infundibuliforme, tube filiforme et à limbe à 4 parties égales. 4 étamines didynamiques. Anthères à deux parties ou à deux dents. Stigmate à 3 valves. Fruit en forme de gousse ou de silique.

Millingtone des jardins, $\boldsymbol{M}$. hortensis, Lin.

Grand et bel arbre dont les feuilles sont deux fois ailéeset les folioles ovales pointues, entières et glabres. Fleurs blanches, trèslongues et d'une odeur désagréable, en grands panicules terminaux.

Lieu. Les Indes orientales, dans les jardins desquelles il est cultivé. b.

Cult. Serre chaude. Cultivé en Angleterre.

\section{Fruit capsulaire, bivalve. Tige arborée ou frutescente.}

\section{Catalpa.}

Cal. à 2 part. Cor. camp., à tube ventru, ả limbe à 4 lobes inégaux. 2 étam. fertiles. 3 filamens stériles. 2 stigm. à 2 lames. Caps. en forme de silique, longue, cylindrique, à 2 valves, dont la cloison leur est opposée. Sem. aigrettées, membrạneuses à la base etau somnet.

* I. Catalpa commun, C. communis. Bignonia catalpa, Lin., H. K.

Arbre de 15 à 20 pieds, dont la tige droite se ramifie à la moitié environ de sa hauteur, et forme une tête ouverte et très-étendue. Feuilles ordinairement disposées 3 par 3 à chaque nœud, t: ès-grandes, cordiformes, pointues , entières, molles, pét., d'un beau vert. Fleurs blanches, marquées de points pour- 
pres, en panicules terminaux. Elles ressemblent assez, par leur port et leur couleur, à celles du marronnier d'Inde.

Lieu. La Caroline. ๖. Fl. en août.

2. C. à longues siliques, C. longissima. B. longissima, Liv。

$B$. quercus, Lamarck. Chêne noir d'Amérique.

Arbre d'environ 40 pieds, dans son pays nat. , droit et branchu dans toute sa hauteur. Feuilles disposées 3 par 3 , ovaleslanc., simples, pointues, entières, très-ondulées. Fleurs d'un blanc purpurin, en panicules term. Siliques très-longues.

Lieu. Les Indes occid., St.-Domingue. Ђ. Fl...

Cult. La I $^{\text {re }}$ est de pleine terre. Cet arbre fait de très-gran 1 progrès dans sa jeunesse, et prend en 5 ou 6 ans presque toute son élévation, quand il n'est pas arrêté par le froid. Il pousse très-vigoureusement dans les bonnes terres franches et argileuses; mais pour peu que le froid se fasse vivement sentir, il perd aussi presque toute sa végétation précédente. Cet accident n'arrive cependant que dans le nord de la France et dans lesterrains favorables à son prompt accroissement. Dans ces pays, il n'y a pas d'autre moyen de lui former son bois, que de l'empailler dans sa jeunesse; ou mieux encore, de le tenir en vase jusqu'à ce que sa tige ait pris une consistance ligneuse : ce qu'elle acquiert au bout de 4 à 5 ans. Alors on le plantera à l'endroit qu'on lui destine. Quand cet arbre a de la force, il est peu sensible au froid; et quand celui-ci l'endom mage, il n'affecte que ses extrémités. Son large feuillage, qui donne beaucoup de prise au vent, exige qu'on lui donne une situation abritée, et celle du nord est à tous égards préférable à celle du midi pour le fortifier dans sa jeunesse, et l'arrêter dans sa sève, trop abondante à d'autres expositions. On le multiplie de boutures et de graines. Les premières se font avec les rameaux de l'année précédente. Elles doivent avoir environ un pied. On les met au printemps dans des pots remplis de bonne terre de potager, qu'on plonge dans une couche de chaleur modérée et ombragée. On les arrose de temps en temps, et au bout de 6 semaines cllessont enracinées. On peut les faire aussi en pleine terre. Les graines se sèment en automne ou au printemps, dans de petites caisses remplies de bonne terre. On les recouvre d'environ un peuce de 
cetie miême terre. Si le semis a éié f́at en automne, il faut le mettre à couvert pendant l'hiver ; s'il a été fait au printemps, on doit le placer à l'exposition du levant. Au bout de trois semaines ou un mois, les jeunes catalpas lévent. On les laisse dans leur semis jusqu'au mois de mars de l'année suivante. A ceite époque on les enlève, et on les plante en pépinière à une situation abritée ou en pots, cormme je l'ai dit précédemment. Si le climat où l'on est permet de mettre ces jeunes catalpas en plein air, il n'est pas moins prudent de les couvrir pendant les deux hivers suivans, car cet arbre est très-sensible au froid dans sa jeunesse. Lorsque les catalpas ont environ 6 pieds de hauteur, et que sur-tout leur tige est ligneuse, on peut alors les planter à demeure. Sans ces premiers soins, on peut être assuré que dans le nord de la France; et particulièrement dans les bons terrains, les caralpas seront tous les ans mutilés, et qu'au lieu de s'éleve: en tige, ils ne formeront que de grosses cépées.

On propage aussi le premier catalpa de marcottes; mais comme cet arbre ne s'y prête pas à cause du peu de flexibilité de ses branches, il faut alors le couper au pied, et couvrir ensuite ses jeunes pousses d'un pied environ de terre.

Obs. La température des saisons est tellement changée depuis 15 à 6 ans, que mes catalpas qui, en 1780 , étoient en feuilles au 20 avril, le sont à présent à peine au 15 ou 20 juin.

La seconde espèce est de serre chaude. - On l'obtient de graines tirées de son pays orig., et semées à la manière indiquée pour les plantes de cette température. Elle doit toujours rester dans la serre, et elle demande une chaleur constante, une terre substantielle, consistante, des arrosemens fréquens dans sa végétation, et presque point dans son état de repos.

Le catalpa commun fait un des ornemens des jardins par ses feuilles et ses fleurs.

\section{Técoma.}

Cal. à 5 dents. Cor. camp., à limbes à 5 lobes inégaux. 4 étan. fertiles, la cinquième stérile. Stign, à z lames. Caps, on forma 
de silique, longue, cylindrique, à 2 valves dont la eloison leur est opposée. Semences membraneuses en leurs bords.

I. TÉcoma à 5 feuilles, $T$. pentaphylla. Bignonia pentaphyllla,

LiN.

Arbrisseau touffu et rameux, de ro à 15 pieds. Feuilles pét., digitées, à 5 fol. ovales, inégales, entières et glabres. Fleurs. purpurines, 5 ou $\mathbf{q}$ ensemble au sommet des branches.

Lieu. Les Antilles. ๖. Fl...

* 2. T. de Virginie, $T$. radicans. $B$. radicans, Liv.

Tiges grimpantes à la manière du lierre, c'est-à-dire qui s'attachent par des mains, glabres, rameuses, de 30 à 40 pieds de haut. Feuilles opp., ailées, à I I fol. ovales, pointues, profondément dentées en scie, d'un beau vert. Fleurs très-grandes, d'un rouge écarlate, en bouquets courts, vers l'extrémité des rameaux.

Lieu. L'Amérique sept. - . Fl. en juillet et aoukt.

Variété à fleurs moins grandes.

* 3. T. à feuilles de frêne, T. stans. B. stans, Liv.

Tige droite, rameuse, assez ferme, de 7 à 8 pieds. Feuilles opp., ailées, à 5 à 7 fol., lanc., pointues, dentées en scie, sess. Fleurs jaunes, nombreuses, en grappes droites, au sommet des rameaux.

Lieu Les Antilles. Ђ. Fl. en août. Toujours vert.

4. T. de la Chine, $\boldsymbol{T}$. chinensis. Bignonia chinensis, LAM.

B. grandiflora, Thunb., Willd.

Cette espece a beaucoup de rapports, sur-tout par son feuillage, à la seconde espece. Elle forme un arbrisseau sarmenteux dont les feuilles opposées, sont ailées avec impaire, à 9 à II folioles ovales, pointues, dentées en scie, vertes et glabres. Fleurs aussi grandes que celles de la seconde espèce, nombreuses, disposées en grappes paniculées. La corolle campanulée n'est pas plus longue que le calice, et s'évase en un grand limbe à 5 divisions larges et arrondies. LAM.

Lieu. La Chine, où cette espèce est cultivée pour la beauté de ses fleurs. ๖. Cultivée en Angleterre.

Cult. La premiere et la troisieme sont de serre chaude. Elles exigent la même chaleur et la nême terre que le câtalpa no 
On les multiplie de même par leurs graines tirées de leurs pays orig. On peut aussi les propager par les boutures fartes en pot au commencement du printemps et en tannée, et par les marcottes. La deuxiène est de pleine terre, et sa vraie place est contre un mur exposé au midi, ou contre tout autre appui à cette exposition. On la multiplio assez facilement, soit en marcottant ses branches, soit par les rejetons qu'elle pousse en abondance. Dans nos climats, elle perd souvent une grande partie de ses tiges nouvelles en hiver; ce qui l'empêche de se fortifier, de s'élever et même de fleurir. Pour y remédier, il faut couvrir de paille sa tige pendant les 2 ou 3 premieres années; lorsqu'elle aura pris la consistance ligneuse, elle bravera alors le grand froid, et fleurira abondamment si elle est placée dans une situation chaude. La troisième peut passer a mois de l'été en plein air. La culture de la quatrième m'est inconnue.

Us. Je ne connois pas la première; mais les deux autres ont des fleurs très-agréables à la vue par leur couleur et leur grandeur. Elles mérient toutes deux les soins des cultivateurs, et contribuent à la décoration des serres et des jardins. La deuxième est très-propre à revêtir des murs et à former des berceaux.

\section{Bignone, Bignonia.}

Cal. denté ou presqu'entier. Cor. camp., à limbe à 5 lobes inegaux. 4 étam. fertiles, une cinquëèe stérile. Stigm. à 2 lames. Caps. en forme de silique, longue, plane ou ovale, courte, à 2 valves, dont la cloison leur est parallèle. Semences membraneuses en leurs bords.

* I. Bignone orangée, B. capreolata.

Tiges grềies, sarmenteuses, de 5 à 6 pieds. Feuilles simples, Janc., opp., pét.; les sup. conjuguées et vrillées. Fleurs d'un jaune orangé à leur sommet, pourpres à leur base; plusieurs ensémble, péd., ax.

Lieu. L'Amérique sept. Ђ. Fl. en juin.

2. B. à ébène, B. leucoxylon. Ebène janne 
Arbre de 30 à 40 pieds, dont les feuilles sont opp., digitées, pét. à 5 fol. entières, ovales, pointues, glabres, inégales. Fl. blanches, ax. odorantes, sol.

Lieu. Les Indes occid. . Fl. en juin.

5. B. de l'Inde, $\boldsymbol{B}$. indica.

Arbre élevé. Feuilles 2 fois ailées, à 5 à 7 fol., très-entières, ovales, acuminées, presqu'en cœur. Fleurs grandes, d'un blanc jaunâtre, marquées de lignes rouges, en grappes term.

Lieu. L'In de. Ђ. Fl...

* 4. B. griffe de chat, B. unguis cati.

Tiges sarmenteuses. Feuilles opp.; 2 folioles sur chaque pétiole, ovales, pointues, glabres, nerveuses. Fleurs jaunes, péd., ax. Le pétiole commun se terminant par une vrille $\grave{a}$ 3 crochets, a fait donner à cette espèce l'épithète qu'elle porte.

Lieu. Les Antilles. In.

* 5. B. équinoxiale, B. aquinoxialis. Liane à crabes, à paniers.

Tigesarmenteuse, grimpante.Fenilles opp.; 2 fol. sar le même pétiole, qui se termine par une vrille simple, ov. - lancéolées. Fleurs grandes, rougeâtres, ax., au nombre de 2 sur chaque péd.

Lieu. Les Anilles. Ђ.

6. B. porte-croix, B. crucigera.

Tige id., raboteuse, chargée de points tubéreux. Feuilles opp.; le pétiole commun porte 2 fol. ovales, et se termine par une vrille. Fleurs grandes, d'un jaune pâle, en grappes ax.

Lieu. L’Amérique mérid. Ђ.

Lorsqu'on coupe la tige de cette espèce, la partie coupée présente la figure d'une croix.

Cult. La première est de pleine terre, et sa culture se rapporte à celle du técoma $n^{\circ}$. 2. Les autres espèces scnt de serre chaude, et doivent être semées et conduites comme la deuxième espèce de catalpa, et toutes les plantes délicates de cette serre. Elles doivent y rester toujours, et ce n'est qu'en leur donnant une chaleur constante, et en leur faisant acquérir de la force qu'elles peuvent fleurir. La première s'obtient facilemen: de graines semées au printemps sur couche. 
Us. Ces bignones sont des plantes d'un véritable ornement. Mais il n'est pas aisé de les faire fleurir, et on ne peut y parvenir qu'avec des soins, excepté la première.

7. Bignone toujours verte, B. sempervirens, Lin. Voyez gelseminum.

\section{Autres espèces cultivées.}

8. B. pandore, B. pandoraea, Vent., Jard.Malm., Andr.

Tige volubile, cylindrique, noueuse, grisâtre, très-rameuse; les rameaux tétragones dans leur jeunesse. Feuilles pétiolées, opposées, naissant aux nœuds, ailées avec impaire, composées de 2 à 4 paires de folioles opposées, elliptiques, presque sessiles, glabres, luisantes, d'un vert foncé en-dessus. Fleurs d'un blanc terne, rayées de pourpre, disposées en grappes composées, penchées, axillaires et terminales. Corolle tubulée, à limbe à 2 lèvres; la supérieure à 2 lobes, l'inférieure à 5 divisions écartées, oblongues et réfléchies en leurs bords.

Lieu. L'île de Norfolck, dans la mer Australe. ๖. Fleurit au printemps.

Cult. Orangerie.

On a observé que lorsque cette plante entroit en végétation, une multitude d'insectes du genre Aplis la couvroient presque entièrement, et que de là, comme de la boîte de Pandore, ils se répandoient sur tous les végétaux de l'île. C'est ce qui Iui a fait donner le nom de Pandoraea.

Cette espèce se multiplie par les marcottes. Elle fleurit dans mon jardin tous les ans en automne; mais il faut alors la mettre dans la serre chaude pour que ses fleurs s'épanouisšent bien, ou dans la serre tempérée. Elle est, dans le temps de sa floraison, d'un très-joli aspect. Ses grappes ont beaucoup de grâces, parce qu'elles sont bien ouvertes et un peu penchées.

9. B. à grandes feuilles, $B$. grandifolia, J JCQ. WrLLD. Tige frutescente, cylindrique, glabre, rameuse, grim- 
pante, d'environ vingt pieds. Rameaux ponctués de brun. Feuilles opposées, conjuguées; les folioles ovales, très-entieres, pointues, fermes, lui antes, d'un vert foncé en-dessus. Vrilles simples. Fleurs jaunes, de 3 pouces de longueur, en bouquets latéraux.

Lieu. L'Amérique mérid. Ђ. Fleurit en sept. Cultivée à Vienne.

Cult. Serre chaude. Celle des espèces de cette température. zo. B. à odeur d'ail, B. alliacea, LAm. Liane à ail.

Tige ligneuse, grimpante. Feuilles opposées, à 2 folioles ovales, grandes, pointues, très-entières, vertes et glabres. Vrille simple. Lam. 5 fleurs réunies et axillaires.

Lieu. La Guyane. ๖.

Ix. B. paniculée, B. paniculata, Lin., Miller.

Tige grimpante. Feuilles conjuguées, ovales, en cœur, un peu velues. Fleurs odorantes, violettes, en grappes. Pédoncules triflores.

Lieu.L'Amérique mér id. Ђ.

12. B. élevée, B. procera, WiLLD. B. à feuilles de fougère.

Arbre de 80 pieds de hauteur. Feuilles très-grandes, opposées, bipinnées; les folioles oblongues, obtuses, pointues et mucronées, glabres, pétiolées. Fleurs bleues, formant un très-ample panicule terminal.

Lieu. La Guyane. ๖.

Ces trois dernieres especes sont aussi de serre chaude, et sont cultivées en Angleterre.

N'ayant pas connoissance de la fructification de ces cinq dernières espèces, je n'ai pu les remettre dans les genres de Jussieu, divisions de celui des bignones, auxquels elles doivent appartenir. 
III. Fruit coriace, ligneux, s'ouvrant par le sommel. Tige herbacée.

\section{Bicorne, Cornaret, Martynia.}

Cor. irrégulière, presque camp., ventrue à sa base, à límbe à 5 lobes inégaux. Cal. 5-fide, et 3 bractées à sa base. 4 étam. didynamiques, souvent fertiles, une $5^{\mathrm{e}}$ en rudiment. Stigm. à 2 lames. Caps. ligneuse, ovale ou longue, terminée par un bec à 2 cornes, denté et sillonné, à 4 valves, 4 loges; les 4 inférieures I-sperme; la sup. 4-sperme.

* . Cornaret vivace, $M$. perennis. Gloxinia maculata, H. K.

Tige d'un pied environ, cylind., rougeâtre, glabre, tendre, succulente. Feuilles opp., assez grandes, pét., cordiformes, dentées, un peu ridées, d'un vert foncé et luisant en-dessus, d'un beau rouge et nerveuses en-dessous. Fleurs bleues, péd., ax., term. Racines écailleuses, colomniformes.

Lieu. L'Amérique mérid. \%. Fl. en août. * 2. G. à feuilles alternes, M. alternifolia, Lamarck. M. probascidea, I. K. M. louisiana, Mrller. M. annua.

Tige cylind., creuse, velue, rameuse, d'un pied. Fenilles alt., cordiformes, obtuses, entières, molles, pét., chargées de poils glutineux. Fleurs blanchâtres, en grappes term. La corne de la capsule est longue et arquée.

Lieu. L'Amérique mérid. 歖. Fl. en juin - août.

3. C. anguleux, M. angulosa, Lamarck. Martynia diantra, WILLD.

Tige cylind., velue, rameuse, d'un pied. Feuilles opp., pét., en cour, anguleuses, molles, velues, visqueuses. Fleurs blanches, tachetées de pourpre, penchées, en grappes courtes dans jes dichotomies de la tige.

Lieu. Id. F.

4. C. à longues fcurs, M. longiflora, H. K. 
Tige simple. Feuilles obrondes, ondulées. Le tube de la corolle ventru à sa base et presque plane.

Lieu. Le Cap. P. Fl. en juillet et août.

Cult. La première est de serre chaude. Sa terre doit être consistante et substantielle. Point d'arrosemens en hiver; très - fréquens dans le temps de sa végétation; dépotée tous les ans au commencement de mars. C'est alors qu'on la multiplie par la séparation de ses racines, qu'il ne faut pas prendre seules, mais. en petites mottes, c'est-à-dire, en partageant la grosse motte du pot en 3 ou 4 parties. Cette plante exige beaucoup de chaleur. Les autres demandent aussi une situation chaude. On les sème tous les ans sur couche, et le moyen le plus sûr pour les faire fructifier est de les y laisser. J'ai vu la $2^{\mathrm{e}}$ dans un jardin de ce pays sur une couche à melons. Le propriétaire ne l'y avoit pas semée, et fut fort étonné de sa fructification cornue. Elle y a mûri sẹs graines sans qu'il lui eût donné le moindre soin.

Us. La $I_{1}$ re a un beau feuillage qui contribue à la décoration des serres pendant l'été. Toutes ont d'assez belles fleurs, surtout la 3e. On les cultive par curiosité, à cause de leurs capsules surmontées de 2 longues cornes, qui les rendent fort singulières.

\section{Pedalium。}

Cal. à 5 part. Cor. tubulée, à limbe camp., à 5 lobes inégaux. 4 étam. didynamiques, à filamens velus à leur base, à anthères en forme de croix ; le 5 e filament stérile. Stigm. Bifide. Noix subéreuse, à 4 angles épineux, à 2 loges et 2 semences tuniquées.

PEDalium à fruit épineux, $P$. mure $x$.

Plante rameuse, trichotome. Feuilles opp. Fleurs axillaixes Fruit imitant celui de la macre. Port des cornarets.

Lieu. Les Indes or. P. FI. en août et sept.

Cult. Cette plante se sème sur couche; et quand elle est levée, on la remet sur une autre couche chaude pour y lleurir et fructifier. Elle a une forte odeur de musc. 


\section{O R D R E X I I I. \\ Les Gentianes ( Gentran AE).}

Calice monophylle, divisé, persistant. Corolle régulière, les divisions de son limbe régulières, souvent en nombre égal à celles du calice, ordinairement cinq. Autant d'étamines insérées au milieu ou au sommet de la corolle; leurs anthères penchées. Un ovaire et un style simple, quelquefois fendu. Stigmate simple ou lobé. Capsule simple ou double, polysperme, à une ou deux loges; les valves rélléchies en-dedans à leur bord; roulées lorsque le fruit est uniloculaire; planes et formant cloison lorsqu'il est à deux loges. Semences menues.

Herbes, rarement arbustes. Feuilles opposées, le plus souvent entières et sessiles.

\section{Capsule simple, uniloculaire.}

\section{Geutiane, Gentiana.}

Cal. presqu'à 5 part. Cor. tubulée à sa base, camp. ou infund. , à limbe à 4 à 5 div. obtuses ou pointues, ciliées ou entières, ouvertes ou droites, q. f. entremêlées d'autres plus petites. 5 étam., rar. 4 . Style à 2 part. 2 stigm.

1. Cor. à 5 div. et plus, en roue, ou campanulée, ou en entonnoir.

* I. Gentrane visqueuse, G. viscosa, H. K. Exacum visco. sum, Smith, Willd. 
Feuilles obl., trinerves. Fleurs en panicules, trichotomes. Les bractées perfoliées. Lescorolles 5-fides, monogynes. Plante visqueuse. Cette espèce a le port de la $4^{\mathrm{e}}$.

Lieu. Les îles Canaries. $\nsucc$. Fl. . .

* 2. G. jaune, grande gentiane, G. lutea.

Racine épaisse, longue et jaunâtre. Tiges de 3 à 4 pieds, droites, simples. Feuilles ovales, grandes, nerveuses, plissées, semblables à celles des vératres ou ellébores blancs, d'un beau vert; celles de la tige opp., connées. Fleurs jaunes, grandes, divisées en 7 à 8 lanières alongées, verticillées, fasciculées, nombreuses, ax. au sommet des tiges.

Lieu. Les hautes montagnes de la France. $\%$. F1. en juillet. * 3. G. pourprée, G. purpurea. G. punctata, Villars.

Tige droite, cylind., de 2 pieds. Feuilles ovales, pointues, nerveuses et glabres. Fleurs plus grandes que celles de l'espèce précédente, jaunes, parsemées de points pourpres, en verticilles, dont le supérieur tres-garni forme un bouquet terminal.

Lieu. Id. $\%$. Fl. . . .

* 4. G. pointue, G. punctala. G. purpurea, Villars.

Tige droite, cylind., d'un pied et demi. Feuilles inf. ovales, pointues; les sup. lanc., aiguës. Toutes nerveuses. Fleurs sess, d'un pourpre jaunâtre, verticillées, ax.

Lieu. Les Alpes. \%. Fl. en juillet.

L'espèce G. pannonica ne differe de la précédente que par les divisions de la corolle qui sont absolument ov.-obrondes.

* 5. G. asclépiade, G. asclepiadea.

Tiges simples, feuillées dans toute leur longtieur. Feuilles sessiles, ovales-lanc. , à 3 nervures, pointues, disposées en croix, Fleurs bleues, sess., axillaires, péd.

Lieu. Id. $₹$. Fl. en août.

* 6. G. d'automne, G. pneumonanthe.

Tige d'un pied environ, simple, rougeâtre. Feuilles opp., étroites, linéaires. Fleurs grandes, droites, presque sess, , campaniformes, d'un beau bleu, ax. et term.

Lieu. Près Amiens. Ind. ₹. Fl. en septemb.

7. G. de Virginie, G. saponaria, Michaux.

Tige de 8 à ro pouces, simple. Feuilles opp., ov.-lanc., poin- 
tues aux deux bouts, trinerves, glanques en-dessous. Fleurs longues, camp., sess., bleues, ax. et fasciculées au sommet des tiges.

Lieu. L'Amérique septent. $\%$. FI. en août et septemb.

* 8. Gentiane à grande fleur, G. acaulis. G. grandiflora,

Villars, Lam.

Feuilles petites, ov.-lanc., trinerves, formant des rosettes sur la terre. Du centre de quelques-unes de ces rosettes s'élève une tige d'un pouce environ, terminée par une fleur fort grande, camp., d'un très-beau bleu d'outre-mer.

Variété plus basse, à tige presque nulle.

Autre à tige plus haute, $G$. cautescens, LAm.

Lieu. Les Alpes, les Pyrénées. $\Psi$. Fl. en avril et mai.

9. G. précoce, G. verna. G. bavarica, JAcQ.

Feuilles ov.-lanc., lisses, très-petites, en rosettes sur la terre. Tiges d'un pouce et demi, feuillées. Fleur term., d'un beau bleu. Corolle crénelée, appendiculée à sa base.

Lieu. Id. $\longleftarrow$.

xо. G. dentée, G. bavarica, Willars.

Feuilles ovales, obtuses, arrondies, en rosette sur la terre. Tige de 2 pouces, feuillée, terminée par une fleur bleue, dont le limbe est à 5 lobes dentelés.

Lieu. La Suisse. $\psi$. Fl...

II. G. maritime, G. maritima. Chironia, Wilud. Erythreea, Pers.

Tige de 4 à 6 pouces, grêle, dichotome. Feuilles opp., ov., sess. Fleurs jaunes, droites, terminales et sol. dans les dichotomies de la tige.

Lieu. La France. $\Psi$ ou Fl. en juillet et août.

12. G. centaurelle, petite centaurée, G. centaurium. Chironia,

Willd. Erythrcea, Pers.

Tiges d'un pied environ, suivant les sols, droites, anguleuses, branchues à leur sommet. Feuilles opp. ou lanc., sess., trinerves, d'un vert glauque. Fleurs roses, en bouquets corymbiformes et term.

Lieu. Les bois, les lieux secs. Ind. Fl. en juillet et août. 
Variété à tige plus basse et plus rameuse. Cốtes du Boulonnois. Fleurs pourpres.

Variété à fleurs blanches.

13. G. à épi, G. spicata. Chironia spicata, Willd. Erya threea, Pers.

Cetle espèce ne differe de la précédente que par ses fleurs purpurines ou blanches, qui sont disposées en épis grêles, lâches et term.

Lieu. La France mérid.

If. G. amarelle, G. amarella. G. germanica, WiLed.

Tige de 8 à ro pouces et plus, selon les terrains, ou moins, anguleuse et brune. Feuilles sess., ovales, pointues, opp., d'un vert foncé. Fleurs d'un pourpre clair et terne, péd. term.

Licu. Les côteaux, les prés secs. Ind. F. Fl. en septemb.

\section{Corolle à 4 divisions.}

15. G. champêtre, G. campestris.

Tige de 4 à 6 pouces, feuillée, simple ou branchue et brune: Feuilles rad. spatulées, obtuses; les caulinaires ov.-lanc.,pointues, d'un vert obscur. Fleurs d'un bleu pâle, barbues à l'entrée de la corolle, term.

Lieu. . . Ind. Đ. Fl. en août.

* I6. G. croisette, G. cruciata.

Tiges simples, feuillées, rougeâtres, cylind., un peu couchées, de 7 à ro pouces. Feuilles lanc., opp., dont les bases sont amplexicaules. Fleurs bleues, sess., ax. term.

Lieu. La France. $\%$. Fl. en juin et juillet.

17. G. fluette, G. pusilla. Chironia inaperia, Willd. Erythreea, Pers.

Tige de 2 ou 3 pouces, filiforme, rameuse, dichotome: Feuilles petites, opp., lin., pointues. Fleurs petites, péd., sol., term. et ax.

Lieu. La France, près Paris.

18. G. filiforme, G. filiformis.

Tige id., très-filiforme; les rameaux capillaires. Feuilles 
très-petites, étroites, opp., pointues. Fleurs petites, d'un jaune pâle, sol., term.

Lieu. La France. F. Fl. en juillet et août.

Cette espèce ne paroît être qu'une variété de la précédente : toutes deux ont de grands rapports avec la $12^{\mathrm{e}}$.

Cult. Excepté la première, qui est d'orangerie, et dont la culture doit se réduire à celle de toutes les plantes vivaces de cette température, toutes les autres espèces sont de pleine terre. Mais tous les terrains ne conviennent pas à ces plantes. Placées la plupart, par la nature, sur les hautes montagnes et dans un terreau frais et léger, on doil tâcher de leur donner à-peu-près le même sol et la même situation. Les espèces $2,5,4,5,6$, 7, 8 et 9 exigent une terre légère, qu'on peut composer avec moitié de terreau de bruyère, un peu de sable, et environ un tiers de bonne terre de potager. Elles doivent être placées un peu à l'ombre, et point exposées au soleil du midi, ou dans des situations trop ouvertes. Mais leur terre est l'aricle le plus essentiel. Elles ne sont pas sensibles au froid, et même de fortes gelées ne leur font aucun tort. Les autres espèces $\longleftarrow$ sont plus faciles í cultiver, et viennent assez bien dans tous les terrains, pourvu qu'ils ne soient pas compactes et trop frais. On les obtient par leurs graines semées dens les terres ci-dessus indiquées, à l'exposition du levant. Quand les espèces $\nsucc$ ont passé une année dans ce semis, on peut les planter à demeure au printemps suivant. On les multiplie ensuite en séparant leurs pieds, ou leurs racines, ou leurs rosettes.

Les espèces fo ne cultivent guère que dans les jardins de botanique. Une partie d'ailleurs est incigène en France; et une des plus utiles, qui est la $12^{\mathrm{e}}$, se trouve abondamment par-tout.

Us. Les gentianes $\%$ sont presque toutes de belles plantes, qui ne peuvent qu'embellir les lieux où elles sont placées. Parmi elles on distingue les neuf premieres. On n'a pas toujours le plaisir de voir les fleurs de la deuxième; sa floraison dépend absolument du terrain qu'on lui donne ou qu'on lui compose, et sur-tout de sa force, qu'elle acquiert lentement. Cetle espèce est d'un usage fréquent en médecine. Sa racine est amère, 
fébrifuge, tonique. Elle peut suppléer au quinquina. Cependant les tiges entières de la $12^{\mathrm{e}}$ ont encore en infusion un effet plus marqué et plus sûr dans les fièvres intermittentes. Mais il faut que la dose soit forte, et ne pas la prendre comme une tisane, ainsi que quelques médecins la prescrivent. Il y. a encore d'autres gentianes de la première division qu'on peut cultiver pour l'ornement des jardins. Telles sont les suivantes :

I9. G. à grandes feuilles, G. macrophylla, Pallas, Grelin.

Tige presque couchée, nue dans sa partie moyenne. Feuilles radicales grandes. Fleurs rassemblées, terminales. Corolles á 5 divisions.

Lieu. La Sibérie. $₹$. Fl. en juin et juillet.

20. G. adscendens, G. decumbens, Liv.

Feuilles radicales alongées, lancéolées. Fleurs presque sess., axillaires. Corolles campanulées, à 5 div.

Lieu. La Sibérie. $\tau$. Fl. id.

Cult. Pleine terre. La même que celles des autres gentianes vivaces et rustiques.

\section{Swertie, Swer :}

Cal. presqu'à 5 part. Cor. en roue, à tube très-court, à limbe plane, à 5 part. lancéolées, chacune ayant à sa base int. un point géminé et cilié. 5 étam. plus courtes que la cor. Ovaire finissant en style court, terminé par un double stigmate.

Swertie vivace, $S$. perennis.

Feuilles ovales, rad., formant une rosette sur la terre, d'un vert foncé. Tiges de 8 à ro pouces, terminées par un petit bou= quet de fleurs bleues.

Lieu. L'Allemagne, l'Angleterre. \% . F1. en juillet.

Cult. Pleine terre. Cette plante, croissant dans les marais, exige une situation à-peu-près semblable:

Elle est cultivée dans plusieurs collections. 


\section{Chlore, Chlora.}

Cal. à 8 part. Cor. hypocr., à tube court, à limbe à 8 part. 8 étam. très-courtes, insérées à l'entrée de la cor. I style. Stigm. 4-fide.

Chlore perfeuillée, $C$. perfoliata.

rige droite, cylind., rameuse à son sommet, d'environ un pied. Feuilles ov., pointues, connées, perfeuillées, distantes, lisses et glauques. Fleurs jaunes, terminales, en cìmes, dont les ramifications sont trifides.

Lieu... Ind. Fl. en juillet et août. Commune.

Cette plante est amère comme la gentiane petite centaurée:

\section{Capsule simple, biloculaire.}

\section{Chirone, Chironia.}

Cal. 5-fide ou presque á 5 part. Tube de la cor. égal au calice; limbe plus grand, à 5 part. 5 étam. à anthères tournées en spirale après la floraison. I style incliné. Stigm. en tête.

* I. Chirone baccifére, C. baccifera.

Tige d'un pied environ, très-rameuse vers son sommet; les rameaux glabres et ramifiés. Feuilles opposées, petites, lin., étroites, pointues, glabres. Fleurs rouges, petites, péd., term. Baies ovales, rouges.

Lieu. Le Cap. 3. F1. en juillet. Toujours verte.

* 2. C. frutescente, C. frutescens.

Tige ligneuse, rameuse, d'un à 5 pieds. Les rameaux pubescens. Feuilles opp., lin.-lanc., légèrement cotonneuses, obtuses. Fleurs grandes, d'un beau rouge purpurin, en bouquets terminaux. Cor. à 4 ou 5 divisions.

Lieu. Id. Ђ.Fl. id. Toujours verte.

Variété à fleurs blanches.

* 3. C. à feuilles en croix, C. decussata, VENT., Hort. Cels.

Tige droite, du double plus grosse que celle de la chirone, frutescente, pubescente ou veloutée. Feuilles aussi nombreuses, formées de même, mais plus grandes, plus cotonneuses, dispo- 
sées en croix. Fleurs de la même couleur, d'un tiers au moins plus grandes.

Lieu. Id. 万. Toujours verte: Fl. id.

* 4. C. linoïde ou à feuilles de lin, C. linoides.

Tiges de 2 à 3 pieds, glabres, très-feuillées, rameuses, droites. Feuilles linéaires, très-étroites, nombreuses, pointues, trèsglabres, d'un vert absolument glauque. Fleurs roses, bien ouvertes, une fois plus petites que celles de la seconde espèce et disposées en panicule terminal, solitaires sur chaque pédoncule.

Lieu. Id. $\%$. Fl. id. Toujours verte.

Cult. Orangerie : mieux en serre tempérée. La ire se conserve assez facilement. Il y a très-long-temps que je l'ai cultivée en simple orangerie; mais les autres demandent plus de soin. L'humidité et la température un peu froide de l'orangerie ne leur conviennent pas. La chaleur de la serre chaude ne leur est pas non plus favorable. La serre tempérée, et encore mieux les châssis où le froid ne peut pénétrer, sont les endroits où ces plantes se maintiennent plus long-temps. Il leur faut un peu de chaleur, beaucoup d'air et de jour, et point de cet air stagnant qui se trouve dans les serres ordinaires. En général, les chirones ne sont pas d'une longue durée; mais la beauté de leurs fleurs fait qu'on cherche les moyens de les conserver. La terre de ces plantes doit être légère. Le terreau de bruyère leur est favorable. Elles languissent dans les terres fortes. Les arrosemens doivent leur être épargnés en hiver, et en été une exposition un peu abritée est la meilleure pour elles, pourvu qu'elle ne soit pas humide. On les obtient par leurs semences qu'on répand dans des pots au printemps, et qu'on plonge dans une couche nouvelle. Souvent les graines ne lèvent pas la même année; mais si elles sont bonnes, elles paroissent au printemps suivant. On doit par conséquent conserver leurs pots de semis dans une serre pendant l'hiver, et les remettre dans la couche au mois de mars. Lorsque les jeunes chirones sont levées et bonnes à transplanter, on les plante séparément dans de petits pots, et dans la terre indiquée ci-dessus. On fait en sorte de les fortifier en les faisant reprendre dans une couche, et les accoutumant un peu, l'air. Ces soins sont essentiels pour leur conservation. 
J'ajoute à celte culture que les chirones se multiplient faciiement de boutures faites dans le printemps et au commencement de l'été, dans des pots ombragés et sous des cloches dè verre blanc, ou dans la couche destinée à cette voie de multiplication. La 3̌ a mûri l'année dernière ses semences dans mon jardin. Elles ont en partie levé au printemps suivant. Je les avois mises dans le terreau de bruyère et conduites comme celles de toutes les plantes de serre. L'année suivante plusieurs ont encore levé.

On les propage aussi par les marcottes, qui s'enracinent aisément. Comme ces plantes ne sont pas de longue durée, il est nécessaire d'en faire tous les ans de nouveaux pieds. L'hiver est leur temps critique, et l'on ne peut parvenir à le leur faire bier passer qu'au moyen d'une serre sèche, ou mieux d'une bache ou châssis, où elles puissent recevoir, dans les jours doux, un air nouveau et la lumière.

$U s$. Les chirones sont des plantes très-agréables. La seconde et la $5^{\mathrm{e}}$ le sont infiniment plus que les autres. Leurs fleurs imitent celles de la pervenche rose.

\section{Capsules à 2 lobes et 2 loges.}

\section{Spigélie, Spigelia.}

Cal. à 5 part. Cor. infund, à limbe ouvert, 5-fide, égal. 5 étam. Ovaire à 2 lobes. I style. I stigm. Capsule à 2 lobes, 2 loges et 4 valves. Plusieurs semences attachées sur l'angle intérieur des loges.

* I. Spigélie du Maryland, S. marylandica. S. lonicera, Miller, éd. 8.

Tiges d'un pied, simples et droites. Feuilles opp., obl., ov. , pointues, entières, sess. et glabres. Fleurs à long tube renflé dans sa partie sup., d'un rouge écarlate en-dehors, d'un vert pomme ou jaunâtre en-dedans, disposées en forme d'épi term.

Lieu. L'Amérique sept. $¥$. Fl. en août.

2. S. annuelle, $S$. anthelmia. 
Tige herbacée. Les feuilles du sommet quaternées. Fleurs ver * dâtres, en épi unilatéral.

Lieu. Les Indes occid. Fl. en juillet.

Cult. La première est de pleine terre et rustique. Elle a supporté, dans mon jardin, les hivers de r 789 et 94 sans en être endommagée. Elle se plaît dans les terres fraîches, légères et douces; mais elle s'étend bien peu ou avec une extrême lenteur. Aussi est-elle fort difficile à multiplier par la séparation de son pied, n'en fournissant les moyens qu'après des années; et par ses graines, qui ne mûrissent pas dans nos climats, ce qui fait que cette plante est encore assez rare. La transplantation lui fait aussi grand tort. J'ai essayé d'en tirer quelques parties pour pouvoir en avoir du moins deux pieds; mais la partie enlevée a péri. Cette plante pousse assez tard. En tirant les semences des pays où elles mûrissent, on la multiplie plus aisément par cette voie. On conduit le semis à la manière indiquée pour les plantes délicates de pleine terre. Le terreau de bruyère lui convient, tant pour ses graines que pour la plante même. La seconde se sème tous les ans sur couche. C'est un bon vermifuge dans son pays originaire. La première mérite, par ses fleurs, une place dans les collections de plantes étrangères, oì elle attirera les regards.

\section{O R D R E X I V.}

\section{Les Apocinées (Apocine Ex).}

Calice à cinq divisions. Corolle régulière, à cinq lobes, le plus souvent obliques, tantôt nue, tantôt garnie intérieurement de cinq appendices. Cinq étamines insérées au bas de la corolle, alternes aux lobes. Ovaire simple ou double, posé souvent sur un réceptacle glanduleux; style simple; stigmate en tête. Fruit en baie dans les genres qui n'ont qu'un ovaire, ordinairement biloculaire, polysperme, 
quelquefois unicapsulaire : dans les ovaires doubles; le fruit est composé de deux follicules conjugués, capsulaires, oblongs, quelquefois en baies courtes, souvrant longitudinalement, remplis de semences aigrettées ou mutiques. Embryon plane, dans un petit périsperme charnu.

Herbes, ou arbustes, ou arbres, souvent laiteux. Feuilles opposées ou alternes. Glandes axillaires, un peu ciliées, quelquefuis peu visibles.

Obs. Cet ordre, dont les caractères généraux et particuliers sont aisés à saisir, se rapproche de plusieurs monopétales par sa corolle régulière, divisée en cinq, et par ses cinq étamines; il en differe par son périsperme, par le limbe de sa corolle souvent oblique, et par son fruit folliculaire. Les genres à baies biloculaires ont trop de rapports avec les ordres voisins pour en être séparés.

\section{Ovaire double. Fruit à 2 follicules. Semences non aigrettées.}

\section{Pervenche, Vinca.}

Cal. à 5 part., persistant. Cor. hypocr., à long tube, dont l'entrée est pentagone, à limbe plane, à 5 lobes obtus. Anthères membraneuses. I style. Stigm. en godet, et en-dessous ombiliqué et orbiculaire. Follicules droits, connivens, oblongs, étroits. Sem. obl., nues.

* 1. Pervenche majeure, grande pervenche, $\boldsymbol{V}$. major.

Tiges de 2 pieds environ, les unes droites, les autres couchées, foibles, cylindriques. Feuilles ovales, opp. , très-entières, fermes, lisses, d'un vert foncé. Fleurs grandes, bleues, péd. , axillaires.,

* Variété à feuilles panachées.

Lieu. La France. ₹ ou . Fl. tout l'été. Toujours verté 
* 2. P. mineure, petite pervenche, $\boldsymbol{V}$. minor.

Tiges couchées, quelques-unes droites, grêles, cylind. Feuilles ovales-lanc. , opp., fermes, très-entières. Fleurs bleues, plus petites que celles de la première, disposées de même.

Lieu.... Ind. $¥$ ou ๖. Fl. id. Toujours verte.

* Variété à fleurs doubles et à fleurs blanches.

* 3. P. rose, $V$. rosea. Pervenche de Madagascar.

Tiges droites, cylind., rameuses, rouges, avec les fleurs de celte couleur; jaunâtres avec les fleurs blanches, de 2 à 3 pieds. Feuilles opp., ovales-oblongues, très-entières, d'un vert vert lisse. Les pétioles garnis de 2 dents à leur base. Fleurs couleur de chair, plus rouges en leur centre, géminées, sess., axillaires.

Variété à fleurs blanches et à centre rouge.

Autre variété à fleurs blanches et centre vert.

Lieu. Les Indes or. 5 . Fl. presque toute l'année. Toujours verte.

Cult. Les deux premières espèces aiment les lieux ombragés. On les multiplie aisément par leurs rejetons qu'elles poussent en abondance.

La troisième est de serre chaude, mais elle n'est point délicate. Sa terre doit être substantielle, consistante. Arrosemens fréquens en été. Dépotée tous les ans en mars. Mult. par sesgraines, qui mûrissent dans nos serres, semées et conduites à la manière indiquée pour les plantes de serre chaude. Les jeunes pervenches fleurissent la même année, pourvu qu'on les pousse dans leur jeunesse. Par le moyen des couches, ceux qui n'ont pas de serres peuvent jouir de leurs fleurs comme de celles d'une plante annuelle.

Obs. Quand on entremêle pour le coup-d'œil la pervenche rose avec sa variété à fleurs blanches, les poussières fécondantes se confondent; et les graines prises sur la variété blanche ne produisent ordinairement que des pervenches roses. Pour être sûr d'avoir des blanches, il faut séparer des rouges. quelques pieds de la variété. Il en est de même quand on veus avoir des rouges. 
Us. La première mérite une place dans les jardins par son beau feuillage toujours vert et ses grandes fleurs. On peut en garnir le dessous des grand arbres. Sa variété panachée est assez jolie. On desireroit seulement que le vert ne s'affoiblît pas et pût mieux trancher sur le blanc des panaches. La variété de la seconde à fleurs doubles a peu d'effet. La troisième fait la décoration des serres pendant tout l'été, sur-tout lorsqu'elle est jointe à sa variété.

Les deux premières sont amères et principalement astringentes.

\section{Tabernier, Tabernamontana.}

Cal. 5-fide ou à 5 part., caduc. Cor. longue, infund., à limbe plane, à 5 lobes. Anthères acuminées, conniventes. Ovaire à 5 glandes bifides à leur base. I style. Stigm. en tête. Folli zules divariqués, horizontaux, ventrus, acuminés, pulpeux int. Semences ridées, plongées dans la pulpe.

1. Tabernier à feuilles de citronnier, $\boldsymbol{T}$. citrifolia.

Tige de 15 à 16 pieds, laiteuse, rameuse, droite. Feuilles épaisses, laiteuses, pét. , opp. , ovales, pointues, d'un rert luisant. Fleurs petites, d'un beau jaune, en ombelles glomérulées et latérales, odorantes.

Lieu les Antilles. Ђ. Fl..... Toujours vert.

2. $T$. à feuilles de laurier, $T$. laurifolia.

Tige de 2 pieds, peu rameuse à son sommet. Feuilles opp., ov., un peu obtuses, d'un beau vert lisse. Fleurs petites, disposées id.

Lieu. L'Amériq. mérid. Ђ. Fl. . Toujours vert.

* 3. T. herbacé, T. amsonia. Amsonia latifolia, Persoon.

Tiges d'un pied et plus, droites, rameuses, formant un buisson ouvert. Feuilles ovales -lancéolées, pointues, très-entières, molles, vertes en-dessus, pâles en-dessous. Fleurs ă'un bleu pâle, en panicules ouverts et terminaux. Corolle tubulée, à 5 divisions ouvertes horizontalement, presque linéaires. Le tube violet, garni en-dedans de cils blancs nombreux, qui fermentson entrée. 5 étamines courtes, à anthères pointues et sagittées. Stignate en plateau, entouré d'un an- 
neau. Calice d'un vert noirâtre, à 5 divisions. Follicules étroits et noirs. Toute la plante très-glabre. Lorsqu'au printemps, ceite plante commence à pousser, ses bourgeons sont très-noirs, ovales, assez gros el en groupe.

Lieu. L'Amérique sept. $\Psi$. Fleurit en mai-juillet.

* 4. T. à feuilles étroites, $T$. angustifolia. Amsonia angustifolia, Vent., Persoon.

Tige herbacée, garnie de poils. Feuilles linéaires, éparses. Fleurs jaunes, pédonculées, disposées en grappes peu nombreuses et terminales.

Lieu. Id. $\%$. Fl. en mai et juin.

Cult. Les 2 premières, étant délicales, sont de serre chaude, où elles doivent toujours rester. Leur terre doit être très-substantielle, et leurs arr. modérés, sur-tout en hiver. Mult. par leurs graines tirées de leur pays orig., semées en terrine sur couche et sous châssis, et conduites à la manière indiquée; par boutures dans le courant de l'été, en pot dans une tannée et dans une terre riche, mais un peu plus légère. On ne doit les mettre dans la terre qu'au bout de 4 à 5 jours, pour que la partie coupée soit bien sèche.

Les deux autres sont de pleine terre. Elles demandent une bonne terre, un peu légère, chaude, et en même temps humectée. Mult. par la séparation de leurs pieds, par leurs rejetons et par leurs graines. Elles se plaisent dans la terre de bruyère.

Us. Les deux premières contribuent, par leur feuillage et leurs fleurs, à l'ornement des serres, et les deux dernières à celui des parterres.

On cultive au Muséum une autre espèce nommée $T$. nernosa. Elle est de l'Amérique méridionale. ๖. De serre chaude.

\section{Franchipanier, Plumeria.}

Cal. petit, obtusément 5-fide. Cor. infund., à tube long, un peu élargi, à limbe à 5 parties ouvertes. Anthères conni- 
ventes et saillantes. Style presque nul. Stigm. bifide. Follicules réfléchis, longs, ventrus. Semences ailées et membraneuses en leurs bords.

* I. Franchipanier rouge, $\boldsymbol{P}$. rubra.

Tige de 12 à 15 pieds, nue jusqu'à son sommet, qui est rameux, et forme une cîme ample et lâche. Feuilles pét., ov.obl., entières, épaisses, planes, glabres, pointues, disposées en rosette au sommet des rameaux. Fleurs grandes, trèsbelles, rouges ou carnées, en corymbe terminal, d'une odeur agréable.

Lieu. L'Amérique mérid. Ђ. Fl. en août. Toujours vert. * 2. F. blanc, P. alba.

Port du précédent. Feuilles pét., obl. - lanc, roulées en leurs bords, luisantes, nerveuses, d'un pied de long, disposées comme celles de la première. Fleurs blanches, d'une odeur suave, en corymbe term.

Lieu. Les Antilles. W. Fl. id.

3. F. à panicule, $P$. obtusa.

Tige un peu moins haute. Feuilles pét., lanc., obtuses ou un peu acuminées. Fleurs blanches, en corymbes paniculés et term.

Lieu. L'Amérique mérid. . Fl. en juillet. Toujours vert. 4. F. à petites feuilles, $P$. parvifolia. 5. F. à longues feuilles, $P$. longifolia. Hort. angl. 6. F. à larges feuilles, $P$. aurantia.

Lieu. L'Amérique mérid. Ђ. Cultivés en Angleterre.

Cult. Serre chaude.'Terre peu substantielle et pas trop consistante. La terre de bruyère me paroît être celle qui leur convient le mieux, ou une terre extrêmement sablonneuse. Presque point d'arrosemens en hiver, et de très-modérés en été.

Ces arbres demandent beaucoup de chaleur, et ne s'élèvent que lorsqu'on la leur donne. Mult. par leurs graines tirées de leur pays orig. et conduitcs à la manière indiquée; et par. boutures en été, faites en pot et dans la tannée. La coupe doit: être bien sèche avant de les mettre en terre. Les franchipaniers. abondant, comme les euphorbes, en sucs laiteux, c'est ce principe qui doit diriger leur culture. 
Us. Ces arbres sont d'un accroissement assez lent; cependant ils portent leurs fleurs lorsqu'ils ont 3 à 4 pieds de hauteur.

Celles-ci sont de l'aspect le plus agréable, et y joignent une odeur qui parfume la serre. Leur lait est fort âcre et corrosif.

\section{Camerier, Cameraria.}

Cal. petit, 5-fide. Cor infund., ventrue à sa base et à son sommet, à limbe plane, à 5 part. Filamens des étam. appendiculés à leur base. Anthères conniventes, garnies de 2 soies à leur sommet. Style court. Stigmate en tête bifide. Follicules divariqués, horizontaux, comprimés, à 3 lobes, deux courts et le troisième beaucoup plus long. Semences comprimées, membraneuses à leur sommet.

Camerier à feuilles larges, C. latifolia, Lin., Andr., Miller.

Arbre de 6 à 9 pieds, selon Miller, plein de suc laiteux, droit, à rameaux fourchus. Feuilles opp., pét. , ovales, acuminées, très-entières, luisantes, transversalement striées. Fleurs blanches, péd. , term.

Lieu. L'Amérique mérid.

Cult. Serre chaude, ou cet arbre doit toujours rester. On l'obtient par ses graines tirées de son pays originaire, et conduites à la manière indiquée pour les plantes de cette température, auxquelles il faut beaucoup de chaleur.

\section{Ovaire double. Fruit bifolliculaire. Semences aigrettées.}

\section{Laurose, Nerium.}

Cal. à 5 part.; petit, persistant. Cor. infund., oblongue, à limbe à 5 part. obtuses, appendiculées, à leur base int. ; ces appendices souvent bifides couronnent l'entrée de la corolle. Anthères conniventes, sagittées, finissant en filet à leur sommet. x style. Stigm. tronqué. Follicules droits, connivens, "longs, acuminés. Sem. obl., aigrettées. 
* I. Laurose commun, Laurier-rose, $N$. oleander.

Arbrisseau naturellement en buisson. Tiges droites, grisâtres: Les rameaux verts ou bruns, trigones dans leur jeunesse, de 7 à 8 pieds. Feuilles opp., la plupart ternées, lin.-lancéolées, pointues, entières, fermes, épaisses, d'un vert foncé. Fleurs rouges ou roses, en corymbes term.

* I. Variété à fleurs blanches.

* 2. à fleurs carnées, $N$. carneum, Hortul.

* 3. à fleurs panachées.

* 4. à fleurs doubles.

Lieu. L'Espagne, le Levant, à Hières. ๖. Fl. en juin-oct. Toujours vert.

* 2. L. odorant, $N$. odoratum.

Port plus élevé et les tiges moins fortes et plus élancées. Feuilles formées et disposées de même, plus étroites et plus longues. Fleurs roses ou blanches, en bouquets terminaux. Les pédoncules sont garnis de petites bractées. La couronne de leur limbe est filamenteuse, les filets des anthères sont barbus et plameux.

* Variété à fleurs doubles, roses. Ses fleurs sont panachées de rose et de blanc. La corolle a deux limbes; l'int. plus grand que l'extérieur.

Variété à fleurs doubles, blanches, odorantes.

Lieu. Les Indes or. ๖. Fl. en juin-sept. Toujours vert.

3. L. antidysenterique, $N$. antidysentericum.

Arbrisseau de 7 à 8 pieds, rameux. Feuilles opp., elliptio ques, acuminées, glabres. Fleurs blanches, imitant celles du jasmin, en corymbe term.

Lieu. Id. ๖.Fl.... Toujours vert.

4. L. à bouquets, $N$. coronarium, H. K., JAcQ.

Arbrisseau de 4 pieds, rameux; les rameaux fourchus, verts et lisses. Feuilles opp., ov.-lanc., pointues, entières, lisses. Fleurs blanches, au nombre de 2 sur les pédoncules qui naissent des dichotomies des rameaux.

Ces fleurs sont doubles et très-odorantes.

Lieu. Id. Fl. tout l'été. Toujours vert.

Cult. Les deux premières espèces sont d'orangerie. Leur terre doit être substantielle et consistante. Les arr. très-fréquens en été. 
Leur exposition, pendant cette saison, doit être, dans le nord de la France, la plus chaude possible. Ces arbrisseaux ne fleurissent qu'au moyen de la chaleur. Dans nos climats, lorsque l'été est humide et froid, la première espèce ne fleurit mêrne pas en plein air, ou ses fleurs tombent à moitié ouvertes. L'humidité pendant l'hiver leur est très-préjudiciable; elle chancit et fait périr les jeunes pousses. Il leur faut beaucoup de jour dans ce temps et un air souvent renouvelé. La variété à fleurs blanches de la première ne fleurit point dehors dans mon jardin; je suis obligé de la mettre dans l'orangerie, contre les fenêtres, pour faire épanouir ses fleurs. La seconde n'est pas plus délicate pendant l'hiver, mais elle ne fleurit pas du tout en plein air. Il lui faut une chaleur d'un tiers plus forte que celle de l'atmosphère, environ 18 à 22 degrés, pour jouir de ses fleurs; je la fais entrer en serre tempérée à toit vitré au mois de mai : elle y reste et fleurit pendant l'été. Dans le courant de septembre je la place en plein air jusqu'à l'époque de la rentrée des plantes d'orangerie ou de serre tempérée. Comme elle s'épuise un peu à force de fleurir dans la serre chaude, et que ses rameaux deviennent plus foibles, je ne fais porter des fleurs à mes individus de cette espèce que tous les deux ans, de manière qu'il y en a une partie en fleurs pendant l'été, et l'autre en plein air, ou ils se fortifient pour mieux fleurir l'année suivante. Ces deux espèces se multiplient par leurs rejetons. La premiere et sa première variété en sont abondamment pourvues; mais la seconde en est avare, et l'on prend alors la voie des marcottes, qui s'enracinent facilement. La seconde variété, à fleurs carnées, ne peut aussi se naultiplier que par les marcottes. Je la mets dans la serre tempérée avec l'espèce odorante, où elle fleurit pendant tout l'été. Dans les pays méridionaux, cette variété et son espèce mûrissent leurs graines. C'est alors un moyen de plus pour leur multiplication.

On peut, avec quelques soins, former une tête à la première. J'ai vu des pieds conduits de celte manière qui faisoient un effet très-agréable et qui étoient chargés de fleurs. Les lauriers-roses ne demandent pas à être changés fréquemment de vases ou de crisses. Quand on leur donne trop de terre ou de la nouvelle, 
ils poussent beaucoup en bois et moins en fleurs. La seconde fait peu de racines, et peut rester plus de six ans sans être renouvelée. Elle demande des arrosemens très-fréquens dans le temps de sa floraison, et lorsqu'elle est alors dans la serre tempérée, on doit lui donner de l'eau deux fois par jour, et dans les jours de soleil ardent, l'ombrager et tenir toutes les croisées ouvertes. Sans ces attentions, ses fleurs se faneroient aussitôt. Comme elle est un peu moins rustique que la première, et qu'elle est sujette à perdre, pendant l'hiver, les sommets de sa végétation précédente, par la stagnation de l'air dans les orangeries, la serre tempérée lui convient mieux à cet égard seulement. On fera bien de couper les panicules de fleurs qui restent, parce qu'en mûrissant pendant l'hiver ils causent la chancissure d'une partie des branches.

Les deux dernières espèces sont de serre chaude et en exigent les soins ordinaires. La quatrième est élégante et mérite l'attention des cultivateurs. Elle est cultivée dans quelques collections.

$U s$. La première espèce et sa variété sont, depuis long-temps, cultivées pour la décoration des jardins. Il est en effet peu d'arbrisseaux qui remplissent mieux cet objet. La première est cultivée en pleine terre dans le midi de la France; j'en ai vu de très-beaux pieds palissés contre un mur dans la Saintonge; ils y fructifioient. Dans les étés chauds, il paroît aussi de petits follicules dans nos climats.

La variété à fleurs doubles de la seconde est de l'aspect le phus riche et le plus charmant. Ses rameaux plient de tous côtés sous le poids de ses bouquets pleins ảe grâce et d'un rose tendre. Quand cet arbrisseau est entièrement fleuri, il présente un coupd'cil ravissant. Ses fleurs sont un peu odorantes. Leur nombre et leur succession durent 5 mois.

Le suc des lauriers-roses est âcre et caustique : c'est un vraỉ poison.

\section{Echite, Echites.}

Cal. à 5 part., petit. Cor. infund., à limbe plane, 5-fide. Anthères rudes, acuminées, convergentes. Piéceptacle de l'ovaire 
à 5 glandes. I style. Stigm. en tête, à 2 lobes. Follicules trèslongs. Sern. à longue aigrette.

I. Eснiт biflore, $\boldsymbol{E}$. biflora.

Arbrisseau laiteux. Tiges sarmenteuses, grimpantes. Feuilles opposées, oblongues, pétiolées, lisses, un peu fermes, obstuses à leur sommet, avec une petite pointe. Fleurs grandes, blanches, imitant celles des lauroses, dont l'entrée et le tube sont d'un jaune pâle, ax., 2 ou 5 sur chaque péd.

Lieu. Les Antilles. Ђ.

2. E. campanulée, E. suberecta. Apocinum speciosissimum, Muller.

Plante laiteuse. Tiges de ro pieds, foibles. Feuilles pét., ov.obl., obtuses, mucronées, glabres. Fleurs grandes, jaunes, camp., en bouquets; le tube velu.

Lieu. La Jamaïque. Ђ. Fl.

5. E. toruleuse, E. torulosa, JAcQ.

Tiges volubiles, menues. Feuilles pét. , lanc., glabres, pointues. Fleurs petites, jaunes, en bouquets ax.

Liги. Id. ๖. Fl...

4. E. ombellée, E. umbellata. 'Apocinum obliquum, Milder. Tiges volubiles, grimpantes. Feuilles opp., pét., ovales, obtuses, mucronées, glabres. Fleurs grandes, pourpres, à long tube, en ombelles ax. Selon Jacquin, elles sont blanches.

Lieu. Id. Ђ. Fl.

5. E. corymbifere, $E$. corymbosa.

Feuilles ovales-lancéolées. Fleurs disposées en corymbes. Etamines saillantes.

Lieu. L'Amérique mérid. Ђ.

6. E. difforme, E. difformis, Hort. angl.

Cult. Serre chaude. Ces plantes n'ont pas encore fleuri en Europe. Elles y sont assez rares et peu répandues dans les jardins des curieux de plantes étrangères. Elles sont cultivées à Kew et à Paris. On les obtient de semences tirées de leur pays originaire. Elles exigent beaucoup de chaleur. On en connoît 29 espèces. 


\section{Céropège, Ceropegia.}

Cal. très-petit, à 5 dents, persistant. Cor. ventrue à sa base, tubulée sup., à limbe à 5 dents ou 5 div. non ouvertes. Antheres petiies. Style presque nul. Follicules droits, cylind. ; très-longs. Sem. aigrettées.

Cérópège sagittée, C. sagiltata, Lin., Lam.

Tige filiforme, cotonneuse, grimpante. Feuilles opp., sagittées, cotonneuses, à bords roulés. Fleurs rouges, presque cylindriques, en ombelles ax.

Lieu. Le Cap. Ђ. Fl.

Cult. Orangerie.

\section{Pergulaire, Pergularia.}

Cal. 5-fide, persistant. Cor. hypocratériforme, à tube cylind., à limbe à 3 part. planes et obtuses. Cinq écailles demi-saz̧itt., mucronécs à leur sommet, dentées à leur base. Anthères sess., enfoncées dans le stigmate. Style nul. Stigmate grand et tronqué.

Ce genre a des rapports avec l'asclépiade. Les tiges sont volubiles, les feuilles opposées et les fleurs en corymbes axillaires.

On cultive en Angleterre deux espèces de ce genre sous les noms de Pergularia odorata et $P$. minor. Elles sont toutes deux des Indes orientales, $\$$ et de serre chaude. Il est apparent qu'elles sont synonymes dè espèces $P$. tomeniosa et $P$. pur. purea, VAHL.

\section{Stapelie, Stapelia.}

Cal. petit, persistant, 5-fide. Cor. en roure, grande, plane, à divicions élargies à leur base, acuminées à leur sommet. Au cenire de la fleur se trouve une étoile double, dẹ deux côtés à 5 div., envircnnant les organes de la fructification. Filamens đes élamines planes. Anthères adnées aux filamens. Styles nuls. 2 stigm. Follicules oblongs, subulés. Sem. aigrettées. 
* I. Stapélte variée, $S$. variegata. Fleur de crapaud.

Plante succulente, garnie de beaucoup de tiges simples ou rameuses, arquées, d'environ 12 à 18 pouces, tétragones, sillonnées, munies sur leurs angles de dents un peu épineuses et ouvertes. Fleurs péd., assez grandes, planes, ridées, glabres, d'un jaune doré un peu pâle, parsemées d'un grand nombre de points bruns de diverses formes, naissant sans ordre sur lcs tiges, et inodores.

Lieu. Le Cap. Ђ. Fl. en juillet. Toujours verte.

* 2. S. velue, S. hirsuta.

Tiges aussi nombreuses et de la même hauteur que celies de la précédente, mais toujours droies, peu rameuses, plus fortes et plus grosses, tétragones, les faces peu sillonnées, les dents de ses angles droites et peu ouvertes. Fleurs péd., du double plus grandes, un peu ridées en-dessus, d'un rouge brun, avec des raies transversales, chargées de longs poils dans le centre et sur les bords, d'une odeur de chair corrompue.

Licu. Id. Ђ. FI. en avril-juillet. Toujours verte.

3. S. à fleur noire, S. pulla, H. K. S. sarciculata, Trune.

Tiges presqu'hexagones, droites, garnies en leurs bords de dents aiguës et très-ouvertes. Fleurs sess., rassemblées. Les div. de la corolle lancéolées et repliées, soyeuses en-dessus, glabres en-dessous.

Lieu. Id. ๖. Fl. en séptemb. Toujours verte.

* 4. S. articulée, S. articulata, H. K.

Tiges articulées. Les articulations oblongues, cylind., chargées de verrues disposées en forme de réseau. Les dents épin., très-petites. Fleurs presque sessiles. Corolles mamelonnées endessus, à divisions triangulaires.

Cette espèce a de grands rapports avec la précédente. Ses rameaux sont de même hexagones et droits; ses tubercules dentés sont un peu réfléchis. Ses lleurs sont glabres, à divisions lancéolées.

Lieu. Id. Fl. en août et septemb. Toujours verte.

* 5. S. mammillaire, $S$. mammillaris.

Tiges et rameaux courts, dont les tubercules sont disposés sur six angles, et terminés par, une pointe blanche, dure et piIII. 18 
quante. Fleurs brunes, glabres, pédonculées. Corolle de deus centimètres de diamètre (neuf lignes), à divisions, pliées longitudinalement, et presque appliquées l'une contre l'autre; le centre forme un godet pentagone entièrement rempli de parties de la fructification. Cette espèce a des rapports avec la précédente.

Lieu. Id. . Fl. en juin et juillet. Toujours verte.

6. StAPÉLIE quadrangulaire, S. quadrangula, Willd.

Tige tétragone, garnie de dents tronquées, d'un vert glauque, grisâtre, légèrement pubescente ou veloutée, rameuse. Les rameaux divergens. Fleurs petites, d'un fauve verdâtre, rassemblées, sessiles et terminales.

Lieu. L'Arabie. Ђ.

* 7. S. en gazon, S. caspilosa, Masson, Wrrld.

Cette esjéce se compose de plusieurs rameaux tétragones, rapprochés, coudés, penchés vers la terre, garnis sur leurs angles de dents pointues et ouvertes. Fleurs naissant près de la base des rameaux, portées sur des pédoncules de la longueur de la corolle, brunes, avec un fond vert, circulaire, à 5 divisions lancéolées, pointues, recourbées et ciliées en leurs bords.

Lieu. Le Cap. 5.

8. S. ciliée, S. ciliata, MASs., Wruld.

Tige tétragone, rameuse, couchée, poussant des racines qui vont s'enfoncer dans la terre, garnie sur ses angles de petites dents ouvertes. Fleurs de la grandeur de celles de la stapélie velue, portées sur des pédoncules courts, jaunâtres, unicolores, à 5 divisions profondes, ciliées sur leurs bords, ovales, pointues, planes et à fond mamelonné.

Lieu. Le Cap. Ђ.

* 9. S. grandiflore, S. grandiflora, Mass., Willd.

Rameaux quadrangulaires, droits, à angles garnis de dents distantes et courbées vers le bas. Fleurs grandes, d'un pourpre noir, velues, planes, à 5 pointes aiguës, ciliées en leurs bords; les pédoncules renflés à leur base.

Lieu. Le Cap. $\zeta$.

* ro. S. astérie, S. asterias, Mass., Willd.

Rameaux droils, tétragones, à dents courtes, Corolle grande. 
à 5 divisions assez profondes, ovales, acuminées, d'un violet obscur, variée de stries transversales, blanches et jaunâtres. Nectaires blancs.

Lieu. Le Cap. 5 .

* Ir.S. réticulée, S. reticulata, Mass., Wrlud.

Rameaux pentagones, étalés, denticulés; les dents ouvertes. Corolle à ro angles, d'un pourpre noir, réticulée de lignes blanches; le milieu s'éleve en plateau orbiculaire, pourpre et barbu.

\section{Lieu. Le Cap. 万。}

12. S. tuberculeuse, $S$. verrucosa, Mass., WiLld.

Rameaux montans, tétragones, floriferes à leur base, avec des dents pointues sur leurs angles. Corolle à 5 divisions ovales; pointues, planes, verruqueuses, jaunes, ponctuées $d$ 'un rouge sanguin, brunes au centre et au sommet; le milieu élevé ét pentagone entoure les parties de la fructification.

Lieu. Le Cáp. Ђ.

13. S. ambiguë, S. ambigua, MAss.

Rameaux quadrangulaires, droits, pointus; les angles dentés, distans, recourbés. Corolle grande et plane, à 5 divisions velues, lancéolées, ciliées sur leurs bords, d'un pourpre roux, variées de stries transversales d'un violet foncé.

Lieu. Le Cap. Ђ.

14. S. roulée, S. revoluta, Mass.

Rameaux tétragones, dentés, droits; les dents ouvertes. Corolle glabre; les divisions ciliées, pointues et roulées, d'un viole pâle. Cette espèce est voisine de la $8 \mathrm{e}$.

Lieu. Le Cap. Ђ.

15. S. coussinette, $S$. pulvinata, Mass.

Rameaux tétragones, couchés, dentés. Corolle grande, à fond roux, élevé, très-velu; les parties de la fructification d'un violet noir.

Lieu. Le Cap. 5.

16. S. à cinq nervures, S. gemmiflora, MAss.

Rameaux droits, tétragones, dentés ; les dents presque droites et pointues. Corolle plane, rude, jaune, tachetée de pourpre, 
5 divisions ovales-lancéolées, narquées de 5 nervures, ciliées era leurs bords.

Lieu. Le Cap. Ђ.

Variété tachetée de points d'un jaune doré.

* I7. Stapélie divergente, $S$. divaricala, Mass.

Rameaux tétragones, divergens, glabres, garnis de petites dents droites. Corolle d'un rouge carné, très-glabre, à 5 divisions lancéolées, ouvertes, ciliées en leurs bords et roulées.

Lieu. Le Cap. Ђ.

18. S. rousse, $S$. rufa, Mass.

Rameaux droits, tétragones, garnis de dents droites. Corolle assez petite, brune, à 5 divisions triangulaires, pointues, ridées, ciliées en leurs bords. La fleur de cette espèce imite celle du periploca graca.

Lieu. Le Cap. Ђ.

r. S. acuminée, $S$. acuminata, Mass.

Rameaux presque droits, tétragones, dentés. Corolle plane, glabre, ridée, à 5 divisions acuminées, marquées de stries ondulées, d'un pourpre noir, garnies de cils blancs en leurs bords.

Lieu. Le Cap. Ђ.

20. S. couchée, S. reclinata, Mass.

Rameaux tétragones, couchés, garnis de dents pointues et ouvertes. Corolle d'un violet noir, petite, à 5 divisions recourbées, ouvertes, repliées et frangées. Nectaires jaunes.

Lieu. Le Cap. Ђ.

21. S. élégante, $S$. elegans, MAss.

Rameaux rassemblés, oblongs, dentés; les dents ouvertes et pointues. Corolle d'un violet noirâtre avec le fond roux, à 5 divisions triangulaires, velues, frangées sur leurs bords. Nectaires jaunes.

\section{Lieu. Le Cap. b.}

22. S. agréable, $S$. concinna, Mass.

Rameaux droits, tétragones, très-glabres, garnis sur leurs angles de dents droites. Corolle cendrée, à 5 divisions planes, marquées de stries ondulées, brunes, chargées de poils blance, le fond brun.

Lieu. Le Cap. 5 . 
25. S. glanduleuse, $S$. glandulifera, MAss.

Rameaux presque droits, tétragones, garnis de dents droites et aiguës. Corolle plane, d'un jaune soufre, couverte de glandes ct de poils blancs, à 5 divisions ovales-lancéolées, pointues.

Lieu. Le Cap. ๖.

24. S. pédonculée, S. pedonculata, MAss.

Rameaux divergens, tétragones, légèrement dentés. Corolle d'uñ pourpre brun, à 5 divisions lancéolées, roulées en leurs bords, et dont les angles sont frangés. Variété à corolle jaune.

Lіеи. Le Cap. $\$$.

25. S. ouverte, S. aperta, M.Ass.

Cette espèce, qui a des rapports à la précédente, en differe par sa corolle pourpre, ridée par des raies obscures, dont le fond cendré est ponctué de noir.

Ces 2 dernières espèces ont leurs $\mathrm{fl}$. portées sur de longs péd. Lieu. Le Cap. Ђ.

26. S. pileuse, $S$. pilifera, MAss.

Rameaux cylindriques, sillonnés, tuberculés, velus. Fleurs sessiles, solitaires. Corolle d'un pourpre noir avec un cercle rouge au milieu.

Lieu. Le Cap.

27. S. carnée, S. incarnata, Mass.

Rameaux droits, tétragones, avec des dents aiguës. Corolie carnée ou blanche, à 5 divisions lancéolées, planes.

Lieu.Id. 万.

28. S. ponctuée, S. punctata, M.sss.

Rameaux articulés, oblongs, un peu tétragones, dentés. Tleurs fasciculées. Corolle d'un blanc carné, ponctuée de rougc sanguin, à 5 divisions ouvertes et pointues.

Lieu. Id. 万.

* 29. S. géminée, S. geminata, M Ass.

Rameaux oblongs, presque tétragones, à petites dents. Fleurs géminées. Corolle d'un jaune orangé, ponctuée d'un rougesanguin, à 5 divisions aiguës et roulées en leurs bords.

Lieu. Le Cap. $\$$.

3o. S. ornée, $S$. decora, Mass.

Rameaux articulés, oblongs, presque cylindriques. Corolle 
à 5 divisions lancéolées, pointues, roulées en leurs bords, Jaunes, chargées de points rudes et d'un pourpre noir; fond pentagone et d'une couleur pâle.

Lieu. Le Cap. b.

З̆. Stapéize vieille, S. vetula, MAss.

Rameaux droits, tétragones, glabres, garnis sur leurs angles de dents à sommet recourbé. Corolle plane, glabre, d'un violet foncé, variée de stries transversales noirâtres, à 5 divisions trinerves et obtuses.

Lieu. Le Cap. Ђ.

32. S. aspergée, S. irrorata, Mass.

Rameaux presque droits, garnis de dents pointues, disposées: en croix. Corolle plane, ridée, d'un jaune soufre, tachetée d'un rouge sanguin, à 5 div. lanc., dont la pointe est pourpre.

Lieu. Le Cap. 5.

33. S. mêlée, S. mixta, WiLrd.

Rameaux tétragones, montans, floriferes à leur base. Corolle à 5 divisions ovales, acuminées, dont le fond circulaire est élevé.

Lieu. Le Cap. h.

34. S. campanulée, S. campanulata, MAss.

Rameaux simples, droits, tétragones, garnis de dents ouvertes et pointues. Corolle à 10 divisions, d'un jaune soufre, marquée de laches d'un rouge noirâtre, asec le fond brun.

Lieu. Le Cap. Ђ.

35. S. barbue S. barbata, MAss.

Rameaux tétragones et pentagones, rassemblés, droits. Cozolle campanulée, à ro divisions, d'un jaune pâle, variée de taches élevées, d'un pourpre noir, et chargée de poils en massue ${ }_{2}$.

Lieu. Le Cap. 5.

*36. S. élégante, S. venusta, MAss.

Rameaux tétragones et pentagones; les petits rameaux trèsهuverts, même divergens, garnis de dents pointues. Corolle à - divisions, d'un jaune soufre, ponctuée de rouge, dont le 
fond, en tube campaniforme, s'agrandit, s'éleve et prend une forme orbiculaire.

Lieu. Le Cap. Ђ.

Outre les espèces que je viens d'indiquer, les Anglaiscultivent encore les suivantes, qu'ils, ont nommées ainsi :
$S$. radiata.
S. picta.
S. orbiculata.
S. clypeata.
S. bufonia.
S. lentiginosa.
S. trisulca.
S. crassa.
S. bisulca.
S. umbellata.

Parmi les espèces que j'ai citées, celles dont les corolles sont divisées en cinq parties et qui sont velues sur leurs bords, sont les $2,7,8,9,10,11,13,14,15,16,17,18,19,20$, 2 I , 22, 23 ; celles qui ont cinq divisions glabres en leurs. bords, 12 , 24, 25, 26, 4, 5, 3, 6, 27, 28, 29, 3о, 3 г , 32, 53 , I ; enfin celles dont les corolles sont à dix divisions, I I, $34,35,36$.

Cult. Serre tempérée ou serre chaude. Terre franche, mêlée de sable et de gravier au fond des pots, pour laisser échapper I'humidité. Arrosemens presque nuls en hiver, à moins que ces plantes ne soient en serre chaude; assez fréquens en été. Il vaut mieux, dans cette saison, les tenir dans une serre ou sous châssis que de les placer en plein air, où la pluie et la grêle les endommagent, et où elles fleurissent rarement. Mult. par leurs tiges ou rameaux enracinés, ou par boutures, ou par leurs graines. Quand on emploie la voie des boutures, il faut attendre, pour les mettre en terre, que la partie coupée soit bien sèche. Elles se font en pot, qu'on plonge dans une couche sous châssis, ou qu'on met simplement sur les tablettes de la serre. Ces plantes se multiplient tant que l'on veut. La première mûrit ses semences dans nos jardins.

Us. Les stapélies forment de grosses touffes vertes et tresgarnies, qui, dans le printempis et l'été, se parent de fleurs Celles de la première sont fort agréables à la vue; mais la plante en donne moins que la seconde, qui a une succession assez lo $a$ gue. Celles-ci sont plus grandes, mais n'ont pas l'aspect de 
celles de la première, et elles exhalent une odeur si forte de chair corrompue, qu'on ne peut en approcher lorsqu'elles sont épanouies. La mouche de la viande, attirée par cette émanation, vient y déposer ses œufs, croyant y trouver la nourriture propre à sa progéniture. Les œufs y éclosent; la fleur est alors couverte de petits vers, mais qui ne tardent pas à périr.

Ces plantes sont cultivées dans toutes les collections de plantes étrangères. Plusieurs ont d̉es fleurs fort agréables à voir par leurs couleurs variées et singulieres.

\section{Périploque, Periploca.}

Cal. très-petit, 6-fide, persistant. Cor. en roue, plane, à 5 parw ties, dont l'entrée est garnie d'une couronne en godet, à 5 div. et 5 pointes sétacées. Filamens des étam. connivens. I style. Stigm. en tête pentagone, garni de 5 glandes pédicellées. Follicules obl., ventrus. Sem. aigrettées.

* I. Périploque de Grèce, P. groeca. Arbre à soie de Virginie.

Tiges et rameaux très-glabres, cylind., longs, très-flexibles, de 25 à 30 pieds, s'entortillant sans vrilles aux appuis qu'ils rencontrent. Feuilles ovales-lanc., opp., presque sess., trèsentières, d'un vert luisant en-dessus. Fleurs d'un pourpre foncé, bordées de vert, velues dans leur intérieur, disposées en bouquets ax. vers le sommet des jeunes rameaux.

Lieu. La Syrie. Ђ. Fl. en août.

2. P. d'Afrique, $P$. africana.

Tige de 3 pieds, volubile et velue. Feuilles ovales, opp. e? velues. Fleurs petites, pourpres, odorantes, en bouquets ax.

Lieu. L'Afrique. Ђ. Fl. en juillet et août.

2. P. d'Afrique, scamonea.

Feuilles lanc., elliptiques. Fleurs velues en-dedans et paniculées. Plus petites et plus nombreuses que celles de la première espèce.

Lieu.... \$. Fl. en juillet.

4. P. lisse, P. levigata, VAnt. P. angutifolia, Bul. Non lavigata, WILLD. 
Tige glabre. Feuilles obl.-lanc., lisses. Fleurs glabres, en cîmes trichotomes. Corolles pourpres, dont les bords sont d'un jaune pâle, avec un point blanc vers le milieu des divisions.

Lieu. Túnis. ๖. Fl...

Cult. La première espèce est de pleine terre. Elle est trèsrustique, et vient dans tous les terrains; mais, à moins de la mettre contre des murs, elle est assez incommode, par la longueur de ses tiges qui s'entortillent à tout ce qu'elles trouvent. On pourroit, en la plantant près de quelques arbres indigènes, les en garnir; elle monteroit sur leur tronc et sur leurs branches, et donneroit à l'arbre un effet particulier. Elle est trèspropre à garnir des berceaux. On la multiplie aisément par les marcottes; la flexibilité de ses rameaux rend ce moyen trèsfacile. Elle se plaît au soleil, et ne fleurit que peu à l'ombre.

Les autres espèces sont d'orangerie. La seconde n'est point délicate ; on la.cultive en pots, qui doivent être proportionnés ¿̀ l'étendue de ses racines, de manière que celles-ci en touchent toujours les bords. On la multiplie de marcottes aussi facilement que la première. Ces espèces, qui sont laiteuses, doivent être très-peu arrosées en hiver, et placées près des jours de la scrre.

Us. La première, lorsqu'clle est conduite avec un peu d'art, fait un effet assez agréable dans le temps de ses fleurs, qui sont assez nombreuses et qui se succèdent long-temps.

\section{Apocin, Apocynum.}

Cal. très-petit, persistant, 5-fide. Cor. camp., à 5 lobes roulé. 5 corpuscules glanduleux environnant l'ovaire. Antheres conniventes, bifides à leur base. Style presque nul. I sigmate large. Follicules lonģs, acuminés. Semences à longues aigreltes.

* I. Apocir gobe-mouche, A. androsamifolium.

Tige d'un pied et demi, rougeâtre, rameuse à son sommet. Feuilles opp., ovales, pointues, enlieres, glabres des cicux cútés. Tlcurs d'un ronge pûle, ponchées, assez petites, crimp., 
disposées en bouquets ombelliformes, un peu pendans et term: Plante traçante.

Lieu. La Virginie. $\tau$. Fl. en août et sept.

* 2. A. à fleurs herbacées, A. cannabinum.

Tiges droiles, de 3 pieds, peu rameuses. Feuilles opp., obl., entières, mucronées, velues et blanchâtres en-dessous. Fleurs petites, verdâtres, en corymbes term.

Lieu. Id. $\%$. Fl. en juillet-sept.

* 3. A. maritime, A. venetum.

Tiges glabres, droites, rameuses, de 3 pieds. Feuilles opp. , presque sess., oblongues, mucronées, vertes des deux côtés. Fleurs blanches, en bouquets lâches et term.

Lieu. Les îles de la mer Adriatique. $\%$. Fl. en juillet et août. 4. A. à feuilles de millepertuis, A. hypericifolium, H. K. $A$. sibiricum, Lrv.

Tige assez droite, herbacée. Feuilles obl., cordiformes, glabres. Fleurs en cîmes, plus courtes que les feuilles.

Lieu. L'Amérique sept. $\longleftarrow$. Fl. en juin et juillet.

Cult. Pleine terre. Les apocins sont assez rustiques. Ils se plaisent dans les terres douces, franches, faciles à percer et un peu fraîches. La nature traçarte de la $I^{\text {se }}$ espèce fournil les moyens de la multiplier; mais ses drageons enracinés ne doivent ètre enlevés que lorsque la plante est assez forte. En les retranchant à mesure qu'ils paroissent, on court le risque de faire pésir le pied. Cette opération se fait avec plus de succès en mars qu'en automne. Quand on présume, par la force des drageons, qu'il y en a d'enracinés, le rueilleur moyen de les avoir bons, sans craindre de faire tort à la plante qui les fournit, seroit d'en sevrer les plus forts en été, sans les arracher, mais en tâchant de couper les racines qui les produisent, à quelque distance du pied principal et du drageon. Cette espèce est si traçante qu'elle envoie ses drageons à 12 à 18 pieds de sa place. Elle est par cette circonstance un peu incommode dans les parterres.

$U_{s}$. La I $^{\text {te }}$ et la $3^{\text {e }}$ ont de jolies fleurs qui contribuent à lornement des jarciins. On appelle la $\mathbf{1}^{\text {re }}$, avec raison, gobemonche, parce que ces insectes, attirés par le miel qui se trouye 
au fond de la fleur, engagent leur trompe dans les filets et corpuscules qui entourent les ovaires, et ne pouvant l'en retirer, quelque effort qu'ils fassent, ils se trouvent pris. J'ai vu des mouches bien plus longues que la fleur se débattre avec leurs ailes, et employer toutes leurs forces pour se tirer du piége, sans pouvoir y parvenir. Cet effet est produit par la contraction qui est, dans cette plante, la suite de l'irritation des organes de la fructification.

La $3^{\mathrm{e}}$ est un peu délicate pour passer en plein air sans dommage et sans risque dans les pays septentrionaux de la France, sur-tout dans les hivers rigoureux. Il est prudent d'en cultiver un ou deux individus en orangerie, et de couvrir de litière ceux qui sont en plein air.

\section{Cynanque, Cynanchum.}

Cal. très-petit, persistant, à 5 dents. Cor. à tube très-court; les div. du limbe longues et linéaires. Une couronne cylindrique, abl., droite et dentée, environnant l'entrée de la corolle. Etam. comme dans l'asclépiade. Style presque nul. 2 stigm. Follicules oblongs, acuminés. Sem. aigrettées.

1. Cynanque nue, $C$. viminale.

Tiges grêles, cylind., verdâtres, lisses, sarmenteuses, volum biles, de 3 à 6 pieds. Point de feuilles. Fleurs peu connues.

Lieu. Le Cap. Ђ. Fl.

* 2. C. à feuilles pointues, C. acutum.

Id, de Montpellier, C. monspeliacum. Scamonée de Montpellier.

Tiges cylind., volubiles, glabres, Iongues, laiteuses. Feuilles opp., pét. , cordiformes, arrondies, pointues, plus larges que longues, molles, d'un vert grisâtre. Fleurs petites, blanchâtres, en corymbes ombelliformes, sol., latéraux, péd.

La première, à feuilles pointues, ne differe de celle-ci que par ses feuilles plus étroites, plus pointues, et par ses pédornqules, plus alongés. 
Lieu. La première, l'Espagne; la deuxieme la France méridionale. $\psi$. Fl. en juillet. - septembre.

3. Cynanque subéreuse, C. suberosum.

Tige volubile, velue, dont la partie inf. est revêtue d'une écorce crevassée. Feuilles opp., cordiformes, pointues, molles, pubescentes, pét. Fleurs petites, ouvertes en étoile, comme celles de la précédente, d'abord vertes, 'ensuite rougeâtres, ax.

Lieu. L'Amérique mérid. Ђ. Fl. en juillet-sept.

4. C. hérissée, $C$. hirtum.

Tige volubile, à écorce crevassée. Feuilles ovales, cordiformes, glảres, opp., pét. Fleurs d'un jaune verdâtre, en bouquets ax.

Lieu. La Jamaïque. ๖.Fl. . . .

* 5. C. droite, C. erectum.

Tiges droites, glabres, de 5 pieds, disposées en touffe. F. opp., pét. cordiformes, pointues, glabres, d'un vert léger. Fl. blanches, en corymbes lâches et latéraux, très-nombreuses.

Lieu. La Syrie. Ђ. Fl. en juillet et août.

6. C. à fleurs crispées, C. crispiflorum.

Tige volubile. Feuilles oblongues, cordiformes, velues endessous. Les divisions de la corolle crispées à leur sommet.

Lieu. L'Amérique mérid, ๖. Fl." en juillet.

7. C. à fleurs velues, C. extensum.

Tige volubile, frutescente. Feuilles cordiformes, aiguës. Les pédoncules des fleurs alongés, et leurs divisions filiformes. Cor. velues en leurs bords. Follicules effilés.

Lieu. Les Indes or. Ђ. Fl. en juillet et août.

Cult. Les espèces 2 et 5 sont de pleine terre; mais dans le nord de la France elles exigent une bonne exposition et des ierres chaudes et légères. En hiver on doit couvrir leurs pieds cruand on craint les gelées un peu fortes. On les multiplie par leurs drageons, qu'elles poussent assez abondamment, et gu'on leve au printemps. Les autres espèces sont de serre chaude. Cependant Miller dit que la troisième pourroit passer en pleine terre dans une situation abritée, et avec quelques soins pour la garantir des grands froids. Au reste, ces plantes sont, pour nos climats, toutes assez délicates pour en conserver 
des individus en pots, et ne mettre en pleine terre que les doubles. Les cynanques de serre chaude s'obtiennent par leurs graines tirées des pays où la nature les a placées, et semées í la manière indiquée pour les plantes de cette serre. La première se multiplie ausssi par boutures.

$U s$. La première est assez singulière. Elle ressemble à uner espèce d'euphorbe. On la cultive pour cette particularité. La 5 e peut contribuer à l'agrément des jard. par ses $\mathrm{f}$. nombreuses.

Le suc laiteux de la deuxième est purgatif. Ce suc, épaissi par la cuisson, se vend souvent pour la vraie scamonée, troisième espèce de liseron de cet ouvrage.

On cultive encore les espèces suivantes. 8. C. couché, C. prostratum, Cav., VVinid.

Tige couchée, herbacée, cotonneuse. Feuilles en cour, réniformes, pointues, cotonneuses en - dessous. Fleurs vertes, à divisions linéaires, obtuses.

Lieu. Le Mexique. $\nsucc$.Cette espèce a des rapports avec la ${ }_{2}$ re, 9. C. de la Caroline, C. carolinense, JAcQ. , WiLLd.

Tige volubile, rude au toucher, herbacée. Feuilles ovales, oblongues, en cœur, velues, acuminées. Fleurs disposées en corymbes axillaires; les divisions oblongues et obtuses. Rapport à la troisième et à la quatrième.

\section{Lieu. La Caroline. $\%$.}

10. C. à fleurs noires, C. melanthos, VAHL.

II. C. de l'Ile de France, C. mauritianum. 万.

Cult. La $8^{\mathrm{e}}$ et la I I $^{\mathrm{e}}$ sont de serre chaude. La $9^{\mathrm{e}} \mathrm{d}^{\text {'orangerie. }}$ La $10^{e} \mathrm{~m}^{\prime}$ est entièrement inconnue.

\section{Asclépiade, Asclepias.}

Cal. pelit, persistant, 5-fide. Cor. à 5 part., plane ou réfléchie. 5 cornets alternes avec les div. de la cor., insérés ext. sur le tube des étam. Filets des étam. réunis en un tube pentagone, environnant l'ovaire, fermé sup. par le stigm. tronqué, à 5 angles, et 5 anthères presque sess., droites, à 2 loges, et membraneuses à leur sommet. Style nul. Stigmate ombiliqué , 'pentagone, posé sur le tube, produisan 
5 focettes angulaires, 5 corpuscules ovales, très-petits, alternes avec les anthères, à 2 valves, garnies à leur base et sur leur côté de deux cornes subulées, inf. géniculées dans leur milieu, spatulées sup. Follicules oblongs, acuminés, ventrus. Sem. aigrettées.

Obs. La composition de cette fleur est tout-á-fait singuliere. Quelle étonnante préparation pour la fructification! Toutes ces parties sont-elles un jeu de la nature, ou sont-elles absolument nécessaires à la reproduction? Pourquoi ce genre a-t-il tant d'accessoires aux organes principaux de la génération, tandis qu'ils manquent à presque toutes les fleurs, qui n'en fructifient pas moins? Je présume qu'il en est de ces parties comme du nombre superflu des pétales de certaines fleurs, dont l'absence de la moitié et plus n'empêcheroit pas la fructification d'avoir lieu. Il faudroit essayer d'en ôter avec adresse quelques parties, lorsque la fleur vient de s'épanouir, pour connoître si elles sont toutes indispensables àl'œuvre dela nature.

\section{Feuilles opposées.}

1. Asclépiade ondulée, A. undulata.

Tiges cylind., de 2 à 3 pieds. Feuilles opp., sess., obl. lanc., ond., glabres. Fleurs assez grandes, verdâtres, en 3 ou 4 ombelles raprochées en épi; les corolles garnies de poils blancs. Lieu. Le Cap. Ђ. Fl. en juillet.

2. A. crépue, $A$ crispa.

Tiges droites, un peu velues, de 3 pieds. Feuilles opposées, presque sess., lin. - lanc., pointues, crépues, très-ondulées. Fleurs pourpres, en ombelles, petites et term.

Lícu. Id. ๖. Fl. .

* 3. A. géante, A. gigantea, H. K.

Tige droite, presque simple, de 5 à 6 pieds. Feuilles ov.obl., pét., cotonneuses en-dessous. Fleurs d'un jaune roum geâtre, grandes, ayant un pouce de diamètre, en bouquets ombelliformes, ax. Les divisions de la corolle réfléchies et roulées.

Les feuilles sont ovales, elliptiques, très-entières, épaisses, d'un vert blanchâtre en-dessus, blanches en-dessous. 
Lieu. Les Indes or. Ђ. Fl. en juillet-sept.

4. A. de Perse, A. procera, H. K. A. gigantea, J J

Cette espèce ne paroît différer de la précédente que par ses fleurs, qui ne sont pas réfléchies, mais presque campanulées.

Lieu. La Perse. Ђ. Fl. id.

* 5. A. de Curacao, A. curassavica.

Tiges de 2 pieds, cylind. Feuilles obl.-lanc., pét., glabres; molles. Fleurs d'un jaune orange, en ombelles droites, sol. , latérales et term. Les div. de la corolle réfléchies.

Lieu. L'Amérique mérid. Ђ. Fl. en juin - sept.

6. A. parviflore, A. parviflora, H. K.

Tige subfrutescente, droite. F. lanc., acuminées, giabres, rétrécies à leur base. Fleurs petites, en ombelles latérales, sol,

Lieu. La Caroline, Ia Floride or. $\%$. Fl. en juillet-oct.

* 7 . A de Syrie, herbe à la ouatte, A. syriaca.

Tiges fortes, droites, simples, cotonneuses, de 4 à 5 pieds. Feuilles ovales, épaisses, très-entières, blanchâtres, douces au toucher. Fleurs rougeâtres, en grosses ombelles ter= minales, globuleuses, penchées, très-garnies.

Lieu. La Syrie, la Virginie. $\Psi$. Fl. en juillet et aott.

* 8. A. élégante, A. arncena.

Tiges simples, glabres, de 3 pieds. Feuilles ovales, pointues, un peu velues en-dessous. Fleurs pourpres, en ombelle droites et term. Les cornets droits.

Lieu. L'Amérique sept. $\Psi$. Fl. en juillet et août.

* 9. A. pourprée, A. purpurascens.

Tige simple. Feuilles ovales, velues en-dessous. Fleurs verdâtres, en ombelle term. penchée. Leurs cornets d'un beau pourpre, sont écartés et presque renversés.

Cette espèce differe peu de la précédente.

Lieu. Id. $\Psi$. Fl. en août et sept.

10. A. panachée, A. variegata.

Tiges tachetées de pourpre, simples. Feuilles ovales, ridées, glabres. Fleurs d'un blanc pâle et les cornets rouges, en om. belles presque sessiles.

Cette espèce a beaucoup de rapports avec la septieme.

Eieu. Id. ₹. Fl. en juillet. 
* i i. Ascréfiade à feuilles d'amandier, A. mivea.

Tiges simples, droites, de 2 pieds. Feuilles oblongues-lanc.; pointues, pét., glabres, d'un vert foncé. Fleurs d'un blanc verdâtre. Les cornets d'un blanc pur, en ombelles latérales et terminales. Rapport avec la cinquieme.

Lieu. Id. $\%$. Fl. id.

* 12. A. carnée, A. incarnata, Mrchaux.

Tiges droites, velues et rameuses vers leur sommet. Feuilles lancéolées, cotonneuses, même lanugineuses sur les deux surfaces. Fleurs d'un pourpre léger, disposées en plusieurs ombelles d'abord géminées; les cornets saillans.

Variété. A. pulchra, Michaux.

Liez. L'Amérique sep̧tentr. $\pi$. Fl. en juillet et aổt.

* 13. A. dompte-venin, $A$. vinceloxicum. Vincetoxicum vuí gare, PERs.

Tiges foibles, droites, de 2 à 5 pieds, flexibles. Feuilles ov., pointues, un peu en cœur à leur base, un peu velues et ciliées en leurs bords, a'un vert obscur. Fleurs petites, d'un jaune pâle, en petites ombelles ax.

Lieu. La France. $\longleftarrow$. Fl. en mai-août.

Variété à fleurs blanches.

* I4. A. noire, A. nigra. Vincetoxicunn nigrnm, Pers.

Tiges flexibles, un peu grimpantes, foibles. Feuilles plus étroites que celles de la précédente, d'un vert noirâtre. Fleurs petites, d'un rouge noirâtre.

Beaucoup de rapports avec la treizième.

Lieu. Id. $飞$. Fl. id.

I5. A. arborescente, A. arborescens.

Tige droite, rameuse, velue et courte. Feuilles ovales, obtuses, épaisses, glabres, un peu mucronées, à veines transparentes. Fleurs blanches, en ombelles latérales. Les feuilles son un peu roulées en leurs bords.

Lieu. Le Cap. Ђ. Fl. en déc.

* 16. A. à feuilles de saule, A. fruticosa, Mrluer, Lir.

Tige de 5 à 6 pieds, droite, grêle, pubescente. Feuilles salic:. formes, lin.-lanc., étroites, longues, pét., roulćes en leur.s bords. Fleurs blanches, en ombelles latéralcs. 


\section{IS A P O CINEES:}

Lieu. Id. Ђ. Fl. en juin-septemb.

r7. A. de Sibérie, A. sibirica, Lrn., Gmelin.

Tiges menues, penchées. Feuilles lin.-lanc.; les unes opp., les autres ternées.

Lieu. La Sibérie. İ. Fl. en juillet et août.

18. A. verticillée, $A$. verlicillata.

Tige simple, droite. Feuilles lin., très-étroites, 4 ensemble, en forme de verticille. Fleurs blanches, en ombelles latérales, opposées aux feuilles.

Lieu. L'Amérique septentr. ₹. Fl...

\section{Feuilles alternes.}

* Ig. A. tubéreuse, A. tuberosa.

Racine tubéreuse. Tige droite, velue, rameuse, d'un pied et demi. Feuilles alt., lanc., velues. Fleurs d'un rouge orangé, en ombelles latérales et term.

Lieu. Id. $\Psi$. Fl. en juillet-septemb.

Cult. Les espèces 7 à 14 inclusivement, excepté la $1 \mathrm{I}^{\mathrm{e}}$, sont de pleine terre, ainsi que les 17, i 8 et 19 e. Elles sont assez rustiques pour la plupart. Cependant dans les fortes gelées du nord de la France, il est prudent de couvrir les espèces étrangères de litière; mais il est rare qu'elles en aient absolument besoin. Elles aiment toutes une terre douce, franche, un peu fraîche et facile à percer. La $19^{\mathrm{e}}$ est un peu délicate, et demande une terre plus chaude, plus lègère et une bonne exposition. On les multiplie par leurs graines semées aussitôt après leur maturité, et tirées des pays où elles mûrissent, car elles ne parviennent pas à la fructification dans nos climats. Ces graines se sement en terrines ou en plate-bande, qu'on couvre pendani l'hiver de litière. Quand, dans l'année suivante, les plantes ont 3 ou 4 pouces, on les place aussitôt à demeure, en les enlevant avec leurs moites; sans cette précaution il seroit douteux qu'elles reprissent. Quand on a une fois obtenu ces asclépiades, on les propage aisément, soit en séparant leurs pieds en mars, soit par leurs rejetons ef drageons.

Les espèces $1,2,6,15$ et 16 sont d'orangerie, et les autres III. 
$5,4,5$ et I r sont de serre chaude. Celles-ci se sement au printemps en terrines, sur couche et sous châssis. On les conduit ensuite à la manière indiquée pour les plantes de ces températures. La $5^{\mathrm{e}}$ n'est pas très-délicate; elle passeroit bien l'hiver en serre tempérée. Elle fleurit ordinairement la première année de son semis; mais elle est plus belle la seconde. Elle dépérit dans la $3^{\mathrm{e}}$, et la $4^{\mathrm{e}}$ elle meurt. La $16^{\mathrm{e}}$, quoiqu indiquée frutescente, n'est que $\sigma^{7}$; mais sa tige est un peu ligneuse. La troisième s'éleve avec lenteur et n'est pas facile à conserver. Elie fleurit rarement, et ne porte guère que 4 ou 6 feuilles à son sommet. Les précédentes tombent aussitôt qu'il en naît de nouvelles.

$U s$. Les asclépiades de pleine terre font un effet remarquable dans les jardins; toutes n'ont cependant pas le même aspect. Celles qui méritent le plus d'être distinguées sont les espèces 7 8 , 1o et 12. Parmi celles de serre, les $5^{\mathrm{e}}$ et $5^{\mathrm{e}}$ sont les plus jolies; ces espèces y fructifient, et leurs graines sont bonnes. La $5^{\text {e }}$ fleurit en plein air pendant l'été, et y mûrit ses semences.

On se sert du duvet des follicules de la $z^{e}$ pour ouatter. On a essayé de le filer et de l'employer en étoffe; mais le succès a été médiocre par son défaut d'élasticité.

$\mathrm{La} I 5^{\mathrm{e}}$ avoit autrefois la réputation d'être alexitère; mais elle a perdu beaucoup de ces vertus dans ce siècle plus éclairé, et l'on pense même que, loin d'être salutaire, elle peut être dangereuse.

Les asclépiades de serre craignent l'humidité en hiver. Il faut les mettre près des jours, les arroser peu dans cette saison, et leur donner une terre un peu sablonneuse.

\section{Autres espèces cultivées.}

20. Asclépiade à feuilles de linaire, A. linaria, Cav., Icon... Muséum. Ann.

Tiges herbacées, cylindriques, droites, grêles, presque simples, de 4 à 5 décinietres. Feuilles pétiolées, nombreuses, glabres, éparses ou verticillées, linéaires, poiniues, vertes. Fleurs blanches, péd., disposées en 2 ou 5 ombelles term.

Lieu. Le Miexique. $\%$. Fl. en autonne. 
* 2x. A. du Mexique, A. mexicana, Cav., Icon. Mus. Ann.

Tiges droites, cylindriques, peu rameuses, légèrement cotonneuses, de 5 à 8 déci nètres. Feuilles pétiolées, verticillées, au nombre de 5 à 6 ; les supérieures à troìs; lancéolées, pédonculées, disposées en ombelles hémisphériques, axillaires. Collerette à plusieurs folioles subulées, ainsi que celle de la précédente. Corolle d'abord violette, ensuite blanche. Les cornets nuancés de violet. Calice cilié.

Lieu. Le Mexique. $\%$. Fl. en automne.

Cult. Orangerie.

Us. Ces deux nouvelles espèces snnt jolies et méritent les soins du cultivateur.

22. A. pubescente, $A$. pubescens, Iriv., sect. I.

Tige droite, ligneuse, velue, peu rameuse. Feuilles opposées, velues, ovales, acuminées, veineuses, rapprochées, peu pétiolées. Fleurs purpurines, en ombelles pédonculées, velues.

Lieu. Le Cap. Ђ.

Cult. Serre chaude. Mult. par marcottes arrosées avec soin. On peut la mettre en plein air pendant 4 mois de l'été.

* 23. A. volubile, A. volubilis, Liv., Suppl., sect. I.

Tige arborée, grimpante, très - glabre. Feuilles pétiolées, opposées, ovales, très-entières, veineuses, acuminées. Fleurs verdâtres, en ombelles simples, pédonculées.

Lieu. Ceylan. Ђ.

Cult. Serre chaude.

Ces deux dernières espèces sont cult. à Milan par M. Armano. *24. A. charnue, A. carnosa, Lin., sect. $x$.

Feuilles ovales, charnues, très-glabres, très-épaisses, opp., luisantes, longues de 4 pouces et demi, larges de 2 .

Lieu. La Chine? . Fl. en juillet. 25. A. linaria, Cav., sect. 2.

Feuilles éparses, pointues, en alêne, canaliculées. Fleurs nombreuses, en ombelles latérales.

Lieu. L'Amérique mérid. Ђ. 26. A. echinata, Hort. angl., sect. 2.

Lieu. Les Indes orient. Ђ.

Cult. Excepté la 25e, qui est d'orangerie, les deux autres sont 
de serre chaude. Ces trois dernières espèces sont cultivées en Angleterre.

\section{Ovaire simple. Fruit à baie. Rarement capsulaire.}

\section{Allamanda.}

Cal. à 5 part. Cor. grande, infund., à long tube et entrée agrandie, à limbe ample, ouvert, 5-fide. Etam. insérées à l'entrée de la cor. Anthères sagittées. Le disque annulaire sous I'ovaire. I style long. Stigm. droit. Caps. coriace, ovale, comprimée, grande, hérissée de longs aiguillons, à I loge et 2 valves polyspermes. Semences orbiculées, membraneuses en leurs bords, fixées au bord des valves.

* Alla manda à feuilles de saule, $A$. cathartica.

Plante laiteuse, grimpante. Feuilles quatern., presque sess., ov.-obl., obtuses, avec une pointe particulière, luisantes. Fleurs jaunes, grandes, pédonculées, solitaires ou géminées, ax. et terminales.

Lieu. La Guyane. Ђ. Fleurit....

Cult. Serre chaude. Cultivée à Kew. J'ai cultivé aussi celle plante, et je l'ai perdue par la difficulté de la conserver. Elle exige beaucoup dechaleur, et n'a besoin que de peu d'arrosemens.

L'infusion des feuilles de cet arbre, selon Linné, est utile dans la colique des peintres.

\section{Mélodin , Melodinus.}

Cal. à 5 part, persistant. Cor. tubulée, à limbe à 5 part. obliqucs, garnie d'une couronne déchirée et 5-fide à son entrée. Étam. courtes. I style. 2 stigm. Baie globuleuse, à 2 loges, pulpeuse, contenant plusieurs sem. comprimées.

Mélodir grimpant, $M$. scandens.

Arbrisseau très-glabre. Tige volubile. Feuilles opp., obl., oy., veineuses, très-entières.

Lieu. La Nouvelle-Calédonie. \$. Fl...

Cult. Serre chaude. Cultivé à Kẹt. 


\section{Rauvolfe, Rauvolfia.}

Cal. à 5 dents, très-petit, persistant. Cor. tubulée, globuleuse à sa base, à limbe à 5 part. Etam. courtes. I style court. Stigm. en tête. Fruit presque gुlobuleux, sillonné d'un côté, contenant un noyau à 2 loges et $2 \mathrm{sem}$.

* I. Rauvolfe luisante, $R$. nitida.

Tiges de 7 à 8 pieds, rameuses, vertes dans leur jeunesse, grises ensuite. Feurlles verticillées, au nombre de 4 à chaque nœud, lanc., légèrement dentées, un peu velues, d'un vert léger et luisant. Fleurs péd., ax.

Lieu. L'Amérique mérid. ๖. Fl. en juillet. Toujours verte.

Cult. Serre chaude. On obtient cette plante par ses graines tirées de son pays originaire, et semées en pots sur couche et sous châssis à la manière indiquée. Elles ne lèvent pas toujours la même année de leur semis. On la propage aussi par les boutures faites en pot dans une couche sous châssis. Cet arbrisseau. n'est point délicat.

2. R. blanchâtre, $R$. canescens WiLLD. $R$. subpubescens, Liv.

Arbre dont les rameaux sont un peu cotonneux; les feuilles quaternées, oblongues, cotonneuses, acuminées, tres-entières. Fleurs pédonculées, axillaires et terminales.

Lieu. L'Amérique mérid.

Cult. Serre chaude.

5. R. épineuse, $R$. spinosa, $\mathrm{C}_{\mathrm{Av}}$.

Cette espece est une plante vivace ou un peu frutescente. épineuse, dont les rameaux sont tétragones, les feuilles opposées, lancéolées, très-entières, et les fleurs d'un blanc jaunâtres

Lieu. Le Pérou. $\nsucc$ ou $५$.

Cult. Serre tempérée. Mult. par les marcottes.

\section{Serpentine, Ophyoxylon.}

Cal. très-petit, à 5 dents. Cor. tubulée, filiforme, un pe grossie dans sa parie moyenne, à limbe à 5 part. Firaria 
courtes. I style. I stigm. en tête. Baie didyme, à 2 loges et $2 \mathrm{sem}$.

* Serpentine glomérulée, $O$. serpentinum.

Racine contournée. Tiges d'un pied et plus, droites, cylind., gुlabres. Feuilles presque verticillées, et d'autres alt. , lanc.-obl. , très-entières, glabres, d'un vert un peu jaunâtre. Fleurs blanches en-dedans, rouges en-dehors, assez nombreuses, ramassées en espèce d'ombelle glomérulée et terminale. Fleurs polygamiques.

Lieu. Les Indes or. Ђं. Fl. en juin - août. Toujours verte.

Cult. Serre chaude. Cette plante demande une terre substantielle, consistante. Elle languit dans la trop légère. Arrosemens fréquens en été, très-modérés en hiver. Elle aime la chaleur, et doil toujours l'avoir. Mult. par la séparation de son pied, lorsqu'il est un peu fort, el qu'on voit qu'il pousse quelques rejetons écartés de la tige principale. Cette opération doit se faire en avril. Les pots dans lesquels seront mis les nouvelles plantes doivent être aussitôt plongés dans une tannée nourelle, ou dans des couches chaudes sous châssis. Cette plante est sujette à être infestée des cochenilles blanches qui se ramassent dans les fleurs, et qu'on a beaucoup de peine à ôter sans nuire à ces dernières. Elle n'en est guère at'aquée lorsqu'elle est dans un Don état de végétation. Elle ne demande pas à être souvent dépotée.

Us. La serpentine, par son feulllage et ses fleurs, ne laisse pas gue de contribuer à la déeoration des serres chaudes.

\section{Ahouai, Cerbera.}

Cal. à 5 part. ouvertes. Cor. infund., à tube en massue, dont l'entrée à 5 angles et 5 dents, et le limbe grand, à 5 part. obliques. Antlières conniventes. I style. Stigm. à 2 lobes. Gros fruit sillonné avec deux points sur un cćté, contenant un noyau 4 valv., 2 loges, 2 sem.

¿. Aftoua du Brésil, C. ahouai.

Arbre de la grandeur d'un pommier, plein d'un suc laiteux et *énéneux. Fenilles disposées au sommet des branches, éparses, 
ovales, très-entières, glabres, pointues. Fleurs d'un blanc jaunâtre, 6 ou 7 ensemble, péd., term.

Lieu. Le Brésil. ๖. Fl. en juillet. Toujours vert.

2. A. des Antilles, C. thevetia.

Arbrisseau de $\mathbf{2} 2$ à 15 pieds, rempli de suc laiteux. Les rameaux parsemés de tubercules causés par la chute des feuilles précédentes. Feuilles étroites, lin., très-longues, rassemblées, très-entières. Fleurs jaunes, grandes, odorantes, sol., ax.

Lieu. Les Artilles. Ђ. Fl... Toujours vert.

3. A. à feuilles de laurier, C. laurifolia, Hort. angl.

Lieu. Les Indes or. ๖.

4. A. ondulé, C. undulata, Andr. C. maculata, Willd. Ochrosia, $\mathrm{J}_{\mathrm{AcQ}}$.

Feuilles lancéolées, pointues aux deux bouts, ondulées, souvent tachetées. Fleurs blanches avec le fond d'un joli rouge, disposees en cînes rameuses, divergentes et axillaires.

Lieu. L'île Bourbon. 5 .

Cult. Serre chaude. Ces arbres exigent une grande chaleur, et doivent rester toujours dans une tannée. Mult. par leurs graines tirées de leur pays nat., et semées comme toutes celles de serre chaude. La terre de leur semis doit être entretenue humide, jusqu'à ce que les graines soient levées. On les repique, quand elles ont. 3 ou 4 pouces, en pots, qu'on plonge dans une couche chaude. Les ahouais, dans leur jeunesse, sont très-délicats, et périssent souvent faute de chaleur suffisante. L'humidité leur est alors contraire. Oń les multiplie aussi par boutures faites en pot sur couche et sous châssis, ou dans une tannée, et par les marcottes.

Us. Les ahouais contribuent, par leur feuillage et leurs fleurs, à l'agrément des serres. Mais ils sont encore rares et difficiles à conserver.

\section{Calac, Carissa.}

Cal. 5 -fide ou à 5 part., petit. Cor. beaucoup plus longue, tubulée, un peu ventrue sous son entrée, à limbe 5-fide. Etam. non saillantes. I style. Stigm. simple ou bifide. Baic 
petite, sphérique, à 2 loges, à une ou plusieurs semences comprimées.

* I. Calac d'Afrique, C. arduinn. Arduina bispinosa, Lin., H. K.

Arbrisseau en forme de buisson rameux et irrégulier, de 2 à 3 pieds; ses rameaux roides, durs, cylind. , sont armés de 2 piquans fermes, opposés et fourchus. Feuilles opp., imitant celles du myrte, sess., en cœur, coriaces, fermes, terminées par une pointe aiguë. Fleurs blanches, petites, fasciculées, term.

Lieu. Le Cap. Ђ. Fl. en été. Toujours vert.

Cult. Orangerie. Terre consistante, substantielle. Il craint en hiver le froid et l'humidité. Pour peu qu'il soit atteint du premier, ses feuilles se fanent et tombent. Mult. par boutures faites en été en pot sur couche ombragée. Elles s'enracinent au bout de deux mois, et peuvent être changées au printemps suivant. Soins ordinaires de l'orangerie.

Us. Cet arbuste est toujours vert; c'est sa principale qualité. Ses fleurs, quoique petites, sont pourtant assez apparentes, à cause de la verdure très-foncée et lisse de son feuillage.

2. C. à feuilles d'ortie, $C$. carandas, Lin., Willd.

Arbre dont les rameaux sont opposés et fourchus. Feuilles pétiolées, opposées, très-entières , obtuses , très-glabres, accompagnées à leur base d'épines axillaires. Fleurs imitant celles du jasmin, au nombre de trois sur des pédoncules presque terminauz et géminés.

Lieu. Les Indes orientales. $\mathrm{b}$.

Cult. Serre chaude. Cultivé en Angleterre.

IV. Genres qui ont des rapports avec les apocinées. Non laiteux.

\section{Vomique, Strychnos.}

Cal. caduc, à 5 part. ou 5-fide. Cor. tubulée, à limbe ouvert, 5 -fide, uu à 5 part. 5 étam. I style. Stigm, ẻpais. Baie globu= 
leuse, petite ou grande, à écorce souvent crustacée et fragile, à $\mathrm{I}$ loge, int. pulpeuse, polysperme. Sem. orbiculaires ou angulaires, situées sur le réceptacle central. Eubbryon de la semence mince et plane, dans le sommet d'un périsperme grand et corné.

Vomique des Indes, Noix vomique, S. nux vomica.

Arbre très-gros, sans épines. Feuilles opp., ovales, entieres, nerveuses. Fleurs en corymbes, ax. et term.

Lieu. Les Indes or. ๖. Fl...

Cult. Serre chaude. Cultivé à Kew. Cet arbre est encore rare en Europe.

Us. La noix vomique est un poison très - actif pour tous les animaux. Il agit sur eux en irritant et secouant avec violence les nerfs de l'estomac. Ses effets commencent au bout d'un quartd'heure, et font périr, peu de temps après, les bêtes de toute espèce qui l'ont avalé. On dit qu'elle n'est point aussi funeste aux hommes; mais il seroit dangereux d'en faire l'essai.

\section{Coquemollier, Theophrasta.}

Cal. à 5 lobes, persistant. Corolle campanulée, courte, à 5 lobes égaux. 5 étamines courtes. I style. I Stigm. Capsule grande, de la forme d'une pormme, tendre et fragile, à une loge presque pulpeuse, polysperme. Semences obrondes, attachées au réceptacle central, cylindrique et libre.

Copuemoluier d'Amérique, Teophrasta americana.

Petit arbre dont le port imite celui des palmiers. Tige nue, très-simple, feuillée à son sommet. Feuilles rassemblées, presque verticillées, grandes, très-longues, lancéolées, coriaces, dentées, épineuses et ondulées en leurs bords. Fleurs naissant entre les fuilles, rassemblées en corymbes terminaux.

Lieu. L'Amérique équinoxiale. 5.

Cult. Serre chaude. 


\section{Jasminée, Gelsemium.}

Cal. petit, á 5 denis. Cor. beaucoup plus longue, infund., à limbe ouvert, à 5 lobes presqu' égaux. 4 étam. I style. Caps. petite, ovale, comprimée, à 2 loges, en forme de follicules, sillonnée au milieu, à 2 valves carénées, formant une cloison par leurs bords réfléchis. Sem. planes, membraneuses à leur sommet, attachées sur les bords des valves.

* Jasminée toujours verte, G. sempervirens , G. nilidum, Michaux. Bignonia sempervirens, LIN.

Tiges sarmenteuses, garnies de beaucoup de petits rameaux flexibles, grimpans et s'entortillant aux arbres voisins. Feuilles opp., étroites, lanc., pét., entières, pointues. Fleurs jaunes, ax., péd., odorantes.

Lieu. L'Amérique sept. , la Caroline. Ђ. Fl. en juillet ou en différens temps, relativement à la température qu'on lui donne.

Cult. Orangerie. Lorsque cette plante a acquis de la force et pris une tige ligneuse, elle peut être placée en plein air contre un mur; mais la litière qu'elle demande sur son pied en hiver, les paillassons pour garantir ses tiges $d u$ grand froid, sont des soins qui, dans le nord de la France sur-tout, doivent la rendre à l'orangerie. On la multiplie par ses semences tirées de son pays orig., et semées à la manière indiquée, et par ses marcottes.

Us. Les fleurs odorantes de cet arbrisseau lui donnent une place dans les jardins. On le nomme aussi jasmin odorant de la Caroline.

\section{O R D R E X V.}

\section{LES SAPOTILLIERS ( $S A P O T$ 尼)。}

Calice divisé, persistant. Corolle régulière, ayant autant de divisions que le calice, avec des appenHices alternes, quelquefois le double de divisions et 
point d'appendices. Etamines en nombre égal et opposées aux divisions, ou le double des appendices alors anthérifères. Un ovaire et un style; le stigmate presque toujours simple. Fruit en baie ou drupacé, à une ou plusieurs loges monospermes. Semences osseuses, luisantes, ayant une cicatrice latérale. Embryon plane, dans un périsperme charnu.

Arbrisseaux ou arbres. Feuilles alternes, le plus souvent entières. Fleurs ordinairement axillaires; pédoncules uviflores. Plantes laiteuses.

Obs. Les sapotilliers different des apocinées par le frusit; ils ont, ainsi que les plaqueminiers de la classe suivante, une baje à plusieurs loges monospermes; un périsperme semblable; une corolle régulière, monopétale, staminifère; les feuilles alternes et les fleurs axillaires. Ils en different par l'insertion de la corolle.

\section{Jacquinier, Jacquinia.}

Cal. à 5 part. Cor camp., ventrue, à limbe ro-fide, dont 5 dìv. alt. et int. plus courtes. 5 étam. Baie à une sem. obronde, cartilagineuse.

1. JACQUINIE ${ }^{\star a}$ à bracelets, $\boldsymbol{J}$. armillaris.

Arbuste de 4 à 5 pieds, dont les branches sont renflées aux articulations, et les rameaux disposées en forme de verticilles. Feuilles ovales, cunéiformes, obtuses avec une pointe, trèsentières, coriaces. Fleurs petites, blanches, de l'odeur du jasmin, en grappes lâches et pendantes.

Lieu. L'Amérique mérid. ๖. Fl...

2. J. à feuilles de fragon, J. ruscifolia. Medeola aculeata, Lin., Sp. pl.

Arbuste de 3 pieds, ramifié commele précédent. Feuilles lanc., acuminées, roides, vantes à leur sommet, vertilées, aı nombre de 7 à 12 ense xible. Pédoncules uniflores.

Lieu. Id. क. Il...

Cult. Serre chaude. Thultiplication par leurs graines tirées de 
leur pays natal, et semées comme toutes celles des plantes de cette température. Ces arbrisseaux sont encore assez rares en Europe, et n'y ont vraisemblablement pas encore fleuri.

Us. La disposition des feuilles et des rameaux de ces arbustes doit faire une variété remarquable dans les serres.

Les Caraibes enfilent leurs fruits, $d$ 'un beau rouge, et s'en font des bracelets.

\section{Argan, Sideroxylon.}

Cal. 5-fide. Cor. en roue, 5-fide. 5 appendices. 5 élam., quelquefois 10 ; les appendices portant alors chacun une anthère. Fruit sec, contenant un noyau monosperme ou à 5 sem. * r. Argan à feuilles ovales, S. inerme. S. cinereum, LAm.

Arbrisseau très-lameux, de 4 à 5 pieds, dont l'écorce grise est crevassée; les rameaux courts, épais, très-ouverts, cylindriques et roides. Feuilles alternes, ovales, lisses, épaisses, fermes, glabres, très-entières. Fleurs petites, blanchâtres, en faisceaux axillaires. Les pédoncules cylindriques.

Lieu. Le Cap. Ђ. Fl. en juillet. Toujours vert.

*2. A. à feuilles de laurier, S. laurifolium, LA M. S. melanophleum, Liv. Manglilla, Persoon.

Arbre d'environ 15 pieds, dont l'écorce est brune et très-ra-

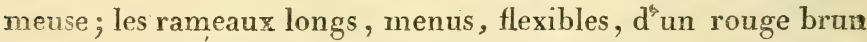
dans leur jeunesse. Feuilles alternes, lancéolées, très-entières, pointues, ondulées, lisses, coriaces, portées sur des pétioles bruns. Fleurs petites, d'abord rouges, ensuite blanches, en petits faisceaux axillaires. Pédoncules charnus, presque transparens, cylindriques.

Lieu. L'Inde, Madagascar. §. Toujours vert.

* 3. A. soyeux, S. sericeum, H. K., Willd.

Tige droite, grise, peu rameuse. Feuilles ovales-lancéolées, très-entières, pointues, d'un beau vert en-dessus, argentées et soyeuses en-dessous.

Lieu. La Nouvelle-Hollande. Ђ. Toujours vert.

* 4. A. doré, S. tenax, Liv. ? Argan soyeux, Lamarck? Bumelia tenax, Wirld. S. chrysophylloides, Mrchaux. 
Arbrisseau d'environ 20 pieds, dont les rameaux flexibles sont, ainsi que les tiges, garnis, lorsqu'ils ont 2 ou 3 ans, d'épines courtes, qu'on n'aperçoit pas sur les nouvelles pousses. Feuilles alt. et rassemblées par bouquets, ovales-lanc., obtuses, très-entières, d'un beau vert clair en-dessus, d'abord soyeuses et argentées en-dessous, ensuite dorées. Fleurs petites, nombreuses sur les anciens rameaux, disposées dans les bouquets de feuilles.

Lieu. La Caroline. Fl. en juillet et août.

*5. A. à petitesfeuilles, argan de Maroc, S. spinosum. Rhamnus siculus, Lin. Cloodendrum argan, Persoon.

Arbuste de 4 à 5 pieds, très-rameux, épineux, en forme de buisson. Feuilles nombreuses, petites, obl., entières, glabres, d'un vert foncé, alt. sur les jeunes rameaux, rassemblées par bouquets sur les vieux. Fleurs petites, verdâtres, sol. ou géminées, ax. Fruit de la forme et grosseur d'une olive, contenant une amande douce.

Lieu. L'Afrique, l'Inde. Fl. en juillet. Toujours vert. 6. A. noirâtre, S. atrovirens, LAM.

Arbrisseau irrégulier, très-rameux, de 4 à 5 pieds; les rameaux, courts, tortus, diffus, remplis d'un suc laiteux. Ecorce d'un gris brun, crevassée. Feuilles ovales, obtuses, épaisses, coriaces, lisses, d'un vert noirâtre en-dessus, avec la nervure blanche, très-finement veinées en-dessus, longues d'environ 2 pouces, larges d'un, munies à leur extrémité d'une dent trèspeiite, à crochet. Pélioles courts. Fleurs petites, blanchâtres, en petits faisceaux axillaires.

Lieu. L'Amérique mérid. Ђ. Toujours vert.

* 7. A. à feuilles de saule, S. Iycioides, Lrn., Lam., DurameL. Bois laiteux du Mississipi, $S$. loeve, WaLt.

Arbrisseau assez droit, de 6 à 8 pieds, très-rameux, épineux, dont l'écorce est d'un gris brun et les rameaux gris, marqués de points blancs. Feuilles lancéolées, assez étroites, assez longues, poiniues, glabres en-dessus et d'un beau vert, légèrement soyeuses en-dessous, alternes sur les jeunes pousses, rassemblées en bouquets sur les vieilles branches. Fleurs petites, 
d'un blanc verdâtre, disposées au nombre d'environ 20 en petits faisceaux axillaires.

Lieu. L'Amérique sept. \$. Presque toujours vert.

*8. Argan courbé, S. reclinatum, Michaux. Bumelia reclinata, Ventenat.

Tige droite, cylindrique, rameuse, épineuse, grise. Branches alternes, rapprochées, très-ouvertes, courbées et arquées vers la terre. Rameaux divergens. Feuilles alternes, pétiolées, ovalesoblongues, obtuses, rassemblées par bouquets sur le vieux bois, Iongues de $\overline{3}$ centimètres (un pouce). Fleurs très-petites, blanches, pédonculées, solitaires, axillaires, rassemblées en petits faisceaux sur le vieux bois.

Lieu. La Géorgie. Ђ. Fl. en été.

9. A. lanugineux, S. lanuginosum, Mrchaux. Bumelia.

Cette espèce a de grands rapports avec la $4^{\circ}$, et peut-être n'en est-ce qu'une variété. Elle est épineuse; ses rameaux sont trèsouverts et pubescens; les feuilles sont ovales-lancéolées, glabres en-dessus, lanugineuses en-dessous, sans être soyeuses.

Lieu. Les bois humides de la Géorgie. $b$.

Cult. Excepté la $\tau^{e}$ espèce, qui peut passer en plein air dans le milieu de la France et dans son nord, en la couvrant en hiver et en ayant d'autres individus en serre froide, toutes les autres sont d'orangerie.

Ces arbrisseaux, poussant beaucoup de racines, demandent à être changés une fois au moins par an. Leur terre doit être consistante et bonne. Les arrosemens ne doivent pas leur manquer en été. On les multiplie par leurs graines tirées de leur pays orig. , et semées à l'ordinaire, et par les marcottes. Celles-ci sont long-temps à s'enraciner; mais à la fin elles y parviennent, surtout lorsqu'on coupe leurs tiges pour faire couler la sève plus abondamment dans les branches couchées. Ils reprennent aussi de bouture, mais lentement.

Us. Toutes les espèces d'argan étant presque toujours vertes, ajoutent à la diversité des feuillages. La couleur dorée et luisante de la $4^{\mathrm{e}}$ fait un effet agréable quand le soleil donne sur ses feuilles., et qu'un vent léger les agite. Cet argan se rapproche beaucoup du genre suivant; sa masse est plus belle encore. L'argan 
de Maroc sert, vraisemblablement, à tanner les cuirs dans cette partie de l'Afrique, car on trouve ses fruits en grande quantité dans les cuirs qui viennent de ce pays.

\section{Mimusope, mimusops.}

Cal. à 8 parties, géminé. Cor. à 8 parties entières ou divisées en 3.8 appendices petits, en forme d'écailles. 8 étamines. Fruit charnu, à une ou deux semences.

Mrmusope à feuilles pointues, $\boldsymbol{M}$. elengi, vulg. Magouden, Cavequi.

Très-grand arbre, dont la cîme est rẻgulière et le tronc fort gros. Rameaux glabres, cylindriques. Feuilles alternes, pétiolées, ovales, entières, fermes, lisses, d'un vert sonabre, imitant colles du poivrier, pétiolées. Fleurs très-odorantes, pédonculées, ax. La corolle a le plus souvent 24 découpures, et, selon Burman, elle représente la face humaine.

Lieu. Les sables des Indes orientales. \$. Cult. en Angleterre.

Cult. Serre chaude. Beaucoup de chaleur et terre légère.

Us. Cet arbre est très-estimé dans les Indes, à cause du grand ombrage qu'il donne, de l'odeur agréable de ses fleurs et de ses fruits, qui sont bons à manger.

\section{Caimitier, Chrysophyllum.}

Cal. à 5 part. Cor. camp., à 5 part., ouverte. 5 étam. Stigmate presque 5-fide. Baie globuleuse, grande, à ro loges, ro sem. comprimées, marquées d'une cicatrice.

* I. Cammitrer à feuilles larges, $C$. cainito.

Arbre de 20 à 30 pieds, très-branchu, dont le sommet est large et étalé. Les rameaux droits tendent à présenter l'éventail; ils sont dans leur jeunesse couverts d'un duvet roux, ainsi que le dessous des jeunes feuilles. Celles-ci sont alt., pét., très-entières, ovales, pointues, nerveuses, assez fermes, d'un beau vert en-dessus, soyeuses et dorées en-dessous. Fleurs petites, en faisceaux ax. Fruit de la grosseur d'une pomme.

Lieu. Les Antilles Ђ. Fl. ... . Toujours vert.

2. C. à feuilles étroites, C. olivaire, C. argenteum, JAç- 
Arbre de la forme et de la hauteur du pommier. Ses rameaux sont fléchis en zig-zag et d'un jaune roussâtre.Feuilles alt., entières, ov.,glabres, luisantes en-dessus, soyeuses et dorées ou argentées en-dessous. Fleurs id. Fruit de la forme d'une grosse olive.

Lіеи. Id. ๖. Fl. Toujours vert.

3. Caimitier glabre, C. glabrum, Lin., JacQ., Mrller.

Arbre d'environ 15 pieds, droit et rameux. Feuilles alternes, ovales-oblongues, pointues, très-entières, glabres et luisantes sur les deux surfaces, de deux pouces environ de longueur. Fruits bleus, elliptiques, glabres.

Lieu. Saint-Domingue, la Martinique. ๖. Toujours vert.

Cult. Serre chaude. Les caimitiers exigent de la chaleur ct doivent rester constamment dans la serre chaude. Leur terre doit être substantielle et consistante; leurs arrosemens modérés en hiver. Lorsque leurs racines ont tapissé leurs pots, il faut les changer de vases; mais ne leur en donner que d'un peu plus grands, ou les mettre dans les mêmes après avoir enlevé l'extérieur de leur motte. De trop grands vases leur font beaucoup de tort. On les multiplie par leurs graines tirées de leur pays orig., et semées selon la manière indiquée ; elles ne lèvent pas si elles ne sont pas fraîches. Les boutures que j'ai faites de la première espèce s'enracinent assez facilement dans des pots remplis de bonne terre, plongés dans une couche chaude et ombragés. Dans le pays où cès arbres croissent naturellement, on les multiplie par cette voie.

$U s$. Ces arbres, par leur beau feuillage, font un effet agréable dans les serres.

\section{Lucuma.}

Cal. à 5 part. Cor. ovale, ventrue dans son milieu, droite, 5 -fide, et garnie int. de 5 écailles. 5 étam. alternes avec ces écailles. Pomme mammiforme, charnue, à ro loges, x-sperme. Plusieurs semences avortées; I à 4 persistantes ou anguleuses.

Mammée à gros fruit. Sapotille, L. mammosa. Achras mammosa, Liv., H. K.

Arbre de 30 à 40 pieds, dont le tronc est droit et l'écorce 
grìise, la cîme régulière. Feuilles lanc., pointues, d'un pied de long, très-nombreuses. Fleurs sol., d'un blanc de crême', naissant sur les branches. Fruit ovale, à peau brune, dont la pulpe est épaisse, roussâtre, d'une saveur douce, et nommée, en Amérique, marmelade.

Lieu. L'Amérique mérid. §. Fl...

Cult. Serre chaude. La même que celle du sapotillier.

\section{Sapotillier, Achras.}

Cal. à 6 part. Cor. camp., à limbe 6-fide, garnie à son entrée de 6 écailles échancrées. 6 étam. Pomme globuleuse, charnue, à 12 loges, I2 semences comprimées, marquées d'une cicatrice longitudinale.

* I. Sapotillier commun, A. sapota.

Arbre de 40 pieds, dont le tronc est droit, la cîme régulière, et le sommet plus élevé que les branches. Feuilles lanc., ov., luisantes en-dessus, très-entières. Fleurs solitairè'.

Lieu. L'Amériqué mérid. Ђ. Fl....

2. S. à feuilles de saule, A. salicifolia. Bumelia salicifolia, Swartz, Willd:

Feuilles id., plus étroites, ovales-lancéolées, acuminées, luisantes. Fleurs petites, d'un jaune pâle, rassemblées sur des pédoncules axillaires, latéraux.

Lieu. Id. b. Fl. Cult. à Pavie.

Cult. Serre chaude. Les espèces de ces deux genres sont délicates et exigent beaucoup de chaleur. Ils craignent aussi la trop grande humidité, et doivent toujours être serrées dans leurs vases. Pour peu que ceux-ci soient trop grands ils languissent, et les insectes les atteignent alors avec affluence. L'air souvent renouvelé est le' moyen le plus sûr, en y joignant une chaleur constante, de les fortifier et de les préserver des animaux qui les endommagent, mais qui ne les accablent cependant que parce qu'ils souffrent.Mult. par leurs graines maintenues fraîches et tirées de leur pays orig. Elles doivent être plantées dans de petits pots aussitôt après leur arrivée, et plongées dans une couche chaudect sous châssis. Les jeunes plantes demandent 
à être attentivement soignées, et conduites de manière a les fortifier.

$\boldsymbol{U}$ s. Ces arbres sont d'un bel effet dans les serres; mais il faut que celles-ci soient assez grandes pour qu'ils puissent $y$ prendre leụr forme régulière. Leurs fruits sont agréables au. goût, et sont comptés parmis les meilleurs de l'Amérique mérid.

\section{Genres qui ont des rapports avec les sapotilliers.}

\section{Myrsine, Myrsine.}

Cal. à 5 part., petit et persistant. Cor. à 5 div. conniventes. 5 étam. courtes sur la corolle, opp. à ses div. I style. Stigm. grand, lanigère, saillant. Baie contenant un noyau à 5 loges et 5 sem.

* I. Myrsine d'Afrique, M. africana.

Petit arbuste de 4 à 5 pieds, très-rameux, très-feuillé, e d'une forme assez régulière; les rameaux d'un rouge brun. Feuilles alt., petites, nombreuses, lanc., ovales, pointues, légèrement dentées, pét., glabres, luisantes, d'un vert foncé en-dessus, pâles en-dessous. Fleurs petites, rougeâtres, fasciculées ou sol., ax. le long des rameaux. Baies violettes, comprimées, ombiliquées.

Lieu. Le Cap. Ђ. Fl. en mai. Toujours vert.

* 2 . M. à feuilles arrondies, $M$. retusa. $M$. rotundifolia, $\mathrm{LA}_{\mathrm{A}}$ MARCK.

Arbrisseau du même port. Les rameaux plus ouverts, verdâtres dans leur jeunesse. Feuilles alt., presque sessiles, ovales, arrondies à leur sommet, où se trouvent quelques petites dents, terminées par une petite pointe particuliere, fermes, luisantes et d'un vert plus léger. Fleurs blanchâtres, tachetées de rouge, dısp. de même.

Lieu. Les Açores. Ђ. Fl. en juin. Toujours vert.

Cult. Orangerie. Ces arbustes ne sont pas délicats, et peuvent recevoir la même culture que celle des jasmins et des orangers. Mult. par les marcottes, par leurs graines semées à la 
maniere ord., et par les boutures faites en pot sur couche oinbragée. Ces dernières sont très-long-temps à s'enraciner; elles restent vertes pendant 2 ans, sans avoir pour cela fait de racines. Quelquefois ces arbustes poussent des rejetons; mais il ne faut les enlever que lorsqu'on est bien sûr qu'ils sont suffisamment enracinés. On facilite leur reprise en les plongeant dans une couche sous châssis ou sous cloche. La I $^{\text {re }}$ espèce mûrissant parfaitement chaque année ses graines, offre ainsi la voie la meilleure, la plus sûre et la plus abondante pour la multiplier. Semées comme toutes celles des plantes d'orangerie, elles levent au bout de six semaines ou de deux mois, si elles sont fraîches; quand elles le sont moins, elles lèvent plus tard, mais elles paroissent presque toujours en plus ou moins de temps. On conduit les jeunes myrsines comme tous les jeunes arbrisseaux de cette serre. La seconde fructifie très-rarement; mais elle pousse des rejetons abondamment lorsque l'arbrisseau a rempli son vase de ses racines.

$U s$. Les myrsines sont de jolis arbrisseaux toujours verts, susceptibles de prendre, comme les petits myrtes, les formes qu'on veut leur donner; mais leur port naturel est assez agréable pour ne pas recourir à l'art. Ils font un bon effet dans les serres par leur petit feuillage très-garni.

\section{Inocarpe, Inocarpus.}

Cal. à deux divisions. Corolle tubuleuse, à 5 divisions longues et linéaires. ro étamines insérées sur le tube par ordre double. Anthères presque sessiles, non saillantes, point de style. r stigmate concave. Gros fruit ovale, un peu comprimé, courbé à son sommet, contenant un noyau fibreux, réticulé, à une semence.

Inocarpe comestible, I. edulis, Fort., Thunb., Lin.

Grand arbrisseau dont les feuilles sont alternes, oblongues, légèrement en cœur, très-entières, peu pétiolées, glabres, de 9 pouces de longueur. Fleurs petites, en épis courts, axillaires, solitaires. 
Lieu. Amboine, Java, les îles de la Société, d'Otaiti, et lę autres de la mer du Sud. b.

Cult. Serre chaude. Cult. en Angleterre.

\section{Lée, Leea.}

Monoïque. Cal. camp. , 5-fide. Cor. tubulée, courte, à limbe 5-fide, égal. Ecailles int. alternes, bifides à leur sommet. Fleurs mâles. 5 étam. insérées au fond de la corolle, entre les écailles. I style. I stig. Ovaire avorté. Fleurs fem. Les mêmes écailles doubles; les int. plus petites. Ovaire sup. I style. Stigm. lacéré. Fruit globuleux, à 6 loges, 6 sem. z. LÉ crépue, L. crispa.

Arbuste dont la tige est angaleuse et frangée. Feuilles alt. ailées, garnies à leurs aisselles d'une stipule simple, presqu'en croissant. Fleurs petites, blanches, en corymbes term.

Lieu. Le Cap. 5. Fl. en octobre.

Cult. Serre tempérée ou chaude.

2. LEE A pinnata, Hort. angl.

Lieu. Les Indes or. $\psi$. Fleurit en août.

Cult. Serre chaude.

\section{Ardisia, Lin., Guelin, Willd.}

Obs. Ce genre est, dans Jussieu, du nombre de ceux dont la place est incertaine. Mais Ventenat ayant observé qu'il devoit faire partie de cet ordre, c'est d'après son autorité que je l'ai mis ici.

Cal. à 5 folioles oblongues, persistantes. Corolle monopétale; le tube très-court; le limbe à 5 part. alongées, ouvertes et réfléchies. 5 étam. insérées sur le tube, tubulées, très-courtes, Anthères grandes, lancéolées, droites. Ovaire supérieur globuleux. Style filiforme. Stigmate simple. Fruit sec, globuleux, à une seule semence.

* I. Ardisia excelsa, H. K. Anguillaria, Gertiner.

Cet arbrisseau drnit est très-branchu, a les branches montantes, les rameaux, ainsi que les jeunes tiges, couverts de poils rous- 
sấtres, ferrugineux. Feuilles alternes, pétiolées, lancéoléesovales, fermes, luisantes, d'un beau vert foncé en - dessus, pâles en-dessous, très-glabres, à bords cartilagineux, munies vers leur sommet de très-petites dents en glandes peu élevées, Iongues de 3 pouces et demi, larges d'un. Je n'ai pas vu ses fleurs. Les bords des feuilles sont souv ent réfléchis en-dessous.

Lieu. Madère. ๖. Toujours vert.

Cult. Cette espèce, que je cultive depuis plusieurs années, n'a besoin que de l'orangerie, où elle se conserve dans toute sa fraîcheur. Cet arbrisseau poussant beaucoup de racines, demande à être changé de vase assez souvent. On le multiplie par les marcottes. J'ai essayé plusieurs fois les boutures et sans succès; il pousse très-tard, souvent aù mois de juillet il n'est̆ pas encore entré en végétation; il conserve la plus belle verdure pendant toute l'année; à peine renouvelle-t-il quelques feuilles. Son port est régulier, et il paroît s'élever à une hauteur assez grande. L'individu que j'ai a 8 à 9 pieds de haut et forme une espèce de pyramide. Ne seroit-ce que pour son beau feuillage et son beau vert, il mérite d'être cultivé dans toutes les collections de plantes étrangères, ou il fera dans toutes les saisons un bel effet.

2. A. crenulata, Vent., Choix de plantes. An id. A. caroliniana, Hortul.

Tige droite, très-rameuse; les branches ouvertes; les rameaux couverts, dans leur jeunesse, d'un duvet ferrugineux. Feuilles alternes, pétiolées, ovales-lancéolées , pointues, glabres, planes, d'un vert foncé, longues de 12 cent., larges de 4 ( 5 pouces sur un et demi). Fleurs très-petites, d'un rouge violet, disposées en petits panicules droits, serrés et terminaux. Quelquefois il y a aussi des grappes axillaires au-dessous de la terminale.

Lieu. Les Antilles. Ђ. Toujours vert.

Cult. Serre chaude ou tempérée. Cet arbre est cullivé à la. Malmaison. L'individu que j'ai vu chez sa majesté l'Impératrice forme, comme l'espèce que je cultive, un haut buisson pyramidal; mais les branches de celui de la Malmaison sont plus. longues, moins nombreuses et plus ouvertes. 
J'ai reçu de M. Parmentier d'Enghien un ardisia qui lui a été envoyé sous le nom de $A$. caroliniana.

Comme il paroît, suivant les auteurs, qu'il n'existe pas d'espéces de ce genre originaire de la Caroline, il seroit probable que cet ardisia ne fût pas celui de Ventenat qu'il indique des Antilles. Ce qu'il y a de certain, c'est que l'espèce dont je parle n'est point délicate, et qu'elle n'exige que l'orangerie. Mais l'espèce crenulata n'est pas aussi décidément de serre chaude; on la conserve fort bien à la Malmaison dans la serre tempérée. I'ai donc tout lieu de croire, quoique les feuilles de I'ardisia nommé caroliniana soient un peu plus longues et plus lancéolées que celles du crenulata, que ces deux plantes. me forment qu'une seule et même espèce.

\section{CLASSE IX.}

\section{IES DICOTYLËDONES MONOPETTALES。}

\section{Corolle périgyne.}

Calice monophylle, quelquefois profondément partagé. Corolle périgyne ou insérée au calice, mo* nopétale, quelquefois à divisions très-profondes, ordinairement régulière. Etamines insérées à la corolle ou au calice. Ovaire simple; souvent un seul style; stigmate simple ou divisé. La conformation du fruit varie.

Obs. Cette classe renferme quatre: ordres. Dans les plaqueminiers le fruit esî supère ou infère, souvent en baie, avec diss loges monospermes. Dans les rosages la capsule est supère, ’̀ loges polyspermes et valves dont les. bords sont rentrés en dedans. Dans les bruyères le fruit est en capsule ou en baie, supère. ou infere, à loges polyspermes, les. valvès avec une cloison: au milieu. Dans les campanulacées la capsule est infere; elle: s'ouvre par les côtés; les loges sont polyspermes. 
tes
?n $\mathrm{c}$
OR D R E P E M I ER.

Les Plaqueminiers ( Guatacan fe $_{\text {) }}$.

Calice monophylle, divisé à son sommet. Corolle partant du fond ou du haut du calice, monopétale, lobée ou profondément divisée. Etamines insérées sur la corolle, en nombre égal ou double de ses divisions, ou réunies par leurs filets en un ou plusieurs corps. Ovaire le plus souvent supère; un style; stigmate simple ou divisé. Fruit supère, quelquefois infère, en baie, quelquefois en capsule ; plusieurs loges monospermes. Embryon plane, dans un périsperme charnu.

Arbrisseaux ou arbres. Feuilles alternes. Fleurs. axillaires.

\section{Nombre d'étamines délerminé.}

\section{Plaqueminier, Diospyros, Guaiacana, Tounn.}

Cal. 4 à 6-fide, souvent en godet. Cor insérée au fond du calice, en godet, 4 à 6 -fide. 8 ä ı 6 étam. courtes, insérées au fond : de la cor. Ovaire sup. Style court, 4-fide. 4 stigm. q. f. bifides. Baie sup., posée sur le calice ouvert ou en coupe, à 8 à 12 loges, et 8 à I 2 sem. comprimées, amygdaliformes.

* i. Plaqueminier d'Europe, D. lotus.

Arbre de 25 a 30 pieds, souvent grand arbrisseau, garni de beaucoup de tiges et de plusieurs rameaux rougeâtres. Feuilles alt., pét., lanc., pointues, très-entières, glabres, luisantes dans leur jeunesse, d'un vert terne ensuite en-dessus . pâles en-dessous. Fleurs ax., presque sess.

Lieu. L'Italie, la Barbarie. ๖. Fl. en juin et juillet. 
On a supposé une ou detx variétés de cette espèce ou de a , suivante, parce qu'il arrive que des individus ont leurs $\mathrm{fe}$. plus ou moins glabres. Mais ces circonstances sont trop accidecá telles pour en faire une distinction.

\section{* 2. Plaqueminier d'Amérique, $D$. virginiana.}

Grand arbre garni de beaucoup de branches et de rameaux. Feuilles id., mais plus larges, ovales-lanc., un peu cotonneuses dans feur jeunesse, douces au toucher, vertes en-dessus, pâles, pubescentes et un peu glauques en-dessous. Fleurs id.

Lieu. L'Amérique septentr. Ђ. Fl. id.

Cult. Les plaqueminiers sont un peu sensibles à nos froids lorsqu'ils sont encore jeunes; et dans leur âge avancé, lorsque leur végétation a été considérable en été et qu'elle n'a pu s'arrêter, les fortes gelées et sur-tout les longs frimats les mutilent. Il est donc prudent de couvrir leurs pieds de litière jusqu'à ce qu'ils aient leur bois bien formé. Ils aiment les terres franches, douces, d'un bon fond et un peu fraîches. Mult. par leurs graines semées en terrines, à la manière indiquée pour les arbres de pleine terre. On doit les tenir en pots pendant les trois premières années pour pouvoir les mettre à couvert des grands froids en hiver. On les propage aussi par les marcottes qui s'enracinent assez facilement, et par leurs rejetons qu'ils poussent quelquefois à une assez grande distance de leurs pieds. Ceux-ci doivent être couverts dans les gelées, et enlevés au printemps quand on les juge enracinés. L'espèce d'Amérique est plus sujette que l'autre à perdre ses pousses précédentes par le froid.

$U_{s}$. Ces arbres ont un assez beau fevillage, et sont cultivés dans toutes les collections de plantes étrangères.

On prétend que les fruits de la première espèce sont le lotier, lotos, des anciens; mais rien n'est moins sûr : c'est plutôt un jujubier,

* 3. P.caque, D. kaki.

Les rameaux de cette espece sont: légèrement cotonneux. Ses feuilles sont ovales, pointues par les deux bouts, très-entières, pubescentes en-dessous. Elles ont beaucoup de rapports à celles 
des espèces précédentes. Les pédoncules solitaires, biflores et pen dans.

Ce plaqueminier est recommandable par son fruit, qu'on dit excellent, et qu'on nomme figue caque.

Lieu. Le Japon. $\square$.

Cult. Cet arbre est plus délicat que les autres de ce genre..II deniande l'orangerie dans le nord de la France, et quand on peut le mettre en pleine terre, une bonne exposition et des abris en hiver. On l'obtient par ses graines tirées de son pays originaire, et on le multiplie, soit par marcottes, soit par la greffe sur les autres plaqueminiers.

4. P. ébène, D. ebenum, Liv. fils.

Arbre très-grand, glabre dans toutes ses parties; les rameaux à écorce grise; les floriferes noirâtres. Feuilles alt. , peu pét., obl., très-entières, obtuses, luisantes, souvent tache té esendessus, veineuses en-dessous. Fl. sess., ax., sol. Baies ovales.

Lieu. Les forêts de Ceylan. Ђ.

Cult. Serre chaude. Cet arbre est rare dans les collections. On ne peut l'obtenir que par ses graines tirées de son pays originaire.

5. P. palmé, D. palmata, Hort. angl.

Lieu. La Chine. Ђ. Cult. en Angleterre.

6. P. à feuilles ovales, D. obovata, JAcQ., WiLLD.

Feuilles alternes, ovales, renversées, membraneuses, trèsglabres et luisantes sur les deux surfaces. Fleurs au nombre de trois ensemble, axillaires, solitaires, pédonculées. Baies contenant 4 semences.

Lieu. Saịnt-Domingue, la Jamaïque. b. Cultivé au Muséum. Fl. en mai.

7. P. digyne, D. digyna, JAcQ., WrLld.

Arbre très-glabre, de 10 pieds. Ecorce noirâtre, striée, tuberculée. Rameaux ouverts. Feuilles alternes, oblongues, pointues, très-entières, très-glabres, fermes et d'un vert foncé endessus. Fleurs à deux styles, d'un pouce de longueur, solitaires, pédonculées, axillaires, penchées. 
Lieu. Saint-Domingue. ऊ. Fl. en mai. Cultivé à Vienne. Ces deux dernières espèces sont de serre chaude.

\section{Royène, Royena.}

Cal. en godet, 5-fide. Cor. en godet, insérée au fond du callice, courte, à 5 lobes. ro. étam. à filamens courts insérés sur la cor. Ovaire sup., finissant en 2 styles. 2 stigm. Caps. sup., à 4 sillons, à I loge et 4 valves; les noyaux trigones et tuniqués.

* I. Royène luisante, $R$. lucida.

Arbrissean d'environ 10 pieds. Feuilles nombreuses, alt., ov., un peu rudes, d'un vert lussant. Fleurs petites, ax. Les feuilles sont velues dans leur jeunesse.

Lieu. Le Cap. \$. Fl. en juin. Toujours vert.

* 2. R. glabre, R. glabra.

Arbrisseau de 5 à 6 pieds, dont les rameaux sont d'un rouge brun et un peu effilés. Feuilles petites, imitant celles du buis, ovales, alt., entières, glabres et d'un vert lisse. Fleurs blanchấtres, ax., presque verticillées.

Lieu. Id. F. Fl. en septemb. Toujours vert.

* 3. R. velue, $R$. hirsuta.

Arbrisseau de 7 à 8 pieds, dont l'écorce est grise, et les rameaux courts et alt. Feuilles alt., lanc., velues, petites, luisantes, quoique couvertes de poils mous, sur-tout sur leurs bords. Fleurs petites, d'un pourpre léger, ax.

Lieu. Id. . Fl. en juillet. Toujaurs vert.

4. R. à feuilles en cœur, R. villosa.

Arbuste peu élevé. Fenilles cordiformes, obl., cotonneuses en-dessous.

Cette espèce a de grands rapports avec la premiere. Ses rameaux sont velus, ses feuilles oblongues, ses fleurs axillaires, pendantes, solitaires; les pédoncules velus, de la longueur des fleurs.

Lieu. Id. Ђ. F1... Toujours verte.

5. R. à feuilles ovales, $R$. polyanara. 
Feuilles ellipiques, cotonneuses en-dessous. Fleurs polyandriques et polygamiques.

Lieu. Id. b. Fl. . . Toujours verte.

Cult. Orangerie. Ces arbrisseaux craignent le froid. Is ne supportent pas les deux premiers degrés de congélation. Leur terre doit être consistante. Peu d'arrosemens en hiver. Mult. par les marcottes assez long-temps à s'enraciner, à moins de couper l'arbuste au pied et d'en faire une mère. Par boutures souvent elles réussissent, et particulièrement celles de la première espèce, qui rarement manquent dans la couche à boutures. Les autres ne sont pas tout-à-fait aussi faciles. La seconde espèce pousse quelquefois des rejetons, ce qui fait qu'on peut la multiplier plus facilement. Quand on peut avoir de bonnes graines fraîches de ces arbrisseaux, c'est la voie la plus sûre et la plus abondante. On les sème en terrine sur couche et sous châssis, suivant la manière indiquée.

$U s$. Les royènes étant toujours vertes, ajoutent à la variété des serres. La première espëce a un feuillage d'une belle verdure et d'une fraîcheur remarquable sur ses jeune pousses, dont la teinte est adoucie par leurs poils soyeux. La troisième a des fleurs basses, petites; mais leur nombre la décore agréablement.

6. R. douteuse, $R$. ambigua, Vent., Jard. Malm.

Tige droite, cylindrique, velue dans sa jeunesse, de 8 décimètres de hauteur. Branches ouvertes. Rameaux courts. Feuilles alternes, portées sur de très-courts pétioles articulés à leur base, rapprochées, ovales, très-entières, fermes, coriaces, douces au toucher, d'un vert foncé en-dessus, jaunâtres en-dessous, de 4 centimètres. Fleurs jaunâtres, assez pelites, pédiculées, solitaires, axillaires. Corolle en godet, comme celle du muguet, à limbe à 6 à 7 divisions réfléchies.

Lie». Le Cap. ๖. Toujours verte. Fl. en automne.

Cult. Orangerie. Celle des autres royènes.

On cultive encore une autre espèce de ce genre qui m'est entièrement inconnue. Desfontaines la nomme $R$. ¿́ feuilles de lycium, $R$. lycioides. Elle est $\boldsymbol{b}$. Peut-être est-ce la même que celle nommáe $R$. angustifolia, WruLd., qui est cuitivéc en 
Angleterre. Ses feuilles sont très-étroites, pointues aux deux bouts, lancéolées, velues en-dessous. b.

Lieu. Le Cap.

Cult. Orangerie.

\section{Aliboufier, Styrax.}

Cal. en godet, entier ou à 5 dents. Cor. à tube court, insérée au fond du calice, à limbe à 5 à 7 part. 6 à i 6 étam. à filamens réunis à leur base, et insérés sur le tube de la corolle. Antî̀res obl., droites. Ovaire sup. I style. I stigm. Fruit sup. coriace, contenant un noyau osseux à I sem. sphérique, ou 2 noyaux convexes d'un côté, planes de l'autre.

* 1. Aliboufier officinal, S. officinale. Storax.

Arbrisseau de moyenne grandeur, très-rameux, irrégulier diffus, en buisson. Feuilles alt., pét., ovales, entières, vertes en-dessus, blanchâtres en-dessous. Fleurs blanches, assez grandes, imitant celles de l'oranger, un peu pendantes, en bouquets peu garnis. ro étam.

Lieu. La France mérid. Fl. en juillet.

* 2. A. d'Amérique, $S$. americanum, LAM. S. lavigatum, H. K. S. glabrum, C.AV.

Arbrisseau qui s'élève plus haut que le précédent, dont la tige est droite, ainsi que ses rameaux, qui sont glabres. Son port est assez régulier. Feuilles alt., ov.-obl., pét., glabres des deux côtés, très-entières. Fleurs blanches, moins grandes que celles du précédent, péd., ax. et term. 8 étam. Les fleurs ne sont pas pendantes.

Lieu. La Caroline mérid. ๖. Fl. id.

3. A à grandes feuilles, S. grandifolium, H. K. S. officinale, WaLT.

Feuilles presqu'ovales, velues en-dessous. Fleurs en grappes terminales. Cette espèce a de grands rapports avec la seconde; mais elle en est certainement distincte.

Lieu. Id. 5. Fl. en juillet.

4. A. pulvérulent, S. pulverulentum, Hort. angl.

Lieu. L'Amérique sept. $Ђ$. Cultivé en Angleterre. 
Cult. Aitonindique ces espèces en pleine terre. J'ignore si elles résistent en Angleterre sans être endommazées par l'hiver; mais jesais bien qu'elles ne peuvent supporter,sans mutilation et même sans perte absolue, les froids rigoureux du nord de la France. Elles peuvent sans doute passer en pleine te re depuis Paris jusqu’à la Méditerranée, et si elles subsistent en Angleterre, c'est que le climat y est tempéré par l'émanation constamment humide de la mer qui entoure cette île. Dans nos clinats elles sont d'orangerie et de pleine terre, c'est-à-dire qu'il est prudent d'en avoir en serre pour remplacer les accidens. $\mathrm{Si}$ on en place des individus en plein air, on doit les mettre conire des murs, ’̀ une exposition méridienne et dans un sol léger ef chend; et lorsque les froids se font sentir, les couvrir de paille et de litiere jusqu'au mois de mars ou d'avril : les gatilliers, vitex, sont dans le même cas. Il est encore une raison qui peut déterminer à mettre ces arbrisseaux en pleine terre, c'est leur végétation languissante en vase, causée par le resserrement nécessité de leurs racines, qui sont longues et nombreuses. Comme en plein air elles peuvent s'étendre, leurs pousses sont non-seulement plus vigoureuses, mais l'arbrisseau prend alors sa forme naturelle et se charge de fleurs, qui sont toujours rares et chétives lorsqu'il est contraint; cependant, ainsi que je l'ai dit plus haut, il faut avoir plusieurs individus en serre pour en planter en plein air. On les multiplie par les graines semées en terrines aussitôt après leur maturité, et les jeunes plantes sont conduites à la manière ordinaire. On peut aussi en faire des marcottes qui s'enracinent assez facilement. La première en donne abondam-ment les moyens. La seconde espèce est souvent languissante.

$U s$. Les aliboufiers, fleurissant en été et se couvrant dans cette saison de fleurs nombreuses, concourent à l'agrément des jardins. Ils se dépouillent à l"entrée de l'hiver.

On tire dans les pays chauds, par incision, de la première espèce, une gomme-résine d'une odeur agréable, connue sous le nom de storax solide. Elle est cordiale ế très-étersive. Elle est fréquemment employée pour nettoyer les plaies. Elle entre aussi dansles parfums. 


\section{Halesie, Halesia.}

Cal. très-petit, à 4 dents. Cor. grande, camp., ventrue, à 4 lobes. I 2 à 16 étam., à filamens réunis en tube à leur base et adnées à la cor. Anthères obl., droites. Ovaire inf. I style. I stigm. Noix obl. '̀ à 4 angles ailés, acuminée par le style persistant, à 4 loges, 4 semences : 2 ou 3 loges souvent avortent.

* Halesie à 4 ailes, $\boldsymbol{H}$. tetraptera.

Grand arbrisseau ciont la tige etles branches sont fort roides et cassantes. Feuilles alt., ov.-lanc., pointues, dentées, vertes en-dessus, pâles en-dessous, un peu cotonneuses et blanchâtres dans leur jeunesse. Fleurs blanches, nombreuses, péd., pendantes, latérales, au nombre de 3 ou 4 ensemble, sur les branches et les rameaux anciens. Elles paroissent avant le développement des feuilles. Fruit à 4 ailes.

Lieu. La Caroline. ๖. Fl. en mai.

* 2. H. à 2 ailes, $\boldsymbol{H}$. diptera.

Cette espèce n'offre que bien peu de différence avec la précédente. Ses feuilles sont un peu plus ovales, un peu plus larges, cotonneuses dans leur jeunesse, glabres ensuite. Ses fruits n'on $t$ que deux ailes.

Lieu. La Pensylvanie. Ђ.

Cult. Pleine terre. Très-rustique; les hivers les plus rigoureux de nos climats ne font aucun tort à ces arbrisseaux. Ils viennent très-bien dans les bons fonds de terre et y fleurissent abondamment. Mult. par leurs graines et par les marcottes faites avec le bois de l'année précédente, le plus vieux n'étant pas flexible. Elles s'enracinent au bout de 2 ans, mais il ne faut les lever que Ia $3^{e}$ année, et quand elles sont bien enracinées. Lorsqu'elles ne sont pas bien pourvues de racines, les jeunes élèves languissent, et il faut beaucoup de temps pour les voir s'élever. On court aussi le risque de les perdre à la transplantation.

Us. Iues halesies sont d'un aspect infiniment agréable dans les premiers jours du printemps lorsqu'ils sont couverts de fleurs. Ils sont très-propres à la décoration des bosquets de cette saison, 

et peuvent être placés avec avantage parmi les cytises, les lilas et les gaîniers.

\section{Andrewsia, Vent. Pogonia, Andr.}

Cal. monophylle, à 5 parties, persistant. Corolle monopétale ; en coupe, dont le tube est de la longueur du calice, l'entrée velue, et le limbe ouvert, à 5 lobes. 5 étamines insérées au milieu du tube; les anthères à son entrée. Ovaire libre, ovale, comprimé. Style cylindrique, légèrement courbé. Stigmate concave. Fruit sec, contenant un noyau à 4 loges et 4 semences.

* i. ANDREwsia glabra, Vent.,Jard. Malm. Pogonia glabra, Andr.

Arbrisseau dont la tige est droite, cylindrique, haute d'un mètre ( 3 pieds ); les rameaux axillaires, alternes. Feuilles alternes, pétiolées, ovales-lancéolées, terminées par une petite pointe, très-entières, très-glabres, un peu luisantes, parsemées de points. Fleurs blanches, pendantes, petites, pédonculées, solitaires ou au nombre de 2 ou 3 axillaires.

Lieu. La Nôuvelle-Hollande. Ђ. Toujours vert. Fleurit au printemps.

* A. scabra. Pogonia scabra, Andr.

Tiges de 4 à 6 pieds, droites, cylindriques, couvertes de petits tubercules, glabres, rameuses; les rameaux montans. Feuilles alternes, sessiles, ovales-lancéolées, bordées, depuis la moitié de leur longueur jusqu'à leur pointe, de dents écartées, un peu épaisses, chargées des mêmes tubercules, très-glabres et d'un beau vert foncé. Fleurs petites, blanches, axillaires, pédonculées. Toute la plante, par ses mamelons, est rude au toucher.

Lieu. Id. Ђ. Toujours vert.

* 3. A. angustifolia, A. à feuilles étroites.

Cette espèce a, par son port, des rapports avec la première : mais elle s'en distingue au premier abord par ses feuilles 
étroites pointues, lancéolées, saliciformes, très-entières, trèsglabres et d'un vert foncé. Je n'ai pas vu ses fleurs.

Lieu. Id. Ђ. Toujours vert.

4. ANDREWSia debilis. Pogonia debilis, ANDr.

Espèce sarmenteuse. Tige rude. Feuilles lancéolées, distiques, dentées à leur sommet. Fleurs bleues, axillaires, solitaires.

Lieu. Id. Ђ.

Cult. Orangerie. La même que celle de tous les arbrisseaux de la Nouvelle-Hollande. Ces arbustes ne sont pas délicats. La terre de bruyère leur convient. On les multiplie assez facilement par les marcottes et les boutures.

\section{Nombre d'étamines indéterminé.}

\section{Hopée, Hopea.}

Calice camp., 5 fide. 5 pétales réunis aux faisceaux des étamines. Plusieurs étamines réunies en 5 corps. Ovaire inférieur. Style persistant. I stigmate. Fruit sec, oblong, couronné par le calice, contenant un noyau glabre, à 5 loges, dont 2 souvent avortées.

HopÉE teignante, Hopea tinctoria. Symplocos tinctoria, WILLD.

Arbrisselau de 8 à 10 pieds. Feuilles alternes, pétiolées, ovales-lancéolées, presque entières, gỉabres, d'un vert jaunâtre. Fleurs jaunes, ou d'un blanc sale, odorantes, en grappes courtes, axillaires. Elles paroissent avant la feuillaison.

Lieu. Les lieux humides de la Caroline. b .

Cult. Orangerie. Cet arbrisseau fort intéressant est cultivé dans quelques collections de plantes étrangères, mais il est encore assez rare par la difficulté de le multiplier. Ses graines tirées de l'Amérique n'arrivent pas ordinairement assez fraîches pour lever. Je les ai semées plusieurs fois et toujours sans succès. Si ceux qui envoient des semences de cet arbrisseau en Europe avoient la précaution de les mettre dans la terre aussitôt qu'elles 
ont été cueillies, il est possible qu'elles lèvent et que cette plante devienne alors plus répandue. Je ne peux rien dire sur sa culture particulière, mais, vu son lieu originaire, on fera bien de lui donner la terre de bruyère et de la maintenir un peu humide.

Us. La décoction de ses feuilles teint les étoffes en jaune.

\section{OR D RE I I.}

\section{Les Rosages ( $R$ HODODENDRA).}

Calice divisé, persistant. Corolle au fond du calice, monopétale, lobée, ou presque polypétale, son limbe étant profondément partagé. Etamines insérées sur la corolle dans les monopétales, ou au fond dans les polypétales. Ovaire supère; un style; stigmate simple, souvent en tête. Capsule supère, multiluculaire, multivalve; les bords des valves rentrant endedans, formant des loges polyspermes, attachées ì l'axe central. Semences très-fines.

Arbrisseaux. Feuilles alternes, quelquefuis opposées; les nouvelles le plus souvent roulées à leurs bords.

Obs. Les rosages different des plaqueminiers par leurs capsules supères, à loges polyspermes. Ils ont beaucoup d'affinité avec les bruyères; ils s'en éloignent par leurs anthères qui ne sont pas à deux cornes, et principalement par leurs valves rentrées endeedans. 


\section{Corolle monopétale.}

\section{Kalmie, Kalmia.}

Cal. à 5 part. Cor. camp., ouverte, dont le bord du limbe est dreit, presque 5-fide, garnie en-dedans de ro fossettes qui formenı ru. hors ro mamelons. ro étam. insées au fond de la coroll ${ }^{\mathrm{p}}$, à filamens courbés; leurs anthòres plongées dans les fossecues, Caps. à 5 loges.

* 1. Kalmie à feuilles larges, $K$. latifolia.

Arbrisseau de 3 à 4 pieds, très-rameux, en gros buisson serré et arrondi, quelquefois ouvert, selon les positions. Feuilles alt., rapprochées, obl., très-entières, pét. , fermes, glabres et d'un vert lisse. Fleurs très-nombreuses, d'un rouge rose ou carné, en larges corymbes term.

Lieu. L'Amériq. sept., la Caroline. Ђ. Fl. en juin. Toujours vert.

* 2. K. à feuilles étroites, $K$. angustifolia.

Arbrisseau de 4 à 5 pieds, très-rameux; les rameaux un peuz grêles. Feuilles rapprochées, ternées, ovales-lanc., glabres, trèsentières, beaucoup moins grandes que celles de la précédente, d'un vert terne, quelquefois glauque. Fleurs d'un rouge vif, plus petites, en corymbes latéraux, qui, par leur rapprochement, semblent former des verticilles; il s'en trouve quelquefois de terminaux.

Lieu. Id. ๖. Fl. en juin et juillet. Toujours vert. * 3 . K. poliée, $\boldsymbol{K}$. polifolia, Hort. angl. $\boldsymbol{K}$. oleoefolia, $\mathbf{N}$.

Cette kalmie, dont on ne fait, je crois, qu'une variété de la précédente, est si distincte, que je ne balance pas à la regarder comme une espèce. Elle ne s'élève jamais plus que d'un pied, plus ou nooins, et forme des buissons très - touffus, arrondis, et qui s'étendent par les drageons. Ses tiges sont très-droites et fermes, ni grêles, ni foibles. Ses feuilles, un peu plus petites que celles de la précédente, ont la même forme et la même disposition ; mais elles sont constamment d'un vert grisâtre, même blanchâtre. Ses fleurs, un peu plus petites, ont la même nuance. 
Elles sont plus nombreuses encore, et forment des corymbes verticillés, latéraux, très-denses.

Lieu. Id. ๖. Fl. en juin et juillet. Toujours verte. * 4. K. glauque, K. glauca, H. K. K. rosmarinifolia, N., éd. I. Arbuste d'un pied et demi environ de hauteur, formant un buisson arrondi. Tiges droittes, très-rameuses; lesrameaux montans, roides, jaunâtres, très-glabres. Feuilles opposées, presque sessiles, lin.-lancéolées, entières, à bords roulés en-dessotıs, vertes et glabres en-dessus, pâles et bien.glauques en-dessous. Fleurs d'un joli rose, en corymbes terminaux, plus grandes que celles des deux espèces précédentes.

Lieu. La Caroline. Ђ. Fl. en mai. Toujours vert. 5. K. velue, K. hirsula, Curtis, Magaz., LamarcK. K. cí liata, Bartram.

Cette espece est vraiment distincte, quoique ses fleurs ressemblent parfaitement à celles de la $2^{\mathrm{e}}$ et de la $3^{\mathrm{e}}$ espèce. Elle forme un petit arbrisseau dont les tiges sont rameuses, montantes et garnies de petites feuilles éparses, ovales, presque sessiles, velues et ciliées en leurs bords. Ses fleurs sont carnées, axillaires, disposées en grappes terminales et spiciformes.

Les feuilles ont beaucoup de rapports avec celles de l'andromeda daboecia ou menzezia.

Lieu. La Caroline, la Géorgie. . Fl. en automne. Toujours verte.

Cult. Pleine terre. La plupart des cultivateurs, dont plusieurs se copient l'un l'autre, recommandent de placer les kalmies et les rosages dans les lieux ombragés. Je puis assurer qu'ils viennent aussi bien dans les situations ouvertes, cependant à l'abri des grands vents. Ceux qu'on plante à l'ombre s'étiolent et fleurissent moins. Ceux qui sont exposés à l'air environnant deviennent plus robustes, plus feuillés, et sont tous les ans chargés de fleurs. Ces arbrisseaux ont le défaut de ne pouvoir croître dans tous les terrains. Il leur faut une terre analogue à celle qu'ils trouvent dans les lieux où la nature les a placés. Ils se refusent absolument aux bonnes terres franches, argileuses, où les grands arbres prospèrent. Ils en exigent une légère, substantielle, trèsperméable à leurs racines extrĉmenent déliées. Le sable noir ous 
le terreau de bruyère sablonnẹux non tourbeux, est le sol qui leur convient le mieux, et même exclusivement à tout antre.

Lorsqu'on plante ces arbrisseaux, il faut faire un trou de 3 pieds de diamètre et d'un de profondeur, et le remplir soit de terre de bruyère, soit de sable noir. Le trou parfaitement rempli, on plante l'arbrisseau au milieu, et quand il est bien garni de terre à l'entour, on couvre la surface du trou de mousse pour le garantir, la première année, de la sécheresse. Si celleci étoit longue et forte, il faudroit l'arroser de temps en temps. J'ai planté beaucoup de kalmies et de rosages de cette manière et à racines nues, et aucun individu n'a péri, quoique très-exposé au soleil.

Il vaut beaucoup mieux encore les planter en masse, avec d'autres arbustes de même nature, dans un endroit défoncé à cet effet et rempli de terre de bruyère. (Voyez l'article, de la terre de bruyère, etc., danș le $\mathrm{I}^{\mathrm{er}}$ vol. de cet ouvrage. )

Les kalmies se multiplient par les marcottes et les rejetons enracinés. Ces derniers se trouvent fréquemment dans les 2 et ze espèces; mais la première n'en pousse pas et les marcoltes sont assez long-temps à faire des racines, ce qui la rend moins commune. Le plus court moyen de la multiplier est de faire d'un pied une mère, dont on marcotie les branches à mesure qu'elles s'y prêtent. Je n'ai pas besoin de dire que ces marcottes doivent être faites dans la sorte de terre indispensable à ces arbrisseaux. J'ai essayé plusieursfois le semis de la première, et toujours sans succès, quoique les graines que j'avois recueillies sur mes kalmies aient toutes assez bien levé; soit que les insectes les aient dévorés, soit que les jeunes germinations n'ai pas trouvé la. terre el la situation favorables, soit encore que les cotylédones n'aientpu fournir à l'cmbryon sa première nourriture, elles ont disparu au bout de quelques jours. Cependant je sais que des cultivateurs ont éle plus heureux, et qu'ils en ont élevé par ce moyen, qui est bien le meilleur et le plus avantageux.

Us. Les kalmies sont de très-jolis arbustes d'un véritable ornement dans les jardins; mais la première est en cela infiniment supérieure aux autres. Pien de si riche et de si agréable à la vue que cette kalmie lorsqu'elle est couverte de ses corymbes fleuris, 
qui ont jusqu'à 8 pouces dè diamétre. Elle ne présente alors qu'un large bouquet de l'aspect le plus charmant. Elle est, parmi les arbrisseaux de pleine terre ce qu'est le laurose à fleurs doubles parmi ceux de serre. Les kalmies ont encore l'avantage d'être toujours vertes, très-rustiques, jamais endommagées par le froid, et d'offrir en hiver une verdure luisante qui peut contribuer à la décoration des bosquets de cette saison.

\section{Rosage, Rhododendrum.}

Cal. à 5 part. Cor. presqu'infund., à limbe ouvert, à 5 lobes. 10 étam. inclinées. Caps. à 5 loges.

* I. Rosage ferrugineux, $R$. ferrugineum.

Arbuste de 2 pieds environ, en buisson élargi. Les rameaux roides et cassans, bruns et gris sur le vieux bois, jaunes dans leur jeunesse. Feuilles ov.-obl., éparses, très-entières, fermes, coriaces, à bords un peu roulés, d'ua vert foncé et luisant endessus, couleur de rouille et un peu velues en-dessous. Fleurs: d'un rouge vif ou rose, en corymbes sess. et term.

Lieu. Les Alpes. . Fl. en juin. Toujours vert. * 2. R. velu, $R$. hirsutum.

Même port. Rameaux cour ts et jaunâtres. Feuilles lancéolées, éparses, entières, fermes, veries et glabres en-dessus, jaunâm tres en-d’essous, légèrement ciliées et velues en leurs bords. Fleurs d'un rouge éclatant, en corymbe term.

Cette espèce a de si grands rapports avec la première, qu'il n'est guère possible de la distinguer à la première vue.Les pet. poil : des bords des feuilles sont souvent très-rares; mais son part est" plus serré et plus garni que dans l'espèce précédente.

Lieu. Id. . Fl. id. Toujours vert.

3. R. de la Daourie, $R$. dauricum.

Tiges droites, nues, feuillées à leur somm et. Feuilles portẻes sur d'assez longs pétioles, oblongues, glabres et nues sur les deux surfaces; mais couvertes de points nombreux et ferrugineux sur l'inférieure. Corolles violettes, plus grandes que les feuilles, en roue. Etamines ouvertes, de la longueur de Ia corolle. Style d'un rouge sanguin. 
Cette espece a beaucoup de rapport à l'azalée de la Laponie.

Lieu. La Daurie. ๖. Toujours vert.

* 4. Rosage à fleurs pourpres, $R$. ponticum.

Arbrisseau de 7 à 8 pieds, formant un buisson très-large et bien garni de tiges et de rameaux. Feuilles lanc., pointues, très-entières, longues de 6 pouces, glabres, luisantes, fermes, d'un vert foncé en-dessus, Fleurs d'un pourpre tirant sur le violet plus ou moins foncé, grandes, bien ouvertes, en cory bes term.

Lieu. Le Levant. Ђ. Fl. en mai. Toujours vert.

Tarietés. I. A fleurs roses.

2. A feuilles étroites.

3. A feuilles panachées.

*5. R. ponctué, $R$. punctatum. R. minus, Michaux. R. parviflorum, Bot. cult., éd. ${ }^{r e}$. Var.

Tige droite, très-rameuse ; les rameaux couverts de petites glandes d'un brun roussâtre, résineuses. Feuilles parsemées en-dessous des mêmes glandes, disposées et formées de même que celles de l'espèce précédente, mais moins grandes. Fleurs couleur de chair, en ombelles terminales de grandeur moyenne.

Lieu. L'Amérique sept. Toujours vert. Fleurit au printemps.

* 6. R. à feuilles larges, $R$. maximum.

Arbrisseau dont le port est à-peu-près le même que celui du quatrième; mais il s'élève un peu moins; ses rameaux sont plus épais, plus roides et plus courts. Feuilles ov. - lanc. de la même longueur, un peu plus larges, moins pointues, presqu'obtuses, entières, fermes, à bords tranchans et roulés en. dessous, d'un vert foncé en-dessus ; pâles en-dessous. Fleurs d'un joli rose, en bouton, d'un blanc rosé étant ouvertes, moins grandes, en corymbes ses. et term.

Obs. Linné dit que les feuilles de cette espèce sont veinées. Elles le sont en effet; mais ces veines ne paroissent que lorsque l'arbrịsseau n'est pas dans toute sa vigueur, et qu'il est à 
l'ombre; on ne les aperçoit pas du tout quand il est dans toute la force de sa végétation.

Lieu. L'Amérique sept ๖. Fl. en juillet. Toujours vert. 7. R. doré, $R$. chrysanthum, PaLLas, Voyage.

Arbrisseau d'un pied environ, diffus et ouvert. Rameaux montans, feuillés et florifères. Feuilles peu nombreuses, situées au sommet des rameaux, alt., ov., rétrécies en pétiole, veineuses, pâles en-dessous, rudes en-dessus, un peu roulées en leurs bords. Fl. naissant, comme celles des autres espèces, d'un bouton écailleux, pédonculées, rassemblées en forme d'ombelle, souvent au nombre de dix, grandes, jaunes, penchées; leur limbe ouvert, à 5 divisions arrondies, dont trois un peu plus grandes et légèrement striées vers le tube. 10 étam. inégales, réfléchies en-dessous, portant des anthères oblongues et pâles. Style filiforme, simple, plus long que les étamines, terminé par un stigm. à 5 lobes. Ovaire sup. à 5 angles. Caps. oblongue, pentagone, à 5 valves, s'ouvrant jar son sommet, et renfermant des semences très-petites et grisâtres.

Lieu. La Sibérie orientale, sur les plus froides montagnes. b. Toujours vert.

8. R. azaléoïde, $R$. azaleoides, Hort. lond.

Je ne connois cette espèce que par un échantillon que m'a envoyé M. Parmentier d'Enghien, qui la cultive depuis quelques années. Ses tiges et ses rameaux sont d'un brun rougeâtre. Ses feuilles sont rassemblées à leur sommet, où elles forment une espèce de rosetle. Elles sont ovales-elliptiques ou lancéolées-elliptiques, très-entières, d'un beau vert, glabres des deux côtés, sans poils ni points ferrugineux, longues de 3 pouces et demi, et larges de 15 à 18 lignes. Je n'ai pas vu ses fleurs, et aucun de mes auteurs ne parle de cette esjèce. Si j’avois aperçu sur les feuilles de mon échantillon des points ferrugineux, je la croirois un double emploi de l'azalée de Laponie : peut-être aussi ces points se perdentils par la culture.

9. R. à petites feuilles, $R$. chamcecistus.

Petit arbuste à moitić couché, garni de beaucoup do $12=$ 
meaux, dont les feuilles sont ovales, fermes, velues sur leurs bords, vertes, glabres, luisantes, imitant celles du serpolet ou des petits cistes. Fleurs d'un rouge vif ou carné, nombreuses, pédonculées; les unes solitaires; les autres au nombre de 3 ou 4 réunies. Filets des étamines blancs. Anthères pourpres.

Lieu. Les hautes montagnes de l'Autriche, de la Carniole. 5 . 10. Rosage du Caucase, R. caucasicum, Pallas.

Cette espèce a de grands rapports avec la septième. Elle forme un buisson très-ouvert et diffus. Feuilles alternes, ovalesoblongues, nombreuses, un peu rudes au toucher, vertes, en-dessus, ferrugineuses et cotonneuses en-dessous. Fleurs blanches, ou d'un rose pâle, disposées en corymbes terminaux.

Lieu. Les sommets du Caucase. Ђ.

I. R. du Kamschatka, R. kamschaticum, PaLLas.

Tiges rameuses, feuilles pétiolées, éparses, petites, vertes; glabres, ciliées en leurs bords. Fleurs de la grandeur de celles du rosage pontique, d'un joli rose, pédonculées, solitaires : terminales. Cette espèce se rapproche beaucoup par son port eb son feuillage des rosages velus et ferrugineux.

Lieu. Les montagnes de la Sibérie et du Kamschatka. Ђ.

Ces deux derniers rosages sont actuellement cultivés en Angleterre.

Cult. Absolument la même que celle des kalmies. Quoique l'espèce 4 paroisse moins difficile sur le terrain que les autres, et qu'en lui donnant une terre légère composée, elle pousse et fleurisse d'abord aussi bien que dans le terreau de bruyère, au bout de deux ou trois ans, on s'apercoit qu'elle n'est pas dans le sol qui lui convient; ses boutons avortent, ses pousses ne s'élevent plus, et elle languit. Il est doncindispensable de planter d'abord tous les rosages dans la terre de bruyère, si l'on veut jouir de leurs belles formes et de leurs fleurs nombreuses, et de la manière indiquée à l'article kalmie. Si l'on desiroit avoir une masse de rosages, de kalmies et d'azalées, il faudroit faire une excavation d'un pied de profondeur et de la dimension qu'on destine au mu sif, en enlcver la terre, 
et la remplacer entièrement par du terreau de bruyère. Cette opération seroit faite pour toujours; on s'éviteroit la peine de faire des trous isolés pour planter chacun de ces arbrisseaux; ceux - ci viendroient mieux, parce qu'ils scrcicnt placés comme naturellement, et leur effet seroit encore plus agréable à la vue. (Voy. l'article, de la terre de bruyère, vol. x.)

On multiplie souvent les rosages de marcottes. Cettc voie a été pour nous, jusqu'à présent, la seule de propager les deux premières espèces dont les graines ne mûrissent pas. On courbe ¿̀ cet effet peu à peu leurs branches inférieures, en les assujettissant avec des fourches dans le terreau qui leur convient, et on les redresse à mesure qu'elles s'alongent, en prenant garde de les casser. Ces deux rosages s'enracinent au bout d'un an, et peuvent, si leurs marcoltes ont été bien conduites, être sevrés la $2^{\mathrm{e}}$ année. On multiplie de même les espèces 4 el, 6 qui s'enracinent aussi facilement. Mais comme elles mûrissent très-bien leurs semences, on doit préférer avec raison ce moyen, qui fournit beaucoup d'incividus et de plus beaux qu'une autre voie. Ce semis se fait dans des terrines remplies de terreau de bruyère, sur lequel on répand les graines infiniment petites , point trop drues, et qu'on couvre légèrement du même terreau tamisé. Après avoir posé dessus la surface un peu de mousse pour conserver la fraîcheur, on plonge les terrines dans unc couche de chaleur modérée. Les rosages paroissent au bout de trois semaines; mais ils ne peuvent être levés que l'année suirante au plus tôt. Il faut sur-tout avoir l'attention de semer clair, car lorsque les graines levent en aboudance, il est rare de ne pas perdre entièrement le semis, parce qu'on ne peut les repiquer, et que les jeunes plantes, se nuisant réciproquement, ne prennent pas d'accroissement. La cueillette de leurs graines doit se faire à la fin de janvier ou au commencement de février, et il vaut mieux les semer de suite que d'attendre le printemps.

Mais si ces rododendrons, et sur-tout le 6 e, lèvent aisément, il n'est pas aussi facile de les conserver jusqu'au point où ils peuvent être repiqués. Souvent tout le semis périt, soit par de petits insectes qui le dévorent, soit par la situation ou l'on met les terrines. On remédiera au prenicr accident en ne se servant é: 
mousse pour couvrir le semis que lorsqu'elle aura passé dans un four assez chaud pour détruire les insectes qui s'y trouvent, ou bien en ne l'employant pas; en visitant chaque jour les terrines pour en expulser ces petits animaux rongeurs, et en plaçant les jeunes plantes levées dans un châssis fort ombragé, et ou il se trouve de la chaleur. Quand ils seront un peu plus forts, c'est-à-dire quand ils auront 4 feuilles, on les placera en plein air à l'ombre. La $6^{\circ}$ espèce est plus difficile à conduire dans son semis que la $4^{\mathrm{e}}$; elle vient aussi beaucoup mieux en masse pleine de terre de bruyère que dans des trous préparés.

Le transplantation des rosages se fait en automne ou en mars. Ils sont tous assez vivaces et ne périssent guère à la suite de cette opération. Il ne faut à la $4^{\mathrm{e}}$ espèce sur-tout, et à la $6^{\mathrm{e}}$, que la moindre radicule pour reprendre en peu de temps, si on la met dans le sol nécessaire.

Les espèces 4 et 6 viemnent á toutes les expositions, pourvu qu'elles ne soient pas trop sèches. A l'égard des deux premières, il faut absolument qu'elles soient placées au nord ou au nordest, et fortement ombragées du côté du midi. Le soleil et la grande chaleur leur sont très-nuisibles. Pendant l'hiver on les couvrira de paille mise sur des cerceaux. La neige seroit sans contredit leur meilleure couverture; mais on ne l'a pas à sa disposition. Je ne connois pas assez les espèces $3,7,8$ et 9 pour en dire quelques particularités relatives à leur culture; mais les cultivateurs ne s'éloigneront pas beaucoup de leur traitement spécial en donnant aux espèces 3 et 7 celle des rosages répandus dans les jardins, et aux deux dernières celle des deux premieres.

J'ajouterai, à l'égard des $R$. ponticum, un fait qui prouve que cette espèce pourroit fort bien n'avoir besoin de la terre de bruyère que dans ses premières années. J'avois planté, il y a environ quatorze à quinze ans, deux pieds de ce rhododendron dans un massif, à trois pieds de chaque côté d'un gros buis et d'un thuya du Canada, dont les racines, comme l'on sait, sont extrêmement nombreuses, s'emparent en peu de temps de la terre de leurs voisins, et serpentent au loin. Ces rosages, quoique accablés des rameaux et de la végétation souterraine de ces 
arbres voraces qui leur ravissent leur terre de bruyère, nonseulement n'en souffrent pas, mais élancent et entremêlent leurs branches parmi les leurs, fleurissent en abondance et sont du plus bel aspect. Cette observation m'a fait connoître que ces arbrisseaux viennent mieux en masse qu'isolés, et $i$ 'en ai profité avec succès dans les plantations que $j$ 'en ai faites. L'espèce $\mathbf{5}$ est plus délicate que les autres depuis quelque temps cultivées. Elle est très-susceptible des gelées un peu fortes, qui la mutilent ou la font périr. J'en ai perdu un pied très-fort par cette cause. Si on la met en plein air, il faut, dans le nord de la France, la couvrir aux approches des grands froids, et en avoir aussi des individus en vases. Quelquefois elle languit et périt, même de cette dernière façon de la conserver, sans qu'on puisse en présumer la cause. L'ombre lui est plus favorable qu'une exposition ouverte. On la multiplie assez aisément par les marcottes.

$U s$. Les rosages ne cèdent en beauté qu'à la première espèce de kalmie; les deux premiers, quoique bas, $s^{\wedge} n$ t'un aspect charmant lorsqu'ils sont en fleur. Les 4 et $6^{e}$ sont tous les ans chargés de corvmbes fleuris; le / $^{\mathrm{e}}$ en est quelquefois si couvert, qu'on ne voit ni feuilles ni tiges.

Les kalmies et les rosages sont snécialement faits pour l'ornement des jardins, et ils ont le mérite, très-précieux pour les climats septentrionaux, d'être presque tous rustiques et de conserver leur verdure sous les neignes et les frimats. Ces arbrisseaux, avec les lauriers-cerises et de Portugal et les arbres résineux, doivent être les bases principales des bosquets toujours verts des jardins du nord.

\section{Azalée, Azalea.}

Cal. à 5 part. Cor. infund., à 5 div. inégales. 5 étam. insérées sous le pistil. Caps. à 5 loges.

* y. Azalé é nudiflore, $A$. nudiflora.

Arbrissean de 3 pieds environ, très-rameux, en buisson assez írrégulier. Feuilles alt. , éparses, et rassemblées vers le sommet des rameaux, ovales, pointues, glabres en-dessus, un peu ve- 
lues en leurs bords, vertes et luisantes. Fleurs dans les nuances du blanc au rouge, suivant les variétés, un peu velues, imitant celles du chèvre-feuille, disposées en ombelles term. Les étamines très-longues.

\section{Fleurs avant l'entier développement des feuilles. Inodores.}

Variétés de l'espèce nudiflore suivant l'ordre de leur floraison.

* I. Azalée à fleurs blanches, A.alba.

Ombelles fleuries, presque nues. Collerette foliacée; les écailles concaves, assez larges, brunes à leur pointe, glabres et vertes. Corolle à limbe blanc et tube blanc ou carné, couverte de poils courts. Filamens blancs. Calice court. Précoce. Fleurit en mai.

* A. bicolore, A. bicolor.

Ombelles fleuries, presque nues. Bractées à leur base. Corolle à limbe d'un blanc rosé et tube rouge garni de poils blancs. Rameaux fauves. Boutons gris. Feuilles vertes des deux côtés. Sur quelques ombelles le tube se fend profondément. Cette circonstance a vräisemblablement donné lieu à la variété d'Ailon nommée $A$. partita.

* 3.A. carnée, A. camea.

Ombelles fleuries, feuillées. Bractées à leur base. Corolle à limbe pâle et à tube rouge à sa base et velu. Filamens couleur de chair. Calice très-velu. Bractées ovales, imbricées, vertes et rouges sur leurs bords, terminées par une pointe courte particulière. Pédicules verts. Pam eaux gris. Boutons jaunâtres dont les écailles sont bordées de rouge et cotonneuses. Feuilles vertes et luisantes en-dessus, pâles en-dessous.

* 4. A. rubiconde, $A$ rubicunda, rutilans, H. K.

Cette variété ressemble beaucoup à la précédente. Elle en differe ainsi.

Boutons gris. Calice d'un brun verdâtre et velu. Bractées ovales, concaves, larges, peu rombreuses. Limbe de la corolle d'un rouge clair plus foncé. Tube très-rouge et velu. Filamens rouges. Jeunes rameaux jaunâtres et souvent colonneux. Feuilles 
vertes, non luisantes en-dessus. En général les jeunes rameaux et les feuilles de cette variété offrent un aspect cotonneux, et ceux de la précédente en présentent un velu. Les boutons en automne sont d'un jaune pâle, et ceux de la carnée sont rouges.

\section{Fleurs lors de l'entier développement des feuilles.} Inodores.

*5. A. orangée, A. auriantiaca, Hortul. A. coccinea major. $\mathrm{N}$.

Ombelles fleuries, entourées de feuilles parvenues à leur gran• deur avant la floraison. Bractées à leur base. Corolle d'un rouge écarlate, plus grande que celles des variétés ci - dessus. Les divisions du limbe un peu plissées. Le tube peu velu. Filamens d'un jaune orangé. Anthères jaunes. Stigmate partagé. Calice vert et cilié. Bractées grandes et concaves. Boutons gros et verts. Feuillès vertes, glabres et luisantes en-dessus, pâles, un peu velues en-dessous, ciliées sur leurs bords.

*6. A. écarlate, A. coccinea. A. coccinea minor, N.

Cette variété différe peu de la précédente. Elle est moins grande dans toutes ses parties. Ses boutons sont jaunes avec un peu de vert; ses feuilles beaucoup moins longues.

7. A. papilionacée, $A$. papilionacea, H.K.

Fleurs rouges; la division inférieure blanche. Calices foliacés , H. K.

\section{Espèces.}

2. A. Blanchâtre, $A$. canescens, Mrchaux.

Corolles roses, non visqueuses et presque glabres. Filamens saillans. Calice très - court. Feuilles blanchâtres et légèrement cotonneuses en-dessous; la nervure principale non ciliée. Cultivée à Londres.

*3. A. pontique, A. pontica.

Tiges, branches et rameaux droits, bruns et glabres. Feuilles de 4 pouces de longueur, lancéolées, d'un vert foncé, luisant, ciliées en leurs bords, rassemblées en touffe au sommet des tiges. Fleurs grandes, campanulées, d'un beau jaune, bien ouvertes, en grappes ombellées et terminales; chacune est pédon- 
culée et sort de l'aisselle d'une bractée blanchâtre. Les feuilles sont, en-dessus, parsenées de poils courts, glanduleux.

4. Azalée éclatante, A. calendulacea, Michaux. A. flammea, Bartram.

Feuilles d'abord pubescentes sur les deux surfaces, ensuite velues. Fleurs presque nues, très-grandes, non visqueuses, d'une couleur éclatante de souci. Calice à dents oblongues. Corolle à tube velu, et ses divisions courtes.

Cultivée à Londres.

Variété à fleurs safranées, $A$. crocea, Michaux., Bartra ar. 5. A. chévrefeuille, $A$. periclymenoides, Michaux.

Feuilles vertes des deux côtés, glabres, excepté la nervure, qui est lanugineuse en-dessus. Corolle rose, à tube velu, plus court quele limbe, qui est très-ample et non visqueux. Filamens trèssaillans.

6. A. visqueuse, A. viscosa.

Feuilles lancéolées, entières, pointues, rudes, un peu velues et d'un beau vert. Fleurs blanches, velues, visqueuses, odorantes, en ombelles terminales, environnées d'une touffe de feuilles. Les étamines dépassent peu la corolle.

Yariétés de l'espèce visqueuse suivant l'ordre de leur floraison. Fleurs odorantes.

* I. A. multiflore, A. floribunda.

Ombelles fleuries, entourées de rameaux feuillés , quelque$\mathrm{f}$ cis sans rameaux. Bractées à leur base. Pédoncules d'un blanc verdâtre. Corolles non épanouies, rougeâtres sur leurs angles, blanches ensuite ; les divisions du limbe terminées en pointe alongée, et canaliculées dans leur milieu. Glandes visqueuses, rouges, portées sur des pédicules blancs. Calice très-court, cilié. Filamens blancs. Anthères briquetées. Style blanc. Stigmate vert, en plateau. Boutons verdâtres. Rameaux fauves; les jeunes d'un vert jaune et pubescens. Feuilles vertes en-dessus, giauques en-dessous ciliées seulement sur leurs bords et sur la nervure principale. Fleurit en juin. 
* 2. A. glauque, $A$. glauca.

Ombelles fleuries au milieu des rameaux feuillés. Bractées peu nombreuses. Pédoncules rouges. Corolles non épanouies, plus rouges que celles de la précédente, blanches, glanduleuses et très-visqueuses à l'extérieur, sans glandes en-dedans. Calice à peine sensible. Rameaux gris. Le reste comme dans la précédente.

Cette variété ne se distingue particulièrement dela multiflore que par ses feuilles glauques sur les deux surfaces et ses pédicules rouges. Ses fleurs sont plus nombreuses dans chaque ombelle et plus visqueuses. Toutes deux ont une odeur infiniment agréable.

* 3. A. d'un vert luisant, A. virens. A. viscosa, Hortul.

Ombelles fleuries id. Bractées nombreuses, ovales, imbricées et caduques. Pédoncules rougeâtres, couverts de poils blancs, non visqueux. Corolles blanches, à divisions pointues, d'un rouge pourpre à leur pointe qui se prolonge sur la côte extérieure. Les poils du tube et de la surface extérieure de la corolle se terminent par une glande rouge et visqueuse. Filamens blancs. Anthères orangées. Style blanc, très-saillant. Stigmate brun et luisant. Feuilles glabres, dentées et ciliées en leurs bords, d'un beau vert lisse, souvent rougeâtres, pâles et ternes en-dessous. Boutons rouges, bordés de blanc. Rameaux nombreux, se divergeant de tous côtés, velus, hispides, d'un rouge foncé dans leur jeunesse.

Sous-variété à feuilles spatulées, A. spathulata, N.

Ses feuilles sont arrondies à leur extrémité, en coin à leur base, peu luisantes. Ses fleurs n'ont qu'une très - légère teinte de rouge. Les poils sont à peine glanduleux et presque entièrement blancs.

* 4. A. rude, A. scabra.

Ombelles fleuries au milieu de rameaux feuillés, mais dont le bouton terminal de l'année suivante n'est pas encore formé. Bractées très-caduques. Corolles entièrement blanches, chargées de poils rougeâtres, glanduleux et visqueux; divisions du limbe pointues. Pédicules d'un vert rougeâtre et velus. Calice presque nul, faisant corps arecle tube. Filamens blancs. Antheres au- 
zores. Style saillant. Stigmate brun et luisant. Rameaux bruns et lisses; les jeunes très - velus. Boutons jaunâtres, assez gros. Feuilles lancéolées-oblongues, bordées de petites dents terminées par un poil, vertes des deux côtés, chargées, sur la surface supérieure etsur la nervure inférieure, de mamelons d'où sortent des poils blancs, couchés et rudes. Ces poils, sur les jeunes feuilles principalement, rendent l'arbrisseau très-sensiblement âpre au toucher, quand on passe la main sur elles.

* 5. Azalée tardive, A. serolina, N. A. fissa, H. K.

Cette variété a beaucoup de rapports avec la précédente. Elle ne fleurit ordinairement que lorsque ses boutons de l'année suivante sont parfaitement formés. Le tube de la corolle est plus court; le limbe se fend quelquefois dans une de ses divisions jusqu'au tiers ou la moitié du tube, même jusqu'à sa base: dans plusieurs corolles il ne se fend pas. Ses jeunes rameaux sont beaucoup moins velus et ne sont jamais rouges ou bruns. Ses feuilles sont d'un vert jaunâtre et ovales; leurs poils sont moins nombreux, plus petits et peu rudes, et elles sont généralement de moitié moins grandes. Fleurit en août. Variété à fleurs semidoubles.

* 6. A. cotonneuse, A. tomentosa.

N'ayant vu qu'une fois les fleurs de cette azalée, depuis quinze ans que je la cultive, et ne les ayant pas alors observées, parce que je m'attendois à sa floraison annuelle, je ne puis être, certain si elle est réellement une variété de l'espèce visques: ou si elle doit constituer une espèce particulière. Elle forme un assez haut buisson très-garni de branches et de rameaux montans, d'un gris brun, couverts de poils cotonneux. Ses feuilles lancéolées-ovales sont couverts, sur les deux surfaces, de poils courts, doux au toucher, vertes sur la supérieure, glauques sur l'inférieure. Ses fleurs, autant que je puis m'en rappeler, sont blanches et odorantes. Elle fleurit tard et rarement.

* 7. A. couchée, $A$. procumbens.

Plante très-basse. Tiges de 7 à 8 pouces au plus, noirâtres, diffuses, étalées sur la terre. Feuilles opposées, petites, ovalessancéolées, à bords roulés, glabres et vertes. Fleurs petites, 
roses, au nombre de trois ou quatre ensemble au sommet des rameaux. Fleurit en avril et mai.

Lieu des azalées. Excepté la troisième espèce, qui est originaire des environs de la mer Noire, et la septiène esjèce, qui croît naturellement dans les montagnes de l'Europe, toutes les autres azalées sont de l'Amérique septentrionale, principa. lement de la Caroline.

\section{Autres espèces récemment introduiles en Angleterre.}

8. A. frangée, A. fimbriata, Hort angl.

Lieu. La Chine.

9. A. en deuil, A. lugens, Hort. angl.

Lieu. Id.

10. A. pourpre, A. purpurea, Hort. angl.

Lieu. Les Indes.

Ix. A. à bandes, A. vittata, Hort. angl.

Lieu. Id.

Cult. Excepté les quatre dernières espèces nouvelles, qui sont ou d'orangerie ou de serre chaude, toutes les autres passent l'hiver en plein air sans dommage. Les azalées ayant beaucoup de rapports aux kalmies et aux rhododendrons, tant par leurs caractères génériques que par leurs racines el leur lieu originaire, leur culture doit être à peu de chose près la même que celle qui convient à ces arbrisseaux; cependant elles paroissent être un peu moins difficiles sur l'espèce de terre. Elles croi assez bien dans les terres douces et légères; mais elles sont jus belles et se multiplient plus facilement dans le terreau de bruvère, sur-tout si elles sont placées en masse avec d'autres arbrisseaux de même nature. De toutes les variétés que je cultive, la seule qui est sujette à perdre une partie de ses pousses nouvelles dans les grands froids, est la sixième de l'eşèce visqueuse, parce qu'elle a une forte végétation en été et que ses'tiges, trop élancées, n'ont pas le temps nécessaire pour s'arrêter; c'est ce qui fait qu'elle fleurit moins que les autres. Quand elle est vieille, elle ne perd presque pas; mais les fortes gelées font avorter ses 
boutons de fleurs. Pareil accident arrive quelquefois aux variétés 5 de l'espèce visqueuse, et à celles 5 et 6 de l'espèce nudiflore. Peut-être les especes 4 et 5 sont-elles de même susceptibles de ces pertes. On multiplie aisément les azalées par les marcoltes. Quoique plusieurs poussent beaucoup de rejetons, il est rare qu'ils s'enracinent s'ils n'ont pas été couchés et arrêtés dans la terre comme les autres marcoltes. Ces dernieres sont enracinées au bout de deux ans suffisamment pour être enlevées; mais comme la reprise n'est sûre que lorsqu'on peut les obtenir en nimasse, pourvues de beaucoup de racines, je conseille d'attendre la troisiène année. Il est rare que les azalées enlevées à racines nues, quelque nombreuses qu'elles soient, reprennent facilement: souvent elles languissent, perdent leurs tiges et ne poussent que de leur collet. Ainsi la précipitation de jouir nuit a la jouissance ou la retarde; une année de plus l'avance au contraire, parce đu'il n'y a pás de pertes à craindre, et que l'ar. brisseau ne se sent presque pas de sa transplantation et de son sevrage. Les espèces ou variétés à fleurs écarlates sont plus lentes à s'enraciner, et si l'on n'attendoit pas leur parfait enracinement et la possibilité de les avoir en motie, on les perdroit presque ceriainement, ainsi qu'il m'est arrivé par une impatience inconsidérée.

Le temps le plus favorable à la plantation des azalées est le mois de mars ou la fin de février, relativement à la douceur ou à l'âpreté de la saison, et à la variété plus ou moins précoce. On pent aussi cependant les planter en novembre; mais il faut alors couvrir les pieds de litiere ou de feuilles mortes, pour que la gelée ne fasse pas de tort aux racines qui n'ont pu s'attacher à la terre:

Les azalées supportent le soleil sans dommage, mais, comme dans une siluation absolument ouverte à ses rayons, la terre de bruyère se sèche aisément et ne s'imbibe plus de l'eau gुu'avec beaucoup de lenteur, il vaut mieux leur donner une demiombre, et ne les faire jouir du soleil que jusqu'à maidi ou une heure; il en est de mêtne de tous les arbrisseaux à terre de bruyère qui exigent d'être plantés ensemble et à l'exp̣osition du sud-est. 
Us. Ces arbustes sont charmans dans le temps de leurs fleurs. Plusieurs variétés se couvrent si bien de leurs ombelles, qu'elles forment des buissons enlièrement fleuris; les unes présentent les couleurs douces de la rose, d'autres parfument au loin l'atmophière de leurs odeurs suares; ceux-là décorent les premier jours du printemps, ceux-ci ouvrent Ieurs corolles et répandent leur parfum aux chaleurs naissantes de l'été. Rien de si riche et de si agréable à la vue qu'un bosquuet de rododendron et d'azalées qui fleurissent dans le même temps.

\section{Corolle presque polypétale.}

\section{Rhodore, Rhodora.}

Cal. très-petit, à 5 dents. Cor. dont 2 div. sont oblongue et conniventes; la sup. profondément divisée, à lobes étroits; linférieure plus large, à 3 lobes à son sommet. 10 étam. insérées sur le calice. Filamens inégaux, inclinés. Anthère didymes, avec 2 petits trous. Caps. à 5 loges.

* Phodore du Canada, $R$. canadensis.

Arbuste d'un à deux pieds, formant un buisson garni de plusieurs branches, droites et brunâtres. Feuilles ovales-lane., pointues, alt., pét., trèswentières, d'un vert glauque, à bord's un peu roulés dans leur jeunesse. Fleurs purpur., de moyenne grandeur, en faisceaux term.

Lieu. Le Canada. Ђ. Fl. en avril.

Cult. et mult. des kalmies et des azalées. Les marcottes s'enracinent assez facilement lorsque l'arbrisseau est en pleine terre de bruyère. On peut les lever l'année suivante et les placer en pépinière pour s'y fortifier. Lorsqu'il n'est pas suffisamment enraciné, il est sujet a languir. Ses branches, fort roides, ne se plient pas assez aisément. On doit prendre de préférence les inférieures, et particulièremert ses rejetons, car ceux-ci ne s'enracinent pas à moins qu'on ne les marcolte. Il se plaît dans les situations un peu fraîches et légèrement ombragées. Il est trèsrustique. Le terreau de bruyère lui est nécessaire.

Us. Le rhodore fait un joli effet dans le temps de ses fleurs ? 
qui paroissent avant le développement des feuilles. Il est trésprécoce, et par conséquent susceptible d'orner les bosquets du retour de l'année.

\section{Lède, Lédier, Ledum.}

Cal. très-pelit, à 5 dents. 5 pét. 10 étam. à anthères oblongues et droites. Caps. acuminée par le style, à 5 loges.

* i. Lédier à feuilles étroites, L. palustre.

Arbuste d'un pied et demi à trois pieds, rameux, diffus; les jeunes rameaux converis d'un duvet roussâtre. Feuilles éparses, rapprochées, linéaires, étroites, oblongues, à bords roulés, velues et couleur de rouille en-dessous. Fleurs blanches, petites, en ombelles sess. et term.

Lieu. Les lieux humides du nord del'Europe. $\$$. Fl. en avril. et mai. Toujours vert.

* Variété à tiges couchées. Beaucoup plus petite dans toutes ses parties. $L$. decumbens. Var. H. K.

Lieu. La baie d'Hudson.

* 2. L. à feuilles larges, L. latifolium. Thé du Labrador.

Arbuste de 3 pieds, très-garni de tiges et de rameaux droits, formant un large buisson arrondi et régulier. Feuilles ovales, obl., à bords roulés, très-entières, fermes, vertes en-dessus, jaunâtres en-dessous et un peu velues. Fleurs blanches, plus grandes que celles du précédent, en corymbes ombelliformes, serrés et term.

Lieu. Le Groenland, le Labrador, la baie d'Hudson. Ђ. Fl. id. Toujours vert.

* 5. L. à feuilles de thym, $L$ thymifolium, Lam. $L$. buxifolium, H. K. L. serpyllifolium, L'HÉRIT.

Arbuste en partie couché, formant un buisson arrondi. Feuilles petites, ovales, planes, vertes et glabres en - dessus, blanches en-dessous. Fleurs petites, blanches, en têtes onabelliformes et term.

Lieu. La Caroline. ๖. Fl. en mai. Toujours vert.

Cult. Pleine terre. Ces arbustes aiment les lieux frais et un peu bumides, et les situations ombragées. Ils sont très-rustigues: 
Leur terre doit être à-peu-près semblable à celle des genres précédens; le terreau de bryyère doit y dominer, ou le sable noir : la sécheresse et le grand soleil leur sont absolument nuisibles. La $3^{\text {e }}$ sur-tout y est très-sensible et périt ou se muile dans ces circonstances. On les multiplie par les marcottes et par leurs rejetons; mais il faut attendre qu'ils soient bien enracinés, et les enlever en février plutôt qu'en automne. La troisieme a les rameaux très-cassans.

Us. Les lédiers sont de jolis arbustes. Le second a une forme et un aspect plus agréables. Il est souvent couvert de fleurs blanches au printemps. Toutes leurs parties, sur-tout les feuilles, sont odorantes. On se sert de celles de la seconde espèce en guise de thé. La troisienne espèce est encore plus fleurie que les deuz autres.

\section{Béfar, Befaria.}

Cal. un peu ventru, 7-fide. 7 pétales. 14 étam. alternativement plus courtes. Anthères penchées. Stigm. un peu épais, à 7 stries. Baie sèche, acuminée par le style, entourée par le calice, à 7 côtes et 7 loges.

* Bérar paniculé, B. paniculata, Cels.

Tige brune, rameuse; les rameaux d'un brun rouge, couverts d'assez longs poils et droits. Feuilles alt., presque sessiles, ovales, très-entières, leurs bords et leur sommet rougeâtres, un peu fermes, très-glabres et vertes. Fleurs en grappes terminales. Corolle d'un blanc lavé de pourpre, de 3 cenlimètres de diamètre. Pédoncules uniflores.

Lieu. Les montagnes de la Caroline. ๖. T ujours vert.

Cult. La même que celle des rosages et des kalmies.

Cet arbrisseau est encore peu répandu, par la difficulté de le conserver et de le multiplier. Je l'ai eu pendant trois ou quatre ans en pot ou il a parfaitement fleuri; comme il $\mathrm{y}$ étoit languissant, je l'ai mis en plein air dans la terre de bruyère où il a péri, non par le froid, mais par sa nature même, ou par l'effet d'une naturalisation imparfaite. Ie l'ai semé aussi plusieurs fois sans succès. Je ne sais si d'autres mltivateurs ont été plus heureux, ou ont pu lui donner le 
traitement qui lui convient; ce qu'il y a de certain, c'est quil est très-rare en France actuellement.

\section{Ité, Itea.}

Call très-petit, 5-fide. 5 pét. 5 étam. Anthères penchées. Caps. mucronée par le style, à 2 loges et 2 valves.

* I. IT té de Virginie, I. vírginica.

Arbrisseau de 3 à 4 pieds, formant, à l'aide de ses rejetons nombreux et droits, un buisson bien garni. Il est glabre dans toutes ses parities. Fecuilles pét., alt., ovales, pointues, dentelées. Fleurs blanches, petites, nombreuses, en épis term.

Lieu. La Virginie. Ђ. Fl. en juillet et août.

Cult. Preine terre. Cet arbuste ne craint point le froid, ou quand celui-ci atteint le summet de ses tiges, il a bientôt réparé ses dommages. Il vient dans tous les terrains, mais beaucoup mieux dans les situations fraîches même un peu humides, et dans les terres de bruyère ou les sables noirs. Mult. par ses rejetons, qu'il pousse abondamment, et qu'on enlève en février pour les planter à demeure.

Us. Les ités contribuent avec les cléthras, auxquels ce genre a beaacoup de rapport, à l'ornement des bosquets d'été pi ci díomne. Leurs épis fleuris fort un effet assez remarquable a 2. I. épineux, 1. spinosa, ANDr.

Arbuste. Feuilles en coin, sessiles, tronquées à Ieur sommet, petites, opposées. Epines axillaires. Fleurs petites, Blanches, tres-nombreuses, en panicule terminal.

Lieu. La Nouvelle-Hollande. 3 .

Cult. Orangerie. Terre de Bruyère. Mult. par bouture, en avril.

\section{Menziezia.}

Cal. monoph. Cor. monop., ovale. Fil. insérés au réceptacle. Caps. à 4 loges, à un grand nombre de semences attachées. aux replis des bords des valves.

3. Menziezra à feuilles de polium, Mr. polifolia, Juśs. Andromeda daboecia, Liv.

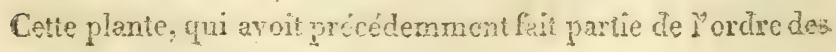


bruyères et du genre andromeda, a été, avec raison, placée par Jussieu et Smith dans celui des rosages, à cause des bords de ses capsules qui rentrent en-dedans.

Elle forme de larges et bas buissons, en tapis, qui couvrent la terre. Ses tiges rampantes, foibles et rameuses, sont garnies de feuilles alternes, pelites, ovales-lancéolées, trèsentières, vertes en-dessus, blanches en-dessous, à bords roulés. Fleurs d'un joli pourpre, assez grosses, ovales, cylindriques, disposées en grappes terminales, ou elles sont écartées.

Lieu. La France mérid., l'Irlande. Ђ. Fl. l'été et l'automne. Toujours verte.

Cult. Plein air. Terre de bruyère. Cette plante est trèsrustique. On la multiplie aisément en couchant ses branches, qui s'enracinent dans l'année, et que l'on peut lever au printemps suivant, pour les mettre en pépinière dans la même terre. Ses fleurs ont une jolie couleur, et leurs grappes ont de la grâce. Elles ornent les jardins pendant long-temps, et elle sera avantageusement placée parmi les bruyères de plein air, et parmi les kalmies et les azalées.

2. M. globuleuse, $M$. globularis, Hort. angl.

Lieu. L'Amérique sept. Ђ. Fl. en juillet:

Cult. Plein air. Celle de la précédente.

\section{OR DREIIT.}

\section{Les Bruyères (ERIC AE)。}

Calice monophylle, persistant, ordinairement in: fère, profondément partagé. Corolle monopétale, quelquefois divisée, attachée rarement au haut, le plus souventau fond du calice, ou posée sur une glande calicinale. Etamines insérées de même, quelquefois au fond de in corolle; anthères souvent bicornes à leur base, Ovaire ordinairement supère; un 
style. Siigmate le plus souvent simple. Fruit supère ou infère, multioculaire, polysperme, quelquefois en baie, ordinairement capsulaire, mulivalve; les valves avec une cloison dans le milieu et altachées par le bas à l'axe central.

Arbrisseaux, sous-arbustes ou herbes. Feuilles alternes, opposées ou verticillées.

\section{Ovaire supérieur.}

\section{Cyrille, Cyrilla.}

Cal. trésøpetiz, à 5 part. Cor. petite, à 5 part. 5 étam. non saillantes. Anthières en cœur. Stigm. bifide. Caps. mucronée par le style, à 2 loges, 2 valves.

* Cyrille en grappes , C. racemiflora. Ltea cyrilla, $\mathbf{H} . \mathbf{K}$. Cyrilla caroliniana, Michaux.

Arbrisseau de 8 à 1 o pieçs, rameux, assez irrégulier. Les rameaux roides et cassans. Feuilles alt., lanc., très-entières, glabres, d'un vert luisant. Fleurs blanches, petites, en grappes spiciformes, latérales, presque verticillées, longues et cylindriques.

Lieu. I a Caroline. Ђ. FI. en juillet et août. Toujours vert.

Cull. Orangerie et pleine terre. Cet arbuste ne demande qu'à être pendant l'hiver à l'abri des grands froids. Sa culture $n$ 'a rien de particulier, et se réduit aux soins ordinaires de l'orangerie. Nult. par les marcottes faites avec le jeune bois, qu'il faut courber peu à peu, à cause de sa nature cassante; et par boulures, en mai ou juin, en pots sur couche ombragée. Ces dernières ne réussissent pas toujours, mais il y en a qui s'enracinent. Cet arbrissear, per délicat, peut passer en pleine. terre, avec quelques abris, dans le nord de la France.

Us. Par sa verdure persistante et luisante, et par la disposition de ses grappes spiciformes, il ajoute a Ia variété et à l’or seceent des jardias. 


\section{Blairie, Bloeria.}

Obs. Ce genre faisant partie de celui des bruyères, l'on trouzvera dans ces dernières, les espèces de blairies cultivées.

\section{Bruyère, Erica.}

Cal. à 4 part. , quelquefois double. Cor. camp., souvent ven* true, 4-fide. 8 étam. à anthères bicornes ou crêtées, saillantes ou renfermées dans la corolle. Stigm. presqu'à 4 lobes. Caps. à 4 loges, 4 valves, entourée par le calice.

C'est à la possession du cap de Bonne-Espérance par les Anglais, pendant les dernières années de la révolution, que nous devons la connoissance du grand nombre d'espèces de bruyères actuellement cultivées en Angleterre et en partie en France. En 1787 , les Hollandais, malgré leur ancien établissement dans cette partie de l'Afrique, et les jardiniers anglais, n'en possédoient qu'une vingtaine, et parmi elles se trouvoient Io à i I indigènes en Europe. En 1789, Aiton, jardinier en chef du roi d'Angleterre, dans son Hortus Kewensis, en indiquoit 41. En 1801, les Anglais ont porté ce nombre à x3o; mais M. Hibbert, dans son jardin de Clapham, en possédoit alors 238, et MM. Kennedy et Lee en cultivoient aussi, dans le mème temps, ìpeu-près ce nombre (I). M. Salisbury en a décrit $246^{\circ}$, sans y comprendre les variétés. En France, dans les

(1) Annales du Muséuna, Thouin. 
collections où se trouvent le plus de bruyeres, qui sont celles de S. M. l'Impératrice à la Malmaison, du Muséum, de Cels et la mienne, je crois ne me pas tromper beaucoup en les portant chacune, vu les pertes qu'elles ont dû faire, à environ 100 à I IO espèces.

De tous les genres de végétaux les plus nombreux en espèces, il n'en est point qui présente plus de difficultés que celui des bruyères, pour déterminer les caraclères différentiels. Aucune des parties de la fructification et de la plante eniière n'est véritablement consiante. Linné et les auteurs qui ont traité ce genre ont fondé leurs divisions sur les anthères et sur les verticilles des feuilles. Mais, à l'exception de quelques espèces moins variables que d'autres, ces parties sont sujetles à changer de forme et de nombre. Si l'on considère les anthères nues ou appendiculées, on remarquera, dans plusieurs espèces, que tantôt elles sont dans le premier cas, tantôt dans l'autre, et souvent les appendices sont si courts et si peu sensibles, qu'on peut aussi bien croire à leur absence qu’à leur présence. Si l'on établit une subdivision sur la saillie des anthères hors de la corolle ou sur leur retraite dans celte dernière, ce caractère est encore plus faukif, en ce que plusierrs espèces les ont au niveau du limbe, par conséquent indélerminées, et que d'autres qui, à l'ouverture de la corolle, les montrent dans leur limbe, les ont véritablement saillantes deux ou trois jours après.

Le nombre des fenilles par verticilles n'est pas. moins variahle. Il n'est pas rare d'ea voir de ternées, gunaternées et quinées sur le même pied, et de 6ées, 
$7^{\text {ees }}, 8^{\text {és, }}$, sur celles dont les verticilles sont composés de beancoup de fevilles.

M. Salisbury, dans sa monographie des bruyères insérée dans les transactions de la société linnéenne de Londres, a si bien senti la difficulté de ces divisions, qu'il y a pour ainsi dire renoncé. Il s'est contenté de les ranger suivant un ordre qu'il a établi sur leurs affinités réciproques. Mais en rendant à ce savant botaniste toute la justice qui lui est due, et lui témoignant la reconnoissance qu'on lui doit d'avoir fail connoître et caractérisé 246 espèces, on pourroit lui observer que si beaucoup d'espèces peuvent constituer, par leurs formes essentielles et respectives, de véritables réunions, il en est plusieurs qui, différant entr'elles par quelques-unes de leurs par. ties, se trouvent membres d'une société à laquelle elles paroissent assez étrangères. M. Salisbury a été obligé d'en isoler quelques-unes, sans donte parce qu'elles ne présentoient pas des caractères propres à entrer dans ses différentes associations. On ne connoît pas trop d'ailleurs quelles ont été les véritables bases sur lesquelles il a établi ses affinités. Ce ne peut être dans la longueur de la corolle, puisque dans la même réunion il y en a de longues et de courtes; cependant il paroît que la dimension a été un de ses principes. Ce n'est pas dans les anthères, plusieurs masses d'affinités en ayant de nues et d'appendiculées, et de non saillantes. Ce n'est pas plus dans le nombre des feuilles de chaque verticille, dans le calice, dans les bractées. On pourroit penser que l'aspect de tontes les parties a principalement déterminé M. Salisbury. Mais ce principe est néces. 
sairement arbiiraire; et les rapports qui naissent de la simple vue doirent céder à ceux de l'analyse.

Comment, dans le nombre de 246 espèces, trouver une bruyère inconnue à l'ohservateur si rien ab. solument ue le guide? Il faudra qu'il passe en revue toutes les bruyères, et il aura beaucoup de peine à s'arrêter, parce que plusieurs caractères conviennent a beaucoup d'espèces tt qu'il est rare qu'il en trouve a'assez saillans pour le fixer. A moins donc d'avoir cous les yeux les trois quarts au moins des bruyères convues pour pouvoir les comparer entr'elles, il est impossible à une personne, quuelqu'instruite qu'elle soit, à un bon botaniste même, de trouver dans l'ordre des affinités une douzaine de bruyères qu'il ne connoîtroit pas du tout et qu'il ne pourroit comparer avec d'autres. Ce n'est done que par la comparaison de toutes les espèces cultivées ft vivantes ous bien conservées, que M. Salisbury a pu établir ses réunions et ses isolemens; et ce travail a eu plutôt pour but de donner la comoissance de toutes les bruyères actuellement connues et leurs rapports respectifs, que d'eu faciliter l'étude et la recherche.

Comme dans le règne végétal il faut nécessairement une méthode pour pouvoir reconnoitre une plante dans la foule immense des espèces qui le com. posent, des divisions et subdivisions sont indispensables à établir dans les grands genres. Elles ne sont pas, il est vrai, toujours sûres et exemptes d'incertitudes; cependant les trois quarts et demi des espèces Y sont ordinairement à leur place; et, à l'égard de celles qui présentent des doutes, la rectifications'opère par le moyen du caractère spécifique. Si par ces es- 
pèces d'analyses on n'arrive pas exactement à l'espèce qu'on cherche, du moins on n'a plus à choisir que dans un petit nombre, et l'on ne tarde pas à la trouver à l'aide de la comparaison et de quelques différences caractéristiques.

Dans le travail que je présente ici aux amateurs de plantes étrangères et aux cultivateurs, je n'ai eu pour but que de leur faciliter la connoissance des bruyères que les jardiniers pourroient leur vendre sous des noms différens; et cette connoissance est d'autant plus imporiante relativement à la culture, qu'ainsi qu'on le verra à la fin de ce genre, toutes les espèces ne peuvent être traitées absolument de même, et qu'il y a, à l'égard de certaines, quelques différences dans la manière de les cultiver. J'ai partagé ce genre en quatre grandes divisions fondées sur la longueur de la corolle, partie qui m’a paru la plus constante. J'avone que les extrémes de ces différentes dimensions peuvent, dans plusieurs espèces, offrir des incertitudes; qu'alors une dimension pourroit convenir à la division suivante commeà la précédente. Mais, comme il est impossible de faire des coupes exactes, si l'espèce qu'on cherche daus une division avoit une longueur de corolle approchant de celle qui fonde la division suivante, et qu'on ne la trouvât pas dans celle-là, il faudroit alors la chercher dans cette dernière, à la même subdivision. Cela n'arrivera cependant qu'à peu d'espèces, et l'on n'en aura jamais beaucoup qui aient une dimension dont la place seroit incertaine, parce qu'il y a une très-grande différence entre la première division et la troisième,ainsi qu'entreladeuxiène et la quatrième. 
Chacune d'elle est divisée en anthères nues sails lantes et non saillantes, et en anthères appendiculées saillantes et non saillantes. La saillie des anthères ou leur retraite dans la corolle est un caractère si variable, qu'on ne doit pas s'y attacher absolument. J'avois d'abord envie de le supprimer; mais des bruyères, comme les socciflora et penicilliflora et leurs affinités, les ont si constamment saillantes, que je l'ai conservé. Chacune de ces subdivisions est partagée en feuilles $3^{\text {ées }}, 4^{\text {ées }}, 5^{\text {ées }}$, etc. La détermination de ces paragraphes a été prise sur le nombre des feuilles composant chaque verticille le plus répandu sur toute la plante.

La dimension de la corolle est celle qu'a indiquée M. Salisbury; mais je préviens qu'elle est plus souvent moindre que plus grande. L'on verra, dans les détails que j’ai ajoutés à plusieurs espèces que j’ai observées, que les corolles que j'ai mesurées sont ordinairement plus longues que les dimensions données par M. Salisbury. Les caractères établis par cet auteur ont été exactement traduits. Quelques noms seulement n'ont pu l'être en français; je leur en ai substitué d'autres qui rendent à peu de chose près le sens du mot, ou plus analogues à notre idliome et à la décence de notre langue. Tous les noms latias de MI. Salisbury sont exactement conservés.

La présence ou l'absence des appendices des filamens ou des anthères n'étant pas, dans plusieurs bruyères, determinée, M. Salishury semble avoir preféré, dans cette incertitude, leur présence à leur absence; il en a par conséguent attribué à queiques espèce auxquelles Limné, Thunberg, Willdenow 
n'en avoient pas donné, et dans lesquelles je n’en ai pas non plus observé. D’après ces autorités et mes observations, $j$ 'aurois pu placer ces bruyères dans les subdivisions d'espèces non appendiculées; mais, comme je dois supposer que IM. Salisbury les a vues, et que celte partie peut d'ailleurs se trouver sur un individu et manquer sur les autres, jai préféré suivre cet auteur, en notant les espéces à appendices incertains, dans les sections où elles devroient se trouver si leurs anthères étoient nues, avec un renvoi à leurs numéros dans celles où elles sont caractérisées et décrites avec appendices.

Je ne parlerai pas des nouveaux noms que $\mathbb{M}$. Salisbury a donnés à presque toutes les bruyères. II sait combien les changemens apportent de confusion dans la botanique. Peut-être auroit-il pu du moins conserver cenx des espèces ancienuement counues. Une nouvelle nomenclature étoit saus doute récessaire pour obvier aux erreurs de noms, età leur double, triple et quadruple emploi. Il falloit bien faire connoître l'abus qu'on a fait de certains qui ont été donnés à plusieurs espèces différentes; par exemple le nom spécifique abietina a été donné par les auteurs à 5 à 6 espèces; celui pribescens a été attribué à 8 à ro; beaucoup d'autres l'ont été à 3 et 4 . Mais, pour éclaircir cette confusion occasionuée par l'incertitude des auteurs et le défant de s'entendre, il étoit inutile, comme je viens de le dire, de tout changer, et de donner de nouveaux noms à des espèces sur-tout qui en avoient de généralement adoptés. Ainsi, il falloil conserver celui he mediter. ranea à cette bruyère, au lieu de hui donner celui 
de lugubris; celui de caffra n'avoit pas besoin d'être substitué à celui de prolifera; l'espèce nommée par Linné halicacaba étoit bien connue sous ce nom; et celui de rupestris que Salisbury lui a donné convenoit beaucoup mieux à l'espèce d'Anùrews, qui ne croît naturellement que sur les rochers qu'elle tapisse, etc.

En adoptant la nomenclature de Salisbury, je ne me suis donc pas déguisé ses défauts, et pour y obvier, j’ai tâché de joindre aux noms de cet autetur les synonymes les plus certains. J'iuvite mème les amateurs et les jardiniers qui voudront se procurer des bruyères, à les demander sous les noms de Willdenow, d'Andrews et autres auteurs connus, de préférence à ceux de Salisbury, qui ne sont pas aussi généralement reçus. On en trouvera la table ci-après, qui a été composée avec le plus grand soin, et sur la véracité de laquelle on peut compter.

Ayant été obligé, dans le second volume de la première édition de cet ouvrage, de me servir des noms des jardiniers pour les nouvelles espèces, et faute de connoissances plus approfondies, de ne les indiquer que d'une manière assez vague, j’ai pensé devoir refaire en entier ce genre intéressant; et comme depuis la composition de ce second volume, je me suis appliqué à la culture de ces espèces et à leur multiplication avec les plus grands soins, et en variant chaque année mes procédés, j'espère que les caltivateurs tronveront avec plaisir, à la fin de ce geure, la méthode que j'ai suivie, et à laquelle je me tieus aujourd'hui, 
IM. Salisbury ayant réuni à ce genre celui de blairie, blaeria (Lin., Juss., Willd.), dont les ، spèces n’ont que 4 à 5 étamines, en a formé dans ses affi:ités, en y joignant quelques autres bruyères qui leur ressemblent par le même nombre d'etamines, une masse distincte. Ou la trouvera en outre séparee à la suite de la table des synonymies.

La plus grande partie des bruyères est originaire du cap de Bonne-Espérance. Les espèces indigènes en Europe sont :

Erica vulgaris, Lin.

- scoparia, Liv.

- viridi purpurea, Hortul.

- arborea, LIN.

- tetralix, Liv.

- cinerea, LiN.

- australis, LiN.
Erica ciliaris, LIv.

- umbellata, LiN.

-purpurascens, Lis, ou vagans.

- herbacea, Lrv

- mediterranea, LIN.

- multiflora, LIN. 


\section{BRUYERES}

\section{Rangées, par M. SAlisbury, suivant l'ordre de leurs affinités.}

Extrait des Transactions de la Société Linnéenne de Londres.

Explication des chiffres et des lettres.

Le chiffre indique le nombre des feuilles qui composent chaque verticille. $m$. Les anthères nues, anthera mutica.

c. Les anthères ou filanaens appendiculés, anthera aut filamenta calcarata

i. Les anthères non saillantes hors de la corolle, antherce inclusa.

e. Les anthères saillantes hors de la corolle, antherce exserta.

E. Scoparia. 3. m. i.

Spiculifolia: 3. m. i.

Virgularis. 3. m. i. Asperifolia. 3. m. c. i. Ferox. 3. m. i.

Oxycoccifolia. 3. c. i. Thymifolia. 3. c.i. e.

Axillaris. 3.4 . c. i.

Sicæfolia. 3. c. i.

Urceolaris. 3. c. i.

Fausta. 3. c. i.

Pallida. 3. c. i.

Tomentosa. 3. c. i.

Auricularis. 3. c. i.

Lameliaris. 3. c. i.

Marifolia. 3. c. i.

Helianthemifolia, 2, c. i.

(a)

Calathiflora. 3. c. i.

Procera. 3. 5. c. i.

Polytrichifolia. 3.5. c. i.

Tenuis. 3. c. i.

Humilis, 3, c. is.
Sal. B. cul.

I I Peduncularis. 3. c. i.

22 Amæna. 3. c. i.

33 Glomiflora. 3. c. i.

\begin{tabular}{ll|l}
3 & 3 & Glomiflora. 3. c. \\
4 & 4 & Formosa. 3. c. i. \\
5 & 5 &
\end{tabular}

Carduifolia. c. i.

$6 \quad 34$

735

$8 \quad 36$

Tubercularis. 3. m. i.

0

Campanularis. 3. m. i.

c

937 Modioliflora. 3. m. i.

o

$10 \quad 162$ Blands. 3. m. i.

97 Hottoniæflora. 5. c. i.

Seriphiiflora. 5. m. i.

I3 38

14 99

$15 \quad 163$

1640

1794

18

Lavandulæfolia. 3. m. i.

Humifusa. 3. m. $\dot{\text { i. }}$

\section{.}

Cristæflora. 3. m.

(1)

Lysimachixfolia. 3. m. i. 37

Sal. B. cul.

$23 \quad 164$

$24 \quad 165$

$25 \quad 102$

$26 \quad 43$

37243

286

$29 \quad 77$

3o I qa

317

$32 \quad 133$

33 I0

$34 \quad 78$

$35 \$$

$36 \quad 59$

$37 \quad$ so

Passerinæfolia. 3. m. i. 38 8r

a

$39 \quad 87$

I9 $4 \mathrm{I}$ Byssina. 3. m. i. c.

20 I 00 Velleriflora. 3. m. e.

2 I 42 Carbasina. 3. m. e.

22 IOI

(6) 
Seariosa. 3. e. e.

Sexfaria. 3. c. e.

Corydalis. 3. c. i.

Azalexfolia. 3. m. e.

Petiolaris. 3. m. i.

Vesicularis. 3. c. i.

Verniciflua. 3. c. i.

Lachnæf lia. 3. c. i.

Volutæflora. 3. c. m. i.

Lyrigera. 3. c. $i$.

Salax. 3. c. i.

Gnidiæfolia. 3. c i.

Cumuliftora, 3. m. i.

Genistæfolia. 3. m. i.

Periplocæflora. 3. c. i.

Lucida. 3, c. i.

Munda. 3. c. $i$.

Grapbaliiflora, 3, c. i.

Fabrilis. 3. c. i.

Dianthifolia. a c. I.

Brevifolia. 3. c. i.

Chlamydiflora. 3. c. i.

Selaginifolia. 3. c. i.

Pannosa. 3.5. c. i.

Hirsuta. 4. m. i.

Plumosa. 4. c. i.

Ciliciiflora. 3. m. i.

Xeranthemifolia. 3. ma. e.

Nodiflora. 3. m. e.

Flosculosa. 4. m. e.

Exilis. 4. m. e.

Labialis. 3. m. e.

Embolifera. 4. c. e.

Dumosa. 4. c. e.

Barbigera. 4. m. e,

Paleacea. 4. m. e.

Bruniæfolia. 6. c. e.

Turmalis. 6. m. e.

Equisetifolia. 3. m. e.

0

Diotæflora. 3. m. e.

Sertiflora. 3. m. e.

Flexilis. 4. m.e.

Saxatilis. 3. 5. m. e.

Lugubris. 4. m. e.

Multiflora. 5. 6, m.e.

Maniputiflora. 3. m. $c$ 。

Vaga. 5. 6. m. c.

Lentiformis. 3. m, e

Pudibunda. 3. 4. m. e.
LES B R U R E S

Sal. B.cul.

\section{4}

4270

4371

$44 \quad 103$

$\begin{array}{ll}45 & \text { I I } \\ 46 & 82\end{array}$

$\begin{array}{ll}46 & 82\end{array}$

$48 \quad 104$

$49 \quad 105$

5o 106

5 I 107

$52 \quad 45$

53 ro8

$54 \quad 83$

$55 \quad 84$

56 i

$57 \quad 46$

$58 \quad 47$

59

6 o

6 I

62

62

64

65

66

67
68

69

7o

it

72

73

74
75

75

76

77

78

79
80

48

49

160

110

I I I

112

I 19

85

53

9

12

I 3

28

29

142
75

92

30

76

93

$8 \mathrm{~s}$

82

83

84

86

87
88

89

90.
Filiformis. 3. c. e.

Turgida. 3. c. e.

Fusiformis. 3. 4. m, e.

Fragilis. 3. m. e.

Vestiflua. 3. m. e.

Baculiflora. 3. m. e.

Cothurnalis. 3. m. e.

Socciflora 3. m. e.

Furturosa. 3. m. e.

Folliculatis. 3 . m. e.

Penicilliflora. 3. m. e.

()

Placentæflora. 3. m. e.

Pyramidalis. 3. en. e.

Squamaflora 3. m. e.

Ciæsia. 3. m. e.

Flexuosa. 3. ma. e.

Lasciva. 3. m. e.

Siylosa. 3. m. e.

Spiceflora. 3. m. e.

Mileflora. 3. c. e.

(.)

Diosmæfolia. 3. c. i.

Palliiflora. 3. c. i.

Fugax. 3 c.i.

Pycoleflora 3.4.c. i

'To 114 '118

I50 I 8 .

$116 \quad 19$

Modesta. 3. c. i.

$117 \mathrm{I} 66$

Holosericea. 3. c.

Glauca 3., $i$

Variifolia. 3. c. i.

Rupestris. 3, c. i.

Versicolor. 3. $\mathrm{m}$, i.

Cupressiformis. 3. c. i.

I 032 T

10422

10523

I06 2 א

10725

$108 \quad 26$

$109 \quad 27$

IIO 74

III IIf

II 50

Decora 3. c. i.

II $\quad$ I67

119168

120218

I2I 2 :9

122192

$12322 \mathrm{I}$

125222

$1.26 \quad 223$

$127 \quad 225$

I28 226

I $29 \quad 226$

I3o $20 \mathrm{~T}$

13 I 198

$\begin{array}{lll}\text { Obpyramidalis. 4. m. i. } & 132 & \text { I } 45 \\ \text { Cyrillaflora. 4. m, i. } & 133 & \text { I } 66 \\ \text { Velitaris. 4. c. i, } & 134 . & \text { I74 }\end{array}$

$\begin{array}{lll}\text { Obpyramidalis. 4. m. i. } & 132 & \text { I } 45 \\ \text { Cyrillaflora. 4. m, i. } & 133 & \text { I } 66 \\ \text { Velitaris. 4. c. i, } & 134 . & \text { I74 }\end{array}$

$\begin{array}{lll}\text { Obpyramidalis. 4. m. i. } & 132 & \text { I } 45 \\ \text { Cyrillaflora. 4. m, i. } & 133 & \text { I } 66 \\ \text { Velitaris. 4. c. i, } & 134 . & \text { I74 }\end{array}$ 
Sal. B cul.

Cutcizflor . 4. c. i. 'Tubiftora. 4. c. i.

Curviflora. 4. c. i.

Cuspidigera. 4. c. i.

$\begin{array}{ll}35 & 227\end{array}$

$136 \quad 228$

Mutabilis. 3. c. i.

137229 Uncifolia. 4. c. i.

138230

Bibax. 4. c. i.

ז39 $23 \mathrm{r}$

Buccinæformis. 4. c. i. I 40232

Caduceifera. 3. c. i.

$178 \quad 121$

Empetrifolia. 6. c. i.

179

Sal. B. cul。

Mauleolaris. 6. c. i.

Pyxidiflora. 6. c. i.

Fastuosa. 4. c. i.

Í1 233

Nolæflora, 6. c. i.

$177 \quad 169$

142200

Stagnalis. 4. m. i.

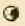

Conspicua. 4. 5. m. i.

Longiflora. 6. m. i.

Verticillaris. 5. 6. m. i.

Flocesa. 5. 6. m, i.

\section{(a)}

$\begin{array}{lll}\text { Radiiflora. 8. c. i. } & 147 & 24 \mathrm{I} \\ \text { Lycopodiifolia. 6. m. i. } & 148 & 205\end{array}$

$$
0
$$

$143 \quad$ I 99

$144 \quad 202$

$145 \quad 203$

$146 \quad 204$

Pharetræformis. 6. m. i. I49 206

Grandiflora. 6. m. e.

Ce!viciflora. 5. 6. c. e.

Pinifolia. 6. c. i.

$150 \quad 217$

$15 \mathrm{I} 19^{\circ}$

$152 \quad 186$

Calamiformis. 6. m. i.

Longifolia. 6. m. c. i.

Costæflora. 6. m. i.

Onosmæflor . 6. m. i.

Pulvinilormis. 6. m. i.

Frondosa. 6. m. i.

Philic rfolia. 6. m. i.

Argutifolia. 6. m. i.

153207

I54 212

$155 \quad 153$

156208

I57 209

I58 2 I

159211

I60 154

Favosa. 6. c. i.

16! 236

Sceptriformis. 8. c. i.

Claveflora. 6. c. i.

Alveiflora. 6. c. i.

Mammosa. 4. c. i.

Brachialis 4. m. $\mathrm{i}$.

Hystriciflora. 4. m. ? i.

Strigilifolia. 4. c. i.

Pectinifolia. 4. c i.

Crinifolia. 6. c. i.

Cernua. 4. c. i.

Doliiformis. 6. c. i

Pistillaris. 4. e. i.

Ciliaris. 3. m. i.

Botuliformis. 4. c. i.

Multicaulis. 6, c. i.

0

162. 240

$163 \quad 237$

164238

$165 \quad 239$

$166 \div 556$.

$167 \quad 175$

$168 \quad 176$

169 177

$170 \quad 234$

$171 \quad 120$

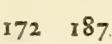

$173 \quad 178$

a

\section{(a)}

$174 \quad 144$

1 $5 \quad 179$

$176 \quad \times 34$
Festa. 4. c. i. et m.

Faliax. 6. c. i.

Parilis. 6. c. i.

Viscida. 6. c. i.

Catervæflora. 4. c. i.

Pubige a. 4. c. i.

Mitreformis. 4. c. i.

Tardiflora. 4. c, i.

Parviflora. 4. c. i.

Exigua. 4. c. i.

Pusilla. 4. c. i.

Tragulifera. 4. c, i.

Gutteflora: 4. c. i.

Curvirostris. 4. c. i.

Obesa. 4. c. i.

Gracilis. 4.c. i.

Intervallaris. 4. c. i.

Quadræflora. 4. c. i.

Prolifera. 4. c. i.

Cyathiformis $4 . c$

Pelviformis

Turrigera 4 .

Lacunæflo:a 3. c. 206 125

Florida. 4. c. i.

5

Turbiniflora. 3.4.c.i, $2086 \mathrm{~S}$

Builularis. 3.4. c. i. $\quad 20969$

Mucosa. 4. 6. c. i.

Piluliformis. 4.5. c. i. $21 \mathrm{I}$ I29

Obliqua. 6. c. i.

Sequax. 4. 6. c. i.

Bienna. 4.5. c. i.

Verecunda. 4 c. i.

Glabella-pulchella $4 \cdot c^{2} 210-12 \pi$

$212 \quad 188$

$213 \quad 180$

214 18I

$215 \quad 121$

(a)

Embotriifolia 3. c. i. 217 xg

Glutinosa.alt.c. i. 218170

Curvifolia. 3. c. i.

Squarrosa. c. i.

Gorterixfolia. $4 \mathrm{~m}, \mathrm{i}_{2} \quad 220 \mathrm{r}$

Ampuilæformis. 4. m, i. 222 196

Capax. 4. na. i, 
Sal, B. cul.

Lagenxformis, 3. 4.m. i, $224 \quad 19^{3}$ Jasminiflora. 3.4.m. i. $225 \quad 194$

Cette famille très-distincte, a pour caractère des anthères à sommet courbé en dedans, et très-amincies en pointes.

\section{Pavettieflora. 4. c. ì.}

Fasciformis. $4 \cdot \mathrm{m}$. i.

Fistuirflora $4 . \mathrm{m}$ i.

Fragians. 4. c. m. i.

Galliiflora. 4. c. i.

Nidiflora. 4. c. i.

Denticularis. $4 . \mathrm{m}$. i.

Pulchia. 4. m. i.

$\begin{array}{ll}226 & 235 \\ 227 & 147 \\ 228 & 148 \\ 229 & 182 \\ 230 & 132 \\ 231 & 183 \\ 232 & 149 \\ 233 & 150\end{array}$

Daphneflorá. 4. m. i.

Pellucida. 4. m. i.

Amabilis. 4 c. i.

Venusta. 4. c. i.

Imbellis. 2. c. i.

Linifolia. 2. c. i.

Br rboniætolia. 2. c. i.

Corifrlia. 3. c. i.

Obvallaris. 3. c. i.

Hyssopifolia. 3. c. i.

Taxifolia. 3 c. i.

Pugionifolia. 3.c.is

Viminalis. 3. c. i.
Sal. B. cul-

234 I5 r

$235 \quad 152$

$236 \quad 184$

$237 \quad 185$

$238 \quad 95$

$239.9^{6}$

240 I6I

$24 \mathrm{I} \quad 52$

24) ${ }_{11} 6$

243 I1 15

$244 \quad 172$

$245172 b$.

$246 \quad 173$

\section{TABLE ALPHABÉTIQUE}

\section{des Bruyères et de leurs principales synonymies.}

A.

E. Abietina. Andr. Hortulanis, Abietiv: Roxb.

Abielinte Linn. Sp. Pl. Ed. I. Abietina. Thunb. Dišs. 68.

Abiecina. Wilid.

Absinthoïles Lin. Willd.

Absinthoïdes. Hortui.

Actea. Hortul.

Acuta. Andr.

Aggregata. Roxb.

Aitoria. Curt. Andr. 2I.

Aitoni. Willt.

Albens. Curtis. Lin. Willd.And.

Alveiflora.

Amabilis .

Amæna.

Ampullacea.And.34.Curt.Willd.

Ampullæeformis.

Andromeda droseroides. Lin. M.

Arborea Lin. Willd.

Arborea. Thunb. Diss. 63.

Archeria. Hortul. Andr。

Ardens. Andr.

Argutifolia.

Aricularis. Hortul.

Articularis. Th. Diss. 68. Willd.

Articularis. Curt. Lin. Mant.

Artieulata, Thunb, Prodr.

Asperifolia:

Aurea. Andr.

Anricularis;
Sal B. cul。

Paludosa. Salisb.

Pharetræformis. S.

Frondosa. S.

Mammosa. $\mathbf{S}$.

Mammosa. S.

Virgularis. S.

Axiliaris.S.

Polytrichifolia. S.

Cumuliflora S.

Jasminiflora. S.

Jasminiflora. S.

Viminalis, S.

ÁmpulIæformis. $\mathbf{S}$.

$130 \quad 203$

149. 206

158210

$365 \quad 239$

165239

$3 \quad 3$

836

20100

$25 \mathrm{x}$

$54 \quad 83$

$225 \quad 194$

$225 \quad 194$

$246 \quad 173$

Ifíf. $23 \mathrm{~S}$

$236 \quad 184$

24. 165

$222 \cdot 19^{6}$

$2 \geq 2 \quad 19^{6}$

$218 \quad 170$

Glutinosa. S

Procera. S.

Axillaris. S.

Frondosa. S.

Equisetifolia. S.

Caduceifera. S.

Corifolia. S.

Paleacea, $S$.

$\begin{array}{ll}39 & 4 \mathrm{I} \\ 8 & 36\end{array}$

$758 \quad 210$

252

$160 \mathrm{r} 5 \mathrm{f}$

8o 15

17976

$2415 \%$

$77 \quad 39$

4 26\%

I5. 99 
E. Australis. Lin. Willd. Axillaris.

Pistillaris. S.

Sal. B. cul,

Azaleæfolia.

B.

E. Baccans. L. Willd. Curt. Andr. Baccæformis. S.

Baccæformis.

Baculiflora.

Banksia. Andr. Willd.

Barbata. Andr.

Fragilis. S.

$116 \quad 119$

I 6 , I I

$96 \quad 215$

94213

Barbigera.

Bergiana. WendI. Lin. Mant. Lacunæflora. S.

Bibax.

Bicolor. Thunb. Diss. 57. Willd. Calathiflora. S.
Bicolor. Andr.

Blæria ciliaris. Lin. Willd. Plumosa. S.

Blreicia labiata. Soland.

Blæria pusilia. Lin. Willd.

Blæria pusilia. Lin. Willd. $\quad$ Enibolifera, S.

Labialis. S.

Blæria. Thunb. Prodr. 72. \} Dumosa. S.

256
76

$206 \quad 126$

139231

1839

261

$67 \quad 53$

$73: \mathrm{I} 4$

$\begin{array}{ll}74 & 142\end{array}$

Blæria articulata. Lin. Willd. Paleacea. S.

$75 \quad 75$

Blanda

Blenna.

Borboniæfolia.

Botuliformis.

Brachialis.

Bracteata. Thunb. Diss. 3 .

Obvallaris. S.

Brevifolia. Soland.

Brevifolia.

Bruniades. Andr.

Bruniades. Lin. Willd.

Bruniæfolia.

Buccinæformis.

Bullularis.

Byssina.

Brevifolia. S.

Velleriflora. S.

Carbasina. S.

7730

$\begin{array}{ll}3 \text { I } & 7\end{array}$

$21418 \mathrm{I}$

240. $16 \mathrm{r}$

$175 \quad 179$

$166 \quad 175$

242 III

62 I10

$62 \quad 10$

$40 \quad 88$

$\begin{array}{ll}41 & 89\end{array}$

$\begin{array}{ll}78 & -6\end{array}$

i $40 \quad 232$

$209 \quad 69$

$39 \quad 87$

E. Caduceifera.

C.

Cæsia.

Caffra. Andr. Hortul.

Caffra. L. Sp. Pl. Ed. I. Willd.? Lamellaris. S.

Calamiformis.

Calathiflora

Calycina. Th. Diss. 78. L.Willd.

Calycina. Andr. 17.

Campanularis.

Candida. Soland.

Capax.

Capitata. Lin. Willd.

Capitata Th. Diss. 15. Willd.

Carbasina.

Carduifolia.

Carnea. Lin. Sp. PI. Ed. 2.

Cainea. Curt. Mag. Jacq. Scop.

Catervæflora.

Cerinthoïdes. Th. Y. Diss. 33. Strigilifo'ia. S,

Gnidiæfolia. S.

Corifolia. S.

Palliifora. S.

$179 \quad 5 x$

10523

$202 \quad 65$

$\begin{array}{ll}15 & 163\end{array}$

153207

I8 39

$53 \quad 108$

$24 \mathrm{I} \quad 52$

$29 \quad 77$

I12 50

$223 \quad 197$

Byssina. S.

Velleriflora. S.

Saxatilis. S.

$\begin{array}{ll}39 & 87\end{array}$

$40 \quad 88$

4 I 89

$27 \quad 243$

8490

8490

$188 \quad 122$

$168 \cdot 176$ 
E. Cerinthoïdes. Th. B. Diss. 33. Pectinifolia. S.

Sal. B. cul.

Cerinthoïdes. Andr. 25. Curtis.
Cerinthoïdes. T. A. D. 33. L. W. Crinifolia. S.

Cernua. Andr. $48 . \quad$ Verecunda, S.

Cernua. Lin. Suppl, Montin.W. Cernua.S.

Cerviciflora.

Chlamydiflora.

Ciliaris. Lin. Willd.

Ciliciiflora.

Cinerea. Lin. Willd.

Clavieflora.

$169 \quad 177$

$170 \quad 234$

215 I3

$171 \quad 120$

15 190

63 I 11

$174 \quad 144$

689

$177 \quad 169$

$\begin{array}{rr}63 & 237\end{array}$

$\left.\begin{array}{l}\text { Coccinea. Wendl. Andr. 4i. H. } \\ \text { Coccinea. Th. Diss. 27. Willd. }\end{array}\right\}$ Frondosa, S.

258210

Coccinea. Lin. Hort. Cliff. Tubiflora. S.

Comosa. Th. Diss. 38. L. W. A. Galiiflora. S-

Conacea. Hortul.

Vesicularis. S.

Concinna. Soland. Willd. Andr. Paludosa. S.

Conferta. Andr.

Conspicua Andr. 29. Sol. H. K,

Conspicna. Kew. Icon. Willd. $\}$ Conspicua. S.

Corifolia. Th. Diss. 77. Willd. Corifolia S.

Corifolia. Hortul.

Corisfolio. I. Clus.

Lamellaris.

Procera. S.

Corisfolio. 4. Clus.

Scoparia, S.

Cornuta. Roxb.

Blanda. S.

Coronata. Andr. Io.

Radiiflora. S.

Corydalis.

Costrflora.

Costata. Andr. $4^{6}$.

Versicolor. S.

Cothurnalis.

Crinifolia.

Cristæflora.

Cruenta. Kew. I. H.K. A. 17.W. Melliflua. S.

Cubica, Lin. Mant. Andr. $39 . \quad$ Hottoniæflora. S.

Cubica. Thunb. Diss. 46. Willd. Seriphiiflora.S.

Culcitæflora.

Cumuliflora.

Cupressiformis.

Cupressina. Hortul.

Turrigera. $\mathrm{S}$.

Curviflora. Lin. Syst. Veget. Curviflora, S.

Curviflora. Th. Diss. 30. Willd. Bibax.S.

Curviflora. Wendl. Andr, 40. Fastuosa, S.

Curvifolia.

Curvirostris.

Cuspidigera.

Cyathiformis.

Cylindrica. T'h. Diss. 29. W. ? Fistulæflora. S.

Cylindriflora.

Cyrillæflora.

$136 \quad 228$

$23013 x$

$47 \quad 44$

$330 \quad 201$

249

143199

$24 \mathrm{I} \quad 52$

162

$194 \pi$

I $\quad \boldsymbol{I}$

3r 7

147248

44.103

$155 \quad 153$

$122 \quad 192$

$97 \quad 216$

$170 \quad 234$

$36 \quad 79$

$125 \quad 222$

$32 \quad 133$

33 Io

$135 \quad 227$

5483

$12322 \mathrm{~T}$

$205 \quad 125$

$137 \quad 229$

$13923 x$

$141 \quad 233$

$219 \quad 17 \mathrm{I}$

19760

138230

20366

$228 \quad 148$

I $29 \quad 226$

I33 I 46

D.

E. Daphneflora.

$234 \quad 197$

Declinata. Hortul.

Decora.

Deptata. Thunb. Diss, 39。

Curvirostris. S.

Denticularis. S.

19760

124220

232149 
E. Denticularis. Lin. Mant. Willd.

Denticulata. Roxb.

Depressa. Th. Di:s. 5o. Willd.

Depressa. Hortul. Andi.

Dianthifoira.

Diosmexiolia.

Dỉtæflora.

Discolor. Andr. 3. WiHd.?

Discolor coccinea. Hortul.

Divaricata. Ho tul.

Doliiformis.

Droseroïdes. Andr. 3o.

Dumosa.

Dura. Soland.
Denticularis. S.

Nidiflora. S

Humilis. S.

Nana. S.

Cupressiformis: $\mathbf{S}$.

Versicolor. S.

T'entis. S.

Glutinosa. S.

Urceolaris. $\mathbf{S}_{\text {. }}$
Sal. B. eu\%?

$232 \quad 149$

$231 \quad 183$

$2210 \mathrm{I}$

126. 223

$61 \quad 160$

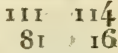

$123^{\prime 2} 2$ I

$122 \quad 192$

$21 \cdot 42$

$172 \quad 187$

$218 \quad 170$

$75 \cdot 75$

10. 162

E.

E. Elata. Hortul Andis.

Elongata. Roxb.

Embolifera.

Embothriifolia.

Empetrifofia.Th. Diss.70.L.W. Empetrifolia. S.

Empetrifolia. Berg. Houttuyn.

Empetrioides. Hortul. Andr.

Enneaphylla. Roxb.

Equisetifolia.

Eriocephala. Andr.

Exigua.

Exilis.

Exsurgens.And.Grandifl.var.W. Eweri. Hortul.

Longiflora. S.

Intervallaris. S.

$344 \quad 202$

$200 \quad 63$

$74 \quad 142$

217 I9

I80 135 .

18 I 136 .

Malieolaris. S.

Pixidiflora. S.

Sceptriformis. $\mathbf{S}$.

$\begin{array}{lll}18 & & \end{array} 37$

$162 \quad 240$

Tardiflora. S.

19

$\operatorname{lig} 3 \quad 5^{8}$

$72 \quad 29$

I 49206 124220

F.

E. Fabrilis.

Pharetræformis. S.

Decora. S.

Fallax.

Fascicularis. Lin. Suppl. Willd: Radiiftora. S.

Fasciformis.

Fastigiata.Ib.D.3r.L.W.Andr. Fasciformis. S.

Fastuosa.

Fausta.

Favosa.

Ferox.

Ferrea. Berg。

Festa,

Nincosa. S.

6 o

185

139

I 47241

$227 \quad 147$

$227 \quad 147$

$14 \mathrm{I} \quad 233$

I. 97

161236

Filarntosa. Andr.

55

$210 \quad 12 S$

184. 85

Filamentosa. Horivl.

266

Filiformais.

Fistulætlora.

Flammea. Hortul.

Bibax. S.

Flava. Andr.

Flexilis.

Flexuosa. Andr.

Floccosa.

Flopida. Th. Diss. 64. Willd.

Fleznosa. S.

91. 72

228 1 48

I $3923 \mathrm{I}$

2,5

$53-34$

1.062 2f

$1\} 6 \quad 204$

Elorida, \$.

207127 
E. FIosculosa.

Follicularis.

Formosa. Th. Diss. 82. Willd. Formosa. S,

Formosa. Hort.

Frondosa. S.

Fragilis.

Fragrans.

Fragrans, Andr.

Sal. B. cul.

Frondosa.

$7 \times \quad 28$

I00 158

$26 \quad 4^{3}$

$158 \quad 210$

$94 \quad 213$

$229 \quad 182$

253

$158 \quad 210$

Fucata, Thunb. Diss. $\left.9 \cdot{ }^{-}\right\}$Scoparia. S.

Fugax.

Furfurosa.

Fusco-rubens, Roxb.

Fusiformis.

Turgida. S.

G.

E. Galiiflora.

Gelida. Hortul. Andr.

Genistæfolia.

Gilva. Hortul.

Glabella. S. Pulchella.

Glabelia. Thunb. Prodr. $7^{3}$.

Glabra. Roxb.

Glauca. Andr.

Glomiflora.

Glutinosa. Roxb.

Glutinosa. Andr.

Gutinosa. Kew. Icon.
Glutinosa. Th. Diss. 48. Willd. Glutinosa. S.

Alveiflora. S.

Alveiflora. S.

I I

$113 \quad 117$

$\begin{array}{lll}99 & 157\end{array}$

$\begin{array}{rr}9^{2} & 755\end{array}$

Graphaliifora.

Gna halodies, Th. Diss. 25. W. Gnaphalifflora, S.

Gridiafolia.

Gorte iætolia.

Gracil s.

Grandiflora.Th.D.28.L.W.And. Grandiflora. S.

Granulata. Lin. Mant.

Gutæeflora.

Buliularis. S.

H.

E. Halicacaba.Th.D.52.L.W.And. Rupestris. S.

Helianthemifolia.

Hemispher ica. Soland.

Herhacea Lin. Willd.

Hirsua. Th. Prods: - 2 .

Hixta. Th. Diss. 56. Willd. ?

Hirta. Andr.

Hirtiflora. Curt. Mag.

Hispida. Andr.

Hispidula. Th. D. 20. L. W.

Hispidula. Hortal.

Chlamydiflora. S.

Velitaris. S.

Glanca. S.

$230 \quad 132$

I64. 238

53 108

164 238

$216 \quad 130$

63 II

$\times 34 \quad 174$

I19. 168

25102

$48 \quad 104$

$156 \quad 208$

218 170

$59 \div 48$

$59 \quad 48$

$55 \quad 84$

$221 \quad 19^{5}$

I $-9 \quad 62$

150.217

$209 \quad 69$

$169 \quad 124$

Holosericea.

Horizontalis. Andr.

Hottoniæflora.

Humifusa.

Brunizfolia, S.

Saxatilis. S.

Hirsuta. S.

Urceolaris. S.

Mitræformis $\mathbf{S}$.

Axillaris. S.

Virgularis. S.

Axillaris. $\mathrm{S}$.

$00-55$

8.26

3.3

836

$118 \quad 167$

248

$\begin{array}{ll}32 & 133\end{array}$

$35 \quad 8$

Hunitis.

Hybrida. Hortul.

Culcritefiora, S. 
E. Hybrida. n.

Hyssopifolia.

Hystriciflora.

I.

E. Ignescens. Andr. Imbecilla. Hortul.

Imbellis.

Imbricata. Roxb.

Imbricata Lin. Mant. et Suppl.

Imbricata. Th. Diss. I I. Willd.

Ináperta. Hortul.

Incarnata. 'Th. Diss. 84. Willd.

Incarnata. Andr. 27.

Inelita. Soland.

Inflata. 'I'hunb. Diss. 67 .

Infundibuliformis. Roxb.

Intervailaris.

Cuspidigera. S.

Gracilis. S.

Squamæflora. S.

Pyramidalis. S.

Lasciva. S.

Cerviciflorá. S.

Amæna. S.

Guttæflora. S.

Tubercularis. S.

Amabilis. S.

Pavettæflora. S.

Sal. B. cul.

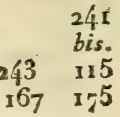

E. Jasminiflora.

J.

E. Labialis.

Lachnea. Hortal.

Lachneæfolia.

Lacunæflora.

Lævis. Hortul.

Lagenæformis.

Lambertia. Andr.

Isamellaris.

Lanata.. Wendl. Willd.

Laniflora. Wendl.

Laricina. Berg.

Lateralis. Willd.

I.atifolia. Andr.

Lasciva.

Lavandulæfolia

Leea. Andr. Willd.

Lentiformis.

Leucanthera, Lin. Willd.

Linifolia.

Linnæi. Hortul. Andr.

L.

Linnæoides.

Lituiflora.

Longiflora.

Longiflora. Kew. Icon. Willd. Longifolia. S.

Longifolia.

Lachneæfolia. S.

Cyathiformis. S.

Verticillaris. S.

Floccosa. S.

Volutæflora. S.

Guttæflora. S.

Lucida. Andr.

Lncida.

Lugubris.

Costæflora. S.

$138 \quad 230$

19962

$238 \quad 9^{5}$

10422

10321

10725

$15 \times 190$

$24 \quad 165$

I $96 \quad 124$

$28 \quad 6$

$236 \quad 184$

$226 \quad 235$

$200 \quad 63$

$225 \quad 194$

-3 14

49 105

$49 \quad 105$

$206 \quad 126$

20366

$224 \quad 19^{3}$

$15 \quad 163$

I 45203

146204

I96 I 24

247

10725

$34 \quad 78$

I55 I53

$89 \quad 19$

Spirexflora. S. $\quad 10927$

Lituiflora. S. $\quad 131$ I08

$131 \quad 198$

131 198

$144 \quad 202$

$154 \quad 212$

$154 \quad 212$

255

$57 \quad 46$

$85 \quad 9^{1}$

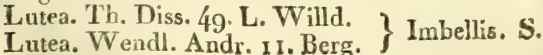

$238 \quad 9^{5}$

Lycopodiifolia.

Lyrigera.

Lysimachiæflora,

148205

$51 \quad 107$

3780 
M.

E. Malleolaris.

Mammosa. Andr. 58. L. M. W. Mammosa. S.

Mammosa. 'Th. Diss. 6y. Willd.? Doliiformis. S.

Manipulifloia.

Margaritacea. Andr. Sol. Willd. Obesa. S.

Marifolia. And. 29. H. K. W. Marifolia. S.

Massoni. And. Curt.Lin. Wilid. Lyeop diitnlia. S.

Mauritanica. Lin. Svst. Nat.

Mediterranea. Lin. Willd.

Melauthera Lin. Mant.

Pelvitnimis.

Lugubris. S.

Lysinachiæflora. $\mathbf{S}$.

Melanthera. Th. Dis. 12. Willd. Cinstreflora. S.

Melastoma, Andr. 43. Follicularis. S.

Melliflua

Milleflora. Berg.

Milleflora. S.

Mitræformis.

Modesta.

Modioliflora.

Monadelpha. Andr. 22. Willd. Furfurósa: S.

Monsoniana. 'T. D. 52. L.W. A. Variffolia. S.

Mucosa Lin. Mant. Willd. And. Mucosa. S.

Multicaulis.

Multiflora. Lin. Willd.

Multiflora. S.

\Multumbellifera, Berg.

Munda.

Muscari Andr.

Mutabilis.

Bullularis. S.

Fragrans. S.

Sal. B. cul.

$181 \quad 136$

$165 \quad 239$

172 187

$87 \quad 18$

I $98 \mathrm{r}$

1640

$148 \quad 205$

$204 \quad 67$

85.91

$37 \quad 80$

3679

$100 \quad 158$

$125 \quad 222$

$110 \quad 24$

$190 \quad 55$

I1 166

3० 142

$99 \quad 157$

120 218

$210 \quad 128$

$176 \quad 134$

$86 \quad 32$

20969

$58 \quad 47$

$229 \quad 182$

177195

N.

E. Nana.

$126 \quad 322$

23 I $\times 83$

Nidiflora.

Nigrita. T. D. 53. L. W. And. Volutæflora. S.

Nigrita Roxb.

Lyrigera. S.

Nivenia. Andr.

5o 106

51107

254

Nodiflora.

Nolæflora.

Nudicaulis. Berg.

Piluliformis. S.

Núdiflora. Smith. L. Mant. W. Sertiflora. S.

Nutans. Weadl.

Pudibunda. S.

20 13

$\mathbf{1 8 3} \mathbf{1 3 8}$

2II. 129

$82 \quad 17$

$90 \quad 20$

o.

¿. Obbata. Andr.

Obesa.

Obliqua. Th. Diss, 73, A. W.? Obliqua. S.

Obpyramidalis.

Obvallaris.

Octophylla. Th. Diss. 72. Willd. Radiiflora. S.

Olympica. Sibthorp.

Onosmæflora.

Spiculifolia. S.

Oxycoccifolia.

$\begin{array}{rr} & 27 r \\ 198 & 6 r \\ 212 & 188 \\ 132 & 145 \\ 242 & 116 \\ 147 & 241 \\ 2 & 2 \\ 156 & 208 \\ 6 & 34\end{array}$

E. Paleacea.

P.

Pallida.

Palliiflora.

Paludosa, 
E. Palustris. Andr.

Paniculata. Lin. Sp. Pl. Ed. 2. Milleflora. S.

Pannosa.

Parilis.

Parviflora.

Passerinæ, Lin. Willd.

Passerinæfolia. S.

Patens. Andr.

Pattersonia. W A. Lin. Willd. Spissifolia. S.

Pavettieflora.

Pectin lia.

Yeduncularis.

Pelncida, Soland.

Pelviformis.

Pendula. Willd.

Pendu'a. Hortul.

Penicilliflora.

Pentaphylla. Linn.

Periplocæflora.

Persoluta.Curt.Th.r.Dis.62.Will. Pelviformis. S.

Persoluta. T. 2 D.62. L. Mant. Prolifera. S.

Perspicua. Wendl. Willd. Lituiflora. S.

Petiolaris.

Petiveriana. Roxb.

Petiveriana. Andr. 25.

Peliverii. Th. B. Diss. 2I.

Petiverii. 'I h. A. D. 21. Willd.

Pellacida. S.

Petiverii. Hortul.

Petiverii vera Hortul.

Ceinuæ atfinis,

Pharetræformis.

Phy,icæfolia.

Physodes. Th. D. 89. A. 44. Wil. Sequax. S.

Pigra. Soland.

Pilulifera. Berg.

Vestiflua. S.

Follicularis. S.

Fusiformis S.

Baculiflo: a. S.

Socciflora. S.

Penirilifflora. S.

Pilulifera. Lin Sp PI. Ed. 2.

Pinea. Andr. 57.

Pinea. Th. Diss. 26 Willd

Pinifolia. Roxb. Hortul. Andr.

Pistillaris. Soland.

Pistillaris.

Pixidiflo:a.

Placentreflora.

Planiflia. Th. D. 6o. Lin. Wil. Thymifolia. S.

Pluknetii. Lin. Willd. Andr. Fusiformis. S.

Pluknetii. Berg.

Plumosa. Andr.

Plumosa.

Prægaans. Soland

Hyssopifolia: $\mathbf{5}$.

Builuaris. S.

Piluliformis. S.

Longifolia. S,

Pinifolia. S.

Longifolia. S.

Diotrefiora. S.

Sal. B. cui.

263

I $10 \quad 74$

65 I 3

$186 \quad 140$

$\begin{array}{rll}182 & -57\end{array}$

$38 \quad 8 \mathbf{r}$

$24^{6}$

$127 \quad 225$

$226 \quad 235$

169177

$23 \quad 164$

$235 \quad 152$

$204 \quad 67$

I 20

125

$101 \quad 159$

$15 \quad 163$

$56 \quad$ I09

$204 \quad 67$

$202 \cdot 65$

$131 \quad 198$

$46 \quad 82$

$95 \quad 214$

$100 \quad 158$

93155

$96 \quad 215$

$98 \quad 156$

I0I 159

I 99206

$15921 \mathrm{E}$

$213 \mathrm{I} 80$

243 II 5

$209 \quad 6_{9}$

2II $\quad 129$

$154 \quad 212$

I52 186

I54 212

$81 \quad 16$

$17-37^{8}$

I82 I37

102. 244

7. 35

93. 155

$97 \quad 216$

Cothurnalis. S.

Princeps. Andr.

Capax. S.

$67 \cdot 53$

$223 \quad 197$

${ }_{2} 64$

Polyerichifolia.

20. 100

Procera.

Prolifera.

19
202 $\quad 65$

Propendens. Andr.

250

Pubescens pilosa. Th. Diss. 6I.

Pubescens. Lin. Willd.

Pubescens. 3 villosa. Th Diss.61.

Pallida. $\mathbf{S}$.

I2. 98

ISS

122 
I. Pubescens, 2 bispida. Th, D, 6I. Mitræformis. S.

Pubescens. Curt. Mag.

Pubescens. Lin. Diss. Berg.

T'ardiflora. S.

Parviflora, S.

Pubescens 4 parviflora.T.D.6r. Exigua. S.

Pubescens parviflora.Lin.Willd. Parviflora. S.

Pubigera.

Pudibunda.

Pugionifolia.

Pulchella.'Th. Diss. 24. Willd. Argutifolia. S.

Pulchella. Andr.5r. Houthuyn, Caduceifera. S.

Puichra.

Pulviniformis.

Purpurascens. Lin. Willd.

Saxatilis.

Puipurascens Lamarek, Encycl. Vaga.S.

Purpurea. Andr. 4. Willd.

Phylicæfolia. S.

Pusilla.

Pyramidalis. C. Sol. Wil. Andr. Obpyramidalis. S $_{*}$

Pyramidalis.

Pyrolæflora.

Q.

E. Quadrangularis. Prodr. 297.

Qnadræflora.

Qualriflora Willd. Andr.

Quinquangularis. Berg.
Quadræflora. S.

Lacunæflora. S. Pyramidalis. S.
I9o, 55

I9I 56

$192 \quad 57$

19358

I92 57

1895

$90 \quad 20$

$245 \quad 172$

$160 \quad 154$

$179-5$

233 I 50

I57 209

$84 \quad 90$

$88 \quad 33$

$1592 \mathrm{IT}$

19\% 59

$132 \times 45$

$1032 \mathrm{r}$

I14 118

$20 I$

201

206

103

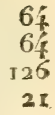

2 I.

R.

E. Racemosa. Th. Diss. 83. Willd. Peduncularis, S.

Radiata. And.

Calamiformis. $\mathrm{S}_{\text {, }}$

Radiiflora.

Ramentacea. L. M. W.Var. And.

Ramosissima. Roxb.

Bullularis. S.

Salax. S.

Regerminans. Lin. Mant. Willd. Uncifolia. S.

Retorta. 'Th. Dis. 9r. An. C. W. Gorteriæfolia. S.

Rosea. Andr.

Rubens, th. Diss. 83. Willd. Peduncularis. S.

Rabens humilis. Wendl. Andr. Guttæflora, S.

Rupestiv. Andr.

Rupestris.

S.

$\begin{array}{rr}23 & 164 \\ 153 & 207 \\ 147 & 245 \\ 209 & 69 \\ 52 & 45 \\ 178 & 121 \\ 221 & 195 \\ & 265 \\ 23 & 164 \\ 196 & 124 \\ & 257 \\ 121 & 219\end{array}$

E. Sacciflora.

$128 \quad 224$

Salax.

Saxatilis.

Scabra. I'hunb. Prod. 72 .

Exilis. S.

Scariosa.

5245

8490

$\begin{array}{ll}72 & 29\end{array}$

$42 \cdot 50$

Sceptriformis,

Scoparia. Th. Diss. So. Lin. Sp. Procera. S.

Scoparia. Lin. Mant.

162240

I9 $4 \mathrm{I}$

Scoparia. S.

Sehana. Kew. Icon. Andr.

Cothurnalis. S:

Sebana. Andr. Wiild. Hortul. Socciflora. S.

I I

$97 \quad 276$

$98 \quad I 56$

6.112

$213 \quad 180$ 
Seriphiiflora.

Sel ratifolia. Andr.

Sertiflora.

Cylindriflora. S.

Sessiliflora. L. W. A. Spic. V. Favosa. S.

Setacea. Andr. 62.

Asperifolia. S.

Sexfaria. Willd.

Sexfaria. S.

Sicæfolia.

Simpliciflora. Willd.

Curviflora. S.

Socciflora.

Solandra. Andr.

Sordida. Andr.

Sparmanni. Th. Diss. 33. L. W. Hystricifora. S.

Floccosa. S.

Speciosa. Andr.

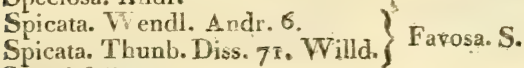

Spiculifoiia.

Spireæflora.

Spissifolia.

Spumosa. Tbunb. Diss. I4.

Spumosa. Roxb.

Sexfaria. $\mathbf{S .}$

Spumosa. Lin. Berg. Willd.

Azaleæiolia. S.

Spuria. Andr.

Scariosa. S.

Squameflora.

Cuicitaflora. S.

Squarrosa.

Stagnalis.

Stricta. Andr. Willd.

Strigilifolia.

Strigosa. Soland. H. K.

Stylosa.

Subdivaricata. Berg.

Subserrata. Roxb.

Multicaulis. S.

Axillaris. S.

Prolifera. S.

Prolifera. S.

Diosmefolia. S.

Sal. B. cul.

33 I0

129226

$82 \quad 17$

I6I 236

44

$43 \quad 7 \mathrm{r}$

$\begin{array}{ll}9 & 37\end{array}$

$137 \quad 229$

(j) 156

259

146204

$167 \quad 175$

269

I6I 236

22

I 0927

$127 \quad 225$

$437 \mathrm{I}$

45 II

$42 \quad 70$

$135 \quad 227$

10422

$220 \quad 189$

142200

$176 \quad 134$

$168 \quad 176$

836

20265

10826

$202 \quad 65$

III $\mathrm{II}_{4}$

T.

E. Tardiflora.

Taxifolia. Wendl. K. I. W. A. Taxifolia. S.

Tegulefolia.

Teneila. Andr.

Tenuifolia. Hortul.

Campanularis. S.

Tenuifolia. Hortul.

Tenuifolia. Lin. Sp. PI. Ed. 2. B.

Tenuifolia. Lin. Hort. Cliff. W. $\}$ Linifolia.S.

Tenuis.

Tetragona. Thunb. Diss. 5. Pugionifolia. S.

Tetralix. Lin. Wilid.

Tetraloba Roxb.

'Thunbergii. Lin. Willd.

Thymifolia. Wend. Wil. Planifolia. Var. E. 'L'hymifolia. A.

Tomentosa.

Totta. Thunb. Diss. 17. Willd. Ferox. S.

Tragulifera.

Transparens. Thunb. Prodr. 71. Strigilifolia. S.

Transparens. Berg.

Botuliformis. S.

Genistæfolia. S.

Modioliflora. S.

19 56

$244 \quad 172$

II 5118

260

29) 27

$239 \quad 9^{6}$

8 r 42

$245 \quad 173$

I75 I79

$55 \quad 84$

3o 143

Thymifolia. S.

735
$13 \quad 38$

$5 \quad 5$

95
123

$168 \quad 176$

Galiitlora. S.

$230 \quad 133$ 
E. Trifora aristata. Wendl.

Triflora. 'Th. Diss. 79. L. Mant. $\}$ Fugax. S.

113 II7

Triflora. Willd.

Pyıolæflora. S.

Tubercularis.

Tubiflora. Thanb. Diss. 31 .

Tubiflora. Lin. Willd.

Tubiflora. Roxb.

Buccinæformis. S.

'T'ubiflora. S.

Turbiniflora.

Stagnalis. S.

Turgida.

Turmalis.

Turrigera.

II 118

286

$140 \quad 232$

136228

142200

$208 \quad 68$

$92 \quad 7^{3}$

$79 \quad 93$

$205 \quad 125$

U.

E. Uhria. Andr.

Umbellata. Lin. Willd. Andr. Lentiformis. S.

Uncifolia.

Urceolaris. Berg. Kew. Icon.W. Lamellaris. S.

Urceolaris.

E. Vaga.

Vagans. Lin. Willd.

Varia. Hortul.

Variifolia.

Velitaris.

Velleriflora.

$\left.\begin{array}{l}\text { Ventricosa. Wendl. Andr. 2. } \\ \text { Ventricosa. Th. Diss. 36. Willd. }\end{array}\right\}$ Venusta. S.

Vaga. S.

Decora, $\mathbf{S}$.

Venusta.

Verecunda.

Verniciflua.

Versicolor. Andr.

Verticiliaris.

Verticillata. Berg.

Verticillata.Andr. 2r. Willd.

Vesicaria. Soland.

Vesicularis.

Vestiflua.

Vestita. Th. Diss. 25. Andr. 20.

Vestita. Curt. Mag. Willd.

Viminalis.

Virgata. Thunb. Diss. I8.

Viridi purpurea. Lin. Diss. $n^{\circ} g$.

Viridi purpurea. Hortul. Fr.

Viridis. Andr.

Viscaria. Roxb.

Viscaria. Th. Diss. 40. L. Mant.

Viscaria. Andr. Kew. Icon. Wil. $\}$ Viscida. S.

Versicolor. S.

Viscida.

Volutæflora,

Vulgaris.

Paludosa.S.

Mammosa. S.

Glomiflora. S.

$\begin{array}{rr}890 \\ 89 & 19 \\ 178 & 121 \\ 15 & 163 \\ 10 & 162\end{array}$

88

$88 \quad 33$

124220

$120 \quad 218$

$134 \quad 174$

$40 \quad 88$

$237 \quad 185$

$237 \quad 185$

215135

$48 \mathrm{ro4}$

$122 \quad 193$

$145 \quad 203$

130201

165239

25 I0ะ

$47 \quad 44$

95214

$154 \quad 212$

$146 \quad 23$

$\begin{array}{rr}3 & 3 \\ 204 & 67\end{array}$

$17^{6} \quad 134$

$154 \quad 212$

63 III

$187 \quad 14 \mathrm{x}$

$187 \quad 14 \pi$

$50 \quad 106$

242

W.

E. Walkeria. Andr,

Pulchra. S.

$233 \times 5 \%$ 
X.

Xeranthemifolia.

$69 \quad 12$

Bruyères qui n'ont que 4 à 5 étamines.

Ces espèces forment une seule réunion dans les affinités;

E. Ciliciiflora

Xeranthemifolia.

Labialis.

Equisetifolia.

Flosculosa.

Exilis.

Paleacea.

Plamosa.

no 9 E. Nodiflora.

I2 Embolifera. blæria.

Dumosa. blæria.

blæria.

14 Dumosa.

I5 Bruniæfolia, 6 étam.

28 Hirsuta.

$\$ 5$

29 Barbigera. 92

blæria. 30 Turmalis.

93

blaria, 53 


\section{PREMIERE DIVISION.}

Corolle d'un à 4 millim. de longueur (une demiligne à une ligne deux tiers ).

P R E M I È RE SE C T I O N.

Antheres nues non saillantes.

\section{Feuilles ternées.}

* i. Bruy yere à balais, E. scoparia, Salisbury , i.

Tige légèrement pubescente. Corolle de $\frac{3}{4}$ de ligne, glabre, à tube en forme de godet. Stigmate ombiliqué.

* E. fucata, Thuns, diss. g. E. scoparia, Lin., Mant. E.co. risfolia Iv, Clus. E. fucata, W WLLD.75, et E. scoparia 48. Excl. Syn. Thuns.

Il est certain que l'E. scoparia et $l^{\prime} E$. fucata ont absoIument les mêmes fleurs, et que leur disposition est entièrement semblable. Leurs feuilles, leurs jeunes tiges jaunâtres et très-peu pubescentes, n'ont aucun caractère différent. Leurs fleurs sont verdâtres, très-petites, ramassées plusieurs ensemble dans les aisselles des feuilles, et presque unilatérales. Le limbe de la corolle est très-ouvert, et ses divisions réfléchies. Filets blancs. Anthères brunes. Stigmate ombiliqué, formant un large plateau circulaire. Calice à folioles droites.

C'est à tort que plusieurs auteurs ont donné à cette bruyère des anthères appendiculées.

Fleurit en mai, juin. Bot. cult., $\mathrm{n}^{\circ}$ 7, éd. $\mathrm{x}^{\mathrm{re}}$.

La variété $E$. fucata a un port très-droit, au lieu que celui de l'E. scoparia est très-diffus, et ses branches se tournent en divers sens. Comme les fleurs sont très-nombreuses, et qu'elles sont unilatérales, elles présentent dans la variété III. 
un coup - d'œil assez singulier pour fixer le spectateur. $N$.

2. Bruyère à feuilles pointues, $E$. spiculifolia, S. 2. E. olympica, Sтвтн.

Pédoncules sans bractées. Calice à 4 divisions courtes. Corolle d'une ligne, à tube en godet, à 4 angles. Fleurs axillaires.

3. BRUY ĖRE effilée, E. virgularis, S. 3.

Feuilles plus ou moins ovales. Corolle de $\frac{2}{3}$ à une ligne, visqueuse. Tube sphérique. Stigmate ombiliqué. Fleurs terminales.

\section{Variétés.}

x. B. absinthoïde, E. absinthoides, Lin., Mant., Willo. 87. Parviflora, Hortul. ?

Petit buisson bien garni de branches et de rameaux courts, jaunâtres et velus. Feuilles courtes, obtuses d'abord, d'une ligne et demie de longueur, et à bords roulés; ensuite parfaitement ovales, et de 2 lignes de longueur, vertes endessus, pâles en-dessous, et bordées de quelques poils glanduleux. Fleurs réunies plusieurs ensemble au sommet des tiges et des rameaux. Corolle de $\frac{3}{4}$ de ligne, globuleuse, blanchâtre, à limbe réfléchi. Anthères brunes. Style très-saillant. Stigmate brun, en plateau circulaire, avec 3 à 4 points élevés. Calice à folioles ovales, canaliculées en-dessus. $\mathbf{N}$.

2. B. à verges, E. virgata, B. Thunb. Diss. I8. Wilid. 87. Syn.

5. B. id. E. virgata, Y. Thuns. Diss. I8.

4. B. hispidule, E. hispidula, Liv。, Suppl., WiLld. 9o。 Non hispidula, Hortul. ?

Tiges couchées, velues, d'un demi-pied de hauteur. Feuilles ovales, pointues, ciliées, presque sessiles, horizontales, ouvertes. Fleurs petites, campanulées, penchées. Style saillant.

5. B. hispide, E. hispida, Thunb. Diss. 20. Willd. 9o. Syn. 
4. B. à feuilles rudes, E. asperifolia, S. 4. E. setacea, ANDR. 62.

Feuilles linéaires. Corolle d'une ligne $\frac{1}{4}$, visqueuse, à tube sphérique. Anthères souvent appendiculées. Capsule laineuse. Fleurs terminales.

Feuilles arquées, ciliées. Fleurs réunies au nombre de trois, sur les branches et les rameaux, où elles forment des espèces d'épis, blanches et petites.

5. B. féroce, E. ferox, S. 5. E. totta. Thunb. Diss. 17. WiLLd. 86 (1).

Calice denté en scie. Corolle d'une ligne $\frac{1}{2}$, glabre, à tube ventru d'abord, et ensuite dilaté. Capsule glabre. Fleurs terminales.

Fleurs blanches, penchées, pédonculées. Folioles calicinales ciliées et blanches. Bractées blanches, ovales, situées à la base du calice. Style non saillant.

6. B. tuberculeuse, E. tubercularis, S. 28. E. inclyta, SoLANDER.

Corolle d'une ligne $\frac{1}{3}$, parsemée de tubercules rudes au toucher, à tube globuleux. Capsule portée sur un long pédicule. Anthères petites, glabres. Fleurs terminales.

7. B. douce, E. blanda, S. 3i. E. cornuta, Roxe.

Fleurs glomérulées. Corolle d'une ligne $\frac{1}{3}$, à limbe plus long d'une demi-ligne que le tube, et à divisions semi-orbiculaires. Stigmate grand. Fleurs terminales. Anthères en crête.

8. B. couchée, E. humifusa, S. 35.

Corolle d'une ligne $\frac{1}{3}$, à limbe grand. Style très-saillanţ.

(I) Je ne cite Willdenow dans ce genre qu'à l'égard des espèces qu'il rapporte à celles de Thunberg et d'Andrews, et dans lesquelles M. Salisbury indique la même synonymie. Cependant il pourroit se faire que, malgré cette identité, les espèces que Willdenow a caractérisées sans y joindre ou en y joignant les dénominations et les phrases de ces deux auteut re fussent pas toutes les mêmes que Salisbury a rapportées aux leurs. 
Fleurs terminales. Cette espèce est entièrement glabre, et ses feuilles sont souvent opposees et ovales.

9. BruY Ère ciliciée, $E$. ciliciiflora, S. 68.

Feuilles très-petites. Calice couvert de poils nombreux et distant des bractées. Corolle d'une ligne $\frac{1}{2}$, velue, à 4 étamines. Fleurs terminales. Anthères à peine didymes, très-barbues.

\section{Feuilles quinées.}

10. B. à feuilles d'armoselle, $\boldsymbol{E}$. seriphiifolia, S.33. E. eubica, Thunb. Diss. 46. Willd. 136.

Folioles calicinales garnies de très - petits cils. Corolle d'une ligne $\frac{1}{2}$, à limbe entier à sa base et obtus. Fleurs axillaires. Feuilles aussi quaternées. Anthères en crête.

Voyez la bruyère cubique, $\mathrm{n}^{\circ} 133$.

\section{SI. Anthères nues saillantes.}

\section{Feuilles ternées.}

3. B. à feuilles d'azalée, E. azaleaffolia, S. 45. E. spumosa, Roxi.

Feuilles lancéolées. Corolle d'une ligne $\frac{1}{2}$, velue. Anthères presque entièrement trouées. Fleurs terminales.

12. B. à feuilles de xéranthème, E. xeranthemifolia, S. 69 .

Feuilles très-courbées en-dedans. Calice laineux, imbricé. Corolle d'une ligne $\frac{1}{3}$, laineuse. Quatre étamines. Fleurs terminales. Cette espèce a l'aspect de plusieurs plantes.

13. B. nodiflore, E. nodiflora, S. 70.

Calice infundibuliforme, très-velu. Corolle d'une ligne $\frac{1}{2}$, velue. Quatre étamines. Anthères à petits trous. Fleurs termizales. Feuilles velues, non laineuses.

4. B. labiée, E. labialis, S. 73. Blceria labiata, Sorand.

Feuilles glabres. Calice à deux levres, plumeux. Corolle d'une ligne $\frac{1}{3}$, à deux lèvres s et à 4 à 5 étamines. Fleurs terminales. 
* Iร. B. à feuilles de prêle, E. equisetifolia, S. 8o. E. articularis, Hortul.

Fleurs au nombre de 5 à 5 réunies en faisceau. Pédoncules langs et glabres. Corolle d'une ligne $\frac{x}{3}$, à 4 à 5 étamines. Fleurs terminales.

Celte espèce ressemble, par son port, à la bruyère foible, $\boldsymbol{E}$. imbellis; mais elle est plus grêle encore.

Port diffus. Rameaux nombreux, longs, minces, se courbant en-divers sens, couverts de feuilles péliolées, linéaires, obtuses, appliquées sur les rameaux, longues d'une ligne. Corolle d'une ligne $\frac{1}{2}$, à limbe peu ouvert. Calice à folioles courtes, serrées contre la corolle. Toute la plante glabre. $\mathrm{N}$.

16. B. en vase, E. diotceflora, S. 8т. E. pistillaris, Soland。

Calice formé en coin élargi. Corolle d'une ligne $\frac{1}{2}$, à tube en forme d'amphore. Anthères peu saillantes. Capsule pubescente. Fleurs dans les jeunes pousses axillaires des rameaux.

* 17 . B. à bouquets, E. sertiflora, S. 82. E. nudiflora, Smiтн. . Liv., Mant., Willd. 7 r.

Calice en coin étroit. Corolle d'une ligne $\frac{1}{3}$, à tube urcéolé. Toutes les anthères saillantes. Capsule glabre. Fleurs axillaires.

Fleurs éparses sur les rameaux, et très-nombreuses. Calice très-petit. Corolle cylindrique de la longueur des feuilles. Style saillant, capillaire. Bot. cult., no $59 . A n$ id. Salisbury.

La bruyère que je crois être celle-ci a la tige glabre, les branches et les rameaux montans et droits. Ses feuilles sont, les. unes ternées, et un grand nombre éparses, légèrement ciliées dans leur jeunesse. Fleurs d'un blanc teint de rose, à tube urcéolé, cylindrique, de 2 lignes de longueur, à limbe presque droit. Anthères brunes, très-saillantes. Style filiforme, à stigmate simple, enfoncé. Calice peiti, à folioles blanches, rouges à leur sommet. Pédicule de 18 millim. (8lig.) rose, capillaire, portant. au tiers environ de sa longueur deux petites bractées.

Cette espèce a ses fleurs axillaires réunies en bouquets le. long de ses rameaux. Elles sont toutes penchées par la longueur et.la ténuité de leurs pédoncules. Elle fleurit en hiver. 
Elle n'a pas, comme le dit Linné, sa tige tomenteuse et flexible; elles est au contraire glabre, ferme et droite.

Sá corolle ayant deux lignes juste, elle devroit être dans la division suivante : elle a des rapports avec la précédente et avec la $164^{\mathrm{e}}$.

C'est , je crois, l'Erica filamentosa, Hortul.

* i8. Bruyère à fleus ramaśsées, E. manipuliflora, S. 87. E. verticillata, FonsK.

Tige blanchâtre. Fleurs ramassées dans les aisselles des feuilles, et formant des groupes interrompus. Cocolle d'une Jigne $\frac{1}{2}$, à tube en godet. Anthères en faisceau droit. Fleurs axillaires. Les anthères sont aussi appendiculées. Rapporis aux numéros 32, 33.

* Ig. B. lentiforme, E. lentiformis, S. 89. E. umbellata, LiN., Andr., Kew., Icon, Willd. 7o. E. corisfolia. 8. CuUs.

Bractées serrées contre le calice. Corolle d'une ligne $\frac{1}{2}$. Anthères trouées contre leur sommet. Tube lentiforme, dont la base a 8 angles. Fleurs terminales au sommet des jeunes rameaux, sans être ombellées.

Tige brune. Branches nombreuses, montantes; rameaux rouges, menus, pubescens. Feuilles ternées, dont le pétiole est blanc, peu ouvertes, presque droites sur les rameaux, légèrement ciliées sur leurs bords dans leur jeunesse, glabres ensuite, vertes, obtuses, d'une ligne $\frac{1}{2}$ de longueur. Fleurs un peu pendantes, au nombre de 6 à 8 ensemble, portées chacune sur un pédoncule rouge. Ces pédoncules partant tous du même point d'insertion, au sommet des rameaux, offrent réellement une petite ombelle terminale. Corolle d'un joli pourpre ou violet léger, renflée à sa base, de 2 lignes $\frac{3}{4}$ de longueur, ì 8 angles, rétrécie vers son limbe, dont les divisions sont droites et pointues. Filamens rouges. Anthères d'un brun noir, trèssaillantes, droites, oblongues. Style carné. Stigmate brun. $\mathrm{Ca}$ lice à folioles étroites, vertes, serrées contre la corolle. Trois à quatre bractées de même forme appliquées contre elles. $\mathbf{N}$.

Fleurit en mai. Bot. cult. , no. 57 , éd. $x^{\text {re. }}$ 20. B. pudibonde, E. pudibunda, S. go. L'. nutans, W ENDL 
Corolle de 2 lignes au plus, visqueuse, à tube ovale. Anthères larges et velues. Capsule turbinée et velue. Fleurs terminales.

Cette espèce n'a été connue de Salisbury que par la figure donnée par Wendland.

21. B. pyramidale, E.pyramidalis, S. ro3. E. imbricata, LIN., Mant. E. quinquangularis, Berg:

Calice imbricé de bractées. Corolle d'une ligne, de la longueur du calice. Anthères longues et étroites. Capsule large. Fleurs terminales.

22. B. à fleurs écailleuses, E. squamceflora, S. 104. E. imbricata, Roхв.

Bractées éparses sur le milieu du pédoncule. Corolle de $\frac{2}{3}$ de ligne, plus courte que le calice. Anthères amincies en pointe. Capsule ovale, élargie. Stigmate étroit. Fleurs terminales.

23. B. bleuâtre, E. ccesia, S. 10.5.

Calice imbricé de bractées. Corolle de $\frac{2}{3}$ de ligne, plus courte que le calice. Anthères obtuses, à large cloison. Capsule ovale. Stigmate large. Fleurs terminales.

* 24. B. fléchie, E. flexuosa, S. 1 06. E. flexuosa, ANDr. 33.

Bractées éparses sur le milieu du pédoncule. Corolle d'une ligne plus longue que le calice. Anthères obtuses, à cloison étroite. Capsule turbinée. Fleurs terminales.

Cette bruyère forme un buisson bas, ouvert, assez étalé, dont les tiges sont grisâtres, tortues, fléchies en divers sens, ainsi que les rameaux. Feuilles ternées, à moitié ouvertes, courtes, d'une ligne $\frac{1}{2}$ de longueur, obtuses, bordées de petites glandes blanches, vertes et glabres. Fleurs horizontales, solitaires, ou au nombre de 2 à 3 , terminant les rameaux. Corolle blanche, ovale, un peu plus longue que le calice, à limbe droit, denté en ses bords, et serrant les filets des étamines, qui sont rouges à leur sommet. Anthères brunes, ser. rant le style qui les dépasse. Style blanc. Stigmate à circonférence, et 4 points d'un beau rouge. Calice blanc, couvrant les deux tiers de la corolle, dont les folioles sont ovales-oblongues. Bractées de la même blancheur que le calice, et de Ia 
même forme que ses folioles, garnissant le pédicule, qui est blanc et un peu cotonneux. Ovaire rouge et à base brune. Fleurit en avril.

Cette espece a des rapports avec la suivante; elle en diffère par sa corolle plus longue que le calice, et par ce dernier non imbricé. $N$.

25. Bruyére lascive, E. lasciva, S. 107. E. imbricata,

Thunz., Diss. I. Willd. 77. Syn.

Calice imbricé de bractées. Corolle de $\frac{2}{3}$ de ligne, un peu plus courte que le calice. Anthères trouées depuis leur base. Siigmate ombiliqué. Fleurs terminales. Feuilles oblongues, dentées en scie.

26. B. à long style, E. stylosa, S. 108. E. bracteata, Rохв.

Pédoncule long, parsemé de bractées jusqu'auprès du caice. Corolle d'une ligne, un peu plus longue que le calice. Anthères acuminées. Capsule ovale. Siyle trés-long. Fleurs terminales.

27. B. à fleurs de spirée, E. spireceflora, S. 109 . E. Teucanthera, Liv. Suppl. Wrutd. 80.

Pédoncules glabres. Corolle d'une à deux lignes $\frac{1}{2}$, à limbe de la longueur du tube et entier. Anthères trouées jusqu'à leur sommet. Corolle et antheres blanches. Fleurs terminales.

Andrews a donné à cette espèce des anthères appendiculées. Elle forme un arbuste d'un à deux pieds dont les rameaux sont filiformes, presque capillaires et flexueux. Ses fleurs petites, blanches et en god̉et, sont terminales et aussi placées en-dessous des sommets, de manière qu'elles forment une grappe terminąle. Les divisions du lirabe son droites.

\section{Feuilles quaternées.}

\section{B. flosculeuse, E. flosculosa, S. 7 1.}

Calice dentelé. Cornlle de $\frac{3}{4}$ de ligne, à tube très-étroit, ouvort et dilaté à son sommet. Quatre étamines à filamens trésérrits. La corclle imite un fleuron des fleurs flosculeuses.

29. B. grêle, E. exilis, S. 72.E.scabra, Thunb., Prodr. 72.

Cálice infundibuliforme, slabre. Corolle de $\frac{3}{4}$ de higne, glar 
bre, à 4 étamines. Fleurs terminales ou axillaires. Deux bractée sur le pédoncule, qui est très-court.

3o. B. à paillettes, E. paleacea, S. 77. E. articulata, Tnunb.,

Prodr.7 . Rloeria articulata, Lin. Mant. Wilud.

Bractées solitaires. Calice infundibuliforme, entièrement velu. Corolle d'une ligne $\frac{1}{2}$. 4 à 5 étamines à filamens nus. Fleurs terminales.

Les feuilles de cette bruyère sont serrées contre les rameaux, ce qui fait paroître ces derniers articulés. Leurs verticilles sont tantòt distincts, tantôt rapprochés. Les feuilles sont tantôt longues, tantôt courtes. Fleurs cylindriques, carnées, en têtes terminales. Anthères étroites et noires.

5ı. B. flexible, E.flexibilis, S. 33. E. racemosa, Thunв. g Diss. 47. Willd. 137.

Pédoncules visqueux, axillaires. Corolle d'une ligne $\frac{x}{2}, \mathfrak{a}$ tube ovale. Capsule laineuse. Rameaux verticillés, droits, pubescens. Feuilles d'une ligne de longueur. Fleurs carnées, un peu penchées', en grappes axillaires. Folioles calicinales trèscourtes. Anthères brunes. Style saillant.

\section{Feuilles $5^{\text {ées }}$ et 6 és:}

* 32. B. multiflore, E. multiflora, S. 86 Lin., Wilın. I32.

Feuilles linéaires. Corolle d'une ligne $\frac{1}{2}$, à tube en godet. Anthère tronées jusqu'à leur sommet. Fleurs axillaires.

Cette bruyère forme un buisson bas, étendu, très-garni de tiges et de rameaux. Fleurs d'un pourpre pâle, très-nombreuses, disposées en grappes et en gros épis, entourant les jeunes raracaux. Anthères brunes. Style saillant. Divisions du calice ciliées. N. Bot. cult., $\mathrm{n}^{\circ} 63$, édit. $\mathbf{r}$.

33. B. pourprée, E. vaga, S. 88. E. vagans, Liv., Mant.

E. purpurascens, Willd. 134. Lam. Encycl.

Tige glabre. Fleurs axillaires, très-rapprochées. Corolle d'une Yigne $\frac{1}{3}$, à tube en godet. Anthères rassemblées en bouquet et droites, non didymes.

Cette bruyere est ordinairensent conchéc. Ses feuilles sont 
petites, linéaires, glabres. Ses fleurs purpurines, latérales, peu nombreuses. Corolle ovale. Bot. cult., $\mathrm{n}^{\circ} 60$, édit. I.

Ces deux espèces ont des rapports aux nos $9^{\circ}, 9^{\text {r }}$.

\section{S E C T IO N II.}

\section{Anthères appendiculées non saillantes.}

\section{Feuilles ternées.}

34. Bruyère à feuilles de canneberge, E.oxycoccifolia, S. 6.

Tige couchée, filiforme. Feuilles ovales. Corolle d'une ligne $\frac{1}{2}$, campanulée et velue. Filamens nus ou appendiculés. Fleurs axillaires. Les feuilles de cette jolie bruyère imttent celles de la canneberge.

* 35. B. à feuilles de thym, E. thymifolia, S. 7. E.planifolia, Lin., Thunb. Diss. 6 o.

Tige diffuse. Feuilles ovales. Corolle d'une ligne à une ligne $\frac{1}{2}$. Filamens très - dilatés à leur base. Capsule velue. Fleurs axillaires.

\section{Variétés.}

I. B. à corolle d'une ligne, visqueuse, pubescente, et anthères non saillantes. $E$. thymifolia, $\Lambda_{\mathrm{N} b \mathrm{r}}$.

Cette variété forme un petit arbuste en buisson, dont les feuilles sont ovales, en cœur, ciliées, glauques en-dessous. Les fleurs sont petites, d'un rouge rose, en godet, axillaires, solitaires, pédonculées. J'ai perdu cette espèce.

2. B. à corolle d'une ligne $\frac{1}{3}$, peu visqueuse et peu pubescente. Anthères saillantes. E. planifolia, WrLLd. I5.

3. B. à corolle d'une ligne $\frac{3}{2}$, glabre, et anthères saillantes. E. thymifolia, Wendi., Willd. i5. Var.

Les bords des feuilles de ces variétés sont tout roulés en-dessous. Les feuilles sont quelquefois quaternées. Les rameaux sonct velus. N.

* 36. B. axillaire, E. axillaris, S. 8. E. strigosa, Sou And., H. K. E. arborea, Thunb., Diss. 63. E. hispida, ANDra 
Feuilles parsemées de poils. Deux bractées. Corolle d'une ligne $\frac{1}{2}$. Les appendices en alêne et velus. Fleurs blanches ou pourpres, suivant la variété, axillaires.

Tige assez droite, branchue, très-rameuse; les rameaux rougeâtres, couverts de poils blancs, glanduleux. Feuilles ternées et quaternées, à verticilles distans, longues de 2 lignes; les unes ovales, les autres linẻaires, obtuses, garnies des mêmes poils glanduleux qui rendent la plante hispide à l'aspect, et rude au toucher. Fleurs disposées en grappes vers le sommet des tiges. Corolle d'un pourpre rose, presque globuleuse, terne sous son limbe, qui est d'un rouge plus foncé et à divisions dioites. Anthères brunes. Style blanc. Calice à folioles velues, vertes à leur base, brunâtres à leur sommet. E. hispidula, Hortul., Bot. cult., $n^{\circ} 40$, édit. $\mathrm{r}^{\mathrm{re}}$.

* Variété à corolle blanche.

Cette variété a les feuilles plus larges, presque toutes ovales; elle est de même chargée de poils glanduleux; les grappes de ses fleurs sont moins formées, et beaucoup plus courtes. $E$. $a b$ sinthoides, Hortul.

Obs. Les anthères de ces variétés ont des appendices trèscourts, et souvent n'en ont pas. J'en ai vu dans la première, el pas encore dans la seconde.

37. B. à feuilles aiguës, $E$. siccefolia, S. 9 .

Feuilles mucronées. Corolle d'une ligne $\frac{2}{3}$, velue en dehors, à tube en godet. Appendices linéaires, très-amincis, en pointe. Capsule glabre. Fleurs terminales.

38. B. tomenteuse, E. tomentosa, S. I3.

Feuilles linéaires, très-étroites. Calice presque plane. Corolle d'une ligne $\frac{1}{2}$, velue en dedans et en dehors. Appendices longs et recourbés. Bractées situées à la base du pédoncule, de la. même couleur que le calice et la corolle. Fleurs terminales. 5. B. en forme de coupe, E. cyathiflora, S. I8. E. bicolor, Thunb. Diss. 17. Willd. I7.

Calice tomenteux. Corolle d'une ligne, glabre. Appenảices. en coin et velus. Capsule colonneuse. Style trés-saillant. Fleurs terminales. 
Feuilles obtuses, vertes, un peu velues, avec un sillon longitudinal, d'une ligne et demie de longueur. Fleurs d'une ligne et un quart de longueur, pédonculées, au nombre d'une à 3 , terminant les rameaux. Corolle ovale, blanche sur sa moitié inférieure, rouge sur la supérieure. Anthères noires, Appendices blancs, à l'entrée de la corolle. Calice d'un vert rougeầtre. 2 bractées opposées, à peu de distance de sa base.

* 4o. Bruyère à feuilles de marum, E. marifolia, S. 17. H. K. , Willd. If́.

Feuilles ovales, larges, presque planes. Corolle d'une ligne $\frac{1}{2}$, pubescente sur les deux surfaces, à tube ovale. Appendices pubescens.

Les feuilles de cette espèce sont un peu épaisses et concaves endessus, d'un vert grisâtre en-dessus, blanchâtres en-dessous. Fleurs en ombelles terminales. N. Bot. cult., no 8 .

Fleurs disposées en têtes ombelliferes, terminales. Corolle de 2 lignes de longueur, blanche, pubescente, à limbe presque droit. Anthères d'un jaune rougeâtre. Appendices blancs. Style violet. Stigmate brun foncé. Calice à folioles velues, concaves et à bords roulés, imbricées de 3 ou 4 autres de même forme.

Fleurit en juin.

* 4I. B. élevée, E. procera, S. i9. E. arborea, Lin. Sp. PI., éd. 2. Willd 25. Miller, Dict. Thunb. Diss. 80. $E$. scoparia.

L'espèce Erica castra, Lix. et Hortul., et E. stylosa, RudouPHI, se rapproche en effet de celle-ci. Mais je la trouve cependant assez différente pour en constituer une espèce distincte. Voyez le $n^{0}$ : 65.

Tige tomenteuse. Bractées rapprochées. Calice en forme de barillet à sa base. Corolle d'une à deux lignes. Stigmate ombiliené. Fleurs terminales. Cette brayère varie par soa style saillant ou non saillant.

Feuilles ternées et quaternées. Arbrisseau de 6 à 7 pieds, dont les branches sont droites et bien garnies de rameaux. Corolle \$lanche, penchée, à limbe droit. Anthères brunes. Style blanc. Appendices courts et cilirs. Stigmate pelté , d'un gris brun: 
Pédoncule et calice blancs. Ce dernier a ses folioles ciliées. it. Bot. cult., no. I I, éd. I.

Fleurit en avril.

Cette espèce a de grands rapports, pour l'aspect, le port et la floraison, avec la $100^{\ominus}, E$. polytrichifolia, qui devroit être placée ici.

* 42. B. menue, E. tenuis, S. 2 I. E. divaricata, Hortul.

Iige divergente. Feuilles linéaires. Corolle de $\frac{3}{4}$ de ligne, campanulée, glabre. Filamens très-courts. Appendices linéaires, amincis. Fleurs terminales.

Petit buisson garni de beaucoup de branches et de rameaux roides, grêles, divergens et rouges. Feuilles petites, étroites, peu ouvertes, presque droites, obtuses, vertes et glabres. Fleurs nombreuses, penchées, en petites grappes unilatérales, presque terminales. Corolle blanche, de $\frac{3}{4}$ de ligne au plus, campanulée, à limbe droit. Filamens très - courts. Anthères blanches. Appendices blancs, aussi longs qu'elles. Stigmate brun. Folioles calicinales verdâtres. Pédoncule rouge, portant dans son milieu deux bractées opposées.

Fleurit en mai. N.

* 43. B. élégante, E. formosa, S. 26. Thunb. Diss. 82. WiLld. 50.

Calice courbé en-dedans. Corolle d'une ligne $\frac{1}{2}$, visqueuse, à tube sphérique, à 8 angles Anthères fortement arquées à leur base. Stigmate large. Fleurs terminales. Feuilles très - petites et ouvertes. Fleurs blanches, ordinairement au nombre de 2 ou 3 au sommet des jeunes rameaux, et penchées. Anthères pourpres. Style non saillant.

44. B. vésiculaire, $E$. vesicularis, S. 47. E. ronacea, Hortul.

Feuilles parsemées de vésicules noires. Corolle d'une ligne, visqueuse, pubescente. Appendices paralleles et en coin. Capsule soyeuse.

Arbuste de 3 pieds; les rameaux droits, réunis en faisceaux.

45. B. très-rameuse, E. salax, S. 52. E. ramosissima, Rox:. 
Feuilles luisantes. Calice serré. Corolle d'une ligne. Filamens très-courts. Stigmate large. Capsule glabre. Fleurs terminales.

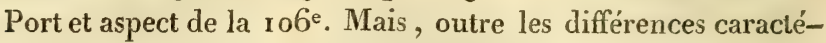
ristiques, les divisions de la corolle sont dans celle-ci distinctes à leur base.

46. Bruxìre luisante, E. lucida, S. 57.

Calice luisant et cilié Corolle d'une ligne. Appendices oreillés, incisés, dentés en scie. Stigmate étroit et non saillant. Fleurs terminales.

47. B. nette, E. munda, S. 58.

Bractées et calice très - entiers. Corolle d'une ligne. Appendices oreillés et ciliés. Capsule velue. Fleurs terminales.

48. B. à fleurs de gnaphale, E. gnaphaliijlora, S. 59. E. gnaphalodes, Thunb. Diss. 75. Willd. 44. Lin. Diss. Berg.

Calice ouvert, sensiblement glanduleux sur ses bords. Corolle d'une ligne, à peine plus longue que le calice. Capsule glabre et lisse. Stigmate grand, à 4 divisions. Style non saillant. Fleurs terminales.

49. B. droite, E. fabrilis, S. 60.

Feuilles serrées, imbricées. Corolle d'une ligne, à peine plus longue que le calice. Appendices très-entiers. Anthères trèspetites, presque didymes. Fleurs terminales.

Cette bruyère est si droite, qu'elle semble placée avec la main.

5o. B. blanche, E. palliiflora, S. Ix2. E. candida, Sorand.

Tige anguleuse. Feuilles lancéolées, en coin. Corolle d'une ligne $\frac{1}{3}$, un peu plus longue que le calice. Appendices oreillés et glabres. Fleurs terminales.

5r. B. caducéenne, E. caduceifera. S. 179. E. pulchella, Andr. 5r. E. aricularis, Thunb. Diss. 58. E. pulchella, Houtruye, an Willd. i8?

Feuilles en coin ou ovales. Corolle de $\frac{2}{3}$ de ligne. Filamens appendiculés au milieu de leur longueur. Fleurs axillaires.

L'insertion des appendices au milieu des filamens, donne i ces derniers la ressemblance du caducée de Mercure.

Tige et rameaux contournés en zig-zag. Fleurs en épis lûches, 
presque verticillés en-dessous des sommets, petites, globuleuses, d'un rouge carné. Le limbe droit.

* 52. B. à feuilles de coris, E. corifolia, S. 241. E. corifolia, Thunв. Diss. 77. E. calycina, And. 17. E. articularis, Curt. Mag. Liv. Mant. E. corifolia, Willd. 45.

Calice ouvert et réfléchi. Corolle d'une ligne $\frac{1}{2}$, presque égale au calice, à tube en godet et à divisions aiguës. Fleurs axillaires. Arbrisseau bien garni de branches droites. Feuilles glabres. Fleurs et calice pourprés.

Depuis 6 ans j'ai cette espèce, et elle n'a pas encore fleuri.

\section{Feuilles quaternées.}

* 53. B. plumeuse, E. plumosa, S. 67. Thunb., Prodr. 73. Blaria ciliaris, Lin., Willd.

Feuilles très-petites. Calice très-velu. Corolle d'une ligne $\frac{1}{3}$, velue, a 4 à 5 étamines. Fleurs terminales.

Je ne sais si l'E. plumosa d'Andrews doit se rapporter à celle-ci. Selon lui, sa tige est flexueuse, ses branches et ses ramenax glabres. Ses feuilles sont quaternées, velues et ouvertes. Ses fleurs sont verticillées et pendantes, presque solitaires. La corolle est en godet, glabre et pourpre. Les divisions du limbe sont droites, et les anthères sont de cette section.

54. B. pubescente, E. pubigera, S. 189.

Calice ouvert, ovale acuminé. Corolle d'une ligne $\frac{1}{2}$, prrbescente, à long limbe recourbé. Capsule velue. Fleurs terminales.

Cette espèce se distingue facilement par son limbe long, recourbé et presque obtus.

* 55. B. en forme de mitre, E. mitraeformis, S. xgo. E. pubescens, Andr. 6o. E. pubescens hispida, Thunb. Diss. 6r. E. hirliflora, Cur't. , Mag. E. pubescens, Willd. 20.

Feuilles peu roulees en-dessous, denteiées. Corolle d'une ligne $\frac{T}{2}$, pubescente, à limbe droit. Capsule glabre. Fleurs terminales.

Toutes les parties de cette bruyère, excepté la capsule, sont pubescentes. Tiges et rameaux assez droits. Ces derniers rou- 
geâtres dans leur jeunesse. Feuilles longues de 3 lignes, planes en-dessus, à bord peu roulés, d'un vert grisâtre, à cause de leurs poils abondans. Fleurs au nombre de 2, 3 et 4 ensemble, terminales et axillaires. Corolle d'un joli pourpre léger, globuleuse, longue d'une ligne $\frac{1}{2}$, velue, à divisions droites. Anthères brunes. Appendice assez long, blanc et cilié. Style et stigmate bruns et luisans. Folioles calicinales étroites, pointues et velues. $\mathrm{N}$.

Fleurit en novembre et tout l'hiver.

* 56. Bruy Ère tardiflore, E. tardiflora, S. Igr.E. pubescens,

Curt., Mag. An E. eriocephala, Andr.

Calice serré , étroit, ovale, en coin. Corolle d'une ligne $\frac{1}{3}$, pubescente, à limbe très-court et recourbé. Capsule velue.

Cette espèce a plusieurs rapports avec la précédente. Toutes ses parties sont couvertes de poils blancs, ce qui la rend d'un aspect grisâtre. Feuilles quaternées et quelques-unes ternées, à bords très-roulés. Fleurs d'une ligne $\frac{1}{3}$ ou $\frac{1}{2}$, ovales, globuleuses, purpurines, velues. Les divisions du limbe courtes et réfléchies. Anthères brunes. Appendices blancs; quelques-uns sont un peu oreillés. Stigmate brun. Calice à folioles ovales, velues, rouges à leur base, vertes à leur sommet.

Fleurit en octobre et tout l'hiver.

57. B. parviflore, E. parviflora, S. 192. E. pubescens, Liv. Diss. Berg. E. pubescens parviflora, Lin. Sp. Pl., Wild. 20.

Var.

Calice serré, rhomboïdal, en coin. Corolle d'une ligne ${ }_{2}^{\prime}$, pubescente. Appendices oreillés. Capsule glabre. Feuilles fortement roulées en-dessous. Fleurs terminales.

Les feuilles sont quaternées sur toute la plante. 58. B. exiguë, E. exigua, S. 193. E. pubescens. 4. Parviflora, Thunв. Diss. 6r.

Calice serré, ovale, acuminé. Corolle d'une ligne, pubescente, à tube ovale et à limbe très - court. Capsule glabre. Appendices linéaires, amincis. Fleurs terminales. Feuilles aussi ternées, plus souvent quaternées.

59. B. petite, E. pusilla, S. 194 .

Calice serré, ovale, en coin. Corolle d'une demi-ligne au 
plus, pubescente, à tube en godet, à limbe de la longueur du tube. Capsule glabre. Fleurs terminales.

Cette espèce se distingue des autres de cette famille, nonseulement par la petitesse de son port, mais par celle de toutes les parties de sa fleur.

6o. B. à style courbé, $E$. curvirostris, S. 197. E. declinata, Hortul.

Feuilles linéaires. Calice serré. Corolle $d^{\prime}$ une ligne $\frac{1}{2}$, à tube sphérique. Appendices pubescens. Style courbé vers le haut.

Espèce basse, dont les fleurs répandent une odeur nauséabonde.

Fleurs Hlanches. Anthères brunes. Stigmate brun. Folioles calicinales concaves, vertes, brunes et obtuses.

Fleurit au printemps.

Cette espèce a beaucoup de rapport avec la $124^{\mathrm{e}}$, qui auroit pu se trouver dans cette division et dans cette famille, si les corolles de ses variétés n'étoient pas plus grandes.

* 6r. B. rondelette, E. obesa, S. ig8. B. perlée, E. marga rilacea, Andr. 54. Soland., H. K., Willd. 58.

Pédoncules glabres. Calice ouvert, courbé en dedans. Corolle d'une ligne $\frac{2}{3}$, à tube sphérique. Appendices oreillés et glabres. Fleurs terminales.

Plante trés-glabre. Tige et rameaux droits. Feuilles de 2 lignes. Corolle blanche, à divisions du limbe arrondies. Anthères brunes. Appendices blancs. Style blanc, saillant. Stigmate brun. Folioles calicinales élargies et blanches à leur base, vertes ensuite jusqu'à leur pointe. N. Bot. cult., n. 34., éd. I . *62. B. naince, E. gracilis, S. 199. E. imbecilla, Hortul.

Calice très-petit. Corolle d'une ligne $\frac{1}{3}$, à tube ovale, à limbe recourbé. Appendices linéaires, amincis et velus. Fleurs terminales.

Cette bruyère n'est ní foible ní mểme grểle. La plạpart de ses branches et de ses rameaux ont de la consistance, et se tiennent d'eux-mêmes assez droits, sur-tout sur les jeunes pousses qui s'élevent perpendiculairement. Ils sont ouverts et jaunâtres daus III. 
leur jeunesse. Fleurs carnées. Anthères brunes. Appendices courts et d'un brun clair. Stigmate rouge. Style non saillant. N. Fleurit en avril.

63 BrUy Ėre intervallaire, E. intervallaris, S. 200. Elongata, Roхв.

Tige menue. Feuilles à verticilles distans. Corolle d'une à deux lignes, à tube ovale, cylindrique, très-ouverte en son limbe. Capsule velue. Fleurs terminales.

Cetie espèce, très-jolie, a presque tous ses jeunes rameaux couverts de petites fleurs rouges, oblongues et penchées.

*64. B. carrée, E. quadraflora, S. 201. E. quadrangularis,

Prodr. 297. E. regerminans, Hortul.

Tige glabre. Corolle d'une ligne $\frac{1}{4}$, à tube en forme de tasse, à limbe droit. Appenciices lancéolés, en coin, très-entiers. Fleurs terminales.

Rameaux pubescens. Feuilles rapprochées, d'une ligne $\frac{1}{4}$, Tinéaires, obtuses, garnies de quelques cils blancs, d'un beau vert léger. Fleurs au nombre de sepi à neuf, rassemblées, te:minant chaque rameau. Corolle blanche, d'une ligne de longueur, très-évasée, en tasse. Anthères brunes. Appendices blancs, simples. Stignate brun. Folioles calicinales velues à leur base. N. An id. Salisbury.

Fleurit en octobre.

*65. B. prolifere, E. prolifera, S. 202. E. strigosa, Willd. 23. Exclus. Syn. et Descrip. E. caffra, And. 5o. E. perso-

luta 2.Thunb. Diss.62. Lin., Mant. E. subdivaricala, Berg.

Tige velue. Corolle d'une ligne $\frac{1}{4}$ à une ligne $\frac{1}{2}$, à tube en godet ; interstices du limbe aigus. Appendices droits. Capsule velue. Fleurs terminales.

Branches nombreuses, ainsi que les rameaux ; les uns droits, les autres recourbés; ces derniers blancs et un peu velus dans leur jeunesse. Feuilles quaternées et quelques-unes ternées, de 2 lignes, garnies de quelques poils. Corolle blanche penchée. Anthères brunes. Appendices blancs. Stigmate brun. Folioles calicinales vertes, 'bordées de cils courts et blancs. N."

Fleurit en octobre. La floraison acherée, Ies jeunes pouses sélèvent du centre des fleurs. 
466. B. en godet, E. cyathiformis, S. 203. E. lavis, Hortul. Pédoncules glabres. Corolle d'une ligne $\frac{1}{2}$, à tube en tasse; interstices du limbe aigus. Appendices courbés en faux. Fleurs terminales.

Cette espèce a beaucoup de rapport avec la suivante.

Tiges brunes. Rameaux bruns. Feuilles d'une ligne $\frac{1}{2}$, pointues et vertes. Fleurs au nombre de quatre ensemble, terminant les rameaux. Corolle blanche, à limbe évasé ; ses divisions droites. Anthères brunes. Appendices blancs. Stigmate brun. Folioles calicinales pointues, blanchâtres, vertes à leur sommet. Toute la plante glabre. $\mathbf{N}$.

Fleurit en avril et mai.

*67. B. bassinette, E. pelviformis, S. 204. E. persoluta, Curt., Mag. I... Thunb. Diss. 62... Willd. 21. E. viridipurpurea, Liv.

Pédoncule légèrement pubescent. Corolle d'une ligne $\frac{1}{2}$, à tube en forme de bassin ; les interstices du limbe ovales a leur base. Appendices sillonnés. Fleurs terminales.

Jolie bruyère, dont les jeunes rameaux nombreux sont rougeâtres et pubescens. Feuilles ternées, glabres. Fleurs d'un rose pâle, nombreuses, à limbe très-évasé. Anthères brunes. Appendices courts et blanes. Stigmate brun, à 4 points et luisant. Folioles calicinales courtes, de la même couleur que la corolle, légèrement ciliées sur leurs bords. $\mathrm{N}$.

Fleurit en avril et mai. Bot, cult., n० 12 , éd. I.

Variété à fleurs blanches. Cette variété que j'ai obtenue des graines de la précédente espèce, $\mathrm{n}^{\circ} 66$, prouve que cette dernière ne differe de celle-ci que par la couleur de ses fleurs. Les corolles ont la même forme.

68. B. turbinée, E. turbiniflora, S. 208.

Tige glabre, Corolle d'une ligne $\frac{1}{2}$, lisse, à tube turbiné, ă 8 angles, à limbe courbé en-dedans. Appendices oreillés et glabres. Fleurs terminales d'un pourpre pâle.

* 69. B. à bulles, E. bullularis, S. 209. E. 'granulata, Liv., Mant. E. ramentacea, Liv., Mant. ANDr. E. multumbellifera, Berg. E. pilulifera, Berg.

Tige légèrement visqueuse. Corolle d'une ligne $\frac{1}{3}, 2$ tube 
sphérique, à 4 angles très-distincts, et à limbe recourbé. Capstile velue. Fleurs terminales.

Rameaux nombreux et droits. Feuilles garnies d'abord de quelques poils blancs, glabres ensuite, et vertes. Fleurs au nombre de sept à quinze, en têtes terminales, quelques-tnes éparses. Corolle d'un rouge obscur, globuleuse, imitant une petite pilule, d'une ligne de diamètre. Anthères brunes. Appendices ciliés. Style brun. Folioles calicinales, très-étroites, pointues, rouges, ainsi que les pédoncules, qui sont capillaires. A l'ouverture de la corolle, les anthères réunies forment une étoile dont les appendices font les rayons. N.

Variété à fleurs blanches.

Obs. Linné donne à peine des appendices à son $E$. granuZata. Son $E$. ramentacea ne differe pas de celle-ci.

\section{\$. Anthères appendiculèes saillantes.}

\section{Feuilles ternées.}

* jo. Bruy Ėre scarieuse, E. scariosa, S. 42. E. spumasa, Berg., Lin., Willd. 82. Antheris muticis.

Bractées presque orbiculaires. Corolle d'une ligne $\frac{1}{2}$, à limbe de la longueur du tube, et ses divisions lancéolées. Stigmate étroit. Fleurs terminales.

* gr. B. hexagone, E. sexfaria, S. 43. E. spumosa, Thunb. Diss. I4. E. sexfaria, Kew., Icon. An E. sexfaria, Willd. 78. Antheris muticis.

Feuilles glabres. Corolle d'une ligne $\frac{1}{3}$, presque couverte par le calice. Appendices longs et capsule glabre. Corolle ovale, glabre, blanche, membraneuse.

Cette espèce se distingue aisément par la disposition de ses feuilles sur six rangs. Elles sont roides, pointues, très-glabres et d'un vert foncé. Je l'ai perdue sans avoir vu ses fleurs. Il y a incertitude sur la saillie des anthères, parce qu'elles tombent peu de temps après que la corolle est ouverte. $\mathrm{N}$. 
72. B. filiforme, $E$. filiformis, S. $9^{\text {r. }}$.

Bractées contre le calice. Corolle d'une ligne, glabre, à limbe recourbé. Anthères à longs trous. Stigmate étroit. Fleurs terminales.

Tige menue, diffuse. Verticilles des feuilles distans. Feuilles étroites, visqueuses, pubescentes, à bords roulés en-dessous. Filamens élargis à leur sommet. Capsule lisse. S.

73. B. enflée, E. turgida, S. 92. E. fusco rubens, Roxз.

Pédoncules très-courts. Corolle d'une ligne et demie, velue, à tube en godet. Appendices en coin. Anthieres très-courtes. Fleurs terminales.

* 74. B. à mille fleurs, E. milleflora, S. r 1 o, Berg. 96. E.paniculata, Liv., Sp. Pl., éd. 2.

Tige cotonneuse. Corolle de $\frac{3}{4}$ de ligne, à divisions imbricées à leur base. Appendices linéaires, glabres. Style trèssaillant. Corolle en godet. Fleurs terminales. Rapport au no $2 \mathbf{I}$ et suivans. Cette espéce, qui a aussi des rapports à la $66^{\circ}$, s'en distingue par son style très-alongé et très-saillant.

\section{Feuilles quaternées.}

* 55. B. buissonnée, E. dumosa, S. 75. E. bleria, Trunz., Prodf. 72. Blceria ericoides, Lin., WiLid.

Feuilles dentelées, glabres en-dessous. Corolle d'une ligne $\frac{1}{2}$, à $\{$ à 5 étamines. Appendices très-droits. Fleurs terminales.

Cetle espèce est velue sur presque toutes ses parties, et d'un vect grisâtre. Ses fleurs sont d'un blanc teint de pourpre, réur nies au nombre de douze à seize en têtes serrées, penchées et terminales. Corolle cylindrique, à divisions droites. Stigmato rouge. Cette espèce est couverte de fleurs, et son buisson est assez régulier. N... Bot. cult., no 72 , éd. $x$.

Fleurit en été.

\section{Feuilles quinées.}

76. B. à feuilles de brunie, E. bruniaefolia, S. 78. E. hemisphe rica, Soland.

Feuilles longues. Bractées contre le calice, dont l'extériesure sut très-longue. Corolle d'une ligne $\frac{1}{2} ; 6$ étamines. 


\section{DEUXIEME DIVISION.}

Corolle de 4 à 6 millim. de longueur ( une ligne 2 tiers à 3 lignes ).

PRETI È E S E T I O N.

Anthères nues non saillantes.

Feuilles ternées.

* 77. BruYère campanulée, E. campanulatis, S. 29. E. tenuifolia, Hortul.

Tige glabre. Feuilles très a étroites. Corolle de 2 lignes $\frac{1}{2}$, campanulée, glabre. Filamens très-courts. Fleurs jaunes, de la forme de celles du muguet, terminales.

Tiges et branches nombreuses, droites, cylindriques, brunes, menues, sans être trop foibles; les rameaux presque capillaires. Feuilles ternées, assez distantes, très-étroites, longues de deux lignes, ouvertes, très-glabres et vertes. Fleurs solitaires, ou au nombre de deux ou trois, terminant les rameaux. Corolle d'un jaune doré, penchée, campanulée, 'tongue de 2 lignes $\frac{\mathrm{r}}{2}$, à limbe presque droit, évasé. Anthères brunes, à filamens planes, verts, et si courts, que les anthères reposent sur l'ovaire. Style blanchâtre. Stigmate brun. Calice à folioles ovales, pointues à leur sommet, de la même couleur que la corolle. Pédicule jounâtre, garni à sa base de deux bractées opposées et même jaunâtres.

Fleurit en avril-mai. $\mathbf{N}$. 78. B. à feuilles de lavande, E. lavandulaefolia, S. 34.

Tige blanchâtre. Bractées près du calice. Corolle de 2 lignes, à tube à 4 angles, et son limbe recourbé. Filamens très-larges a leur base. Fleurs terminales.

29. B. crêtée, E. cristceflora, S. 36. E. melanthera, Thunb.

Diss. 12. Willd. 79. 
Calice à 4 folioles. Corolle de 2 lignes, à limbe trois fois plus long que le tube, entier à sa base. Capsule glabre. Fleurs terminales.

Feuilles linéaires, obtuses, glabres. Fleurs"éparses, un peu penchées. Corolle d'un rouge sanguin, campanulée; division du limbe ovale. Anthères noires. Calice de la même couleur que la corolle, plus large que long, mucroné à son sommet: Pédoncules de la longueur de la corolle. Bractées colorées.

8o. B. à fleurs de lysimachie, E. lysimachiaflora, S. $37 . E$. melanthera, Liv., Mant. An id. Wilud. 19.

Calice quadrifide. Corolle de 2 lignes, 2 limbe deux fois plus long que le tube, entier à sa base. Capsule soyeuse. Style trèssaillant. Fleurs terminales.

8 r. B. à feuilles de passerine, E. passerinafolia, S. 38. E. pas. serina, Lir., Suppl... Wirld. 85.

Bractées très-petites. Calice à 4 divisions courtes, couvertes d'un coton dense. Corolle de 2 lignes $\frac{1}{2}$. Capsule cotonneuse. Fleurs terminales.

Fleurs solitaires, terminales, pédonculées. Pédoncules blancs, cotonneux. Corolle campanulée, deux fois plus grande que le calice. Filamens extrêmement courts. Style saillant. Stigmate un peu en tête. Lxw.

82. B. pétiolée, E. petiolaris, S. 46. E. petiolata, Thunв. Diss. 7 ... WrLLd. 72.

Pétioles longs, uniformes, dentelés. Corolle de 2 lignes $\frac{1}{2}$, pubescente à son sommet. Capsule rarement velue. Fleurs terminales. Cette bruyère a l'aspect du romarin.

Tige couchée. Fleurs en ombelles.

83. B. à fleurs rassemblées, $E$. cumuliflora, S. 54. E. aggregata, Rохв.

Sept à douze fleurs rassemblées en faisceau. Calice blanchâtre. Corolle de deux lignes $\frac{1}{2}$, à limbe inférieurement cilié. Stigmate étroit. Capsule velue. Fleurs terminales.

84. B. à feuilles de genêt, E. genistafolia, S. 55. E. tetraloba, Roxв.

Trois fleurs rassemblées en faisceau. Calice visqueux Co- 
rolle de 2 lignes, à limbe cilié inférieurement. Capsule glabre. Stigmate large. Fleurs terminales.

Cette espèce est à peine distinguée de la précédente. Ses semences sont petites, lisses, alvéolées; et dans la précédente, elles sont luisantes et planes.

\section{Feuilles quaternées.}

85. Bruyère velue, E. hirsuta, S. 66. Thunb., Prodr. 72.

Bractées et calice très-chargés de poils. Corolle de 2 lignes, velue, à 4 à 5 étamines. Filamens très-élargis à leur sommet. Fleurs terminales.

86. B. fauve, E. festa, S. I48.

Tige fortement anguleuse. Corolle de 2 lignes $\frac{1}{2}$, visqueuse, à tube étroit et en godet, à filamens ordinairement nus. Fleurs fauves, axillaires. Dans la phrase de Salisbury, cette bruyère a les filamens nus. C'est apparemment par une faute d'impression que, dans l'ordre des affinités, elle est désignée avec des appendices.

Voyez ses affinités, no8 $139,140,141$.

Erica cubica, Lın., Wilid. Antheris muticis. N. Voyez l'espece no. 133, et Obs.

\section{§. Anthères nuies saillantes.}

\section{Feuilles ternées.}

* 87. B. byssine, E. byssina, S. 39. E. capitata, LrNw., ANDr. 38. Bera. Willd. 83.

Calice couvert d'un coton soyeux et dense, à 4 divisions, et entouré de bractées. Corolle de 2 lignes, guère plus longue que le calice. Fleurs terminales.

Tiges fermes, tortueuses, couvertes, ainsi que les rameaux, de poils blancs. Feuilles très-velues. Fleurs au nombre de 2 à 3 , en têtes terminales. Corolle d'un blanc jaunâtre, à limbe 
droit. Filamens, style et stigmate verts. Antheres brunes, que!quefois non-saillantes. La plante en fleur a un aspect d'un gris verdâtre et jaunâtre.

Flearit en juin. N. Bot. cult., $\mathrm{n}^{\circ} .38$, éd. 1 .

88. B. laineuse, E. velleriflora, S. 40. E. bruniades, ANDr:

61. E. capitata, Thunb. Diss. 15. Willd. 84. Var.

Calice couvert d'un coton dense, distant des bractées, à 4 divisions. Corolle de près de 2 lignes, guère plus longue que le calice. Fleurs terminales, d'un pourpre pâle.

* 89. B. à fin lin, E. carbasina, S. 4o. E.bruniades, Lir.

Mant. Willd. 84.

Calice couvert d'un coton dense ou lin fin, distant des bractées, à 4 folioles. Corolle d'une ligne $\frac{3}{4}$, plus longue que le calice. Fleurs terminales, blanches, d'un rose pâle ou jaune. Tige un peu grêle, couverte, ainsi que les branches et les rameaux; de poils assez longs; les derniers rougeâtres. Feuilles ternées ou quaternées, ou éparses, chargées des mêmes poils. Fleurs au nombre de trois à huit, en têtes cotonneuses. Corolle blanche, couverte de poils blancs en dehors, glabre en dedans. Anthères et filets d'un brun foncé et velouté. Style et stigmate bruns et saillans.

Cette espèce se distingue de la précédente par ses feuilles plus larges et plus cotonneuses. N.

Erica sertiflora. Corolle de 2 lignes. Voyez le $n^{\circ} .17$.

\section{Feuilles quaternées.}

* 9o. B. des pierres, E. saxatilis, S. 84. E. carnea, Curt., Mag. Lin., Sp. Pl. E. herbacea, Lin., id. Willd, 133. E. purpurascens, Lin. id. WILLd. 134.

Feuilles très-roulées en-dessous. Corolle de 2 lignés $\frac{1}{2}$, à iube pyramidal. Anthères trouées au milieu de leur longueur. Fleurs axillaires.

Calice de la même couleur que la corolle.

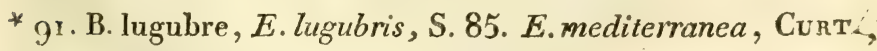
Mag, Liw., Wruld. I3r.

Feuilles en coin étroit. Fleurs unilatérales. Corolle de 2 
lignes, à tube 'en godet. Anthères trouées au-dessous de leur milieu. Fleurs axillaires.

Cette espèce est élevée. Ses feuilles sont d'un vert foncé. Ses fleurs d'un pourpre léger et rose. Les divisions du limbe droites. Calice de la même couleur que la corolle. Anthères brunes. Style blanc. Stigmate étroit. N. Bot. cult., no. 62., éd. I.

Ces deux espèces sont propres aux parties méridionales de l'Europe.

92. B. barbue, E. barbigera, S. 76 .

Calice imbricé de bractées, à 4 divisions profondes et barbues. Corolle de 2 lignes, glabre, à 4 à 5 élamines. Style très-étroit. Fleurs terminales.

Cette espèce a des rapports avec la $75^{\mathrm{e}}$, et ses̄ affinités à 4 étamines.

Erica comosa, Lin., WrLud. N. Antheris muticis. Voyez l'espèce 152 , var. 2 .

\section{Feuilles 6ées.}

93. Bruyère agrégée, $E$. turmalis, S. 79.

Pédoncules très-courts. Calice petit, serré. Corolle de 2 lignes, 4 à 5 étamines. Anthères larges. Fleurs terminales.

Cette espèce a l'aspect de celle à feuilles de brunie, $n^{0} \cdot 7^{6}$; mais son calice est trois fois plus petit, et ses antheres sont nues.

\section{S E C T I O N I I.}

\section{Anthères appendiculées non saillantes.}

\section{Feuilles opposées.}

9个. B. à feuilles d'hélianthème, E. helianthemifolia, S. I7.

Fcuilles deux à deux, ovales, presque planes. Corolle de 2 lignes, pubescente sur les deux surfaces, Appendices longs. Fleurs terminales.

* 95. B. lâche , E. imbellis, S. 238. E. lutea, Wendu., Andr. I I. Thunb. Diss. 49. Linn., Mant, Berg., WILld. 2.

Feuilles deux à deux. Calice d'une ligne $\frac{1}{2}$, ovale, étroit, 
en coin. Corolle de 2 lignes $\frac{1}{2}$, à tube ovale, pyramidal. Capsule presque ovale. Fleurs axillaires.

Variétés. I. A corolle blanche.

2. A corolle d'un jaune pâle.

3. A corolle jaune.

Cette espèce est remarquable par le grand nombre de tiges, branches et rameaux foibles, grệles, pendans, incapables de se soutenir sans appui, cylindriques, glabres, couverts de feuilles opposées, presque imbricées, appliquées contre la tige, concaves en-dedans, d'une ligne $\frac{\mathrm{r}}{2}$ de longueur, obtuses, vertes et glabres. Fleurs pédonculées, au nombre de deux à quatre ensemble, axillaires au-dessous du sommet des rameaux. Corolle blanche ou jaune, ovale et pyramidale, de 2 lignes $\frac{1}{2}$ de longueur, un peu resserrée sous son limbe, dont les divisions bien ouvertes sont obtusément pointues. Filamens blancs. Anthères brunes. Appendices très - courts et blanchâtres. Style rouge. Stigmate brun et luisant. Ovaire rouge. Calice à folioles peu serrées contre la corolle, lorsque celle-ci est ouverte; ovaleselliptiques, blanches ou jaunes. Semences ponctuées.

Fleurit en mai.

Le nom lutea, qu'on a donné à cette bruyère, n'est pas admissible. La couleur de ses fleurs est aussi souvent blanche que jaune; d'ailleurs plusieurs autres bruyères ont aussi la corolle jaune. Le nom imbellis lui convient mieux.

96. B. à feuilles de lin, E. linifolia, S. 239 .

Feuilles deux à deux. Calice d'une ligne $\frac{1}{2}$, ovale, large, acuminé. Corolle de 2 lignes, à tube ovale. Capsule turbinée. Fleurs axillaires.

Variétés. 1. A corolle d'un rouge très-pâle.

Feuilles lancéolées - opposées, imbricées, etc. Liv. Hort. Cliff.

2. A corolle d'un joli rouge.

E. tenuifolia, Lin., Sp. Pl... Berg... Willd . 65. Antheris muticis.

Selon Salisbury, celte espèce, ainsi que la précédente, a bien certainement ses filamens appendiculés. 
Feuilles ternées.

97. BruY Ère fortunée, E. fausta, S. I I .

Feuilles garnies de poils. Corolle de 2 lignes $\frac{1}{3}$, pubescente en dehors, à tube en godet. Appendices oreillés et amincis, fortement dentés en scie. Fleurs terminales.

Cette bruyère ressemble beaucoup à l'urcéolée $\mathbf{6} 62$. Elle en differe par ses anthères, qui, dans celle-ci, ont les bords parallèles, et dans l'urcéolée se rétrécissent vers le sommet. $\mathbf{S}$.

98. B. pâle, E. pallida, S. 12. E. pubescens pilosa, Thunв,

Diss. 6r. E. pubescens, Liv., Sp. Pl. 32.

Feuilles linéaires. Folioles calicinales réfléchies en leurs bord̉s. Corolle de 2 lignes, pubescente sur les deux surfaces. Appendices courts. Fleurs terminales.

Cette bruyère varie dans sa grandeur et dans ses feuilles plus ou moins pubescentes. $S$.

99. B. auriculée, E. auricularis, S. 14 .

Feuilles linéaires-lancéolées. Corolle de 2 lignes, pubescente en-dehors, à tube ovale. Appendices petits et oreillés. Fleurs terminales.

Cette espèce ressemble beaucoup à la bruyère lamellée, $\boldsymbol{E}$. Zamellaris.

Voyez, pour les affinités de ces trois espèces, les nos 38, 162, I 63 .

Les bruyères qui composent ces affinités ont souvent leurs appendices si courts, qu'ils sont à peine visibles, et qu'on peut regarder les filamens ou lesanthères comme en étant dépourvus. * 1 о. B. à feuilles de polytric, E. polytrichifolia, S. 20.

Tige cotonneuse. Bractées distantes. Calice étroit à sa base. Corolle d'une ligne $\frac{1}{2}$ ou 2 lignes. Appendices en coin. Fleurs terminales.

Lieu. Près de Lisboa.

Cette bruyère, selon Salisbury, a beaucoup de ressemblance avec la $4 \mathrm{I}^{\mathrm{e}}$; mais ses feuilles sont plus étroites encore; sa corolle est oblongue; son stigmate moins pelté; sa cansule est pyriforme.

Tige et branches droites, tomenteuses, d'un brun grisitte 
cylindriques, peu étalées, formant un faisceau de 4 pieds environ de hauteur et plus, garnies sur toute leur longueur de rameaux courts, très-nombreux et rapprochés. Feuilles ternéesquinées, linéaires, très-étroites, pointues, glabres et d'un vert gai. Fleurs disposées le plus souvent au nombre de trois au sommet des ranceaux, pédonculées et pendantes. Corolle d'un pourpre rose avant de fleurir, ensuite blanche, ovale, cylindrique, lengue de 2 lignes et d'une de diamètre. Le limbe ouvert et droit. Anthères brunes; les appendices en coin, fauves à leur base, blancs ensuite et ciliés. Style saillant. Stigmate peu élargi et brun. Calice très-court, à divisions ovales et pointues et rétréci à sa base 2 ; petites bractées situées vers le milieu du pédoncule. $\mathrm{N}$.

Fleurit en février et mars, avant la $4 \mathrm{I}^{\mathrm{e}}$, à laquelle cette espèce a beaucoup de rapport. $E$. actea, Hortul. lond.

Comme les jardiniers-pépiniéristes de France confondent ordinairement cette bruyère avec celle arborée, $E$. arborea, $n^{\circ} 41$, voici les principaux caracteres qui la distinguent. Ses feuilles sont plus menues et plus nombreuses; la corolle est rose avant de s'ouvrir, étant ouverte elle est oblongue; son style est très-saillant, son stigmate petit; les divisions du limbe sont ovales, entières.

Dans l'E. arborea les feuilles sont moins nombreuses, plus longues, et d'un vert brunâtre sur les jeunes pousses; la corolle est ovale-globuleuse, toujours blanche; son style n'est pas saillant; le stigmate est épais ; les divisions du limbe sont échancrées à leur sommet.

L'aspect de ces deux espèces est d'ailleurs différent. Voyez, pour les autres parties distinctives, les descriptions qui ont été faites sur les individus vivans.

101. B. basse, E. humilis, E. depressa, Trunb., Diss. 5o...

WiLld. 4. S. 22.

Tige glabre. Feuilles fortement roulées en leurs bords, presque doublées. Corolle de 2 lignes $\frac{1}{3}$. Appendices longs, en alêne et velus. Fleurs terminales.

I02. B. pelotonnée, E. glomifiora, S. 25. E. vesicaria, So= IAND. 
Feuilles étroites en coin. Calice imbricé de braclées. Corolle de 2 lignes $\frac{1}{2}$, visqueuse, à tube sphérique. Appendices trèsvelus. Fleurs terminales.

103. BRUẏ́re à anthères en casque, E. corydalis, S. 44 .

Feuilles lancéolées, en coin. Corolle de 2 lignes, à limbe entier à sa base. Anthères ailées sur leur dos. Fleurs terminales.

104. B. vernissée, E. verniciflua, S. 48. E. glutinosa, Roхв.

Feuilles obtusément acuminées, garnies, sur leurs bords repliés, de glandes desquelles il découle une liqueur qui les rend visqueuses. Corolle de 2 lignes $\frac{1}{3}$, à limbe recourbé. Appendices oreillés, en coin et velus. Capsule glabre. Fleurs term. 105. B. à feuilles de lachnée, E. lachnecefolia, S. 49. E. lachnea, Hortul.

Feuilles ovales, pubescentes. Corolle de 2 lignes, à limbe recourbé. Appendices longs, étroits, en coin et glabres. Fleurs terminales.

Cette espèce differe de la précédente par ses feuilles toutà-fait obtuses et point visqueuses, et par ses appendices glabres.

* 1 06. B. roulée, E. volutaflora, S. 5o. E. nigrita, Thunb., Diss. 53... Lin., Mant... Willd. I o. E. laricina, Berg. E. nigrita, ANDr.

Feuilles luisantes. Bords des folioles du calice recourbés en bas. Corolle de 2 lignes, à limbe roulé. Capsule velue. Anthères souvent nues. Appendices courts, parallele, en coin. Fleurs terminales. Quelquefois les appendices manquent.

Tiges jaunâtres et un peu velues dans leur jeunesse. Rameaux assez courts. Feuilles courtes, luisantes, épaisses. Fleurs disposées trois par trois au sommet des rameaux, un peu penchées. Corolle en godet, d'un blanc pur et glabre, très-ouverte en son limbe, dont les divisions sont roulées en-dessous, de manière que les anthères et le style sont presque saillans. Anthères noires. Appendices courts. Style brun. Folioles calicinales de la longueur de la corolle, blanches, ainsi que les bractées, i leur sommet, et velues. $\mathrm{N}$.

Fleurit en mai. 
107. B. lyrée, E. lyrigera, S. 5x. E. nigrila, Roxв.

Feuilles luisantes. Corolle de 2 lignes, à limbe recourbé. Appendices dentés en scie. Capsule velue. Les anthères, aussitôt après l'épanouissement de la corolle, représentent une lyre. Fleurs terminales.

Cette espèce ne differe que bien peu de la précédente.

* ro8. B. à feuilles de gnidienne, E. gnidiafolia, S. 53. E. ca. lycina, Thunb., Diss. 78... Lin., Suppl... Willd. 46.

Feuilles luisantes, linéaires - lancéolées, légèrement pubescentes. Calice grand et en coin. Corolle de 2 lignes. Appendices oreillés. Fleurs terminales.

Folioles calicinales aussi longues que la corolle, pointues, d'un pourpre léger, avec une ligne verte à leur sommet, accompagnées à leur base de 2 bractées de la même couleur. Les divisions du limbe se replient en - dedans et cachent les anthères; celles-ci sont d'un pourpre foncé et leurs appendices courts. Le stigmate est plus long qu'elles.

Fleurit en différens temps. N... Bot. cult. , $\mathrm{n}^{\ell} 23$, éd. 1 . ${ }_{0}$. B. à fleurs de scamonée, E. periplocafolia, S. 56.

Feuilles lancéolées, en coin. Pédoncules longs. Calice court, orbiculaire. Corolle de 2 lignes. Stigmate étroit. Fleurs terminales.

Cette espèce a tantôt des appendices très-courts et en coin, et tantôt n'en a point du tout. S.

I $о$. B. à feuilles courtes, E. brewifolia, S. 62. Soland.

Feuilles ovales. Corolle de près de 2 lignes, plus longue d'une demi-ligne que le calice. Appendices linéaires, amincis. Semences striées. Fleurs terminales.

II . B. habillée, E. chlamydiflora, S. 33. E. viscaria, Roxв.

Feuilles linéaires, velues. Corolle de 2 lignes, à peine plus longue que le calice. Appendices oreillés. Semences planes. Fleurs terminales.

Les folioles du calice, droites et recourbées, qui entourent la corolle, semblent la garantir par un vêtement.

112. B. à feuilles de selague, E. selaginifolia, S. 64 .

Tige cotonneuse. Corolle de 2 lignes, glabre, à tube glo- 
buleux. Appendices très-larges, orbiculaires. Fleurs terminales.

I 3 . BruÝ̇́re mal vêtue, $E$. pannosa, S. 65.

Feuilles peu roulées en leurs bords. Corolle de 2 lignes, laineuse. Filamens larges, à appendices courts. Style saillant. Fleurs terminales. Feuilles souvent quaternées. Cette espèce a des rapports avec la $88^{\mathrm{e}}$.

i 4. B. à feuilles de diosma, E. diosmafolia, S. r r . E. subserrata, Rохв.

Feuilles luisantes, plus larges que celles de la plupart des espèces. Corolle de 2 lignes, imbricée. Filamens très - étroits. Appendices amincis et dentés en scie. Fleurs terminales.

I 15. B. à feuilles d'hyssope, E. hyssopifolia, S. 243. E. pigra,

Soland.

Feuilles ciliées de poils doux et denses. Corolle de 2 lignes, velue vers son sommet, à divisions crispées et émoussées. Fleurs axillaires. 2 bractées; une troisieme plus large et ordinairement colorée.

I 6. B. à bractées, E. obvallaris, S. $2\{2$. E. bracteata, Thunв.,

Diss. 3.

Bractées grandes, presque ovales, situées sur le milieu du pédoncule. Corolle de 2 lignes, à divisions crénelées. Fleurs axillaires.

I 1 7. B. fugace, E. fugax, S. 1 13. E. triflora, Trunb., Diss.

79... Lin., Mant. E. triflora aristata, WendL., Willp. 47 , var. 6.

Feuilles en coin. Calice presqu'en coin. Corolle de près de 2. lignes, à tube à 4 angles peu distincts et turbinés. Appendices étroits et en coin. Fleurs terminales.

La floraison de cette espèce s'achève promptement.

* I 8 . B. à fleurs de pyrole, E. pyrolceflora, S. 124. E. triflora, Lin., Sp., Pl. E. triflora, Wilud. 17. Excl. Syn.

Feuilles en coin. Calice ovale, en coin. Corolle de 2 lignes, à tube à 4 angles élevés et sphẹriques. Appendices légèrement oreillés. Fleurs terminales.

Cette espèce ressemble beaucoup à la précédente; mais quand 
on l'observe avec attention, on voit que la corolle, sous les sinus de son limbe, a autant d'élévation que de stries. S.

Feuilles souvent quaternées, longues de 5 lignes, vertes et glabres. Tige forle et droite, branchue; les rameaux couverts d'un duvet blanc. Fleurs au nombre de trois à quatre ensemble, terminales. Pédoncules cotonneux. Corolle blanche, globuleuse, à limbe peu ouvert et à 4 angles. Folioles calicinalo ovales, carénées, presque aussi longues que la corolle et de la même blanciseur, serrées contre elle et accompagnées de 3 ou 4 bractées aussi blanches. Filamens rouges et courbés à leur sommet. Anthères brunes. Appendices ovales, velus ou oreillés, jaunes au milieu, blancs sur leurs bords, de la forrne d'une petite feuille. Stigmate en tête avec 4 points rouges. $\mathrm{N}$... Bot. cult., no. 27 , éd. $x$.

Fleurit en juin.

Cette bruyère, par la forme de ses fleurs, a les plus grands rapports à la 119 e.

x 8 bis. B. tuilée, E. tegulcefolia, S. 115.

Feuilles ovales, larges, imbricées' à rangs droits et pubescentes. Corolle de 2 lignes, à tube à 4 angles peu saillans et turbinés. Appendices grands et orbiculaires. Fleurs terminales.

\section{Feuilles quaternées.}

* 1 19. B. bacciforme, E.baccaformis, S. 116. E. baccans, Lin., Willd. 59. Andr.

Tige anguleuse. Feuilles ordinairement quaternées. Corolle de 2 lignes $\frac{1}{2}$, à tube à 4 angles saillans et turbinés. Appendices oreillés. Fleurs terminales.

La tige n'est anguleuse que par la décurrence des pétioles, ce quia lieu sur plusieurs bruyères. Fleurs au nombre de trois à quatre, pendantes, non réellement terminales, mais situées contre le sommet des rameaux. Corolle rose, globuleuse, 4 angles saillans, rétrécie sous son limbe, dont les divisions sont droites et arrondies. Anthères d'un brun clair. Appendices plus lárges et plus longs qu'elles, jaunes, granulés, ovales, pointus. Filamens très-courts. Style épais et brun. Stiginate,

III. 
d'un brun noirâtre, à 4 points saillans. Calice à folioles de la même couleur que la corolle, placées contre elle dans l'intervalle de ses angles. Pédoncules et bractées roses.

Fleurit en mai. N... Bot. cult. , $\mathrm{n}^{\circ}$ 3o., éd. $\mathbf{I}^{\mathrm{re}}$.

* i20. Bruyère penchée, E. cernua, S. izi. Lin. Suppl. Willd. 62. Andr.

Bractées décurrentes. Calice dentelé. Corolle de 2 lignes $\frac{1}{2}$, à trbe globuleux. Appendices oreillés. Fleurs terminales.

Feuilles longues de 3 lignes, munies de quelques petites élévations ciliées. Fleurs disposées en grappes penchées et terminales. Corolle de 2 lignes $\frac{3}{4}$, d'un blanc carné, ovale, glabre, resserrée sous son limbe, dont les divisions sont peu réfléchies. Anthères brunes. Appendices longs et blancs. Style rouge. Stigmate brun, à 4 points. Calice petit, ’̀ folioles presque dentelées, par la présence de cils glanduleux. 2 bractées opposées sous le calice. Pédoncule grêle et rouge. $\mathrm{N}$.

Fleurit en septembre. Bot. cult., $\mathrm{n}^{\circ} 53$, éd. I.

I21. B. à crochets, $\boldsymbol{E}$. uncifolia, S. I78. E. regerminans,

Lix. , Mant... Willd. 12. Tige glabre. Feuilles recourbées et amincies en pointe. Corolle d'une ligne $\frac{3}{4}$, presque ovale. Appendices très-longs. Fleurs axillaires.

Tige rameuse; les rameaux jonciformes. F. quaternées, et ternées, suivant Linné, acuminées, glabres, ouvertes. Fleurs en grappes latérales, penchées. Corolle rouge, ovale, globuleuse, à limbe ubtus. Calice rouge, très-petit, à folioles lancéolées. Anthères appendiculées, un peu jlus courtes que la corolle. Style de la longueur de la corolle. Pédoncule de la longueur des fleurs et carné. Braciées pelites et colorées, Liv. , Mant. I22.

122. B. à fleurs nombreuses, E. catervaflora, S. 188. E. pubescens. 3 villosa, Tнunв. Diss. 61.

Tige anguleuse. Corolle de 2 lignes, pubescente, à tube étroit, presque ovale. Anthères à longs trous. Fleurs terminales.

Celte espèce se rapporte à celles n ${ }^{05} 54,55$ et suivans, 123. B. porte-pique, E. tragulifera, S. 195.

Calice imbricé. Corolle de 2 lignes $\frac{1}{2}$, à tube en godet et 
à limbe recourbé. Appendices velus. Anthères à trous très-larges, velues. Fleurs terminales.

* 124. B. à goutte, E. guttaflora, S. Ig6.

Feuilles linéaires, amincies en pointe. Corolle d'une à 2 lignes $\frac{1}{2}$; les divisions du limbe enduites à leur sommet d'une petite goutte. Appendices pubescens. Fleurs terminales.

Ces deux espèces se rapportent à celles numéros 60,6 i et suiv.

\section{Variétés.}

I. Tige fasciculée. Corolle d'une ligne à une ligne $\frac{1}{2}$, à tube hémisphérique. Style très-saillant. E. lateralis, WILLD.57. ANDR.

2. Tiges pendantes. Corolle de 2 lignes, à tube large et ovale. Style peu saillant. E. incarnata, $A_{N D R} 27$.

Cette variété est une espèce d'Andrews. Ses rameaux sont contournés, flexueux. Ses fleurs sont en bouquets serrés et terminaux, et nombreuses. La corolle ovale-globuleuse, est d'un rouge pâle ou carné ; son limbe est resserré.

3. Tiges un peu pendantes. Corolle de 2 lignes $\frac{1}{2}$, à tube ovale. Style peu saillant, $E$. rubens humilis, WendL. E. rubens, Andr.

Tige assez droite, rameaux ouverts, très-glabres. Feuilles étroites, linéaires, pointues, peu ouvertes, serrées en partie contre les tiges. Fleurs en bouquets terminaux, pendans. Corolle penchée, d'une lige $\frac{1}{4}$, d'un pourprecarné, ovale, resserrée sous son limbe, dont les divisions sont droites et les interstices renflés. Anthères brunes. Appendices larges et blanchâtres. Folioles calicinales larges et pourpres à leur base, étroiles et vertes à leur sommet. 3 bractées vers le milieu du pédoncule.

Fleurit en septembre. N.

* I25. B. turrigère, E. turrigera, S, 205. E. cupressina, Hort.

E. pendula, Willd. id. Hortul.

Feuilles étroites. Calice recourbé, horizontal. Corolle de 2 lignes, à tube hémisphérique et à divisions imbricées. Feuilles presque sans nervure. Feurs terminales.

Cette bruyère forme un buisson assez élargi , mais peu élevé. Rameaux nombreux. Feuilles de deux lignes de longueur, à ver- 
ticilles rapprochés, à bords très-roulés. Fleurs nombreuses au sommet des jeunes rameaux et éparses. Corolle pendante, d'un blanc carné, de près de 2 lignes, globuleuse, resserrée sous son limbe dont les divisions sont droites et ferment presque l'entrée de la corolle. Anthères et appendices bruns. Style rouge. Stignate brun. Folioles calicinales d'un blanc carné à leur base, avec une pointe d'un vert brun, ouvertes presque horizontalement.

Fleurit toute l'année. $N$.

* 126. B.r Uy ère quadriflore, E. lacunceflora, S. zo6. E. qua drifiora, Andr., Wrlud. 56. E. bergiana, Lrv., Mant. Feuilles larges. Calice ouvert et courbé. Corolle de 2 lignes $\frac{3}{3}$, à tube large et ovale. Les interstices du limbe ovales à leur base. Feuilles à une nervure dislincte. Fleurs terminales. Feuiiles aussi quinées.

Cette espece a des rapports avec la précédente par sou port et ses fleurs. Ses rameaux sont velus et plus nombreux, et ses fleurs en plus grande quantité. Ses feuilles sont garnies de cils blancs, distans l'un de l'autre. Ses fleurs sont terminales, au nombre de 4, de 3 , de 2 : les inférieures solitaires.

Corolle globuleuse, de deux lignes ex demie, d'un joli pourpre pâle; le limbe d'un roage foncé; ses divisions courtes et leurs interstices arrondis. Filels des étamines d'un blanc carné. Anthères brunes. Appendices assez longs, ciliés, d'un blanc rougeâtre. Style d'un ronge brun. Stigmate en tête et brun. Calice à folioles rouges à leur base, ciliées et vertes à leur sommet, réfléchies dans la | arfaite floraison, sur le pédoncule, qui est d'un rouge foncé, et garni, vers le tiers de sa longueur, de 2 à 5 bractées verdâtres et velues: N. Fleurit en mai.

Cette bruyère est souvent envoyée par les jardiniers aussł sous le nom de $E$. pendula.

127. B. fleurie, E. florida, S. 207. Thuni Diss. 64. WILLD. 27.

Bractées très-petites. Calice courbé en - dedans. Corclle de 2 lignes, à tube globuleux et à divisions imbricées à leur base. Appendices lancéolés. Fleurs terisinales. 
* r28. B. muqueuse, E. mucosa, S. $210 . \mathrm{KEW}$, Icon. Liv., Mant. Wrlld., 28. E. ferrea, Berg. E. mucosa, Andr.

Tige glabre. Corolle de 2 lignes, visqueuse, à lube plus ou moins ovale, et à interstices du limbe un peu renflés. Fleursterminales. Fenilles linéaires ou ovales, $4^{\text {ées }}-6$ ées.

Tige droite. Les branches et les rameaux glabres, un peu grêles. Feuilles évidemment quaternées, linéaires, ouvertes, courbées, glabres, de 3 lignes. Fleurs disposées au nombre de trois à huit en bouquets terminaux. Corolle globuleuse, d'un pourpre ferrugineux, visqueuse, resserrée sous son limbe, dont les divisions sont peu réfléchies et les interstices saillans. Anthères et stigmate bruns. Folioles calicinales lancéolées, serrées contre la corolle, de la même couleur qu'elle sur les deux tiers inférieurs, vertes sur l'autre tiers.

Fleurit en avril et mai. N... Bot. cult, nº.5., éd. $\mathrm{r}^{\mathrm{re}}$. ז29. B. piluliforme, E. piluliformis, S. 211 . E. pilulifera, Lin. Sp. Pl. E. nudicaulis, Berg.

Feuilles éparses. Corolle de 2 lignes $\frac{1}{2}$, glabre, à tube de la longueur du calice. Appendices linéaires, amincis. Capsule glabre. Fleurs terminales. Les bords roulés des feuilles sont garnis de très-petits cils.

30. B. jolie, E. pulchella, S. 216 .

Corolle de 2 lignes, gुlabre, à tube en godet, un peu quadrangulaire. Appendices en coin et velus. Antheres velues. Fleurs terminales.

Cette espèce a le port de la $132^{\mathrm{e}}$. * 15ז. B. à é is serrés, E. verecunda, S. 2 r5. E. cermua, Andr. 48.

Fleurs en têtes serrées. Corolle de 2 lignes $\frac{1}{2}$, glabre à tube amphoriforme et à limbe crénelé. Fleurs couleur de chair pâle: Les têtes sont pendantes. Celte bruyère ne s'élève guère qu'à deux pieds. Sa tige souvent nue n'est rameuse que vers son sommet.

3.32. B. à fteurs de caille-lait, E. gateiflora, S. 230 .

Tige pubescente. Corolle de 2 lignes $\frac{1}{2}$, i lube ovale, pyra. raidal. Appendices oreillés. Capsule sphérique. Fleurs terminales. 
Variétés. Y. A fleurs blanches, E.transparens, Berg. E. romosa, Avdr. Cette variété est plus petite dans toutes ses parties. Elle est très-jolie.

*2. A fleurs rouges, E. comosa, Тнunв. $38 \ldots$ Lin., Mant... Willd. 126. Antheris muticis.

Cette dernière variété dans l'individu que j'ai observé, et suivant Linné et Willdenow, n'a pas ses filamens appendiculés.

Cette jolie bruyère forme un buisson peu élevé, mais trèsdense par la quantité de ses rameaux, menus et pubescens. Feuilles d'une ligne $\frac{1}{2}$. Fleurs nombreuses, au nombre de trois à cinq, terminant les rameaux. Corolle de 2 lignes $\frac{\mathrm{r}}{2}$ à 3 lignes, d'un rouge de fleurs de pêcher, ovale, cylindrique, à limbe ouvert horizontalement. Filamens capillaires et blancs. Anthères brunes et nues. Style rouge. Stigmate brun et luisant. Folioles calicinales de la moitié de la longueur de la.corolle, rougeâtres et ciliées sur leurs bords.

Fleurit en juillet et août. N... Bot. cul, $\mathrm{n}^{0} .49$, éd. $\mathrm{I}^{\mathrm{re}}$.

* 153. BRUY Ère cubique, E. hotioniceflora, S. 32. E. cubica, Andr. 3g... Lin., Mant.

Folioles du calice dentées en scie. Corolle de 2 lignes $\frac{1}{2}$, a limbe entier à sa base, un peu échancré. Filamens appendiculés. Fleurs axillaires.

Cette bruyère, suivant Linné et mon observation, n'a pas d'appendices; mais ses anthères sont légèrement ciliées en forme d'appendices à leur sommet.

Feuilles aussi souvent quaternées que quinées, longues de 2 lignes, recourbées en-dessus, glabres, d'un vert foncé. Fleurs portées sur d'assez longs pédoncules rouges, disposées audessous du sommet des rameaux en espèces de verticilles. Corolle pourpre, de 3 lignes de longueur, à limbe évasé et ses divisions droites. Calice tétragone, presque de la longueur de la moitié de la corolle, í folioles larges, carénées, de la couleur de la corolle, dont la base forme un bourrelet arrondi. Anthères fauves, garnies sur leurs bords de petits cils blanchâtres. Style rouge. Stigmate d'un brun noir.

Fleurit en mars. N. Bot. cult., no .53 , éd. $1^{\text {re }}$. 
Obs. Cette description conviendroit peut-être autant à $l$ 'Erica seriphiiflora, S. nº. Io, qui paroît avoir les plus grands rapports avec celle-ci. Je l'y aurois mềne jointe à cause de ses anthères; mais sa corolle n'a pas la moitié de la longueur de celle-ci.

\section{Feuilles $5^{\text {ées }}-6^{\text {ées }}$.}

* 134. B. à tiges nombreuses, E. multicaulis, S. 176. E. stricta, Andr., Willd. 26. E. viridi purpurea, Hortul.

Feuilles à 2 sillons en-dessous. Calice ouvert. Corolle. de 2 lignes $\frac{1}{2}$, glabre. Appendices oreillés. Tiges diffuses. Fleurs terminales.

Tiges, branches et rameaux nombreux, longs et droits, couvert de feuilles ternées ou quaternées vers le bas des rameaux, quinées ensuite, souvent $6^{\text {ées }}$ à leur sommet, lancéolées, longues de 2 lignes, glabres et d'un vert foncé. Fleurs ramassées, au nombre de 5 à 12 et même plus, en tếtes terminales, penchées. Corolle d'un pourpre léger, campanulée, longue de 2 lignes $\frac{1}{4}$ ou $\frac{1}{2}$, à limbe ouvert et ses divisions réfléchies. Anthères brunes. Appendices blancs, dirigés vers le bas. Style d'un pourpre foncé. Stigmate brun. Calice à folioles étroites, très-glabres, ouvertes et d'un rouge brun.

Fleurit en août. N. Bot. cult, , no. 10., éd. $\mathbf{x}^{\mathrm{re}}$.

* 135. B. à feuilles de camarine, E. empetrifolia., S. 180. Thunb. Diss. 7o. Lin., Mant. Willd. 38.

Cette espèce a le feuillage plus vert que celui de la pixidiflore, dont l'aspect est glauque. Les feuilles sont disposées de même, aussi serrées et aussi velues. Ses fleurs sont situées au-dessous du sommet des rameaux qu'elles entourent; mais leur masse est moins lon'gue que celle de la $137^{\mathrm{e}}$. La corolle et d'un beau pourpre, globuleuse à sa base, en gorlet, et les divisions de son limbe bien arrondies. Anthères d'un noir brun. Apperıdices d'un rouge brun à leur base, blancs à leur pointe. Stigmate en plateau, d'un gris rougeâtre, luisant, et marqué de points bruns. Folioles du calice velues et ouvertes. $\mathrm{N}$.

Fleurit en avril et mai. 
356. Bryyère malićolaire, E. malleolaris, S. 181. E. empetrifolia, Schneer, Hout., Brrg.

Calice à 4 divisions. Corolle de moins de 2 ligncs, à tube en godet, et à limbe recourbé et très-ouvert. Capsule velue. Fleurs axillaires.

Cette espèce n'est qu'une très-légère variété de la précédente.

* 157. B. pixidiflore, E. pixidiflora, S. r82. E. empetrioides, Hortul., ANDr.

Calice $\dot{a} 4$ divisions. Corolle de 2 lignes, glabre, à tube presque cvale, ct à limbe courbé en-dedans et ouvert. Capsule hémisphérique et glabre. Flenrs axillaires.

Ces trois espèces se ressemblent beaucoup par leur port, leur aspect, la situation de leurs fenilles et leurs fleurs. Elles on toutes des feuilles très-nombreuses, très-rapprochées, couvrant toute la longueur des rameaux, longues de 2 lignes, garnies plus ou moins de poils. Leurs fleurs sont solitaires, sessiles, nombreuses, situées autour des rameaux, au-dessous. de leur sommet. La corolle de la dernière est rougeâtre, à limbe droit et à divisions arrondies. Antheres brunes. Appendices très-couris, de la même couleur. Stigmate à 4 points. Calice à divisions linéaires, pointues, garnies d'assez longs cils blancs.

Fleurit en juin. N. 158. B. à longs pédoncules, E. nolåfora, S. i 83.

Calice à 4 folioles. Corolle de 2 lignes, glabre, à tube en coupe, à limbe recourbé et ouvert. Pédoncules beaúcoup plus longs que ceux des trois espèces précédentes, auxquelies celleci a beaucop de rapport. Ils excedent la longueur des feuilles. Fleurs axillaires.

¥37. B. trompeuse, E. fallax, S. 185.

Corolle de 2 lignes, visqueuse, à tube en goc̉et, un peù côtes. Filamens de la longueur du tube. Capsule visqueuse. Fleurs axillaires. Anthères à deux parties, à peine effectivement didymes.

$\$ 4$ o. B. semblable, E. parilis, S. r 86 .

Corolle de 3 lignes, visqueuse, à tube en godet, un peu 
côtes. Filarnens à pieine de la longueur du tube. Petits appendices. Port de la précédenie. Les folioles du calice plus étroites; les anthères deux fois plus grandes et les appendices courant sur le sommet des filamens. Fleurs axillaires.

* r 4 r. B. visqueuse, $E$. viscida, S. $x 87$.

Corolle de 3 lignes, visqueuse, - à tube en coupe et à côtes. Filamens très-courts. Capsule soyeuse. Fleurs axillaires, $\gamma$ ariétés. I. A feuilles blanchâtres, d'une ligne $\frac{1}{2}$ de longueur. E. viscaria, Lin., Mant. Willd. 129 . Antheris. muticis.

* 2. A feuilles vertes, de 3 à 5 lignes de longueur. E. viscaria, KEw., Icon., Andr., 55.

Cette dernière variété devroit être, ainsi que la première, dans la section des anthères nues non saillantes, suivant Linné , Willdenow et mon observation, et dans le paragraphe des feuilles quaternées, quoique Salisbury en pense autrement.

Tige droite, ainsi que ses branches. Feuilles longues de 4 lignes, quaternées et quinées, ouvertes et glabres. Corolle ovale, globuleuse, visqueuse, longue de 4 lignes, d'un blanc rougeâtre. Etamines très-courtes et nues. Anthères et stigmate bruns. Folioles calicinales pointues. Fleurs en grappes courtes et verticillées au-dessous du sommet des rameaux.

Fleurit en mai. N. Bot. cult., $n^{\circ} .5 \mathrm{r}$, ed. $\mathrm{i}^{\mathrm{re}}$.

La dernière ou seconde variété forme un arbuste de 2 à 3 pieds, droit ; les rameaux simples, longs et lâches. Feuilles quaternées, linéaires. Fleurs ovales, campanulées ou en grelot, petites, pourpres, très-muqueuses, disposées en épis vers le milieu de la longueur des jeunes branches; les divisions du limbe réfléchies; le calice très-visqueux.

\section{§. Anthères appendiculées saillantes.}

\section{Feuilles quaternées.}

\$42. B. à pistons, E. embolifera, S. 74. E. glabella, Truvis., Pronr. 73. Blaria pusilla, Lis., Mant, Wrua. 
Blaria purpurea, Berg., Synon. de Blceria glabella; WILLd.

Bractées solitaires. Calice infundibuliforme, à 4 angles. Corolle de 2 lignes, à 4 étamines. Appendices courbés. Fleurs terminales.

Les feuilles sont contamment velues. Ses fleurs, comme toutes celles des blairies et de leurs affinités, sont en épis courts, fasciculés. Les pédoncules très-courts, verticillés, ont chacun une bractée.

Cette espèce est de la famille des blairies, que Salisbury a réunies.

\section{TROISIÈ ME DIVISION.}

Corolle de 7 à 18 millimètres de longueur (trois à huit lignes).

PRE MIÈ E SECTION.

Anthères nues non saillantes.

Feuilles ternées.

145. BRUY ÈRE barillette, E. modilioflora, S. 3o. E. Thunbergii, Lrn., Suppl... Wruld. 68.

Calice à 4 folioles. Corolle de 4 lignes, glabre, à tube en baril, et à limbe entier à sa base. Anthères granulées. Fleurs terminales.

Tige peu rameuse. Feuilles linéaires, pointues, glabres, un peu serrées contre les rameaux. Corolle presque globuleuse, à divisions ovales et ouvertes. Anthères pourpres. Style de la longueur des étamines. Stigmate obtus. Liv., S.

* 14 4. B. ciliée, E. ciliaris, S. I74. Lin. Cunt. Mag. Willd. 88. Feuilles ovales. Corolle de 4 lignes, glabre, à tube ovale, pyramidal, plus ventru d'un côté et sur sa partie supérieure. Fleurs axillaires.

Feuilles ovales, ternées et quaternées, de 2 lignes, blanchâttres 
en-dessous, munies de cils blancs et glanduleux. Fleurs situées un peu au-dessous du sommet des tiges et des rameaux, en grappes unilatérales. Corolle pourpre, de 4 lignes de longueur, ovale, cylindrique, à divisions courtes et droites, renflée du côté supérieur. Anthères brunes. Style rouge, sillant. Stigmate brun. Folioles calicinales ovales, rouges à leur base, vertesà leur sommet et ciliées.

Ind. Fleurit en août et septembre. N... Bot. cult., nº 37 , éd. I. E. albens, Liv., Mant... Willd... N. Antheris muticis. Voyez l'espèce $\mathrm{n}^{\circ}$. 173 .

E. taxifolia, Willd... N. Antheris muticis. Voyez l'espèce no. 172 .

\section{Feuilles quaternées.}

* I 45. B. absolument pyramidale, E. obpyramidalis, S. r32. E. pyramidalis, Curt., Mag...Soland... H. K.., Willd. 130. ANDR.

Corolle d'environ 4 lignes, pubescente, à tube infundibuliforme, à limbe, dont les interstices sont renflés en dehors. Capsule sphérique. Fleurs terminales.

Rameaux distans les uns des autres, souvent disposés par étage, foibles, pendans et pubescens. Feuilles distantes, ouvertes, pubescentes, longues de 5 lignes. Fleurs au nombre de deux à quatre, situées le long des rameaux, et aussi terminales. Corolle pyramidale, longue de 4 à 5 lignes, à tube d'un blanc carné, et limbe d'un pourpre rose. Anthères brunes. Style carné, et toujours courbé. Calice petit. La corolle, avant de s'ouvrir, présente une pointe tétragone.

Fleurit en hiver. N... Bot. cult., $\mathbf{n}^{\circ} .47$, éd. I.

* I 46 . B.à fleurs de cyrille, E. cyrillaflora, S. 135. E. semicampanulata, Hortul.

Tige menue. Corolle d'environ 5 lignes, pubescente, à tube étroit, cámpanulé et à limbe court. Fleurs d'une écarlate pâle; terminales.

Cette espèce a plusieurs rapports avec la précédente. Sa tige et droite, assez élevée. Ses branches montantes sont garnies de beaucoup de rameaux grêles, cylindriques, rougeâires, pubes- 
cens. Feuilles nombreuses, quaternées, linéaires, pointues, très-étroites, à bords entièrement roulés, longues de 2 lignes $\frac{1}{2}$, velues, vertes, et donnant naissance dans leurs aisselles à des rudimens de rameaux. Fleurs rassemblées au nombre de deux à trois et quatre au sommet des rameaux. Corolle blancise, lavée de rose ou d'écarlate, presque à quatre angles, à tube campanulé; les divisions du limbe un peu réfléchies; longue de 5 lignes. Anthères brunes. Stignate rouge, luisant, saillant, à 4 points noirs. Calices à folioles lancéolées, étroites et vertes. La corolle, avant de s'ouvrir, présente un bouton à 4 angles, pyramidal, sur lequel les antières forment une couronne de 8 points bruns. $\mathrm{N}$.

Fleurit en hiver. Cette description est bien celle de l' $E$ semicampanulata, Hortul; mais je ne suis pas aussi sûr que l'espèce de Salisbury soit son synonyme.

* I 17. BruY Ère fasciculée, E. fasciformis, S. 227. E. fastigiala, Thunb., Diss. 37... Lin., Mant... Willd. 123. Andr.

Pédoncules très-courts. Corolle de 5 à 6 lignes, à limbe farineux en-dedans. Anthères droites. Fleurs terminales.

Tige brune, assez drorte. Rameaux nombreux, tétragones, rouges dans leur jeunesse, et glabres. Feuilles trigones, de 2 lignes $\frac{1}{2}$. Fleurs disposées au nombre de quatre, en faisceau ierminal. Corolle blanche, de 5 à 6 lignes, cylindrique, lisse et luisante en-dehors et sur son tube; d'un blanc mat sur son limbe, dont les divisions réfléchies sont d'une roideur remarquable, rougeâtre à sa base. Anthères brunes. Stigmate d'un blanc verdâtre, luisant et sans points. Folioles calicinales serrant la corolle, vertes, membraneuses el ciliées sur leurs bords, ansi longues que la moitié de la corolle. 2 bractées de même forme.

Fleurit en hiver. $\mathrm{N}$.

Variété à fleurs rougeâtres.

I43. B. fistulire, E. fistulceflora, S. 228. E. cylindrica, Thunb., Diss. 39. An Wilsd. rog. Non cylindrica. Andr.

Calice couyert de trés-petits cils, Corolle de 5 a 6 lignes. 
tube étroit, cylindrique, en godet, et à limbe court. Capsule presque ovale et glabre. Fleurs terminales.

1 99. B. dentée, E. denticularis, S. 232 . E. dentata, Thuns.

Diss. 39. E. denticularis, Liv., Mant... Willd. 127.

Tige pubescente. Calice presqu'en coin, denté en scie. Corolle de 3 lignes, à limbe moitié plus court que le tube. Anthères à trous alongés. Fleurs pourpres, terminales. Feuilles trigones, linéaires, glabres. Fleurs en têtes terminales. Corolle ovale, infundibuliforme. Calice à folioles membraneuses, ciliées, dentées en scie. Lin...

150. B. agréable, E. pulchra, S. 233. E. walkeria, Andr。 45.

mige glabre. Calice étroit, lancéolé, denté en scie. Corolle de 4 à 5 lignes, à limbe deux fois plus court que le tube. Anthères à petits trous. Fleurs terminales.

Arbrisseau de 4 à 5 pieds, garni de longues branches. Feuilles 6ées. Fleurs verticillées au-dessous des sommets, en forme d'épis. Corolle de 6 à 1 o lignes, d'un jaune orangé. Son limbe trèsouvert.

* 15 r. B. à fleurs de daphné, E. daphneflora, S. 234.

Calice ovale, en pointe, à peine denté en scie. Corolle de 5 lignes, à limbe plus court que le tube, recourbé et plié. Fleurs terminales.

152. B. transparente, E. pellucida, S. 235.

Tige grêle, en faicceau. Verticilles des jeunes rameaux distans. Feuilles étroites, linéaires, amincies. Calice spatulé, denté en scie. Corolle de 5 à 6 lignes, à limbe trois fois plus court que le tube. Fleurs blanches, teintes de rouge, terminales.

E. viscaria, Lxn., Mant... Wilud... Andr. et N. Antheris

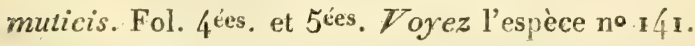

E. sparmanni, Liv., Willd. Antheris muticis. Voyez l'espèce no 175 .

E. transparens, Thunв., Diss... Winld. Antheris muticis. Voyez le no $1 ; 6$.

E. muscari, Wxuld... N. Antheris muticis. Dojez le $1 n^{\circ} 182$. 
E. ventricosa, Willd. N. Antheris muticis. Vojez le no 185.

\section{Fenilles 6ées.}

153. Bruy Ère à côtes, E. costeflora, S. I55. E. leca, ANdr. 20... WILLD. 104 .

Calice serré. Corolle de 5 à 6 lignes, visqueuse, à tube claviforme et à côtes. Anthères trouées près de leur sommet. Fleurs axillaires.

Cette bruyère forme un petit buisson de 6 à 8 pouces de haut, très-branchu. Ses feuilles sont quaternées, épaisses, glabres et luisantes. Ses fleurs sont réunies au nombre de quatre au sommet des rameaux. Leur tube est verdâtre, renflé et c urt; leur limbe est d'un rouge pâle en - dehors, blanc en - dedans, recourbé. La corolle entière et luisante.

154. B. à bords rudes, E. argutifolia, S. 160. E. pulchella,

Thunb., Diss. 24... Willd, 100.

Feuilles très-amincies, roulées en-dessous. Corolle de 5 à 6 lignes, viqueuse, à tube infundibuliforme. Fleurs axillaires. E. pinea, Willd... Thunв. Antheris muticis. Vojez le no $\mathrm{r} 86$.

\section{§. Anthères nues saillantes.}

\section{Feuilles ternées.}

* 155. B. fusiforme, E. fusiformis, S. 93 .

Calice dislant des bractées, en coin, variant en longueur. Corolle de 4 à 7 lignes, glabre, à tube ovale, pyramidal. Fleurs terminales.

\section{Variétés.}

1. A calice d'une ligne $\frac{1}{3}$, et corolle, écarlate de 6 à 7 lignes. E. pluknetii, Lin., Sp. Pl. Willd. 95. Avec la variété suivante. $E$. pluknetii, ANDr. Variété naine.

2. A calice de 2 lignes $\frac{1}{2}$, et corolle écarlate, de 6 à 7 lignes. E. pulknetiana, KEw., Icon. E. pulknetii. LIN., Sp., éd. 2. 
Cette variélé a un aspect grisâtre. Ses tiges et ses rameaux sont droits. Feuilles très-rapprochées, longues de 7 lignes, pointues, un peu cour ées en-dessus, glabres. Fleurs pendantes, en assez grand nombre, au sommet des rameaux courts, souvent unilatérales. Corolle d'une écarlate pourprée, ovale, alongée, longue de 6 lignes, ’̀ 4 côtes peu saillantes, à limbe court et serrant les an'hères. Celles - ci, réunies en un faisceau. courbé, terminé par le style, sont brunes, et leur saillie est de la longueu: de la corolle. Calice à folioles lancéolées, étroites, pointues, rougeâtres, de la longueur de la moitié de la corolle, appliquées contre elle.

Fleurit en mai. N... Bot. cult., no 55, éd. r.

* Variété à feuilles vertes, à corolle d'un beau rouge, dont les côtes sont saillantes, à limbe aussi verdâtre.

Fleurit après la précédente.

3. A cálice d'une ligne, et corolle blanche de 5 lignes $\frac{1}{2}$. $E$. petiverii, B. Thunb., Diss. 21... Willd. 9r.

4. A calice de 5 li, nes $\frac{1}{2}$, et corolle blanche de 3 lignes $\frac{1}{2}$.

5. A calice de 5 lignes. Corolle blanche de 5 lignes. Variété très-distincte.

ฐ56. B. chaussée, E. socciflora, S. 98. E. sebana, Willd.

Feuilles à bords réfléc'is et ouverts. Corolle de 4 à 6 lignes, à tube ovale, pyramidal. Capsule ovale.

Variétés. * x. A corolle jaune.

E. sebana viridis, Andr., 59. Sebana lutea, Andr. Var.

* 2. A corolle rousse.

E. sebana sordida, Hortul. Sebana aurantiaca, Andr.

3. A corolle d'une belle écarlate légère.

* E. petiverii, Hortul.

Ces variétés se ressemblent beaucoup. La couleur de leurs fleurs fait seule la différence. Leurs tiges et leurs branches sont fortes, fermes, droites, blanches et pubescentes, couvertes, sur presque toute leur longueur, de rameaux courts, ternés; rapprochés, très-feuillés. Feuilles ouvertes en touffe, de 2 lignes $\frac{1}{4}$, à bords contigus, courbées en-dessous, glabres et d'un 
beau vert foncé. Fleurs nombreuses, pendantes, disposées au nombre de trois à quatre au sommet des jeunes rameaux. Corolle de 5 à 7 lignes, à tube ovale, pyramidal, courbé, à limbe serrant les étamines. Anthères réunies en faisceau long de 3 à 4 lignes, courbé de même que la corolle. Style blanc verdâtre.

La premiere variété a la corolle d'un jaune verdâtre, les anthères d'un rouge brun, courbées, et le stigmate vert. La corolle plus renflée à sa base que celle de la suivante, et peu courbée. Son calice a 6 folioles vertes, courtes, larges, et membraneuses en leurs bords.

La deuxième a la corolle d'un rouge foncé.

Fleurit en automne. N... Bot. cult., $n^{\circ} 69$, éd. 1.

* 157. Bruyìre farineuse, E. furfutosa, 99. E. monadelpha, Andr. 22. Wreld. 94.

Feuilles courbées et ouvertes. Corolle de 4 à 6 lignes, visqueuse. Filamens très-larges. Fleurs terminales et au-dessous des sommets.

Arbuste de deux pieds, rameux à son sommet. Feuilles ternées, obtuses. Fleurs au nombre de 2 ou 3 ensemble au sommet des jeunes rameaux, formant un bel épi. Corolle conique, de 8 à ro lignes, d'un rouge foncé, les étamines saillantes et réunies comme celles des espèces de ce paragraphe. I58. B. folliculaire, $\boldsymbol{E}$. follicularis, S. roo.

Feuilles à bords ouverts. Fleurs solitaires. Corolle de 5 à 7 lignes, enflée à sa base. Fleurs terminales.

Variétés. I. A limbe légèrement ferrugineux. Fleurs jaunes. E. petiveriana, ANDR. 25.

2. A limbe noirâtre.

* E. melastoma, Andr. 43.

Les deux dernières feuilles ne sont pas dilatées à leur base.

La variété $2, E$. melastoma, forme un arbrisseau de 2 à 3 pieds, dont les rameaux nombreux et droits sont couverts de feuilles ternées et quaternées, pointues, serrées contre les rameaux et rudes.Fleurs solitaires terminant les petits ra* meaux, pendantes, coniques, jaunes. La disposition et la 
forme réunie des étamines, comme toutes les espèces de ce paragraphe.

Les espèces d'Andrews, au nombre de 3, sous le nom de petiveriana, ne me paroissent que des variétés l'une de l'autre. La corolle est plus ou moins foncée. Les autres caractères principaux sont les mêmes.

* 159. B. à pinceaux, E. penicilliflora, S. ıо r, E. petiverii vera, Hortul.

Corolle de 3 lignes, couverte par le calice, à tube sphérique. Anthères réunies en forme de pinceau pointu. Fleurs terminales.

Espèce très-belle. Ses bractées et ses calices sont d'un blane de neige. Bot. cult. , $\mathrm{n}^{\circ} 56$, éd. I.

Voyez, pour les affinités des bruyères de cette section, la division suivante, même section.

\section{SECTION II.}

\section{Anthères appendiculées non saillantes.}

\section{Feuilles opposées.}

r6o. B. à feuilles d'œillet, $\boldsymbol{E}$. dianthifolia, S. 6r .

Feuilles deux à deux, longues. Calice ovale, en coin. Corolle de 5 lignes au moins. Appendices dentés en scie. Capsule glabre. Fleurs d'un pourpre très - pâle, terminales. 16r. B. à feuilles de borbone, E. borbonicefolia, S. 240.

Feuilles deux à deux. Calice de 3 lignes $\frac{1}{2}$, ovale, large, 2cuminé. Corolle de même longueur, à tube ovale. Capsule presque ovale. Fleurs axillaires.

\section{Feuilles ternées:}

* 162. B. urcéolée, E. urceolaris, S. 10. F. dura, Sotand. E. hirta, Thunb., Lin. 56. An Willd. 16 ?

Feuilles poileuses. Corolle de 3 lignes, pubescente en dehors, III. 
à tube en godet. Appendices linéaires, amincis. Fleurs terminales, d'un pourpre pâle.

* 163. Bru ỳ̀re lamellée, E. lamellaris , S. I 5. F. urceolaris, Kew, Icon.., Berg.., Willd. 13. E. pentaphylla, Lin. Sp., ed. -2. E. caffra, id. ed. r. E. corifolia, Hortul. An etiam aggregata, Hortul. ?

Feuilles longues, linéaires, lancéolées, presque planes. Corolle de 3 lignes, à tube pyramidal, pubescente à l'extérieur. Appendices glabres. Fleurs terminales.

Tige de 6 à 7 pieds. Feuilles d'un vert grisâtre, blanchâtres en-dessous. Fleurs peu nombreuses, terminales, solitaires ou. deux à trois. Corolle d'un blanc terne, pubescente en dehors, à limbe ouvert et ses divisions réfléchies. Anthères fauves. Filets blancs. Style rouge. Stigmate brun, luisant, à 4 points. Calice à folioles pointues, pubescentes.

Fleurit en été. N... Bot. cult., n॰.6, éd. $\mathrm{I}$. 164. B. pédonculée, E. pedoncularis, S.23. E. rubens, Thunb. Diss. 83. Willm. 5 I.

Feuilles linéaires. Corolle de 3 lignes, à tube globuleux. Anthères à longs trous et laineuses. Fleurs terminales.

Les pédoncules sont longs d'un pouce.

Corolle globuleuse, d'un rouge sanguin. Folioles calicinales lancéolées, serrées contre la corolle, courtes et d'un pourpre verdâtre.

165. B. charmante, E. amcena, S. 24. E. incarnata, ThUnв. Diss. 84... Willd. 52.

Feuilles lancéolées. Corolle de 4 à 5 lignes, à tube en godet et à limbe très-court. Anthères à petits trous et glabres._Fleurs terminales.

Corolle oblongue, campanulée, blanche. Style de la longueur de la corolle. Folioles calicinales lancéolées, entières , glabres, pourpres, serrées contre la corolle, et quatre fois plus courtes qu'elle.

Cette espèce est tout-à-fait différente decelle nommée par les jardiniers $E$. incarnata.

166. B. modeste, E. modesta, S. I17.

Feuilles petites, serrées et imbricées. Corolle de 3 lignes $\frac{1}{3}$ a 
velue, cotonneuse, à tube large et ovale, et à limbe recourbé. Appendices linéaires, amincis. Fleurs couleur de chair, pâles, terminales. 167. B. soyeuse, E. holosericea, S. 118 .

Feuilles à bords très-repliés. Corolle de 3 lignes, soyeuse, à tube ovale. Anthères velues. Fleurs terminales.

Selon M. Salisbury, cette espèce est, de toutes les bruyères connues, la plus belle. Elle se distingue par ses fleurs soyeuses, par sa floraison et le nombre de ses bractées, de celle à feuilles d'if, $E$. taxifolia, à laquelle elle ressemble à la première vue.

168. B. glauque, E. glauca, And. 47. S. I I9.

Feuilles glauques, succulentes. Corolle de 3 lignes, couverte à l'extérieur d'une espèce de rosée. Appendices presque orbiculaires. Fleurs terminales.

Tige de 3 pieds, cylindrique. Feuilles ternées, réfléchies, pubescentes en - dessous. Pédoncules longs. Bractées, calice et corolle d'un pourpre livide. Style non-saillant.

Tige droite, fragile, de deux pieds. Rameaux droits et longs. Feuilles linéaires, pointues, ouvertes, glabres, charnues, glauques. Fleurs en ombelles terminales. Pédoncules trèslongs. Corolle conique, d'un pourpre noirâtre ; les divisions du limbe réfléchies. Les pédoncules et les bractées de la couleur de la corolle. Andr., Traité des Bruyeres.

* 169. B. changeante, E. mutabilis, S. 177.E. cinerea, Lin., Wilcd. 53.

Fleurs verticillées sur les tiges nues. Corolle de 3 lignes, tube urcéolé. Appendices oreillés. Fleurs pourpres, terminales et latérales.

Plante glabre. Feuilles à bords entièrement roulếs et à verticilles distans. Fleurs en grappes courtes sur le sommet nu des liges. Corolle purpurine, ovale, resserrée sous son limbe, de 3 lignes de longueur. Anthères d'un brun noir. Appendices fauves. Style rouge. Stigmate brun. Folioles calicinales simples, pointues, canaliculées.

Fleurit en aout. N. Bot. cult, $\mathrm{n}^{\circ} .36$, éd.

Variété à fleurs blanchęs. 
170. BrUY Ýre glutineuse, E. glutinosa, S. 2 I 8.

Feuilles éparses. Epis serrés. Corolle de 3 a 5 lignes, visqueuse, à tube ovale, pyramidale. Appendices oreillés. Fleurs latérales.

Variétés. I, A corolle de 5 lignes.

E. glutinosa, KEw. Icon.

2. A corolle de 5 lignes.

E. droseroides, ANDr.3o. E. glutinosa, Thuns.

Diss. 48. Berg , Andromeda-droseroides.

Liv. Mant. Willd. 1. Foliis oppositis.

Tige rameuse. Feuilles alternes, linéaires, obtuses, presque sessiles, parsemées de poils glanduleux. Fleurs en grappes terminales et penchées. Corolle ovale, violette, pourpre à son collet, à limbe petit, blanc et obtus. Pédoncules pourpres. Anthères saillantes. Appendices sétacés.

x7 x. B. à feuilles courbes, $E$. curvifolia, S. 219.

Feuilles recourbées. Epis serrés. Corolle de 4 lignes, visqueuse, à tube ovale, pyramidal. Appendices linéaires, amincis. Capsule peu velue. Fleurs latérales.

* I72. B. à feuilles d'if. E. taxifolia, S. 244. Wendu, KEW.,

Icon. Willd. 8I. Antheris muticis. E. taxifolia, Andr.

Feuilles ourbées, terminées par une pointe aiguë. Corolle de 3 lignes, à divisions ovales, en coin, et bifide. Fleurs axillaires.

Feuilles de 6 lignes, bordées d'une ligne blanchâtre, terminées par une pointe pariculière. Fleurs en bouquets presque terminaux. Corolle de 4 lignes, glabre, couleur de rose, à divisions du limbe très-ouvertes. Folioles calicinales d'un rose tendre, presque aussi longues que la corolle, bordées de très-petites glandes noires. 2 bractées près du calice. Filets blancs. Anthères fauves non sarllantes, ainsi que le style. Ovaire velouté.

Cette espèce a un feuillage remarquable. Ses tiges et ses branches sont grises, couvertes des vestiges des anciennes feuilles. Celles-ci sont ternées, rapprochées, ouvertes, longues de 4 à 5 lignes,épaisses, d'un beau vert, bordées d'une membrane blanche, transparente, également terminées par une pointe blanche. N.

Fleurit en septembre. 
172 bis. B. à calice pointu, E. pugionifolia, S. 245. E. tetragona, Thunb. Diss. 5.

Fleurs dans les rudimens des rameaux axillaires. Calice en pointe, garni de longs cils. Corolle de 4 lignes, pyramidale. Anthères trouées au milieu de leur longueur. Fleurs jaunes, axillaires?

* 173. B. liante, E. viminalis, S. 2/46 E.albens, Lin. Mant. Andr., Willd. 66. Antheris muticis.

Fleurs clans lerudinent axillaire des rameaux. Calice acuminé. Corolle de 3 lignes, ovale. Anthères trouées près de leur sommet. Fleurs d'un blanc jaunâtre.

Plante entièrement glabre. Tige droite. Rameaux montans, droits et fauves. Feuilles étroites, linéaires, pointues, plus longues que les entre-nœuds et vertes. Fleurs en grappes unilatérales, au-dessous du. sommet des tiges. Corolle d'un blanc bleuâtre, de 3 lignes, ovæle, ventrue, resserrée sur son limbe, dont les divisions sont très-réfléchies. Anthères brunes. Stigmate brun Folioles calicinales ovales, blanches, avec une ligne verdâtre et élevée, plus courtes que la moitié de la corolle.

Fleurit au printemps, N. Bot., cult., $\mathrm{n}^{\circ} .3_{7}$, éd. I.

\section{Feuilles quaternées.}

I74. B. armée, $E$. velitaris, S. I34. E. glabra, Roxв.

Corolle d'environ 3 lignes, pubescente, à tube presque ovale, et à limbe recourbé et ouvert. Appendices longs, très en coin, un peu dentés en scie. Fleurs terminales.

M. Salisbury a donné à cette bruyère le nom de velitaris, à cause de ses feuilles très-étroites et pointues, qui imitent un. petit dard.

* 175. B. hérissonne, E. hystriciflora, S. 167. E. sparmanni, Thunb. Diss. 34. Lin. Suppl. Willd. IIg. Antheris: muticis.

Feuilles linéaires, amincies, garnies de poils. Calice en coin. Corolle de 4 à 6 lignes, entièrement couverte de poils à l'extérieur. Fleurs terminales.

Cette bruyère s'éleye droit. Ses rameaux sont montans. Ses. 
feuilles nombreuses, étroites, pointues, sont rassemblées par touffes et d'un beau vert.

Les anthères de cette bruyère sont avec ou sans appendices. J'ai préféré la placer ici, à cause de ses rapports avec les espèces suivantes. Bot. cult., éd. I.

175 bis. BrUY Ėre à longues anthères, E. brachialis, S. 166.

Corolle de 6 à 8 lignes, velue sur les deux surfaces, à tube courbé, pyramidal. Anthères très-longues, non saillantes.

176. B. pectinellée, E. strigilifolia, S. 168. E. transparens;

Thunb., Prodr., Willd. II 7 . Antheris muticis. E. cerinthö̈des.

Feuilles ovales, en coin, légèrement pectinées. Calice en coin. Corolle de 6 à 7 lignes, poileuse en dehors à son sommet. Fleurs terminales.

\$77. B. pectinée, E. pectinifolia, S. 169. E. cerinthoüdes. 65. Thunb. Diss. 33.

Feuilles étroites, ovales, en coin , pectinées. Calice rhomboïdal, spatulé. Corolle de 5 à 7 lignes, laineuse en dedans. Fleurs terminales.

E. crinifolia. Affinité des précédentes. $\boldsymbol{V}$. la division suivante, $n^{\circ} \cdot 23$ 个.

* I78. B. pistillaire, E. pistillaris, S. 173. E. australis, LIN. Mant. Wrlld. 54 .

Pédoncules couverts de jeunes feuilles. Corolle de 3 lignes, glabre, in tube un peu courbé, infundibuliforme, et à limbe recourbé. Fleurs terminales. Les semences ont un appendice fongueux.

Tige de 4 à 5 pieds. Feuilles ternées et quaternées, longues de 2 lignes, un peu velucs. Fleurs disposées au nombre de trois à cinq au sommet des rameaux. Corolle d'un pourpre pâle, ou d'un rose léger, de 3 à 4 lignes, à limbe droit et peu recourbé. Anthères brunes. Appendices blancs spiraliformes. Style blanc et saillant. Stigmate en plateau et noirâtre. Folioles calicinales ovales, velues, à bords blancs et dos vert.

Fleurit en avril et mai. N. Bot. cult., $n^{\circ} .28$, éd. $\mathbf{r}$. * 179. B. quaternée, $\boldsymbol{E}$. botuliformis, S. I-5. E. tetratix,

LIN., WILID. 5x. 
Feuilles ciliées. Calice serré. Corolle de 3 lignes, pubescente à son sommet. Appendices lancéolés. Fleurs terminales.

Buisson large, touffu, rempli de tiges. Feuilles disposées en croix, d'un vert grisâtre. Fleurs au nombre de huit à dix, en têtes terminales. Corolle d'un pourpre rose, de 3 lignes, ré. trécie aux deux bouts. Anthères et stigmate bruns. Folioles calicinales bordées de cils blancs et glanduleux. Pédoncules cotonneux, avec une ou deux bractées.

Fleurit en septembre. N. Bot. cult., no. 14, éd. r.

* Variété à fleurs blanches.

* 180 . B. gluante, E. sequax, S. 2 ×3.

Jeunes feuilles couvertes d'un tissu glutineux. Faisceau de 4 à 6 fleurs. Corolle de 3 à 4 lignes, visqueuse. Interstices du limbe renflés en crochet. Fleurs terminales.

Variétés. r. Corolle de 3 lignes, à tube large et ovale. E. physodes, Thunb. Diss. $89 \ldots$ Lin, Sp. Pl... Berg., Willd. 6r.

2. Corolle de 4 lignes, à tube ovale. E. physodes, Andr. 44. Curt. Mag.

Semences, avant leur maturité, tuberculées.

Tige, branches et rameaux montans et droits; ces derniers simples et d'un blanc jaunâtre. Feuilles longues de 3 lignes, obtuses, vertes, munies de petites glandes glutineuses. Fleurs pendantes, en petites ombelles assez nombreuses, terminales. Corolle blanche, longue de 3 lignes et un peu plus, presque transparente, luisante, visqueuse, ovale, globuleuse, renflée, à limbe droit et peu ouvert. Anthères brunes. Stigmate brun. Folioles calicinales blanches à leur base, vertes à leur sommet, avec une ligne dorsale blanche.

Fleurit en février et mars. La corolle avant de s'ouvrir est rétrécie sous son limbe, et celui-ci offre alors une croix extérieure très-saillante, fermée par ses divisions. Cette espèce pourroit être nommée attrape-mouche. N. Bot. cult., no. 3 I * éd. I.

IS . B. jaune et verte, E. blenna, S. 214.

Ecuilles ovales, en coin. Corolle de í à 5 lignes, visqueuse, 
à tube urcéolé, à divisions imbricées à leur base. Filamens très-larges. Fleurs terminales.

Belle bruyère à corolle jaune et entrée verte. Feuilles aussi quinées.

* 182. Bruyère odorante, E. fragrans, S. 229. E. muscari; ANDr. I.... Willd I28. Antheris muticis.

Tige glabre. Corolle de 3 lignes, à tube étroit, pyramidal, et à base plane. Appendices à demi-lancéolés. Capsule presque pyramidale. Fleurs terminales.

Selon Willdenow, et d'après mon observation sur l'individu vivant, cette bruyère a ses anthères ou filamens nus. Elle varie sans doute à anthères appendiculées

Tige et branches fortes et très-r ameuses. Feuilles de 4 lignes; ouvertes, pointues, d'un vert foncé. Fleurs au nombre de deux, trois, quatre, au sommet des jeunes rameaux. Corolle blanche, de 5 à 4 lignes, cylindrique, glabre, lisse, luisante, resserrée sous son limbe, dont les divisions d'un blanc mat, sont roulées en-dessous. Anthères brunes. Stigmate brun et luisant. Calice à folioles lancéolées, blanches, élargies à leur base, vertes et étroites à leur sommet.

Fleurit en mai. N.

Les fleurs ont une odeur douce infiniment agréable, qui a des rapports avec celle de la vanille.

183. B. nidiflore, E. nidiflora, S. 23 г. E. denticulata, Rохв:

Tige pubescente. Calice presque en coin, denté en scie. Corolle de 5 lignes, à limbe moitié plus court que le tube. Appendices très-petits, oreillés. Fleurs terminales.

On confond souvent, dans les jardins, cette espèce avec la $149^{\mathrm{e}}$, à cause de leur ressemblance ; mais celle-ci a des appendices et les trous des anthères plus courts.

* 184. B. aimable, E. amabilis, S. 256. E. inflata, Thune. Diss. 67... Willd. 32.

Deux bractées. Corolle de 5 à 6 lignes, à tube ovale, pyramidal, à limbe très-court. Appendices très-longs, en alêne. Fleurs axillaires.

Jolie bruyère qui forme un buisson arrondi, composé de beaucoup de branches et de rameaux. Feuilles ternées et qua- 
ternées, longues de 2 lignes $\frac{1}{2}$ à 5 lignes, ouvertes, linéaires, pointues, glabres et vertes. Fleurs horizontales, disposées ordinairement, au nombre de trois, au-dessous du sommet des rameaux. Corolle d'un pourpre rose, de 7 à 8 lignesde longueur, ovale, ventrue vers sa base, resserrée sous son limbe, dont les divisions sont courtes et arrondies, lisse et luisante. Anthères brunes ainsi que leurs appendices. Style rouge. Stigmate brun. Calice à folioles ovales, pointues, d'un rouge brun, à bords verdâtres. $\mathrm{N}$.

Fleurit en août et septembre. An E. magnifica, Hortul.? * 185 . B. superbe, E. venusta, $S^{\circ} .257$. E. ventricosa. Wendl., Andr., Curt., Mag. Thunb. Diss. 36. Willd. 121. Antheris muticis, an etiam E. princeps, $A_{\mathrm{NDR}}$, S. varielas.

Deux bractées. Corolle de 6 à 7 lignes, à tube ovale, pyramidal, un peu ventru vers son sommet. Appendices trèscourts, oreillés. Fleurs axillaires.

Charmante bruyère, dont les tiges et les branches sont diffuses et courbées sans ordre. Feuilles inférieures de 5 à 6 lignes, terminées par une pointe brune, presque glabres. Les supérieures longues de 8 à io lignes, lancéolées, pointues, planes et vertes en-dessus, bordées de longs cils blancs, qui, en se réunissant, forment des espèces de dents, arquées et recourbées vers le bas. Fleurs nombreuses, en ombelles presque terminales. Corolle couleur de chair, de 6 à 8 lignes, ovale, ventrue, très-lisse et luisante, resserrée sous son limbe, dont l'entrée est d'un beau rouge, et ses divisions très-recourbées. Anthères brunes avec des appendices si courts qu'ils échappent à la vue et ressemblent à deux petiles dents. Stigmate à 4 points élevés et luisans. Folioles calicinales trés-pointues, de la longueur d'environ la moitié de la corolle. $\mathrm{N}$.

Fleurit l'été et l'automne. Bot. cult. , no. 66, éd. I.

La fructificalion de cetle bruyère est parliculière. Le réceptacle ou la partie inféricure de l'ovaire s'alonge, et a alors c'eux lignes au moins de longueur, et une forme cylindrique, un peu plus longue vers le haut. C'est dans cetie dernière partie 
que se formentles semences. Elles couvrent entièrement le réceptacle et sont recouvertes par les parois de la capsule. Les graines sont très - fines et rouges, et à moins de les observer avec Ia loupe, on ne peut guère s'imaginer qu'elles existent, d'autant plus qu'on peut prendre l'ovaire et le réceptacle alongé pour unesimple base du style.

\section{Variétés.}

J'ai cultivé une variété de cette bruyère qui lui ressemble beaucoup, mais qui cependant s'en distingue. Son port est plus droit. Ses feuilles sont moins ciliées. Ses fleurs sont plus ventrues et plus rouges. Leur limbe se conserve toujours plane, même lorsque la corolle est fanée, ce qui n'est point dans l'espèce précédente, dont les divisions du limbe se réfléchissent et se collent contre la corolle peu de temps après son épanouissement. Elle fleurit dans le même temps.

\section{Feuilles 6ées.}

186. Bruy ̇̀re à feuilles de pin, E. pinifolia, S. 152. E. pinea,

Thunb. Diss. 26... Willd. 103. Antheris muticis.

Folioles du calice imbricées, terminées par une longue pointe. Corolle de 6 à 7 lignes, glabre, à tube claviforme. Capsule glabre. Fleurs axillaires.

Selon Thunberg et Willdenow, les antheres sont nues.

Corolle blanche, obtuse. Anthères pourpres. Calice à folioles élargies à leur base, ensuite linéaires, amincies en alêne et glabres, de la longueur du tiers de la corolle. Тнunв.

187. B. à vaisseau, $\boldsymbol{E}$. doliiformis, S. 172. E. mammosa,

Thunb. Diss. 69... Willd. 37 .

Feuilles velues. Bractées près du calice. Corolle de 4 à 5 lignes, visqueuse, à tube en forme de vase. Appendices courts et en coin. Fleurs terminales.

* 188 . B. oblique, E. obliqua, S. 2 1 2 . Kew. Icon... Thuхв. Diss. 73... Willd. 42. Andr.

Feuilles obliquement verticillées. Epis des fleurs serrés. Co 
rolle de 3 lignes $\frac{1}{2}$, visqueuse. Interstices du limbe renflés en crochet. Fleurs d'un pourpre pâle, latérales.

Tige droite, ainsi que les branches et les rameaux la plupart. simples. Feuilles éparses ou imparfaitement verticillées, rapprochées, un peu courbées, longues de 5 lignes, comme tronquées, vertes et glabres. Fleurs au nombre de trois à cinq ensemble; les unes terminales, les autres au-dessous du sommet, et penchées. Corolle d'un pourpre léger, lisse, visqueuse, de 4 lignes, ovale-globuleuse, resserrée sous son limbe, dont les divisions forment le tiers de sa longueur. Anthères brunes. Appendices dentés. Style non saillant. Stigmate brun. Calice à folioles obtuses, d'un brun verdâtre, ponctuées, visqueuses et luisantes. $\mathrm{N}$.

Fleurit en août et septembre. I 89 . B. squarreuse, E. squarrosa, S. 220.

Corolle de 5 lignes, visqueuse, à tube ovale, pyramidal, à limbe obtus. Appendices sur les bords. Anthères lisses. Fleurs terminales. Feuilles très-denses.

Erica favosa, var. 2. Corolle de 6 à 7 lignes. Voyez le $n^{\circ} 236$.

\section{§. Anthères appendiculées saillantes.}

Feuilles $5^{\text {és }}$ et $6^{\text {eess. }}$

I90. B. en tête, E. cerviciflora, S. I5 r. E. inaperta, Hortul.

Corolle de 3 à 6 lignes, légèrement pubescente, à tube étroit et en godet, à limbe ouvert. Appendices très-petits. Fleurs axillaires. Trois bractées sur chaque pédoncule.

19ı. B. à feuilles d'embothrion, E. embothriifolia, S. 217.

Feuilles linéaires, lancéolées. Epi des fleurs serré. Corolle de 4 lignes, à tube un peu ventru dans sa partie supérieure. Anthères saillantes. Fleurs latérales. Vue Sèche. Salisb. 


\title{
QUATRIÉME DIVISION.
}

\section{Corolle de 2 à 5 centimètres de longueur ( 8 à 20 lignes ).}

\author{
PREMIÈ E SETION.
}

\section{Anthères nues non saillantes.}

\section{Feuilles ternées.}

Yg2. BRUẏ̀re versicolore, $E$, versicolor, S. 122.

Calice droit et recourbé en dedans. Corolle de 8 à ro lignes, á tube plus ou moins à côtes. Filamens dilatés à leur base. Fleurs terminales.

\section{Variétés.}

ฐ. A feuilles vertes. Corolle écarlate, à tube, dont les côtes sont peu élevées. Anthères échancrées à leur base.

E. versicolor, Andr. 12.

* 2. A feuilles vertes. Corolle d'une écarlate foncée, à tube dont les côtes sont peu élevées. Anthères obliques à leur base.

3. A feuilles glauques. Corolle d'une écarlate foncée, à tube dont les cótes sont peu élevées. Anthères obliques à leur base.

E. discolor. Coccinea, Hortul.

* 4. A feuilles glauques. Corolle rose, à tube dont les côtes sont très-peu élevées. Anthères obliques, au bas de leur base.

E. costata, AnDr. 46. An E. versicolor, Willd. 96?

Il y a encore d'autres variétés,

Les variétés de cette bruyère différent assez entre elles par la couleur de leur feuillage et celle de leurs fleurs. Aussi An- 
drews a-t-il fait avec raison une espèce de la $4^{\mathrm{e}}$, et "pourroiton en faire, avec autant de fondement, une autre de la $3^{\circledR}$.

Les deux premières variétés ont un port différent des autres et un feuillage très-vert. Leurs tiges et leurs branches sont plus grosses, et leurs rameaux sont presque tous imparfaitement verticillés. Leurs feuilles sont plus fortes, plus longues, ovaleslancéolées, obtuses et ouvertes. Les corolles sont au nombre de trois, terminales; elles ont ro lignes de longueur au moins, et sont d'une écarlate foncée et éclatante, avec le limbe verdâtre. Les côtes sont peu saillantes. L'extrémité du style et le stigmate sont verts.

Fleurissent en mars-mai.

Quatrième variété. Bruyères à côtes, E. costata, Andr;

Tiges et branches très-droites, cendrées, pubescentes; les rameaux nom!reux et courts, presque toujours verticillés. Feuilles courtes, obtuses, rapprochées, d'un vert glauque, garnies de poils blancs sur leurs bords. Fleurs au nombre de trois ordinairement, terminant les rameaux. Corolle d'un blanc pourpré ou. carné , plus ou moins colorée, d'un joli rose à l'air libre, de $\mathbf{o}$ à I I lignes de longueur, cylindrique, un peu courbée, relevée de plusieurs côtes assez saillantes. Le limbe court, verdâtre ou blanchâtre. Anthères brunes. Stigmate brun ou vert. Calice à folioles imbricées de bractées; les intérieures de la couleur de la corolle, avec la pointe verte; les extérieures à base rouge et à surface verte. Les pédoncules courts.

Fleurit en mars-mai. N.

Toyez, pour les affinités, les numéros 220, 221 , 222.

193. B. en forme de flacon, E. lagenaformis, S. 224. E. jas. miniflora, Andr. 49... E. lagenceformis, Ventenat. Jard. Malmaison. Descrip. et Icon... Exquis...

Corolle de 12 à 14 lignes, visqueuse, à tube ovale, ventru ḋ son sommet, à limbe quatre fois plus court que le tube, et ovale. Fleurs terminales.

Tige droite et brunâtre, rameuse. Rameaux rapprochés, peu ouverts. Feuilles linéaires, pointues, de 3 lignes, d'un vert foncé, garnies sur leurs bords de cils glanduleux. Fleurs au nombre de trois, visqueuses, couleur de chair, marqunces 
de lignes rouges, longues de $\mathbf{1} 6$ à 18 lignes, à tube ventru à sa base, et se rétrécissant jusqu'à son limbe, dont les divisions sont ouvertes. Filets blancs, coudés et recourbés. Style pourpre, à 4 points. Calice à folioles linéaires, ciliées, visqueuses en dedans.

Fleurit en été jusqu'en automne, Vent.

* I94. Bruyère à fleurs de jasmin, E. jasminiflora, S. 225.

E. aitonia, Curt. Mag... Andr. 2 I. E. jasminiflora, Prod. 293. WiLld. 98 .

Corolle de 16 à 19 lignes, visqueuse, à tube cylindrique, ventru à son sommet, à limbe trois fois plus court que le tube et ovale. Fleurs terminales.

La fleur ressemble à celle du jasmin d'Espagne.

J'ai perdu cette espèce sans avoir vu ses fleurs.

Selon Andrews, les anthères de cette espèce sont appendiculées. Sa tige branchue porte des rameaux simples, flexibles et longs. Ses fleurs sontau nombre de trois ensemble, blanches en . dedans, carnées en-dehors. Le tube a un pouce et demi de lon. gueur. Feuilles ouvertes, dentées, épaisses.

Cette bruyère pourroit être une variété de la précédente. Elles ne different guère l'une de l'autre, et je crois mêmeque l' $E$. aim tonia d'Andrews seroit la précédente.

\section{Feuilles quaternées.}

195. B. à feuilles de gortère, E. gorteriafolia, S. 22 r.

Corolle de 8 à s x lignes, visqueuse, à tube ovale, pyramidal, à limbe pointu. Anthèr es laineuses. Fleurs terminales.

Variétés. I. Corolle de 8 à 9 lignes, dont le tube est presque entièrement blanc.

* 2. Corolle de 10 à 1 I lignes.

E. retorta, Curt... Mag... Andr. I5...Thuni, Diss. 9o... Willd. 63.

Cette bruyère est très-diffuse; ses branches sont tournées et recourbées en divers sens. Ses feuilles sont petites, velues, un peu roides et rudes au toucher. Bot. cult., $\mathrm{n}^{\circ} 35$, éd. I.

J'ai perdu aussi cette bruyère sans avoir vu ses fleurs. Elles 
ont une corolle ventrue, pointue, à son sommet, carnée, pourpre sur son limbe, qui est ouvert.

Cette espèce, et les deux suivantes, ont beaucoup de rapports avec les bruyères 184 et 145 .

196. B. en forme de bouteille, E. ampullaformis, S. 222.

E. ampullacea, Andr. 34... Curt. Mag... Willd. 122.

Feuilles lancéolées, en coin. Corolle de 8 à ro lignes, visqueuse, à tube en forme de bouteille, à limbe obtus. Anthères à sommet courbé en - dedans et très-amincies. Fleurs terminales.

Cette bruyère ne s'élève guère qu'à environ un pied. Elle est très-rameuse. Feuilles quaternées, courtes, linéaires, velues, mucronées, rudes en leurs bords, formant 8 rangs sur les tiges. Fleurs couleur de chair, striées de lignes plus foncées, ventrues à leur base, rétrécies vers le haut; à limbe plane, à 4 divis sions, disposées au nombre de 4 à 5 au sommet de chaque rameau.

197. B. à gros ventre, E. capax, S. 223. E. prognans, Soland.

Feuilles ovales, en coin. Corolle de 9 à I I lignes, visqueuse; à tube en large bouteille, à limbe obtus. Fleurs terminales. * I98. B. en forme de clairon, E. lituiflora, S. 13 r. E. linncei, Andr., Hortul. E. perspicua, Wendl... Wrlld. 97.

Calice presque ovale. Corolle de 6 à 8 lignes, pubescente, à tube fortement claviforme. Filamens barbus sur le dos de leur sommet. Fleurs terminales.

Tige très-droite, élancée, garnie d'un grand nombre de rameaux courts, floriferes, rougeâtres et velus. Feuilles ordinairement quaternées, très - étroites, longues d'une ligne $\frac{1}{3}$, rapprochées, obtuses et velues. Fleurs solitaires ou géminées, horizontales, sessiles, terminant les rameaux. Corolle cylindrique, longue de 7 à 8 lignes, un peu voûtée, d'un beau blanc, abondamment couverte de poils blancs, à divisions du limbe droites. Anthères d'un rouge brun, paroissant au travers de la corolle. Style rougeâtre. Stigmate brun, à 8 points. Calice très-m court.

Fleurit en mars - avril. N... Bot. cult., $n^{\circ} \cdot 7 \overline{3}$, éd. I. 
* ig9. Bruyère remarquable, E. conspicua, S. I 43. E. conspía cua, Kew. Icon... H. K., Soland.., Annr. 29... Wilid. I 15.

Pédoncules pubescens. Calice droit, courbé en-dedans, à base concave à l'extéricur. Corolle de 15 liones, pubescente, à limbe émoussé. Fleurs terminales. F euilles aussi 5 .

Tige droite, élancée, de 6 pieds et plus, ferme, brune, peu branchue. Les rameaux nombreux, rougeâtres et glabres. Feuilles de 2 lignes, ovales - alongées, ouvertes, à verticilles distans, vertes et gl: bres. Fleurs peu nombreuses et souvent solitaires, terminant les tiges et les rameaux. Corolle jaune, un peu rougeâtre en - dessus, cylindrique, légèrement courbée, longue de 16 lignes, un peu velue, à limbe large et peu réfléchi. Filamens jaunâtres. Anthères brunes. Style jaunâtre. Stigmate brun. Calice à folioles ovales, membraneuses en leurs bords, glabres, vertes et luisantes.

Fleurit en juillet. N... Bot. cult., $\mathrm{n}^{\circ} .48$, éd. 1 . 200. B. aquatique, E. stagnalis, S. r42. E. tubiflora, Roxв:

Feuilles velues. Pédoncules glabres. Corolle de r o à I r lignes, velue. Anthères droites, granulées. Fleurs terminales.

Cette espèce ressemble beaucoup à la précédente. Ses fleurs sont également jaunes. Elle est entièrement velue.

Tige droite, élevée, ainsi que les branches, rouges et velues dans leur jeunesse; les rameaux verticillés et courts. Feuilles quaternées, linéaires, pointucs, longues de 4 lignes, ouvertes, bordées de poils blanchâtres; vertes et glabres sur leure surfaces. Fleurs souvent solilaires, presque sessiles, terminales. Corolle d'un jaune rougeâtre, presque de la couleur des bruyères verticillées et à flocons, longue de ı 2 à 13 lignes, cylindrique, un peu évasée, légèrement courbée, couverte de poils très-courts; les divisions du limbe très-ouvertes et roulées en dehors. Filets jaunàtres. Anthères droiles, d'un brun clair, avec des rudimens d'appendices. Style rouge. Stigmate brun, un peu concave. Calice à folioles étroites, linéaires, pointues, bordées de cils, écartées l'une de l'autre, peu ouvertes, et recourbées en-dedans.

Fleurit en avril - mai. An revera stagnalis, Salisb? $\mathrm{N}$. 


\section{Feuilles $4-7^{\text {éeq. }}$}

* 20r. B. des marais , E. paludosa, S. I30 et Hortul.. E. concinna, Soland., H. K., Willd. 107. Andr., Horiul. E. versicillata, Berg.

Corolle de 7 à $g$ lignes, pubescente, à tube ü peu en clou. Anthères garnies d'un bec à leur base. Fleurs terminales.

Tige droite, de 7 à 9 pieds de haut, garnie rle raineaux verticillés par éiage. Feuilles $5^{\text {ées }}$ et 6 ées, très-étroites, de 5 lignes, d'un vert foncé et glabres. Fleurs, les unes rassemblées au sonmet des rameaux, les autres formant au-dessous du sommet de la tige et des branches droites, une ou deux grappes distantes, composées de 6 verticilles l'un sur l'autre. Corolle cylindrique, de 7 lignes de longuear, d'un b'anc feint de violet ou gris de lin, a limbe ouve t et presque dr it. Anthères brunes. Stignate brun. Calice caliculé par les bractées, à folioles linéaires, obtuses, roulées en leurs b rds.

Fleur it en septembre et octobre. $\mathbb{N}$. Less anthères sont trèscourtes, luisantes et recourbées en crochet. Bot. eult., nos 15 et 54 , éd. $\mathbf{x}$.

Le nom spécifique abietina ayant été donne par plusieurs auteurs à 5 à 6 espèces différentes, il en est résiulté ứne eonfũsion telle qu'on a de la peine à s'entendre. Il a donc fallu, pour y olvier, réformer ce nom spécifique et ne le citer que comme synonỷme. S'il convient à une espece de bruyere, ón ne peut le donner avec de plus justes titres qu'àcelle-ci, $E$. páludosă, $\mathbf{S}$. E. concinna, H. K., Wrlln., à eatse de ses tíges droites, garnies de rameaux verticillés par étages:

* 202. B. à longues fleurs, F. longiflorta, S. 144. E. elata, Hortul.

Pédoncules glabres. Calice recourbé et ouvert, eonfexe en dehors à sa base. Corolle de 18 à 20 lignes, pubeséente, a limbe obtus. Fleurs terminales. Espèce très-pulvérulente, en l'observant attentivement.

Tige très-droile, élancée et élevée, per branchue, pubescente, et légèrement rougeâtre sur dés individus, d'ur rouge III. 
brun sur d'autres, ainsi que les rameaux dans leur jeunesse. Feuilles $5^{\text {ées }}$ et 6 ées, plus souvent 5 ées, de 3 lignes $\frac{2}{3}$ de longueur, ouvertes, courbées en-dessous, obtuses, tres lisses et luisantes. Sur les jeunes pousses, les verticilles que forment ces feuilles sont assez distans l'un de l'autre. Fleurs longues de plus d'un pouce, d'un jaune teint de rouge.

* 205. BruYère verticillée, E. verticillaris, S. 145. E. lanata, Wendu. Willd. II 2.

Rameaux verticillés, laineux. Calice recourbé en dedans et ouvert, concave en dehors à sa base. Corolle de 9 à 11 lignes, rarement laineuse. Fleurs d'un fauve roussâtre foncé, terminales.

Cette bruyère, qui a le feuillage aussi velu et l'aspect aussi grisâtre ou cendré que la suivante, s'en distingue par ses rameaux plus nombreux, et formant distinctement plusieurs verticilles.

Tige et branches droites, garnies de poils blancs. Feuilles souvent quaternées, courtes, presque cylindriques, obtuses, velues. Fleurs ordinairement solitaires, non réellement terminales, mais au sommet d'un pédoncule feuillé et court, qui naît au-dessous de celui du rameau. Corolle velue, d'un fauve rougeâtre, longue de ro lignes, cylindrique, un peu évasée, et un peu courbée, presque horizontale; les civisions du liwbe très-ouvertes, roulées en-dessous, et glabres en dedans. Anthères petites et brunes. Style jaunâtre, plus long qu'elles. Stigmate simple. Calice à folioles concaves, recourbées endedans, vertes, velues: convexes et canaliculées en dehors, accompagnées de 2 bractées de la même forme, et presque de la même longueur qu'elles.

Fleurit en avril. N.

* 204. B. laineuse, E. floccosa, S. 146 . E. sordida, Ardr., 56. E. laniflora, Wendu. Procera, Wilid. ?

Rameaux épars, laineux. Fleurs souvent solitaires. Calice serré, convexe en dehors, à sa base. Corolle de I 2 lignes, rarement laineuse. Fleurs terminales.

Cette bruvère a beaucoup de rapport à la précédente; mais elle en differe par son port, le temps de sa floraison, ses feuilles recourbées, ses teurs souvent solitaires, ses corolles plus.larges, 
ড̂ limbe plus réfléchi, et par les valves de ses anthères, échancrées obliquement à leur base.

Tige très-droite, élevée, rougeâtre el velue. Les rameaux epars et plusieurs verticillés, au nombre de 3 à 4 par étage. Feuilles quaternées et quinées, longues de 5 à 4 lignes, linéairesobtuses, garnies de poils blancs, laineux,abondans. Fleurs ordinairement solitaires ou géminées, à pédoncules trés-courts, et terminant les jeunes rameaux. Corolle d'un rou ge jaunâtre, terne, longue de 12 à 13 lignes, pubescente, crurbée, à limbe évasé, dont les divisions sont roulées en dehors. Filamens jaunâtres. Anthères rousses. Stigmate simple. Calice à folioles, serré contre la corolle, à bords roulés et velus.

Fleurit en août.

Ces denx espèces ont un aspect cotonneux et d'un gris blan châtre. Leurs anthères sont souvent saillantes; le style est trèssaillant.

205. B. à feuilles de Iycopode, E lycopodiffolia, S. 148. E. massoni, Curt., Mag., Andr. 9. Liv., Suppl., Willo. ío.

Feuilles velues. Corolle de ro à i i lignes, visqueuse, a tube cylindrique, urcéolé, ventru à son sommet. Fleurs latérales.

Feuilles disposées sur huit rangs, couvrant entièrement les tiges et les rameaux, imbricées, pubescentes, très-courtes, obtuses et ciliées. Fleurs en têtes sessiles et latérales. Corolle cylindrique, à divisions du limbe droites et pointues. Bota cult., $\mathbf{n}^{\circ} .44$.

Arbuste de deux pieds; les rameaux droits, couverts de feuilles très-nombreuses, quaternées, garnies de longs poils cotonneux. Fleurs verticillées au-dessous des sommets, pendantes, cylindriques, éléga tnment colorées de rouge et de jaune, avec le limbe vert. Très-belle espèce.

206. B. en carquois, E. $p^{\text {h }}$ aretreformis, S. r 49.

Feuilles recourbées, pointues. Corolle de 13 à 15 lignes ; visqueuse, à tube en entonnoir, et à divisions ovales, en coin. Fleurs axillaires. 
Var. * A corolle orangée.

E. exsurgens, ANDr. 13 .

2. A corolle éclatante.

E. abietina, Roxв.

Cette espèce se distingue par les divisions de sa corolle, qui sont amincies en pointe à leur sommet, et bifides.

Cette bruyère élève sa tige et ses branches droites, avec peu de rameaux, à la manièré des espèces grandiflores, et à longues feuilles ou vêtues. Elles son couvertes de feuilles assez nombreuses, 6ées, très-rapprochées, ouvertes horizontalement, un peu courbées, de 6 à 8 lignes, étroites, acuminées, à bords contigus, glabres et d'un vert foncé. Fleurs nombreuses, disposées en verticilles pressés, au-dessous du sommet des tiges et des rameaux. Corolle jaune et rouge, sur-tout en-dessus, ou orangée, de I 4 lignes, courbée, cylindrique, renflée vers les divisions du linbe, qui sont réfléchies et très-pointues. Anthères d'un brun fauve. - Style rougeâtre. Stigmate brun. Calice à folioles ovales, vertes, terminées par une pointe de même longueur qu'elles, et brune.

Fleurit en octobre et novembre.

La fleur, avant de s'ouvrir, présente un cylindre terminé par un cône très-pointu. Les anthères sont souvent un peu saillantes; le style les surpasse beaucoup. N.

207. Bruyère à chalumeau, E. calamiformis, S. 153. E. radiata, ANDR. 53.

Calice serré. Corolle de 9 à ro lignes, glabre, à tube cylindrique et en godet, à limbe recourbé. Capsule lisse. Fleurs axillaires. Bractées situées au-dessous du milieu du pédoncule.

Tige droite, d'un pied, branches et rameaux simples. Feuilles quaternées. Fleurs verticillées, terminales et au-dessous des sommets, cylindriques, rouges. Le limbe très-ouvert. Belle espece, *208. B. à fleurs d'onosme, E. onosmáflora, S. 156. E. glutinosa, ANdr. 3 I.

Calice un peu recourbẻ á son sommet. Corolle de ga í lígnes; visqueuse, à tube claviforme et à côtes. Anthères trouées àu milieu. Fleurs d'un jaune soufre, axillaires,

Tige droite. Rameaux droits, peu nombreut, rougentres. 
Feuilles $\eta^{\text {kes }}$, longues de 9 lignes, ouvertes, pointues, vertes et glabres; vues à la luupe, elles sont parsemées de points blancs. Fleurs nombreuses, axillaires, horizontales, pédonculées, solitaires ou géminées, verticillées, au nombre de sept à huit audessous du sommet des tiges et des rameaux, où elles forment des grappes distantes. Corolle d'un jaune soufre verdâtre, de I lignes, cylindrique, un peu ventrue vers le milieu, relevée de côtes longitudinales, très-visqueuse, à limbe ouvert et droit. Anthères brunes. Style verdâtre. Stigmate brun, à 4 points luisans. Calice à folioles ovales-lancéolées, de la longueur de la moicié de la corolle, d'un vert jaunâtre, glabres et visqueuses.

Fleurit en octobre. N. Rapports à l'espèce $\mathbf{n}^{\circ}$. I 86.

209. B. coussinette, E. pulviniformis, S. 157 .

Feuilles amincies en pointe, élevées et dentées en scie. Fleurs dans les rudimens un peu alongés des rameaux. Corolle de $7 a$ 9 lignes, visqueuse, à tube cy̆lindrique, en godet. Fleurs axilfaires.

Port et aspect de la $254^{e}, B$. chevelue, cependant diștincte par ses anthères nues, par sa floraison et par les mêmes poils doux qu'ont les filamens des deux especes suivantes.

* 2 r o. B. feuillée, E.frondosa, S. 158. E. coccinea, Wendu., Andr. 4 1... Thunb. Diss. 27.. Willd. 105. et Hortul. Ei. abietina, Lin. Sp. éd. 1. E. archeria, Hortul., ANDR.

Tige anguleuse. Feuilles amincies en pointe. Calice ouvert. Corolle de 9 à 1 o lignes, yisqueuse, à tube à peine claviforme. Fleurs axillaires.

Tige droite; les branches et les rameaux presque cylindriques, souvent d'un violet pâle, marqués par les bases blanchâtres des feuilles. Celles - ci sont $6^{\text {ées }}$, bien ouvertes, un peu glauques, légèrement pubescentes, pointues, feu courbées. Fleurs nombreuses, formant ordinairement deux masses de verdxilles distans l'un de l'autre. Corolle d'une légère écarlate rose, parsemée de poils rouges, peu visqueuse, longue de 7 à 8 lignes, à divisions courtes et droites. Anthères brunes. Style verdìtre. Stigmate d'wun brun grisâtre 'à quatre élévations. Calice i folioles oyalcs, pointues pubescentes, rougcâtres, ouvertes . 
velues, et garnies sur leurs bords de cils glanduleux, rouges, et imbricées de 2 à 3 bractées.

Fleurit en septembre et l'hiver. N...

Cette espèce en grandissant jusqu'à 4 à 5 pieds et plus, se dégarnit de ses branches, qui n'existent plas que vers son sommet.

* 21 . Bruyìre à feuilles de phylique, E. phylicafolia, S. I 59 . E. purpurea, ANDr. 4. Willd. 106. Anth. exsertis. E. coccinea et formosa, Hortul., ANDR.

Tige cylindrique. Feuilles courtes, peu amincies. Calice courbé en dedans et droit. Corolle de 8 à 9 lignes, visqueuse, à tube légèrement claviforme. Fleurs axillaires. Cette espèce a beaucoup de rapport avec la précédente.

Cette bruyère ressemble en effet si fortement à la précédente, qu'on pourroit n'en faire qu'une variété. Son port est le même. Ses tiges sont marıuuées d'autant d'angles qu'il y a de feuilles par verticille; ses angles n'étant fornés que par la décurrence de ces dernières, qui sont glauques, très-ouvertes, et ordinairement $\eta^{\text {ées }}$, les fleurs sont disposées de même. La corolle un peu plus longue et plus courbée, décidément visqueuse, d'un pourpre tirant sur l'écarlate, à divisions droites. Anihères brunes. Style rouge. Stigmate brun et luisant. Calice a folioles un peu plus longues et plus pointues, moins ouvertes, nordées des mênes cils et yelues.

Fleurit en hiver, avec la précédente. $\mathrm{N}$.

Obs. ? On voit, par ba decription de ces deux espèces, qu'elles ne s'accordent pas tout-à- ait avec les caractères que leur assigne S lisbury, sur-tuut à l'égard de la forme de leur tige. Je ne sais si cet auteur ne s'est pas un peu trompé à cet égard. Ce r. 'il y a de cetain, c'est que la première, $n$ ?. 210 , est certainewent 'ericn coccinea de Willdenow et de Thunberg, et que la seconde, $n^{\circ} .211$, est l'erier purpurea de Willdenow et d'Androvs, excopté 'que ses anthères re sont réellement pas saillantes La princinale différence entre ces deux espèces est d'avoir, ai'isi que les auteurs que je viens de citer l'ont observé, Ja corol'e pars ${ }^{\circ}$ mée de poils, dans la première peu visqueuse, et dans laseconde glabre ou point visguneuse. 
* 21 2. B. à longues feuilles, $E$. longifolia, S. 154 .

Pétioles très-étroits. Corolle de 9 à I I lignes, pubescente, à tube plus ou moins claviforme. Capsule-soyeuseà son sommet, Fleurs axillaires.

\section{Tariétés.}

* 1. A corolle blanche.

E. vestita alba, Andr. 20... Thunb. Diss. 25...WrLld: 10.2. Var.

2. A tige serrée et corolle blanche.

E. pinífolia, Hortul.

* 3. A tiges serrées et corolle rouge.

E. pinifolia, Roxв., Andr.

4. A tige épaisse et corolle couleur de chair pâle.

E. longifolia, Kew., Icon... Willd. 10.1 .

* 5. A corolle écarlate.

E. vestita coccinea, ANDr. 33.

* A corolle pourpre.

E. vestila purpurea, Andr. 8... Willd. 102. Var.

* 7. A tige épaisse et corolle carnée.

E. pinea, Andr. 57. Willd. Ior. Var.

Cette dernière variété dont Andrews a fait une espèce, a les fleurs de la forme des autres, d'un pouce environ de longueur, blanches ou légèrement carnées. Le limbe réfléchi.

* 8. A. fleurs éclatantes.

E. vestita fulgida.

Cette variété pourroit être considérée comme une espèce. Ses feuilles sont moins nombreuses et moins serrées que dans les autres. Elle s'éleve jusqu'à 10 à 12 pieds de hauteur, et offre, au sommet de ses tiges et de ses branches, des épis assez longs de fleurs d'un rouge éclatant, non terminales.

9. A. fleurs roses.

E. vestita rosea, ANDr.

30. A fleurs carnées.

E. incarmata, ANDr. Corolle blanche à sa base, rose a. son sommet.

31. A flears vertes:

E. viridis, ANDR. 
Tige droite Rameaux simples et droits. Fleurs verticillées. sous les sommets. Corolle d'un pouce, d'un vert foncé, visqueuse; les divisions du limbe réfléchies. Cetle espèce d'Andrews a tant de rapports aux vestita, que j'ai cru devoir en faire une variété, mais distincte.

Cette espèce varie aussi dans ses feullles, qui sont plus ou moins longues et plus ou moins rapprochées.

Cette bruyère se distingue de toutes les autres par le grand nombre de feuilles étroites, longues, linéaires, si rapprochées qu'elles couvrent les tiges et les branches. Feuilles $6^{\text {ées }}$ ou $7^{\text {ées. }}$ ouverles, tiès-pointues, d'un verţ assez foncé. Fleurs disposées en verticilles serrés, au-dessous du sommet des tiges et des branches. Corollo de 12 à 15 lignes, cylindrique, pabescente, uri peu courbée, à divisions d̉a limbe réfléchies. Filets de la couleur de la corolle. Anthères brunes. Sligmate brun, luisant. Calice à folioles linéaires, glanduleuses sur leurs bords, de 4 lignes de longueur.

Ces variétés fleurissent dans différens temps. Celle à corollepourpre est bien nommée vestit', par la quantité de ses feuilles. Jongues qui semblent la vétir. Bot. cult., $\mathrm{n}^{\circ} 6_{7}$, éd. $\mathbf{1}$.

Les antlières déjassent plas souvent le limbe qu'elles n'y sont renfermées.

Obs. Dans les bruyères qui composent la section suivante, Salisbury a donné à plucieurs des anthères appendiculées Je ne doute as qu'il ne les ait observées ainsi ; nai il est également ceitain qu'elles ne le sont pas dans tous les individus. Limé , Willdenow , Thunberg, n'ont pas aperça ces ap. pendices, et mes observations répétées ne me les ont pas rendu plus se sỉhles. J'aurois donc pu placer ici ces espéces, d'après ces autori és et la vérification que j'ai faite de ce caractère; cependant, conne il y a beancoup d'i ce titude sur la présence ou l'absence des appendices, et qu'il est vraisemblable que Salisbury les a remarqués comme il les a désignés dans snn ordre d'i, ffinités, $j$ 'ai référé laisser leurs descriptions et l'indicaitun de leur caractere dans la section ou il a cru devoir les. placer, et les noter seulement icı avec leurs renyos. 
Bruyères de la section suivante à anthères nues non saillantes, LiN., WILLD,,$N$.
E. tubiflora.
V. no 228.
E. curviflora.
V. $n^{0} 229$ :
E. cuspidigera.
V. $n^{\circ} 230$.
E. bibax.
V. no $23 \mathrm{r}$.
E. buccinaformis.
V. $n^{\circ}{ }_{23} 3$ ?
E. cylindriflora.
V. $n^{\circ} 226$, ou appendices extrêmement courrss.
E. crinifolia.
V. no 234 .

\section{S. Anthères nues saillantes.}

Feuilles ternées.

* 215. B. fragile, E. fragilis, S. 94. E. banksia, ANDR. 26 . WILLD. $9^{2}$.

Feuilles terminées par une pointe aiguë. Corolle de 7 à 9 lignes, à limbe recourbé, horizontal. Capsule barbue. Fleurs term.

Cette espèce ne s'élève guère. Elle forme un petit buisson fort touffu et serré, dont les branches grisâtres sont très-fermes, roides, non pliantes, la plupart horizontales ou peu montantes, d'autres recourbées vers la terre. Rameaux nombreux, for mant presque un angle droit avec la branche. Feuilles de 2 lignes $\frac{1}{2}$ de longueur, ternées, épaisses, presque cylindriques, terminées par une pointe assez longue, aiguë, blanche et transparente; glabres et d'un beau vert. N. Fleurs solitaires ou géminées, terminales. Corolle d'un jaune verdâtre, cylindrique, un peu ventrue à sa base, deux fois plus longue que le calice, à divisions du limbe roulées en dehors. Anthères d'un brun clair. Style vert. Stigmate en tête et verdâtre. Calice à folioles de la même couleur que la corolle, oblongues; obtuses, garni de lractées colorées đe même. WiLLD.

*214. B. longuevêtue, E. vestiflua, S. 95. E.petiveriana, Roх в.

Feuilles courbées en-dedans et ouvertes; les jeunes velues. Fleurs solitaires. Corolle de 7 à 9 lignes, à tube cylindrique. Fleurs rousses, terminales. 
Obs. M. Salisbury avou e que, dans cette famille, oi les espéces se distinguent à la première vue des autres réunions, par leurs anthères et par leurs corolles pendantes, les parties de la fleur ne présentent pas des différerces assez sensibles pour pouvoir isoler chaque espéce et la faire connoitre sans incertitude. Mais, da s cette circonstance, il auroit pu avoir recours au port et au fenillage de chacune d'elles, par lesquels on les auroit assez facilement rapportées à leur nomenclature.

Cette famille ou réunion très-distincte, est composée, savoir :

Dans la 3 e division, des nos $155,156,157,158,159$;

Dans la $4^{e}$, des nos $213,214,215,216 . N$.

* 215. Bruyère à baguette, E. baculiflora, S. 96 .

Feuilles recourbées et ouvertes. Fleurs solitaires. Corolle de 6 à 8 lignes, à tube cylindrique. Capsule ovale. Fleurs term.

Variétés. I A. corolle jaune, E. petiverii, Liv., Manta, WILLD. $9 \mathrm{I}$.

2. A, corolle d'un roux sale, $E$. petiverii, THunb.

Diss. 21. WILLD. 9I.

Le limbe de la corolle, dans cette espèce et ses affinités, est obtus et légèrement crénelé.

236. B. a cothurne, E. cothurnalis, S. 97. E. sebana aurantiaca, Andr.

Feuilles recourbées et ouvertes. Corolle de 7 à glignes, à tube cylindrique, ventru à sa base. Capsule ovale. Fleurs termınales.

Variélés. * . Bractées et calice presque glabres. E. sebana, KEW, Icon. E. coccinea, Lin. Sp. éd. 2. WILLd. $9^{3}$.

Cette bruyere forme un petit buisson dont les tiges sont fortes, fermes et blanches, et les rameaux courts, chargés de feuilles rassemblées, serrées, ouvertes, et courbées en-dessous, pointues, étroites, d'un vert foncé. Fleurs au nombre de trois ou quatre ensemble, terminant les rameaux. Corolle d'une écarlate terne et foncée, longue de 8 à 9 lignes, cylindrique, renflée à sa base, très-courbée en-dessous, ainsi que les anthères, qui sont d'un brun rouge. Calice long de 3 lignes, imbricé de 8 écailles assez grandes, concaves, rougeâtres, ciliées sur leurs bords. Style blanc verdâtre à son sommet. Ces fleurs-, 
par leur couleur et leur courbure, ont l'air de pattes de crabe cuites.

Fleurit en octobre. N.

* 2. à bractées et calice pubescens, $\boldsymbol{E}$. bluknetii, Berg., Willd. 93. Var.

La corolle de ces deux variétés est d'un roux vif, et à 4 angles. Elles ont les plus grands rapports avec les variétés de la $156^{\mathrm{e}}$, auprès de laquelle cette espèce auroit été placée, si sa corolle n'étoit pas plus longue.

Voyez, pour les affinités de ces quatre espèces, les $n^{08} 155$ à 159 .

\section{Feuilles 6ées.}

* 2 17. B. grandiflore, E. grandiflora, S. 150. Curt., Mag., Kew. , Icon., Thunb. Diss. 28. Lin. Suppl. Willd. 108. Andr.

Feuilles courbées, obtuses. Corolle de 12 à I 4 lignes, visqueuse, à tube claviforme. Fleurs axillaires.

Tige et branches droites. Feuilles $5^{\text {ées }}$ et $6{ }^{\text {ées }}$, linéaires, courbées en-dessus; longues de 9 à 10 lignes, vertes et glabres. Fleurs disposées en verticilles serrés, au-dessous du sommet des branches et de la tige. Corolle lisse, luisante, visqueuse un peu courbée, d'un rouge orangé en-dessus, jaune en-dessous, de I3 à I 5 lignes, à limbe réfléchi. Filets et style rouges. Anthères brunes. Stigmate brun. Calice à folioles élargies à leur base, linéaires, ensuite vertes et pointues. Anthères et style trèssaillans.

Fleurit en juillet. N. Bot. cult., $n^{\circ} 64$, éd. $x^{\text {re }}$.

* Variété plus belle et d'un beau port. Ses feuilles sont

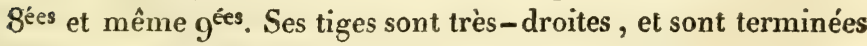
par des verlicilles très-garnis defleurs, d'un rouge écarlate faux, qui se dévelop ent successivement et durent pendant quatre a cinq mois. C'est, je crois, l'Erica grandiflora superba, Hortul., ou grandiflora coccinea. A la première vue $j$ 'aurois remis cette variété à l'espèce $E$. sceptriformis de Salisbury, $n^{\circ} 240$, par ses feuilles au nombre de neuf par verticille, et par son port en forme de sceptre; mais ses calices l'en éloignent. 


\section{S E C T ION II.}

Antỉères appendiculèes non saillaníes.

\section{Feuilles ternées.}

* 2 I8. Bruy Ére à feuilles diverses, E. variifolia, S. i2o. E. mono sonia, $\mathrm{K}$ EW., Icon. E. monsoniana, ThUnв. Diss. 52. Lin. Suppl. WiLLd. 6. ANDR.

Feuilles linéaires, amincies ou ovales. Calice recourbé et ouvert. Corolle de 7 à 9 lignes. Capsule globuleuse, à 4 angles. Fleurs terminales.

Tige droite. Rameaux nombreux. Feuilles, les unes oyales, les autres courtes, linéaires, pointues, très-étroites, un peu rudes sur leurs bords. Fleurs blanches, longues de 8 à io lignes, solitaires, ou au nombre de trois, terminant les rameanx. $\mathrm{Ca}-$ lice à folioles oblongues, ouvertes, recourbées à leur sommet, blanches, de la longueur de la moitié de la corolle, et environnćes de bractées de la même forme et de la même couleur. Bot. cult. , $\mathrm{n}^{\circ} 4$, éd. $\mathrm{r}$.

* 2!9. B. des rochers, E. rupestris, S. 121. E. halicacaba, Krw. Icon... Thunb. Diss. 5 r. Lin. Sp. éd. 2. Wiuld. 5. ANDR.

Calice serré. Corolle de 7 à 8 lignes, à limbe pyramidal, roulé en dedans, un peu recourbé en dehors à son sommet. Capsule hémisphérique. Fleurs terminales.

Arbrisseau droit, formant un buisson épais, garni de beaucoup de branches et de rameaux courts, blanchâtres et pubescens. Feuilles très-rapprochées, assez courtes, pointues, glahres, d'un vert foncé, un peu rudes sur leurs bords. Corolle grosse, pyramidale, blanche ou purpurine, glabre, longue de 8 à ro lignes. Calice à folioles serrées contre la corolie.

Bot. cult, no. 3 , éd. $\mathrm{r}$.

* 220. B. ornée, E. decora, S. 12f. E. eweri et varia, Hortul.

Calice plane, is bords épais. Corolle de $S$ à ro lignes. 
tisquetise, pubescente, à tube claviforme. Appendices longs et pubescens. Fleurs très-belles, roses et vértes, terminaleś.

Tige et branches trèz-droites. Rameaux nombreux, verticillés, au nombre de trois. Feuilles de 2 lignes, pointues, ponctuéeś, glabres et d'un beau vert. Fleurs nombreuses, verticillées. Corolle d'un rouge rose, pubescente, visqueuse, de I2 à If lingnes de longueur, cylindrique, un peu courbée, un peu évasée vers le limbe, dont les divisions sont ouvertes, droites, et d'un joli vert pomme. Anthères brunes. Appendices longs, filiformes, blancs, dirigés vers le bas. Style vert. Calice à folioles larges, ovales, serrant la corolle, rougès, pointues, à bords épais et roulés en-dessoùs.

Celle bruyère a, par ses fleurs, beaucoutp de rapport à ia $12^{2}$, ainsi que la suivante.

Fleurit en août - septèmbre. $\mathrm{N}$.

* 221. B. en forme de cyprès, E. ctipressiformis, S. 125.

E discolor, Andr., Willo. 7 .

Cali e serre. Corollè de 9 à i i lignes, très-glutinetuse, a tube légèrement strié. Appendices courts et glabres. Fleurs terminales.

Tige et branches droites, d'un gris fauve, légèrenent cotonneuses, couvertes de rameaux vericillés, au nombre de trois par étage, pủbescens et rougeâtres.- Feuilles ternées, courte. , de 5 à 4 millimètres de longueur, obtuses, tre ouvertes, peu distantes, vertes et glabres; vues à la loupe, bordées de petits cils glanduleux. Fleurs au nombre de deux ou trois ou solitaires, pédonculées, terminales. Corolle d'un pourpre rose , peu courbée, de 9 à 10 lignes de longueur, très-visqueuse, dont le tube est finement strié et les divisions đú limbe droites et d'un vert pâle. Filets capillaires. Anthères brunes. Appendices courts et menus, de la çouleur des an= thères. Style saillant. Stigmate simple. Calice à folioles serrées contre la corolle, vertes, membianeuses, et légerement deritées sur leurs bords, accompagnées de 3 a 4 braétés serrées contre elles et vertes.

Fleurit en avril - mai. N.

*222 B. nielle, E. mellifiua, S. 125 . 
Bractée inférieure contre la base du pédoncule. Corolle de 9 à 12 lignes, luisante, à tube claviforme, plus ou moins comprimé. Capsule ovale. Fleurs terminales.

Tariétés. 1. A calice très-denté en scie. Corolle d'un rouge sanguin. E. cruenta, Kew., Icon.... Wruzd. 9 .

2. A calice peu denté. Corolle écarlate $E$. cruenta, Añdr. 17... H. K.

Cette dernière variété est plus forte et plus belle.

Tiges, les unes droites, les autres courbées, couvertes d'un duvet court et grisâtre. Rameaux pubescens et blanchâties, souvent disposés trois par trois. Feuilles très-ouvertes, longues de 3 lignes, obtuses, glabres et vertes. Fleurs solitaires ou géminées, terminant les petits rameaux, vers le sommet des tiges. Pédoncules garnis de 2 bractées près de la fleur, et d'une autre à sa base. Corolle d'un rouge pourpre, de II à 12 lignes de longueur, cylindrique, un peu courbée, luisante, à limbe ouvert et ses divisions larges. Filets blancs. Anthères brunes. Style verdâtre. Stigmate brun à points élevés et luisans. Calice à folioles ovales, acuminées, dilatées à leur base, vertes et légèrement ciliées ou dentées sur leurs bouts.

Fleurit en septembre. N... Bot. cult., $n_{0} .9$, éd. I.

\section{Feuilles $4^{\text {ees }}, 5^{\text {ées }}, 6^{\text {ees }}$.}

\section{* 223. Bruyère naine, E. nana, S. 126. E. depressa, Hortul.; Andr.}

Tige couchée sur la terre. Feuilles obtuses. Corolle de 9 à I I lignes, couverte en dehors de papilles, à tube claviforme, comprimé. Appendices longs. Fleurs terminales.

Cette espèce joint assez singulièrement, à une tige basse, des Aleurs grandes et jaunes.

Tige et branches fortes, très-fermes, d'un gris brun, peu élevées, peu montantes; la plupart courbées et se dirigeant vers la terre. Feuilles ternées et quaternées, de 5 à 4 lignes de longueur, linéaires-lancéolées, obtuses, un peu épaisses, glabres et vertes. Fleurs eu nombreuses, solitaires ou géminées, droites, terminales. Corolle jaune, claviforæae, très-glabre, renflée vers 
son sommet, resserrée sous son limbe très-ouvert, et dont les divisions longues et courtes sont réfléchies. A uthères brunes. Appendices rouggeâtres, simples, pointus, assez longs, Style vert. Stigmate noirâtre, en tête. Calice à folioles convexes en-dehors, membraneuses, pointues, accompagnées de quelyues bractées semblables aux feuilles, mais plus petites. Anthères trèscourtes Appendices plus longs qu'elles. Stigmate obtus.

Fleurit en mai. N.

224. B. boursette, E. sacciflora, S. I 28.

Calice ovale, large, acu...iné. Corolle de 6 à 8 lignes, glabre, à tube cylindrique. Appendices longs. Anthères linéaires, trèscouvertes de papilles. Fleurs terminales.

* 225. B. à feuilles rassemblées, E. spissifolia, S. I27. E. pattersonia, Wendl... Andr. 7... Willd. 36. E. abietina, Sp. Pl. éd. 2. Lin.

Feuilles très-denses. Calice à longue pointe. Corolle de 8 lignes, glabre, à tube cylindrique. Appendices longs. Fleurs terminales.

Tige et branches très-droites, absolument couvertes de rameaux courts et de feuilles quaternées et quinées très-rapprochées, linéaires, pointues, très-glabres, d'un beau vert fonce, et de 4 à 5 lignes de longueur. Fleurs solitaires ou géminées, terminant les rameaux, peu nombreuses. Corolle jaune, de 9 à 1o lignes, à tube claviforme, légèrement pubescente, à limbe ouvert, dont les divisions sont imbricées ou posées l'une sur l'autre. N.., Bot. cult, $n^{\circ} \cdot 76$, éd..

Cette espèce est trèstremarquable par son feuillage touffu et serré.

* 226. B. à fleurs cylindriques, $\boldsymbol{E}$. cylindriflora, S. 129. E. serratifolia, ANDr. 36.

Feuilles ciliées, à poils décomposés. Calice un peu recourbé. Corolle de 9 lignes, glabre, à tube cylindrique. Appendices courts. Fleurs terminales.

Tige droite, brune. Rameaux ouverts et fermes. Feuilles quaternées, rapprochées, verticillées sur 8 rangs, longues de 2 lignes $\frac{1}{2}$, garnies sur leurs bords de dents ciliées. Fleurs au nombre de deux à quatre, horizontales, terminant les ravzeaux. 
Corolle de 9 lignes et plus, cylindrique, un peu courbée, rougeâtre vers sa base, jaunâtre à son sommèt, lisse et luisante, verte sur son limbe à divisions réfléchies. Anthères brunes. Appendices très-courts. Stigmate verdâtre, luisant, à 4 points. Calice à folioles glabres, lancéolées, pointues et vertes.

Fleurit en août et septembre. $\mathbf{N}$.

* 227. BRu Y'̀ E bâtarde, E. culcitaflora, S. 135. E. spuria, ANDR. 46. E. hybrida, Hortul.

Calice ovale, en coin. Corolle de 7 à 8 lignes, pubescente, à tube cylindrique, en godet et à limbe roulé en dehors. Capsule presque pyramidale. Fleurs terminales. Port de la suivante, mais certainement appendiculé. S.

Cette espèce a en effet des rapports avec la suivante; mais elle s'en distingue par son aspect d'un beau vert, et par plusieurs autres parties. Tige très-droite ainsi que ses branches. Rameaux nombreux et velus. Feuilles quaternées, longues de 4 lignes, linéaires, pointues, garnies de quelques poils courts, ouvertes, et d'un vert assez foncé. Fleurs au nombre de deux à quatre ensemble ; quelques-unes solitaires, terminant les rameaux. Corolle cylindrique, peu courbée, longue de 9 à io lignes, d'une couleur de chair vive, pubescente, à limbe bien ouvert, et à divisions roulées en-dessous. Filets błancs. Anthères et appendices bruns. Style rouge. Stigmate brun, tétragone et luisant. Calice accompagné de 3 à 4 bractées, à folioles étroites, pointues, serrées contre la cŏrolle, sur laquelle elles se prolongent jusqu'aux deux tiers de sa longueur.

Fleurit en mai-juin. N.

\section{Anthères nues. Noв., Obs.}

228. B. tubiflore, E. tubiflora, S. 136. Lin.., Willd. 112.

Pédoncules glabres. Calice étroit et lyré. Corolle de 9 à ro lignes, puhescente. Interstices du linabe lancéolées à leur base; Fleurs terminales. 
Fariétés. * I. A corolle couleur de chair pâle. E. tubiflora, Lin.

* 2. A corolle couleur de chair vive. E. coccinea, Lrv. Diss...

Dans cette dernière variété, les trous des anthères sont longs.

Aspect grisâtre. Tiges et branches droites, élancées, un peu foibles et velues. Feuilles quaternées, droites, peu ouvertes, velues, ciliées, rapprochées. Fleurs nombreuses, solitaires, terminant chaque rameau. Corolle un peu courbée, de i 2 lignes de longueur, d'un pourpre rose, à divisions du limbe profondes, roulées en-dehors. Filets blancs. Anthères brunes. Style rouge. Stigmate brun et luisant

Fleurit en mai. N... Bot. cult., $\mathrm{n}^{\circ} 42$, éd. 1 . * 229. B. curviflore, E. curviflor , S. 137 . E. simpliciflora; Willd. 1 ix. E. curviflora, Liv. Syst. végét.

Pédoncules pubescens. Calice ovale, en coin. Corolle de $\mathbf{9}$ lignes, pubescente. Interstices du limbe lancéolés à leur base. Feuilles constamment linéaires, amincies en pointe. Fleurs roussâtres en-dessus, terminales.

Aspect d'un vert un peu jaunâtre. Tige branchue, très-rameuse. Rameaux grêles, un peu rougeâtres. Feuilles quaternées, ouvertes, petites, étroites, linéaires, pointues, vertes et glabres. Fleurs nombreuses, solitaires ou géminées, terminant les rameaux. Corolle jaune, rougeâtre en-dessus, longue de 12 lignes, pubescente, un peu courbée, cylindrique, cannelée à sa base, à limbe ouvert et ses divisions peu réfléchies. Anthères brunes. Style verdâtre. Stigmate brun, à 4 points luisans. Calice à folioles élargies, ovales et membraneuses à leur base, étroites, vertes et pointues à leur sommet.

Fleurit cn août. N... Bot. cult., n 43 , éd. x. 250. B. porte-dard, E. cuspidigera, S. 158. E. ignescens,

ANDR...

Pédoncules glabres. Calice ovale, en pointe. Corolle de I 1 à 12 lignes, pubescente. Interstices du limbe lancéolés à leur base. Antheres velues. Filamens rarement velus. Fleurs terminales.

Tige très-droite, élevée, garnie de peu de branches droites, mais de beaucoup de rameaux qui revêtent presque toute la lon- 
gueur de la tige. Feuilles quaternées, linéaires, pointues, d'un beau vert, glabres sur les deux surfaces, garnies de cils blancs sur leurs bords. Fleurs solitaires, terminales. Corolle de I l lignes de longueur, légèrement courbée, d'un jaune ronge sur le tube, rouge sur son limbe, veiue; les divisions du limbe larges, un peu rétrécies à leur base, très-séparées l'une de l'autre par des sinus profonds et ovaleś; réfléchies en - dehors. Anthères brunes, nues, au niveau du limbe. Style rougeàtre, saillant. Stigmate brun et simple. Calice à folioles ovales, poin $\rightarrow$ tues, ciliées en leurs bords.

Fleurit à la fin de l'hiver. $N$.

Le nom que Salisbury a donné à celte bruyère lui convient parfaitement. Les fleurs qui terminent chaque rameau presque horizontalement, et dont le limbe est pointu avant son épanouissement, ont t'aspect de plusieurs dards.

Cette espèce a certainement beaucoup de rapport à la $252^{\mathrm{e}}$; mais ses péloncules et ses filamens ne sont pas du tout pubescens.

* 25r. Bruyère altérée, E. bibax, S. r3g. E. Alammea, Hortul. E. curviflora, Thuxв. Diss. 50. E. curviflora, Wilid. 110.

Folioles du calice imbricées, inégales. Corolle de 8 lignes, pubescente, à tube très en clou. Les divisions imbricées à leur base. Fleurs terminales.

Tiges droites, brunes. Les branches et les rameaux montans et verts. Feuilles quaternées, longues de 3 lignes, linéaires, poinitues, droites, peu ouvertes, glabres et d'un beau vert. Fleurs nombreuses, solitaires, terminant les rameaux. Corolle d'un jaune rouge, luisante, courbée et glabre. $N$.

* 232. B. trompette, E. buccinceformis, S. I 40. E. tubiflora, Thuns. Diss. 5r.... Willd., Syn. An E. cylindriga, Andi.

Pédoncules pubescens. Corolle de gà ro lignes, pubsscente, à limbe ouvert et recourbé. Filamens pubescens. Fleurs ternanales.

Tige et branches droites, brunes; les rameaux nombreux, presque droits, pubescens et rouges. Feuilles qualernées, 
verticilles distincts, linéaires, étroites, pointues, longues de 4 lignes, ouvertes, garnies de poils blancs, d'un beau vert. Fleurs au nombre de deux, trois et quatre ensemble, rarement solitaires, terminant les rameaux; les pédoncules très-courts. Corolle cylindrique, un peu renflée dans son milieu, pointue aux deux bouts, et ayant la forme d'un petit fuseau avant l'ouverture du limbe. Iongue de 10 lignes, d'un blanc carné ou couleur de chair, pubescente; le limbe d'un beau rouge rose, ouvert horizontalement, à divisions courtes, et à bords parallèles, roulées en-dessous et d'une roideur sensible. Filamens blancs, glabres sur l'individu que je décris. Anthères brunes, nues; cependant, élant vues á la loupe, on y remarque de petits rudimens d'appendices. Style d'un beau rouge. Stigmate simple et brun. Calice à folioles ovales à leur base, ensuite étroites, pointues et velues.

Cette bruyère, de la famille des tubiffores, a plusieurs rapports avec la $22 \mathrm{~F}^{\mathrm{e}}$. Elle en a le port, la verdure, et fleurit dans le même temps. $N$.

253. B. fastutuse, E. fastuosa. E. curviflora (I ). Wendu. Andr. 40... Lin. Diss.

(I) L'inconstance de quelques caractères spécifiques des brnyères, I'incertitude même de ceux que leur assigne M. Salisbury, et que mes ohservations x'ont pas toujours trouvé conformes'( principalement dans celles qui composent la quatrième division ), l'absence de certaines parties accessoires que cet anteur a négligées, et qui auroient pu lever des doutes dans les espèces qui présentent, à peu de chose près, les mêmes caractères, peuvent m'avoir occasionné quelques erreurs : il seroit donc possible que mes descriptions ne convinssent pas absolument toutes aux espèces de Salisbury, sous lesquelles je les ai placécs, sur-tout à l'égard des bruyères de la famille des tubiflores, chez la plupart desquelies les appendices manquent ou ne peuvent être regardés que comme des rudimens. Mes descriptions étant, j'ose le direm exactes, parce qu'elles ont ćté faites sur les individus en fleur et en pleine végétation, je prie le lecteur de vouloir bien y suppléer. Je le préviens aussi qu'il ne doit pas trop s'attacher anx subdivisions fondées sur la sailie ou la non saillie des antheres, parce que ce caractère est inconstant et douteux, sur-tout dans les longues corolles. Je ne m'en suis servi que pour me conformer aux observations de Salisbury. 
Pédoncules glabres. Corolle de 10 à I I lignes, glabre, â limbe recourbé et très - ouvert. Capsule largement turbinée. Fleurs terminales.

Cette bruyère s'élève souvent, en quatre années , à 15 pieds de hauteur. S. I $4 \mathrm{I}$.

\section{Anthères nues saillantes.}

* Bruyère élevée, E. grandis, N. An E. elata, Andr.?

J'ai nommé ainsi cette espèce, parce que, bien qu'elle ait plusieurs rapports avec l' $E$. fastuosa de Salisbury, elle en a aussi d'autres qui l'en éloignent. Elle differe, suivant les caractères établis par cet auteur, de l'E. longiflorc par sa corolle très-glabre, de l' $E$. fastuosa par ses anthères nues, et des deux par ses anthères très - saillantes. Elle ressemble à la première par la longueur de ses fleurs, et à la seconde par sa tige élevée, qui, selon l'observation de Salisbury, à l'article de cette dernière, prend, comine elle, beaucoup de hauteur en peu de temps. Elle ressemble aussi à l' $E$. grandiflora, et à la variété à corolle presqu'entièrement jaune, par la forme et la dis. position de ses fleurs, et par ses anthères très-saillantes; mais ses feuilles sont beaucoup plus courtes, et la corolle n'est pas visqueuse.

Espèce très-glabre et d'une verdure foncée dont les tiges et les branches sont montantes et élevées, mais les dernières étalées de tous côtés à cause de leur longueur, et nues inférieurement. Feuilles 4, 5, 6ées, à verticilles distans, de 5 à 6 lignes de longueur, ouvertes, peu recourbées, linéaires, pointues, glabres, d'un vert foncé ; les jeunes b ordées seulement de quelques petits poils qui ne tardent pas à tomber. Fleurs au nombre de deux à quatre ensemble, quelques - unes solitaires, d'abord horizontales, ensuite pendantes, imparfaitement verticillées, terminant de très-courts rameaux, ou axillaires incertaines. Corolle d'un jaune jonquille, un peu rougeâtre en-dessus lorsqu'elle fleurit en plein air, courbée, longue de 16 à 18 lignes, claviforme, évasée vers son sommet, très-glabre, point visqueuse; les divisions du limbe ouvertes, arrondies et peu réfléchies. Filamers 
jaunes, aplatis, courbés et bruns vers l'anthère. Anthères nues et brunes, très-saillantes. Style et stigmate bruns qui les dépassent. Calice à folioles convexes à leur base ; étroites, ouvertes, et même légèrement réfléchies à leur sommet, vertes et glabres. Ovaire vert et turbiné.

Le trou des anthères est étroit et alongé, et celui des anthères de l'E. grandifiora est ovale et fort large.

Fleurit en avril-juin, et même une grande partie de l'été. * 234. B. chevelue, E. crinifolia, S. 170. E. cerinthoüdes, Andr. 26... Curt. Mag... Th. Diss. 33... Berg., Lin. Sp. Pl... WILLd. II 8 .

Feuilles linéaires, Iancéolées, poileuses. Calice en coin. Corolle de 8 à ı lignes, velue et visqueuse en-dehors. Fleurs terminales.

Aspect grisâtre. Tige et branches assez droites, roides, couvertes de feuilles quaternées, très - rapprochées et serrées de manière qu'on n'apercoit pas la tige, couverte de poils grisâtres. Fleurs au nombre de douxe à dix-huit, rassemblées en têtes terminales. Corolle de I I à I 2 lignes de longueur, cylindrique, velue, visqueuse, d'une belle écarlate, à divisions du limbe un peu réfléchies. Anthères d'un rouge de brique. Filets blancs. Style verdâtre. Stigmate vert, à 4 gros mamelons luisans. Calice à folioles lancéolées, pointues, vertes et ve-lues.

Fleurit dans différens temps de l'année. N... Bot. cult., $\mathrm{n}^{\circ} 45$, éd. $\mathbf{I}^{\mathrm{re}}$.

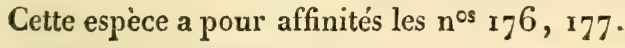

\section{Anthères sensiblement appendiculées.}

235. B. infundibuliforme, E. paveltaflora, S, 226. E. infundibuliformis, Rохв.

Pédoncules très-courts. Corolle de 9 à ro lignes, à limbe farineux intérieurement. Filamens appendiculés vers le sommet. de l'anthère. Fleurs terminales.

Les appendices sont plutôt insérés sur les filamens que sur les. antheres. 
236. Bruy Ère à épis, E. favosa, S. I6I.

Pèdoncules très-courts. Calice calleux, à folioles rhomboidàm les, spatulées, très-entières. Corolle de 5 à 9 lignes, couverte de papilles. Fleurs axillaires ou terminales.

Variétés. * I. A corolle de 7 à 9 lignes, à divisions contiguës à leur base. E. spicata, Wendu., Thunb. Diss. 7 I. Willd. 3g. E. sessiliflora, Lin., Supp., ANDR.

*2. A. corolle de 5 á 7 lignes, à divisions imbricéè à leur base. $\boldsymbol{E}$. spicata, ANDR. 6. Bot. cult., $n^{\text {os }}$ I 7 et 20 , éd. I $^{\mathrm{re}}$.

Les fleurs de cetle bruyère sont situées au sommet des jeunes rameaux, qui font la fonction de pédoncules; ou les fleurs sont presque sessiles. S.

La variété 2 forme un buisson bien garni de branches et de rameaux fermes, assez droits, peu alongés, bruns, très-feuillés. Feuilles 5 , bees, linéaires, terminées par une pointe blanche, ouvertes, arquées vers le haut, presque cylindriques; leurs bords se joignant en-dessous, gabres et d'un beau vert. Fleurs sessiles, situées au sommet des branches, sans être tout-à-fait terminales, disposées en épi serré et court. Corolle d'un blanc verdâtre, à tube étroit à sa base, et se renflant jusqu'au sommet; horizantale, un peu courbée en-lessus, longue de 6 à 7 lignes. Les divisions du limbe vertes, arrondies et droites. Filets des étamines très minces. Anthères brunes. Appendices longs et d'un roux clair. Style vert. Stigmate en tête, à 4 points verts, au niveau du limbe. Calice à folioles spatulées, un peu rhomboïdales, concaves et creusées en cuiller en-dedans, très-entières, et entourées à leur base de plusieurs feuilles plus courtes que celles des rameaux. Toutes les parties de la fleur sont glabres. Je n'ai remarqué aucune papille sur la corolle.

Fleurit en hiver.

Obs. Les fleurs des épis acquièrent, lorsqu'elles se fanent, une roideur remarquable et subsistent long-temps dans cet état. Après leur chute, les capsules, serrées les unes contre les autres, entourées chacune de leur calice, restent attachées à la tige et aux branches, ou elles forment une assez grosse masse qu'elles 
environnent. Ces circonstances sont d'autant plus singulières, qu'elles n'ont lieu sur aucune des bruyères que j'ai observées. 237 . B. claviforme, E. claviflora, S. 163.

Pédoncules très - courts. Folioles calicinales orbiculées - spatulées, très-entières. Corolle de ro à I I lignes, couverte de papilles. Fleurs axillaires.

Celte espèce ressemble beaucoup à la suivante.

* 258. B. alvéolée, E. alveiflora, S. r64. E. gelidasgilva, Hortul, Willd. 37. Andr.

Pédoncules glabres. Corolle de 7 à 9 lignes, couverte de papilles, à tube cylindrique, à 4 angles à sa base. Fleurs axillaires.

Tige, branches et rameaux droits, élevés, d'un vert jaunâtre. Feuilles quaternées, de 4 lignes, linéaires, terminées par une pointe particulière blanche et piquante, fermes, ouvertes, glaw bres, d'un vert foncé. Fleurs pendantes, presque unilatérales, rassemblées plusieurs ensemble en sorte d'épi, au-dessous du. sommet des rameaux. Corolle cylindrique légèrement courbée, đe ro à 12 lignes de longucur, blanche, ferme, très-glabre, tétragone à sa base, à divisions du limbe vertes, courtes et arrondies. Filets blancs. Anthères brunes. Style verdâtre. Stigmate brun et luisant. Calice à folioles larges, ovales, concaves, bordées d'une membrane blanche, serrées contre la corolle.

Fleurit en juin et juillet. N. Bot. cult., no. 7 I , éd. I re. * 25 g. B. mamelonnée, E: mammosa, S. 165.

Pédoncules pubescens. Corolle de 8 à ro lignes, parsemée de papilles, à tube cylindrique, urcéolé, avec quatre enfoncemensà sa base. Fleurs axillaires.

Lariélés. * I. A corolle écarlate, ou couleur de vermillon.

E. verticillata, WILLD. 35. ANDR. 21. E. speciosa, Schnéer.

* A. corolle d'un pourpre vif.

Autre d'un pourpre pâlee.

E. mammosa, ANdr. 58. Lin., Mant. E. abicu tina, Thunb. Diss. 68. Berg.

*3. A corolle d'un pourpre obscur.

E abielina, Wurd. 54. 
Les variétés de celte espèce ont leur style saillant ou non saillant.

Tige assez droite, souvent très-rameuse. Rameaux inférieurs souvent courbés, les uns verticillẻs, les autres très-droits, principalement les floriferes. Feuilles quaternées, de 3 lignes de longueur, pointues, assez rapprochées. Fleurs pendantes, nombreuses, verticillées, et formant, au-dessous du sommet des tiges et des branches, des grappes serrées. Corolle de 8 à II lignes, cylindrique, écarlate ou pourpre, peu courbée, légèrement tétragone, remarquable par sa roideur et par quatre enfoncemens à sa base, à limbe obtus, et ses divisions arrondies, petites et droites. Anthères brunes. Style blanc. Stigmate brun. Calice à folioles ovales, pointues, de la même couleur que la corolle. A mesure que la corolle tend à se flétrir, elle acquiert plus de roideur encore et se sillonne de stries longitudinales très-sensibles.

Fleuriten septemb. et octob. N.Bot. cult., $\mathrm{n}^{0 \mathrm{~s}} 20$ et 73 , éd. $\mathbf{1}^{\text {se. }}$

\section{Feuilles gées.}

240. Bruyìre en forme de sceptre, E. sceptriformis, S. 162: E. enneaphylla, Roxв.

Tige droite. Pédoncules très-courts. Calice calleux, à folioles large, même spatulées, incisées, dentées en scie. Corolle de 7 à 10 lignes, couverte de papilles. Fleurs axillaires.

* 24 I. B. à fleurs radiées, E. radiiflora, S. 147. E. octophylla, Wrlld. 40. E. fascicularis, Willd. 4. Kew. Icon. Lin., Suppl. E. coronata, ANDr. Io. E. octophylla, Thunb. Diss. 72.

Pétioles très-étroits. Corolle de 13 lignes, visqueuse, à tube cylindrique, en godet, ventru à son sommet. Appendices en alêne. Fleurs latérales.

Tige droite. Rameaux glabres. Feuilles Sées, très-rapprochées, courbées, linéaires, très-étroites, denticulées en leurs bords, portées sur d'assez longs pétioles, glabres. Fleurs nombreuses, au nombre de dix-huit à vingt-quatre, formant sous le sommet des rameaux des verticilles. Corolle de 12 à I 5 lignes. 
pourpre ou d'un rouge sanguin, cylindrique, verte ou jaune sur son limbe, dont les divisions sont ovales, pointues et rapprochées. Anthères brunes. Style vert. Stigmate brun. Calice ì folioles lancéolées, vertes et glabres. Belle espèce.

Fleurit en aoûl. N. Bot. cult., $\mathrm{n}^{0} \cdot 22$, éd. $\mathbf{r}^{\text {re }}$. $24 \mathrm{r}$ bis. B. hybride, E. hybrida, N,

J'ai nommé ainsi cette bruyère, que M. Godefroy, pépiniériste à Villedavray près Sèvres, m’a communiquée en échantillon, et qu'il a obtenue de graines du Cap, parce qu'elle a du rapport avec plusieurs espèces de cette division. Ses caractères m'ont paru aussi inconstans que ceux de quelques-uns des paragraphes précédens.

Elle a le port de la $227^{e}$, et les feuilles de l'espèce versicolor. Celles-ci sont ternées, rassemblées en faisceaux sur les rudimens des jeunes rameaux, glabres et pointues. Ses fleurs sont au norabre de deux ou trois ensemble au sommet des rameaux. La corolle, d'un pouce de longueur, est presque cylindrique; les divisions du limbe arrondies, d'un beau rouge et trèsglabres. Antheres saillantes, brunes; les unes nues, les autrcs munies de petits appendices très-minces. Style verdâtre. Stigmate tétragone, brun. Folioles calicinales pointues, élargies et membraneuses à leur base. Cette espèce est belle, ct pourroit être, ainsi que quelques autres, une variété forméc au Cap. Fleurit en automne.

242. B. commune, E. vulgaris, Lir., WiLld. 43 . cb E. europea.

Cette plante, selon les observations de Salisbury et de Jussieu, a des caractères qui l'éloignent de ce genre et en constituent un distinct. Le caractère essentiel par lequel elle differe des bruyères, est d'avoir une capsule dont les valves s'ouvrent par le côté des loges, et dont les cloisons restent atlachées ir l'axe. Ses fleurs et ses feuilles sont aussi absolument sessiles; elles n'ont aucune apparence de pédoncule et de pétiole. Sૂlisbury nomme ce nouveau genre Calluna.

En conservant cette plante dans la famille des bruyères, clle devroit être dans la première division, section des anthères appendiculées. Feuilles opposées, sagittées. 
Elle est très-commune par-tout. Bot. cult., $n^{\circ}$. I, éd. $\mathbb{I}$.

* Varietés à fleurs doubles.

Cette variété est extrêmement jolie.

Ses fleurs sont, dans quelques individus, blanches; mais le grand nombre porte des fleurs roses.

N'ayant pu connoître le nombre des feuilles de la première espèce suivante et la longueur de la corolle de la seconde, il ne m'a pas été possible de les insérer dans les divisions de ce genre.

243. Bruyère à feuilles de chardon, $E$. carduifolia, S. 27.

Feuilles garnies de poils. Longs pédoncules. Corolle de 2. lignes $\frac{1}{2}$, glabre, à tube globuleux et filamens très-courts. Anthères appendiculées, non-saillantes. Fleurs terminales.

244. B. blanchâtre, E. placentceflora, S. 102.

Feuilles très-obtuses. Corolle couverte par le calice, à tube rapiforme. Filamens peu à peu dilatés. Stigmate étroit. Ana. thères nues, saillantes. Fleurs terminales. Fleurs ternées.

\section{Autres Bruyères cultivées.}

\section{Espèces qui font partie des deux premières. divisions.}

SECTION PREMI ÉRE。

\section{Anthères nues.}

245. B. jaune, E. Alava, Andr.

Tige droite; les rameaux distans. Feuilles ternées, ouvertes; linéaires, un peu épaisses, luisantes, très-finement ciliées en leurs bords. Fleurs nombreuses, ovales, muarquées de côtes, jaunes; leur limbe obtus et ouvert; penchées, rassemblées andessous des sommets; les pédoncules plus longs qu'elles. Anthères à peine saillantes.

246. B. ouverte, $E$. patens, ANDs. 
Tige droite, élevée; les ram. verticillés; les jeunes nombreuz et ouverts. Feuilles ternées, ovales, obtuses, ciliées, ouvertes. Fleurs au nombre de trois ensemble au sommet de chaque rameau. Corolle campanulée, pourpre, à tube très-court; les divisions du limbe grandes, ovales, concaves. Anthères à peine saillantes.

247. B. à larges feuilles, $\boldsymbol{E}$. latifolia, ANnr.

Buisson rameux, d'un pied. Rarneaux flexueux, verticillés: Feuilles ternées, larges, ovales, acuminées, velues en-dessus; concaves et blanchâtres en-dessous, roulées en leurs bords. Corolle globuleuse, glabre, d’un rouge léger; les divisions du limbe droites. Anthères saillantes.

2 f8. B. horizontale, E. horizontalis, ANDR.

Arbuste d'un pied, en buisson rameux; les rameaux horizontaux. Fleurs au nombre de 3 ou 4 , terminales, penchées. Corolle ovale, glabre, blanche à sa base, pourpre à son sommet, assez petite; les divisions du limbe droites et d'un pourpre noirâtre. Anthères saillantes.

249. B. assemblée, E. conferta, ANDr.

Tige forte, droite, simple, élevée. Les jeunes rameaux courts, verticillés, très-feuillés. Feuilles quaternées, glabres, mucronées. Fleurs rassemblées en têtes serrées, souvent au nombre de douze au sommet des rameaux. Corolle globuleuse, glabre, petite, blanchâtre. Anthères à peine saillantes. Les feuilles de cette espèce sont aussi nombreuses que celles des $\boldsymbol{E}$. vestita.

250. B. pendante, E. propendens, ANDR.

Tige d'un pied et plus, flexueuse, ainsi que les rameaux. Feuilles quaternées, pubescentes. Fleurs géminées, terminales sur les jeunes rameaux. Corolle campanulée, d'un pourpre rouge. Les divisions du limbe ouvertes. Anthères non saillantes.

\section{SECTION P R E I ER E.}

\section{Anthères appendiculées,}

* 25r. B. aiguë, E. acuta, Andr. E. tenuifolia, Hortul. Tige foible, flexucuse, peu élevée. Feuilles quaternées, 
glabres, ternées au sommet des rameaux. Corolle pourpre, en godet. Les divisions du limbe très-ouvertes, aiguës et un peu réfléchies. Anthères non saillantes. La corolle non encore ouverte est très-pointue à son sommet.

252. Bruyère ardente, $\boldsymbol{E}$. ardens, Andr.

Tige flexueuse, élevée. Les rameaux droits et ouverts. Feuilles ternées, réfléchies vers le bas. Fleurs latérales, presqu'au nombre de trois ensemble, pendantes, globuleuses, couleur de feu. Les divisions du limbe droites. Anthères non saillantes.

Cette espèce a des rapports à l' $E$. baccans et ses affinités. 253. B. odorante, $\boldsymbol{E}$. fragrans, ANDr.

Arbuste d'un pied, formant un buisson très-rameux. Feuilles ternées, droites, glauques, en alêne, presque imbricées. Fleurs petites, campanulées, très-odorantes, d'un pourpre pâle; les divisions du limbe réfléchies. Anthères saillantes. Rapports à l' $E$. vulgaris.

254. B. de Nivent, E. nivenia, Andr.

Arbuste en buisson, de 5 à 6 pouces de hauteur; les rameaux divergens. Feuilles ternées, lancéolées-linéaires, obtuses, très-velues sur leurs bords. Fleurs en ombelles terminales. Corolle turbinée, à côtes, pourpre; les divisions du limbe roulées. Anthères saillantes.

255. B. luisante, $\boldsymbol{E}$. lucida, ANDr.

Tige de deux à trois pieds, Rameaux grêles, souvent ternés, quelquefois opposés, ouverts. Fleurs en ombelles terminales de 3 fleurs. Corolle campanulée, carnée, luisante, petite. Anthères à peine saillantes. N.

256. B. barbue, E. barbata, ANDr.

Tige flexueuse. Rameaux filiformes, foibles et velus. Feuilles quaternées, ovales-lancéolées, ciliées , ouvertes, glanduleuses en-dessus. Fleurs blanches, en godet, visqueuses, couvertes de poils, penchées, en ombelles terminales. Le limbe droit. Anthères non saillantes. Variété plus petite , barbata minor, Andr.

257. B. des roches, E. rupestris, ArDr.

Arbuste très-petit, rampant sur les rochers ou dans leurs. 
fentes; les rameaux divergens. Feuilles quaternées, rassemblées, ouvertes, très-obtuses, luisantes, cartilagineuses en leurs bords. Fleurs au nombre de trois ensemble, penchées ou peu droites, terminales. Corolle blanche, campanulée ; les divisions du limbe membraneuses en leurs bords. Anthères barbues, non saillantes.

Cette espèce est très-jolie.

258. B. de Lambert, E. lamberia, ANDr.

Arbuste en buisson, dont les branches et les rameaux sont divergens. Feuilles quaternées, pointues, glabres. Fleurs solitaires ou au nombre de trois ensemble, pendantes, situées vers le milieu de la longueur des rameaux. Corolle globuleuse, renflée, glabre, blanche, de la grosseur d'un pois. Les divisions du limbe droites. Les pédoncules colorés. Anthères non saillantes.

25g. B. de Solander, E. solandra, Andr.

Tige d'un demi-pied environ, flexueuse, ainsi que ses rameaux, qui sont filiformes et hispides. Feuilles quaternées, trèspetites, rassemblées en têtes serrées et terminales. Corolle nue, rougeâtre. Les divisions du limbe ovales et ouvertes. Les fleurs sont très-petites.

* 26o. B. mignone, E. tenella, ANdr.

Petit buisson à rameaux filiformes, divergens; les jeunes et supérieurs verticillés. Feuilles quaternées, très-petites, linéaires, glabres. Fleurs nombreuses, rassemblées en têtes au sommet des rameaux. Corolle petite, pourpre, ventrue. Les divisions du limbe ovales, droites et ouvertes.

Cette espèce est, je crois, dans celles de Salisbury; mais je n'ai pu la mettre dans une de ses espèces avec quelque certitude. Elle est très - jolie, et est presque toujours en fleur. Elle a des rapports avec l'E. acuta $25 \mathrm{r}$. 


\section{CLASSEX, ORJREII. zear 3 . \\ II. Espèces qui font partı des deux dernieres divisions.}

\section{SECTION PREMIER E.}

\section{Anthères nues.}

261. BRUY Ėre bicolore, E. bicolor, ANDr.

Tige élevée, flexueuse. Jeunes rameaux nombreux, droits ef pubescens. Feuilles ternées, velues. Fleurs tubuleuses, d'un pouce de longueur, d'un rouge pourpre à leur base, vertes depuis le milieu de leur longueur jusqu'à leur sommet, au nombre de trois ensemble, terminant les jeunes rameaux. Anthères non saillantes. Rapports aux tubiflores.

* 262. B. linné oïde, $E$. linnceoides, ANDr.

Cette espèce a, par son port et ses feuilles, des rapports à l' $E$. linnai. E. lituiflora, S SLISBUry, no $1 g^{8}$ de cet ouvrage.

Tige droite ainsi que ses rameaux, qui sont nombreux. FeuilIes quaternées, linéaires, velues, ouvertes. Fleurs au nombre de 3 ou 4 ensemble, presque sessiles, terminant les jeunes rameaux très - courts. Corolle presque cylindrique, tubuleuse, velue, d'un beau rouge carmin à sa base, blanche jusqu'à son sommet où le limbe a ses divisions ovales et ouvertes. Anthères non saillantes. J'ai perdu cette jolie espèce, et je ne crois pas que Salisbury en ait fait mention.

263. B. desmarais, E. palustris, AvDr.

Tiges grêles, flexueuses. Rameaux divergens, menus; les jeunes très-courts. Feuilles quaternées, ouvertes, recourbées, obiuses, linéaires, pubescentes Fleurs souvent au nombre de trois au sommet des jeunes rameaux et garnissant aussi les branches. Corolle presque cylindrique ou étroite, campanulée, pubescente, carnée ; les divisions du limbe ovales, obtuses, blanches. Anthères non saillantes.

264. B. princesse, E. princeps, ANDr. 
Arbuste de deux pied" environ ou plus, très-ramenx"; les rameaux droits. Feuilles quaternées, linéaires, élargies, recourbées, ciliées et même pileuses ou barbues. Fleurs élégantes, en ombelles terminales de 6 à ı o fleurs; les pédoncules colorés. Corolle ovale-alongée en sorte de petite bouteille, ventrue, lisse, rosée, rétrécie à son sommet; les divisions du limbe arrondies et roulées. Anthères non saillantes. Cette espèce a tant de rapports à celle que je cultive sous les noms ven ricosa, $\mathrm{ANDr}_{\mathrm{N}}$, et venusta, S., no 185 de cet ouvrage, que je crois que c'est la même. Elle est rare et chère, mais superbe.

265. B. rose, E. rosea, ANDr.

Tiges et rameaux droits, couverts de feuilles; ces derniers souvent aliernes. Feuilles quinées ei fiées, droites, sétacées. Fleurs ordinairement au nombre de trois, terminales et solitaires, ou deux à deux sur les rameaux. Corolle cylindrique, un peu courbée, d'un pouce de longueur, d'un rose léger; les divisions du limbe ùroites. Rapports aux tubiflores. Antheres. non saillantes.

266. B. filamenteuse, E. filamentosa.

Tige droite, rameuse; les rameaux verticillés, très-feuillés. Gées. F. linéaires, très-étroites, glabres. Fleurs verticillées au-dessous des sommets, très-nombreuses. Pédoncules longos, filiformes, pourpres. Corolle tubuleuse, campanulée, pourpre, de 6 à 7 lignes de longueur, dilatée en son sommet, ou les divisions du limbe sont très - ouvertes et réfléchies. Anthères non saillantes.

267. B. dorée, E. aurea.

Arbrissean dont la tige est droite et les rameaux vertieillés, ouverts, couverts de feuilles $6^{\text {ées }}$, linéaires, très - ouvertes. Fleurs verticillées au-dessous des sommets, cylindriques, glabres, orangées, de 8 à ro lignes. Rapports aux coccinea ou frondosa, $\mathrm{S}$. 


\section{SECTIO N I I.}

\section{Anthères appendiculées.}

268. Bnuyère hérissée, $\boldsymbol{E}$. hirta, Andr. non Thunb.

Tige droite, rameuse, velue; les branches et les rameaux opposés. Feuilles ternées, linéaires, velues, ouvertes. Fleurs au nombre de trois ensemble, droites et terminales. Corolle iubuleuse, ventrue vers son sommet, d'un beau pourpre rouge, verte en son limbe, dont les divisions sont distinctes ê droites. Anthères non saillantes. Rapports au venusta. Belle espèce.

* 269 . B. magnifique, E. speciosa, AND.

Arbrisseau de deux à trois pieds, droit et rameux; les rameaux droits et souvent opposés. Feuilles ternées, linéaires, obtuses, pubescentes. Fleurs au nombre de 2, 3 et 4 , pendantes, situées au sommet des jeunes rameaux. Corolle cylindrique, d'un pouce de longueur, courbée, visqueuse, luisante, d'un beau rouge léger ou foncé, verte à son sommet; les divisions du limbe ouver'es. Antlieres non saillantes. Rapports aux versicolores et à l'E. decora, no. 220.

2jo. B. d'Uhr, E. uhria, ANDr.

Tiges de deux pieds et plus, peu rameuses; les jeunes rameaux nombreux et droits. Feuilles ternées, linéaires, glabres, ouvertes. Fleuis solitaires, axillaires, formant une grappe assez Iongue vers le sommet des tiges. Corolle tubpleuse, cotonneuse, d'un rouge sanguin, verte à sommet, tétragone à sa base, visqueuse. Les divisions du limbe droites, un peu courbées. Anthères à demi-saillantes. Rapport à l'E. venusta et aux versicolores.

Variété. E. Uhria pilosa, Annr. Feuilles velues. Fleurs ordinairement au nombre de deux ensemble, nombreuses, velues, courbées, tubuleuses, d'un rouge pourpre; verte à son sommet.... Belle espece. 
27 x. B. en vase, E. obbata, Andr.

Arbrisseau très-branchu, dont les rameaux sont grêles et̂t nombreux. Feuilles quaternées, réfléchies, rudes, ciliées, d'un vert pâle. Fleurs au nombre de 4 ensemb̆le, terminales, très-glabres, sessiles. Corolle ventrue à sa base, rétrécie à son sornmet, en forme de petite caraffe, légèrement striée, trèsglabre et blanche. Les divisions du limbe très-grandes, rougeâtres, arrondies, crénelées, très-ouvertes. 8 glandes à l'entrée du tube: Anthères non saillantes. Rapport à l'E. venusia. Belle espece.

Variété à fleurs plus vantrues, d'un blanc lisse et disposées en ombelles.

Je $m$ 'arrềte dans l'indication des espèces de ce genre de crainte de contribuer encore, en en nommant d'autres, à la confusion qui ne règne déjả que trop dans les bruyères, par le nombre des espéces et par les différens noms qu'on leur a donnés. D'ailleurs celles que j'ajouterois pourroient être des doubles sous une autre nomenclature, et peut-être s'en trouve-t-il déjà. J'ai quelque raison de penser que l'on pourroit diminuer le nombre des espèces en faisant des variétés de quelques-unes. Quand des bruyères ont à-peu-près le même feuillage, la même forme de corolle et les mênes anthères, il me semble qu'on pourroit les rapporter à celles qui ont les mêmes caractères. La clarté s'ensuivroit etl'on parviendroit plus facilement à leurconnoissance. Les géranions sont bien aussi nombreux, mais la forme de toutes leurs parties les rend beaucoup plus aisés à distinguer au premier aspect. Beaucoup de bruyères, au contraire, offrent le même feuillage : il faut voir les fleurs et leur caractere pour en faire la différence.

Oncultive actuellement en Angleterre plus de 300 espèces de bruyère, suivant les catalogues et la nomenclature anglaise. Mais je doute que ces espèces soient toutes réelles. Lorsqu'un jour on aura pu semer un plus grand nombre de bruyères, peutêtre verra-t-on ces espèces adoptées devenir des variétés. 
Culture des Bruyères.

Le joli genre des bruyères, qui charme et satisfait Jes yeux par la légèreté du port de ses espèces, par leur verdure agréable, la forme, l'élégance, l'éclat ou la douceur de leurs fleurs, présente, à l'égard de plusieurs, quelquesincertitudes surla manière de les conserver et de les multiplier, d'autant plus difficiles à vaincre encore, qu'elles semblent júsqu’à présent dèpendre de leur nature plutôt que de l'inexpérience du cultivateur. Cependant les observations que j'ai faites sur les bruyères nouvellement cultivées, comparati$\nabla$ ement avec celles depuis assez long temps introluites dans nos jardins, m’autorisent à croire que dans peı d'années les premières, qui s'opposent le plus à nos soins, n'y seront pas plus rebelles que les dernieres. Leur durée doit être à-peu-près la même, parce quil n'y a pas de raison de penser que les espèces cultivées avant les nouvelles ont une carrière plus longue que celles-ci. J'ai des individus des premières qui ont actuellement seize ans, et qui n'offrent aucune apparencerle caducité. Il est donc très-probable, qu'à l'exception peut-être de certaines qui pourroient n'être pas aussi vivaces, presque toutes doivent avoir le même cours d'existence, quand leur traitement et les accidens ne s'y opposent pas.

Les bruyères croissent toutes au cap de BonneEspérance, du moins celles dont il est ici question, ou dans les lieux peu éloignés de cette pointe. Ellıs demandent toutes la mème température; elles sont presque toules toujours en végétation; mais le temps 
de leur floraison est différent selon les espèces. Les unes fleurissent en été, les autres en automne, une grande partie dans notre printemps; plusieurs ne por. tent de fleurs qu'une fois par an; quelques-unes fleu. rissent deux fois. Le temps de leur repos, pour la plupart, est après leur floraison; cependant il y en a, sur-tout celles qui ont leurs fleurs axillaires ou disposées en verticilles, qui alongent leur sommet en même temps qu'elles fleurissent, et dans lesquelles la végetation est par conséquent toujours en activité. Il s'en trouve dont la succession de leurs fleurs est telle, qu'elles n'en sont jamais dénuées : telle est l'Erica turrigera (Salisb.), qui en est couverte pen. dant toute l'année. Leur floraison plus ou moins abon. dante et son époque, qui ne peut être absolument déterminée, dépendent de leur état actuel, et cet état est évidemment la suite de leur culture.

- Plusieurs bruyères nouvelles périssent au moment qu'on s'y attend le moins, et dans la pl us belle apparence de vie. Couvertes de fleurs, et dans la plus fraîche verdure, leurs tiges et leurs branches sont déjà mortes, lorsqu'elles sont encore parées de tout l'éclat que leur a prodigué la nature. C'est dans cet élat que j'ai perdu quelques espèces. La cause de leur mort. est le plus ordinairement dans les racines, quelquefois dans les tiges. Dans le premier cas, la plante n'a plus de verdure à son collet, quoiqu'elle en ait dans ses tiges, et elle est perdue sans ressource, Dans le second, le bas de la tige est vert; alors il faut couper la plante jusqu'au vert pur; plus on la rabattra, plus il y aura d'espoir qu'elle repoussera. J'en ai rabattu ainsi jusqu’à un pouce de la surface de la terre, qui 
ont fait, peu de temps après, de nouveaux jets de la partie de la tige restée. Ces morts subites ne sont assurément pas ies effets du peu de durée supposé de leur vie, car les jeunes périssent comme les plus âgées; et de plusieurs individus de la même espèce, les uns meurent, $t$ andis que les autres sont pleins d'existence. Je les crois dues, $I^{\circ}$. au changement d'hémisphère et à celui d'un climat auquel elles ne sont pas encore habituées, et qui exige pour leur conservation des déplacemens qui peuvent influer sur ces plantes sensibles aux différens airs, ainsi qu'aux différens lieux; $2^{\circ}$. à l'espèce de terre qu'on leur donne; $3^{\circ}$. au sol dans lequel on enfonce leurs vases pendant tout le temps qu'elles jouissent de l'air libre.

Il n'est pas douteux que le changement d'hémisphère et de climat ne doive avoir beaucoup d'effet sur les plantes nouvellement arrivées de leur pays originaire, où le cours des saisons et la température sont opposés aux nôtres. Le plus grand nombre cependant semble ne pas le prouver, et s'y font aisément; mais il en est d'autres, comme vraisemblablèment les bruyères, qui, par leur nature, y sont infiniment sensibles. Plus la plante est nouvellement arrivée plus elle est dans ce cas; et cette assertiou se prouve par la susceptibilité des bruyères récemment cultivées, et l'indifférence des anciennes. Depuis que j'en cultive, je n'ai pas encore éprouvé de ces pertes subites, à l'égard des espèces connues depuis quelques années; mais plusieurs des nouvelles ont eu ce sort. Il seroit invraisemblable de penser que, lorsque les voyageurs au Cap ont apporté en Europe les bruyères qu'il y a une quinzaine d'années que nous cultivons, le hasard 
ait fait qu'ils aient précisément choisi les plus rustiques. Il faudroit cependant le supposer, si l'on ne vouloit pas admettre les trois causes énoncées ci-dessus. Lorsque ces bruyères ont étéintroduites dans nos jardins, on en perdoit quelquefois, comme il arrive actuellement des nouvelles. L'habitude de nos climats les a préservées ensuite de ces accidens. Il est donc probable que la différence de température et du cours des saisons peut être une des causes de leur perte subite; mais comme il est assez naturel de croire que les premières espèces qui nous sont parvenues ont été cueillies aux environs du Cap, où, exposées à toutes les intempéries de l'air, elles pouvoient être réellement plus rustiques, et que les voyageurs qui nous ont fait présent des nouvelles les ont été prendre dans les plaines chaudes et souvent marécageuses de l'intérieur de ce pays, la seconde cause me paroît avoir des effets plus prochains et plus directs sur leurs maladies mortelles. Ce que l'on verra dans la suite de cet article.

- La situation que l'on donne aux bruyéres pen. dant l'été et l'automne n'est pas du tout indifférente ¿̀ leur santé.Quoiqu'elles aiment la chaleur, et qu'elles y soient beaucoup plus belles que lorsque l'été ne la fournit pas, ce n'est pas I'influence directe des rayons solaires sur elles qui les rend telles, mais la chaleur également répandue dans l'atmosphère. L'exposition méridienne leur est plus nuisible qu'avantageuse lorsqu'elle n'est pas tempérée par les pluies; elle les des. sèche et oblige à multiplier les arrosemens. Lia plus f'avorable est celle đe l'est, où elles ne puissent rece. voir le soleil que six.à sept heures, $c^{4}$ est-à-dire tout le 
inätin, depuis son lever jusqu'à midi et une heure. Elles doivent être abritées par des charmilles élevées et taillées, et placées à un mètre environ de ces dernières, qui les rafraîchissent, et les parent des vents d'ouest et des orages du sud. La fin de mai est le temps où l'on peut les mettre sans danger à cettè exposition. Rentrées à la fín d'octobre, leur domicile d'hiver doit être, pour ainsi dire, uniquement fait pour elles. La serre qui les renfermera aura des croisées en devant, et son toit sera formé de vitraux. Placées sur un amphithéâtre (I), et les petites sur les tablettes des croi-

(I) Depuis la première édition de cet ouvrage et de la publication du cinquième volume supplémentaire , j'ai observé que les amphithéâtres, loin d'être favorables aux plantes, peuvent contribuer à leur langueur et même à leur perte, à moins que la serre ne soit très-élevée et spacieuse, encore ne seroientelles pas à l'abri de quelques inconvéniens.

Sur ces gradins les bruyères et plusieurs autres plantes sont toujours dans un état de sécheresse, parce que leurs vases n'ont au-dessous d'eux aucune émanation terrestre, qu'elles se trouvent, pour ainsi dire, suspendues dans l'atmosphère de la serre, que le soleil frappe directement sur elles, et que les fréquens arrosemens qu'on est obligé de leur donner neles désaltérant que pour quelques heures, usent continuellement leur terre. J'ajouterai que ces amphithéâtres prenant une place considérable, ne laissent que peu d'air libre si nécessaire à touies les plantes, et que l'air vicié qui se perpétue et s'accumule sous ces gradins se répand sur les plantes et dans l'air supérieur qu'il rend délétère.

J'ai réformé ces amphithéâtres et je n'ai qu'à m'en louer. Les plantes posées simplement sur l'aire de la serre, par rang de hauteur, forment de même une espèce d'amphithéâtre plus agréable à l'œil que ces gradins élevés d'ou les plantes semblent 
sées, de manière que l'air puisse circuler librement autour d'elles, elles jouiront ainsi de tonte la lumière possible quileur est indispensablement nécessaire; et en ouvrant tous les jours, pendant quatre ou cinq heures, une à trois croisées du devant, excepté dans les jours froids et pluvieux, l'air de cetie manière renouvelé les conservera dans leur végétation subsistante, fortiliera leurs nouvelles pouses, et la pluparl, décorées de leurs fleurs, présenteront dans le coeur de l'hiver, au milieu des glaces et des frimats, le contraste de la plus riante verdure, et les couleurs les plus agréables à la vue. $\mathrm{Si}$ la serre destinée pou elles avoit encore des places à remplir, les diosma, pliylica, brunia, struthiola, gnidia, et généralement toutes les plantes ligneuses dont le petit fenillage ressemble à celui des bruyères, seroient intniment préférables, pour occuper les places vides, à celles à larges feuilles qui pompent continuellement l'air, s'en alimentent aux dépens de leurs voisines, et exhalent pendant la nuit beaucoup de cet élément vicié. Les orangeries ordinaires, mème celles dont le devant est entièrement vitré, ne conviennent pas du tout aux bruyères. Elles leur sont non-seulement nuisibles, mais causent leur perte, ou au moins une altération dont elles se ressentent long-temps lorsqu'elles en réchappent. La lumière à peine pénètre dans le fond de ces serres; l'air y est ordinaire.

vous tomber sur la tête. Elles jouissent alors toutes du même air renouvelé, et celles qui se trouvent contre le mur du fond sont aussi éclairées que celles du devant. Les arrosemens sont auss. beaucoup moins répélés. 
ment humide et stagnant par les plantes de toute espèce qu'on y renferme, dont plusieurs de leurs branches chancissent, et par l'impossibilite de le renouveler dans toute leur capacité. La serre à toit vitré n'a aucun de ces inconvéniens, et leur fournit tout ce qui est nécessaire à leur vie et à leur accroissement. Elle a encore l'avantage, lorsque les bruyères sont sorties, de former pendant cinq mois une espèce de serre chaude sèche, dont on peut modérer la chaleur à volonté, quand on a pratiqué au sommet du toit un châssis qui puisse s'ouvrir, et par le. quel on puisse donner autant d'air supérieur que I"on en a besoin. Certaines plantes qui ne fleurissent pas en plein air dans nos climats, ainsi que des plantes. grasses, que lcs grandes pluies, la grêle et une humidité trop constante altèrent ou gâtent seront trèsbien placées dans celte serre. Je suis, pour ainsi dire, convaincu que c'est à la serre d'orangerie et à la situation pendant l'élé que nous devons la perte de plusieurs bruyères. Depuis que je tes ai placées dans la serre indiquée, elles sont toujours dans le meilleur état de santé et de végétation. Mais comme la température de cette serre n'est pas comme celle de la serre chaude, qui ne permet pas à la gelée de se fixer sur son toit vitré, il arriveroit, si l'on n'y remédioit pas, que les vitres du toit de celle eu question se casseroient, par l'effet de la gelée sur l'eau qui se trouve dans les recouvremens. On préviendra ces accidens par des paillassons qu'on pourra lais: ser pendant les jour's de gelée sans soleil, mais qu'on ôtera le matin pour les remettre l'après-midi lorsque le soleil donnera, et qu'on enlèvera tout-à-fait 
lorsque le froid sera passé. Il ne faut jamais perdre de vue que la lumière est absolument nécessaire aux plantes, et sur-tout aux bruyères, à laquelle ces dernières doivent leur état de vigueur et leur conservation.

Les bruyères ne sont pas délicates par rapport au froid. Il ne leur faut que la température de l'orangerie. Pourvu qu'il ne gêle pas du tout dans leur asile d'hiver, ou que le thermomètre n'y descende pas plus bas que 2 degrés au-dessus du point de congélation, elles se soutiendront beaucoup mieux que dans une serre de 5 à 6 degrés de minimum, où elles pousseroieut trop dans celle saison et où elles pourroient s'affoiblir.

Faate d'instructions préalables sur la position des bruyères dans leur pays, on cultive assez généralement toutes les espèces de la même manière, et on leux. donne la même terre. Cependant les sortes de terre et de situation duivent toujours être relatives à celles où la nature les a originairement placées. Il y a des espècesqui croissent sur les montagnes et dansles lieux secs, dans les lieux humides et même marécageux, et plusieurs dans les terrains intermédiaires. Ces dernières paroissent être en plus grand nombre que les autres; ce sont celles qui couvrent une partie des plaines de la Hollande Hottentote. A l'aide de quel. ques indications que m'ont fournies Salisbury, d'autres auteurs et mes observations, j’ai formé une pefite liste, qu'on trouvera à la suile de cet article, des bruyères qui croissent sur les endroits élevés, et de celles qui viennent naturellement dans les lieux bas et humides. Les espèces des planes non marćcia- 
geuses doivent avoir une terre compasée de quatre cinquièmes de terre de bruyère et un de terre fran. che, douce au toucher : ce mélange m'a paru être celui dans lequel ces plantes se plaisent le plus et où elles se fortifient davantage. Cependant le terreau de bruyère pur est également favorable. Laterre de celles placées par la nature sur les hauteurs et sur les sols sablonneux, ne doit guère en différer; le cinquième de terre franche sera seulement plus sablonneux, et la modération des arrosemens fera en partie la distinction. Quant à celles des marais, ou qui viennent sur les bords des rivières, et généralement dans les endroits constamment humides, leur terre pourra étre composée de même, mais les arrosemens seront beaucoup plus fréquens.

Pour conserver la fraîcheur de la terre des vases où les plantes sont restreintes, il est d'usage et d'une utilité reconnue d'enfoncer leurs pots dans la terre de l'endroit où elles sont destinées à passer les cinq mois de l'été. Cette méthode est très-bonne en ce qu'elle les fortifie beaucoup, leur fournit ane belle verdure, épargne des arrosemens, et les porte àpeu-près à l'état où elles seroient si elles étoient planfées en pleine terre, avec l'attention de les lever de temps en temps pour que les racines ne pé. nétreut pas dans le sol. Mais pour les bruyères et les plantes de même nature qu'clles, la terre qui recoit leurs vases n'est pas aussi indifférente qu'on pourroit se l'imaginer. J'en citerai un exemple. J'avois mis, l'an passé, mes pots de bruyères dans une espèce de couche d'environ 7 décimères de profondeur, dont les quatre inférieurs étoicut en 
mousse verte et en feuilles mortes, et les trois supérieurs en terreau de bruyère. Mes plantes ont parfaitement réussi dans ce lit exposé au sud-est, et les racines de plusieurs ont traversé le trou du pot et passé dans le terrean. Ayant eu besoin, celte année, de cette couche pour des multiplications; et n'ayant pas eu le temps d'en faire faire une pareille, j'ai été obligé d'enfoncer mes pots de bruyère à la même exposition, mais dans le sol naturel, qui est jaunâtre, argileux, dur et compacte. Pendant tout l'été mes bruyères ont poussé foiblement, et malgré les arrosemens que je leur prodignois pour étancher leur soif, elles n'ont pas vegété ni fleuri comme elles avoient fait l'année précédente, et lorsque je les ai sorties de leur terre et visité leur motte, en les ôtant de leurs pots, j'ai remarqué, qu'à l'exception des communes, la plupart n'avoient poussé que peu de racines; que loin d'avoir traversé dans la terre qui les avoit reçues, elles avoient à peine atteint le fond de leurs vases, et que le terr eau du fond étoit presque sec malgré l'abondance d'eau que je leur avois fournie. Un Anglais d'une considération distinguée me disoit à ce sujet que plusieurs particuliers d'Angleterre, qui possèdent beaucoup de bruyères, faisoient faire des couches d'un mètre et demi de profondeur au moins, remplies de terreau tourbeux, dans lesquelles ils plantoient leurs bruyères, après les avoir ôtées de leurs pots pour y passer l'été. Ce procédé est certainement excellent pour donner aux plantes toute leur force et toute leur beauté, et pour avoir aussi de meilleures boutures; mais comme elles doivent beaucoup pousser dans ces 
couches, et que leurs racines, au bout de trois ou quatre mois, ont dû y pénétrer considérablement, ce ne peut être qu'avec beaucoup de soin et par le moyen de grands déplantoirs qu'on peut les remettre dans des vases; et ceux-ci devant être beaucoup plus grands que ceux dans lesquels elles étoient avant de les placer dans ces lits, il faut par conséquent des serres plus vastes pour les contenir en hiver, ou peut-être, par leurs progrès dans l'été, elles pourroient être susceptibles de s'affoiblir pendant cette saison. Mais si, à l'égard des bruyères hautes et bien enracinées, ce moyen de leur donner encore plus d'extension a des inconvéniens, je le crois très-bon pour les jeunes plañtes et pour les languissantes. Ces lits, composés de manière qu'ils renferment une humidité légèrement fermentescible, sont d'un grand avantage pour les bruyères, soit qu'on les y plante nues ou avec leurs pots, en ce que leur molte se maintient toujours dans un état de fraîcheur salutaire, par l'émanation des vapeurs qui. montent et pénètrent dans leurs racines; ce à quoi on parvient difficilement dans les temps secs et chauds, quelque multipliés que soient les arrosemens.

Les bruyères étant continuellement en sève, on doit visiter leurs mottes deux fois par an, un mois avant leur sortie de la serre et quelques jours avant de les y entrer: Si leurs racines ont tapissé entièrement la circonférence de la motte, il faut leur donzer de plus grands vases; mais.lorsque le volume de leurs racines est assez considérable pour exiger des pots de 2 à 3 décimètres de diamètre, il n'y a nul 
danger d'enlever la terre autour de la motte et dans sa partie inférieure, de l'épaisseur d'un pouce environ, pour remplacer la partie ôtée par de nouvelles terres. Les racines de ces plantes étant très-nombreuses et très-menues, ne tardent pas à former une quantité de radicules blanches qui ont bientôt pénétré au travers des terreaux neufs. J'ai vu peu de plantes languir par cette opération, sur-tout celles à racines abondantes formant des tissus serrés; mais j'ai éprouvé depuis la publication du cinquième volume de cet ouvrage, où j'avois dit qu'on pouvoit couper nettement le tour et le fond de la motte, que plusieurs espèces ne reprenoient pas sans danger de leur perte après ce yetranchement; ce qui n'arrive pas lorsqu'on se sert'd'un petit bâton pour ôter une partie du chevelu extérieur.

Les bruyères, toutes délicates qu'elles nous paroissent, reprennent facilement à la transplantation. J'en ai fait l'épreuve par un semis nombreux, dans la terrine duquel j'avois laissé plusieurs pieds les uns dans les autres, élevés à la hauteur de 3 à 4 centimètres; j’ai été obligé, à la fin, de les séparer à racines nues; et quoiqu'ils fussent tous assez forts, très-roides et très-ligneux, ils ont tous parfaitement repris simplement placés à l'ombre.

Les bruyères, en général, quelle que soit leur situa. tion dans leur pays originaire, aiment l'eau. Il est trèsrare qu'elles s'alterent par son abondance, si elles sont en bon état; mais il ne l'est pas qu'elles s'affoiblissent par la sécheresse de leur motte. Il en est qui en demandent beaucoup plus que les autres, et on les connoítra non-seulement dans la liste à la fir de cet 
article, mais, dans le temps des chaleurs, par l'abaissement de leurs jeunes pousses, malgré que la surface de leur terre soit encore humide. Pendant les jours sereins et chauds de l'été , elles doivent ètre arrosées tous les jours vers le soir, d'abord séparément dans leur vase, ensuite sur leurs tiges, avec la pomme d'un arrosoir qui verse l'eau en forme de pluie légère. Pendant l'hiver, les arrosemens ne seront pas aussi abondans, cependant toujours à raison de la sécheresse de la serreet du temps. Celui fait avec la pomme de l'arrosoir ne peut avoir lieu dans cette saison , à cause de l'humidité stagnante qui en résulteroit, mais bien quelques jours avant leur sortie.

Quand une bruyère faite languit si elle n'a pas besoin de nouvelle terre, il ne faut quela mettre à l'ombre, ou la dépoter et la planter dans le litindiqué plus haut, ou dans une conche qui a perdu presque toute sa chaleur, exposée au nord. La chaleur des couches nouvelles sous des châssis qui est si favorable pour redonner aux plantes la vigueur qui leur manque, est pernicieuse en élé aux bruyères languissantes. Elle ne fait le plus souvent alors que hâter jeur perte, ou les altérer eucore davantage; mais au printemps elle les excite à réparer leur foiblesse, et à leur faire reprendre leur verdure, moyennant cependant une grande lumière et un air de temps en temps renouvelé. Il arcive quelquefois à certaines espèces de jaunir: cette maladie peut venir de plusieurs causes, d'un excès d'humidité occasionné par le défaut de végétation : il faut alors cesser les arrosemens; de la qualité de la terre ou trop maigre ou trop forte; dans ces deux cas, quand le premier le rend 
possible, un arrosement ou deux d'eau légère de crottin peut produire un bon effet; il est étonnant combien les plantes en général reverdissent en peu de temps, reprennent de la vigueur et fleurissent en abondance par ce moyen, quand elles ne sont point atteintes d'un vice radicale que la nature seule peut combattre.

J'ajouterai encore dans celte nouvelle édition, que l'espèce de terrean de bruyère influe beaucoup sur la conservation et la végétation des bruyères. J'ai éprouvé que le meilleur pour elle, ct celui mêrme qui lui redonne la vigueur, est la terre de bruyère très-sablonneuse, d'un gris roux et extrêmement légère. J'ai remarqué une très-grande différence dans l'effet de cette qualité de terre, et par l'expérience que j'en ai faite, je suis bien fondé à inviter les cultivateurs à se servir uniquement de cette espèce.

\section{U L T I P L I C A T I ON.}

Il y a, comme à l'égard de presque toutes les plantes, trois manières de multiplier les bruyères, - par les graines, par les marcottes et par les boutures.

La meilleure est certainement celle de leur semis. Non-seulement les nouveaux individus sont plus forts, mieux nourris et plus beaux, mais par elle on peut obtenir de nouvelles variétés intéressantes. Plusieurs espèces mûrissent leurs graines dans nos jardins, et il est probable que lorsqu'elles y seront plus acclimatées, et qu'elles auront reçu la culture la plus convenable, toutes perfectionneront de même leurs semences. On ne doit les recueillir que lorsque 
les capsules ne peuvent plus tirer de la plante aucune nourriture. Les fleurs passées qui tombent naturellement peu après qu'eiles sont fanées ou desséchées, ne contiennent pas de bonnes graines; mais celles qui resteut sur les tiges les ont ordinairement mûres. On les sème soit aussitôt après leur maturité, soit au printemps suivant, en les conservant dans leurs capsules. J'en ai semé plusieurs espèces aussitôt après qu'elles ont été recueillies, et elles ont levé au bout d'un mois; j'en ai semé d'autres au prin. temps suivant qui ont eu le mème succès; bien plus, j'ai semé des graines de 3 et 4 ans, gardées dans leurs capsules, qui m'ont donné de bonnes planles. Ce n'est donc pas une règle à suivre que de confier à la terre les semences de bruyères peu de temps après qu'elles ont été recueillies; mais je crois cependant qu'il vautmieux les semer plus tôt que plus tard. Dailleurs la graine ne s'altère pas dans la terre, et peut au contraire perdre à l'air sa taculté germinative.

On sème ces graines dans de moyens pots, ou mieux dans de petites terrines, remplies de boune terre de bruyère légère et sablonneuse, et au fond desquelles on a mis préalablement un bon tuileau, pour laisser couler l'eau des arrosemens, et empêcher une humidité stagnante. Après avoir aplati légèrement la surface de la terre, on répand les graines de chaque espèce dans chaque pot, après les avoir ôtées de leurs capsules, et aussi uniformément qu'il est possible. On tamise ensuite sur claie du terreau de bruyère, dont on met environ une ligne d'épaisseur, et on arrose ensuite les terrines en pluie légère et abondamment. Les arrosemens 
doivent avoir lieu tous les juurs pour entretenir la terre dans unétat continuel de fraîcheur. Lorsque le semis est fait, on plonge les terrines dans une couche de chaleur modérée et sous châssis, qu'on ombrage de manière que le soleil ne puisse donner sur elles, avec l'attention d'y donner de l'air dans les jours doux.

La chaleur d'une couche n'est pas absolument nécessaire pour la germination des graines. Dès-lors qu'elles ont une température de 12 à 14 degrés, elles lèveront également. J'en ai semé en hiver, j’ai misleurs terrines sur les tablettes de ma serre chaude, et les semences y ont parfaitement levé : cependant le printemps est prëférable.

Il n'y a pas d'époque fixe pour la germination des semences de bruyère. Les unes, comme je l'ai dit déjà, lèvent au bout d'un mois, d'autres en mettent deux, trois et quatre pour paroître; et si, à la fin de ce dernier temps, et même d'un plus long encore, l'on ne voyoit aucune bruyère paroître, ce ne seroit pas une raison pour désespérer de leur succès. Je suis témoin, tous les ans, de plusieurs de ces semis, dont les graines lèvent encore au bout d'un an et de dix-huit mois. Il faut donc conserver leurs terrines, et attendre avec patience. Tant de circonstances, que nous ne connoissons pas, en favorisent la germination ou s'y opposent, que nous aurions tort d'abandonner nos soins, par la raison seule que la nature semble contrarier nos desirs.

Lorsque les jeunes bruyères ont acquis deux poucesà deux pouces et demi de hauteur, il est temps de les repiquer chacuue dans de très-petits pots. Il III. 
est inutile et même préjudiciable de les enlever en motte; ce qu'on ne peut d'ailleurs faire lorsqu'elles sont levées en assez grand nombre. On dépotera la terrine qui les contient, on la partagera doucement pour ne pas casser les racines, et on prendra alors chaque individu pour le planter dans le vase qui lui est destiné, et qui doit être préalablement rempli de terreau de bruyère léger, dans lequel on met la jeune plante, soit en formant le trou avec le doigt ou avec un petit bâton. On arrose ensuite toute la plantation le plus légèrement possible, et l'on porte les pots dans une couche qui a perdu une partie de sa chaleur, que l'on ombrage etoù ils restent jusqu'd̀ leur parfaite reprise. Quand les bruyères sont bien reprises, on leur donne la quantite d'air nécessaire pour les fortifier, avant leur rentrée dans la serre, où on les placera sur les tablettes contre les croisées. Elles n'ont plus alors besoin que des soins ordinaires pour les bruyères faites.

Les marcottes de bruyères se font dans tous les temps, soit en pliant leurs branches inférieures dans des pots où on les assujétit, et que l'on couvre de mousse, soit en les laissant dans leur vase, soit en couchant le pied entièrement dans une couche de terre de bruyére. Quel que soit le moyen que l'on emploie, elles demandent toujours des arrosemens très-fréquens pour provoquer leur enracinement. Il y a des espèces qui s'enracinent promptement par cette voix, d'autres qui s'y refusent entièrement.

Les jardiniers anglais ne multiplient leurs bruyères que de boutures. Mais quoique nous connois- 
sions leurs procédés et que je les aie exactement suivis, je me crois encore éloigné des succès étonnans qu'ils ont dans ce moyen de multiplication, non-seulement pour ce geure, mais pour la plupart des plantes. Ce n'est que par une pralique exercée et une sorte de tact, que l'expérience seule donne, qu'on peut acquérir cette espèce de manipulation qui as. sure la réussite. Cette façon de multiplier les bruyères offre tant d'avantages, que je crois devoir entrer. dans un détail très-circonstancié sur la manière d'en. faire usage.

Deux matières servent à recevoir les boutures; l'une est une terre composée de deux tiers de terreau de bruyères, et d'un de terre douce et franche, passée au tamis fin; c'est celle qui a été indiquée à monsieur Thouin, et qu'il a consignée dans les Annales du Muséum d'Histoire naturelle; l'autre est un sable pur et très-fin; c'est celle qu'emploient avec succès plusieurs jardiniers anglais, et qu'a indiquée pareillement Miller. L'une et l'autre peuvent être prospères; mais, d'après les essais que j'ai faits des deux, je donne la préférence à la seconde, et je vais en déduire les raisons. Quoique les bruyères faites aiment généralement l'humidité, une trop constante nuit certainement aux boutures. Ce principe qu'on m'a recommandé de suivre, et dont j'ai reconnu les bons effets, doit régler le cultivateur. Si l'on emploie le terreau composé, les arrosemens subséquens de= viennent inutiles, parce qu'une fois que la terre a été bien mouillée après la plantation des boutures, et couverte de cloches, elle reste dans une humidité stagnante; il s'y forme non-seulement des byssus . 
mais de vraies mousses qui s'enracinent dans sa surface, et ôtent aux boutures la petite portion d'air dont elles ont besoin, ainsi que la substance que provoquent leurs racines. Si l'on veut enlever ces tapis à mesure qu'ils se forment, ou après qu'ils sont formés et qu'ils ont acquis 3 ou 4 millirnètres d'épaisseur, on dégarnit si considérablement les petites boutures, qu'à peine il leur en reste autant dans la terre. Cette opération d'ailleurs, quelque délicatement qu'on la pratique, ne peut se faire sans les ébranler et sans causer ou lear perte, ou du dommage. Cette humidité permanente gâte en peu de temps l'extrémité des bovitures, qui seule donne naissance aux bourrelets radicaux. J'en ai levé plusieurs faites dans cecomposé, qui se trouvoient ainsi au bout de huit jours. La bouture, dans cet étai, est nécessairement perdue , quoique son sommet reste souvent vert pendant très-longtemps. Ces circonstances nuisibles n'ont pas à beaucoup près autant lieu dans le sable pur. Mais tous les sables ne sont pas également bons; le sable de terre jaune, le gros, le sable de mer ne conviennent guère parce qu'ils ne peuvent joindre et serrer immédiatement les boutures. Celui que l'on doit employer, blanc ou gris, sera extrêmement fin. On en trouve de cette sorte sous les gazons du terreau de bruyère. Ce sable sera passé au tamis de soie, et pour en faire usage il ne sera ni trop sec, ni trop humide. Trop sec, on ne pourroit y planter les boutures, parce que les trous se rempliroient aussitôt; trop humide, il ne serreroit pas assez fortement les boutures après le premier arrosement. 
Le diamètre supérieur des terrines destinées aux boutures doit être proportionné à celui des cloches, mais un peu plus grand, de manière qu'il reste autour de la cloche posée, entre ses parois extérieures et le bord intérieur du vase, une circonférence libre d'environ Io à 12 millimètres de largeur ( 4 à 5 lig.): La hauteur desterrines ne doit guère excéder un dé. cimètre ou I I centimètres. Soit qu'on se serve de terreau composé ou de sable pur, on garnira leur fond d'environ 3 à 4 centimètres ( I pouce à I pouce et demi ) de petits tuileaux, et on les remplira ensuite jusquà 12 à 14 millimètres (environ 6 lignes) de leur bord. Les terrines ainsi préparées, on cueillera les boutures. Il y a quelque attention à prendre dans cette opération. Les sommets bien verts des jeunes pousses des rameaux forment les meilleures boutures. Elles ne doivent pas avoir moins de 27 millimètres ( I pouce), et pas plus de 4 centimètres ( I pouce et demi) de longueur. Comme elles ne reprennent que par leur extrémité, il est utile de les arracher des rameaux qui les portent, de ma* nière qu'il reste à leur base une petite partie de la tige qui forme un talon, plutôt que de les couper. Cependant, quoique je trouve cette circonstance favorable, j'ai eu autant de bruyères reprises après avoir été simplement coupées, que d'arrachées. Ainsi ce n'est pas une règle qu'on ne puisse franchir pour avoir une meilleure bouture. Quelquefois la partie enlevée de la tige ou de la branche est assez longue; il faut alors la couper et ne laisser gue le vrai talon; cct excédant est tout-à-fail inutile et peut tre préjudicieroit à la reprise, parce qu'on ne l'en- 
fonceroit pas aisément dans la terre, et qu'en l'y placant on pourroit rebrousser l'écorce et causer ainsi une blessure mortelle. La quantité de boutures nécessaire pour remplir une terrine étant cueillie, on Ies effeuille aussitôt jusqu'aux deux tiers de leur longueur, en coupant les bases des feuilles avec des ciseaux et prenant garde d'offenser l'épiderme. Si I'on craint qu'elles ne se sèchent pendant cette opéraLion qui demande quelques momens, on aura à côté de soi un petit pot à moitié rempli de mousse fraîche, dans lequel on les mettra à mesure qu'on les effeuilTera. On les plantera ensuite avec un petit plantoir un peu plus gros qu'elles, à I 4 à i 5 millimètres de la place du bord intérieur de la cloche, et à 4 centimè. tres environ les unes des autres. La plantation faite, on les arrosera en plein, avec une pomme d'arrosoir à petits trous, jusqu'à ce qu'on soit sûr que la terre est bien imprégnée d'eau; mais comme il arrive souvent, malgré tontes les précautions, que plasieurs boutures foibles soient versées par le poids de l'eau, il est préférable de les arroser avec une éponge bien imbibée d'eau que l'on passe avec la main sur. elles; de cette manière on met l'eau où l'on veut, ct les boutures restent diroites. On portera ensuite ies terrines dans un endroit où l'air ait un libre accès, où le soleil, la pluie et le vent ne puissent donner sur elles, et dans lequel elles resteront pendant Irois à quatre jours. Cette particularité est tressessentielle au succès. Il en résulte que les boutures se redressent, prennent de la force et deviennent plus susceptibles d'un prompt enracinement. Au bout de ce temps les terrines seront plongées, jusqu'à leurs 
bords, dans une couche de tan, dont la chaleur n'excède pas 18 à 20 degrés, et on les couvrira chacune de leur cloche. Si la couche a un châssis vitré, ce qui me paroît plus favorable, il est peu de jours où il sera nécessaire de couvrir les cloches pour garantir les boutures du soleil trop ardent; les rayons ayant à traverser deux verres à quelque distance l'un de l'autre, ne sont plus assez forts pour leur faire tort; d'ailleurs ces boutures fanent rarement par le soleil. Mais si cette couche est à l'air libre, il faut alors les ombrager pendant la grande lumière; mais il faut ôter leur couverture dans l'après-midi jusqu'au matin sur les neuf heures. On lèvera aussi les cloçhes de temps en temps pour visiter les boutures, ôter celles qui sont mortes et voir si elles n'ont pas besoin d'arrosemens. Le moins qu'on pourra leur en donner, tant qu'elles ne seront pas reprises, sera le mieux. Il suffit que leur terre soit maintenue fraîche, mais non humide. Je n'ai pas besoin de dire que la surface des terrines doit toujours être tenue propre et absolument sans ordures et sans herbes ni mousse : à mesure qu'on voit pousser de ces dernières, on doit les arracher sur-le-champ.

II est indispensable que les cloches soient de verre blanc et d'une seule pièce, non-seulement pour les boutures des bruyères, mais pour toutes celles des plantes dont la nature est délicate, qui ne s'enracinent pas sans soins, et qui demandent un terreau léger. Elles doivent être pour celles-ci, comme je l'ai déjà dit, moins grandes que le diamètre des ter- 
rines, en supposant cependant que la pluie ne puisse pénétrer dans le châssis.

Comme il y a des espèces naturellement grêles et foibles, dont les boutures, plus molles encore, ne résisteroient pas, sans plier, à la chute des premiers arrosemens, quelque légers qu'ils puissent être, il est prudent de les planter dans des terrines séparées, et de mouiller leur terre, en versant de l'eau sur la cloche qu'on aura mise sur elles. L'eau coulera dans l'espace de la circonférence laissée, et s'insinuera de là dans toute la capacité de la terrine, sur-tout si l'cn soulève un peu la cloche pendant ce temps, et si la terrine est parfaitement horizontale. C'est aussi par ce moyen qu'on pourra rafraîchir aisément toutes les terrines quand elles en auront besoin, ce qui arrive assez rarement si l'on emploie la terre, mais plus souvent si l'on se sert du sable. Quoique cette méthode soit bonne, je préfère encore l'éponge, ainsi que je l'ai indiqué plus haut.

Le temps de l'enracinement des boutures est incertain. Il y en a qui y parviennent beaucoup plus tôt que les autres. Plusieurs restent vertes pendant trois ou quatre mois sans pousser; beaucoup périssent malgré nos soins ; d'autres s'alongent de 2 à 4 centimètres, et n'ont pas pour cela de racines. En général, on ne peut être certain de la reprise de ces boutures que lorsqu'elles grandissent continuellement, qu'elles se ramifient, et que la verdure de leur accroissement est tendre et animée. Dans ce dernier cas, elles sont sûrement reprises, et si on les a faites dans le sable, on peut les enlever au moyen d'un déplantoir de 8 centimètres (I pouce) de di ta. 
mètre, de la même forme que celui figuré dans le premier volume de cet Ouvrage, pour les planter chacune dans un petit pot de 6 centimètres ( 2 ponces) de diamètre environ, rempli du terreau ordinaire dè bruyère, et les placer ensuite à l'ombre ou dans une couche ombragée, comme il a été dit pour les jeunes plantes de semis. Si elles ont été faites dans le terreau, elles peuvent y rester plus long-temps, ̀̀ moins qu'elles ne s'élèvent trop, car alors, leurs racines ne tardant pas à pénétrer dans tout l'intérieur du vase, et dans les tuileaux de son fond, il sera plus difficile de les déplanter sans risque, que si on les avoit enlevées plus tôt. Quand on laisse les boutures dans leur terrine, comme plusieurs jardiniers anglais le font, pendant quelque temps, on peut les mettre sur les tablettes des croisées des serres et contre leurs vitres, ayant grand soin de les arroser et de maintenir leur terre humide : on peut aussi les placer à l'ombre en plein air; mais il faut alors les garantir des pluies d'orage et de la grêle, qui leur font un grand tort.

Les boutures se font depuis le commencement de mai jusqu'à la fin d'août : mais quoique les Anglais emploient ce moyen de multiplication pendant tout cet espace de temps, j'ai cependant remarqué que le temps où elles réussissent le mieux étoit le printemps, c'est-à-dire en mai et juin. J'en ai eu de reprises en juillet et août, mais en très-petit nombre. Les bruyères à petit feuillage paroissent reprendre plus facilement que celles à feuilles plus longues; celles depuis quelque temps cultivées mieux que les 
nouvelles, et les aquatiques plus sûrement que les espèces des lieux secs. Cependant le succès me paroît plus particulièrement dù à la vigueur de l'espèce qui les a fournies, à sa végétation, et à sa sève abondante.

Lorsque les boutures sont bien reprises après leur transplantation, elles nont plus besoin d'autres soins que ceux que l'on donne aux bruyères faites. On leur fera passer l'été avec elles dans le lieu qui leur est destiné; la plupart aurout en automne trois à cinq décimètres de hauteur, et fleuriront cette même année.

Cet article est bien long et pourra paroître tel à plusieurs personnes; mais $j$ 'ai cru devoir entrer dans les plus grands détails pour ne rien omettre de ce dont j’ai pu m'instruire, et de ce que mes essais et mes observations m'ont fourni. Ce sont souvent de petites circonstances, qu'à peine on considère, qui assurent ou empêchent la réussite. Les cultivateurs qui pensent comme moi ne les trouveront pas minutieuses, parce qu'ils savent combien la culture des plantes nouvelles est d'abord incertaine, et qu'il n'y a pas de légers détails qui ne contribuent à établir des bases propres à la fixer. M. Thouin, de l'Inslitut de France, aussi célèbre par ses conuoissances en botanique et en culture qu'estimable par son caractère, verra que les procédés que je présente ici diffèrent peu de ceux qu ill a consignés dans les Annales. du Muséum : je desire qu'ils puissent obtenir son suffrage. Loin que je regarde la méthode que je suis et que je viens d'indiquer comme la meilleure, $j$ 'invite les amateurs à la modifier et à faire d'autres es\$2is plus fructueux : ils mobligeront infiniment de 
me faire connoître les procédés par lesquels ils seront parvenus à de plus certains et à de plus grands. succès. Dans les sciences et dans les arts rien ne doir être ni secret ni exclusif; tout doit tendre au bien et à l'avantage général. Dans la possession des plantes, comme dans leur culture, la communicatiou des unes et des pratiques de l'autre, sont les objets principaux à considérer. C'est par cette correspondance mu. tuelle d'échanges et d'ilées que l'on accroît et multiplie les jouissances, que l'art se perfectionne, et que l'on se procure ces satisfactions qui deviennent d'autant plus douces qu'elles sont partagées.

Parmi les espèces de bruyères de l'Europe, celles qui passent sans altération en pleine terre dans les pays septentrionaux de la Francesont: Erica vulgaris et sa variété à fleurs doubles, $E$. scoparia, $E$. tetralix, E. cinere $a, E$. ciliaris, E. herbacea, E. multiflora, E. vagans. Dans les grands froids seulement, les E. multiflora et cinerea sont un peu endommagées, mais elles réparent au printemps leurs pertes.

Toutes les bruyères, par leur verdure persistante, leur végétation continuelle, leur joli feuillage, les couleurs et souvent l'élégance de leurs fleurs, sont spécialement faites pour la décoration de nos jardins et de nos serres. II n'y a point véritablement d'époque fixe pour leur floraison : tandis que les unes ont paré nos bosquels pendant la saison des beaux jours, les autres charment le triste hiver en répandant sur sa nudité quelques rayons qui la. voilent. La plupart, toujours empressées de s'orner de leurs fleurs, et ne végétant pour ainsi dire que paour s'en couvrir, étalent en tout temps une magni. 
ficence que tous nos arts de luxe ne peuvent rendre, et qui sont pour l'amateur de la nature autant de plaisirs qu'il goûte à peu de frais, sans fatigue et sans regrets.

Bruyères qui demandent plus d'eau.

E. Bibax.

Culcitæflora.

Curviflora.

Cuspidigera.

Cyrillæflora.

Fastuosa.

Fragrans.

Grandiflora.

Histriciflora.

Lagenæformis.
E. Lamellaris.

Lituiflora.

Longiflora.

Obpyramidalis.

Oxycoccifolia.

Paludosa.

Pellucida.

Stagnalis.

Tetralix.

Tubiflora.

Bruyères qui demandent moins d'eau:

E. Absinthoides.

Baccæformis.

Catervæflora.

Corifolia.

Crinifolia.

Fragilis.

Fusiformis.

Gnaphaliiflora:

Gnidiæfolia.

Lasciva.

Nana.

Obvallaris.
E. Peduncularis

Pelviformis.

Prolifera.

Pyrolæflora.

Rupestris.

Salax.

Seriphiiflorz.

Variifolia.

Vesicularis.

Volutæflora.

Xeranthemifolia: 


\section{Andromède, Andromeda.}

Cal. petit, à 5 part. Cor. camp. ou globuleuse, à 5 div. réfléchies. ro étam non saillantes. Caps. à 5 loges, 5 valves.

* I. Androviède poliée, A. polifolia.

Petit arbuste d'un pied, formant une touffe arrondie. Tiges et rameaux nombreux. Feuilles alternes, lin.-lanc., entières, fermes, à bords roulés, vertes en-dessus, blanchâtres en-dessous. Fleurs rouges, mêlées de blanc, 4 à 6 ensemble au sommet des rameaux, en forme de grelot. Caps. rouges. Anthères appendiculées.

Lieu. La France. ๖. Fl. en mai. Toujours vert. Var. * I. A. feuilles larges, A. polifolia latifolia.

Feuilles obl., glauques, blanchâtres en-dessous. Corolles globuleuses, blanches. Les divisions du calice ouvertes et blanches.

Nota. Cette variété pourroit former une espèce.

* 2. Moyenne, $A$. polifolia media.

* 3. A. feuilles étroites, $A$. polifolia angustifolia.

Feuilles linéaires, très-étroites et longues. Corolles globuleuses, d'un rose léger. Divisions calicinales roses.

Lieu de la première variété : l'Amériq. sept.; de la seconde: le Labrador. Toujours verte.

* 2. A. du Maryland, A. mariana.

Arbuste en buisson ouvert, de 2 pieds environ; les rameaux fléchis en zig-zag. Feuilles alternes, ovales, très-entières, glabres, luisantes, fermes, ponctuées en-dessous. Fleurs blanches, au nombre de 4 à 8 ensemble, assez grandes, cylindriques, en grappes unilatérales, au-dessous du sommet des rameaux qui se trouve alors nu.

Lieu. Le Maryland, la Virginie. 5. Fl. en juillet. Presque boujours vert.

Variété à feuilles lancéolées, A. mariana lanceolata. 
* 3. Andromède luisante, A. lucida. A. coriacea, H. K. A. nitida, Bartram. A.myrtifolia, Hortul.

Arbuste en buisson ouvert, de 3 pieds. Rameaux glabres, a angles tranchans. Feuilles alternes, ovales, entières, fermes, luisantes, remarquables par une nervure qui règne dans leur circonscription près de leurs bords, ponctuées en-dessous, d'un beau vert. Fleurs d'un blanc rougeâtre, 4 à 7 ensemble en bouquets axillaires. Calices assez grands.

Lieu. La Caroline, la Floride. b. Fl. en août. Toujours vert.

* 4. A. axillaire, A. axillaris, LAM. A. catesbai, WALT.

Arbuste de trois à 4 pieds et plus, en buisson fort touffu et élargi, composé de beaucoup de tiges, de branches longues et de rameaux d'un rouge vif dans leur jeunesse. Feuilles alternes, ovales, fermes, pointues, légèrement dentées, d'un beau vert lisse etluisant, avec la nervure souvent rouge. Fleurs blanches, nombreuses, en grappes serrées, axillaires.

Var. 1. A feuilles plus étroites et à fleurs plus petites.

2. A feuilles ovales. A. ax... ovata.

Lieu. La Caroline, la Virginie. ๖. Fleurit en juin-août. Toujours vert.

* 5. A. paniculée, A. paniculata, A. ramosa, Lamarck, Walt.

Arbrisseau de 4 à 5 piєds, très-garni de tiges et de rameaux; les derniers menus et flexibles. Feuilles alternes, ovales - lancéolées, pointues, dentelées, glabres, menues en comparaison de celles des autres espèces. Fleurs blanches, au nombre de 5 à 5 ensemble, pédiculées, naissant du même point d'insertion. sur ce pédoncule commun; toutes les petites grappes alternes cur l'axe commun forment ensemble des espéces de panicules ou de longues grappes terminales.

Var. 1. A grappes nues, nudiflora.

2. A grappes feuillées, foliosiflora.

Lieu. Dans les forêts marécageuses de la Caroline, 马 .Fl. en mai et juin. 
* 6. A cotonneuse, A. tomentosa, $\mathrm{N}$.

Cette andromède a de grands rapports avec la précédente. Peut-être est-ce la sous-variété $\boldsymbol{B}$. de Michaux. Cependant son aspect, la disposition de ses fleurs, les observations que j’ai faites sur elle me la font regarder comme une véritable espèce.

Arbrisseau de 3 à 4 pieds. Tiges droites, d'un blanc jaunâtre, cotonneuses, cylindriques. Feuilles alternes, ovales-elliptiques, très - entières, nerveuses, terminées par un bouton rougeâtre, à bords roulés en-dessous, revêtues de poils cotonneux, courts et couchés sur les deux surfaces, vertes en-dessus, pâles en - dessous. Panicule terminal composé de plusieurs grappes alternes, droites, fermes, dont les fleurs pédiculées sont alternes; les unes solitaires, les autres au nombre de 2 à 3 , naissant du même point d'insertion. Corolles blanches, plus grandes que celles de la précédente, cotonneuses ainsi que les calices et les pédoncules, presque toujours vertes.

* 7. A. à grappes, A. racemosa. A. paniculata, W Alt.

Arbrisseau de 3 pieds environ, formant un épais buisson très. garni de tiges, de branches et de rameaux. Feuilles oblongueslancéolées, dentées en scie, membraneuses, minces, veineuses en-dessous. Fleurs blanches, petites, cylindriques, en grappes terminales. Anthères à 4 barbes.

Lieu. La Pensylvanie. Ђ. Fl. en juillet.

* 8. A. en arbre, A. arborea.

Arbre de la hauteur de 50 à 60 pieds, très-branchu et trèsrameux. Les rameaux cylind, , jaunâtres ou rougeâtres, relativement à l'air qui les frappe, comme dans plusieurs autres espèces. Feuilles alternes, oblongues, ovales, pointues, denticulées en scie, un peu velues sur leurs nervures, souvent tachetées de rouge, d'un beau vert. Fleurs en épis paniculés et terminaux. Corolles ovales-cylindriques, blanches, pubescentes. Anthères linéaires, nues.

Lieu. Sur les montagnes de la Pensylvanie. 3 . Fl. en juillet. Toujours verte.

* 9. A. à feuilles de laurier, A. laurina, Micr. A. formosissima* 
Bartra m. Reticulata, Walt. Populifolia, Lam. Acuminate, H. K. Lucida, JAcQ.

Arbrisseau très-glabre sur toutes ses parties. Tiges droites, élevées, peu rameuses; les rameaux d'un vert jaunâtre. Feuilles ovales-oblongues, très-entières, acuminées, glabres, lisses, membraneuses en leurs bords, d'un beau vert luisant sur les deux surfaces. Fleurs blanches, cylindriques, disposées en grappes simples, axillaires, nues, courtes et penchées. Anthères nues, renflées à leur base.

Variété distincte, à rameaux d'un rouge foncé et à feuilles dentées. A. laurina dentata, N. Michaux n'a pas cru devoir faire une espèce de cette andromède; il l'a réunie à la précédente. Cependant ses dents en scie qui se trouvent toujours sur ses feuilles et jamais sur celles de l'autre, et ses rameaux d'un rouge foncé, tandis que ceux de l'espècesontverts, me semblent: devoir constituer au moins une variété.

Lieu. La Floride. Ђ. Toujours verte. Fleurit en août et septembre.

* го. A N D R о м $\mathrm{D}$ E ferrugineuse, $A$. ferruginea, H. K., VEnt., Jardin. Malmaison.

Tige droite, cylindrique, parsemée d'écailles ferrugineuses, de deux pieds environ de hauteur. Rameaux d'un brun noirâtre, anguleux. Feuilles alternes, elliptiques ou ovales-lancéolées, très-entières, scarieuses, ponctuées en-dessous de points ferrugineux, d'un vert foncé en - dessus. Fleurs blanches, en grelot, penchées, disposées en petits bouquets axillaires.

Lieu. La Virginie, la Floride, la Géorgie. 5 . Presque toujours verte.

* Ix. A. caliculée, A. caliculata.

Arbrisseau de 2 pieds environ, bien garni de tiges et de rameaux cylindriques, jaunâtres, souvent courbés et diffus, qui forment un buisson fort étalé. Feuilles alternes, ovales, fermes, coriaces, parsemées de points blancs en-dessus, chargées de points roussâtres en-dessous, presque toujours tournées d'un même côté opposé aux fleurs. Fleurs petites, blanches, globuleuses, en grappes pendantes, axillaires et unilatérales. Anthères barbues sous leur sommet. 
Liezı. Le Canada, l'Amérique sept. Ђ. Fleurit en marja Toujours verte.

Variété à feuilles très étroites et à tiges droites. $A$. calyculata angustifolia. Cette variété est très-distincte.

* 12. A. à feuilles de cassine, A. cassinefolia, Vent... A. dealbata, Hort. lond. A. speciosa, Місн.

Tiges et rameaux cylindriques, glabres, rougeâtres, de trois pieds environ. Feuilles alternes, pétiolées, très-ouvertes, ovales, pointues, dentées, glabres, coriaces, d'un vert foncé en-dessus Fleurs d'un blanc pur, plus grandes que toutes celles des autres andromèdes, naissant au nombre de cinq à 8 dans les aisselles des feuilles, pédiculées, disposées en grappes pendantes. Corolles campanulées, à cinq divisions réfléchies. Anthères d'un brun safrané, appendiculées, où le pollen forme deux taches étroites, d'un blanc pur. Huit à dix glandes vertes entourent l'ovaire à sa base.

Lieu. La Floride. ๖. Fl. en été. Toujours verte.

Variété à feuilles pulvérulentes, $A$. pulverulenta, Bartramá

Cette variété se distingue de l'espèce par ses feuilles couvertes d'une poussière d'un blanc glauque, qui rend l'arbrisseau plus agréable à la vue. Mais, comme le pense Ventenat, cette teinte ne paroît être que l'effet de certaines circonstances locales et accidenvelles, toutes les parties de cette variété ayant les mêmes formes et les mêmes caractères que celles de l'espèce glabre. Bartram l'attribue à une maladie, et cela pourroit être. Nous voyons asser souvent quelques-uns de nos arbres et de nos plantes indigènes prendre cette même surface blanche, dont la cause semble être dans l'air. Quelques saules, des arroches, des spirées sont sujets à ces changemens de couleurs.

13. A. à feuilles de rossolis, A. droseroides. Erica droseroides,'

LAM.

Arbuste de 9 à 10 pouces. Rameaux grêles. Feuilles alternes; linéaires, obtuses, velues, visqueuses. Fleurs d'un pourpre violet, assez grandes, en grappes terminales.

Lieu. Le Cap. ๖. Fl. en juillet. Toujours vert. 14. A. mousseuse, A. hypnoides, Lin.

Cette espèce ressemble à une mousse dont les tiges menues III. 
et rameuses sont couchées sur la terre. Feuilles très-étroìtes; aiguës, serrées et couvrant les rameaux, d'une ligne de longueur. Fleur petite, d'un beau rouge vif, solitaire, pédonculée, terminant chaque rameau.

Lieu. La Laponie, la Sibérie. $\$$. Fl. en juin. Cultivée en Angleterre.

Cult. Excepté la treizième espèce, qui est absolument d'orangerie, les autres sont de pleine terre et sont assez rustiques, à la réserve cependant de la troisième et de la neuvième qui, dans les grands froids, perdent souvent leurs tiges, et même périssent. On les préservera de ces accidens en mettant une assez grande quantité de litière sur leurs pieds, et en empaillant fortement leurs tiges; cependant, malgré ces couvertures, si les tiges précédentes ont été luxuriantes, elles ne résisteront qu'en partie. La troisième étant encore plus délicate que la neuvième', il est prudent d'en avoir des individus en orangerie. Ces arbrisseaux se plaisent dans les lieux abrités, frais et légèrement ombragés; ils les exigent même, et la plupart languissent dans les situations trop ouvertes et trop exposées au soleil. Les espèces $\mathbf{I}$, $4,5,6,7$ et I I viennent cependant assez bien par-tout. Leur đerre doit être légère, substantielle, douce, facile à percer, telle que celle indiquée pour les azalées, et toujours un peu fraîche. Elles viennent mieux dans la terre de bruyère que dans aucune autre, quelle que soit sa composition. L'exposition du nord leur est en général plus favorable que celle du midi. Elles y résistent beaucoup mieux, et sont moins sensibles à la gelée.

Toutes les espèces se multiplient facilement par leurs rejetons, par la séparation de leurs pieds et par les marcottes. Elles reprennent toutes très-bien à la transplantation. On plante avec plus de succès les andromèdes en février ou en mars qu'en automne.

Us. Les andromedes sont d'assez jolis arbrisseaux, quoique dens la plupart les fleurs ne soient pas très-apparentes. Les plus agrilln: s.nt la premiere et ses variétés, qui présentent au os hien garnies de fleurs roses; la deuxième,

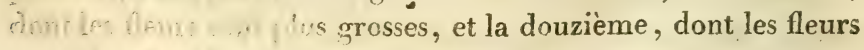
nontubreuses, ainsi que sa variété dis. 
tincte, dont le feuillage a une couleur particulière. Les autres contribuent aussi à la variété et à l'ornement des jardins.

\section{Arbousier, Arbutus.}

Cal. trés-petit, à 5 parties. Corolle ovale, à limbe petit, 5-fide et réfléchi. zo étam. ron saillantes. Baie à 5 loges i $\circ$ spermes ou polyspermes.

* r. Arbousier commun, A. unedo.

Arbrisseau de 10 à $\mathbf{1} 5$ pieds, branchú, rameux, irrégulier. Les jeunes rameaux, ainsi que les pétioles, d'un beau rouge qui s'étend sur la nervure des feuilies; celles-ci sont alt., pét., ov.-obl., dentées, fermes, coriaces, d'un vert luisant. Fleurs blanches, en grappes courtes, ax., pendantes vers l'extrémité des rameaux. Fruit rouge, charnu, semblable á la fraise.

Lieu. La Fr. mérid., l'Irlande، Ђ. Fl. en sept. - décembre: Toujours vert.

\section{Variétés. * i. A fleurs rouges. \\ 2. A fleurs doubles.}

Cette variété fait peu d'effet. * 2. A. à panicules, $A$. andrachne.

Port id. Fcorce d'abord verte, ensuite d'un fauve rougeấtre, très-lisse, qui se dépouille tous les ans. Feuilles alt., pét., ov., entières ou très - légèrement dentées, un peu plus grandes que celles de l'espèce précédente, d'un vert foncé et luisant endessus, pâles en-dessous. Fleurs blanches, en panieule, d'abord droites, ensuite un peu penchées, terminales, composées do plusieurs grappes.

Lieu. Le Levant. . Fl. en mars et avril. Toujours vert. 3. A. des Alpes, $A$, alpina.

Arbuste très-petit, rampant, dont les tiges, étalées sur la terre, n'ont que 7 à 8 pouces. Feuilles obl., dentées, ridées, ciliées, vertes en-dessus. Fleurs petites, blanches, ramassées vers l'extrémité deś rameaux.

Lieu. Les hautes montagnes, l'Angleterre. 3 . Fl. en avril et mai.

* 4. A. busserolle, raisin d'ours, A. uva unsi. 
Tiges couchées sur la terre, en touffe élargie. Feuilles éparses'; petites, ov., obtuses, entieres, fermes et luisantes. Fleurs blanches, en petites grappes ax. Baies d'un beau rouge, monospermes.

Lieu. Id. Ђ. Fl. id. Toujours vert.

5. A. à feuilles de thym, A thymifolia, H. K. Vaccinium hispidulum. An arbutus filiformis? LaMARCK. Oxycoccus hispidulus, Pers.

Tiges couchées. Feuilles ovales, aiguës, légèrement ou obtusément dentées, âpres au toucher en-dessus. Fleurs ax., octandriques.

Les baies de cette espèce sont sans doute à 5 loges.

Lieu. Le Canada. Ђ. Fl. en juin.

Cult. Aiton met tous les arbousiers en pleine terre. Il est vrai que dans les situations tempérées ces arbrisseaux peuvent y subsister ; mais les 2 premières espèces, et sur-lout la $2^{\circ}$, seront certainement mutilées dans les grands froids du nord de la France. J'en ai eu long-temps en plein air, mais lorsque la gelée passoit le 7 à 8 e degré de congélation, ou que les frimats duroient quelques jours, ils éprouvoient toujours ces dommages et ne s'élevoient pas. Je les ai perdus tous par l'hiver de 1796 . Le seul moyen, dans ces climats, de pouvoir les conserver en pleine terre, est $I^{\circ}$., à l'égard de la première, de la tirer de l'Angleterre; $2^{\circ}$. de ne la mettre en plein air que lorsque sa tige sera haute, forte et bien ligneuse; 30. de lui donner une terre médiocre et une situation abritée et exposée au nord-ouest. Les arbousiers qu'on obtient, soit de graines, soit en pied, de l'Angleterre, sont plus rustiques que ceux qui viennent de la France méridionale, et l'or est beaucoup plus sûr de les maintenir dehors. La seconde espèce peut aussi y rester avec les abris nécessaires et dans les mêmes sols; mais les cultivateurs feront bien d'avoir de ces deux espèces quelques pieds en orangerie. Les autres arbousiers sont de très-petits arbustes qui aiment les terres légères, les terreaux de bruyères et les situations un peu ombragées, telles qu'ils les ont sur les revers des rochers des hautes montagnes, où j'ai vu la quatrième en quantité.

Les arbousiers s'obtiennent par leurs graines semées en ter- 
rines remplies de terre demi - légère, aussitôt après leur maturité ou leur réception; elles lèvent souvent la même année. On met ces terrines à l'exp. du sud-est, jusqu'à ce que les semences levent. Quand ces dernières sont levées, et que les jeunes arbousiers ont un pouce seulement de haut, on les plante chacun dans de petits pots qu'on place l'hiver en orangerie ou sous des châssis, jusqu'à ce qu'ils aient la force d'être plantés en pleine terre. On les multiplie aussi par les marcottes, qui s'enracinent la $2^{\mathrm{e}}$ ou $3^{\mathrm{e}}$ année, mais qu'il ne faut sevrer ou lever que lorsqu'elles sont suffisamment enracinées. Cette opération doit se faire en février ou au comm. de mars. Si elles sont fortes, on peut les mettre en pleine terre dans un lieu ábrité; mais il est encore plus prudent de les planter en pots, et de,les y laisser 2 ou 3 ans avant de les placer en plein air. J'ai essayé plusieurs fois les boutures sans le moindre succès.

$\boldsymbol{U}$ s. Les 2 premiers arbousiers seroient un véritable ornement pour nos bosquets d'hiver s'ils n'étoient pas aussi sensibles au. froid. Ils rempliront parfaitement cet objet dans le milieu de la France. Ces arbres sont d'autant plus agréables qu'ils réunissent, comme l'oranger, un beau feuillage, des fleurs et des fruits en même temps. La variété de la première espèce, à fleurs rouges, est' fort jolie; la seconde espèce est plus belle que la première; elle Aleurit de bonne heure, et se couvre au printemps de beaucoup de panicules qui lui donnent un aspect intéressant.

\section{Cléthra, Clethra.}

Cal. à 5 part. Cor à 5 part., presqu’à 5 pét. élargis à leur base. 10 étam. non saillantes. Stigm. presque à 3 lobes. Caps. obronde,entourée par le calice, à 3 loges et 3 valves à son sommet. * I. Cléthra glabre, C. alnifolia.

Arbrisseau de 4 à 5 pieds, garni de branches. Ecorce grise, fauve sur les jeunes rameaux. Feuilles alt., pét., ovales, élargies à leur sommet, dentées, glabres. Fleurs blanches, nombreuses, en épis term.

Lieu. La Virginie. ๖. FI, en aøût $=0 c t o b$. 
*2. Cléthra pubescent, C. pubescens. C. tomentosa, LAM: Variété de la première, H. K.

Cette espèce ne diffère guère de la précédente que par le duvet blanchâtre qui couvre ses jeunes pousses et le dessous. de ses feuilles.

Lieu... Id. ๖. Fl. id.

* 3. C. paniculé, C. paniculata, H. K.

Feuilles lancéolées, glabres des deux côtés. Fleurs paniculées. Cette espèce tient le milieu entre les deux premières. On pourroit ne la considérer que comme une variété.

Lieu. LA Amérique sept. Ђ. Fi. id.

* 4. C. en arbre, C. arborea, H. K.

Tige très-droite, qui paroît devoir s'élever à quelque hauteur: Ecorce brune. Les rameaux d'un beau rouge dans leur jeunesse, ainsi que les pétioles, dont la couleur s'étend sur la nervure des feuilles. Celles-ci sont oblongues-lanc., alt. , pét., très-glabres des deux côtés, dentées, pointues, un peu fernies, d'un beau vert lisse. Fleurs blanches, en grappes paniculées et terminales.

Lieu. Madere. Ђ. Toujours vert. Fl. en sept.-janvier.

Description de la fleur de cette espèce.

Fleurs disposées en panicule terminat, composé de plusieurs. epis qui portent chacun plusieurs fleurs solitaires, pédonculées, penchées, et ordinairement toutes tournées d'un même côté.

Les pédoncules sont velus et rougeâtres ; chaque fleur a un calice à 5 folioles ovales, dont 5 rougeâtres et 2 blanches. La corolle est blanche, à 5 divisions ouvertes et arrondies à leur sommet.

Chacune porte à sa base deux filamens qui soutiennent chacun deux anthères jaunâtres et en cornet. Le stigmate est à 5 lobes; et l'ovaire à 5 loges est velu.

Les fleurs đe ce cléthra ont une odeur qui approche beaucoup de celle du seringa, mais moins forte.

* 5. C. acuminé, C. acuminata, Michaux. Affinis paniculala. Celte espèce est arborescente. Ses feuilles, plus grandes que: 
celles des autres espèces, sont pétiolées, ovales, non-rétrécies à leur base, acuminées, dentées en scie, glabres et glauques endessous. Les épis de ses fleurs sont presque solitaires, ot les bractées surpassent les fleurs, Mich.

Lieu. Les montagnes élevées de la Caroline. Ђ.

6. C. rude, C. scabra, Hort. angl. ๖.

Lieu. L'Amériq. sept.

Ces deux dernières espèces sont cultivées en Angleterre.

Cult. Les 3 premières espéces sont de pleine terre, trésai rustiques, et se plaisent, avec l'ité, dans les terres douces, franches, fraîches, dans les terreaux de bruyere sur-tout ou elles font des progrès rapides, et ḋans les lieux légèrement ombragés. On les multiplie ordinairement par leurs rejetons et par les marcottes qui s'enracinent au bout d'un an, et qu'on peut lever la deuxième année en automne, ou en février suivant. On peut aussi les obtenir de graines tirées des pays où elles mûrissent, semées et conduites comme celles de l'arbousier, excepté que les jeunes plants peuvent être mis de suite en pleine terre; mais ces soins sont inutiles lorsqu'on plante les trois premières espèces dans la terre de bruyère pure : elles s'y multiplient alors en abondance par leurs rejetons. En général le terreau sablonneux et léger convient spécialement à toutes les plantes qui composentles. familles des rhododendrons et des bruyères. Aucune autre terre , quelle qu'elle puisse être, ne produit les mêmes effets. La $4^{\mathrm{e}}$ est d'orangerie, et $n^{2} e n$ demande que les soins ordinaires; un bonne terre consistante comme celle de l'oranger, des arrosemens modérés en hiver, fréquens en été, et à l'abri du vent dans cette saison. Mult, par les marcoltes faites au printemps; elles sont enracinées en automne, et peuvent être sevrées dans; ce temps ou au printemps suivant. Je ne connois guère d'arbres. qui s'enracinent aussi facilement et aussi promptement qua celui-ci.

A l'égard de la 5 e et de la 6 espece, je ne peux rien äre sur leur culture, ne les possédant pas. Mais il est à présuna que celle que i’ai inảiquée pour les cléthras de pleine terre doił leur convenir.

Us. Les cléthras de pleine terre sont d'assez jolis arbustes 2 
qui con'ribuent à orner les bosquets de l'été et de l'automne part leurs fleurs. Ils borderont très-bien les bords d'un ruisseau avec I'ité et le céphalanthe. Le $4^{\mathrm{e}}$ est un des plus beaux arbres d'orangerie; son port et son feuillage le font remarquer avec avantage en serre comme en plein air. Son aspect est infiniment gracieux lorsqu'il est couvert de ses grappes blanches, qui décorent la scène automnale et ensuite les serres.

\section{Pyrole, Pyrola.}

Cal. très-petit, à 5 part. Cor à 5 parti. , presqu'à 5 pét. connivens et élargis à leur base. ro étam. non saillantes. Stignate. à 5 crénelures. Caps à 5 loges et 5 valves.

* y. Pyrole à feuilles rondes, $\boldsymbol{P}$. rotundifolia.

Tige d'un pied environ. Feuilles rad. pét. , arrondies, entières, un peu épaisses, d'un vert lisse. Fleurs blanches, er grappe lâche et term. Le style très-incliné.

Lieu. Ind. Je l'ai trouvée dans les dunes. $\%$. Fl. en juin et juillet.

2. P. minewre, P. minor:

Tige de 4 à 5 pouces, simple. Feuilles pét. , arrondies. Fleurs blanches, en grappe terminale. Le style droit; le stigm. étoilé.

Lieu. Ind. $\Psi$. Fl. id.

3. P. unilatérale, $P$. secrunda.

Tiges petites, grếles, droiles, simples. Feuilles ovales, pointues, dentées, veinées, pét. Fleurs blanches, petites, era Jrappe unilatérale.

Lieu. La France. $\%$. Fl. en juin.

4. P. ombellée, $\boldsymbol{P}$. umbellata.

Fleurs pédonculées, presqu'en ombelles.

Lieu. L'Amérique septentr. $\%$. Fl...

5. P. à feuilles maculées, $\boldsymbol{P}$. maculata.

Feuilles étroites, pointues, dentées, remarquables par leurs mervures blanches sur le fond vert des feuilles. Tiges presque 
ligneuses, d'un pied et demi. Fleurs pâles, petites, au nombre de deúx sur chaque pédoncule term.

Lieu. L'Amérique septentr. $\%$. Fl. en juin.

6. P. uniflore, $P$. uniflora.

Tige de 3 à 4 pouces. Feuilles arrondies, légèrement crénelées, pét. Fleur sol., assez grande, un peu penchée, term.

Lieu. La France, l'Amérique septentr. $\nsucc$. Fl. en juin et juillet.

Cult. Pleine terre. Ces plantes, qui sont assez jolies, sont très-difficiles à faire subsister dans les jardins. Quand on veut les y placer, il faut prendre les individus en motte des lieux ois elles croissent naturellement, et les planter dans les endroits un peu couverts et ombragés; encore avec ces soins ne réussissentelles pas toujours. Elles aiment les lieux herbeux; la terre de bruyère leur convient. Leur transplantation se fait en octobre. Les pyroles sont astringentes.

\section{Epigée, Epigaea.}

Cal. à 5 part., entouré d'un calicule 3 -phylle ou à 3 bractées. Cor. hypocr., tubulée à sa base, à limbe ouvert, à 5 part. Io étam. non saillantes, insérées au fond de la cor. Anthères obl. Stigm. presque 5-fide. Caps, à 5 loges, 5 valves; le réceptacle à 5 part.

* Epigée rampante, E. repens.

Très-petit arbuste. Tiges menues, rameuses, couchées, tram cantes. Feuilles alt., ovales, veinées, coriaces. Fleurs carnées ๑u blanches, 3 à 6 ensemble, en petites grappes ax. et term.

Lieu. La Virginie. ๖. Fl. en juillet. Toujours verte.

Cult. Pleine terre. La même que celle des andromèdes et dẹ bruyères de pleine terre. Mult. par ses branches enracinées ou ses rejetons levés en mars.

Us. Cette plante peut être placée parmi les bruyères. Ses fleurs sont assez jolies et exhalent une odeur extrêmement suave. 


\section{Styphélie, Slyphelia, Sмritu., Vent, , Cav., Icon,}

Calice douḃle; l'extérieur imbricé; l'intérieur à 5 folioles. Corolle monopétale, infundibuliforme, à tube ventru à son sommet, rétréci à son entrée; à limbe à 5 parties lancéolées, velues en-dedans. Cinq étamines insérées sur le tube, tomenteuses à leur base. Anthères ovales; ovaire supere ovale, entouré à sa base d'une pellicule en forme d'anneau. Style filiforme, de la longueur de la corolle. Stigmate globuleux et velu. Noix à 5 loges monospermes. Semences oblongues, comprimées.

* I. Strphélre gnidienne, S. gnidium, Vent., Jard. Maln.

Tige d'un mètre environ, droite, cylindrique, très-rameuse: Branches et rameaux nombreux, alternes, rapprochés, plians et courbés. Feuilles sessiles, éparses, ỉnéaires-lancéolées, trèsentieres, pointues, glanduleuses à leur sommet, glabres, d'un vert un peu giauque, de deux centimètres de longueur. Fleurs blanches, très-petites, droites, de l'odeur de celles du muguet gdisposées en épi au sommet des anciens rameaux, dont l'aze est imbricé d'écailles. Corolle monopétale, tubulée. Anthères d'un jaune doré.

Lieu. La Nouvelle-Hollande. Б. Toujours verte. Fleurit àla fin du printemps.

* 2. S. à trois fleurs, S. triflora, Anor.

Arbuste dont la tige est droite. Feuilles imbricées, serrées; éparses, glauques, ovales, mucronées. Fleurs rouges et jaunes, Iongues, au nombre de trois ensemble, axillaires.

Lieu. Id. Ђ. Toujours vert.

3. S. verte, S. viridis, Andr.

Arbuste dont la tige est droite et rameuse. Feuilles obliques; pointues, acuminées, alternes, très - glabrés. Fleurs à long. tube, et les divisions roulées, vertes, asillaires, solitairæs,

Lieu. Id. ๖. Toujours vert.

* $\frac{1}{3}$ S. daphnoide, S. daphnoides, SnzTa: 
Arbuste. Feuilles elliptiques, concaves en-dessus, alternes. Fleurs axillaires, solitaires. Corolle pubescente.

Lieu. Id. Ђ. Toujours vert.

5. S. à petites fleurs, $S$. parviflora, Hort. angl.

Lieu. Id. Cultivée en Angleterre.

Cult. Serre tempérée. Ces arbustes ne sont pas d'une conservation facile. J'ai cultivé la quatrième espèce et je l'ai perdue en peu de temps. Il leur faut une terre légère ou de bruyère, et les préserver de l'humidité, sur-tout de celle des serres en hiver. Une bache, pendant cette saison, leur seroit plus convenable, en leur donnant de l'air dans les jours où il ne gêle pas. On les multiplie par les boutures, qu'on traite selon la manière indiquée pour les plantes délicates.

\section{Gaultherie, Gaultheria, Palommier.}

Cal. camp., 5-fide, avec 2 écailles ext. Cor. ovale, à limbe presque 5-fide, et un peu roulé en ses bords. Io étam. insérées au fond de la corolle, à filamens velus, et anthères à 2 cornes. 10 écailles très-petites, entremêlées dans les filamens, entourant l'ovaire. Caps. à 5 loges, 5 valves, couverte par le calice bacciforme, troué sup.

* i. Gaultherie rampante, G. procumbens.

Petit arbuste de 5 à 6 pouces, traçant. Tiges les unes rampantes, les autres redressées, d'un beau rouge dans leur jeunesse. Fenilles ovales, arrondies, très-entières, fermes, lisses, luisantes, pét Fleurs d'un rouge vif, péd., 3 à 5 ensemble, ax. Baies rouges.

Lieu. L'Amérique septentr. ऊ.Fl. en été et dans différens temps. Toujours vert.

Cult. des andromèdes et des bruyères de pleine terre. Ces srbuste vient bien dans le terreau de bruyère et les lieux un peu frais. Niult. par ses rejets rampans et enracinés, dont il n'es: pas avare, levés en mars.

Us. La gaultherie, par ses feuilles d'un beau vert, sur lesquuelles se peignent ses fleurs et ses baies d'un beau rouge, rné- 
rite les soins du cultivateur, et peut répandre une variété agréable parmi les bruyères.

2. Gaultherie droite, G. erecta, Vent., Jard. Cels.

Tiges droites, rameuses, purpurines, d'un pied et demi. Rameaux alternes, d'un rouge vif et visqueux. Feuilles alternes, pétiolées, ovales, pointues, à bords roulés, avec de petites dents, presque glabres, d'un vert foncé en-dessus, chargées de poils ferrugineux en-dessous. Fleurs d'un beau rouge, en grelot, solitaires, pédiculées, disposées en grappes axillaires et terminales.

Lieu. Le Pérou. Ђ. Fl. en été. Toujours verte.

Cult. Orangerie. Ce petit arbuste, qui a de grands rapports au premier, doit se cultiver dans la terre de bruyère.

\section{Solenandria, Vent.}

Calice à 5 parties, persistant. Corolle du double plus Tongue que le calice, à 5 pétales fixés au bas du tube des étamines. Tube staminif'ere, plus court que la corolle, à limbe ro-fide; 5 divisions stériles, 5 fertiles. Ovaire libre, obrond. Style très-court. Stigmate à 3 lobes. Capsule entourée par le calice, à 3 loges, 3 valves portant une cloison dans leur milieu. Plusieurs semences fixées à l'axe central.

SOzENANDRTA cordifolia, Vent., Jard. Malm. Erythrorhiza rotundifolia, Michaux.

Feuilles radicales pétiolées, en cœur, arrondies, garnies de dents inégales et glanduleuses, glabres, d'un vert foncé, rougeâtres sur leurs bords, de quatre centimètres. Hampe solitaire , droite, haute de 3 décimètres, portant une grappe simple, en. forme d'épi , de fleurs pédiculées, éparses, d'un blanc pur: et très-petites.

Lieu. Les hautes montagnes de la Caroline. $\%$. FI. au printemps.

Cult. Orangerie. Terre de bruyére. 


\section{Ovaire inférieur ou demi-inférieur.}

\section{Airelle, Vaccinium.}

Cal. sup. , à 4 dents ou entier. Cor. camp., à 4 div. réflèchiês. 8 étam. non sur la corolle, q. f. saillantes. Anthères ì 2 cornes, et 3 barbes sur leur dos. Ovaire inf. Baie petite, globuleuse, ombiliquée, à 4 loges et plusieurs semences.

\section{Feuilies caduques.}

* 1. Airelle myrtille, $V$. myrillus, Mauret.

Arbuste très-rameux, de deux pieds; les rameaux anguleux. Feuilles alt., ovales, finement dentées et glabres. Fleurs blanches, en grelot, péd., ax., sol. Baie d'un bleu noirâtre.

Lieu... Ind. 5. Fl. en avril.

2. A. pâle, $\boldsymbol{V}$. pallidum, H. K.

Feuilles ovales, pointues, dentées, glabres. Fleurs cylind., camp., en grappes, garnies de bractées.

Lieu. L'Amérique sept. Ђ. Fl en mai et juin.

* 3. A. à étamines longues, $V$. stamineum.

Petit arbuste. Feuilles alt., ov., obl., pointues, très-entières, un peu glauques en-dessous. Fleurs péd., sol., ax. Les anthères plus longues que la corolle.

Lieu. Id. Ђ. Fl. id.

* 4. A. veinée, V. uliginosum. Myrtillus grandis, J. B.

Tiges et rameaux étalés sur la terre et droits, d'un pied.' Feuilles petites, ovales, obtuses, entières, glabres, veinées et glauques en-dessous. Fleurs blanches ou carnées, ovales, ax. Fruit noir dans sa maturité.

Lieu. La France. b. Fl. id.

Cette espèce seroit mieux placée dans la section suivante, parce qu'elle conserve, du moins dans mon jardin, presque toutes ses feuilles en hiver.

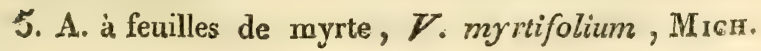


Arbuste d'un pied, très-rameux. Feuilles petites, ovales $\vec{g}$ sessiles, luisantes, pointues. Fleurs ovales, 5 ou 6 ensemble , en corymbes term. Corolle d'un joli pourpre, à 5 dents.

Lieu. La Floride. 引。

* 6. Arrelle glauque, $V$. glaucum, Lamarck.

Petit arbuste d'un pied. Rameaux làches. Feuilles obl.-lanc., , entières, d'un vert glauque. Fleurs blanches, camp., en petites grappes sur la partie nue des rameaux.

Lieu. L'Amérique sept. Ђ. Fl. en juin.

Cette espèce a beaucoup de rapports avec la dixième. * 7. A. de Pensylvanie, $V$. pensylvanicum, H. P., LAM.

Arbuste de 2 pieds. Feuilles lanc., pointues, légèrement dentées, lisses et luisantes, presque sess. Fleurs blanchâtres, 5 ou 6 ensemble en bouquets glomérulés.

Lieu. Id. 万.

8. A. de Cappadoce, 7 . arctostaphylos.

Arbrisseau de 5 à 6 pieds. Tige grosse. Ecorce brune. Feuilles ovales, pointues, crénelées, lisses, vertes, alt. Fleurs blanches ou rougeâtres, assez grandes, en grappes lâches.

Lieu. Le Levant, Madere. ๖. Fl. en juin et juillet.

- 9. A. à feuilles larges, $V$. amonum. $V$. corymbosum, Liv: $\boldsymbol{V}$. disomorphum, Мгсн.

Arbrisseau de 4 à 5 pieds, rameux. Les rameaux alternes: Écorce rougeâtre. Feuilles ovales-elliptiques, légèrement dentées en scie, pointues, velues sur leurs veines en-dessous. Fleurs blanches, cylind., assez grandes, en grappes nombreuses et lâches. Leur calice est rougeâtre, et en même temps bleuâtre, ce qui lui donne quelque ressemblance avec les couleurs de l'arcen-ciel. Baie d'un bleu noirâtre, d'un acide léger et agréable.

Lieu. L'Amériq. sept. ๖. Fl. en mai-juin.

* ro. A. résineuse, $V$. resinosum, $\mathbf{H}$. K.

Feuilles elliptiques, pointues, très-entières, parsemées de points résineux. Fleurs ovales, en grappes, garnies de bractéesai Lieu. Id. Ђ. Fl. en mai et juin.

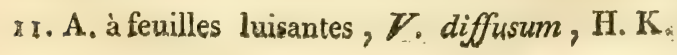


Feuilies ovales, pointues, obtusément dentées, un peu velues en-dessous. Fleurs sol., péd., sans bractées.

Lieu. La Caroline mérid. Ђ. Fl. en mai-juillet. \2. A. à feuilles étroites, $V$. angustifolium, H. K.

Feuilles ovales-lanc., glabres, obtusément dentées en scie: Fleuirs sol. , péd.

Lieu. Le Labrador. Ђ. Fl. en avril et mai. ₹3. A. à fleurs giomérulées, $V$. fuscatum, H. K.

Feuilles ovales, aiguës, très-entières, velues en-dessous sur leurs veines. Fleurs cylind., ovales, en grappes presque nues. Div. cal. aiguës.

Licu. L'Amérique sept, Ђ.Fl. en mai et juin. I4. A. rouge, $V$. venustum, H. K.

Feuilles ovales, pointues, très-entières et glabres. Fleurs presque camp., en grappes garnies de bractées, ainsi que ses divisions.

Lieu. Id. ๖. Fl. id.

* 15. A. à rameaux alongés, V. virgatum, ANDr.

Feuilles obl., elliptiques, dentées en scie, glabres des deux côtés; les rameaux floriferes, alongés. Fleurs presque cylind., en grappes sessiles.

Lieu. Id. Ђ. Fl. en avril et mai. 16. A. à feuilles de galé, $\mathscr{V}$. tenellum. $V$.galerans, Mich.

Feuilles oblongues, elliptiques, presque cunéiformes, dentées en scie, presque glabres. Fleurs ov.-cylind, en grappes sessiles, garnies de bractées.

Lieu. Id. Ђ. Fl. en mai et juin.

[7. A. à feuilles de troëne, $V$. ligustrinum, Liv., Miсн.]

Arbuste droit et serré ; les rameaux anguleux. Feuilles presque sessiles, droites, lancéolées, mucronées, finement dentées, pubescentes, avec les nervures pourpres. Fleurs ovales-oblongues, à 5 dents pourpres, en faisceaux sessiles.

Lieu. La Virginie. ๖. Fleurit en juin. 18. A. en arbre, $V$. arboreum, $\mathrm{MicH}$.

Arbre de 15 à 20 pieds, très-élégant. Feuilles pétiolées; ovales, mucronées, luisantes, légèrement bordées de points glanduleux, un peu pubescentes en-dessous, glabres en- 
dessus; quelques-unes orbiculaires. Fleurs campanulées, divisées en 5 segmens aigus, en grappes accompagnées de bractées. Baies globuleuses, noires.

Lieu. La Caroline, la Floride. Ђ. Fleurit en juin.

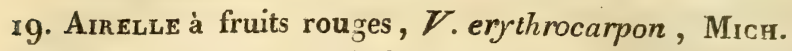

Feuilles ovales, acuminées, dentées, ciliées. Corolle longue, un peu velue. Baies écarlates.

20. A. à feuilles épaisses, $\boldsymbol{V}$. crassifolium, Hort. angl.

2x. A. à feuilles de buis, $V$. buxifolium, Hort. angl.

Lieu. L'Amérique sept. ๖. Fleurissent en mai et juin.

Ces 5 dernières espèces sont cultivées en Angleterre.

\section{Feuilles persistantes.}

* 22. A. ponctuée, $V$. punctatum, Lamarck. Vitis idaea, Lin., H. K.

Tiges menues, rameuses, brunes, d'un pied. Feuilles ov., obtuses, fermes, lisses, d'un vert foncé en-dessus, parsemées de points noirâtres en-dessous. FJeurs d'un blanc rougeâtre, en petites grappes term., penchées. Baies d'un beau rouge.

* Variété à feuilles panachées.

Lieu. La France. Ђ. Fl. en avril et mai. Toujours verte. * 23. A. canneberge, $\boldsymbol{V}$. oxycoccos. Oxycoccus europaus,

\section{Persoon.}

Tiges nombreuses, rampantes, filiformes, rameuses. Feuilles petites, ovales, glauques et blanchâtres en-dessous. Fleurs rouges sur des péd. capillaires. Baies rouges, avec des points pourpres.

Lieu. .... Ind. ๖. Fl. en mai. Toujours verte.

* 24.A. d'Amérique, $V$. macrocarpon. Oxycoccus macrocarpus, Persoon. $V$. oxycoccus, Var. $\beta$. Lam.

Feuilles obl., obtuses, planes, très-entières, luisantes, Hlanchâtres en-dessous. Tiges rampantes, filiformes. Fruit assez gros et rouge.

Cette espèce n'a été regardée par Lamarck que comme une variété de la précédente. Cependant elle en diflère à la 
simple vue, non-seulement par ses fruits plus gros et bons à manger, mais par ses tiges longues et ses feuilles lancéoléesoblongues.

Lieu. L'Amérique sept. . Fl. en mai. Toujours verte. 25. A. méridionale, $\mathscr{V}$. meridionale.

Feuilles ov. - obl., aiguës, dentées en scie, planes, luisantes. Fleurs prismatiques, en grappes droites et term.

Lieu. La Jamaïque. Ђ. Fl. . . . Toujours verte.

Cult. Excepté les espèces 8, 22, 23, 24 et 25, qui exigent la serre, toutes les autres sont de pleine terre. Cependant la $I_{1}{ }^{\circ}$ doit être plus sensible au froid que les autres, et peut-être encore 1a 5 e. Les airelles croissant dans les marais ou dans les lieux frais ou humides, doivent avoir des situations à-peu-près semblables. Du moins faut-il les placer dans les endroits un peu ombragés, et leur donner des terreaux très-légers, comme ceux de bruyères ou des sables noirs. Avec tous ces soins, la plupart des espèces sont-elles fort difficiles à cultiver et à conserver dans les jardins. Parmi les espèces que je cultive et que j'ai cultivées, la $\mathbf{1}^{\text {re }}$, la $5^{\mathrm{e}}$, la $9^{\mathrm{e}}$ se sont assez bien soutenues. La $9^{\mathrm{e}} \mathrm{me}$ paroît une des moins susceptibles du terrain et de l'exposition. Lec airelles souffrent de la transplantation, et souvent périssent à la suite de cette opération. Quand on est obligé de la faire, il faut tâcher de les enlever en grosse motte avec toute leur terre; autrement on risque beaucoup de les perdre. On les multiplie par leurs rejetons ou par leurs semences : ces dernières sont assez difficiles à conduire. La voie la plus sûre est celle des marcottes, qui s'enracinent assez promptement et peuvent être enlevées la seconde année. La $2.2^{\mathrm{e}}$ est, de toutes les espèces, celle qui se refuse le plus à nos cultures. Il n'est pas aisé de la conserver dans les jardins, à moins de lui procu rer à-peu-près la situation que la nature lui a donnée. La culture indiquée pour les plantes alpines à l'article arésic lui convient. Quoique la plupart des airelles puissent être cultivées en plein air, il est prudent cependant de garantir celles de l'Amérique des grands froids du nord de la France, et surtout des gelées printanières qui très-souvent les mutilent et même causent la perte totale de leurs branckes.

III. 
Us. Plusieurs espèces d'airelles sont jolies lorsqu'elles sont en fteur et en fruit. Je crois que la $9^{\text {e est }}$ une des plus belles, et une de celles qui doivent fixer davantage l'attention des cultivateurs. La 18 doit l'emporter en agrément sur toutes les autres.

Les fruits de la première sont assez agréables au goût. Les enfans les recherchent pour les manger. On les confit, ainsi que ceux de la vingt-deuxième.

\section{Genre qui a des rapports avec les bruyères.}

\section{Camarine, Empetrum.}

Dioïque. Cal. à 3 divisions persistantès. Fl. mâles. 3 pét. desséchés. 3 étam. à filamens longs et anthères courtes, à 2 parties. Fem. Ovaire sup. aplati. Style nul ou très - court. 9 stigm. ouverts et réfléchis. Baie orbiculaire, aplatie, à 9 semences disposees en rond.

* y. Camarine à fruits noirs, $E$. nigrum.

Petit arbuste. Tiges étalées sur la terre, d'un pied et plus. Feuilles peities, nombreuses, ebtuses, glabres, très-rapprochées. Fleurs petites, herbacées, sess., ax. Baies noires.

Lieu. Les hautes montagnes de la France, I'Angleterre. 5 . Fl. en avril. Toujours vert.

O trouve cette camarine sous le cercle polaire.

2. C. à fruits blancs, E. album.

Tiges droites. Rameaux pubescens. Feuilles linéaires, roulées en leurs bords, rudes au toucher en-dessus, canaliculées endessous. Baies blanches.

Lieu. Le Portugal.

Cult. Pleine terre. Terre de bruyère. La culture des airelles leur convieat parfaitement. Lieux ombragés. Mult. par les marcottes. $\mathrm{La}_{2}{ }^{\circ}$ espèce est assez délicate.

Us. Les camarines sont cultivées ảans les collections des ama* teurs de plantes étrangères. 


\section{Pénée, I’encea. Sarcocollier, Juss. Pl. incertce sedis.}

Cal. à 2 folioles opposées, en forme de bractées caduques. Corolle deux fois plus longue, en entonnoir, à limbe court, à 4 div. \& étamines au sommet de la corolle. Anthères droites. Ovaire supère. Style filiforme. Stigmate à 4 lobes. Capsule à 4 loges, 4 valves avec une cloison dans leur milieu dont les loges contiennent 2 semences. Point d'axe central.

1. PÉNÉE mucronée, pencea mucronata, Vent. Jard. Malm: Lin., Wilid., Lam.

Tige droite, cylindrique, brune, un peu rude au toucher, rameuse, haute de 4 décimètres; les branches opposées en croix; les rameaux très-rapprochés, couverts de feuilles opposées en croix, serrées, horizontales, presque sessiles, très - entières, ovales, pointues, glabres, d'un vert foncé, petites. Fleurs d'un jaune soufre, sessiles, de la grandeur de celles de l'erica tetralix, disposées sur 4 rangs, en épis terminaux.

Lieu. Le Cap. Ђ. Fleurit au printemps. Toujours verte.

2. P. écailleuse, $P$. squamosa, Lin., Thuni.

Arbrisseau dont les feuilles sont ovales-rhomboïdales, en coin, un peu charnues, glabres, avec une ligne longitudinale et le sommet presque glanduleux; imbricées sur 4 rangs. Fleurs sessiles, rassemblées au sommet, accompagnées de bractées écailleuses, glutineuses et ciliées.

Lieu. Le Cap. Ђ.

Cult. Orangerie. Celle des bruyères et des gnidiennes doit convenir à ces plantes.

\section{Pyxidantera, Michaux.}

Calice garni de bractées, divisé en 5 parties oblongues, membraneuses. Corolle courte, campanulée, dont le tube est plus court que le calice. Le limbe à 5 parties courtes et spatulées. 5 étamines à filamens lamellés. Anthères appenc zulées ì leur base. Ovaire un peu trigone. $x$ style épais. 3 stigmates courts. Fruit à 3 loges. 
PYXIDANTHERA barbulata, Michaux.

Plante rampante, très-petite, qui a des rapports avec l'azalea procumbens, dont les feuilles petites, en coin, lancéolées, trèspointues et semblables à celles des bruyères, mais plus fermes, sont barbues et ciliées à leur base. Fleur solitaire, sessile, termimale, entourée de beancoup de petites feuilles. Bractées fermes.

Lieu. La Caroline supérieure. $ろ$.

Cult. Celle des azalées et des bruyères. Orangerie.

\section{Springelia, Sviтr.}

Calice à 5 parties, persistant. Corolle à 5 pétales. Etamines insérées sur le réceptacle. Anthères connées. Capsule à 5 loges, 5 valves; les cloisons au milieu des valves.

Springélie rose, $S$. incarnata, Smith., Andr. Poiretia cucullata, CAv. Icon...

Joli arbrisseau de deux pieds, très-rameux, très-glabre, et couvert de fleurs dans le temps de sa floraison. Rameaux cylindriques, à écorce brune. Feuilles alternes, imbricées, amplexicaules et en capuchon à leur base, très-ouvertes , lancéolées, pointues, très-entières, concaves, glauques, rudes au toucher. Fleurs roses avecle calice de la même couleur, pédicellées, disposées en faisceaux terminaux.

Lieu. La Nouvelle-Hollande. \$. Fleurit tout l'été.

Cult. Celle des bruyères. Mult. par boutures.

\section{Hudsone, Hudsonia.}

Calice à 5 parties conniventes, tubuleux, oblong. Point de corolle, ou 5 petits pétales. I 5 étamines non-saillantes. Anthères obrondes. Ovaire supérieur. I style. I stigmate. Capsule cylindrique, plus courte que le calice, à une loge, 3 valves et 3 semences.

Hudsone bruyériforme, $\boldsymbol{H}$. ericoides, Liv.

Arbrisseau du port et de l'aspect d'une bruyère. Rameaux fiiformes, épars, imbricés. Feuilles en alêne, velues; les jeunes 
Blanchâtres. Fleurs très-petites, portées sur des pédoncules solitaires, filiformes, plus longs que les feuilles. Calice pubescent.

Lieu. La Virginie. $¥$.

Cult. Pleine terre. Celle des bruyères ou des myrtilles.

Le genre epacris, qui a des rapports à ceux epigara et gaultheria, est composé de plusieurs espèces dont une seule est actuellement cultivée en Angleterre sous le nom d'epacris tubiflora. Ce sont des arbustes ligneux qui doiventêtre intéressans par leurs fleurs et leurs fruits. Ils sont tous originaires de la NouvelleHollande et de la Nouvelle-Zélande.

\section{O R D R E I V.}

\section{Les Campanulacées (Campanutaces.)}

Calice ordinairement supère, à limbe divisé. Corolle au haut du calice, presque toujours régulière, à bord divisé. Etamines insérées sous la corolle, alternes et en nombre égal à ses divisions, ordinairement au nombre de cinq. Anthères quelquefois réunies. Ovaire infere, rarement semi-infère, glanduJeux en-dessus; un style; stigmate simple ou divisé. Capsule presque toujours infère, souvent trilocu. laire, quelquefois à deux, cinq ou six loges, le plus souvent polysperme.

Herbes, quelquefois arbrisseaux. Plantes laiteuses. Feuilles ordinairement alternes. Fleurs quelquefois rassemblées dans un calice commun.

Obs. Les campanulacées se rapprochent des chicoracées qui ouvrent la classe suivante, ayant les feuilles alternes, étant laiteuses, monopétales, ayant l'ovaire infère, et quelquefois les Heurs aggrégées, leurs anthères enfin étant réunies dans quelques genrẹs. Elles en different par les autres caraç̧̀res. 


\section{Anthères distinctes.}

\section{'Mindium, Juss. Michauxia, L'HéRtT.}

Cal. à 8 divisions. Corolle campanulée, à 8 div. 8 étamines. Stigmate à 8 rayons. Caps. à 8 loges polyspermes, couronnées par les divisions calicinales.

I. MICH AVXI A campanuloides, M. rude, L'HéRIT.

Tige d'un mètre et plus, assez droite, ferme, cylindrique, un peu velue, rameuse. Feuilles radicales en lyre; celles de la tige semi-amplexicaules, découpées, dentées, ciliées en leurs bords. Fleurs blanches, grardes, pédonculées, axillaires eř terminales.

Lieu. La Syrie. ơ ou trois ans. Fl. en juillet et août.

2. M. lisse, M. loevigata, Vent.

Tige droite, cylindrique, moelleuse, glabre, lisse, d'un vert glauque, simple, d'un demi-mètre de hauteur. Feailles radicales droites, pétiolées, ovales, pointues, inégalement dentées; celles de la tige alternes, distantes, sessiles, oblorgues, dentées et ciliées; les supérieures courtes, d'un vert glauque, hérissées de poils. Fleurs blanchâtres, éparses, pédonculées, axillaires. Corolle à 8 à ro divisions profondes, linéaires, roulées à leur sommet; celles du calice de la mếme forme que cellés de la corolle.

Lieu. La Perse. o . Fl. en été.

Cult. Pleine terre. Ces plantes se sèment sur couche au prin: temps, et se repiquent en pot pour passer le premier hiver ả l'abri du froid, qui les feroit périr, sur-tout dans le nord de la: France. Au printemps suivant on les plante en plein air, dans une bonne terre, et à une exposition chaude, afin qu'elles puissent fleurir de banne heure et fructifier. Les michauxies n'ayant pas par-tout mûri leurs semences, sont actuellement assez rares dans les collections. Ce ne peut guère être que par des pieds cultivés dans les pays méridionaux que nous pouvons conserver ce genre dans nos jardins, parce qu'il paroît que leurs graines ne sont bonnes que dans ces climats. Je crois cependant qu'on poup - 
roit les multiplier de boutures lorsqu'elles commencent à élever leurs tiges pour fleurir.

Ces plantes ont le port des campanules, et font un effet agréable dans le temps de leur floraison, qui dure assez long-temps.

\section{Canarine, Canarina.}

Cal. 6-fide. Cor. camp., 6-fide. 6 étam. à filamens larges à leur base. Stigm. à 6 part. Caps. à 6 loges.

* Canarine campanulée, C. campanula.

Tige de 3 à 4 pieds, droite, noueuse et rameuse. Fenilles opp. ou ternées, pét., hastées, inégalenient dentées, glabres, molles, glauques. Fleurs orangées, assez grandes, sol., pendantes dans les dichotomies des rameaux.

Lieus Les Canaries. ₹. Fl, en déc.-mars.

Cult. Orangerie. Cette plante demande une terre un peu légère, mais substantielle. Très-peu d'arrosemens en été, qui est le temps de son repos. Vers l'automne, et lorsqu'elle commence à pousser, on l'avancera en la mettant sous un châssis, et on la placera ensuite en serre avec les autres plantes, le plus près des jours qu'il est possible. Comme elle est en végétation tout l'hiver, et qu'elle doit fleurir à la fin ou au milieu de cette saison, on doit prendre garde que le froid ne l'attaque, l'entretenir dans sa sève, et principalement la fortifier en lui donnant le plus d'air possible pour qu'elle ne s'étiole pas. En général, toutes les plantes qui poussent pendant l'hiver sont mieux en serre tempérée qu'en simple crangerie, où le froid et l'humidité leur sont préjudiciables, à moins que ces orangeries ne soient en vitraux. On la multiplie par la séparation de son pied en été; mais il ne faut pratiquer ce moyen que lorsque la plante est forte, et ne le pas répéter trop souvent. Les nouveaux pieds seront mis dans des pots que l'on placera ou sous des châssis ombragés ou à l'ombre, et qu'on n'arrosera que lorsque la terre sera sèche.

Us. Cette plante mérite quelque soin; elle a l'avantage assez rare de fleurir dans un temps ou il y a peu de fleurs; mais ellta ae nous le donne pas souvent. 


\section{Campanule, Campanula.}

Cal., dans des espèces, ,5-fide; dans d'autres, à ro divisions, dont 5 réfléchies. Cor. camp., 5-fide. 5 étam. à filamens élargis à leur base. Anthères plus longues et droites. I stigm. à 5 parties. Caps. à 5 loges, rarement à 5 , de formes diverses.

1. Feuilles lisses et étroiies. Calices à sinus non réfléchis.

1. Campanule du mont Cénis, C. cenisia.

Tiges de 2 pouces, menues, simples. Feuilles radicales ov., très-entières, glabres, un peu ciliées, arrondies à leur sommet, en rosette sur la terre. Fleur bleue, assez grande, sol., term.

Lieu. Le mont Cénis, la Suisse. $\Psi$. Fl. en juin et juillet.

Cette espèce est traçante, et ses rejets ne donnent que des feuilles radicales.

2. C. gentianoïde ou grandiflore, C. gentianoides, H. P. C. grandiflora, H. K., J $\mathrm{ACQ}$.

Tiges menues, simples, foibles, peu rameuses, d'un pied et demi. Feuilies presque sessiles, ov.-lanc., dentées' en scie, glahres, ternées. Fleurs d'un bleu superbe, assez grandes, term.

Lieu. La Sibérie. ₹. FI. en juillet.

* 3. C. à feuilles rondes, C. rotundifolia.

Tiges filiformes, glabres, simples, de 6 pouces. Feuilles rad. réniformes; les caulinaires lin., étroites, pointues. Fleurs peu nombreuses, assez grandes, d'un beau bleu, penchées et term.

Lieu... Ind. ₹. Fl. en juin et juillet. Elle croît sous le cercle polaire. Cette campanule a plusieurs variétés qui sunt : $C$. reniformis, ccespilosa ou pusilla, tenuifolia.

4. C. à feuilles en cœur, C. carpatica, H. K., JAcQ.

Toutes les feuilles cordiformes, dentées en scie, pét., glabres. Les rameaux filiformes, uniflores.

Lieu. Les Alpes. ₹. Fl. id. 
5. C. lobélioïde, C. lobelioides.

Tiges cylind., droites et glabres. Feuill es lin.-lanc., denticulées. Fleurs presqu'infund., trifides et quadrifides, petites, en panicule term.

Lieu. Madere.

6. C. étalée, C. patulata et decurrens.

Tige droite, d'un pied, anguleuse, rameuse. Feuilles rad. ovales, disposées en rosette. Les caulinaires sessiles, étroites, pointues, légèrement dentées. Fleurs blanches ou purpurines.

Lieu. L'Angleterre, les Alpes, près Abbeville. Ind. ơ. Fl. id. * 7. C. raiponce, C. rapunculus. Raiponce des jardiniers.

Racine fusiforme, blanche, cassante et tendre. Tige d'un pied et demi, simple, anguleuse. Feuilles rad. obl., vertes, molles. Celles de la tige pointues, sessiles. Fleurs d'un bleu pâle, en panicule term. et un peu serré.

Lieu. .. Ind. $\sigma^{7}$. Fl. en juillet-septemb. Cultivée. * 8. C. à feuilles de pêcher, C. persicifolia.

Tiges droites, lisses, simples, de 2 pieds. Feuilles obl., retrécies à leur base, étroites, lin., pointues, sessiles, légèrement dentelées. Fleurs bleues ou blanches, fort évasées, assez grandes, en épis lâches et term.

Variété à fleurs doubles des deux couleurs.

Lieu. L'Europe sept., les lieux ombragés. $\psi$. Fl. en juillet - septembre.

* 9. C. pyramidale, C. pyramidalis.

Tiges très-droites, simples, glabres, de 4 à 5 pieds. Feuilles nombreuses sur les tiges, pét. , glabres, crénelées, ovales-lanc. Les radicales cordiformes, dentées. Fleurs bleues ou blanches, grandes, en bouquets latéraux, sessiles, et en épi terminal et pyramidal.

Lieu.... $\sigma^{7}$, Fl. id.

10. C. d'Amérique, C. americana, H. K. An C. planiflora, Lam.

Feulles cordiformes et lanc., dentées en scie. Les pétioles des feuilles inf. ciliés. Fleurs ax., sess. Corolles à 5 part. planes. Style plus long que la corolle.

Lieu. La Pensylvanie. Fl. en juillet. 
II. Campanule à longs styles, C. stylosa, Lamarck.

Plante glabre. Tige simple, d'un pied et demi. Feuilles pét., ẻparses, cordiformes, pointues, dentées en scie. Les pétioles nombreux. Fleurs petites, péd., bleuâtres, en panicule term.

Lieu. La Sibérie.

12. C. à feuilles de périploque, C. periplocifolia. An var. pracedentis.

Tiges basses, couchées. Feuilles pét., en cœur, pointues, glabres, un peu dentées. Fleurs d'un bleu pâle, term.

Lieu. Id.

13. C. luisante, C. nitida, H. K.

Feuilles rad. obl., crénelées, lisses. Les caulinaires lanc., presqu'entières. Corolle campanulée, en roue, bleue et ouverte.

Lieu. L'Amériq. sept. $\%$. Fl. en juillet. 14. C. à feuilles de lys, C. liliifolia.

Feuilles lanc. celles de la tige aiguës et dentées en scie. Fleurs en panicule penché.

Lieu. La Sibérie. $¥$. Fl. une grande partie de l'été.

* I5. C. rhomboidale, C. rhomboidalis, et var. Azurea.

Tiges simples, menues, anguleuses, d'un pied. Feuilles sess., éparses, nombreuses, petites, ovales, dentées. Fleurs bleues, en épi court et unilatéral.

Lieu. Les hautes montagnes de la France. $\Psi$. Fl: en juillet:

2. Feuilles rudes au toucher et larges. Calices id.

* 16. C. à feuilles larges, C. latifolia.

Tiges droites, simples, de 2 à 3 pieds. Feuilles pét., éparses, ovales-lanc., pointues, dentées. Fleurs grandes, bleues, sol. , ax., péd.

Lieu. L'Angleterre, la Suisse. $\%$. Fl. en juillet.

* I 7. C. rapunculoïde, C. rapunculaides.

Tige de 2 pieds, rougeàtre. Feuilles cordiformes, lanc. , pointues, dentées, rudes. Fleurs d'un bleu rougeâtre, pendantes, en épi long et term. Cette espèce est incommode par sa nombreuse multiplication séminale.

Liet. La France. $\%$. Fl, en juin et juillet. 
18. C. de Bologne, C. Bononiensis.

Tige de 3 pieds, rude, laineuse. Feuilles sess., ov.-lanc., légèrement dentées, garnies en-dessous de poils blancs. Fleurs petites, bleuâtres, en épis term.

Lieu. L'Italie. $\%$. Fl. en août-sept.

* 19. C. gantelée, vulg. Gants de Notre-Dane, C. trachelium. Tiges droites, velues, anguleuses, rudes, de 2 à 3 pieds. Feuilles alt., en cœur, pointues, dentées en scie, velues. Fl. grandes, bleues, term., ax.

Lieu. Les bois. Ind. $\%$. Fl. en juillet.

An C. betonicifolia trachelii var?

Lieu. La Sibérie. $\Psi$.

* 20. C. glomérulée, C. glomerata.

Tiges d'un pied, simples, anguleuses, un peu velues. Fevilles rad. ov.-lanc. cordiformes, pointues, crénelées, velues. Fleurs bleues, droites, sess., en faisceau term.

Lieu...Ind. ₹. Fl, tout l'été.

* 21. C. cervicaire, C. cenvicaria.

Tige d'un pied environ, hérissée de poils blancs. Feuilles étroites, lanc.-lin., crénelées, ondulées, émoussées, d'un verit blanchâtre, velues. Fleurs bleues, sess. , en têtes term.

Lieu. Les montagnes de l'Europe. $\sigma^{7}$. Fl. en juillet.

* 22. C. thyrsoide, C. thyrsoidea.

Tige simple, droite, hérissée de poils blancs, d'un piøç. Feuilles nombreuses, éparses, lanc.-lin., étroites, velues. Fletrrs d'un blanc jaunâtre, sess., nombreuses, en épi dense, cylind., pyramidal et term.

Lieu. Les hautes montagnes. $\sigma^{7}$. Fl. id.

* 23. C. lanugineuse, C. Eanuginosa, Lamarck. C. peregrina. LiN.

Tige d'un pied et plus, simple, droite, chargée de poils blancs. Feuilles rad. ovales, obtuses, crénelées, rétrécies en pétiole, d'un vert pâle. Les caulinaires sessiles. Fleurs bleues . sol., latérales, sess., en épi court, term.

Lieu: La Tartarie.

24. C. érine, $C$. erinus. 
Tige de 5 à 6 pouces, très-rameuse et velue. Feuilles sess., orales, dentées et velues. Fleurs petites, d'un bleu pâle.

Lieu. L'Italie, l'Espagne. Cette espece pourroit faire partie de la section suivante.

\section{Calices à sinus réfléchis.}

25. Campanule naine, C. nana, Lam. C. allioni, Willd.

Tige de 2 à 5 pouces, garnie de 2 feuilles alt, , lanc., étroites, dentées et terminées par une grosse fleur droite.

Cette espèce ne differe de la campanule uniflore que par ses calices réfléchis.

Lieu. Les Alpes.

* 26 . C. à grosses fleurs, C. medium.

Tige de 2 pieds, droite, velue, rude. Feuilles obl., sess., légèrement crénelées, velues, rudes. Fleurs grandes, obl., bleues ou blanches, péd. Les sinus très-réfléchis et fort gros.

Lieu. L'Italie. ơ. Fl, en juin-sept. 27. C. barbue, C. barbata.

Tige de 6 à 9 pouces, simple, velue. Feuilles rad. obl., lanc., velues, rudes, en rosette. Les caulinaires plus petites et sessiles. Fleurs bleues, pendantes, unilatérales, très-velues endedans.

Lieu. L'Italie, la Suisse. $\%$. Fl. en juin et juillet. * 28. C. à épi, C. spicata.

Tige simple, tres-velue, de 3 a 4 pieds. Feuilles longues, linéaires, rétrécies à leur base, éparses, velues, rudes. Fleurs bleues, sess., ax., en épi làche et term. qui occupe les 2 tiers de la tige.

Lieu. La Suisse. ot. Fl. en juillet.

29. C. de Sibérie, C. sibirica.

Tige d'un pied, droite, velue. Feuilles oblongues, semiamplexicaules, rudes, ondulées. Fleurs petites, oblongues.

Lieu. La Sibérie, l'Autriche. $\sigma^{\top}$. Fl. en juillet-sept.

* 5o. C. dorée, C. aurea.

Tige d'un à deux pieds, grisâtre, épaisse, charnue. Feuilles ov.-lanc., glabres, dentées en scie, assez longues. Fleurs en 
panicule. Le calice coloré, les divisions de la corolle linéaires et rẻfléchies.

Lieu. Madère. Ђ. Fl. en août-sept. Toujours verte.

Description de la fleur de cette espèce.

La tige s'alonge en panicule ouvert, étalé, feuillé et rameux. Les rameaux portent chacun 3 à 4 fleurs pédonculées, avec une bractée sessile et lanc. à leur base.

La fleur de cette campanule a un aspect bien différent de celui des autres espèces. Son calice jaune, monophylle, a quinze lignes de longueur et 5 angles, avec nne nervure saillante au milieu de chaque face. Il se divise ensuite jusqu'à près de moitié en 5 part. ovales, larges de 4 lignes, dont la pointe acuminée se réfléchit vers le dedans de la fleur. La base de la corolle est attachée au calice et ne fait qu'un corps avec lui. Elle est campaniforme, et son limbe se divise en 3 lanières longues de 7 a 8 lignes, étroites, linéaires, pointues, d'un jaune foncé d'abord, ouvertes horizontalement, en forme d'étoile. Les filets des étamines sont attachés au limbe de la corolle et portent des anthères d'un jaune pâle, droites et cannelées. Le style a 6 lignes de hauteur sur une de diamètre à sa base; il est jaune et se divise à son sommet en 5 stigmates de 5 à 6 lignes de longueur, verdàtres, linéaires, ondulés en leurs bords, et roulés en crosse en-dessous à leur extrémité. L'ovaire est recouvert par la partie inféricure du calice.

Cette fleur est visqueuse; son style l'est davantage.

\section{Capsules prismatiques.}

3ı. C. doucette, miroir de Vénus, C. speculum.

Tiges de 8 à 10 pouces, rameuses, diffuses, en partie couchées. Feuilles petites, ovales, dentes, sessiles. Fleurs d'un bleu violet, péd., sol. et term. Caps. prismatiques.

Lieu. Les champs. Ind. Fl. en juin et juillet. 32. C. bâtarde, C. hybrida.

Tige plus basse, draite, simple. Feuilles obl., up peu cré- 
nelées. Fleurs petites, sess., 2 à 4 ensemble, qui souvent ne s'épanouissent pas. Caps. id.

Lieu. Les champs. Ind. Fl. id.

33. Campanule perfoliée, C. perfoliata. C. amplexicaulis, Michaux.

Tige droite, anguleuse, simple, un peu velue, de 8 à ro pouces, garnie, dans toute sa longueur, de feuilles en cour, arrondies, dentées, concaves, amplexicaules. Fleurs petites, violettes, axillaires, sessiles, trois ou quatre ensemble. Caps. id.

Lieu. La Virginie. Fl. en juin.

34. C. à longues capsules. C. prismatocarpos, l'HÉRIT., H. K.

Tige inclinée. Feuilles lanc., très-glabres, dentées en scie. Caps. linéaires, prismatiques, à 2 loges.

Lieu.Le Cap. Fl. en sept.

35. C. frutescente, C. fruticosa, l'HÉrit, Willd.

Tige frutescente. Feuilles lin., subulées. Péd. très-longs. Caps. colomnaires, à 5 loges.

Lieu. Le Cap. G. Fl. en août.

Cult. Excepté les espèces 3o, 34, 35, qui sont d'orangerie, toutes les autres sont de pleine terre. Celles-ci sont rustiques et croissent assez bien dans tous les terrains; mais en considérant cependant les lieux où la nature les a placées, on voit qu'elles se plaisent dans les terres assez légères, un peu chaudes et dans les situations ouvertes. Quelques-unes viennent cependant aussi dans les lieux ombragés, mais elles s'y étiolent; en général elles sont toujours plus belles et plus vigoureuses dans les endroits exposés au soleil. On obtient toutes les campanules de pleine terre par leurs graines semées aussitôt après leur maturité ; car si l'on attend au printemps, peu d'especes levent; c'est ce que j'ai éprouvé plusieurs fois. Ce semis se fait dans des planches ou plates-bandes de terre légère et substantielle, à l'exp. du sud-est; et quand, dans l'année suivante, les plantes sont assez fortes pour être mises en place, on les plante et on les arrose jusqu'à leur parfaite reprise. Quelques espèces évitent ces soins en se semant elles-mêmes. Lorsqu'une fois on a obtenu les autres, on peut les multiplier en séparant leurs pieds en automne ou en mars. 
La $\eta^{\bullet}$ est kne plante potagère dont on mange les racines en salade. Elles ont un goût de noisette, mais sont un peu dures. On la sème en juin dans une terre très-légère. On la recouvre d'un peu de terreau, et on l'arrose de temps en temps. Quand les raiponces sont levées, on n'a plus d'autre soin à prendre que de les sarcler. Cette plante ne leve pas toujours, et est assez difficile sur le terrain et l'exposition. Le plus sûr moyen. d'y réussir est de ne pas trop couvrir la graine, de la mouiller légèrement, de lui donner une terre très-veule, et de la semer à l'ombre ou sur des ados. On recueille ses racines à l'entrée de l'hiver.

Les 3 espèces d'orangerie se multiplient de marcottes, et même de boutures. $\mathrm{La} 29^{\mathrm{e}}$ est assez délicate, et la serre tempérée lui convient mieux que l'orangerie. On la multiplie aussi par ses graines qui mûrissent en France, et que l'on sème selon la manière indiquée pour les plantes de cette serre.

Us. La plupart des campanules ont des fleurs agréables à la vue, et plusieurs espèces sont employées depuis long-temps à la décoration des jardins. Parmi elles on distingue les 2, 3, 8, 9, 16, 23, 26 et 3 .

\section{Autres espèces cultivées.}

36. C. cotonneuse, C. tomentosa, Lam., Vent., Jard. Cels, section. 2 .

Tiges droites, légèrement anguleuses, très-rameuses, de 3 à 4 décimètres. Feuilles radicales et inférieures couchées, pétiolées, lyrées, à lobe terminal, ovale et denté; les supérieures sessiles, ovales-oblongues, pointues, inégalement dẹntées ; toutes d'un vert cendré en - dessus, blanchâtre endessous. Fleurs d'un violet clair, solitaires ou trois à trois, pé。 donculées, axillaires et terminales. Corolle presque infundibuliforme, à tube long, cylindrique, anguleux ; le limbe à 5 divisions ovales-pointues, relevées par une nervure.

Lieu. Le Levant. $\sigma^{x}$. Fl. au commencement du printemps:

Cult. Pleine terre. Cette plante intéressante par la couleur de sos fleurs, n'existe peut-être plus en France, si ses se- 
mences n'ont pas mûri dans le jardin de Cels, cu elle a été cultivée.

37. Campanule à F. molles, C. mollis, Willd. , sect. 3.

Tiges couchées, peu rameuses, velues. Feuilles petites, sessiles, presque orbiculaires, presque entières, cotonneuses. Fleurs bleues, de la grandeur de celles de l'espèce à grandes fleurs, pendantes, solitaires, axillaires, portées sur de longs pédoncules. Calices grands, à sinus réfléchis.

Lieu. L'Espagne, la Sicile.

Cette campanule a des rapports avec celle $n^{\circ}{ }_{2} 5$.

Cult. Pleine terre. Semée sur couche, et repiquée ensuite dans la place où elle doit fleurir et fructifier.

38. C. à fleurs de pervenche, C. vincaflora, Vent., Jard.

Malm. C. gracilis, Forst., Hort. angl., sect. I.

Tige grêle, fistuleuse, cylindrique, droite, très-rameuse, de 6 décim. Feuilles inférieures opposées; les supérieures alternes, sessiles, linéaires-lancéolées, pointues, presque glabres, d'un beau vert. Fleurs bleues, de la grandeur de celles de la petite pervenche, solitaires, terminales. Le limbe à 5 divisions peu ouvertes. Toute la plante parsemée de poils courts.

Lieu. La Nouvelle-Zélande. $\%$. Fleurit pendant l'été et l'automne.

Cult. Orangerie.

39. C. diffuse, C. diffusa, VArr., Pers., sect. 3.

Tige diffuse. Feuilles pétiolées, dentées en scie, lancéolées; les inférieures en cœur, toutes petites. Fleurs grandes, d'un bleu léger, nombreuses, solitaires, pédonculées.

Lieu. La Calabre. ' $v$.

Cult. Orangerie. Cette plante, selon M. Armano, qui la cultive à Milan, aime les lieux frais; mais elle périt par une humidité trop constante.

40. C. d'Autriche, C. pulla, BAuHri, JACQ., sect. I.

Tiges droites, filiformes, flexueuses, peu rameuses. Feuilles pétiolées, ovales, crénelées. Fleurs bleues, penchées, solitaires ou rassemblées, terminales.

Lieu. L'Autriche. $\%$.

4I. C. verticillée, C. verticillata, sect. I. 
Feuilles verticillées, au nombre de 5 ou 6 , lancéolées, dentées.Tiges droites, d'un pied. Fleurs bleues, pendantes, verticillées, sur la partie supérieure des tiges. Calices petits, simples.

Lieu. La Tartarie. $\%$.

Cette espèce est singulière. 42. C. des Alpes, C. alpina, sect. 3.

Tige très-simple. Feuilles linéaires, obtuses, entières, velues. Fleurs solitaires, pédonculées, axillaires. 2 bractées sur les pédoncules.

Lieu. Les Alpes, la Suisse. $\mathcal{\psi}$.

43. C. des rochers, C. saxatilis, sect. 3. C. à feuilles de paquerette, LAM.

Feuilles ovales, crénelées, imitant celles de la paquerette. Fleurs bleues, grandes, en bouquets. Capsules à 5 angles.

Lieu. La Crète. $\%$.

44. C. à feuilles d'alliaire, C. alliariafolia, Willd., Tourn., sect. 5 .

Feuilles rad.réniformes, en cœur, doublement dentées, rudes, grandes, portées sur de longs pétioles. Les supérieures petites, ovales. Fleur solitaire, blanche, penchée, pyramidale.

Lieu. Le Levant.

45. C. à feuilles de sauge, C. collina, Hort. angl.

Lieu. Le mont Caucase. $\Psi$.

46. C. capitata, Hort. angl.

Lieu. La'Grèce. $\%$.

47. C. lingulata, Hort. angl.

Lieu. La Hongrie. $\sigma^{7}$.

48. C. aspera, Hort. angl.

Lieu. L'Amérique sept. $\%$.

Cult. Les 40, 4r , 42, 44 et suivantes sont de pleine terre; la $43^{e}$ est d'orangerie. 


\section{Trachelie, Trachelium.}

Cal. 5-fide. Cor. infund., à tube long, à limbe à 5 lobes.

5 étam. dont les filamens ne sont pas élargis à leur base. Stigm. globuleux. Caps. à 3 loges.

* i. Trachelie bleue, $T$. cœruleum.

Tige d'un pied, feuilles rad. ov.-lanc., dentées, pointues; les caulinaires éparses, plus petites, alt. au sommet, et rassemblées sous l'ombelle. Fleurs petites, très-nombreuses, d'un bleu d'azur, en corymbe ombelliforme, term.

Lieu. L'Afrique. $\psi$. Fl. en juillet-sept.

2. T. diffuse, $T$. diffusum.

Plante ligneuse, très-rameuse et diffuse. Feuilles on alêne. Les rameaux divariqués et recourbés.

Lieu Le Cap. Ђ. Fl. 'en août.

Cult. La première espèce, selon Aiton, seroit de pleine terre; mais, selon mes observations, elle est, ainsi que la seconde, d'orangerie. On les multiplie par leurs graines semées sur couche, et traitées comme tous les autres semis de plantes de cette serre. La première ne mûrissant pas ordinairement ses semences dans nos jardins, se propage de boutures faites dans la couche indiquée, au printemps. Elles s'enracinent avec lenteur, mais y parviennent et font de bons pieds l'année suivante. Cette espèce n'est pas délicate; le plus simple abri en hiver lui suffit; elle aime la chaleur en été, et les situations seches.

Ses fleurs très-petites, mais extrêmement nombreuses, sont agréables à la vue pendant l'été. Elle mérite d'être cultivés pour l'ornement; et dans les pays méridionaux, où elle pourroit passer en pleine terre, son effet seroit encore beaucoup plus remarquable.

\section{Roella.}

Cal. turbiné , à 5 grandes div. dentées. Cor. infund. , à limbè à 5 part. 5 étam., à filamens élargis à leur base. I stigm. bi fide. Caps. cylind. , à 2 loges, couronnée par les div. cal. 
* Roella ciliée, $R$. ciliata, Lin.

Cette plante a l'aspect d'une bruyère : les feuilles nombreuses, étroites, pointues, petites, ciliées, garnissent ses rameaux sur toute leur longueur. Les fleurs sont solitaires, terminales. La corolle, assez grande et bien ouverte, est blanche dans le fond du limbe, ensuite marquée d'un cercle d'un bleu foncé, qui est immédiatement succédé par un autre de la même couleur pâle. Les bords du limbe sont d'un pourpre Jéger.

Lieu. Le Cap. Ђ. Fl. en juillet-sept.

2. R. rampante, $R$. squarrosa, LAM.

Tige herbacée, diffuse. Feuilles ovales, recourbẻes, dentẻes. Fleurs terminales, rassemblées.

Lieu. Id. $\Psi$. Fleurit en juin.

3. R. à feuilles décurrentes, $R$. decurrens.

Feuilles lanc., ciliées, décurrentes. Les pédoncules trèslongs et axillaires.

Lieu. Id. Fl. en sept.

4. R. mousseuse, $R$. mucosa, Thunb.

Feuilles ovales, dentées, glabres, réfléchies. Fl. sol., term. Lieu. Le Cap. $\odot$. Cult. en Angleterre

Cult. Orangerie. Ces plantes sont d'une culture et d'une conservation difficiles; et l'on ne les multiplie pas plus aisément. La terre de bruyère leur convient. Elles sont fort rares dans les collections. Les deux dernières espèces étant annuelles, peuvent passer en plein air, à une exposition chaude, leur courte existence.

\section{Gesnère, Gesneria.}

Cal. 5-fide. Cor. à tube large, courbé, rétréci à son sommet, à entrée infund., à limbe à 5 lobes, dont 2. sup., 'concaves, et les 3 inf. planes et ouverts. 4 étam. didynamıques. x stigm. en tête. Caps. obronde, à 2 loges, couronnée par le calice.

* Gesnère cotonneuse, G. tomentosa. Tiges droites, de 5 à 6 pieds, rameuses, rougeâtres, li- 
gneuses, velues, visqueuses. Feuilles lanc., longues, pointues, crénelées, ridées, rétrécies à leur base, alt., presque sess., molles, un peu velues, et glutineuse; d'un beau vert; elles sont beaucoup plus nombreuses au sommet des tiges et des rameaux, où elles sont rassemblées en forme de rosette. Fleurs jaunâtres et rougeâtres, irrégulières, en cîme corymbiforme.

Lieu. L'Amérique mérid. Ђ. Fl. une grande partie de l'année. Toujours verte.

Cult. Serre chaude sur la tannée. Terre substantielle, consistante. Arrosemens très-fréquens en été, modérés en hiver. Cette plante est presque toujours en végétation. Elle demande à être dépotée au moins une fois l'an, et souvent deux fois. Comme elle pousse assez en racines, il faut prendre garde que ces dernières ne pénètrent dans la tannée; le retranchement qu'il faudroit en faire feroit ensuite faner l'arbrisseau. Mult. par boutures faites en pot et en tannée vers le mois d'avril ou de mai, et ombragées. Elles ne s'enracinent pas toutes; mais sur 4 il y en a presque toujours deux ; et j'ai remarqué que c'étoient toujours les plus grosses qui réussissoient le mieux. On doit donc les faire en coupant les tiges inférieures de l'année précédente, qui partent ord. du collet de la plante; celles qu'on prend sur les rameaux supérieurs ne s'enracinent pas aussi bien, et manquent le plus souvent.

Miller dit que celte plante n'est pas de longue durée, et qu'elle ne subsiste que 3 ou 4 ans. J'en ai un pied qui a 9 ans, et qui est aussi vigoureux que dans sa jeunesse.

Us.Les fleurs de cet arbrisseau ne sont pas d'un grand effet; mais son feuillage apporte dans la serre une variété remarquable.

\section{Phyteume, Phyleuma.}

Cal. 5-fide. Cor en roue, à tube très-long, à 5 lanières longues et linéaires. 5 étam. I stigm. à 3 part. Caps. à 3 loges.

1. Phy teume orbiculaire, $P$. orbicularis.

Feuilles radicales cordıformes, dentées en scie. Les cauli- 


\section{Z I S C A T A N U A CEES.}

naires sessiles, aiguës et aussi dentées. Fleurs rassemblées en épi orbiculaire et term.

Lieu. L'Angleterre. $\%$. F1. en juin et juillet.

* 2. P. en épi. P. spicatum.

Feuilles rad. cordiformes. Fleurs petites, verdâtres, en épi oblong. Caps. à 2 loges.

Lieu. L’Europe. $\%$. Fl. en juin.

3. P. hémisphérique, $P$. hemisphericum.

Feuilles linéaires, presqu'entières. Fleurs en tête obronde.

Lieu. La Suisse. $\longleftarrow$. Fl...

4. $\mathbf{P}$. à feuilles pinnées, $\boldsymbol{P}$. pinnatum. Petromarula, $\mathbf{B}_{\mathbf{A U H}}$, Persoon. $P$. pinnata, Ventenat , Hort. Cels.

Feuilles pinnées. Fleurs éparses, en grappes.

Lieu. L’île de Candie. $\longleftarrow$. Fl. ...

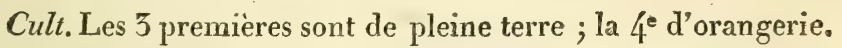
La culture des campanules convient parfaitement à ces plantes, ainsi que la manière de les multiplier. Les graines seront préférablement semées dans la place où les plantes doivent rester, et aussitôt après leur maturité. Les phyteumes ne sont pas d'une longue durée, et ne sont guère cultivées que dans les jardins de botanique.

\section{Anthères connées.}

\section{Lobélie, Lobelia. Rapuntium, Tourn. et Miller, éd. 8.}

Cal. à 5 dents. Cor. irrégulière, fendue Iongitudinalement dans sa partie sup., à limbe à 2 lèvres, à 5 div. inégales; la lèv. sup. à 2 part.; l'inf. 3-fide. 5 étam. à anthères réunies en tube. I stigm. simple et velu. Caps. à 2 à 3 loges, s'ouvrant pas son sommet.

1. Feuilles très-entières.

1. Lobélie à feuilles de pin, $L$. pinifolia.

Arbuste d'un pied et demi. Rameaux efflés et droits. Feuilles. 
lin., sessiles , nombreuses, rapprochées, comme imbricées: Fleurs bleues, velues en-dehors, en grappes. courtes.

Lieu. Le Cap. Ђ. Fl...

2. LовÉLIE tubulaire, L. dortmanna.

Plante aquatique. Feuilles rad. dans l'eau, en touffe arrondie, linéaires, comprimées, formant deux cavités longitudinales. Tige d'un pied et demi, au-dessus de l'eau, portant 8 à zo fleurs blanches, teintes de pourpre, alt., péd., pendantes, en grappes lâches.

Lieu. L'Angleterre, I'Europe sept. $\%$. Fl. en juillet et aqût.

2. Tige droite. Feuilles incisées ou dentées.

\section{L. trigone, L. triquetra.}

Tige droite, ord simple, glabre, feuillée, d'un pied et demi. Feuilles alt., sessiles, lin. - lanc., étroites, fortement dena. tées., molles, glabres. Fleurs bleues, nombreuses, péd., en grappes term.

Lieu. Le Cap. ¥. Fl. en mai-septembre.

* 4. L. à longues fleurs, L. longiflora.

Tige d'un pied, rameuse, velue. Feuilles alt. , lanc. , irrégulièrement dentées, presque roncinées, un peu velues. Fleurs blanches, péd., ax., sol. Le tube a 4 pouces de long, et le Jimbe est régulier.

La tige de cette plante a rarement un pied de haut. Le limbe de la corolle est sibien collé à son sommet, que sil'on n'ouvre pas les divisions, elle se fane quelquefois sans s'ouvrir. Elle demande beaucoup de chaleur.

Lieu, La Jamaïque. ¥. Fl. en juin-ąoût.

5. L. en arbre, $L$. assurgens.

Tige rameuse, de 3 pieds environ. Feuilles très - iongues, lanc., dentées en scie. Fleurs en grappes, composées et term.

Lieu. Les Indes occid. b. Fl. .

*6. L. cardinale, L. cardinalis.

Tiges de zà 3 pieds, simples, cylind., velues. Feuilles alt, éparses, ovales. pointues, dentées, molles, un peu velues. 
Flenrs grandes, d'un rouge écarlate, en grappe simple et term.

Cette grappe n'èst souvent unilatérale que par l'effet de la lumière qui attire les fleurs d'un côté, car celles-ci, avant de s'épanouir, sont disposées autour de l'axe de l'ép̃.

Lieu. La Virginie. $\%$. Fl. en juillet-nov.

7. L. effilée, L. debilis.

Tige droite. Feuilles lanc. , dentées en scie, glabres. Fleurs. latérales, dont les péd. sont plus longs que les feuilles.

Lieu. Le Cap. Fl. en juillet.

*8. L. siphilitique, L. siphilitica:

Tige droite, simple, de zpieds, un peu anguleuse et un peu velue. Feuilles ovales, lanc., sessiles, légèrement dentées, un peu ridées, d'un vert jaune. Fleurs bleues, péd., ax., sol., formant un épi au sommet des tiges.

Zieu. La Virginie: $\longleftarrow$. Fl. en août-oct.

9. L. à fruits gonflés, L. inflata.

Tige droite, anguleuse, velue, rameuse, d'un pied et demi. Feuiles alt., ovales, inégalement dentées. Fleurs petites, bleuâtres., en grappes spiciformes et term.

Lieu, La Virginie, le Canada. F. Fl, en juillet et août.

1. L. de Cliffort, L. clifforliana.

Tige d'un pied et demi, droite, grêle, simple ou rameuse. Feuilles alt., pét., cordiformes, glabres, dentées, sinuées. Fleurapetites, rougeâtres, en grappe làche et term.

Lieu. Les Antilles. Fl. en juillet-oct

I I. L. Grûlante, L. urens.

Tige droite, grêle, simple, glabre, d'un pied et demi: Feuilles inf. obrondes, crénelées ; les sup. lanc., sess., dentées en scie. Fleurs bleues, en grappe term.

Lieu. La France, l'Angleterre. Fl. en juĩ,

12. L. naine, L. minuta.

Tres-petite plante en petit gazon, d'un pouce de haut Feuilles ovales, obtuses, pét., glabres, deniées on sinuées. Hampes droites, poriant une petite fleur blanche. Cetle espèce n'est peut-être qu'une variété de la $x^{5} 2$. Elle y 2 du moins bazu- 
coup de rapports. Elle pourroit être aussi bien dans la section. suivante.

Lieu. Le Cap. ₹. Fl. en été.

13. LobÉLIE glabre, L. lavigata, LIN. L. surinamensis,H. K., suppl.

Tige glabre, de 2 pieds. Feuilles alt., pét. , ovales - lanc. , pointues, dentées, molles et glabres. Fleurs d'un pourpre pâle, ax., sol., péd. Corolle pentagone, courbée, blanche en-dedans, aussi longue que les feuilles.

Lieu. Les Indes occid. ๖.Fl. en avril.

\section{Tige couchée. Feuilles id.}

4. L. à feuilles pubescentes, L. pubescens, H. K., sup.

Tiges anguleuses, diffuses, couchées. Feuilles lanc., dentées, velues. Péd. ax., uniflores. Fleurs blanches.

Lieu. Le Cap. $\%$. Fl. en mai-août.

* 15. L. d'Italie, L. laurentia.

Tige couchée, rameuse, filiforme, de 5 à 7 pouces. Feuilles petites, lanc. - ovales, crénelées, alt., glabres. Fleurs petites, bleues, sol., portées sur de longs péd. et term.

Lieu. L'Italie. Fl. en juillet.

16. L. erinole, L. erinus.

Tiges étalées, foibles, de 6 pouces. Feuilles ovales-lanc. , entières ou dentées. Fleurs petites, violettes ou bleues, péd., ax. sol.

Lieu. Le Cap. $\%$ ou . Fl. en juin-sept. 17. L. jaune, L. lutea.

Tiges simples, striées, un peu velues, de 6 à 9 pouces; les unes droites, les autres étalées sur la terre. Feuilles alt. , sess. , lanc., pointues, dentées. Fleurs jaunes, sess., alt., en épi term.

Lieu. Le Cap. Fl. en juin et juillet. 8. L. corne de cerf, L. coronopifolia. 
Tige courte, feuillée, velue. Feuilles lin.-lanc., éparses, dentéesà leur sommet, un peu velues à leur base. Fleurs bleues, assez grandes, tachées de blanc, portées sur de longs pédoncules, biflores et ax.

Lieu. Le Cap. ₹. Fl. en juillet et août.

Cult. Les espèces 4, 5 et i 3 sont de serre chaude ou de serre tempérée. Les espèces I , 3 ; I2, 14, I6, 18 sont d'orangerie. On peut y joindre, du moins pour quelques pieds et dans les climats septentrionaux, les espèces 6 et 8 . Les autres, quoiqu'il y en ait de délicates, sont de plein air ou de serre pendant l'été seulement, étant toutes. La terre des lobélies doit être plus consistante que légère; les arrosemens fréquens dans le temps de leur végétation, et très-modérés dans celui de leur repos. On les multiplie toutes par leurs graines, qu'on sème en terrine sur couche et sous châssis, et qu'on conduit à la manière indiquée suivant leur température. Parmi les : ne pouvant fleurir qu'à l'aide de la chaleur, doivent être mises à cet effet sous un châssis ouvert pendant l'été. Dans les pays plus chauds que celui que j'habite, les espèces 6 et 8 sont cultivées en pleine terre : elles pourroient l'être aussi dans nos climals, comme elles le sont en Angleterre, en leur donnant une terre un peu légère, chaude etl'exposition méridienne, et en les couvrant en hiver; mais cette litiere qu'on leur donneroit pour les garantir du grand froid leur seroit préjudiciable, parce que ces plantes sont très-susceptibles de pourrir en hiver par l'humidité. Quand on prend le parti d'en mettre en pleine terre, il faut aussi en avoir en orangerie, et dans cette serre il faut les placer dans l'endroit le plus sec et contre les jours. Ces deux espéces peuvent aussi se multiplier par la séparation de leurs pieds en février ou en mars. Leurs graînes peuvent mûrir dans le nord de la France, en plaçant les plantes dans une serre lorsqu'elles sont en fleur.

J'ajoute à ce précis de culture, que la $8^{\mathrm{e}}$ est en pleine ierre depuis l'impression de la $1^{\text {re }}$ édition de cet ouvrage, et qu'elle a passé les hivers sans le moindre dommage. J'ai essayé de même la 6 e , qui est cultivée à Paris en plein air ; mais soit que ma terre ne lui ait pas convenu, soit que le froid lui ait fait tort, je $n^{\prime} a i$ 
pu I'y conserver. Ce n'est pas une raison pour qu'on ne l'y miette pas, et je pense qu'au moyen de quelques couvertures en hiver, d'une bonne terre légère et d'une exposition chaude et abritée, elle se maintiendroit sans dommage dans le nord de la France.

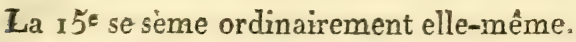

Us. Je connois peu de lobélies, mais il me paroît que les plus belles sont les espèces 6 et 8 , qui sont aussile plus généralement cultivées pour l'agrément et la couleur de leurs fleurs. La 6 e fait un très-bel effet lorsqu'elle est bien fleurie. La $8^{\mathrm{e}}$ lui est un peu inférieure, mais elle plaît aussi à la vue. La $4^{\mathbf{e}}$ renferme un suc très-vénéneux. C'est, dit Ingenhouz, une des plantes les plus malfaisantes que l'on connoisse. Pour peu que son suc touche la peau, il s'y élève à l'instant des ulcères rongeans, qui ne se guérissent pas aisément. Celui de la lobélie du Chyli, qui a été cultivée à Paris, ne l'est pas moins. Son odeur même, dit Feuillée, excite des vomissemens, et l'on perdroit infailliblement la vue si le lait de sa racine touchoit les yeux.

Les fleurs nombreuses et d'un joli bleu de la $15^{\mathrm{e}}$, qui se succèdent pendant tout l'été, donnent à cette planté annuelle un mérite qui la distingue.

* 19. LobÉIIE éclatante, L. fulgens, sect. 2.

Tiges cylindriques, d'un rouge-brun, couvertes d'un duvet très-léger qui les fait paroître un peu veloutées, droites, simples, feuillées, hautes de deux pieds et plus. Feuilles alternes, sessiles, lancéolées, oblongues, pointues, un peu-courbées en arc, légèrement dentées; dans quelques-unes, un peu incisées à leur sommet, douces au toucher et d'un vert léger. Fleurs d'une écarlate brillante qu'on a peine à fixer, plus grandes que celles de la cardinale, à laquelle cette espèce a queiques rapports; les deux divisions supérieures linéaires, érigées, toujours courbées, et même légèrement torses à leur base; la division inférieure partagée en trois grands lobes entiers, pointus, recourbés à leur extrémité, et munis chacun d'une nervure; pédonculées, solitaires, axillaires, formant au sommet des tiges une grappe ou un épi assez long dont les fleurs s'épanouissent. 
successivement. Calice à 5 longues divisions presque égales et veloutées comme les feuilles.

Lieu. $¥$. Fleurit à la fin de l'été et en automne.

Cull. Orangerie. La même que celle de la cardinale $n^{\circ} 6$ : On la multiplie aisément en couvrant son collet de terre dans laquelle les bases des tiges font des racines, et que l'on sèvre lorsqu'elles en ont assez pour reprendre. Je pense aussi qu'en coupant les tiges non fleuries, à leur insertion sur le collet, ces boutares s'enracineroient aussi facilement; mais il est plus sûr de les faire enraciner auparavant; la reprise en est alors certaine, sur-tout si on met les individus séparés dans une couche dont la chaleur est tempérée. Ir faut garantir cette plante des limaces, qui en sont très friandes.

Cette belle et nouvelle espèce nuit à la cardinale, par de fleurs plus éclatantes et plus grandes. C'est une charmante acquisilion pour la décoration des serres et des jardins.

20. L. bicolor. Lieu. Le Cap. $\%$.

21. L: gracilis. Lieu. Id. $\sigma^{7}$.

22. L. pallida. Lieu. Id. ఒ.

23. L. bidentata. Lieu. Id. $¥$.

24. I. ilicifolia. Lieu. Id. \%.

Horl. angl. Orangerie

\section{Jasione, Jasione.}

Cal. 5-fide. Cor. en roue, à tube très-court, à 5 lanières lon gues et linéaires. 5 étam., à anthères réunies en tube. Stigm. bifide. Caps. pentagone, à 2 loges, couronnée par le calice. Fleurs rassemblées dans un calice commun, polyphylle, sur un réceptacle nu.

I. JASIONE vivace, $J$. perennis.

Tige droite, simple ou rameuse àsa base. Feuilles inf. nombreuses, éparses, entières, planes, un peu velues. Fleurs bleues, en têtes terminales. Collerette de 12 à 13 folioles dentées.

Lieu. Les montagnes, l'Angleterre, la France. *. Fl. ew. été. 
2. J J SIONE annuelle, J. montaina.

Cette espèce diffère peu de la précédente. Tiges grêles, d'un pied, striées, velues et rudes. Feuilles étroites, lin., velues, très-ondulées. Fleurs id.

Lieu. Dans les sables des dunes. Ind. Fl. id.

Culi. Pleine terre. Ces plantes sont peu cultivées. Leurs fleurs imitent celles du bleuet et de la scabieuse des bois. Ces plantes semblent former le passage avec celles qui composent la classe suivante.

\section{Goodenie, Goodenia.}

Cor. fendue longitudinalement, à limbe 5-fide, unilatéral ; les parties sexuelles situées dehors et de l'autre côté de la corolle. Anthères linéaires. Stigm. en godet, cilié. Caps. à 2 loges, 2 valves polyspermes; la cloison parallèle. Sem. imbricées. Sмiтн.

* I. Goodrire à feuilles ovales, G. ovata, Smith, WillDenow, Curtis, Mag.

Arbrisseau dont les rameaux sont bruns, glabres, alt., grêles, de 3 à 4 pieds. Feuilles alt., pét., ovales, presque cordiformes à leur base, pointues, finement denticulées, un peu rudes, trinerves, d'un vert foncé et terne. Fleurs jaunes, péd., ax.

\section{Description de la fleur.}

La fleur de cette plante est irrégulière. Le pédoncule pentagone se divise à son sommet en 5 parties étroites, pointues, un peu réfléchies qui forment le calice. Dans la position de la fleur sur la plante, 3 divisions cal. soutiennent les parties sup. de la corolle; les deux autres l'inf.

La corolle est monopétale, insérée sur le calice, et offre à sa base une sorte de cornet. Elle a 5 divisions principales, 2 sup. et une inf.; celle-ci est composée de 3 parties égales, qui forment une sorte de levre plane et réfléchie. Chacune de ces divisions et des deux sup. est soutenue en-dessous par une lane un peu 
concave et pointue, qui fait corps avec elle, comme dans la fleur du menyanthes ovata. Ces divisions sont ovales, légèrement ondulées, et un peu chiffonnées en leurs bords.

Les étamines et le pistil sortent de l'espèce de cornet de la base de la corolle, et hors de cette dernière dans sa partie sup. Les étamines sont au nombre de 5, et portent chacune une anthère longue et brune. Le style est situé devant elles, entre les deux div. sup.; il est un peu plus long qu'elles, élargi à son sommet, où il prend une forme concave en-dessous, recourbé vers la div. inf. de la corolle, velu et renflé à l'endroit de sa eourbure, marqué ensuite d'une bande brune, et terminé par un stigmate blanchâtre.

Toutes les parties de la fructification sont derriere la corolle, qui a environ 6 lignes de diamètre.

Lieu. La Nouvelle-Hollande. ๖. Fl. une partie del'année. Toujourś vert.

2. G. lisse. G. lavigata, Smith, Willdenow, Curtis, Mag.

Tige d'un pied et demi, très-rameuse, cylindrique, glabre, verte à sa base, brune à son sommet. Feuilles alt., finissant en pétiole à leur base, profondément dentées, glabres, d'un beau vert. Fleurs violettes ou d'un bleu pâle, sess., ax. au sommet de la tige et des rameaux, légèrement odorantes.

Lieu. Id. b.

* 3. G. à feuilles de souci, G. calendulacea, An G. strictce, Andr:, Smith, varietas?

Tige droite, cylindrique, rameuse. Feuilles alternes, canaliculées, ámplexicaules et finissant en pétioles, à leur base; spatulées, obtuses, larges de neuf lignes, légèrement velues en leurs bords, très-entières, ou avec une ou deux petites dents à leur sommet, épaisses, glabres et d'un beau vert. Fleurs bleues, solitaires et rassemblées au sommet de la plante.

Lieu. Id. b.

4. G. grandiflora, Hort. angl.

Lieu. Id. $\sigma^{\top}$. Fl. en juillet et ao ût.

Cult. Orangerie. Ces arbrisscaux ne sont pas délicats. Ils ne 
demandent que les soins ordinaires donnés aux plantes de cette serre. On les multiplie de marcottes et de boutures qui s'enracinent assez facilement. Terre légère ou de bruyère.

Obs. Ce genre n'est pas dans Jussieu. On a vu dans l'exposition de son caractère, que j'ai pris sur la plante vivante, combien il se rapproche de celui du genre lobelia, quoique les anthères ne soient point connées. 


\section{S U P P LE M EN T.}

Page 9. Sauge officinale, variété 5, salvia grandiflora, Willd., Vahl., Desf.

La sauge $4^{\circ} n^{\prime}$ a pas touies ses feuilles à trois lobes; plusieurs n'en ont qu'un ou point, sur-tout quand elle est cultivée. Ces Iobes sont alors des oreillettes. Celte espèce est plus branchue que les précédentes : c'est la salvia auriculata, Milter.

Page ı. Sauge des prés. Variété à fleurs roses d'un effet agréable. *

Page 18, no 43. Salvia tingitana., Syn. S. foetida, DrsF.

Page 3I , no 35 au lieu de 36. Cette germandrée a le port et les tiges droites; ses feuilles sont ovales - rhomboïdales, pointues, dentelées ou crénelées, blanches en-dessous, roulées en leurs bords. Fleurs en verticilles composés de 2 à 4 fleurs, dont les calices sont hérissés de poils. (Desfontaines, Histoire des Arbres.)

Page 66. Marrube. Usages. La $6^{\text {e }}$ espèce est encore d'un usage plus fréquent en médecine.

Page го . Capraire biflore. Il est rare que cette plante s'élève à 5 à 4 pieds. Elle n'a ordinairement qu'un à deux pieds, et elle ne dure que deux ou trois ans. Ses premières feuilles ont $2 \dot{a}$ 5 pouces de longueur; les suivantes ont à peine 8 à ro lignes.

$\boldsymbol{P}_{\text {age }}$ 1 02. Haller luisant. Selon M. Desfontaines, cet arbrisw seau s'élève à 4 à 5 mètres.

Page $121, n^{\circ} 7$. Digitale à fleurs rousses. C'est par inattention que celle espèce et sa variété ont étéindiquées de plein air: elles sont, du moins pour le nord de la France, d'orangerie. Ce sont des plantes sous-ligneuses qui doivent avoir le même traitement et la même culture que l'espèce suivante des Canaries. Les espèces 10 et I I ont aussi des rapports à la $6^{e}$, quant à leurs ports; la $\mathrm{I}_{1}^{\mathrm{e}}$ en differe, sans fleurs, par sa tige brune. 
Page 1 $24, n^{\circ} 3$. Colomnée à feuilles rondes, $\boldsymbol{C}$. roturitifolia, Hort. angl., l'île de la 'Trinité. ๖. Serre chaude. Fleuriž en oct.-janvier.

Idem. 4. C. écarlate, C. caccinea, Hort. angl. L'Amér. mérid. $Ъ$. Serre chaude. Fl. dans le même $t$ mps.

Ces deux espèces sont nouvellement cultivées en Angleterre.

Page I 29. Broualle. Les deux espèces de ce genre se ressemblent tellement qu'elles pourroient être considérées comme variétés l'une de l'autre. La première est autant culivée dans les jardins que la seconde.

Page 150. Celsia nana, Hort. angl. Nouvelle espèce cult. en Angleterre. Jolie plante.

Page i 7. Solanum. L'espèce no 52, S grandiflorum, que je cultive, a de grands rapports avec l'espèce de Buenos-Agres, $n^{0} 16$; elle en a le port. Ses feuilles sont de la même grandeur, mais elles sont anguleuses. Sa tige est droite, souvent brune, sans piquans, ou hérissée de quelques-uns courts et rares. Ses fleurs, de la grandeur de celles de l'espèce de Buenos.Ayres, sont bleues, et quelquefois blanches.

Page 174 . Lycium barbarum $\mathrm{n}^{\circ}$ 2. Syn. Lycium chinense, Dunamel. Arbr. éd. nova.

Page $240, n^{\circ}$ 13. Bignonia ophtalmica, Hort. angl. La Guyane. Fleurs jaunes en août. Ђ. S. ch.

Page 242. Il ne faut pas confondre le genre nillingtonia avec un autre des Anglais du même nom, qui est de l'ordre des papilionacées ou légumineuses. Ce dernier a trois especes cultivées en Angleicre, quisontmillingtonia trinervia, stricta et semi alata. Elles sont toutes des Indes orientales. b. Serre chaude.

Page 252. Gentiana caucasica, Hort. angl. Le mơnt Caucase. gelida, Hort. angl. La Sibérie. septem fida, PAllas. La Taurie. algida, PALIAS, Willd. Sibérie.

Ces quatre espèces sont depuis peu cultivées en Angleterre. Elles sont $\psi$, et leur culture doit être la même que celle indiquée pour les autres. 
Pnge 255. Genticna 18. Syn. Exacum filiforme, Prrs.

Page 257. Chironia angustifolia, Hort. angl. Le Cap. Ђ. Or. Cultivée en Angleterre.

\section{Page 258. Frasère, Frasera. (Ordre des Gentianes.)}

Cal. ouvert, à 4 parties aiguës. Cor. plus grande, ouverte, ’̇ 4 parties ovales, avec une glande élégamment barbue dans leur partie moyenne. 4 étam. Anthères oblongues. Ovaire ovale, finissant ev un style à 2 stigmates épais et divergens. Caps. assez grande, ovale, comprimée, termi ée par le s'yle, à une loge et 2 valves. Semences planes, elliptiques, bordées d'une membrane.

Frasère de Walter, F. walteri, Michaux. F.carolinensis, Giaelin.

Tige très-élevée et droite. Feuilles ovales-oblongues, rerticillées et opposées.

Lieu. Les marais de la Caroline.

Cull. Je connois trop imparfaitement cette plante pour donner des indications sur sa culture. Son lieu originaire me fait présumer qu'elle doit être, à peu de chose près, cultivée comme la proserpine, proserpinaca palustris.

Page 291. Asclepias, n 25. A. linaria. Cette espèce est, par inadvertance, en double emploi. C'est la même que celle $n^{\circ} 20$.

Page id. Asclepias volubilis, Syn. A. scandens, Hort. angl.

Page 5o:. Sideroxylum atrovirens. Cette espèce de Lamarck pourroit être la même que celle $S$. melanophleum $\mathrm{n}^{\circ} 2$.

Page 3г 4. Royena, 亏е espèce, $R$. hirsuta, Syn. Diospyros hirsuta, Desfont. Hist. des Arbres.

Cet auteur a mis aussi dans le genre diospyros, royena lycioides, dont les feuilles, toujours vertes, sont lancéolées, planes, obtuses, glabres, lisses et très-entières. D'après cette indication de Desfontaines, cetle espẹce ne peut être celle nom- 
mée anguslifolia, WILlD, et Hort. angl., ainsi que je l'avois soupconné.

Page 332. Azalée à fleurs blanches. * Variété absolument blanche, à limbe blanc et tube verdâtre.

Page 335. Azalée rude, n 4. Cette variété, qui peut être considérée comıme une espèce, n'a pas seulement un bouton d'ombelle terminale à chaque rameau de l'année précédente, comme les autres espèces, mais 4 à 8 ensemble sessiles.

Page 337 et 338. Azalée. Cult. Plusieurs espèces d'azalées mûrissent leurs graines et peuvent aisément se multiplier par ce moyen, en les semant en pots sur couche dans la terre de bruyere. Elles lèvent fort bien et en abondance. On peut les planter en pépinière, ou même en place, au printemps de la $\zeta^{\mathrm{e}}$ année de leur semis.

Page 374. Bruyère 19. Cette espèce ainsi que la $17{ }^{\circ}$ devroient être dans la seconde division, premiere section. J'ignore si Salisbury a fait son traité des bruyères sur la nature vivante ou sur des herbiers. J'ai vu les fleurs des especes que je cultive, presque dans toutes, d'une dimension plus grande qu'il ne l'indique.

Page 382. Bruyère 5r. Cette espèce a beaucoup de rapport dans son port, son feuillage et ses fleurs, avec la $6 \mathrm{I}^{\mathrm{e}}$. Ajouter une ${ }^{*}$.

Page 385. Bruyere 62. Cette espèce est, sur des individus, assez droite; mais sur d'autres ses branches et ses rameaux, assez nombreux et grêles, se courbent en divers sens, sur-tout lorsqu'elle acquiert de l'âge.

Page 387. Bruyère 67. Variété à fleurs blanches. Lisez ensuile: Cette varieté, que j'ai obtenue des graines de cette espèce 67 , prouve que la précédente, $n^{\circ} 66$, n’est qu'une variété de celle-ci, et qu'elle n'en differe que par la couleur de ses fleurs, roses en bouton, blanches ensuite. La corolle des fleurs blanches est un peu moins évasée. Des jardiniers leur donneni le nom de E. persoluta alba.

Page 588. Bruyère 69. Variélé à fleurs blanches. Je crois que cette variété est véritablement l'espece E. ramentacea de 
Lin. et Willd., dont les rameáux sont très-longs et s'élevent à une assez grande hauteur; c'est celle connue sous ce nom des jardiniers. L'espèce est vraisemblablement l'erica pilulifera, dont la tige est moins haute et les fleurs rouges très-petites et presque globuleuses.

Page 395. Bruyere 9o. Cetle espèce est actuellement trèscommune dans les jardins, oì elle forme des touffes très-denses et qui s'élargissent considérablement. Ses fleurs, d'un joli pourpre rose au printemps, commencent à paroître dès l'automne; elles sont verdâtres tout l'hiver et se colorent au mois de mars.

Page 418. Bruyère 163 . Je cultive une bruyère que les jardiniers anglais ont nommé $E$. corifolia, nom qui a été donné assez indifféremment à plusieurs espèces. C'est une variété très-légère de la $163^{\mathrm{e}}$, et une autre que j'ai reçue sous le nom d'aggregata. Celle-ci est un peu différente. Ses feuilles sont velues. C'est, je crois, la précédente $162^{\mathrm{e}}$. Elle a aussi des rapports avec la bruyère $n^{\circ} 85$, aux appendices près.

Page 45. Bruyère 197. Je crois cette espèce peu différente de celle $n^{\circ}$ I 85 . C'est peut-être sa variété indiquée.

Page 432. Bruyères 199, 200, 201, 202, 203 et 233 B. élevée. Ces espèces s'élèvent à plus de 12 pieds.

Page 444. Bruyère 218. Cette espèce s'élève jusqu'à 12 pieds de haut. Elle est, selon Linné, la plus belle et la plus, rare de toutes. Il y a ro ans que $\mathbf{j}$ : la possède et elle n'a pas encore fleuri.

Page 449, n 229. Quoique l'erica simpliciflora soit, selon Salisbury, synonyme de l' $E$. curviflora, j'en cultive une espèce différente et que je crois la vraie simpliciflora, $W_{\mathbf{I L L D}}$. Ses fleurs sont d'un blanc rosé, soliaires et longues d'un pouce, non courbées.

Page 468. Avant l'alinéa, après ces mots, de l'air libre, ajoutez : $4^{\circ}$ A l'espèce de serre où on les place en hiver.

Page 482. Cult. des bruyères. On peut mettre en effet les jeunes bruyères de semis et de bouture, pendant l'biver, sur los tablettes des croisées de la serre; mais j’ai éprouvé cette 
année qu'elles étuient encore mieux placées, et beaucoup plus avantageusement pour elles, dans un châssis bas, bien garanti de la gelée par un entourage de paille serrée et de paillassons.

Page 485. Boutures de bruyères. D'après une conversation que j’ai eue avec un jardinier propriélaire établi à Paris, qui a travaillé chez les jaräniers d'Angletcre, ou il a fait des boutures de toutcs leurs espèces qui ont eu les plus grands succès, tandis qu'en France, en employant la même pratique et les mêmes soins, il n'en a obtenu presque aucun, je me crois fondé à croire que ce ne sont ni la manipulation ni les procédés qui nous privent de la réus ite, et que les Anglais ne la doivent qu'd leur atmosphère plus douce, plus constamment humide, et peut - être plus chargée de principes végétatifs. Cependant, malgré ces raisons probables, j'invite les culivateurs à employer un autre moyen, qui ne consiste que dans un léger changement dans la maniere que j'ai indiquée. C'est, au lieu de mettre les terrines remplies de boutures pendant 3 ou 4 jours seulement à l'ombre et à l'exposition du nord, de façon que le soleil ne puisse aucunement donner sur elles, de les y laisser 2 à 3 semaines. Les cloches doivent absolument embrasser les terrines pour que la pluie n'y pénètre pas. J'ai actuellement deux cents boutures qui ont siz semaincs, bien vertes, et commençant à s'élever par ce procédé. D'ailleurs, ainsi que ne l'a recommandé un jardinier anglais, il ne faut, pour l'enracinement des boutures de bruyères, cue la température de l'atmosphère telle qu'elle l'est à l'ombre pendant l'été. Une plus grande chaleur leur nuit certainement; j'en ai eu plusieurs fois la preuve. Lorsque ces boutures ont passé environ deux semaines a l'ombre, comme elles sont toutes alors bien droites et fermes, on les mettra, sans risque qu'elles baissent ou fanent, dans un châssis pour faciliter davantage l'enracinement, mais couvertes encore de leurs cloches pendant au moins les premiers jours, et ombragées.

Page i95. Andromède. M. Desfontaines, dans son Histoire des Arbres, etc., cite une autre espèce de ce gcnre qui m'est inconnue : il la nomme Andromède crépue, $A$. crispa. Ses feuilles sont lancéolées, crépues en leurs bords, ponctuées 
d'écailles; les pédoncules sont solitaires, axiliaires et unilatéraux.

Page 5or. Arbousier. Cull. L'arbousier commun crôî natu= rellement dans le département des Côtes-du-Norord; il s'y trouve aussi une espèce dont les feuilles sont elliptiques. C'est à M. Olagnier, inspecteur des forêts de ce pays, que j'en dois la connoissance.

Page 506. Styphélie. Culture. La première espèce se conserve aisément dans les serres, et n'est pas plus difficile que les mélaleuques. On la muliplie par les marcottes et les boutures.

Page 5r7. J'ai dit à cette page qu'il n'y avoit encore qu'une espece d'epacris cultivée en Angleterre; mais depuis j'ai appris qu'il y en avoit actuellement plusieurs autres parmi lesquelles se trouve l'epacris pulchella, C.Av., qui est très-jolie. Les autres sont $E$. diosmafolia, E. pungens, Cav. E. recurva, E. juniperina, E. grandiflora. Elles sont toutes de la Nouv.-Holl. $\rightrightarrows$. Or., terre de bruyères. Peut-être celle nommée grandiflora estelle l'E. longiflora de Cavanilles. Toutes sont des plantes fort agréables à la vue. Leurs fleurs ont beaucoup de rapports a celles des bruyères. Elles doivent recevoir la même culture.

Page 532. Gesnère. Cult. Ses semences, plus petites encore que celles du tabac, mûrissent dans nos serres. On peut donc multiplier cet arbrisseau par ce inoyen, en conduisant le semis comme il a été indiqué pour les plantes délicates ou de serre chaude.

Page 541. Goodenia lcevigata. Syn. Scoevola microcarpa, Cay. S. lavigata, Pers.

TIN DU SUPRLÉARENT AU TOME TROISIËME, 


\section{$\mathrm{ERRATA}$}

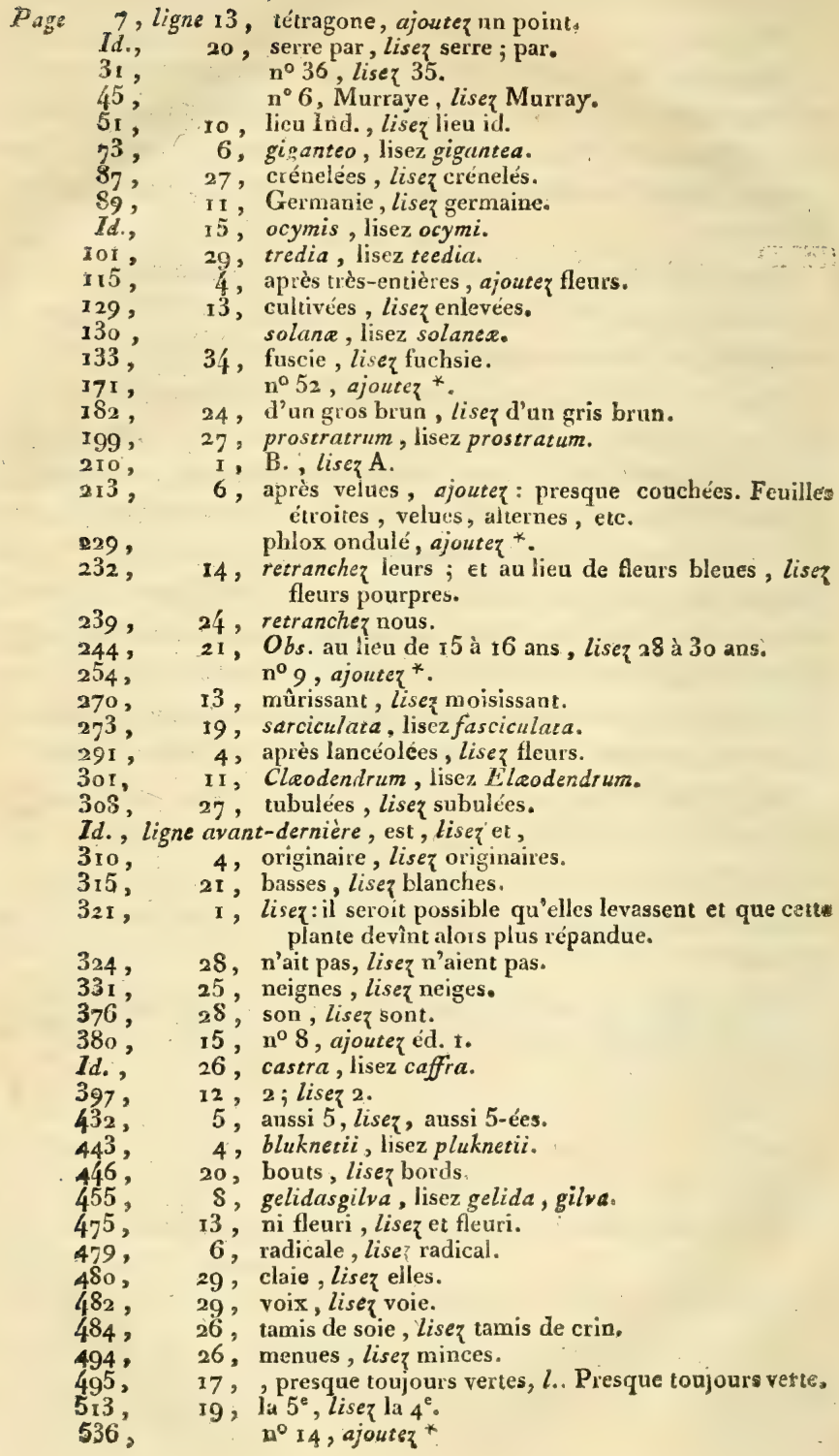





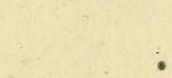

-

$-\cdots$

요

c.

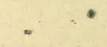

I

$\bullet$

, 
garano

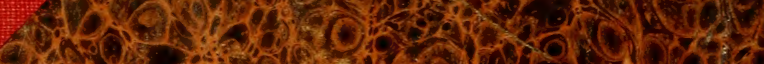

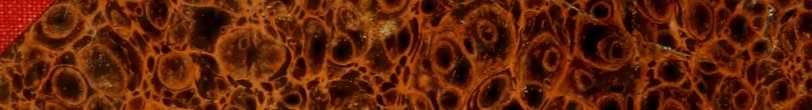

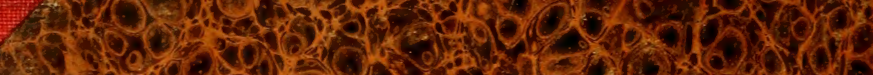

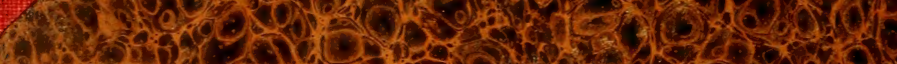

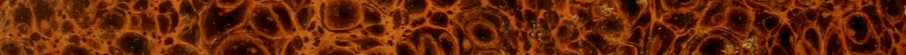

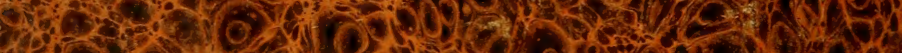

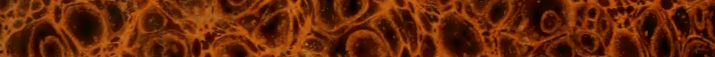

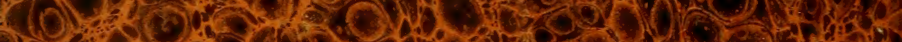

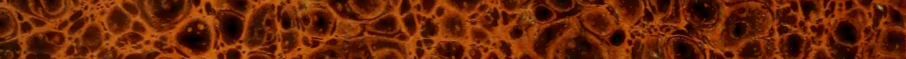

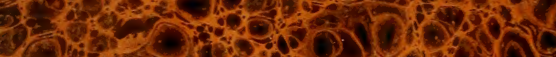

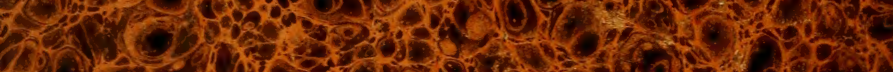

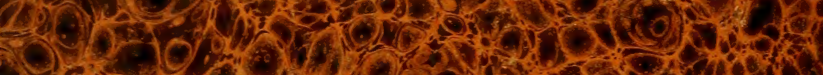

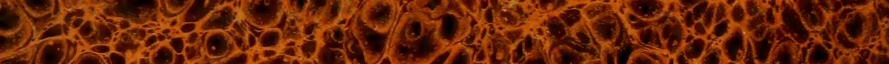
1 (1) of 1)

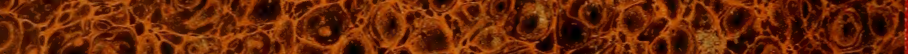

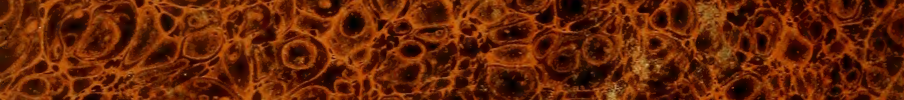
1.9.

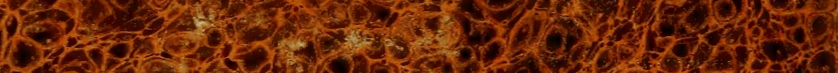
(2)

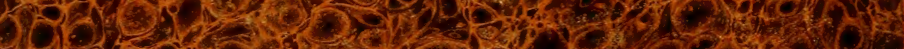

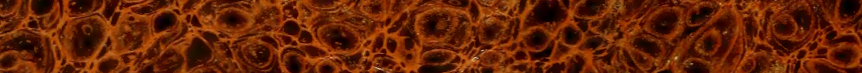

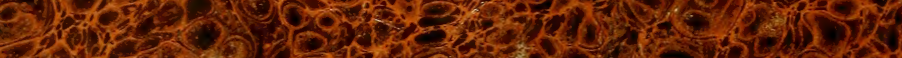

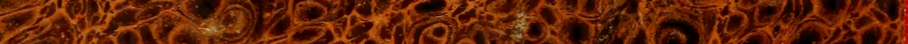

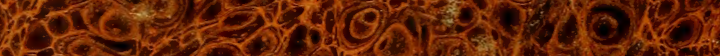

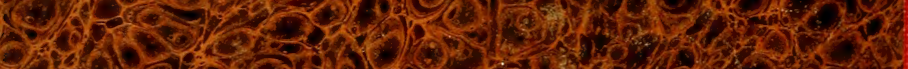

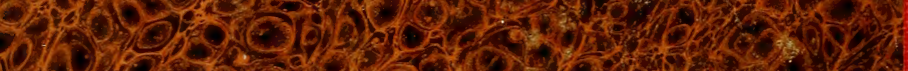
1. 1 - a T. - 13 (c)

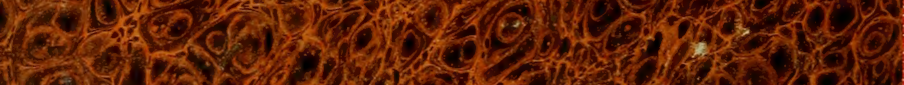
The

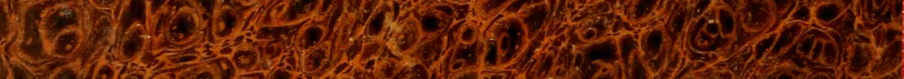
20.9. 19.

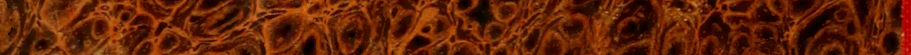

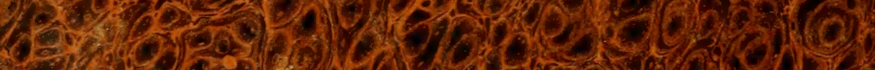

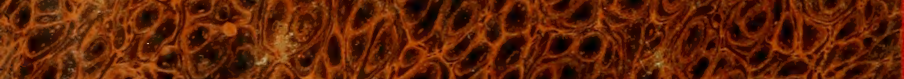

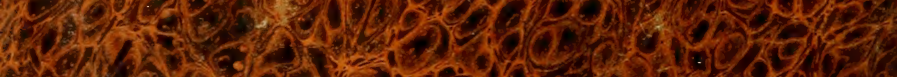

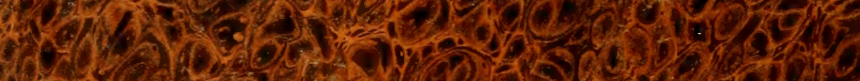
(15)

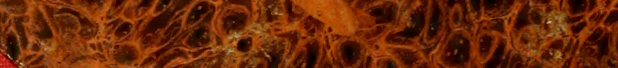

